\title{
The Use of Ion-Exchange Resins for the Recovery of Valuable Species from Slurries of Sparingly Soluble Solids
}

by

\section{Pieter Gabriël Retief De Villiers}

\author{
Dissertation presented for the Degree \\ of \\ DOCTOR OF PHILOSOPHY IN ENGINEERING \\ (Metallurgical Engineering) \\ In the Department of Chemical Engineering \\ at the University of Stellenbosch
}

Promoters:

Prof. L. Lorenzen

Prof. J.S.J. van Deventer

DECEMBER 2002 


\section{Declaration}

I hereby certify that this dissertation is my own original work, except where specifically acknowledged in the text. Neither the present dissertation nor any part thereof, has previously been submitted at any other university.

Pieter Gabriël Retief De Villiers 
VOLUME I 


\begin{abstract}
The availability of vast deposits of high-grade ore bodies are rapidly becoming something of the past in the modern mining and metallurgical scenario. Apart from the lower grade content of these ore bodies, complex mineralogy are an even greater obstacle in the recovery of valuable metal species. The development of new technology to deal with these type of ore bodies is therefore critical and worth investigating, as the world's easily exploitable high grade ore deposits are decreasing.
\end{abstract}

Valuable species can be recovered from sparingly soluble solids, which slightly dissociate to give traces of the valuable ions in solution, with the use of ion-exchange resins in a slurry mixture. A dissociation equilibrium exists between the dissolved ions in solution and the solid ore body. If the dissolved ions are removed from the solution by ion-exchange, the solid / liquid dissociation equilibrium is continually displaced. According to Le Chatelier's principle further dissolution of the sparingly soluble solid is required to restore the equilibrium concentration of the valuable species in solution.

It is possible to recover valuable metal species from metal precipitates, such as metal sulphides, by contacting a slurry of the precipitate with a suitable ion-exchange resin. The resulting ion exchange reaction between the valuable metal species and counter ions creates electrolyte solutions that may facilitate the further dissolution of the metal precipitate. These counter ion electrolyte solutions may easily become significantly concentrated. This occurs in the event of a Resin-in-Leach (RIL) mixture that results in a continuous ion-exchange reaction taking place due to the continually changing electrolyte composition of the mixture, which significantly changes the activities and hence the solubility of the valuable metal species in solution. Complete dissolution and liberation of the metal precipitate can often be achieved provided that a sufficient amount 
of a suitable high capacity ion-exchange resin is used in a properly engineered Resin-inLeach (RIL) circuit.

The simultaneous dissolution and adsorption of various base metal precipitates were tested. Various interactions that take place in the slurry at molecular level as well as the effects of various variables on the "adsorption by dissolution process" are discussed through the development of fundamental thermodynamic models. These thermodynamic mathematical models are developed for the three phase system that exists in a Resin-inLeach mixture, i.e. the solid ore body, the electrolyte solution and the ion-exchange resin, and can be used for possible other applications such as the recovery of rare earths from low grade ores in the minerals processing industry. A typical example of an industrial process for the recovery of rare earth species is the percolation leaching of rare earths from low-grade kaolinitic ores, which continually shifts the solid / liquid dissociation equilibrium condition. The rare earth content of these ores is usually between $0.05 \%$ and $0.3 \%$, which is very low by any modern industrial extraction and refining standards. 


\section{Opsomming}

Die beskikbaarheid van ryk mineraal ertsneerslae is spoedig besig om iets van die verlede te word in die huidige mineraal ontginning en metallurgiese veredelings industrie. Afgesien van die lae graad van die huidige mineraal ertsneerslae, blyk die komplekse mineralogiese samestelling van hierdie neerslae ' $n$ veel groter struikelblok te wees in die herwinning en veredeling van die edelmetale teenwoordig in hierdie ertse. Die ontwikkeling van nuwe veredelings en ekstratiewe tegnologie vir die herwinning van edel metale, vanuit hierdie lae graad mineraal ertsneerslae, word dus benodig wat verdere navorsing in hierdie gebied regverdig.

Dit is wel moontlik om metaal spesies afkomstig van ertse met ' $n$ baie lae oplosbaarheid in waterige oplossings te herwin met ioon-uitruilings harse vanweë die feit dat die metaal spesies wel teen baie lae konsentrasies in die waterige oplossings teenwoordig is. Die metaal spesies los op in die waterige oplossings volgens hulle karakteristieke oplossings termodinamika. Indien die opgeloste metaal spesies vanuit die waterige oplossing verwyder word, sal die vaste stof / vloeistof ewewigs balans weer herstel word deurdat die vaste stof verder sal oplos as gevolg van Le Chatelier se beginsel.

Dit is dus moontlik om metaalagtige spesies, soos metaal sulfiedes, te herwin deur ' $n$ waterige oplossing wat die metaal erts bevat in kontak te bring met ' $n$ ioon-uitruilings hars. Die daaropvolgende ioon-uitruilings reaksie tussen die metaalagtige spesies en die spesies teenswoordig op die ioon-uitruilingshars het tot gevolg dat die elektrolitiese samestelling van die waterige oplossing verander. Dit is die gevolg van die migrasie van spesies aanvanklik teenswoordig op die hars wat in die waterige fase eindig. Die veranderende samestelling van die waterige oplossing mag verder tot gevolg hê dat die oplosbaarheid van die metaalagtige spesie verder verhoog mag word. Die gevolg van 
bogenoemde reaksies is dat die waterige oplossing ionies sterk gekonsentreerd kan word soos meer en meer spesies aanvanklik teenswoordig op die hars migreer na die oplossing. Die ioniese verandering van die waterige oplossing van 'n suiwer waterige fase tot ' $n$ ionies sterk gekonsentreerde oplossing vind plaas tydens die oplos van erste in " $n$ hars-inpulp (HIP) oplossing. Die nuwe ioniese aktiwiteit in die oplossing kan die oplosbaarheid van die vaste stof drasties verander. Die volledige oplossing van ' $n$ bepaalde kwantiteit van die vaste stof kan bereik word deur die genoegsame toevoeging van 'n geskikte hars tot die waterige oplossing wat die vaste stof bevat.

Die gelyktydige oplossing en absorpsie van die metaalagtige vastestowwe vanuit waterige oplossings met behulp van ioon-uitruilings harse is eksperimenteel getoets vir die doeleindes van hierdie werkstuk. Verskeie interaksies wat op molekulêre vlak in die pulp plaasvind asook die adsorpsie proses van die spesies vanuit die waterige oplossing op die harse word bespreek en gemodelleer. Wiskundige modelle wat die termodinamika van die verskillende fases wiskundig verteenwoordig is ontwikkel vanaf bestaande termodinamiese beginsels. Die drie verskillende fases wat in ag geneem is, is die waterige fase met opgeloste metaal spesies, die vaste stof fase wat as die erts in bostaande paragrawe beskryf is en die ioon-uitruilings fase wat ' $n$ komplekse vastestof en water fase gekombineerd is. Die doel van die werkstuk is om die basis te skep vir die ontwikkeling van modelle wat gebruik kan word om die herwinning van skaars-aarde mertale vanuit lae oplosbare erstse te modelleer en beskryf. 'n Tipiese industriële voorbeeld is die herwinning van skaars-aarde metale van lae-graadse kalkagtige erste deur gebruik te mak van perkolerende logings reaksies wat geduring die vastestof / vloeistof ewewig versteur. Die konsentrasie van die skaars-aarde metale in hierde erts gesteentes kan wissel vanaf so laag as $0.05 \%$ tot $0.3 \%$ per massa. Hierdie konsentrasies is uiters laag gesien vanuit enige industriële herwinnings proses oogpunt. 
viii

\section{Acknowledgements}

The experimental data contained in this dissertation was collected over a time period of four years via experimental procedures carried out in the Department of Chemical Engineering at the University of Stellenbosch as well as at MINTEK in Johannesburg, South Africa. I would like to express my sincere appreciation to the following persons and companies in particular, whom made this research project a reality:

Firstly, I would like to extend my gratitude towards MINTEK for their financial support, which I received for the complete duration of this research project during the last four years.

Prof. Leon Lorenzen and Prof. Jannie van Deventer for their encouragement and intellectual guidance throughout this research project.

The personnel of the technical workshop at the Department of Chemical Engineering at the University of Stellenbosch. This project was experimentally intensive and utilised a lot of equipment built by Jannie Barnard, to whom I would like to express my gratitude in particular.

To Vincent Carolissen, for the weeks of continued support in helping me to carefully screen hundreds of litres of various ion-exchange resins into different size fractions.

To Hanlie Botha for her generous support and hours of effort in front of the troublesome "Dionex" in enabling me to perform the much needed anion analyses. 
I would further like to thank Peter Cole, the late Mark Johns and Martie Kotze of Mintek for their support in performing analyses on resin samples to determine specific physical properties needed in the mathematical modelling of the RIP process.

My family for their encouragement and support during the duration of this research project, especially my father (Gabriël De Villiers) and mother (Marietha De Villiers).

My wife, Elizabeth, for all of her generous support and patience.

Finally to the Almighty God for giving me the opportunity to fulfil this dream. 


\section{CONTENTS}

\section{VOLUME I}

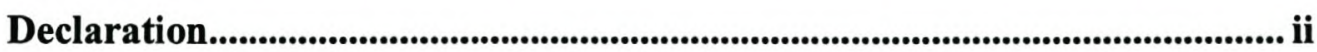

Abstract........................................................................................................................................ iv

Opsomming............................................................................................................................ vi

Acknowledgements .................................................................................... viii

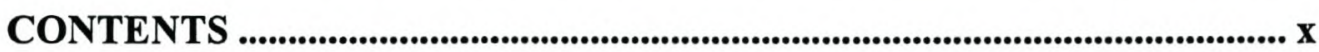

LIST OF FIGURE TITLES ........................................................................... xxvi

LIST OF TABLE TITLES........................................................................

Chapter $\quad \underline{\text { Page }}$

CHAPTER 1

INTRODUCTION

1.1 HYDROMETALLURGICAL EXTRACTION 2

1.2 RECOVERY OF VALUABLE CHEMICAL SPECIES FROM 4 SPARINGLY SOLUBLE ORE BODIES USING THE RESIN-IN-PULP (RIP) AND RESIN-IN-LEACH (RIL) PROCESS

1.3 ION-EXCHANGE PROCESSES EMPLOYING RIP TECHNOLOGY 8

1.4 GENERAL CONSIDERATIONS BASED ON A CASE STUDY OF 13 CaSO4 IN A RESIN-IN-PULP MLXTURE CONTAINING A CATION AND ANION EXCHANGE RESIN 
1.4.1 The sparingly soluble solid and aqueous phase equilibrium 17 condition

1.4.2 Aqueous phase speciation and equilibrium considerations 18

1.4.3 General considerations on the equilibrium behaviour of the resin 19 phase

1.4.4 Ion-exchange resin and aqueous phase equilibrium interactions 20

1.5 OBJECTIVES OF THIS STUDY 21

1.6 THEORETICAL CONTRIBUTIONS OF THIS STUDY 23

CHAPTER 2

GENERAL THERMODYNAMIC CONSIDERATIONS ON THE SOLUBILITY OF SPARINGLY SOLUBLE SOLIDS IN AQUEOUS ELECTROLYTE SOLUTIONS

2.1 OBJECTIVES OF THIS CHAPTER 25

2.2 GENERAL CONSIDERATIONS ON THE ROLE OF SOLVENTS IN 28 THE DISSOLUTION OF SPARINGLY SOLUBLE SOLIDS

2.3 MECHANISTIC CONSIDERATIONS FOR THE DISSOLUTION OF 30 SPARINGLY SOLUBLE SOLIDS IN SOLVENTS AT EQUILIBRIUM

2.4 KINETIC RATE THEORY FOR THE SOLUBILITY PRODUCT OF A 34 PRECIPITATE

2.5 THERMODYNAMIC CONSIDERATIONS OF IONIC SPECIES AT 35 EQUILIBRIUM IN SOLUTIONS

2.5.1 Phase equilibrium 36

2.5.2 Ionic reaction equilibrium 36

2.5.3 Solubility equilibrium between crystals and saturated solutions $\quad 40$

2.6 SOLUBILITY PRODUCTS OF PRECIPITATES 41

2.6.1 Equilibrium considerations for stoichiometrically not one-to-one 42 dissolving precipitates 
2.6.2 Equilibrium considerations for stoichiometrically one-to-one 43 dissolving precipitate

2.6.3 Calculating the solubility of a precipitate from its solubility 43 product

2.7 PARAMETERS INFLUENCING THE SOLUBILITY OF PRECIPITATES 45

2.7.1 The influence of dissolved electrolytes on the solubility of a 46 sparingly soluble solid in an aqueous electrolyte solution

2.7.2 The common ion effect $\quad 48$

$\begin{array}{ll}\text { 2.7.3 Weak acid formation } & 50\end{array}$

2.7.4 Complex formation with a ligand 53

2.8 SUMMARY 58

$\begin{array}{lr}\text { CHAPTER } 3 & 61\end{array}$

THERMODYNAMIC MODELS FOR THE PREDICTION OF ELECTROLYTE ACTIVITY COEFFICIENTS IN NON-IDEAL AQUEOUS ELECTROLYTE SOLUTIONS

3.1 OBJECTIVES OF THIS CHAPTER 63

3.2 OVERVIEW OF INDUSTRIAL PROCESSES IN AN AQUEOUS 64 ELECTROLYTE SYSTEM ENVIRONMENT

3.3 BASIC THERMODYNAMIC RELATIONSHIPS 67

3.4 THERMODYNAMIC MODELS AVAILABLE FOR THE PREDICTION 71 OF SINGLE STRONG ELECTROLYTE ACTIVITY COEFFICIENTS IN AQUEOUS SOLUTIONS

3.4.1 The Debye-Hückel limiting law 72

$\begin{array}{lll}3.4 .2 & \text { Bromley's correlation } & 74\end{array}$

$\begin{array}{lll}3.4 .3 & \text { Meissner's method } & 75\end{array}$

$\begin{array}{lll}3.4 .4 & \text { Pitzer's method } & 80\end{array}$

$\begin{array}{lll}3.4 .5 & \text { Harvie and Weare model } & 83\end{array}$ 
3.5 THERMODYNAMIC MODELS AVAILABLE FOR THE PREDICTION 86 OF SPECIES ACTIVITY COEFFICIENTS IN MULTICOMPONENT AQUEOUS ELECTROLYTE SOLUTIONS

3.5.1 Bromley's method 86

$\begin{array}{lll}\text { 3.5.2 The Lietzke-Stoughton (LS) method } & 87\end{array}$

3.5.3 Meissner's method $\quad 89$

$\begin{array}{lll}\text { 3.5.4 Pitzer's equation } & 91\end{array}$

3.5.5 The Reilly-Wood-Robinson (RWR) method 95

3.6 OVERVIEW OF EXISTING ACTIVITY COEFFICIENT MODELS 98

$\begin{array}{lll}3.7 & \text { SUMMARY } & 101\end{array}$

$\begin{array}{lr}\text { CHAPTER } 4 & 103\end{array}$

GENERAL CONSIDERATIONS ON ION-EXCHANGE EQUILIBRIA

4.1 OBJECTIVES OF THIS CHAPTER 104

$\begin{array}{lll}4.2 & \text { ION-EXCHANGE PRINCIPLES } & 107\end{array}$

4.2.1 Definition of an ion exchanger 107

4.2.2 Structures and properties of ion exchangers 109

$\begin{array}{ll}\text { 4.2.3 Capacity of an ion exchanger } & 114\end{array}$

4.2.4 Parameters influencing the equilibrium loading of species on ion- 117 exchange resins

4.2.5 Phase-boundry potentials and the electric Double layer (Donnan 122 potential)

4.2.6 Parameters influencing electrolyte sorption by ion-exchange resins 123

$\begin{array}{lll}4.3 & \text { SUMMARY } & 127\end{array}$ 
EXISTING METHODS FOR THE PREDICTION OF MULTICOMPONENT ION-EXCHANGE EQUILIBRIA

5.1 OBJECTIVES OF THIS CHAPTER

5.2 GENERAL CONSIDERATIONS ON THE HISTORICAL 131 DEVELOPMENT OF ION-EXCHNAGE EQUILIBRIUM MODELS

5.3 EMPIRICAL AND SEMI-EMPIRICAL ADSORPTION MODELS 133

5.4 THERMODYNAMIC BASED EQUILIBRIUM MODELS 136

5.4.1 The ion-exchange isotherm 140

5.4.2 Ion-exchange affinity and selectivity represented by the separation 140 factor

5.4.3 Ion-exchange equilibrium represented by equilibrium constants $\quad 142$

5.4.4 The ion-exchange selectivity coefficient 143

5.4.5 The ion-exchange thermodynamic equilibrium constant 144

5.5 MODEL PREDICTIONS OF THE RESIN PHASE ACTIVITY 146 COEFFICIENTS

5.6 MODEL PREDICTIONS OF THE RESIN PHASE ACTIVITY 147 COEFFICIENTS

5.7 CHOICE OF THE OBJECTIVE FUNCTION 152

5.8 SUMMARY 154

$\begin{array}{ll}\text { CHAPTER } 6 & 157\end{array}$

COMPUTATIONAL PROCEDURES FOR THE CONSOLIDATED EQUILIBRIUM MODEL

6.1 OBJECTIVES OF THIS CHAPTER 158

6.2 DEFINITION OF THE VARIOUS PHASES CONSIDERED IN THE 160 CONSOLIDATED EQUILIBRIUM MODEL FOR A RIP SLURRY MIXTURE 
6.2.1 The dissolution reaction for the sparingly soluble solid

6.2.2 The cation exchange reaction for the sorption of the dissolved 164 cation species of the sparingly soluble solid

6.2.3 The anion exchange reaction for the sorption of the dissolved 165 anion species of the sparingly soluble solid

6.3 MODEL ASSUMPTIONS USED IN THE SYNTHESIS OF THE 169 CONSOLIDATED EQUILIBRIUM MODEL FOR THE RIP SLURRY MIXTURE

6.4 EQUILIBRIUM MASS AND NEUTRALITY BALANCE FOR A RIP 172 SLURRY MIXTURE SYSTEM

6.4.1 Set the initial resin phase conditions 172

6.4.2 Set the initial solution phase conditions 173

6.4.3 Mass balance equation for species species $A^{z_{A}}$ between the 174 solution and the resin phase

6.4.4 Mass balance equation for species $B^{z_{B}}$ between the solution and 176 the resin phase

6.4.5 Calculate the total number of moles of the solid that have 176 dissolved

6.4.6 Mass balance equations for species $Y^{z_{Y}}$

6.4.7 Modifying the thermodynamic equilibrium constant for the cation 180 exchange resin

6.5 CALCUlation OF THE SOLUTION PHASE ACTIVITY 180 COEFFICIENTS IN THE EQUILIBRIUM CACLCULATIONS

6.5.1 Pitzer equations for the MX-NY electrolyte system

6.5.2 Pitzer equations for the MX-NX electrolyte system

6.5.3 Pitzer equations for the MX-MY electrolyte system

6.6 CALCULATIONS OF THE THERMODYNAMIC EQUILIBRIUM 186 CONSTANT FOR THE ION-EXCHANGE REACTION AND THE RESIN PHASE ACTIVITY COEFFICIENTS 
6.7 DETAILED ITERATIVE SOLUTION PROCEDURE FOLLOWED TO 188 SOLVE THE CONSOLIDTED MODEL EQAUTIONS

6.8 THERMODYNAMIC DATA BASE CONSTRUCTED FOR USE IN THE 198 CONSOLIDATED EQUILIBRIUM MODEL FOR THE RIP SLURRY MIXTURE SYSTEM

6.9 SUMMARY 200

CHAPTER 7 203

EXPERIMENTAL PROCEDURES AND ANALYSES

7.1 PREPARATION OF ION EXCHANGE RESINS FOR USE IN KINETIC 203 AND EQUILIBRIUM EXPERIMENTS

7.1.1 Initial resin batch washing 204

7.1.2 Sizing the resin particles by screening into distinct size fractions 205

7.1.3 Final washing and particle selection in a fluidised column set-up 206

7.1.4 Converting the resin matrix functional groups to a specific ionic 208 form

7.1.5 Removal of excess electrolyte solution by washing with distilled 209 water

7.2 PREPARATION OF ION EXCHANGE RESINS AND CARBON 210 SAMPLES FOR THE DETERMINATION OF TRACE ELEMENTS BY ATOMIC ABSORPTION SPECTROPHOTOMETRY

$\begin{array}{lll}\text { 7.2.1 Preparation procedure } & 210\end{array}$

$\begin{array}{lll}\text { 7.2.2. Reagents } & 218\end{array}$

7.3 CALCULATION OF PARAMETERS NEEDED IN KINETIC AND 218 EQUILIBRIUM PROCESS MODELLING

$\begin{array}{lll}\text { 7.3.1 Experimental procedure } & 219\end{array}$

7.3.2 Calculation of the total surface area 222

7.3.3 Calculation of the volume fraction and resin density for the resins 226 
7.4 EXPERIMENTAL PROCEDURES FOLLOWED IN EQUILIBRIUM 233 AND KINETIC EXPERIMENTS

7.4.1 Ion-exchange equilibrium experiments with aqueous electrolyte 233 solutions and slurries of sparingly soluble solids

CHAPTER 8

RESULTS FOR THE SOLUTION RESIN SYSTEM

8.1 OBJECTIVES OF THIS CHAPTER

8.2 EXPERIMENTAL TEST WORK ON ELECTROLYTIC SOPTION IN THE DETERMINATION OF BINARY ION-EXCHANGE EQUILIBRIUM ISOTHERMS

8.2.1 Electrolytic sorption of co-ionic species at equilibrium as observed during the experimental determination of binary ion-exchange equilibrium isotherms

8.2.2 Experimental data on electrolyte sorption for binary ion-exchange 245 reactions

\subsection{EXPERIMENTAL DATA AND ELECTROLYTIC SORPTION 251} CONSIDERATIONS IN THE DETERMINATION OF BINARY IONEXCHANGE EQUILIBRIUM ISOTHERMS

8.3.1 Experimental data for binary ion-exchange equilibrium isotherms for the anion exchange reaction between $\mathrm{F}^{-}$and $\mathrm{NO}_{3}{ }^{-}$and $\mathrm{F}^{-}$and $\mathrm{Cl}^{-}$

8.3.2 Experimental data for the binary ion-exchange equilibrium isotherms for the anion exchange reaction between $\mathrm{SO}_{4}{ }^{2-}$ and $\mathrm{Cl}^{-}$, $\mathrm{SO}_{4}{ }^{2-}$ and $\mathrm{NO}_{3}{ }^{-}$and $\mathrm{SO}_{4}{ }^{2-}$ and $\mathrm{OH}^{-}$

8.3.3 Experimental data for the binary ion-exchange equilibrium isotherms for the anion exchange reaction between $\mathrm{OH}^{-}$and $\mathrm{NO}_{3}{ }^{-}$ and $\mathrm{OH}^{-}$and $\mathrm{Cl}^{-}$

8.3.4 Experimental data for the binary ion-exchange equilibrium 255 
isotherms for the anion exchange reaction between $\mathrm{CO}_{3}{ }^{2-}$ and $\mathrm{Cl}^{-}$ and $\mathrm{CO}_{3}{ }^{2-}$ and $\mathrm{NO}_{3}{ }^{-}$

8.3.5 Experimental data for the binary ion-exchange equilibrium 256 isotherms for the anion exchange reaction between $\mathrm{HCO}_{3}{ }^{-}$and $\mathrm{Cl}^{-}$ and $\mathrm{HCO}_{3}{ }^{-}$and $\mathrm{NO}_{3}{ }^{-}$

8.4 EXPERIMENTAL DATA FOR THE RESIN / SOLUTION PHASE 257 ISOTHERMS FOR CATION-EXCHANGE REACTIONS

8.4.1 Experimental data for the binary ion-exchange equilibrium 257 isotherms for the cation exchange reaction between $\mathrm{Mg}^{+2}$ and $\mathrm{H}^{+}$; $\mathrm{Mg}^{+2}$ and $\mathrm{K}^{+} ; \mathrm{Mg}^{+2}$ and $\mathrm{Cu}^{+2}$ and $\mathrm{Mg}^{+2}$ and $\mathrm{Al}^{+3}$

8.4.2 Experimental data for the binary ion-exchange isotherms for the cation exchange reaction between $\mathrm{Ca}^{+2}$ and $\mathrm{H}^{+} ; \mathrm{Ca}^{+2}$ and $\mathrm{Na}^{+} ; \mathrm{Ca}^{+2}$ and $\mathrm{K}^{+}$; and $\mathrm{Ca}^{+2}$ and $\mathrm{Cu}^{+2}$ and $\mathrm{Ca}^{+2}$ and $\mathrm{Al}^{+3}$

8.4.3 Experimental data for the binary ion-exchange equilibrium 260 isotherms for the cation exchange reaction between $\mathrm{Ba}^{+2}$ and $\mathrm{H}^{+}$; $\mathrm{Ba}^{+2}$ and $\mathrm{Na}^{+} ; \mathrm{Ba}^{+2}$ and $\mathrm{K}^{+} ; \mathrm{Ba}^{+2}$ and $\mathrm{Cu}^{+2}$ and $\mathrm{Ba}^{+2}$ and $\mathrm{Al}^{+3}$

8.4.4 Experimental data for the binary ion-exchange equilibrium 262 isotherms for the cation exchange reaction between $\mathrm{Pb}^{+2}$ and $\mathrm{H}^{+}$; $\mathrm{Pb}^{+2}$ and $\mathrm{Na}^{+} ; \mathrm{Pb}^{+2}$ and $\mathrm{K}^{+} ; \mathrm{Pb}^{+2}$ and $\mathrm{Cu}^{+2}$ and $\mathrm{Pb}^{+2}$ and $\mathrm{Al}^{+3}$

8.4.5 Experimental data for the binary ion-exchange equilibrium 263 isotherms for the cation exchange reaction between $\mathrm{Al}^{+3}$ and $\mathrm{H}^{+}$; $\mathrm{Al}^{+3}$ and $\mathrm{Na}^{+}$and $\mathrm{Al}^{+3}$ and $\mathrm{K}^{+}$

8.5 MODEL CALCULATIONS TO DETERMINE THE THERMODYNAMIC 263 EQUILIBRIUM CONSTANT FOR AN ION-EXCHANGE REACTION 
9.1 OBJECTIVES OF THIS CHAPTER 279

9.2 GENERAL MECHANISTIC CONSIDERATIONS FOR THE 281 SIMULTANEOUS DISSOLUTION AND SORPTION REACTION OF $\mathrm{PbSO}_{4}$ IN A RIP SLURRY MIXTURE SYSTEM

9.3 CALCULATION OF THE RESIN THERMODYNAMIC EQUILIBRIUM 298 CONSTANT FOR THE VARIOUS RESIN / SOLUTION SYSTEMS

9.3.1 Calculation of the thermodynamic equilibrium constant $K_{A}^{B}$ for the 301 bivalent-monovalent exchange reaction between $\mathrm{Ca}^{+2}$ and monovalent cations $\mathrm{H}^{+}, \mathrm{Na}^{+}$and $\mathrm{K}^{+}$

9.4 SOLUBILITY CALCULATIONS FOR THE SPARINGLY SOLUBLE 316 SOLIDS

9.5 SOLUBILITY CALCULATIONS $\quad$ FOR $\mathrm{CaSO}_{4}$ IN DIFFERENT 318 AQUEOUS PHASE ELECTROLYTE SYSTEMS

9.6 CONSOLIDATED EQUILIBRIUM MODEL CALCULATIONS FOR THE CaSO ${ }_{4}$ RIP 321 SLURRY MIXTURE SYSTEM

9.7 SUMMARY

CHAPTER 10 344

RESULTS FOR THE BIVALENT-BIVALENT SLURRY RESIN SYSTEM

10.1 OBJECTIVES OF THIS CHAPTER 345

10.2 GENERAL MECHANISTIC CONSIDERATIONS FOR THE 346 DISSOLUTION AND SORPTION OF $\mathrm{CaSO}_{4}$ IN A BIVALENTBIVALENT RIP SLURRY MIXTURE SYSTEM

10.3 CALCULATION OF THE THERMODYNAMIC EQUILIBRIUM 349 CONSTANT $K_{A}^{B}$ FOR THE BIVALENT-BIVALENT RIP SLURRY MIXTURE SYSTEM BETWEEN $\mathrm{Ca}^{+2} \mathrm{AND} \mathrm{Cu}^{+2}$ 
10.4 CONSOLIDATED EQUILIBRIUM MODEL CALCULATIONS FOR 354 THE BIVALENT-BIVALENT CaSO4 RIP SLURRY MIXTURE SYSTEM

10.5 SUMMARY

CHAPTER 11

369

RESULTS FOR THE BIVALENT-TRIVALENT SLURRY RESIN SYSTEM

$\begin{array}{lll}11.1 & \text { OBJECTIVES OF THIS CHAPTER } & 369\end{array}$

11.2 GENERAL MECHANISTIC CONSIDERATIONS FOR THE 370 DISSOLUTION AND $\begin{array}{llllllll}\text { SORPTION } & \text { OF } & \mathrm{CaSO}_{4} & \mathrm{AND} & \mathrm{PbSO}_{4} & \text { IN } & \mathrm{A}\end{array}$ BIVALENT-TRIVALENT RIP SLURRY MIXTURE SYSTEM

11.3 CALCULATION OF THE THERMODYNAMIC EQUILIBRIUM 373 CONSTANT $K_{A}^{B}$ FOR THE BIVALENT-TRIVALENT RIP SLURRY MIXTURE SYSTEM OF CaSO $4 \mathrm{AND} \mathrm{PbSO}_{4}$

11.4 CONSOLIDATED EQUILIBRIUM MODEL CALCULATIONS FOR 378 $\begin{array}{llllllll}\text { THE } & \text { SOLUBILITY } & \text { OF } & \mathrm{CaSO}_{4} & \mathrm{AND} & \mathrm{PbSO}_{4} & \mathrm{IN} & \text { ELECTROLYTE }\end{array}$ SOLUTIONS

11.5 CONSOLIDATED EQUILIBRIUM MODEL CALCULATIONS FOR 383 THE BIVALENT-TRIVALENT $\mathrm{CaSO}_{4}$ AND $\mathrm{PbSO}_{4} \quad \mathrm{RIP} \quad \mathrm{SLURRY}$ MIXTURE SYSTEM

11.6 SUMMARY

CHAPTER 12

405

CONCLUSIONS

REFERENCES 


\section{ABBREVIATIONS}

\section{Symbol Description}

BRAC indicates a bracketed term in an equation

CHEMAPP Software program used to model species solubility and aqueous phase activities

CIP Carbon-in-Pulp

DPRV Densely packed resin volume

DVB Divinyl benzene

FWSV Free wet settled resin volume

ppm Parts per million, defined in Appendix 1

RIL Resin-in-Leach

REM Rare earth metals

RIP Resin-in-Pulp

RWR Reilly-Wood-Robinson

SQL Structured query language

TRPO Trialkyl phosphine oxide 


\section{NOMENCLATURE}

\section{Symbol Description}

A Debye-Hückel constant

$A_{m} \quad$ molal scale Debye-Hückel constant

$A_{\phi} \quad$ Debye-Hückel constant for the osmotic coefficient

$a_{i} \quad$ solution phase activity of species $i$, or distance

parameter in extended Debye-Hückel equation

$a_{w} \quad$ activity of water

$B_{m}$

$C_{i}$

$C_{T}$

$d_{0}$

$D$

$\Delta E_{c}$

e

F

G

$\overline{G_{i}^{0}}$

$\Delta G_{f}^{0}$

H

I

$I_{c}$

$I_{m}$

K molal scale Debye-Hückel constant, or Bromley's constant. Defined by Equation (3.16).

molar solution phase concentration of species $i$

total molar solution phase concentration

density of pure solvent, Debye-Hückel equation

dielectric constant of solvent

lattice energy of pure solid precipitate

electronic charge $=1.6021 \times 10^{-19}$ coulomb

force between two ions

Gibbs free energy

partial molar Gibbs free energy of species $i$

Gibbs free energy of formation of species $i$

Enthalpy

ionic strength

molar scale ionic strength

molal scale ionic strength

thermodynamic equilibrium constant, or dissociation

constant

\section{$\underline{\text { SI Units }}$}

[depends definition]

$\left[\mathrm{kg}^{0.5} \mathrm{~mol}^{-0.5}\right]$

[depends definition]

$[-],[\mathrm{cm}]$

[一]

$\left[\mathrm{kg}^{0.5} \mathrm{~mol}^{-0.5} \mathrm{~cm}^{-1}\right]$

[mol/1]

$[\mathrm{mol} / \mathrm{l}]$

$\left[\mathrm{g} / \mathrm{cm}^{3}\right]$

$[$ - ]

$[\mathrm{kJ} / \mathrm{mol}]$

[C]

[N]

$[\mathrm{kJ} / \mathrm{kmol}]$

$[\mathrm{kJ} / \mathrm{kmol}]$

[kJ/kmol]

[depends definition]

[mol/1]

[mol/kg solvent] 


$\begin{array}{lll}K_{a} & \text { dissociation constant for acids } & {[-]} \\ K_{s p} & \text { molar scale solubility product of pure substance } & {\left[\mathrm{mol}^{\left.\mathrm{v} / 1^{\mathrm{v}}\right]}\right.} \\ k & \text { Boltzmann's constant }=1.3806 \times 10^{-23} & {[\mathrm{~J} / \mathrm{K}]} \\ m & \text { number of moles of common ion added to solution } & {[\mathrm{mol} / 1]} \\ m_{i} & \text { molal solution phase concentration of species } i & {[\mathrm{~mol} / \mathrm{kg} \mathrm{solvent}]} \\ M & \text { mass } & {[\mathrm{g}]} \\ M r & \text { solute molecular weight } & {[\mathrm{g} / \mathrm{mol}]} \\ N_{A} & \text { Avogadro's number }=0.60225 \times 10^{24} & {\left[\mathrm{~mol}{ }^{-1}\right]} \\ n_{i} & \text { number of moles of species } i & {[\mathrm{~mol}]} \\ p p m & \text { parts per million, defined in Appendix 1 } & {[-],[\mathrm{mg} / 1 \mathrm{water}]} \\ P(\ldots) & \text { probability } & {[-]} \\ p K & =- \text { log K } & {[-]} \\ q_{i} & \text { resin loading of species } i \text { or empirical parameter in } & {[\mathrm{eq} \mathrm{mol} / 1 \mathrm{resin}]} \\ & \text { Meissner's method. } & \\ Q & \text { resin capacity } & {[\mathrm{eq} \mathrm{mol} / 1 \mathrm{resin}]} \\ R & \text { gas law constant } & {[\mathrm{kJ} / \mathrm{kmol} \mathrm{K}]} \\ r & \text { distance between molecules, ions } & {[\mathrm{m}]} \\ S & \text { entropy or solubility of precipitate } & {[\mathrm{kJ} / \mathrm{kmol}],[\mathrm{mol} / 1]} \\ T & \text { temperature, Kelvin } & {\left[{ }^{\circ} \mathrm{K}\right]} \\ t & \text { temperature, Celsius, and time } & {\left[{ }^{\circ} \mathrm{C}\right]} \\ V & \text { volume } & {[\mathrm{litre}]} \\ V_{w} & \text { volume of pure water } & {[\mathrm{litre}]} \\ V_{s} & \text { volume of electrolyte solution } & {[\mathrm{litre}]} \\ y_{i} & \text { liquid mole fraction of species } i & {[-]} \\ z_{i} & \text { resin mole fraction of species } i & {[-]} \\ & \text { valency of species } i, \text { number of charges on ion } i & {[-]} \\ & & \\ & & \end{array}$




\section{GREEK}

$\varepsilon$

$\varepsilon_{0}$

$\Delta$

$\pi$

$v^{+}$

$v$

$v$

$v_{i}$

$\mu_{i}$

$\mu_{i, j}$

$\mu_{i}^{0}$

dielectric constant

permittivity of free space $=8.85 \times 10^{-12} \mathrm{C}^{2} \mathrm{~N}^{-1} \mathrm{~m}^{-2}$

difference

pi

stoichiometric number of cations formed when solute dissociates in solution phase

stoichiometric number of anions formed when solute dissociates in solution phase

stoichiometric number of ions formed when solute dissociates, $v=v^{+}+v^{-}$

stoichiometric number of species $i$

partial molar Gibbs free energy or chemical potential of species $i$

chemical potential of species $i$ in phase $j$

reference state chemical potential of species $i$

solution phase activity coefficient of species $i$

solution phase molar activity coefficient of species $i$

solution phase molal activity coefficient of species $i$

solution phase mole fraction scale activity coefficient of species $i$

mean ion activity coefficient

Bromley ion interaction parameter

Reduced activity coefficient in Meissner's method, defined by Equation (3.19)

Dimensionless parameter which is a function of $\left[H^{+}\right], K_{a 1}, K_{a 2}$ defined in Chapter 2 of this dissertation or Pitzer parameter

$\Lambda_{i j} \quad$ Wilson interaction coefficient for the resin phase 


\section{Subscripts}

1

cal

col

crys

diss

DH

ef

$\exp$

$i$

f

R

$s$

S

solid

ve

w

\section{Superscripts}

0

(0)

(1)

(2) indicates the pure solvent

indicates a calculated value

indicates probability of a collision between ions or molecules

indicates crystallisation process

indicates dissolution process

indicates the Debye-Hückel term

indicates the probability of an effective collision of a solvent dipole with crystal surface

indicates an experimentally obtained value

indicates species $i$

indicates solution phase properties

indicates resin phase properties

indicates the solid phase of a precipitate

indicates a specific surface site on a crystal surface

indicates the solid phase of a precipitate

indicates the probability that surface ions have sufficient vibration energy

indicates pure water

indicates reference state of pure (single solute) substances and solutions

indicates Pitzer parameter $\beta^{(0)}$

indicates Pitzer parameter $\beta^{(1)}$

indicates Pitzer parameter $\beta^{(2)}$ 


\section{LIST OF FIGURE TITLES}

$\underline{\text { Page }}$

\section{Chapter 1}

Figure 1.1 Equilibrium species formation for a Resin-in-Slurry mixture of 15 $\mathrm{CaSO}_{4}$ with a cation and anion exchange resin

\section{Chapter 2}

Figure 2.1 Solid / aqueous phase equilibrium considerations for the 26 dissolution of sparingly soluble solids for a Resin-in-Slurry mixture of $\mathrm{CaSO}_{4}$ with a cation and anion exchange resin

\section{Chapter 3}

Figure 3.1 Aqueous phase equilibrium considerations for the dissolution of 62 sparingly soluble solids of a Resin-in-Slurry mixture of $\mathrm{CaSO}_{4}$ with a cation and anion exchange resin

\section{Chapter 4}

Figure 4.1 Ion-exchange resin phase equilibrium considerations for the 105 dissolution of sparingly soluble solids of a Resin-in-Slurry mixture of $\mathrm{CaSO}_{4}$ with a cation and anion exchange resin

Figure 4.2 A synthetic strong-acid cation exchange resin with sulphonic 111 
functional groups $\left(-\mathrm{SO}_{3}{ }^{-}\right)$with a styrene-divinylbenzene polymer crosslinked matrix. The sulphonic acid groups are replaced by carboxylic acid groups $\left(-\mathrm{COO}^{-}\right)$in the case of a weak-acid cation exchange resin

Figure 4.3 A typical synthetic organic anion exchange resin matrix 112 constructed of polystyrene polymers crosslinked with divinylbenzene with basic ionic functional groups introduced by chloromethylation and treatment with (A) tertiary amino groups to form a strong-base anion exchange resin, and (B) with ammonia to form a weak-base anion exchange resin

\section{Chapter 5}

Figure 5.1 Resin / aqueous phase equilibrium considerations for the dissolution of sparingly soluble solids for a Resin-in-Slurry mixture of $\mathrm{CaSO}_{4}$ with a cation and anion exchange resin

\section{Chapter 7}

Figure 7.1 A schematic diagram of the column set-up used to convert the functional groups of a specific size fraction of the ion exchanger to the desired ionic form

Figure 7.2 Conceptual diagram of a volume of measured resin beads of 220 uniform particle size in a volumetric flask filled to volume with distilled water

Figure 7.3 Experimental data for the cation exchange resin $\mathrm{C} 26$ in the $\mathrm{Na}^{+} 226$ ionic form, for various resin sizes and water temperatures

Figure 7.4 Experimental data for the cation exchange resin C26 in the $\mathrm{K}^{+} \quad 227$ ionic form, for various resin sizes and water temperatures

Figure 7.5 Experimental data for the cation exchange resin $\mathrm{C} 26$ in the $\mathrm{H}^{+} \quad 228$ 
ionic form, for various resin sizes and water temperatures

Figure 7.6 Experimental data for the cation exchange resin $\mathrm{C} 26$ in the $\mathrm{Cu}^{+2} 229$ ionic form, for various resin sizes and water temperatures

Figure 7.7 Experimental data for the cation exchange resin $\mathrm{C} 26$ in the $\mathrm{Al}^{+3} \quad 230$ ionic form, for various resin sizes and water temperatures

Figure 7.8 Experimental data for the anion exchange resin $\mathrm{A} 161$ in the $\mathrm{Cl}^{-}$ ionic form, for various resin sizes and water temperatures

Figure 7.9 Experimental data for the anion exchange resin A161 in the $\mathrm{NO}_{3}{ }^{-}$ionic form, for various resin sizes and water temperatures

Figure 7.10 Experimental data for the anion exchange resin A161 in the $\mathrm{OH}^{-}$ ionic form, for various resin sizes and water temperatures

Figure 7.11 Experimental calculated data for the true wet densities of the 233 cation exchange (C26) and anion exchange (A161) resin for different ionic forms

\section{Chapter 8}

Figure 8.1 Equilibrium electrolyte absorption of $\mathrm{Na}^{+}$ions by a 246 macroreticular anion exchange resin, Duolite A161, for the binary anion exchange reaction between $\mathrm{F}^{-}$and $\mathrm{Cl}^{-}$

Figure 8.2 Equilibrium electrolyte absorption of $\mathrm{Na}^{+}$ions by a 247 macroreticular anion exchange resin, Duolite A161, for the binary anion exchange reaction between $\mathrm{F}^{-}$and $\mathrm{Cl}^{-}$expressed as a resin phase mole fraction of the capacity of the anion exchange resin

Figure 8.3 equilibrium electrolyte absorption of $\mathrm{Na}^{+}$ions by a 248 macroreticular anion exchange resin, Duolite A161, for the binary anion exchange reaction between $\mathrm{F}^{-}$and $\mathrm{NO}_{3}{ }^{-}$

Figure 8.4 Equilibrium electrolyte absorption of $\mathrm{Na}^{+}$ions by a 250 macroreticular anion exchange resin, Duolite A161, for the 
binary anion exchange reaction between $\mathrm{F}^{-}$and $\mathrm{NO}_{3}{ }^{-}$expressed as a resin phase mole fraction of the capacity of the anion exchange resin

Figure 8.5 Equilibrium solution and resin phase mole fractions for the ionexchange reaction between $\mathrm{F}^{-}$and $\mathrm{Cl}^{-}$and $\mathrm{F}^{-}$and $\mathrm{NO}_{3}{ }^{-}$on a macroreticular strong base anion exchange resin Duolite A161. Data obtained experimentally for different initial $F^{-}$ concentrations as indicated by legend in figure

Figure 8.6 Equilibrium solution and resin phase mole fractions for the ionexchange reaction between $\mathrm{SO}_{4}{ }^{2-}$ and $\mathrm{Cl}^{-}, \mathrm{SO}_{4}{ }^{2-}$ and $\mathrm{NO}_{3}{ }^{-}$and $\mathrm{SO}_{4}{ }^{2-}$ and $\mathrm{OH}^{-}$on a macroreticular strong base anion exchange resin Duolite A161. Data obtained experimentally for different initial $\mathrm{SO}_{4}{ }^{2-}$ concentrations as indicated by legend in figure

Figure 8.7 Equilibrium solution and resin phase mole fractions for the ion- 254 exchange reaction between $\mathrm{OH}^{-}$and $\mathrm{NO}_{3}{ }^{-}$and $\mathrm{OH}^{-}$and $\mathrm{Cl}^{-}$on a macroreticular strong base anion exchange resin Duolite A161. Data obtained experimentally for different initial $\mathrm{NaOH}$ concentrations, of which the initial $\mathrm{Na}^{+}$concentration is indicated by the legend in figure

Figure 8.8 Equilibrium solution and resin phase mole fractions for the ion255 exchange reaction between $\mathrm{CO}_{3}{ }^{2-}$ and $\mathrm{Cl}^{-}$and $\mathrm{CO}_{3}{ }^{2-}$ and $\mathrm{NO}_{3}{ }^{-}$ on a macroreticular strong base anion exchange resin Duolite A161. Data obtained experimentally for different initial $\mathrm{CO}_{3}{ }^{2-}$ concentrations as indicated by legend in the figure

Figure 8.9 Equilibrium solution and resin phase mole fractions for the ion256 exchange reaction between $\mathrm{HCO}_{3}{ }^{-}$and $\mathrm{Cl}^{-}$and $\mathrm{HCO}_{3}{ }^{-}$and $\mathrm{NO}_{3}{ }^{-}$ on a macroreticular strong base anion exchange resin Duolite A161. Data obtained experimentally for different initial $\mathrm{HCO}_{3}{ }^{-}$ concentrations as indicated by legend in figure

Figure 8.10 Equilibrium solution and resin phase mole fractions for the ion- 
exchange reaction between $\mathrm{Mg}^{+2}$ and $\mathrm{H}^{+}, \mathrm{Mg}^{+2}$ and $\mathrm{Na}^{+}, \mathrm{Mg}^{+2}$ and $\mathrm{K}^{+}, \mathrm{Mg}^{+2}$ and $\mathrm{Cu}^{+2}$ and $\mathrm{Mg}^{+2}$ and $\mathrm{Al}^{+2}$ on a macroreticular strong acid cation exchange resin Duolite C26. Data obtained experimentally for different initial $\mathrm{Mg}^{+2}$ concentrations as indicated by the legend in the figure

Figure 8.11 Equilibrium solution and resin phase mole fractions for the ion-

exchange reaction between $\mathrm{Ca}^{+2}$ and $\mathrm{H}^{+}, \mathrm{Ca}^{+2}$ and $\mathrm{Na}^{+}, \mathrm{Ca}^{+2}$ and $\mathrm{K}^{+}, \mathrm{Ca}^{+2}$ and $\mathrm{Cu}^{+2}$ and $\mathrm{Ca}^{+2}$ and $\mathrm{Al}^{+3}$ on a macroreticular strong acid cation exchange resin Duolite C26. Data obtained experimentally for different initial $\mathrm{Ca}^{+2}$ concentrations as indicated by the legend in the figure

Figure 8.12 Equilibrium solution and resin phase mole fractions for the ionexchange reaction between $\mathrm{Ba}^{+2}$ and $\mathrm{H}^{+}, \mathrm{Ba}^{+2}$ and $\mathrm{Na}^{+}, \mathrm{Ba}^{+2}$ and $\mathrm{K}^{+}, \mathrm{Ba}^{+2}$ and $\mathrm{Cu}^{+2}$ and $\mathrm{Ba}^{+2}$ and $\mathrm{Al}^{+3}$ on a macroreticular strong acid cation exchange resin Duolite C26. Data obtained experimentally for different initial $\mathrm{Ba}^{+2}$ concentrations as indicated by the legend in the figure

Figure 8.13 Equilibrium solution and resin phase mole fractions for the ionexchange reaction between $\mathrm{Pb}^{+2}$ and $\mathrm{H}^{+}, \mathrm{Pb}^{+2}$ and $\mathrm{Na}^{+}, \mathrm{Pb}^{+2}$ and $\mathrm{K}^{+}, \mathrm{Pb}^{+2}$ and $\mathrm{Cu}^{+2}$ and $\mathrm{Pb}^{+2}$ and $\mathrm{Al}^{+3}$ on a macroreticular strong acid cation exchange resin Duolite C26. Data obtained experimentally for different initial $\mathrm{Pb}^{+2}$ concentrations as indicated by the legend in the figure

Figure 8.14 Equilibrium solution and resin phase mole fractions for the ionexchange reaction between $\mathrm{Al}^{+3}$ and $\mathrm{H}^{+} ; \mathrm{Al}^{+3}$ and $\mathrm{Na}^{+}$and $\mathrm{Al}^{+3}$ and $\mathrm{K}^{+}$on a macroreticular strong acid cation exchange resin Duolite C26. Data obtained experimentally for different initial $\mathrm{Al}^{+3}$ concentrations as indicated by the legend in the figure

Figure 8.15 Experimental and model values for the equilibrium quotient for 269 the exchange reaction between $\mathrm{F}^{-}$and $\mathrm{Cl}^{-}$, with $\mathrm{Co}(\mathrm{F})$ of 52 
ppm

Figure 8.16 Experimental and model values for the equilibrium quotient for

the exchange reaction between $\mathrm{F}^{-}$and $\mathrm{Cl}^{-}$, with $\mathrm{Co}\left(\mathrm{F}^{-}\right)$of 99.5 ppm

Figure 8.17 Experimental and model values for the equilibrium quotient for the exchange reaction between $\mathrm{F}^{-}$and $\mathrm{Cl}^{-}$, with $\mathrm{Co}\left(\mathrm{F}^{-}\right)$of 208 ppm

Figure 8.18 Experimental and model values for the equilibrium quotient for 270 the exchange reaction between $\mathrm{F}^{-}$and $\mathrm{Cl}^{-}$, with $\mathrm{Co}\left(\mathrm{F}^{-}\right)$of 510 ppm

\section{Chapter 9}

Figure 9.1 Equilibrium isotherms for the adsorption of $\mathrm{Pb}^{+2}$ ions by a 282 strong acid cation exchange resin, Duolite C26, from a clear aqueous $\mathrm{Pb}\left(\mathrm{NO}_{3}\right)_{2}$ solution for different initial cationic forms of the resin at $18.0^{\circ} \mathrm{C}$

Figure 9.2 Equilibrium isotherms at different total solution concentrations for the adsorption of $\mathrm{Ba}^{+2}$ ions by Duolite $\mathrm{C} 26$, saturated with $\mathrm{Na}^{+}$ions, from a clear aqueous $\mathrm{BaCl}_{2}$ solution at $19.8^{\circ} \mathrm{C}$

Figure 9.3 Equilibrium isotherms at different total solution concentrations for the sorption of $\mathrm{Ba}^{+2}$ ions by Duolite $\mathrm{C} 26$, saturated with $\mathrm{Cu}^{+2}$ ions, from a clear aqueous $\mathrm{BaCl}_{2}$ solution at $19.8^{\circ} \mathrm{C}$

Figure 9.4 Equilibrium isotherms at different total solution concentrations for the sorption of $\mathrm{Ba}^{+2}$ ions by Duolite $\mathrm{C} 26$, saturated with $\mathrm{Al}^{+3}$ ions, from a clear aqueous $\mathrm{BaCl}_{2}$ solution at $19.8^{\circ} \mathrm{C}$

Figure 9.5 Decrease in the equilibrium solution concentration of $\mathrm{Pb}^{+2}$ ions 286 in a pure $\mathrm{PbSO}_{4}$ slurry mixture with an increase in the $\mathrm{SO}_{4}{ }^{2-}$ concentration, common ion effect

Figure 9.6 Equilibrium solution phase concentrations of $\mathrm{Pb}^{+2}$ and $\mathrm{SO}_{4}{ }^{2-} 288$ 
ions in an aqueous $\mathrm{PbSO}_{4}$ resin-in-pulp slurry mixture containing a strong acid cation exchange resin, Duolite $\mathrm{C} 26$, for different initial cationic forms of the resin at $19.0^{\circ} \mathrm{C}$

Figure 9.7 Equilibrium solution phase concentrations of $\mathrm{Pb}^{+2}$ ions, from an aqueous $\mathrm{PbSO}_{4} \mathrm{RIP}$ slurry mixture as a function of the volume of resin added per litre of solution

Figure 9.8 Equilibrium resin loading isotherms for the sorption of $\mathrm{Pb}^{+2}$ 290 onto Duolite $\mathrm{C} 26$, from an aqueous $\mathrm{PbSO}_{4} \mathrm{RIP}$ slurry mixture as a function of the volume of resin added per litre of solution

Figure 9.9 Resin/solution equilibrium loading isotherms for the sorption of $\mathrm{Pb}^{+2}$ ions onto Duolite $\mathrm{C} 26$, from a $\mathrm{PbSO}_{4} \mathrm{RIP}$ slurry mixture for different initial ionic forms of the cation exchange resin at $19.0^{\circ} \mathrm{C}$

Figure 9.10 Equilibrium resin loading of $\mathrm{Pb}^{+2}$ ions onto Duolite $\mathrm{C} 26$, from an aqueous $\mathrm{PbSO}_{4} \mathrm{RIP}$ slurry mixture containing the cation resin in the $\mathrm{K}^{+}$ionic form and the anion resin, Duolite $\mathrm{A} 161$, in the $\mathrm{NO}_{3}{ }^{-}$ionic form, as a function of the ratio of the equivalent volume of cation resin to equivalent volume of anion resin

Figure 9.11 Equilibrium resin loading of $\mathrm{Pb}^{+2}$ ions onto Duolite $\mathrm{C} 26$, from 295 an aqueous $\mathrm{PbSO}_{4} \mathrm{RIP}$ slurry mixture containing the cation resin in the $\mathrm{Al}^{+3}$ ionic form and the anion resin, Duolite $\mathrm{A} 161$, in the $\mathrm{NO}_{3}{ }^{-}$ionic form, as a function of the ratio of the equivalent volume of cation resin to equivalent volume of anion resin

Figure 9.12 Total molar solution ionic strength I and equilibrium solution phase concentrations of $\mathrm{Pb}^{+2}, \mathrm{SO}_{4}{ }^{2-}$ and $\mathrm{K}^{+}$in an aqueous $\mathrm{PbSO}_{4} \mathrm{RIP}$ slurry mixture containing Duolite C26 initially in the potassium ionic form $\left(\mathrm{R}^{-}\right) \mathrm{K}^{+}$, as a function of the volume of resin added per litre of solution at $19.0^{\circ} \mathrm{C}$

Figure 9.13 Total molar solution ionic strength $\mathrm{I}$ in an aqueous $\mathrm{PbSO}_{4} \mathrm{RIP}$ 
slurry mixture containing Duolite C26, for different initial ionic forms as a function of the volume of resin added per litre of solution at $19.0^{\circ} \mathrm{C}$

Figure 9.14 The Pitzer model activity coefficients for the aqueous phase 304 species in the resin / solution system for the cation-exchange reaction between the cations $\mathrm{Ca}^{+2}$ and $\mathrm{H}^{+}$with $\mathrm{Cl}^{-}$anions for different total solution phase concentrations of the $\mathrm{Ca}^{+2}$ ions

Figure 9.15 The equilibrium quotient calculated with the Pitzer model 305 activity coefficients the resin / solution cation-exchange reaction between the cations $\mathrm{Ca}^{+2}$ and $\mathrm{H}^{+}$with anions $\mathrm{Cl}^{-}$

Figure 9.16 The Pitzer model activity coefficients for the aqueous phase 308 species in the resin / solution system for the cation-exchange reaction between the cations $\mathrm{Ca}^{+2}$ and $\mathrm{Na}^{+}$with $\mathrm{Cl}^{-}$anions for different total solution phase concentrations of the $\mathrm{Ca}^{+2}$ ions

Figure 9.17 The equilibrium quotient calculated with the Pitzer model 309 activity coefficients the resin / solution cation-exchange reaction between the cations $\mathrm{Ca}^{+2}$ and $\mathrm{Na}^{+}$with anions $\mathrm{Cl}^{-}$

Figure 9.18 The Pitzer model activity coefficients for the aqueous phase species in the resin / solution system for the cation-exchange reaction between the cations $\mathrm{Ca}^{+2}$ and $\mathrm{K}^{+}$with $\mathrm{Cl}^{-}$anions for different solution phase concentrations of the $\mathrm{Ca}^{+2}$ ions

Figure 9.19 The equilibrium quotient calculated with the Pitzer model 315 activity coefficients the resin / solution cation-exchange reaction between the cations $\mathrm{Ca}^{+2}$ and $\mathrm{K}^{+}$with anions $\mathrm{Cl}^{-}$

Figure 9.20 Calculated solubility of $\mathrm{CaSO}_{4} \cdot 2 \mathrm{H}_{2} \mathrm{O}$ in a $\mathrm{NaCl}$ aqueous electrolyte solution at $25^{\circ} \mathrm{C}$ and $101.325 \mathrm{kPa}$ pressure with the use of a Pitzer activity coefficient model

Figure 9.21 Calculated aqueous phase activity coefficients for the solubility of $\mathrm{CaSO}_{4} \cdot 2 \mathrm{H}_{2} \mathrm{O}$ in a $\mathrm{NaCl}$ aqueous electrolyte solution at $25^{\circ} \mathrm{C}$ and $101.325 \mathrm{kPa}$ pressure with the use of a Pitzer activity 
coefficient model

Figure 9.22 Calculated solubility of $\mathrm{CaSO}_{4} \cdot 2 \mathrm{H}_{2} \mathrm{O}$ in a $\mathrm{KCl}$ aqueous 319 electrolyte solution at $25^{\circ} \mathrm{C}$ and $101.325 \mathrm{kPa}$ pressure with the use of a Pitzer activity coefficient model

Figure 9.23 Calculated aqueous phase activity coefficients for the solubility 320 of $\mathrm{CaSO}_{4} \cdot 2 \mathrm{H}_{2} \mathrm{O}$ in a $\mathrm{KCl}$ aqueous electrolyte solution at $25^{\circ} \mathrm{C}$ and $101.325 \mathrm{kPa}$ pressure with the use of a Pitzer activity coefficient model

Figure 9.24 Model prediction of the equilibrium quotient for the exchange reaction between $\mathrm{Ca}^{+2}$ and $\mathrm{Na}^{+}$for a solution phase concentration of 0.0243 moles/litre

Figure 9.25 Model prediction of the equilibrium quotient for the exchange reaction between $\mathrm{Ca}^{+2}$ and $\mathrm{Na}^{+}$for a solution phase concentration of 0.0123 moles/litre

Figure 9.26 Model prediction of the equilibrium quotient for the exchange 324 reaction between $\mathrm{Ca}^{+2}$ and $\mathrm{Na}^{+}$for a solution phase concentration of $0.0024 \mathrm{moles} / \mathrm{litre}$

Figure 9.27 Thermodynamic equilibrium constant $\mathrm{K}_{\mathrm{NaCa}}$ and Wilson interaction parameters for the ion-exchange reaction between $\mathrm{Ca}^{+2}$ and $\mathrm{Na}^{+}$for different solution phase concentrations of the $\mathrm{Ca}^{+2}$ ions on Duolite $\mathrm{C} 26$

Figure 9.28 Resin activity coefficients for $\mathrm{Na}^{+}-\mathrm{Ca}^{+2}$ exchange at $974 \mathrm{ppm}$ $\mathrm{Ca}^{+2}$

Figure 9.29 Resin activity coefficients for $\mathrm{Na}^{+}-\mathrm{Ca}^{+2}$ exchange at $494 \mathrm{ppm}$ $\mathrm{Ca}^{+2}$

Figure 9.30 Resin activity coefficients for $\mathrm{Na}^{+}-\mathrm{Ca}^{+2}$ exchange at $98 \mathrm{ppm}$ $\mathrm{Ca}^{+2}$

Figure 9.31 Model prediction of the equilibrium quotient for the exchange reaction between $\mathrm{Ca}^{+2}$ and $\mathrm{K}^{+}$for a solution phase concentration of 0.0243 moles/litre 
Figure 9.32 Model prediction of the equilibrium quotient for the exchange reaction between $\mathrm{Ca}^{+2}$ and $\mathrm{K}^{+}$for a solution phase concentration of $0.0123 \mathrm{moles} / \mathrm{litre}$

Figure 9.33 Model prediction of the equilibrium quotient for the exchange 334 reaction between $\mathrm{Ca}^{+2}$ and $\mathrm{K}^{+}$for a solution phase concentration of 0.0024 moles/litre

Figure 9.34 Resin activity coefficients for $\mathrm{K}^{+}-\mathrm{Ca}^{+2}$ exchange at $974 \mathrm{ppm}$ $\mathrm{Ca}^{+2}$

Figure 9.35 Resin activity coefficients for $\mathrm{K}^{+}-\mathrm{Ca}^{+2}$ exchange at $494 \mathrm{ppm}$ $\mathrm{Ca}^{+2}$

Figure 9.34 Resin activity coefficients for $\mathrm{K}^{+}-\mathrm{Ca}^{+2}$ exchange at $98 \mathrm{ppm} 336$ $\mathrm{Ca}^{+2}$

Figure 9.37 Model Prediction of the $\mathrm{Ca}^{+2}$ resin loading on the Cation exchange resin Duolite $\mathrm{C} 26$ for the $\mathrm{CaSO}_{4} \cdot 2 \mathrm{H}_{2} \mathrm{O}$ RIP slurry mixture system

Figure 9.38 Model Prediction of the $\mathrm{Ca}^{+2}$ resin loading on the Cation 339 exchange resin Duolite C26 for the $\mathrm{CaSO}_{4} \cdot 2 \mathrm{H}_{2} \mathrm{O}$ RIP slurry mixture system

\section{Chapter 10}

Figure 10.1 Calculated Pitzer model activity coefficients for the aqueous phase species in the resin / solution system for the cationexchange reaction between $\mathrm{Ca}^{+2}$ and $\mathrm{Cu}^{+2}$ with $\mathrm{Cl}^{-}$as the coion for total solution phase concentrations of the $\mathrm{Ca}^{+2}$ species

Figure 10.2 Model prediction of the equilibrium quotient for the exchange reaction between $\mathrm{Ca}^{+2}$ and $\mathrm{Cu}^{+2}$ for a solution phase concentration of $0.0243 \mathrm{moles} / \mathrm{litre}$

Figure 10.3 Model prediction of the equilibrium quotient for the exchange reaction between $\mathrm{Ca}^{+2}$ and $\mathrm{Cu}^{+2}$ for a solution phase 
concentration of 0.0123 moles/litre

Figure 10.4 Model prediction of the equilibrium quotient for the exchange reaction between $\mathrm{Ca}^{+2}$ and $\mathrm{Cu}^{+2}$ for a solution phase concentration of 0.0024 moles/litre

Figure 10.5 Thermodynamic equilibrium constant $\mathrm{K}_{\mathrm{CuCa}}$ and Wilson 358 interaction parameters for the ion-exchange reaction between $\mathrm{Ca}^{+2}$ and $\mathrm{Cu}^{+2}$ for different solution phase concentrations of the $\mathrm{Ca}^{+2}$ ions on Duolite $\mathrm{C} 26$

Figure 10.6 Resin activity coefficients for $\mathrm{Cu}^{+2}-\mathrm{Ca}^{+2}$ exchange at $974 \mathrm{ppm} 360$ $\mathrm{Ca}^{+2}$

Figure 10.7 Resin activity coefficients for $\mathrm{Cu}^{+2}-\mathrm{Ca}^{+2}$ exchange at $494 \mathrm{ppm} 360$ $\mathrm{Ca}^{+2}$

Figure 10.8 Resin activity coefficients for $\mathrm{Cu}^{+2}-\mathrm{Ca}^{+2}$ exchange at $98 \mathrm{ppm} 361$ $\mathrm{Ca}^{+2}$

Figure 10.9 Objective function value versus generation number for the 363 differential evolution optimisation simulation in the calculation of the consolidated equilibrium model for the RIP slurry mixture system

Figure 10.10 Equilibrium electrolyte adsorption of $\mathrm{Cl}^{-}$ions by a 364 macroreticular cation exchange resin, Duolite $\mathrm{C} 26$, for the binary anion exchange reaction between $\mathrm{Ca}^{+2}$ and $\mathrm{Cu}^{+2}$

Figure 10.11 Calculated aqueous phase activity coefficients for the 365 solubility of $\mathrm{CaSO}_{4} \cdot 2 \mathrm{H}_{2} \mathrm{O}$ in a $\mathrm{CuCl}_{2}$ aqueous electrolyte solution at $25^{\circ} \mathrm{C}$ and $101.325 \mathrm{kPa}$ pressure with the use of a Pitzer activity coefficient model

Figure 10.12 Calculated solubility of $\mathrm{CaSO}_{4} \cdot 2 \mathrm{H}_{2} \mathrm{O}$ in a $\mathrm{CuCl}_{2}$ aqueous 366 electrolyte solution at $25^{\circ} \mathrm{C}$ and $101.325 \mathrm{kPa}$ pressure with the use of a Pitzer activity coefficient model

\section{Chapter 11}


Figure 11.1 Extrapolation curves for the saturation solution phase 378 concentration of $\mathrm{Ca}^{+2}$ ions in a RIP slurry mixture system containing only a cation exchange resin

Figure 11.2 Extrapolation curves for the saturation solution phase 379 concentration of $\mathrm{Ca}^{+2}$ ions in a RIP slurry mixture system containing only an anion exchange resin

Figure 11.3 Extrapolation curves for the saturation solution phase 380 concentration of $\mathrm{SO}_{4}{ }^{2-}$ ions in a RIP slurry mixture system containing only a cation exchange resin

Figure 11.4 Extrapolation curves for the saturation solution phase 381 concentration of $\mathrm{SO}_{4}{ }^{2-}$ ions in a RIP slurry mixture system containing only an anion exchange resin

Figure 11.5 Model prediction of the equilibrium quotient for the exchange reaction between $\mathrm{Ca}^{+2}$ and $\mathrm{Al}^{+3}$ for a solution phase concentration of $0.0243 \mathrm{moles} / \mathrm{litre}$

Figure 11.6 Model prediction of the equilibrium quotient for the exchange 384 reaction between $\mathrm{Ca}^{+2}$ and $\mathrm{Al}^{+3}$ for a solution phase concentration of $0.0123 \mathrm{moles} / \mathrm{litre}$

Figure 11.7 Model prediction of the equilibrium quotient for the exchange 385 reaction between $\mathrm{Ca}^{+2}$ and $\mathrm{Al}^{+3}$ for a solution phase concentration of 0.0024 moles/litre

Figure 11.8 Model prediction of the equilibrium quotient for the exchange reaction between $\mathrm{Pb}^{+2}$ and $\mathrm{Al}^{+3}$ for a solution phase concentration of 0.0049 moles/litre

Figure 11.9 Model prediction of the equilibrium quotient for the exchange reaction between $\mathrm{Pb}^{+2}$ and $\mathrm{Al}^{+3}$ for a solution phase concentration of $0.0024 \mathrm{moles} / \mathrm{litre}$

Figure 11.10 Model prediction of the equilibrium quotient for the exchange 388 reaction between $\mathrm{Pb}^{+2}$ and $\mathrm{Al}^{+3}$ for a solution phase 
concentration of 0.0012 moles/litre

Figure 11.11 Resin activity coefficients for $\mathrm{Al}^{+3}-\mathrm{Ca}^{+2}$ exchange at 974389 ppm $\mathrm{Ca}^{+2}$

Figure 11.12 Resin activity coefficients for $\mathrm{Al}^{+3}-\mathrm{Ca}^{+2}$ exchange at 494390 ppm $\mathrm{Ca}^{+2}$

Figure 11.13 Resin activity coefficients for $\mathrm{Al}^{+3}-\mathrm{Ca}^{+2}$ exchange at $98 \mathrm{ppm} 391$ $\mathrm{Ca}^{+2}$

Figure 11.14 Resin activity coefficients for $\mathrm{Al}^{+3}-\mathrm{Pb}^{+2}$ exchange at 1018391 $\mathrm{ppm} \mathrm{Pb}^{+2}$

Figure 11.15 Resin activity coefficients for $\mathrm{Al}^{+3}-\mathrm{Pb}^{+2}$ exchange at 497392 ppm $\mathrm{Pb}^{+2}$

Figure 11.16 Resin activity coefficients for $\mathrm{Al}^{+3}-\mathrm{Pb}^{+2}$ exchange at 253392 ppm $\mathrm{Pb}^{+2}$

Figure 11.17 Equilibrium electrolyte adsorption of $\mathrm{Cl}^{-}$ions by a 393 macroreticular cation exchange resin, Duolite $\mathrm{C} 26$, for the binary anion exchange reaction between $\mathrm{Ca}^{+2}$ and $\mathrm{Al}^{+3}$

Figure 11.18 Model prediction of the equilibrium quotient for the exchange 398 reaction between $\mathrm{NO}_{3}{ }^{-}$and $\mathrm{SO}_{4}{ }^{2-}$ for a solution phase concentration of 0.0249 moles/litre

Figure 11.19 Model prediction of the equilibrium quotient for the exchange 398 reaction between $\mathrm{NO}_{3}{ }^{-}$and $\mathrm{SO}_{4}{ }^{2-}$ for a solution phase concentration of 0.0099 moles/litre

Figure 11.20 Model prediction of the equilibrium quotient for the exchange 399 reaction between $\mathrm{NO}_{3}{ }^{-}$and $\mathrm{SO}_{4}{ }^{2-}$ for a solution phase concentration of 0.0025 moles/litre

Figure 11.21 Model prediction of the equilibrium quotient for the exchange reaction between $\mathrm{Cl}^{-}$and $\mathrm{SO}_{4}{ }^{2-}$ for a solution phase concentration of $0.0249 \mathrm{moles} / \mathrm{litre}$

Figure 11.22 Model prediction of the equilibrium quotient for the exchange 400 reaction between $\mathrm{Cl}^{-}$and $\mathrm{SO}_{4}{ }^{2-}$ for a solution phase 
concentration of $0.0099 \mathrm{moles} / \mathrm{litre}$

Figure 11.23 Model prediction of the equilibrium quotient for the exchange 401 reaction between $\mathrm{Cl}^{-}$and $\mathrm{SO}_{4}{ }^{2-}$ for a solution phase concentration of $0.0025 \mathrm{moles} / \mathrm{litre}$

Figure 11.24 Calculated aqueous phase activity coefficients for the 402 solubility of $\mathrm{CaSO}_{4} \cdot 2 \mathrm{H}_{2} \mathrm{O}$ in an $\mathrm{AlCl}_{3}$ aqueous electrolyte solution at $25^{\circ} \mathrm{C}$ and $101.325 \mathrm{kPa}$ pressure with the use of a Pitzer activity coefficient model

Figure 11.25 Calculated solubility of $\mathrm{CaSO}_{4} \cdot 2 \mathrm{H}_{2} \mathrm{O}$ in an $\mathrm{AlCl}_{3}$ aqueous 403 electrolyte solution at $25^{\circ} \mathrm{C}$ and $101.325 \mathrm{kPa}$ pressure with the use of a Pitzer activity coefficient model 


\section{LIST OF TABLE TITLES}

$\underline{\text { Page }}$

\section{Chapter 2}

Table 2.1 Dielectric constants for polar and non-polar solvents (Basset et al.,1966)

Table 2.2 The solubility of precipitates as a function of the solubility 45 product

\section{Chapter 6}

Table 6.1 Thermodynamic dissolution coefficients for different resin-in- 166 pulp mixtures containing a cation exchange resin only

Table 6.2 Thermodynamic dissolution coefficients for different resin-in- 167 pulp mixtures containing an anion exchange resin only

Table 6.3 Detailed Pitzer parameters for various electrolyte species as 198 used in above detailed equations at $25^{\circ} \mathrm{C}$, selected from the data base

Table 6.4 Thermodynamic properties stored for various species in the 199 SQL database for use in model equations. Properties shown are those at $25^{\circ} \mathrm{C}(298.15 \mathrm{~K})$ as selected from the database

\section{Chapter 7}

Table 7.1 Conventional screen and constructed square surface screen 205 
sizes used for screening the resin particles into different size fractions

Table 7.2 Chemicals used to convert the ion exchange resins to a specific 209 ionic form. (All chemicals were of analytical reagent grade.)

Table 7.3 Methods and background solutions needed to analyse for the 212 different species

Table 7.27 Sparingly soluble solids used in experimental procedures 234

\section{Chapter 8}

Table 8.1 Extent of the number of experimental data points for binary 239 ion-exchange equilibrium isotherms between different cations with different anions as co-ions for various concentration and temperature ranges

Table 8.2 The extent of the number of experimental data points for 240 binary ion-exchange equilibrium isotherms between different anions with different cations as co-ions for various concentration and temperature ranges

Table 8.3 Experimentally determined and model prediction values of the equilibrium quotient for the anion-exchange reaction between $\mathrm{F}^{-}$and $\mathrm{Cl}^{-}$as a function of the equilibrium fractional loading of $\mathrm{F}^{-}$for an initial solution phase concentration of $52.19 \mathrm{ppm} \mathrm{F}^{-}$

Table 8.4 Experimentally determined and model prediction values of the equilibrium quotient for the anion-exchange reaction between $\mathrm{F}^{-}$and $\mathrm{Cl}^{-}$as a function of the equilibrium fractional loading of $\mathrm{F}^{-}$for an initial solution phase concentration of $208.17 \mathrm{ppm} \mathrm{F}$

Table 8.5 Experimentally determined and model prediction values of the equilibrium quotient for the anion-exchange reaction between $\mathrm{F}^{-}$and $\mathrm{Cl}^{-}$as a function of the equilibrium fractional loading of $\mathrm{F}^{-}$for an initial solution phase concentration of $510.23 \mathrm{ppm} \mathrm{F}^{-}$ 
Table 8.6 Experimentally determined and model prediction values of the 268 equilibrium quotient for the anion-exchange reaction between $\mathrm{F}^{-}$and $\mathrm{Cl}^{-}$as a function of the equilibrium fractional loading of $\mathrm{F}^{-}$for an initial solution phase concentration of $99.56 \mathrm{ppm} \mathrm{F}^{-}$

Table 8.7 Summary results for the model prediction of the 271 thermodynamic equilibrium constant for the anion-exchange reaction between $\mathrm{F}^{-}$and $\mathrm{Cl}^{-}$with $\mathrm{Na}^{+}$as the co-ionic species for various initial solution phase concentrations of $\mathrm{F}^{-}$

\section{Chapter 9}

Table 9.1 Various Resin-in-Pulp slurry mixture systems studied 276 experimentally for different ionic forms of the cation and anion exchange resin

Table 9.2 Values for the Pitzer model parameters $\beta^{(0)}, \beta^{(1)}, C^{\phi}, \phi$ and 303 $\psi$ used in the calculation of the thermodynamic equilibrium constant $K_{H}^{\mathrm{Ca}}$ for the exchange reaction between $\mathrm{Ca}^{+2}$ and $\mathrm{H}^{+}$ with $\mathrm{Cl}^{-}$as the co-ion. Parameters obtained from SQL7 data base. All Pitzer values shown are multiplied with the gas constant $R=8.31441 \mathrm{~kJ} / \mathrm{kmol} . \mathrm{K}$

Table 9.3 Calculated solution phase activity coefficients, resin fractional 307 loading of $\mathrm{Ca}^{+2}$ and equilibrium quotient for the cationexchange reaction between $\mathrm{Ca}^{+2}$ and $\mathrm{H}^{+2}$ on Duolite $\mathrm{C} 26$

Table 9.4 Values for the Pitzer model parameters $\beta^{(0)}, \beta^{(1)}, C^{\phi}, \phi$ and $\psi$ used in the calculation of the thermodynamic equilibrium constant $K_{N a}^{\mathrm{Ca}}$ for the exchange reaction between $\mathrm{Ca}^{+2}$ and $\mathrm{Na}^{+}$ with $\mathrm{Cl}^{-}$as the co-ion. Parameters obtained from SQL7 data base. All Pitzer values shown are multiplied with the gas constant $R=8.31441 \mathrm{~kJ} / \mathrm{kmol} . \mathrm{K}$ 
Table 9.5 Values for the Pitzer model parameters $\beta^{(0)}, \beta^{(1)}, C^{\phi}, \phi$ and $\psi$ used in the calculation of the thermodynamic equilibrium constant $K_{K}^{\mathrm{Ca}}$ for the exchange reaction between $\mathrm{Ca}^{+2}$ and $\mathrm{K}^{+}$ with $\mathrm{Cl}^{-}$as the co-ion. Parameters obtained from SQL7 data base. All Pitzer values shown are multiplied with the gas constant $R=8.31441 \mathrm{~kJ} / \mathrm{kmol} . \mathrm{K}$

Table 9.6 Calculated values for thermodynamic equilibrium constant and Wilson parameters for the exchange reaction between $\mathrm{Ca}^{+2}$ and $\mathrm{Na}^{+}$ions on Duolite $\mathrm{C} 26$

Table 9.7 Calculated values for thermodynamic equilibrium constant and 328 Wilson parameters for the exchange reaction between $\mathrm{Ca}^{+2}$ and $\mathrm{K}^{+}$ions on Duolite $\mathrm{C} 26$

\section{Chapter 10}

Table 10.1 Values for the Pitzer model parameters $\beta^{(0)}, \beta^{(1)}, C^{\phi}, \phi$ and $\psi$ used in the calculation of the thermodynamic equilibrium constant $K_{C u}^{C a}$ for the exchange reaction between $\mathrm{Ca}^{+2}$ and $\mathrm{Cu}^{+2}$ with $\mathrm{Cl}^{-}$as the co-ion. Parameters obtained from SQL7 data base. All Pitzer values shown are multiplied with the gas constant $R=8.31441 \mathrm{~kJ} / \mathrm{kmol} . \mathrm{K}$

Table 10.2 Calculated solution phase activity coefficients, resin phase fractional loading for $\mathrm{Ca}^{+2}$ and equilibrium quotient for the cation-exchange reaction between $\mathrm{Ca}^{+2}$ and $\mathrm{Cu}^{+2}$ on Duolite $\mathrm{C} 26$ at a total solution phase concentration for $\mathrm{Ca}^{+2}$ of 0.0243 moles/litre

Table 10.3 Calculated values for thermodynamic equilibrium constant and

Wilson parameters for the exchange reaction between $\mathrm{Ca}^{+2}$ and $\mathrm{Cu}^{+2}$ ions on Duolite $\mathrm{C} 26$ 
Table 10.4 Parameters used in the differential evolution optimisation 362 procedure in the calculation of the consolidated equilibrium model parameters for a typical RIP slurry mixture system

\section{Chapter 11}

Table 11.1 Values for the Pitzer model parameters $\beta^{(0)}, \beta^{(1)}, C^{\phi}, \phi$ and $\psi$ used in the calculation of the thermodynamic equilibrium constant $K_{A l}^{P b}$ for the exchange reaction between $\mathrm{Pb}^{+2}$ and $\mathrm{Al}^{+3}$ with $\mathrm{NO}_{3}{ }^{-}$as the co-ion. Parameters obtained from SQL7 data base. All Pitzer values shown are multiplied with the gas constant $R=8.31441 \mathrm{~kJ} / \mathrm{kmol} . \mathrm{K}$

Table 11.2 Values for the Pitzer model parameters $\beta^{(0)}, \beta^{(1)}, C^{\phi}, \phi$ and $\psi$ used in the calculation of the thermodynamic equilibrium constant $K_{A l}^{C a}$ for the exchange reaction between $\mathrm{Ca}^{+2}$ and $\mathrm{Al}^{+3}$ with $\mathrm{Cl}^{-}$as the co-ion. Parameters obtained from SQL7 data base. All Pitzer values shown are multiplied with the gas constant $R=8.31441 \mathrm{~kJ} / \mathrm{kmol} . \mathrm{K}$

Table 11.3 Calculated solution phase activity coefficients, resin phase fractional loading for $\mathrm{Ca}^{+2}$ and equilibrium quotient for the cation-exchange reaction between $\mathrm{Ca}^{+2}$ and $\mathrm{Al}^{+3}$ on Duolite C26 for different total solution phase concentrations for $\mathrm{Ca}^{+2}$

Table 11.4 Calculated solution phase activity coefficients, resin phase fractional loading for $\mathrm{Pb}^{+2}$ and equilibrium quotient for the cation-exchange reaction between $\mathrm{Pb}^{+2}$ and $\mathrm{Al}^{+3}$ on Duolite $\mathrm{C} 26$ for different total solution phase concentrations for $\mathrm{Pb}^{+2}$

Table 11.5 Values for the solubility of $\mathrm{CaSO}_{4} \cdot 2 \mathrm{H}_{2} \mathrm{O}$ obtained from various literature sources

Table 11.6 Calculated values for thermodynamic equilibrium constant and 
Wilson parameters for the exchange reaction between $\mathrm{Ca}^{+2}$ and $\mathrm{Al}^{+3}$ ions on Duolite $\mathrm{C} 26$

Table 11.7 Calculated values for thermodynamic equilibrium constant and

Wilson parameters for the exchange reaction between $\mathrm{Pb}^{+2}$ and $\mathrm{Al}^{+3}$ ions on Duolite $\mathrm{C} 26$

Table 11.8 Pitzer model parameters $\beta^{(0)}, \beta^{(1)}, C^{\phi}, \phi$ and $\psi$ used in the calculation of the thermodynamic equilibrium constant $K_{C l}^{S O 4}$ for the exchange reaction between $\mathrm{SO}_{4}{ }^{2-}$ and $\mathrm{Cl}^{-}$with $\mathrm{Na}^{+}$as the co-ion. Values shown are multiplied with $R=8.31441$ $\mathrm{kJ} / \mathrm{kmol} . \mathrm{K}$

Table 11.9 Values for the Pitzer model parameters $\beta^{(0)}, \beta^{(1)}, C^{\phi}, \phi$ and $\psi$ used in the calculation of the thermodynamic equilibrium constant $K_{N O 3}^{\mathrm{SO} 4}$ for the exchange reaction between $\mathrm{SO}_{4}{ }^{2-}$ and $\mathrm{NO}_{3}{ }^{-}$with $\mathrm{Na}^{+}$as the co-ion. Parameters obtained from SQL7 data base. All Pitzer values shown are multiplied with the gas constant $R=8.31441 \mathrm{~kJ} / \mathrm{kmol} . \mathrm{K}$

Table 11.10 Calculated values for thermodynamic equilibrium constant and 396 Wilson parameters for the exchange reaction between $\mathrm{Cl}^{-}$and $\mathrm{SO}_{4}{ }^{2-}$ ions on Duolite $\mathrm{A} 161$

Table 11.11 Calculated values for thermodynamic equilibrium constant and Wilson parameters for the exchange reaction between $\mathrm{NO}_{3}{ }^{-}$ and $\mathrm{SO}_{4}{ }^{2-}$ ions on Duolite $\mathrm{A} 161$ 


\section{CHAPTER 1}

\section{INTRODUCTION}

Many metallurgical industries are experiencing the reality of becoming marginal profit operations due to lowering ore grades, high-energy operation costs, unstable markets and an unpredictable economic climate. In many valuable metal recovery operations it is the by-products that have made deposits economically workable, and nowadays it is a wellestablished and accepted way of thought that this potential must be fully exploited. To achieve this in a marginal hydrometallurgical process is problematic, as it becomes necessary for the metallurgical engineer to consider every valuable metal present in a process stream as economically recoverable. Usually this is not possible due to a lack of proper technology, which is strongly reflected by the all but non-zero valuable metal content of many process tailings.

Moreover, the interplay between metal recovery and plant throughput is critical to long term production strategies. Improvements in recovery technology are consequently pivotal to the future of mineral processing, particularly in view of increased importance placed upon recovering valuable metal species in tailings and that which naturally occurs as trace components. In the case of the latter, it is not too uncommon to find rare earth metals with an ore content of $0.05 \%$, which is very low by any modern hydrometallurgical recovery standard. This is aggravated by complex metallurgy that inhibits efficient extraction of the wanted metal species, without liberating contaminants (unwanted species) associated with the valuable metal.

Renewed interest in the application of low-grade recovery technology is not entirely focused on the recovery of valuable metals in the hydrometallurgical ore processing 
industry. The recovery of valuable metals from artificial ore bodies can prove to be economically justifiable and challenging. This includes the recovery of metals such as nickel from spent catalysts used by the chemical industry, cobalt, molybdenum and gold from fly ash generated by power stations, and gold from recycled electronic circuit boards. However, the economic viability of such a process depends largely on the technology employed, which needs to be highly selective and energy efficient in nature. This is necessary to compensate for the low valuable metal content of the "ore". The current accessibility of technology for the manufacturing of ion-exchange resins poses a new paradigm in the task of improved recovery. High degrees of artificially induced selectivity of valuable metal combined with properties such as ultra high capacities, make ion-exchange resins superior to most other adsorbents. Furthermore, extremely low solution phase concentration of the valuable metal is adequate to give mass transfer that will result in significantly high loading of valuable species onto the resin.

In view of the above, it is the objective of this chapter to describe the historical process development of hydrometallurgical extractive strategies. The next section will briefly outline the deficiencies in current practices, thus motivating the use of selective ion exchange resins. Particular reference will be made to the simultaneous dissolution and adsorption of valuable metals from low grade ore bodies with ion-exchangers. This is achieved with the complete absence of any leaching reagent, except for minimal usage when the ion-exchange reaction provides the leaching reagent.

\subsection{HYDROMETALLURGICAL EXTRACTION}

Leaching, which is the liberation of metals from ore bodies by chemical dissolution forms the basis of most hydrometallurgical extraction processes. The principal objective of leaching is to liberate the maximum amount of the valuable metal content of the ore as selectively as possible. A compromise exists between the recovery and the grade of the valuable metal in the pregnant solution during leaching, with the former usually being the stronger economic incentive. The leaching procedure is typically brutal, especially in the 
case of refractory ores, in that the precious metals as well as contaminants (unwanted species) associated with the valuable metal are liberated. Nevertheless, leaching is an established and relatively successful metal extraction tool, especially when treating high grade ores. In contrast, low grade ore treatment proves to be costly, mainly due to the resultant pregnant solution being of a low valuable metal content relative to the contaminants. This implies that large volumes of this pregnant solution must be processed in down-stream refining unit operations in order to obtain sufficient concentration of valuable metal. In view of the processing costs alone, it would be difficult to economically accept low grade ore leaching before testing other options.

Furthermore, the leaching of valuable metal from ore bodies is concentration dependent. This means that it becomes increasingly more difficult to leach valuable metal from the ore body into solution with increasing valuable metal content of the pregnant solution, which is easily explained by Le Chatelier's principle. To counteract this phenomenon, multistage leaching circuits are required and it is not uncommon to encounter industrial scale processes employing four or five leaching stages. This increases the number of unit operations and leaching reagent consumption, with increased volumes of the pregnant solution being sent to down-stream refining units, due to the lower valuable metal content of the solution.

In view of the above discussion, great importance is placed upon the development of a method that refines the extractive process to be more selective to the valuable metal than the contaminants. This will inevitably greatly enhance efforts to reduce down-stream processing. In addition, the procedure must also concentrate the liberated valuable species in an easily accessible extractive phase, hence decreasing solution volume that further reduces subsequent processing. Other necessary improvements include minimising chemical consumption in large scale applications and reducing the number of required unit operations. 
One of the most promising new approaches to the treatment of low grade, valuable metal content ores is that of ion exchange resins. Although the potential benefits of resin technology in the chemical and metal processing industries have long been recognised, little progress regarding such systems has been made. This was until the synthesis of organic ion-exchange resins was accomplished, which made it possible to control and manipulate the properties of synthesised resins. Until recently, the technology of resin synthesis was still in its infant stages. However, development in ion exchange technology progressed so rapidly that highly selective, chemically and physically stable ion-exchange resins could be synthesised today compared with the first relatively non-selective and low capacity resins. This achievement, together with recent developments in the fundamental understanding and mathematical treatment of ion exchange principles, rendered the ionexchange process to be an extremely valuable and cost effective unit operation. Ionexchange can also pose to be a valuable supplement to other hydrometallurgical operations, of which the possibilities are limitless. The next section will present some technical background on ion-exchange resins and discuss the Resin-in-Pulp (RIP) and Resin-in-Leach (RIL) processes. The effect of different ion-exchange resins and ionexchange resin functional groups on the simultaneous leaching and sorption process will be discussed.

\subsection{RECOVERY OF VALUABLE CHEMICAL SPECIES FROM SPARINGLY SOLUBLE ORE BODIES USING THE RESIN-IN-PULP (RIP) AND RESIN-IN-LEACH (RIL) PROCESS}

Terms such as "insoluble", "degree of solubility" and "sparingly soluble" are frequently encountered in the literature on hydrometallurgical unit operations, such as leaching and precipitation, and need to be defined for the purposes of this dissertation. A solid substance is defined as "insoluble" or "sparingly soluble" when its thermodynamic dissolution constant (called the solubility product) has a value of $10^{-5}$ or less. Equation 
(1.1) is a general representation of the dissociation (dissolution) reaction of substance $B_{v_{B}} Y_{v_{Y}}$ into $v_{B}$ moles of its constituent cation $B^{z_{B}}$ and $v_{Y}$ moles of its anion $Y^{z_{Y}}$.

$$
\left[B_{v_{B}} Y_{v_{Y}}\right]_{\text {solid }} \stackrel{K s p}{\longleftrightarrow} v_{B} B^{z_{B}}+v_{Y} Y^{z_{Y}}
$$

The solubility product, $\mathrm{K}_{\mathrm{sp}}$, for the reaction is defined by Equation (1.2).

$$
\begin{aligned}
K_{s p} & =\left[a_{B}\right]^{v_{B}}\left[a_{Y}\right]^{\nu_{Y}} \\
& =\left[C_{B} \gamma_{B}\right]^{v_{B}}\left[C_{Y} \gamma_{Y}\right]^{\nu_{Y}}
\end{aligned}
$$

In Equation (1.2) $C_{i}, a_{i}$ and $\gamma_{i}$ represent the solution phase concentration, activity and activity coefficient of species i respectively. Species $B^{z_{B}}$ represents a valuable metal, which is associated with contaminant species $Y^{z_{Y}}$ (unwanted species), present as a sparingly soluble substance $B_{v_{B}} Y_{v_{Y}}$ in an ore. The supernatant solution in equilibrium with the ore body contains both species $B^{z_{B}}$ and $Y^{z_{Y}}$ at trace level concentrations (small $\mathrm{K}_{\mathrm{sp}}$ value for Equation (1.2)), which is considered as zero for all practical purposes in hydrometallurgical recovery processes. In order to recover species $B^{z_{B}}$, it must be leached (chemically dissolved) from the ore body into solution. The pregnant solution is treated by down-stream unit operations, which separate and recover species $B^{z_{B}}$ from the solution phase containing the contaminants (species $Y^{z_{Y}}$ ).

During the leaching procedure, the solution phase concentration of species $B^{z_{B}}$ increases dramatically. Unfortunately the solution phase concentration of the contaminants increases simultaneously, and according to Le Chatelier's principle Equation (1.1) will be shifted to the left at some total solution concentration of species $B^{z_{B}}$ and $Y^{z_{Y}}$. To counteract this re-precipitation reaction, more leaching reagent is required to "pull" species $B^{z_{B}}$ back into solution. This results in higher consumption of the leaching reagent per unit mass of species $B^{z_{B}}$ leached, which decreases the effective usage of the 
reagent and increases the operational costs. To counteract higher chemical consumption, multi stage leaching circuits are used where pure leaching reagent (containing no $B^{z_{B}}$ or $Y^{z_{Y}}$ ions) is introduced to the partially leached ore body. The dissociation equilibrium that exists between the solid $B_{v_{B}} Y_{v_{Y}}$ and its dissolved constituent ions $B^{z_{B}}$ and $Y^{z_{Y}}$, is disturbed when the pregnant solution in contact with ore body is removed between the different leaching stages. When the ore body is contacted with a fresh aqueous solution in the next leaching stage, the solution phase concentrations of species $B^{z_{B}}$ and $Y^{z_{Y}}$ is reestablished by the further dissolution of the solid according to Le Chatelier's principle. However, these stages result in larger accumulative volumes of pregnant solution being sent to down-stream unit operations, which also increases the processing costs regardless of the lower chemical consumption.

In view of the above discussion it is evident that a significant reduction in down-stream processing and operating costs is required from modern hydrometallurgical processes. This can be achieved if the process results in the simultaneous dissolution and adsorption of the valuable metal species $B^{2_{B}}$, concentrated in an easily accessible extractive phase. Ion-exchange technology provides us with such a system.

Valuable metal species can be recovered from a slurry mixture of the sparingly soluble solid containing it, using ion-exchange resins. This slurry mixture containing the ore and the ion-exchange resin is called a Resin-in-Pulp (RIP) mixture. The sparingly soluble solid slightly dissociates to give traces of the valuable metal species $B^{z_{B}}$ in solution, which are removed from the solution by the ion-exchange reaction. This sorption reaction disturbs the solid/liquid dissociation equilibrium condition of species $B^{z_{B}}$. Further dissolution of the solid is required (Le Chatelier principle) to restore the equilibrium concentration of the valuable metal $B^{z_{B}}$ in solution, which is again removed by the ion-exchange reaction. Complete dissolution of the solid $B_{v_{B}} Y_{v_{Y}}$ and hence complete liberation of the valuable metal can therefore be achieved by continually displacing the solid/liquid equilibrium condition, provided that an excess of the ion- 
exchanger is added. It is evident that the principal mechanism in the RIP recovery of valuable metals from sparingly soluble solids involves the shifting of equilibrium conditions existing between the solid and the solution phases.

In principle, the ion-exchange process is governed by electrostatic interactions between the different migrating species and the fixed functional groups of the ion-exchanger. In order to maintain electrical neutrality in both the solution and ion-exchanger phase, the ion-exchange reaction must involve the transfer of stoichiometrically equivalent amounts of similar charged species. This means that the metal species $B^{z_{B}}$ can only migrate into the ion-exchanger phase if a stoichiometrically equivalent amount of cation species $A^{z_{1}}$ simultaneously migrates from the inside of the ion-exchanger into the external bulk solution. The formation of species $A^{z_{A}}$, which is stoichiometrically expelled from the resin phase, depends largely on the chemical nature of the ionogenic functional groups and the interactions with the valuable metal.

The functional groups (where chemical exchange reaction occurs) of the ion exchanger may initially be saturated with species $A^{z_{A}}$. This results in a stoichiometrically equivalent ion-exchange reaction between species $B^{z_{B}}$ and $A^{z_{A}}$, which are called the counter ions of the ion-exchange reaction. This type of ion-exchange reaction is usually encountered with what is commonly known as strong acid cation or strong base anion exchange resins. However, species $A^{z_{A}}$ may be introduced to the solution in a completely different way, compared with the above mentioned example.

The counter ion $A^{z_{A}}$ may initially be a component of the non-dissociating part of the resin functional groups, before it is "activated" into participating in the ion-exchange reaction by changes in the chemical composition of the solution phase. In the "activated" form, species $A^{z_{A}}$ participate in the stoichiometrically equivalent ion-exchange reaction with species $B^{z_{B}}$, provided that specific conditions predominate in the solution phase. Ion-exchange reactions of this nature are encountered with weak acid cation or weak base anion exchangers, where the solution phase $\mathrm{pH}$ acts as the "activator". 
Another type of ion-exchange reaction occurs when species $A^{z_{A}}$ was initially part of species $B^{z_{B}}$. Species $A^{z_{A}}$ can be the chemical product of the ion-exchange reaction between species $B^{z_{B}}$ and the functional groups of the ion-exchanger. Ion-exchange reactions exhibiting behaviour of this nature are usually associated with what is known as chelating resins.

As a result of the ion exchange reaction, electrolyte solutions are created containing species $A^{z_{A}}$ and $Y^{z_{Y}}$, which may change the solubility of the sparingly soluble solid and consequently also the equilibrium conditions between the phases. Species $A^{z_{A}}$ and $Y^{z_{r}}$ may also participate in chemical reactions such as precipitation and complex formation. Few qualitative descriptions of ion-exchange processes related to the above discussed RIP process are found in the literature. These references give very little or no quantitative mathematical description of the RIP related processes. This deficiency in existing models motivates the development of a comprehensive thermodynamic model, which will predict the equilibrium distribution of the species between the different phases for different RIP processes. The next section will present some qualitative descriptions on RIP related processes obtained from the literature.

\subsection{ION-EXCHANGE PROCESSES EMPLOYING RIP TECHNOLOGY}

Nishino (1991) studied the dissolution and hydration mechanism of several kinds of inorganic materials. This was achieved by comparing conventional metal acid dissolution mechanisms with dissolution mechanisms obtained from an aqueous RIP slurry mixture. Nishino (1991) stated that an ion-exchange dissolution process had significant advantages over the metal acid dissolution process when studying and identifying the dissolution mechanisms of a substance. These advantages included

i) The ability to continuously follow the dissolution process by monitoring the $\mathrm{pH}$ and the conductivity, $\mathrm{k}$, of the aqueous solution phase of the RIP mixture, 
ii) More precise analysis of the solute due to the absence of foreign ions associated with the use of metal acids, and

iii) The identification of a new dissolution mechanism from changes in $\mathrm{pH}, \mathrm{k}$ and ion concentrations, which is a function of the amount of the ion-exchange resin added.

The dissolution mechanism of Portland cement powder in an aqueous RIP mixture was studied and the dissolution mechanisms were successfully identified by measuring the above mentioned variables. The RIP mixture contained a strong acid cation exchange resin used in the hydrogen form. Complete dissolution of the Portland cement in the aqueous RIP slurry mixture was indicated by constant values of the conductivity and the $\mathrm{pH}$ with further additions of the cation exchange resin. This occurred when the amount of the cation-exchange resin added equalled about ten times the weight of the cement. Nishino (1991) concluded that this dissolution method could be used as a unique analytical tool to study the hydration chemistry of the cement to evaluate the dissolution mechanism.

Yang et al. (1991) studied the recovery of sorbic acid from dilute aqueous solutions with an ion-exchange resin. The resin contained trialkyl phosphine oxide, TRPO, as functional groups. Sorbic acid is widely used in food products as a preservative and its removal from the mother liquor during its preparation or other dilute solutions is increasingly attracting attention of researchers and manufacturers. The sorbic acid has a dissociation constant of $1.73 \times 10^{-5} \mathrm{kmol} / \mathrm{m}^{3}$ at $298 \mathrm{~K}$, which makes it a border case according to the definition of a sparingly soluble solid, $\left(\mathrm{Ksp} \leq 10^{-5}\right)$. Experimental determination of the resin adsorption isotherm of the sorbic acid appeared to be an Sshaped curve. These S-shaped curves are frequently encountered in the adsorption and extraction of various acids by ion-exchange resins where simultaneous dissociation and adsorption occur (Yang et al., 1991).

The main disadvantage of water deionisation with the use of ion-exchange resins is the inevitable increase in the electrolyte content of the effluent waste streams resulting from 
the resin regeneration circuits. Approximately 1.2 - 2 equivalents of extra salts are added to the effluent streams of the regeneration circuits due to the ion-exchange reactions (Kadlec et al., 1988). This is the case even with modern, counter current circuits using proper combinations of strong and weak electrolyte resins. Kadlec et al. (1988) studied the combined ion-exchange and precipitation reactions in the regeneration of cation exchangers with $\mathrm{H}_{2} \mathrm{SO}_{4}$. If $\mathrm{Ca}^{+2}$ ions are the prevailing cations removed from the water in the softening step, the possibility exists to reduce the electrolyte content of the regeneration effluent streams. This can be achieved by precipitating the eluted $\mathrm{Ca}^{+2}$ ions with the excess $\mathrm{SO}_{4}{ }^{2-}$ ions in the effluent streams as the solid $\mathrm{CaSO}_{4}$, which can be separated from the resin phase and reused in industry. The regeneration process therefore involves a simultaneous two-step reaction mechanism, resin elution followed by the precipitation of the eluted species. The next paragraph presents an example of an ionexchange process that is similar in nature to the above mentioned example, but opposite in direction regarding the reaction mechanism, i.e. dissolution followed by elution.

Cloete and Marais (1995) studied the recovery of acetic acid from dilute $1 \%$ aqueous solutions using a weakly basic anion exchange resin, Duolite A-375, in the free-base form. To minimise chemical consumption of the elution reagent $\left(\mathrm{OH}^{-}\right.$ions $)$the sorbed acetic acid was eluted from the anion resin with a slurry of lime $\left(\mathrm{Ca}(\mathrm{OH})_{2}\right)$ in a $\mathrm{RIP}$ mixture, which resulted in the formation of calcium acetate solution. This solution can then be evaporated to crystallise calcium acetate or reacted with sulphuric acid to form acetic acid and gypsum, which resulted in product solutions of $15-20 \%$ acetic acid.

Rare earth metals can be recovered from low grade ores with RIP ion-exchange technology. Rare earth metals (REM) are usually found in very complex ore bodies at extremely low concentrations, which makes recovery difficult. Padayachee et al. (1996) studied the recovery of REM from apatite gypsum residue. The phosphate type mineral apatite, is used in the production of phosphoric acid. A sulphuric acid attack is carried out on the apatite ore body, producing a dilute impure phosphoric acid stream and the 
mentioned apatite gypsum. The bulk of the rare earth content of the apatite ore $(0.4 \%$ $0.9 \%$ ) is precipitated with the gypsum residue.

Ion-exchange resins containing phosphorus acid groups were identified to be suitable for the extraction of the REM from the gypsum residue. Leach and Resin-in-Leach tests were performed on the gypsum residue and compared with one another. The use of a RIL slurry mixture to extract the REM from the gypsum was found to increase the leaching efficiency of the REM. Shifting the solid/liquid equilibrium condition, which favoured the further dissolution of REM from the residue, facilitated this increase. Padayachee $e t$ al. (1996) concluded that the overall leaching efficiency of the REM from the gypsum residue was substantially enhanced with the use of a selective ion-exchange resin in a Resin-in-Leach slurry mixture.

Ru'an (1988) studied the extraction of rare earth metals from low-grade kaolinitic ore by percolation leaching, without the use of any synthetic ion-exchange resins. Either ammonium chloride, ammonium nitrate or ammonium sulphate solutions were used to leach the REM from the ore body. The REM was leached from the ore as a result of ionexchange reactions occurring due to the natural ion-exchange properties exhibited by the ore. This process shifts the solid/liquid dissociation equilibrium condition of the REM, which enhances further dissolution. The REM content of the kaolinitic ore is low, ranging from $0.05 \%$ to $0.3 \%$. The REM was recovered from the pregnant leaching solution by precipitation with oxalic acid after a filtration step that removed the barrenleached ore body. The precipitated residue was then washed with a $1 \%$ oxalic acid solution and calcined at $850^{\circ} \mathrm{C}$ to yield the rare-earth oxides.

It is evident from the above mentioned examples that the RIP and RIL processes, for the simultaneous dissolution and adsorption of valuable species from an "insoluble" ore body, are potentially useful hydrometallurgical tools. This is especially the case where the valuable species are present at trace levels in the ore bodies. The overall extraction capability of the process depends on the solubility of the valuable species and the 
selectivity of the ion exchange resin for the valuable species in a multicomponent aqueous electrolyte solution. The solubility of the valuable metal in a slurry mixture of the ore body is usually constant if no leaching reagent is added. Because of this fact, much emphasis is placed on the role of the ion-exchange resin to improve the overall extraction of the valuable metal in the RIP slurry mixture.

The rapid development in modern ion-exchange synthesis technology made the synthesis of selective ion exchange resins a possibility. The desired selectivity can be awarded to the ion-exchange resin with the introduction of selective functional groups to the polymer structure (matrix) of the resin. A selective leaching reagent for the valuable metal can also be introduced into the RIP slurry mixture through the ion-exchange reaction, such as a complex forming ligand. Initially the ion-exchange resin is saturated with the ligand, which becomes available for complex formation once exchanged. In this way the selective leaching reagent (ligand) is used very sparingly. This prevents the creation of high tonnage of effluent streams containing unused leaching reagent at low concentrations, which are costly and usually uneconomical to recover. Moreover, it will also reduce the problem of creating high tonnages of multicomponent effluent streams containing unwanted electrolyte species, due to over excessive leaching. Over excessive leaching is prevented because of the fact that the ion-exchange reaction stops introducing new leaching reagent into the solution once the ion-exchange sorption of the valuable metal ends.

Ion exchange resins have other definite advantages over other solid phase and liquid adsorbents, such as activated carbon and solvent extractants respectively. One such an advantage is the relatively high concentration of the functional groups on the resin polymer matrix, which determine its capacity. This is due to the cross-linking of the functional group carriers, which substantially decrease the volume of material containing a specific amount of the extractive functional groups. Consequently, smaller volumes of this relatively high capacity ion-exchange material are needed to recover a specific amount of the valuable metal, compared with other adsorbents. Smaller equipment can 
therefore be used due to smaller tonnage of the loaded ion-exchange material that needs to be treated. The use of Resin-in-Leach circuits, instead of solvent extraction circuits, also removes the need for a costly solid/liquid separation unit needed to separate the barren-leached ore material from the pregnant leach liquor that is to be treated in the solvent extraction unit.

Another advantage of ion exchange resins is the high species loading that can be obtained in equilibrium with extremely low solution phase concentrations. This property makes ion-exchange resins suitable for the recovery of valuable metals from trace level concentrations in the solution phase. Furthermore, the valuable metal species is concentrated in the resin phase to a degree of several orders of magnitude compared with its trace level concentration in the solution phase. This is especially true for the very dilute concentration region of the valuable metal in the solution phase.

\subsection{GENERAL CONSIDERATIONS BASED ON A CASE STUDY OF CaSO IN A RESIN-IN-SLURRY MIXTURE CONTAINING A CATION AND ANION EXCHANGE RESIN}

Figure 1.1 is a schematic representation of a $\mathrm{CaSO}_{4}$ Resin-in-Pulp slurry mixture containing both a cation and anion exchange resin with various aqueous phase species resulting from the dissolution and ion-exchange reactions. The schematic diagram as represented by Figure 1.1 will be used to broadly describe the various equilibrium conditions established in a typical RIP slurry mixture as well as the possible formation of various aqueous electrolyte species that may have a significant effect on the solubility of the sparingly soluble solid. The $\mathrm{CaSO}_{4} \mathrm{RIP}$ mixture was chosen for explanatory purposes for this dissertation due to the fact that the general modelling of the solubility of $\mathrm{CaSO}_{4}$ in various aqueous phase electrolyte solutions have been well documented in the literature (Zemaitis et al., 1986). The $\mathrm{CaSO}_{4} \mathrm{RIP}$ system is also one of many RIP systems studied experimentally for the purposes of this dissertation and is also an interesting system due to the fact that it allows for the formation of various other precipitates as a result of the 
ion-exchange reactions occurring. In Figure 1.1 the possible formation of various "new" precipitates is indicated. The term "new" precipitates refers to precipitates that were not present at the start of equilibrium attainment when the ion-exchange resins were added to the $\mathrm{CaSO}_{4}$ slurry mixture. The formation of precipitates such as $\mathrm{Ca}(\mathrm{OH})_{2}$ is highly likely provided that sufficient ion-exchange reaction occurs, which will increase the solution phase concentration to such an extent that precipitation occurs. The increase in the solution phase concentration is typical of batch RIP slurry mixture reactions and is described in more detail in Chapter 8. For the purposes of this dissertation the increase in the solution phase concentration will be referred to as an increase in the total solution phase ionic strength, defined in Chapter 3.

When $\mathrm{CaSO}_{4}$ dissolves into its constituent $\mathrm{Ca}^{+2}$ and $\mathrm{SO}_{4}{ }^{2-}$ ions the reaction occurs according to the dissolution reaction represented by Equation 1.1. The solubility product of $\mathrm{CaSO}_{4}$ governs the aqueous phase concentrations of the $\mathrm{Ca}^{+2}$ and $\mathrm{SO}_{4}{ }^{2-}$ ions. Due to the fact that $\mathrm{CaSO}_{4}$ is a sparingly soluble solid, typical aqueous phase concentrations of the $\mathrm{Ca}^{+2}$ and $\mathrm{SO}_{4}{ }^{2-}$ ions are in the region of 0.0151 moles $/ \mathrm{kg}$ solvent at $25^{\circ} \mathrm{C}$ (Zemaitis et al., 1986).

The $\mathrm{Ca}^{+2}$ and $\mathrm{SO}_{4}{ }^{2-}$ ions formed by the dissolution reaction are then exchanged for $\mathrm{Na}^{+}$ and $\mathrm{Cl}^{-}$ions on the cation and anion exchange resins respectively. Due to the removal of the $\mathrm{Ca}^{+2}$ and $\mathrm{SO}_{4}{ }^{2-}$ ions by the exchange reactions more of the $\mathrm{CaSO}_{4}$ solid dissolves to restore the equilibrium concentrations according to Equation 1.1. Subsequent exchange of the dissolved species occurs again and is repeated until the resin phase is in equilibrium with the solution phase composition. It is evident that during this equilibrium attainment process the solution phase concentration of both the $\mathrm{Na}^{+}$and $\mathrm{Cl}^{-}$ions has increased steadily due to the exchange process. The solution phase now not only comprises of the dissolved $\mathrm{Ca}^{+2}$ and $\mathrm{SO}_{4}{ }^{2-}$ ions for the sparingly soluble solid, but also of the $\mathrm{Na}^{+}$and $\mathrm{Cl}^{-}$ ions. 


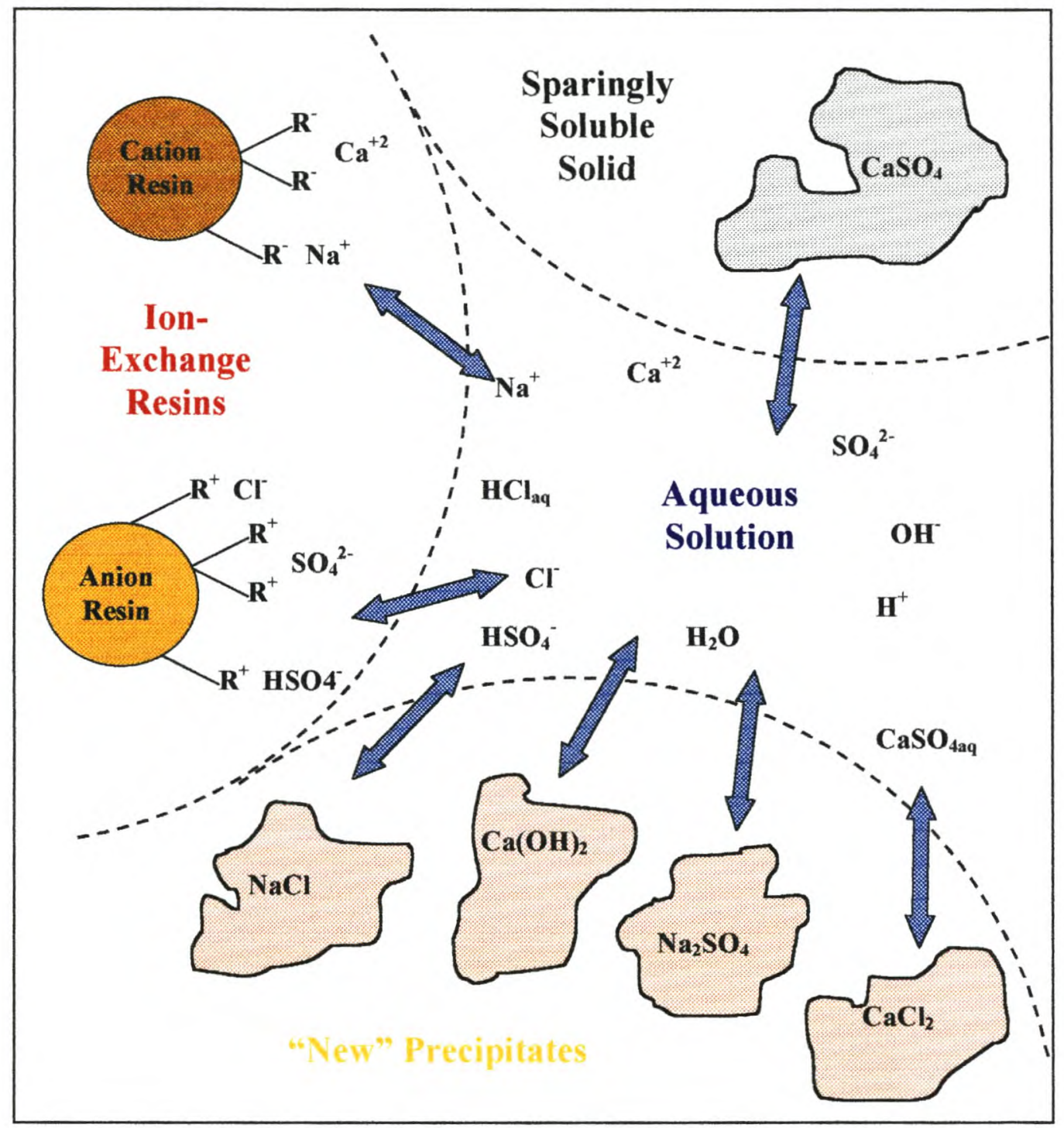

Figure 1.1 Equilibrium species formation for a Resin-in-Slurry mixture of $\mathrm{CaSO}_{4}$ with a cation and anion exchange resin 
Hence the RIP slurry mixture's aqueous phase composition at equilibrium differs significantly from that at the start of the equilibrium attainment process. This change in the solution phase composition has several effects. The formation of new aqueous species become a possibility. For the system of interest species such as aqueous $\mathrm{HCl}_{(\mathrm{aq})}$, $\mathrm{HSO}_{4}{ }^{-}$and aqueous $\mathrm{CaSO}_{4(\mathrm{aq})}$ becomes a possibility, depending on the total solution ionic strength and composition. The formation of these species at certain solution phase concentrations will also disturb the equilibrium conditions, which will result in the further dissolution of the sparingly soluble solid and other possible ion-exchange reactions. The exchange of both $\mathrm{SO}_{4}{ }^{2-}$ and $\mathrm{HSO}_{4}{ }^{-}$ions for $\mathrm{Cl}^{-}$ions on the anion exchanger may occur. Under specific conditions the formation of "new" precipitates may also occur, which will also change the solution phase composition and hence disturb the equilibrium conditions resulting in the further dissolution of sparingly soluble solid.

From Figure 1.1 it is evident that there are three major phases involved in the RIP mixture. These phases are the sparingly soluble solid(s), the aqueous phase and the ionexchange resin phase(s) (cation and/or anion exchange resins). The aqueous phase forms the "intermediate" phase for the migration of species from the sparingly soluble solid phases to the ion-exchange resin phase and vice versa. The equilibrium conditions between the various phases are therefore a collection of equilibrium conditions existing between the sparingly solid phase(s) and the aqueous phase and the ion-exchange resin phase(s) and the aqueous phase. If all of the solid and resin phases (resin and sparingly soluble species) are to be in equilibrium with another they must be in equilibrium with the aqueous phase. The general modelling of aqueous phase equilibria is therefore of significant importance to this dissertation and forms an integral part of the RIP equilibrium model proposed in Chapter 6.

From the above discussion it is evident that there are several equilibrium conditions, various aqueous phase species and various "new" precipitates to account for in a representative model for this system. The model needs to consider all of the above together with the ion-exchange resin phases and the equilibrium conditions associated 
with it. All of the above considerations need to be consolidated in one thermodynamic model if an attempt is made to comprehensively model such RIP slurry mixture systems. If the composition of the aqueous phase changes due to a reaction between any one of the possible solid phases (resin or solid phases) and the aqueous phase itself, the composition of all of the other solid phases may potentially change due to the initial reaction. In order to model this "linked" equilibrium behaviour between the various phases, it is necessary to be able to model the equilibrium interaction between each of the solid and resin phases and the aqueous phase in separate detail. In Figure 1.1 the various equilibrium interactions between the aqueous phase and the solid and resin phases to be considered by the model are represented by the dotted lines. In order to derive the consolidated equilibrium model for a RIP slurry mixture it is necessary to study each of these equilibrium "interfaces" in detail. This is done in detail in Chapters 2 to 5.

After the study of each of the separate equilibrium "interfaces" in Chapters 2 to 5 , the consolidated equilibrium model is proposed in Chapter 6 of this dissertation. All of the models discussed in Chapters 2 to 5 are consolidated into a general model for the modelling of all the equilibrium reactions between the various phases in a Resin-in-Slurry mixture of varying composition. Chapter 7 provides detailed descriptions on the experimental procedures followed in the collection of the experimental data as well as detailed information on the various analytical procedures followed in the analysis of the samples. The data collected according to the procedures of Chapter 7 are used to verify the various components of the consolidated equilibrium model for a RIP slurry mixture as defined in Chapter 6. The contents of each of Chapters 2 to 5 are briefly discussed below to give an overview and provide the necessary information on the construction of the consolidated equilibrium model for a RIP slurry mixture.

\subsubsection{The sparingly soluble solid and aqueous phase equilibrium condition}

Chapter 2 considers the general equilibrium reactions for a sparingly soluble solid in an aqueous phase solution in more detail. Various interactions between constituent ionic 
species of the sparingly soluble solid and the species in the aqueous phase are considered. It will be evident from Chapter 2 that the composition of the aqueous phase solution has a significant influence on the solubility of the solid. The change in the solubility of the solid species with changing aqueous phase composition is of particular interest to this dissertation. It has been shown experimentally in this dissertation (Chapter 9) that the total solution phase concentration (Ionic strength) increases from the initial solution phase concentration of the RIP slurry mixture as the equilibrium attainment process progresses. This change in equilibrium solution phase concentration is a result of the continuous dissolution of the sparingly soluble solid due to the exchange reactions with the ion-exchange resins. The initial species on the resin phases are replaced from the ionexchange resins phases into the aqueous phase solution due to the exchange reactions with the sparingly soluble solid species, increasing the solution's ionic strength and changing its composition. In Figure $1.1 \mathrm{Na}^{+}$ions from the cation exchange resin and $\mathrm{Cl}^{-}$ ions from the anion exchange resin are exchanged for the $\mathrm{Ca}^{+2}$ and $\mathrm{SO}_{4}{ }^{2-}$ ions of the sparingly soluble solid. The $\mathrm{Na}^{+}$and $\mathrm{Cl}^{-}$ions exchanged increase the aqueous phase concentration, which then influence the solubility of $\mathrm{CaSO}_{4}$. The influence of a changing aqueous phase composition on the solubility of the sparingly soluble solid is of significant importance to the consolidated equilibrium model proposed in Chapter 6 . This component of the model is therefore studied in more detail in Chapter 2.

\subsubsection{Aqueous phase speciation and equilibrium considerations}

It is evident from the above discussion that the composition of the aqueous phase will influence the solubility of the sparingly soluble solid. The various "mechanisms" are discussed in detail in Chapter 2, which includes processes such as the formation of a "weak acid" between the constituent ionic species of the sparingly soluble solid and the aqueous phase ionic species. The term "weak acid" is used for an aqueous phase "acidic" molecular species that does not dissociate completely, of which $\mathrm{HSO}_{4}{ }^{-}$is an example in Figure 1.1. It is therefore of significant importance to this dissertation to include the modelling of aqueous phase speciation in the consolidated model for a RIP slurry 
mixture. The modelling of aqueous speciation requires the prediction of aqueous phase species activities, which is discussed in detail in Chapter 3 of this dissertation.

Various models exist in the literature for the prediction of aqueous phase species activities. A detailed literature survey was performed in which the most significant of these models were studied in detail. For the purposes of this dissertation it is important to have an species activities model that has the ability to model the species activity coefficient over a wide solution phase concentration range. This is necessary due to the fact that the aqueous phase concentration of a RIP slurry mixture may increase significantly during the equilibrium attainment process. The choice of the activity coefficient model will therefore depend on the model's ability to accurately model a species activity coefficient for changing solution phase concentrations and compositions as this will be the case for the aqueous phase of the RIP slurry mixture. It is therefore the objective of Chapter 3 of this dissertation to obtain a species activity coefficient model that will adhere to the requirements as mentioned above.

\subsubsection{General considerations on the equilibrium behaviour of the resin phase}

Ion-exchange resin equilibrium reactions may be extremely complex to model. Various interactions between the ionic species and the resin's structure occur that influence the equilibrium capacity of the ion-exchange resin. Other important processes to consider are the absorption of aqueous phase solution known as "electrolytic sorption". In the experimental data collected for the purposes of this dissertation, evidence of these electrolytic sorption processes was found as represented by the experimental data in Chapter 7. Because of the importance of these and other equilibrium processes belonging to the ion-exchange resin phase, such as resin swelling, a general discussion on these topics is given in Chapter 4. The definition of the ion-exchange resin capacity is also defined in Chapter 4 for the purposes of this dissertation and applied to the experimental data as discussed in Chapter 7. 


\subsubsection{Ion-exchange resin and aqueous phase equilibrium interactions}

Ion-exchange resins are complex phases with various interactions that need to be considered, such as electrolytic sorption and resin phase non-idealities. Various types of models exist for the modelling of ion-exchange resin phase systems and the most useful are those with a sound thermodynamic approach. Various models are available in the literature and the most significant of these models are discussed in more detail in Chapter 5. Various interactions between the resin phase and the aqueous phase need to be considered by these models. The purpose of Chapter 4 of this dissertation is to discuss general considerations that influence the resin phase equilibrium behaviour in more detail, which provides the necessary information required for Chapter 5 . The resin phase equilibrium isotherms are relatively "steep" curves, i.e. high equilibrium resin loading for a species is obtained for extremely low solution phase concentrations of the same species. This means that a very low solution phase concentration driving force is required to obtain high resin loading of the species at equilibrium.

Experimentally derived curves for various cation-exchange and anion-exchange reactions are shown in Chapter 8. The equilibrium isotherm curves are especially "steep" at the very low solution phase concentration end, which is the area of particular interest to this dissertation for the constituent species of the sparingly soluble solid. Although the overall solution phase concentration (Ionic strength) may increase significantly due to the ion-exchange reactions, the solution phase concentration for the constituent ions of the sparingly soluble solid remains low. This means that the species of interest in the models, which are those of the sparingly soluble solid, will always be present at extremely low solution phase concentrations. With a small change in the solution phase concentration of these species a significant change in the equilibrium resin loading may be obtained due to the steep nature of the resin equilibrium isotherm curves. Hence the resin phase equilibrium models need to be sensitive enough to account for this phenomenon. As mentioned above, Chapter 5 addresses this area of the consolidated model. 


\subsection{OBJECTIVES OF THIS STUDY}

In view of the above discussion, the following objectives were identified for this dissertation.

i.) The first objective of this dissertation is to improve our general knowledge on ion exchange principles by investigating the simultaneous dissolution and sorption of metal species from sparingly soluble solids when contacted with ion exchange resins in a Resin-in-Leach (RIL) slurry mixture.

ii.) An extensive literature survey has revealed very few publications related to this subject containing quantitative experimental data that could be used in the development of a general fundamental model. It is therefore the second objective of this dissertation to gather quantitative experimental data on a broad scale covering all the various parameters that have an influence on the RIL process. These parameters included the solubility of the valuable species from a sparingly soluble solid; different cation and anion resins; different initial resin ionic forms; precipitation reactions resulting from the ion exchange reaction; complex formation between the exchanged ions and the dissolved ions of the sparingly soluble solid; weak acid formation between the exchanged ions and the dissolved ions of the solid; RIL slurries containing different equilibrium ratio mixtures of cation and anion exchange resins; different combinations of the initial ionic form of the cation and anion exchange resins; the effect of species valence by using cations and anions of different valences; changes in the solubility of the sparingly soluble solid with changing solution phase composition due to new electrolyte solutions being created by the cation and anion exchange reactions.

iii.) The mathematical modelling of transport phenomena in processing systems forms an integral part of development in the metallurgical and chemical industry. The 
rapid development of technology in the field of process engineering commonly facilitates improved controlling through improved models and a better understanding of the process fundamentals. Predictive models are used for process control, process optimisation with regard to model parameters, design of processing equipment as well as directing future research sparked by current understanding and interpretation of the process fundamentals.

Resin-in-Pulp and Resin-in-Leach slurry mixtures employing ion exchange principles are such a processing system. It is therefore the objective of this dissertation to develop a fundamental thermodynamic model for the modelling of RIP and RIL mixtures. This is achieved by combining thermodynamic models describing the three separate phases, i.e. the solid ore, solution and resin phase. This model can quantitatively predict the equilibrium distribution of the species among the three phases in a RIP or RIL slurry mixture, for a particular set of physical conditions.

iv.) The systematic development of a consolidated model for the simulation of the equilibrium condition between various phases in a RIP slurry mixture will be presented. Chapters 2 to 5 of this dissertation consider the various equilibrium interfaces as represented by Figure 1.1. Thermodynamic models contributing to the final consolidated model are discussed in detail in each of these chapters and combined in Chapter 6 to form the consolidated model. It is therefore the objective of Chapters 2 to 5 to introduce the various underlying models of the consolidated model, derived in Chapter 6, in a systematic and logical manner to the reader. It is of significant importance that the reader understands the contributions of the various phases in a RIP slurry mixture towards the attainment of the complete equilibrium condition for the RIP system as a whole. This logical breakdown of concepts is required in order to derive and discuss the underlying fundamentals and capability of the consolidated equilibrium model for a RIP 
slurry mixture and its contribution towards the better understanding of such multiphased systems.

\subsection{THEORETICAL CONTRIBUTIONS OF THIS STUDY}

i.) A consolidated thermodynamically based model is proposed to model the equilibrium distribution of species between the three phases (resin, solution and ore precipitate) of a RIP or RIL slurry mixture. The consolidated model combines thermodynamic models describing multicomponent electrolyte aqueous solutions in equilibrium with multicomponent ion-exchange phases and precipitate ore body phases.

ii.) Large numbers of equilibrium data points for various RIP and RIL slurry mixtures were gathered under a wide range of experimental conditions. This was done for different types of ores and solids, which included chemically pure sparingly soluble solids, natural dolomite ores and activated carbon.

iii.) A thermodynamic based equilibrium model is proposed that can model the simultaneous leaching and sorption of species from sparingly soluble solids onto ion exchange resins. The model predicts the equilibrium distribution of the species between the phases as well as the change in the solubility of the sparingly soluble solid for various aqueous phase compositions. 


\section{CHAPTER 2}

\section{GENERAL THERMODYNAMIC CONSIDERATIONS ON THE SOLUBILITY OF SPARINGLY SOLUBLE SOLIDS IN AQUEOUS ELECTROLYTE SOLUTIONS}

The need to fundamentally understand and characterise aqueous electrolyte systems has become important to the modern chemical engineer. Aqueous processes in industry continually need to be more efficient users of water, which is becoming a scarce commodity. These processes also need to comply with pollution-control laws on effluent streams. Industrial applications of aqueous systems cover a diverse range of processes. These processes include wastewater treatment; hydrometallurgical extraction from lowgrade ores; separation processes such as distillation; solvent extraction; ion-exchange; osmosis and crystallisation as well as biotechnology; bioseparations; paper and food production as well as petroleum engineering (Linkson, 1996).

From Chapter 1 it is evident that the composition of the aqueous phase in the Resin-inPulp (RIP) slurry system is of paramount importance in dictating the equilibrium distribution of the dissolved species between the resin and solid precipitate phases. Because of this it is of significant importance to the derivation of the consolidated equilibrium model (Discussed in Chapter 6) to include the fundamental modelling of the aqueous phase interactions and its effect on the solubility of the sparingly soluble solids.

From Figure 1.1 (Chapter 1) it is evident that several sparingly soluble solid phases may exist in the RIP slurry mixture. As the original sparingly soluble solid in the RIP slurry mixture dissolves, due to the ion-exchange reactions and the aqueous phase interactions, it is possible to form new precipitates as the aqueous phase ionic strength increases, 
which is a direct result of the ion-exchange reactions (discussed in more detail in Chapter 9).

\subsection{OBJECTIVES OF THIS CHAPTER}

Because of the importance of the composition of the aqueous phase and its effect on the solubility of the sparingly soluble solid, it is the objective of this Chapter to investigate this in more detail and the role it would play in the consolidated equilibrium model for a RIP slurry mixture system. This chapter deals with the parameters influencing the aqueous solubility of metal precipitates in the hydrometallurgical extraction of metals from low-grade ores. Various interactions in the solution phase are discussed on macroscopic level and explained by mathematical equations. These aqueous phase interactions on the dissolved ions of the sparingly soluble solid include the effect of the solution phase composition and concentration, effects such as the "common ion effect", "weak acid formation" and complex formation. All of these interactions are discussed in more detail and on a conceptual basis in paragraph 2.7 of this dissertation. Little attention will be paid to the role of gaseous solvents due to the inert nature of the gas phase present during all experimental results, which was air at ambient conditions.

An investigation is also launched into the various techniques used to model the solubility of a sparingly soluble solid in aqueous electrolyte solutions. The most simplistic of these techniques involves the use of the sparingly soluble solid's solubility product, $\mathrm{K}_{\mathrm{sp}}$ value discussed in detail in paragraphs 2.3 and 2.4 below. When using the solubility product approach, it is still necessary to consider the formation of all possible species in the aqueous solution. This is necessary because all of these aqueous phase species will influence the aqueous phase activities of the sparingly soluble solid's constituent ions. The right-hand side of Equation (2.30) represents the activities of the solid's dissolved constituent ions in the aqueous phase. 


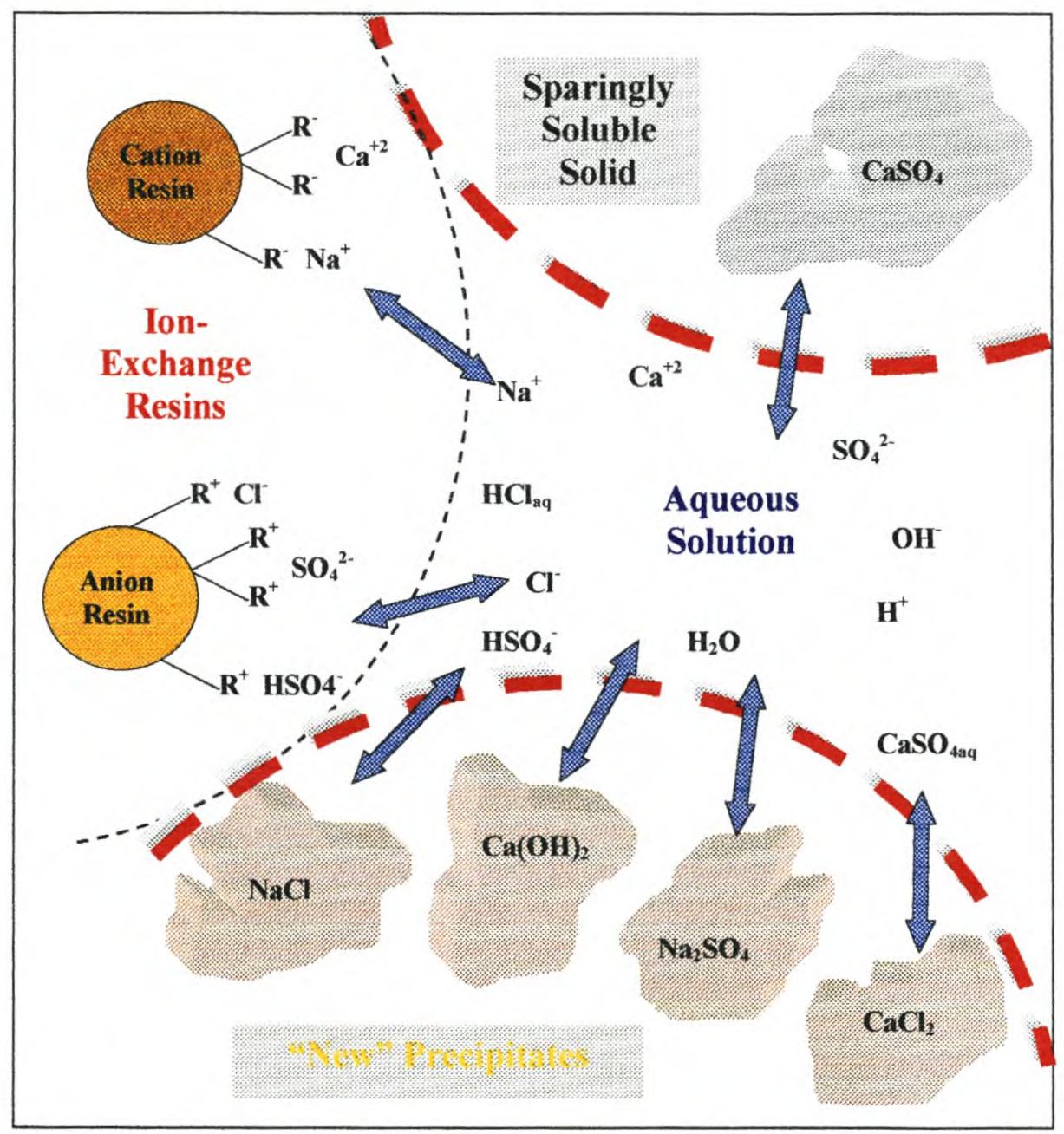

Figure 2.1 Solid / aqueous phase equilibrium considerations for the dissolution of sparingly soluble solids for a Resin-in-Slurry mixture of $\mathrm{CaSO}_{4}$ with a cation and anion exchange resin

It is evident from Equation (2.30) that the activity coefficients for the species are required in order to calculate their activities, as represented by Equation (2.15). Chapter 3 deals 
extensively with this subject and discusses various models that may be used to calculate the species activity coefficient for various aqueous phase compositions. Figure 2.1 is a modified version of Figure 1.1, indicating the equilibrium interactions on which this chapter will focus as the two bold dashed lines separating the sparingly soluble solid and the "new" precipitates from the aqueous phase solution. From Figure 2.1 it is therefore evident that this chapter will focus on the equilibrium conditions that exist between the aqueous phase and solid precipitate phases and the factors that influence the solubility of precipitates.

The solubility for a sparingly soluble solid's constituent ions in an aqueous phase solution may also be calculated using a more thermodynamic fundamental approach. Paragraph 2.5 shows the equations and their derivation that will be used in this approach. To calculate a sparingly soluble solids solubility using this technique requires thermodynamic data on the free Gibbs energy of formation for all of the species. The formation of all possible species still needs to be considered, which is also the case for the calculation of the solubility of the solid's constituent ions using the solubility product calculations. This technique for calculating the solubility of a precipitate in an aqueous electrolyte solution from the various species free Gibbs energy of formation is generally referred to as a "Gibbs free energy minimisation" technique. Various researchers have published extensive literature sources on these techniques and several software packages are available to model the solubility of sparingly soluble solids using the "Gibbs free energy minimisation" technique. For the purposes of this dissertation these techniques were investigated in detail and a software package called CHEMAPP (developed by GTT Technologies, Herzogenrath, Germany) have been identified as a potential candidate to perform "Gibbs free energy minimisation" calculations. 


\subsection{GENERAL CONSIDERATIONS ON THE ROLE OF SOLVENTS IN THE DISSOLUTION OF SPARINGLY SOLUBLE SOLIDS}

To understand the role of the aqueous phase in the dissolution of the sparingly soluble solid, it is necessary to look at the properties and stability of metal precipitates in solvents in general. The solubility of any sparingly soluble solid is directly related to the interaction between the constituent ions in the crystalline solid as well as the interactions between the constituent ions and the molecules of the solvent, which will be water for the purposes of this dissertation.

The process of solubility usually occurs where the magnitude of the attractive forces between the molecules in both the solute and solvent, are of the same order. The extent to which one substance will dissolve in another depends on the physical and chemical nature of the solute and solvent as well as the external physical conditions such as temperature and pressure.

The aqueous dissolution of metal precipitates is the cause of mainly strong polar attractions between the solute and solvent molecules, called solvation. This is the case when ionic solids dissolve in a polar solvent, such as water. Strong forces of attraction exist between the positive and negative ions of the solid and water dipoles. The strong attractive forces between the ions of the solid diminished due to the solvation of these interacting ions, which allows them to break free from the crystalline structure and enter the solution. The crystalline solid will only dissolve in water if the solvation energy of the constituent ions can overcome the lattice energy, $\Delta E_{c}$, of the compound.

Equation (2.1) represents a simplified method for predicting the lattice energy in a crystalline solid by viewing the different ions as electrical point charges (Laidler and Meisner, 1982). 


$$
\Delta E_{c}=\frac{1}{2} \sum_{i j} \frac{-z_{i} z_{j} e^{2}}{4 \pi \varepsilon_{0} \varepsilon r_{i j}}+\frac{1}{2} b \sum_{i j} e^{-\frac{r_{i j}}{\rho}}
$$

The first term on the right hand side of Equation (2.1) represents the energy contribution of the electrostatic interactions between the ions $i$ and $j$ in the solid to the lattice energy, summed over all possible ion pairs. The second term represents the energy contribution of the van der Waals repulsive forces between the different ion pairs.

Table 2.1 Dielectric constants for polar and non-polar solvents (Basset et al., 1966).

\begin{tabular}{|c|c|c|c|}
\hline Solvent & Polarity & Dielectric constant & Temperature \\
\hline $\mathrm{CCl}_{4}$ & non-polar & 2.238 & $20^{\circ} \mathrm{C}$ \\
\hline $\mathrm{C}_{6} \mathrm{H}_{6}$ & non-polar & 2.284 & $20^{\circ} \mathrm{C}$ \\
\hline $\mathrm{H}_{2} \mathrm{O}$ & polar & 80.36 & $20^{\circ} \mathrm{C}$ \\
\hline $\mathrm{NH}_{3}$ & polar & 22.4 & $-33.4^{\circ} \mathrm{C}$ \\
\hline
\end{tabular}

The dielectric constant of a solvent, $\varepsilon$, is an indication of the extent to which the polar solvent diminishes the forces in the ionic crystalline structure of the metal precipitate. The larger the value of the dielectric constant of the solvent, the stronger the solvation effects due to stronger ion-dipole association that will diminish the charge density of the crystalline ions, and hence their inter ionic electrostatic interactions. This reduces the lattice energy that makes the precipitate more soluble in the solvent. Table 2.1 shows the dielectric constants for different polar and non-polar solvents. It is evident that the dielectric constants for polar solvents, such as water, are much larger than those of nonpolar solvents, which make the polar solvents more effective dissolvers of ionic metal precipitates. 


\subsection{MECHANISTIC CONSIDERATIONS FOR THE DISSOLUTION OF SPARINGLY SOLUBLE SOLIDS IN SOLVENTS AT EQUILIBRIUM}

An equilibrium condition between a sparingly soluble solid and a solvent exists when equal but opposite dissolution and crystallisation rates maintain constant constituent ion concentrations of the solid in the solvent. A crystalline solid dissolves in a solvent when a surface ion has enough energy at a particular moment to "overcome" the strong ionic electrostatic attractive forces of its neighbouring ions in the lattice structure.

A random energy distribution exists between the surface ions of the crystal (Bassett et al., 1966) resulting in some ions having sufficient energy and others insufficient energy to overcome the energy barriers of the lattice structure. A fraction of the surface ions of the crystal therefore has sufficient energy and will consequently vibrate far enough from the surface of the crystal to be solvated by the solvent molecules. The average particle energy and the number of particles with sufficient energy depend only upon the temperature of the system. If the temperature is raised, the internal energy of system increases. A larger number of particles will consequently have enough energy to vibrate far enough from the crystal surface to be solvated. Hence, the number of particles with sufficient energy to escape the lattice structure will increase with an increase in temperature, which makes the precipitate more soluble at elevated temperatures.

Equation (2.2) gives the general dissolution reaction of the sparingly soluble solid, $B Y$, in water, which results in the formation of at least traces of its constituent ions in the water,

$$
\left[\left(B^{z_{B}}\right)_{v_{B}}\left(Y^{z_{Y}}\right)_{v_{Y}}\right]_{S} \stackrel{K_{s p}}{\longleftrightarrow} v_{B} B^{z_{B}}+v_{Y} Y^{z_{Y}}
$$

where $B$ represents the cation and $Y$ the anion of the sparingly soluble solid. The valences of the cation and anion are represented by $z_{B}$ and $z_{Y}$ respectively. The number of moles of the cation $B$ and anion $Y$ that are formed when one mole of the precipitate dissolves 
completely, are given by $v_{B}$ and $v_{Y}$ respectively. Electrical neutrality is maintained in all natural solutions, hence species $B^{z_{B}}$ and $Y^{z_{Y}}$ must dissolve simultaneously and stoichiometrically.

At equilibrium equal and opposite dissolution and crystallisation rates maintain a constant constituent ion concentration of the solid in the solvent. The probability of an increase in the solvent ion content of species $B^{z_{B}}$ and $Y^{z_{Y}}$ must therefore be equal to the probability of a decrease in the solvent ion content of species $B^{z_{B}}$ and $Y^{z_{Y}}$ at equilibrium, as represented by Equation (2.3).

$$
P\left(B^{z_{B}}, Y^{z_{Y}}{ }_{\text {increase }}\right)=P\left(B^{z_{B}}, Y^{z_{Y}} \text { decrease }\right)
$$

The probability for an increase in the concentration of species $B^{z_{B}}$ and $Y^{z_{Y}}$ in the solvent, because of the dissolution reaction, is given by Equation (2.4)

$$
\begin{aligned}
& P\left(B^{z_{B}}, Y^{z_{Y}}{ }_{\text {increase }}\right)=P\left(S_{\text {col }}\right) \cdot P\left(B^{z_{B}}{ }_{\text {ve }}\right)^{z_{Y} \mid} \cdot P\left(Y^{z_{Y}}{ }_{\text {ve }}\right)^{\left|z_{B}\right|} P\left(\text { Solvent }_{\text {ef }}\right) \\
& =P\left(B^{z_{B}}\right)^{\left|z_{Y}\right|} \cdot P\left(Y^{z_{y}}\right)^{\left|z_{B}\right|} P(\text { Solvation })
\end{aligned}
$$

where

$P\left(S_{c o l}\right) \quad=\quad$ The probability that a solvent dipole will collide with a particular surface site of the crystal from the bulk phase.

$P\left(B^{z_{B}}\right)^{\left|z_{Y}\right|}=$ The probability that $\left|z_{Y}\right|$ surface ions of species $B^{z_{B}}$ on the surface site of interest have sufficient energy to vibrate far enough from the crystal face to be solvated. 
$P\left(Y^{z_{Y}}{ }_{v e}\right)^{\left|z_{B}\right|}=$ The probability that $\left|z_{B}\right|$ surface ions of species $Y^{z_{Y}}$ on the surface site of interest have sufficient energy to vibrate far enough from the crystal face to be solvated.

$P\left(\right.$ Solvent $\left._{e f}\right)=$ The probability that if such a collision occurs the solvent dipole will be orientated correctly for the collision to be an effective collision and species $B^{z_{B}}$ and $Y^{z_{Y}}$ to be solvated simultaneously.

$P($ Solvation $)=P\left(S_{\text {col }}\right) \times P\left(\right.$ Solvent $\left._{e f}\right)$. The product of the first and last probability can be defined as the probability that a solvent molecule will effectively solvate the species during a collision of the solvent molecule with the specific surface site.

The probability for a decrease in the concentration of species $B^{z_{B}}$ and $Y^{z_{Y}}$ in the solvent, because of the crystallisation reaction, is given by Equation (2.5)

$$
P\left(B^{z_{B}}, Y^{z_{Y}} \text { decrease }\right)=P\left(B^{z_{B}}\right)^{z_{Y} \mid} \cdot P\left(Y^{z_{Y}}\right)^{z_{B} \mid} P\left(\text { Solvated }_{e f}\right)
$$

where

$$
\begin{array}{r}
P\left(B^{z_{B}} S\right)^{\left|z_{Y}\right|}=\quad \text { The probability that }\left|z_{Y}\right| \text { solvated ions of species } B^{z_{B}} \text { from the bulk } \\
\text { phase collide with the surface site of interest on the crystal face. }
\end{array}
$$

$$
\begin{aligned}
P\left(Y^{z_{Y}} s\right)^{\left|z_{B}\right|}= & \text { The probability that }\left|z_{B}\right| \text { solvated ions of species } Y^{z_{Y}} \text { from the bulk } \\
& \text { phase collide simultaneously with the same surface site on the } \\
& \text { crystal face as species } B^{z_{B}} \text { did. }
\end{aligned}
$$


$P\left(\right.$ Solvated $\left._{\text {ef }}\right)=\quad$ The probability that if such a collision of the solvated ions from the bulk with the site on the crystal face occurs, it is successful in pushing aside the solvent molecules and leaving the ions in the exact sites to be held to the crystal.

\section{Assumptions}

1)

The probability that species $\mathrm{j}$ from the bulk phase will collide with a particular site on the crystal surface is taken as equal to the ratio in which the species is present in the solution phase under ideal bulk phase properties, which again is equal to its ionic fraction in solution, $x_{j}$.

2) The solvent is considered to be an extra species.

3) The fraction of the surface ions of the precipitate that has sufficient energy to vibrate far enough from the crystal face depends only upon the temperature of the system. The probability that the surface ions of species $\mathrm{j}$ on the particular surface site have sufficient energy to vibrate far enough from the crystal surface is, therefore, constant for a constant temperature (equal to $K_{\text {Temperature }}$ ).

4)

The total solution concentration, $C_{T}$, stays constant at a constant set of physical conditions (temperature and pressure).

5)

At equilibrium the probability of an increase/decrease in the concentration of a given species must be equal as represented in Equation (2.3). Substituting Equations (2.4) and (2.5) into Equation (2.3) and simplifying resulted in Equation (2.6), the solubility product of the precipitate at a constant temperature. 


$$
\begin{aligned}
& P\left(B^{z_{B}}\right)^{\left|z_{Y}\right|} \cdot P\left(Y^{z_{Y}}{ }_{v e}\right)^{\left|z_{B}\right|} \cdot P(\text { Solvation })=P\left(B^{z_{B}} s\right)^{\left|z_{Y}\right|} \cdot P\left(Y^{z_{Y}} s\right)^{\left|z_{B}\right|} \cdot P\left(\text { Solvated }_{\text {ef }}\right) \\
& \Rightarrow \quad K_{\text {Temperature }} \cdot P(\text { Solvation })=\left[x_{B}\right]^{\left|z_{Y}\right|} \cdot\left[x_{Y}\right]^{\left|z_{B}\right|} \cdot P\left(\text { Solvated }_{\text {ef }}\right) \\
& \Rightarrow \frac{K_{\text {Temperature }} \cdot P(\text { Solvation })}{P\left(\text { Solvated }_{\text {ef }}\right)}=\left[\frac{C_{B}}{C_{T}}\right]^{\left|z_{Y}\right|}\left[\frac{C_{Y}}{C_{T}}\right]^{\left|z_{B}\right|} \\
& \Rightarrow \frac{K_{\text {Temperature }} \cdot P(\text { Solvation }) \cdot C_{T}^{\left(\left|z_{Y}\right|+\left|z_{B}\right|\right)}}{P\left(\text { Solvated }_{\text {ef }}\right)}=\left[C_{B}\right]^{\left|z_{Y}\right|}\left[C_{Y}\right]^{\left|z_{B}\right|} \\
& =K_{s p}
\end{aligned}
$$

\subsection{KINETIC RATE THEORY FOR THE SOLUBILITY PRODUCT OF A PRECIPITATE}

A sparingly soluble solid is in equilibrium with its constituent ions (Equation (2.2)) in a solvent because the rates of dissolution and crystallisation are equal and opposite in direction to each other.

The rate of dissolution of ions from the crystal into the solvent phase depends upon the area of the crystal surface available for collisions of the solvent molecules to occur from the bulk phase onto the crystal surface, the temperature of the system (hence the number of high-energy ions in the system and the average energy of an ion) and the solvating capabilities of the solvent (the value of its dielectric constant). For a particular solvent and a set temperature, the dissolution rate is only dependent on the total crystal surface area, given by Equation (2.7). 


$$
\frac{d_{\text {dissolution }}}{d t}=k_{\text {diss }} \cdot \text { Area }
$$

The rate of crystallisation of ions from the bulk phase (solvent) onto the crystal surface depends upon the area of the crystal surface available for collisions to occur, the temperature of the system, the solvent and the concentration of the solvated ions in the bulk phase which will determine the frequency of collisions of solvated ions on the crystal surface. For a particular solvent and set temperature the crystallisation rate is only dependent on the crystal surface and ion concentrations in solution. The crystallisation rate is presented by Equation (2.8),

$$
\frac{d_{c y s s a l l i z a t i o n}}{d t}=k_{c r y s} \cdot \text { Area } \cdot\left[C_{B}\right]^{z_{Y}} \cdot\left[C_{Y}\right]^{z_{B}}
$$

At equilibrium the two reactions occur at equal and opposite rates in order to maintain constant solution phase ionic concentrations of the constituent ions. Equating Equations (2.7) and (2.8) and simplifying resulted in Equation (2.9), the solubility product for the solid at a given temperature, which is the ratio of the dissolution and crystallisation reaction rate constants.

$$
K_{s p}=\frac{k_{\text {diss }}}{k_{c y y s}}=\left[C_{B}\right]^{z_{Y}} \cdot\left[C_{Y}\right]^{z_{B}}
$$

\subsection{THERMODYNAMIC CONSIDERATIONS OF IONIC SPECIES AT EQUILIBRIUM IN SOLUTIONS}

With aqueous solutions of electrolyte species there are two types of equilibrium to consider, phase equilibrium and chemical or ionic reaction equilibrium (Zemaitis et al., 1986). Phase equilibrium of interest is primarily vapour-liquid and liquid-solid 
equilibrium, though vapour-liquid-solid is also of great importance in particular hydrometallurgical systems.

\subsubsection{Phase equilibrium}

When two different phases are in chemical equilibrium with one another, the chemical potential of any species $i$, in one phase is equal to the chemical potential of the same species in the other phase. Equation (2.10) represents the equilibrium condition existing for species $i$ between phases $a$ and $b$ that are in chemical equilibrium with one another, with $\mu_{i}$ representing the chemical potential of species $i$.

$$
\mu_{i, a}=\mu_{i, b}
$$

\subsubsection{Ionic reaction equilibrium}

The equilibrium condition for chemical equilibrium in a particular phase has the same form as the chemical equation. For the solution phase ionic reaction represented by Equation (2.11)

$$
a A+b B \quad \leftrightarrow \quad c C+d D
$$

The equilibrium condition is denoted by Equation (2.12)

$$
a \mu_{A}+b \mu_{B}=c \mu_{C}+d \mu_{D}
$$

which can be represented in a generalised form by Equation (2.13),

$$
\sum_{i} v_{i} \mu_{i}=0
$$


where $v_{i}$ is the stoichiometric coefficient of species $i$ in the reaction of interest; (it is positive if the species are a product and negative if a reactant).

It is more convenient to describe the chemical potential of a species in aqueous solution thermodynamics in terms of its solution phase activity, $a_{i}$. The chemical potential of species $i$ in a multicomponent mixture is defined by Equation (2.14) in terms of its activity $a_{i}$, as

$$
\mu_{i}=\mu_{i}^{o}+R T \ln \left(a_{i}\right)
$$

where $\mu_{i}^{o}$ is the reference chemical potential or the standard chemical potential of an arbitrarily chosen standard state. In an ideal solution, where the components in the multicomponent solution do not influence one another, the activities of the components are equal to their concentrations. In a real electrolyte solution the activity of a component is not equal to its concentration, due the non-ideal behaviour caused by the interactions between the different components. The activity of a particular species, behaving nonideally, is expressed as a product of its concentration and a term representing the deviation from ideality at the given concentration, represented by Equation (2.15).

$$
a_{i}=C_{i} \gamma_{i}
$$

$C_{i}$ is the molar solution phase concentration and $\gamma_{i}$ the molar solution phase activity coefficient of species $i$. For ideal bulk solution phase conditions the activity coefficients of all the dissolved ionic species are equal to unity, hence the activity of a particular species is equal to its solution phase concentration. This is usually the case for dilute aqueous electrolyte solutions, where ideal behaviour of the dissolved ionic species in the solution phase is assumed. Substituting Equation (2.15) into Equation (2.14) gives the 
chemical potential as a function of the activity coefficient, represented by Equation (2.16).

$$
\mu_{i}=\mu_{i}^{o}+R T \ln \left(C_{i} \gamma_{i}\right)
$$

The general expression for the ionic equilibrium reaction, defined by Equation (2.11), can be expanded to Equation (2.17) by substituting Equation (2.16) into Equation (2.11) for the different ionic species.

$$
\begin{aligned}
& a\left(\mu_{A}^{0}+R T \ln \left(C_{A} \mu_{A}\right)\right)+b\left(\mu_{B}^{0}+R T \ln \left(C_{B} \mu_{B}\right)\right)= \\
& c\left(\mu_{C}^{0}+R T \ln \left(C_{C} \gamma_{C}\right)\right)+d\left(\mu_{D}^{0}+R T \ln \left(C_{D} \gamma_{D}\right)\right)
\end{aligned}
$$

Equation (2.17) can be simplified to Equation (2.18).

$$
a \mu_{A}^{0}+b \mu_{B}^{0}-c \mu_{C}^{0}-d \mu_{D}^{0}=R T \ln \left(\frac{\left(C_{C} \gamma_{C}\right)^{c}\left(C_{D} \gamma_{D}\right)^{d}}{\left(C_{A} \gamma_{A}\right)^{a}\left(C_{B} \gamma_{B}\right)^{b}}\right)
$$

The partial molar Gibbs free energy, $\overline{G_{i}^{0}}$, is also known and defined as the chemical potential, $\mu_{i}^{0}$, at the same arbitrarily chosen standard state. Tabulations of the partial molar Gibbs free energy are available in the form of tabulations of $\Delta G_{f}^{0}$, which represents the free energy when one gram-formula weight of the substance is formed, isothermally at the indicated temperature of the standard state (Zemaitis et al., 1986). Equation (2.18) can be simplified to Equation (2.19) by substituting the partial molar Gibbs free energy for the reference chemical potential of each particular species at the reference conditions. 


$$
\frac{\left[a \Delta G_{f A}^{0}+b \Delta G_{f B}^{0}-\left(c \Delta G_{f C}^{0}+d \Delta G_{f D}^{0}\right)\right]}{R T}=\ln \left(\frac{\left(C_{C} \gamma_{C}\right)^{c}\left(C_{D} \gamma_{D}\right)^{d}}{\left(C_{A} \gamma_{A}\right)^{a}\left(C_{B} \gamma_{B}\right)^{b}}\right)
$$

The thermodynamic equilibrium constant for the ionic reaction given by Equation (2.11), is defined as:

$$
K_{T}=\exp \left(\frac{a \Delta G_{f A}^{0}+b \Delta G_{f B}^{0}-\left(c \Delta G_{f C}^{0}+d \Delta G_{f D}^{0}\right)}{R T}\right)
$$

which is the left-hand side of Equation (2.19) for a specific temperature, which in turn is equal to that of the chosen reference state. Substituting Equation (2.20) into Equation (2.19) and simplifying gives the complete expression for the thermodynamic equilibrium constant of the ionic reaction, given by Equation (2.21)

$$
K_{T}=\left(\frac{\left(C_{C} \gamma_{C}\right)^{c}\left(C_{D} \gamma_{D}\right)^{d}}{\left(C_{A} \gamma_{A}\right)^{a}\left(C_{B} \gamma_{B}\right)^{b}}\right)
$$

The equilibrium constant, $\mathrm{K}_{\mathrm{T}}$, for the ionic reaction can be calculated from the free energy change for the reaction with Equation (2.22),

$$
K_{T}=\exp \left(\frac{-\Delta G_{R X N}^{0}(T)}{R T}\right)
$$

with

$$
\Delta G_{R X N}^{0}(T)=\sum_{i} v_{i} \Delta G_{f i}^{0}(T)-\sum_{j} v_{j} \Delta G_{f j}^{0}(T)
$$


The products formed in the ionic reaction are represented by $i$ where $j$ represents the reactants.

\subsubsection{Solubility equilibrium between crystals and saturated solutions}

The dissociation reaction of a pure ionic salt, $B Y$, into its constituent ions in an aqueous solution is represented by Equation (2.2). Equation (2.24) can be derived from Equations (2.17) to (2.21) for the dissolution reaction of the pure ionic salt $B Y$.

$$
\begin{aligned}
K & =\frac{\left[a_{B}\right]^{v_{B}}\left[a_{Y}\right]^{v_{Y}}}{\left[\left[\left(B^{z_{B}}\right)_{v_{B}}\left(Y^{2_{Y}}\right)_{v_{Y}}\right]_{S}\right]} \\
& =\frac{\left[a_{B}\right]^{v_{B}}\left[a_{Y}\right]^{v_{Y}}}{\left[a_{\left(B_{v_{B}} Y_{v_{Y}}\right)}\right]}
\end{aligned}
$$

The pure precipitate, $\left[\left(B^{z_{B}}\right)_{v_{B}}\left(Y^{z_{Y}}\right)_{v_{Y}}\right]_{S}$, is a separate phase from the solution and its concentration or activity, $a_{\left(B_{v_{B}} Y_{v_{Y}}\right)}$, is constant and equal to unity. Equation (2.24) reduces to Equation (2.25), where $a_{i}$ is the activity of species $i$ in the solution phase, and the thermodynamic equilibrium constant becomes the solubility product constant of the precipitate for a given set of physical conditions.

The solubility product constant of a precipitate, $K_{s p}$, is simply an equilibrium constant defined by the product of the solution phase ionic concentrations raised to the power of the number of moles of each ion that dissolves per litre of solution for each mole of precipitate that dissolves.

$$
K_{s p}=\left(C_{B} \gamma_{B}\right)^{v_{B}}\left(C_{Y} \gamma_{Y}\right)^{v_{Y}}
$$


The thermodynamic equilibrium constant for the dissolution reaction, the solubility product, can be calculated from the partial molar Gibbs free energy using Equation (2.26), which is similar to Equation (2.22),

$$
K_{s p}=\exp \left(\frac{-\Delta G_{K_{s p}}^{0}}{R T}\right)
$$

where,

$$
\Delta G_{K_{s p}}^{0}=v_{B} \Delta G_{f B}^{0}+v_{Y} \Delta G_{f Y}^{0}-\Delta G_{f B Y}^{0}
$$

\subsection{SOLUBILITY PRODUCTS OF PRECIPITATES}

The solubility of a precipitate, Equation (2.28), is defined as the number of moles of a particular precipitate that will dissolve in one litre of a given solution, designated by $S$ in units of moles per litre of solution for a given set of physical conditions. A solution is saturated with a precipitate when so many moles that can dissolve in the solution under its given composition and physical conditions, have dissolved and is thus a solution at equilibrium.

Definition of the solubility of a precipitate

$\mathrm{S}=$ Number of moles of precipitate that dissolve per litre of solution

The precipitate is in equilibrium with its slightly dissolved ions, the extent of which is controlled by the solubility of the precipitate under a given set of physical conditions. The general dissolution reaction for a precipitate is given by Equation (2.2), from which 
the thermodynamic equilibrium reaction constant can be derived, given by Equation (2.25).

\subsubsection{Equilibrium considerations for stoichiometrically not one-to-one dissolving precipitates}

When the stoichiometry of the dissolution process is not one-to-one, where $\left|z_{B}\right| \neq\left|z_{Y}\right|, v_{B}=$ $\left|z_{Y}\right|$ and $v_{Y}=\left|z_{B}\right|$, Equation (2.2) reduces to Equation (2.29).

$$
\left[\left(B^{z_{B}}\right)_{z_{Y}}\left(Y^{z_{Y}}\right)_{z_{B}}\right]_{S} \stackrel{K_{s p}}{\longleftrightarrow} z_{Y} B^{z_{B}}+z_{B} Y^{z_{Y}}
$$

Equation (2.29) is only valid for precipitate dissolution reactions where the stoichiometric ratio of the dissolved ions is not one-to-one (one-to-one is the case when $\left|z_{B}\right|:\left|z_{Y}\right|=2: 2$, $3: 3$, etc.) except in the case of a monovalent-monovalent precipitate (where $\left|z_{B}\right|:\left|z_{Y}\right|=$ 1:1). Equation (2.29) is therefore valid for all precipitate dissolution reactions where the stoichiometric ratio of the dissolved ions is not one-to-one, which is the case when the ratio of $\left|z_{B}\right|:\left|z_{Y}\right|$ is typically equal to $1: 2,2: 1,1: 3,3: 1,2: 3,3: 2$, etc.

The solubility product of the sparingly soluble solid in the dissolution reaction, represented by Equation (2.29), is given by Equation (2.30),

$$
\begin{aligned}
K_{s p} & =\left(a_{B}\right)^{z_{Y}}\left(a_{Y}\right)^{z_{B}} \\
& =\left(C_{B} \gamma_{B}\right)^{z_{Y}}\left(C_{Y} \gamma_{Y}\right)^{z_{B}}
\end{aligned}
$$

where $a_{B}$ and $a_{Y}$ represent the activities and $\gamma_{B}$ and $\gamma_{Y}$ the activity coefficients of species $B$ and $Y$ in the aqueous slurry solution respectively. 


\subsubsection{Equilibrium considerations for a stoichiometrically one-to-one dissolving precipitate}

When the stoichiometry of the dissolution process is one-to-one $\left(v_{B}=v_{Y}=1\right.$ when $\left|z_{B}\right|=$ $\left.\left|z_{Y}\right|\right)$, Equation (2.2) reduces to Equation (2.31).

$$
\left[\left(B^{z_{B}}\right)\left(Y^{z_{Y}}\right)\right]_{S} \stackrel{K_{s p}}{\longleftrightarrow} B^{z_{B}}+Y^{z_{Y}}
$$

The solubility product of the sparingly soluble solid in the above reaction is given by Equation (2.32).

$$
\begin{aligned}
K_{s p} & =\left(a_{B}\right)\left(a_{Y}\right) \\
& =\left(C_{B} \gamma_{B}\right)\left(C_{Y} \gamma_{Y}\right)
\end{aligned}
$$

Equation (2.32) is valid for precipitate dissolution reactions where the stoichiometric ratio of the dissolved ions is one-to-one, which is the case when $\left|z_{B}\right|:\left|z_{Y}\right|=1: 1,2: 2,3: 3$, etc.

\subsubsection{Calculating the solubility of a precipitate from its solubility product}

The solubility of a precipitate can be calculated from the solubility product for a given set of physical conditions using Equation (2.28). For each mole of precipitate $\left[\left(B^{z_{B}}\right)_{v_{B}}\left(Y^{z_{Y}}\right)_{v_{Y}}\right]_{S}$ that dissolves, $v_{B}$ moles of species $B$ and $v_{Y}$ moles of $Y$ are formed in solution. 
Substituting these moles of dissolved ions into Equation (2.25) and using the definition of the solubility $S$, Equation (2.25) becomes Equation (2.33),

$$
\begin{aligned}
K_{s p} & =\left[v_{B} S \gamma_{B}\right]^{v_{B}}\left[v_{Y} S \gamma_{Y}\right]^{\nu_{Y}} \\
& =\left[v_{B} \gamma_{B}\right]^{v_{B}}\left[v_{Y} \gamma_{Y}\right]^{\nu_{Y}}[S]^{\left(v_{B}+v_{Y}\right)}
\end{aligned}
$$

from which the solubility, $S$, of the precipitate can be calculated.

$$
S=\left(\frac{K_{s p}}{\left[v_{B} \gamma_{B}\right]^{v_{B}}\left[v_{Y} \gamma_{Y}\right]^{\nu_{Y}}}\right)^{\frac{1}{v_{B}+v_{Y}}}
$$

In the case of a stoichiometrically one-to-one dissolving precipitate, Equation (2.34) reduces to Equation (2.35).

$$
S=\left(\frac{K_{s p}}{\left[\gamma_{B}\right]\left[\gamma_{Y}\right]}\right)^{\frac{1}{2}}
$$

In the case of ideal solutions the activity coefficients of all the species in the solution phase are equal to one. Equation (2.35) reduces to Equation (2.36), from which it follows that the solubility of a stoichiometrically one-to-one dissolving precipitate is equal to the square root of its solubility product for a given set of physical conditions.

$$
\begin{aligned}
K_{s p} & =S^{2} \\
\Rightarrow \quad S & =\sqrt{K_{s p}}
\end{aligned}
$$


Table 2.2 gives the solubility of various precipitates, $S$, that dissolve stoichiometrically in a one-to-one and non one-to-one manner, as a function of the solubility product.

The solubility product of a precipitate is constant for a given set of physical conditions, but can be manipulated by varying the physical conditions (solution temperature and pressure) and chemical composition (solution composition) of the system.

The control of solubility thus allows the control of dissolution of different precipitates and hence the separation of chemical species in a multicomponent solution phase. The solubility of a precipitate can therefore be a useful tool for the separation and extraction of species in hydrometallurgical and chemical processes and is worth being investigated.

Table 2.2 The solubility of precipitates as a function of the solubility product.

\begin{tabular}{|c|c|}
\hline \multicolumn{2}{|c|}{ Precipitates dissolving in a one-to-one stoichiometric manner } \\
\hline $1: 1,2: 2,3: 3$, etc. & $S=\left(K_{s p}\right)^{\frac{1}{2}}$ \\
\hline Precipitates dissolving in a non one-to-one stoichiometric manner \\
\hline $1: 2,2: 1$ & $S=\left(\frac{K_{s p}}{4}\right)^{\frac{1}{3}}$ \\
\hline $1: 3,3: 1$ & $S=\left(\frac{K_{s p}}{27}\right)^{\frac{1}{4}}$ \\
\hline $2: 3,3: 2$ & $S=\left(\frac{K_{s p}}{108}\right)^{\frac{1}{5}}$ \\
\hline
\end{tabular}

\subsection{PARAMETERS INFLUENCING THE SOLUBILITY OF PRECIPITATES}

In order to mathematically predict the solubility of a sparingly soluble solid in an aqueous electrolyte solution, there are some essential steps that need to be followed. The first step 
involves the formulation of the equations for the material balances, phase equilibria, reaction equilibria and electroneutrality conditions in the thermodynamic form. These equations usually involve dissolution and dissociation reactions. The second step is obtaining values for the different equilibrium constants and species activity coefficients from published data in the literature. The thermodynamic information must then be solved simultaneously for all of the species present in the aqueous electrolyte solution phase and solid phase.

The following chemical processes influence the solubility of a sparingly soluble solid in an aqueous electrolyte solution:

i) the presence of strong electrolytes,

ii) the common ion effect,

iii) weak acid formation, and

iv) complex formation with a ligand.

\subsubsection{The influence of dissolved electrolytes on the solubility of a sparingly soluble solid in an aqueous electrolyte solution}

When a sparingly soluble solid is placed in an aqueous electrolyte solution containing ionic species that do not form a precipitate with the constituent ions of the solid, the chemical activities of the constituent ions are changed, which will influence the solubility of the sparingly soluble solid. Equation (2.2) gives a general representation of the dissolution reaction of a sparingly soluble solid, with the thermodynamic equilibrium constant defined by Equation (2.25).

The value of the solubility product constant of a sparingly soluble solid is always constant for a given set of physical conditions, and it follows from Equation (2.25) that the solution phase concentrations of the dissolved ions will increase if the activity coefficients of these species decrease in order to keep the right hand side of Equation 
(2.25) constant. A decrease in the solution phase activity coefficients of the species indicates a departure from ideal bulk behaviour of the dissolved ions in the solution, and usually occurs with the introduction of other ionic species that may or may not participate in the overall dissolution reaction.

To calculate the solubility of the sparingly soluble solid in the aqueous electrolyte solution, all the participating equations must be written in their thermodynamic forms. Zemaitis et al. (1986) discuss the importance of considering all the species and species interactions, even species that are present at very low concentration levels relative to the other species present, since they usually may have a significant effect on the activities of the other species. Complete dissociation is assumed for the sparingly soluble solid and the electrolyte, hence the formation of ionic complexes between the constituent ions of the solid and the electrolyte is disregarded. The system is described by the following reactions:

Water dissociation:

$$
\mathrm{H}_{2} \mathrm{O} \stackrel{\mathrm{K}_{w}}{\longleftrightarrow} \mathrm{H}^{+}+\mathrm{OH}^{-}
$$

Dissolution of the sparingly soluble solid, containing crystal water:

$$
\left[\left(B^{z_{B}}\right)_{v_{B}}\left(Y^{z_{Y}}\right)_{v_{Y}} \cdot \kappa H_{2} O\right]_{s} \stackrel{K_{s p}}{\longleftrightarrow} v_{B} B^{z_{B}}+v_{Y} Y^{z_{Y}}+\kappa H_{2} O
$$

Dissociation of the strong electrolyte AE:

$$
\left[\left(A^{z_{A}}\right)_{v_{A}}\left(E^{z_{E}}\right)_{v_{E}}\right]_{C} \stackrel{K_{A E}}{\longleftrightarrow} v_{A} A^{z_{A}}+v_{E} E^{z_{E}}
$$

These three equilibrium reactions result in the following three thermodynamic equilibrium constants in the water-precipitate-electrolyte system. 


$$
\begin{aligned}
& K_{w}=\frac{\left[C_{H^{+}} \gamma_{H^{+}}\right]\left[C_{O H^{-}} \gamma_{O H^{-}}\right]}{a_{w}} \\
& K_{s p}=\left[C_{B} \gamma_{B}\right]^{v_{B}}\left[C_{Y} \gamma_{Y}\right]^{\nu_{Y}}\left[a_{w}\right]^{\kappa}
\end{aligned}
$$

The water activity term in Equation (2.41), $a_{w}$, disappears for anhydrous precipitates.

$$
K_{A E}=\left[C_{A} \gamma_{A}\right]^{\nu_{A}}\left[C_{E} \gamma_{E}\right]^{\nu_{E}}
$$

An elemental mass balance must also be performed for each of the species present in the aqueous slurry solution to be able to solve the complete set of equations for the system. The activity of each species is also a function of the total solution ionic strength and composition, and must be obtained from direct experimental measurements or from the abundant literature data available for the concentration range of interest. A literature survey of the most prominent and fundamental activity coefficient models is given in Chapter 3. Investigators such as Pitzer and Mayorga (1973) and Kusik and Meissner (1973) have developed reliable correlations. Difficulties are encountered in the determination of activity coefficients of species in solutions of sparingly soluble electrolytes, especially in supersaturated solutions (Sohnel and Garside, 1992). The high degree of supersaturation in these types of solutions makes the experimental determination of the activity coefficients for the different species in the solution phase impossible, since small variations in the chemical composition of the solution can trigger precipitation reactions. In these cases the values of the activity coefficients are dependent on theoretical estimates and correlations.

\subsubsection{The common ion effect}


The solubility of a precipitate in an aqueous slurry can often be depressed with the addition of a highly soluble salt to the slurry solution that contains an ion that is common to one of the constituent ions of the precipitate. According to Le Chatelier's principle, the addition of $\mathrm{m}$ moles of $\mathrm{Y}$ ions per litre of aqueous solution will force the dissolution reaction, represented by Equation (2.2), to the left. This shift in the equilibrium condition which occurs when an ion common to the equilibrium reaction is introduced, is called the common ion effect (Brewer, 1980). From the definition of the solubility of a sparingly soluble solid, Equation (2.28), and taking into account the increase in solution concentration of species $\mathrm{Y}$ with m moles/litre, Equation (2.25) reduces to Equation (2.43) for anhydrous precipitates.

$$
K_{s p}=\left[v_{B} S \gamma_{B}\right]^{v_{B}}\left[\left(v_{Y} S+m\right) \gamma_{Y}\right]^{v_{Y}}
$$

The solubility of the sparingly soluble solid can be calculated from the above equation if the values of the activity coefficients for the different species in the solution are known at the total solution ionic strength. If the sparingly soluble solid dissolves in a stoichiometric one-to-one way and if the species in the solution behave ideally so that the solution phase activity coefficients of all the species are equal to unity, Equation (2.43) reduces to Equation (2.44).

$$
K_{s p}=[S][S+m]
$$

From Equation (2.44) it follows that the solubility of the constituent ions of the sparingly soluble solid is given by Equation (2.45).

$$
S=\frac{-m+\sqrt{m^{2}+4 K_{s p}}}{2}
$$

Equation (2.45) holds only for an ideal water-precipitate-electrolyte system, which is seldom the case. To calculate the solubility of the sparingly soluble solid in true 
electrolyte solutions containing an ion common to the constituent ions of the solid, Equation (2.43) must be used. It is evident that the values of the activity coefficients of the constituent ions in Equation (2.43) are needed in order to calculate the solubility $S$.

\subsubsection{Weak acid formation}

\section{Step 1:}

$$
\begin{aligned}
& Y^{z_{Y}}{ }_{(a q)}+H^{+}{ }_{(a q)} \leftrightarrow H Y^{z_{Y}+1}{ }_{(a q)} \\
& K a_{\left|z_{y}\right|}=\frac{\left[Y^{z_{Y}}(a q)\right]\left[H^{+}{ }_{(a q)}\right]}{\left[H Y^{z_{Y}+1}{ }_{(a q)}\right]}
\end{aligned}
$$

\section{Step 2:}

$$
\begin{aligned}
& H Y^{z_{Y}+1}{ }_{(a q)}+H^{+}(a q) \leftrightarrow H_{2} Y^{z_{Y}+2}{ }_{(a q)} \\
& K a_{\left|z_{Y}\right|-1}=\frac{\left[H Y^{z_{Y}+1}{ }_{(a q)}\right]\left[H^{+}(a q)\right]}{\left[H_{2} Y^{z_{Y}+2}{ }_{(a q)}\right]}
\end{aligned}
$$

Step $\left|z_{Y}\right|$

$$
\begin{aligned}
& H_{\left|z_{Y}\right|-1} Y^{-}(a q)+H^{+}(a q) \leftrightarrow H_{\left|z_{Y}\right|} Y_{(a q)} \\
& K a_{1}=\frac{\left[H_{\left|z_{Y}\right|-1} Y^{-}(a q)\right]\left[H^{+}(a q)\right]}{\left[H_{\left|z_{Y}\right|} Y_{(a q)}\right]}
\end{aligned}
$$


The solubility of sparingly soluble salts (precipitates) can be enhanced or decreased by changing the $\mathrm{pH}$ of the solution if the anion of the precipitate is the conjugate base of a weak acid. The precipitate dissolves according to Equation (2.2) and can form weak acids by combining with the free hydrogen ions in the solution according to the successive reaction steps represented by Equations (2.46) to (2.48), each with its own thermodynamic equilibrium constant:

The hydrogen ions from the surrounding bulk solution form weak acids with the $Y^{z_{Y}}$ anions of the precipitate, which are the conjugate bases of the weak acid $H_{\left|z_{Y}\right|} Y$. According to Le Chatelier's principle, more of the sparingly soluble solid has to dissolve to restore the equilibrium concentration of the $Y^{z_{Y}}$ anions as it combines with the $\mathrm{H}^{+}$ ions to form the weak acids. The sparingly soluble solid, $\left[\left(B^{z_{B}}\right)_{v_{B}}\left(Y^{z_{Y}}\right)_{v_{Y}}\right]_{S}$, is thus more soluble in acidic solutions than neutral or basic ones. The extent to which the solubility of the precipitate is increased, due to weak acid formation, depends on the number of hydrogen ions available in the solution, thus the $\mathrm{pH}$ of the solution, and the dissociation constants of the weak acids formed in the successive reactions described by Equations (2.46) to (2.48).

The solubility of a sparingly soluble solid in a solution, containing no other source of anions that is the same as the constituent anion of the solid, buffered to certain $\mathrm{pH}$ can be calculated from the above Equations, representing the overall chemical process. The total number of $Y^{z_{Y}}$ anions produced in the overall dissolution reaction, $Y^{z_{Y}}$ Total, is given by Equation (2.49).

$$
Y^{z_{Y}} \text { Total }=\left[Y^{z_{Y}}\right]+\left[H Y^{z_{Y}+1}\right]+\left[H_{2} Y^{z_{Y}+2}\right]+\cdots+\left[H_{\left|z_{Y}\right|} Y\right]
$$

From Equations (2.46), (2.47) and (2.48) it follows that 


$$
\begin{aligned}
& {\left[H Y^{z_{Y}+1}{ }_{(a q)}\right]=\frac{\left[Y^{z_{Y}}(a q)\right]\left[H^{+}(a q)\right.}{K a_{\left|z_{Y}\right|}}} \\
& {\left[H_{2} Y^{z_{Y}+2}(a q)\right]=\frac{\left[H Y^{z_{Y}+1}(a q)\right]\left[H^{+}(a q)\right]}{K a_{\left|z_{Y}\right|-1}}} \\
& {\left[H_{\left|z_{Y}\right|} Y_{(a q)}\right]=\frac{\left[H_{\left|z_{Y}\right|-1} Y^{-}(a q)\right]\left[H^{+}(a q)\right]}{K a_{1}}}
\end{aligned}
$$

Substituting Equations (2.50) to (2.52) into Equation (2.49) and simplifying gives Equation (2.53).

$$
\begin{aligned}
Y^{z_{Y}} \text { Total } & =\left[\frac{\left(K a_{\left|z_{Y}\right|} \cdot K a_{\left|z_{Y}\right|-1} \cdot \ldots \cdot K a_{1}\right)+\left(K a_{\left|z_{Y}\right|-1} \cdot \ldots \cdot K a_{1}\right)\left[H^{+}\right]+\cdot \ldots \cdot\left[H^{+}\right]^{\left|z_{Y}\right|}}{K a_{\left|z_{Y}\right|} \cdot K a_{\left|z_{Y}\right|-1} \cdot \ldots \cdot K a_{1}}\right]\left[Y^{z_{Y}}\right] \\
& =\frac{\left[Y^{z_{Y}}\right]}{\beta}
\end{aligned}
$$

where

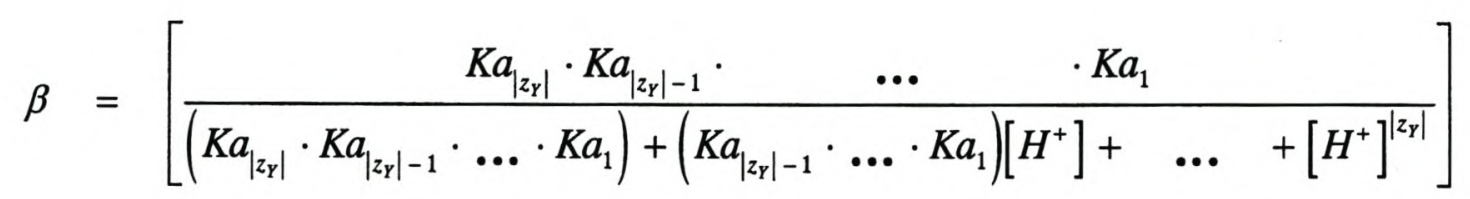

The stoichiometry of the dissolution reaction, Equation (2.2), is one-to- $v_{Y}$ with respect to the $Y^{z_{r}}$ anions. The solubility is given by Equation (2.55). 


$$
\text { Solubility }=S=\frac{\left[Y^{z_{Y}} \text { Total }\right]}{v_{Y}}
$$

Substituting Equation (2.53) into Equation (2.55) and rearranging gives Equation (2.56)

$$
\left[Y^{z_{Y}}\right]=v_{Y} S \beta
$$

which can in turn be substituted into the solubility product equation (Equation (2.30) or (2.32)) and solved for the solubility.

\subsubsection{Complex formation with a ligand}

Metal ions have the property that they can act as electron pair acceptors, i.e. Lewis acids, towards water molecules or as electron pair donors, i.e. Lewis bases. It is this property of metal ions to act as Lewis acids that makes it possible for Lewis bases, other than water, to interact with the metal ions. This is especially the case with the transition metal hydroxides and oxides that are relatively insoluble in neutral water but dissolve more regularly in either strongly acidic or strongly basic aqueous solutions, such as $\mathrm{Al}^{3+}$, $\mathrm{Cr}^{3+}, \mathrm{Zn}^{2+}$ and $\mathrm{Sn}^{2+}$. Such Lewis acid base interactions can have a significant effect on the solubility of a metal precipitate as the solubility of the precipitate is enhanced by complex formation.

The ligand is competing with the precipitate anions to bond with the precipitate metal cations. For the Lewis base (the ligand) to bond with the precipitate metal cations, it must interact more strongly with the metal cations than the solvating water molecules do, in order to displace them. This competition for the metal cations results in an increase of the solubility of the precipitate as the metal cations are removed from the solution, and its equilibrium concentration needs to be restored by the further dissolution of the 
precipitate. The extent to which the solubility of the precipitate can be enhanced by complexation depends on the following factors (Brewer, 1980).

\subsubsection{The solubility product of the precipitate}

It is clear that the greater the solubility product of the precipitate, the higher the concentration of the metal cations in the solution, which are available for complex formation with the ligand. The solubility can therefore be enhanced to a greater extent compared with a smaller solubility product.

\subsubsection{The equilibrium concentration of the ligand}

According to Le Chatelier's principle, the higher the equilibrium concentration of the ligand the more readily will it form complexes with the cations of the precipitate.

\subsubsection{The thermodynamic equilibrium constants of the successive complexation reactions and the activities of the species}

During complex formation there may be successive complexation reactions and the extent to which each of these reactions will proceed depends on their equilibrium constants. The equilibrium constants of each reaction give the equilibrium concentrations of the complexes formed, hence the stability of these complex ions in the aqueous solution. Large equilibrium constants, which favour the forward complexation reaction, will result in almost complete complexation of the precipitate. The dissolution of the precipitate will therefore be favoured by larger forward complexation equilibrium constants, which enhance the further dissolution of the precipitate to restore the equilibrium concentration of the metal ion. 
A stoichiometric treatment of the simultaneous dissolution and complexation process of a metal precipitate will be conducted to quantify the "extent" to which the solubility of a solid precipitate can be enhanced by forming complexes. The metal precipitate is designated by $\left[\left(B^{z_{B}}\right)_{v_{B}}\left(Y^{z_{Y}}\right)_{v_{Y}}\right]_{S}$, where $B^{z_{B}}$ represents the metal cations and $Y^{z_{Y}}$ the anions. The ligand, designated by $X$, forms a series of complex ions with the metal cation $B^{z_{B}}$ with successive formation constants $k_{1}, k_{2}$ and so forth. The reactions are:

Metal precipitate dissolution reaction

$$
\left[\left(B^{z_{B}}\right)_{v_{B}}\left(Y^{z_{Y}}\right)_{v_{Y}}\right]_{s} \stackrel{K_{s p}}{\longleftrightarrow} v_{B} B^{z_{B}}+v_{Y} Y^{z_{Y}}
$$

with solubility product given by Equation (2.58)

$$
K_{s p}=\left[a_{B}\right]^{v_{B}}\left[a_{Y}\right]^{v_{Y}}
$$

$\underline{\text { Successive complexation reactions }}$

$$
\begin{aligned}
& B^{z_{B}}(a q)+X_{(a q)} \leftrightarrow B X^{z_{B}}(a q) \quad K_{1}=\frac{\left[B X^{z_{B}}\right]}{\left[B^{z_{B}}\right][X]} \\
& B X^{z_{B}}(a q)+X_{(a q)} \leftrightarrow B X_{2}^{z_{B}}(a q) \quad K_{2}=\frac{\left[B X_{2}^{z_{B}}\right]}{\left[B X^{z_{B}}\right][X]} \\
& B X_{2(a q)}^{z_{B}}+X_{(a q)} \leftrightarrow B X_{3(a q)}^{z_{B}} \quad K_{3}=\frac{\left[B X_{3}^{z_{B}}\right]}{\left[B X_{2}^{z_{B}}\right][X]} \\
& B X_{n-1(a q)}^{z_{B}}+X_{(a q)} \leftrightarrow B X_{n(a q)}^{z_{B}} \quad K_{n}=\frac{\left[B X_{n}^{z_{B}}\right]}{\left[B X_{n-1}^{z_{B}}\right][X]}
\end{aligned}
$$


It is assumed that no other complexes are formed except the ones occurring in the above equations. The solubility of the precipitate is defined by Equation (2.28), which is equal to the total number of moles of the precipitate that dissolves per litre of solution. Because none of the $Y^{z_{Y}}$ anions forms any complexes, the solubility of the precipitate is equal to the equilibrium concentration of the $Y^{z_{Y}}$ anions. The stoichiometry of the dissolution reaction, Equation (2.2), is one-to- $v_{Y}$ with respect to the $Y^{z_{Y}}$ anions, meaning that $v_{Y}$ moles of the $Y^{z_{Y}}$ anions are produced in solution for every mole of the precipitate that dissolves.

$$
\text { Solubility }=S=\frac{\left[Y^{z_{Y}}\right]}{v_{Y}}
$$

There are many complex species containing the dissolved $B^{z_{B}}$ metal cations produced by the dissolution reaction of Equation (2.2). The stoichiometry of the dissolution reaction is one-to- $v_{B}$ with respect to the $B^{z_{B}}$ cations. The total number of moles of $B^{z_{B}}$ cations will be designated by $B^{z_{B}}$ Total. The solubility is given by

$$
\text { Solubility }=S=\frac{\left[B^{z_{B}} \text { Total }\right]}{v_{B}}
$$

where

$$
B^{z_{B}} \text { Total }=\left[B^{z_{B}}\right]+\left[B X^{z_{B}}\right]+\left[B X_{2}^{z_{B}}\right]+\cdots\left[B X_{n}^{z_{B}}\right]
$$

The term $\beta$ is defined by Equation (2.66), given below. 


$$
\begin{aligned}
\beta & =\frac{\left[B^{z_{B}}\right]}{\left[B^{z_{B}} \text { Toatl }\right]} \\
& =\frac{\left[B^{z_{B}}\right]}{\left[B^{z_{B}}\right]+\left[B X^{z_{B}}\right]+\left[B X_{2}^{z_{B}}\right]+\left[B X_{3}^{z_{B}}\right]+\cdots+\left[B X_{n}^{z_{B}}\right]}
\end{aligned}
$$

From Equations (2.59) to (2.62), expressions can be obtained for all the $B$-bearing complex species in terms of the formation constants, $k_{1}$ to $k_{n}$, and the concentrations $\left[B^{z_{B}}\right]$ and $[X]$. The expressions are

from Equation (2.59)

$$
\left[B X^{z_{B}}\right]=k_{1}\left[B^{z_{B}}\right][X]
$$

from Equations (2.60) and (2.67)

$$
\begin{gathered}
{\left[B X_{2}^{z_{B}}\right]=k_{2}\left[B X^{z_{B}}\right][X]} \\
=k_{1} k_{2}\left[B^{z_{B}}\right][X]^{2}
\end{gathered}
$$

from Equations (2.61) and (2.68) $\quad\left[B X_{3}^{z_{B}}\right]=k_{3}\left[B X_{2}^{z_{B}}\right][X]$

$$
=k_{1} k_{2} k_{3}\left[B^{z_{B}}\right][X]^{3}
$$

Similarly it follows that

$$
\begin{aligned}
& {\left[B X_{n}^{z_{B}}\right]=k_{n}\left[B X_{n-1}^{z_{B}}\right][X]} \\
& =k_{1} k_{2} k_{3} \cdots k_{n}\left[B^{z_{B}}\right][X]^{n}
\end{aligned}
$$

Substituting Equations (2.67) to (2.70) into Equation (2.66) and simplifying gives Equation (2.71).

$$
\beta=\frac{1}{1+k_{1}[X]+k_{1} k_{2}[X]^{2}+k_{1} k_{2} k_{3}[X]^{3}+\cdots k_{1} k_{2} k_{3} \cdots k_{n}[X]^{n}}
$$

From Equation (2.64) and (2.66) it follows that, 


$$
\text { Solubility }=S=\frac{\left[B^{z_{B}}\right]}{v_{B} \beta}
$$

From Equation (2.72) the equilibrium concentration of the free metal cations is given by

$$
\left[B^{z_{B}}\right]=v_{B} S \beta
$$

Substituting the equilibrium concentration values of $Y^{z_{Y}}$ from Equation (2.63) and $B^{z_{B}}$ from Equation (2.73) into Equation (2.30), describing the solubility product, and rearranging gives Equation (2.74), the solubility $S$ of the metal precipitate at equilibrium.

$$
\text { Solubility }=S=\left(\frac{K_{s p}}{v_{B}^{v_{B}} v_{Y}^{v_{Y}} \beta^{v_{B}}}\right)^{\frac{1}{v_{B}+v_{Y}}}
$$

\subsection{SUMMARY}

Predictive chemical models for aqueous systems are best identified by the study of the chemical equilibria characterising the process, which facilitate the interpretation of observed phenomena. To gain fundamental insight into the nature of such aqueous chemical processes, special electrolyte thermodynamic models are needed to describe the non-ideal behaviour of aqueous solutions. The species in electrolyte solutions differ from those in molecular solutions, in both type and number in that electroneutrality has to be satisfied at all times. Furthermore, the existence of ions and multiple forms of the same molecule results in a large number of species present, with chemical interactions between each of them, the extent of which is governed by the relevant equilibrium conditions (Linkson, 1996). The chemical interactions between these species in the aqueous phase determine the equilibrium composition of the solution, which in turn governs the vapouraqueous phase and solid-aqueous phase equilibria. 
It is therefore highly desirable to synthesise a chemical model which can predict the solubility of a species in a multicomponent aqueous system under a variety of conditions, as evidenced by the numerous work in this area (Zemaitis et al., 1986). A simplified approach to the prediction of the equilibrium solubility of a species in a multicomponent aqueous solution can be found from the literature, as described in paragraphs (2.7.2), (2.7.3) and (2.7.4). Predictive models of this nature usually give a fair representation of observed experimental data at very low total solution concentrations in aqueous systems.

This low concentration scenario is hardly ever encountered in the hydrometallurgical extraction of valuable species from low-grade ores. The aqueous phase concentration of the valuable species is usually low, with the overall solution phase concentration high due to the presence of other ionic species. These species include leaching reagents, which are added to facilitate the dissolution of the valuable species from the low-grade ore. This rapidly increases the total solution phase concentration. This increase in the solution phase concentration is accompanied by an increase in the number of different ionic species. This results in non-ideal behaviour between the different species and also in an increase in the number of multiple forms of the same ionic molecule. To model the nonideal behaviour in these systems, caused by the increased number of equilibrium reactions, accurate representations of the activity coefficients of the different ionic species are needed.

Consequently, considerable effort has been made to develop special electrolyte thermodynamic models needed for accurate representation of the deviations from ideal solution behaviour, which are discussed in Chapter 3. This includes thermodynamic models such as Pitzer's "ion-interaction" model (Zemaitis et al., 1986), which has been successfully used throughout the literature to accurately represent the aqueous phase activity coefficients of various ionic species under a variety of non-ideal conditions. 
It also became evident from paragraphs $2.1,2.5$ and 2.6 that various techniques may be used to calculate the equilibrium solution phase concentration of the dissolved constituent ions of a sparingly soluble solid. These techniques include the use of the solid's solubility product, $\mathrm{K}_{\mathrm{sp}}$, or the Gibbs free energy of formation for the species present in the aqueous phase solution. It is important to notice that irrespective of which technique is used, the user still needs to consider and define the formation of all relevant species in the aqueous phase. This highlights the importance of a general understanding of the aqueous phase solution chemistry required in the synthesis of the consolidated equilibrium model for a RIP slurry mixture. In order to ensure this, a comprehensive data base has been designed and populated with relevant data for all of the species considered in this dissertation as defined in Chapter 7, which contains the experimental procedures and chemicals used. The use of the designed thermodynamic data base will be discussed in more detail in Chapter 8 of this dissertation.

From the mathematical equations presented in this chapter it is evident that the calculation of the species activity is of paramount importance for any solubility calculation, irrespective of which technique is used $\left(\mathrm{K}_{\mathrm{sp}}\right.$ or Gibbs free energy minimisation). Because of this a detailed study has been launched into the various models available in the literature that allow for the accurate calculation of the species activity for various aqueous phase compositions and concentrations. Chapter 3 that follows provides a detailed study and discussion on the most prominent of these models. 


\section{CHAPTER 3}

\section{THERMODYNAMIC MODELS FOR THE PREDICTION OF ELECTROLYTE ACTIVITY COEFFICIENTS IN NON-IDEAL AQUEOUS ELECTROLYTE SOLUTIONS}

From the discussions in Chapter 1 it was evident that the aqueous phase played an important role in the equilibrium distribution of the dissolved species of the sparingly soluble solid between the various precipitate and ion-exchange resin phases. This was also evident from Figure 1.1 (Chapter 1), which showed the various equilibrium conditions existing between the various solid and resin phases with the aqueous phase, indicated by the dashed lines in the schematic. In Chapter 2 the focus of the discussion was on the various solid phase equilibrium conditions with the aqueous phase and how it influences the solubility of the sparingly soluble solids in the aqueous phase. This focus on the solid precipitate / aqueous phase equilibrium conditions of Chapter 2 is schematically represented by Figure 2.1 (Chapter 2), which indicated the equilibrium conditions of interest with the bold dashed lines.

From Chapter 2 it is evident that the ability to model the activity of any species in the aqueous phase is of utmost importance in predicting the solubility of a sparingly soluble solid in the aqueous phase for different aqueous phase compositions. From Equation 2.14 (repeated below) it is evident that the modelling of the species activity boils down to the prediction of the species activity coefficient in the aqueous phase. It is therefore the focus of this chapter to investigate various activity coefficient models available in the literature. 


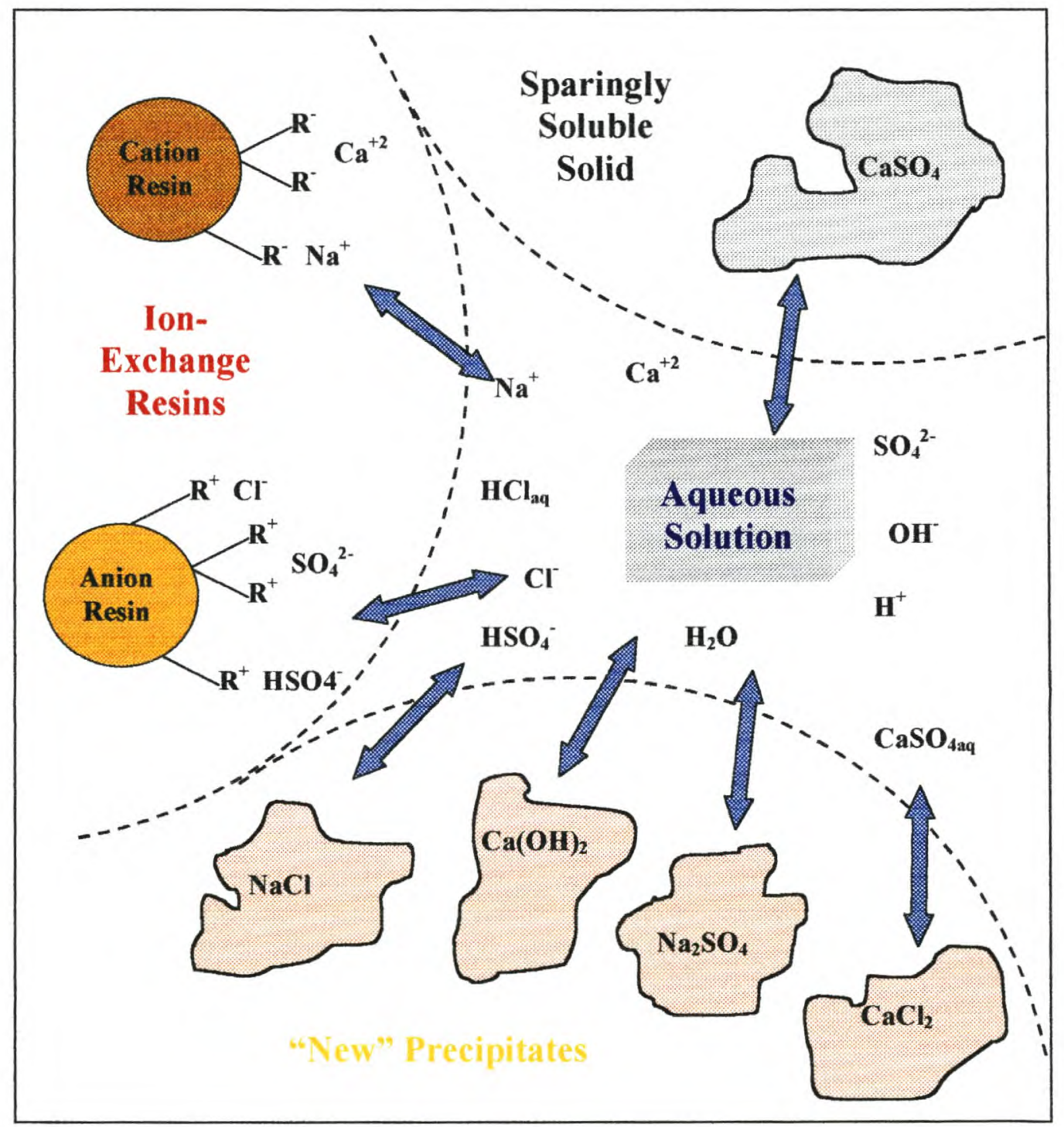

Figure 3.1 Aqueous phase equilibrium considerations for the dissolution of sparingly soluble solids of a Resin-in-Slurry mixture of $\mathrm{CaSO}_{4}$ with a cation and anion exchange resin 
Due the nature of a Resin-in-Pulp (RIP) slurry mixture that causes the ionic strength (total aqueous phase concentration) of the aqueous phase to increase during equilibrium attainment, the activity coefficient model should have the ability to predict the species activity coefficient over a wide concentration as well as composition range.

Figure 3.1 is a modified version of Figure 1.1, indicating the various equilibrium conditions existing in a RIP slurry mixture. By comparing Figure 1.1 and Figure 3.1 it is evident that internal equilibrium conditions belonging to the aqueous phase are under investigation in this chapter, required in the synthesis of a consolidated equilibrium model for a RIP slurry mixture as defined in Chapter 6 of this dissertation.

\subsection{OBJECTIVES OF THIS CHAPTER}

From the above discussion it is evident that the primary focus of this chapter is the investigation into the various aqueous phase activity coefficient models available in the literature. To understand the underlying importance of these models and the role they play in understanding aqueous electrolyte processes in industry, an overview is given below of some of the industrial processes requiring a sound fundamental understanding of aqueous phase equilibrium modelling.

From Figure 3.1 the importance of these models towards the synthesis of a consolidated equilibrium model for a RIP slurry mixture is evident. It is clear that the ability of the proposed consolidated model to be able to predict the aqueous phase equilibrium conditions is of significant importance due to the fact that all of the ion-exchange resin and solid phases are in equilibrium with the aqueous phase.

It is also an objective of this chapter to improve the fundamental knowledge of the reader on aqueous phase equilibria, which forms an important part of the synthesis of the consolidated model. The activity coefficient model chosen to be used in the consolidated model must have the ability to predict the species activity coefficient over a significant 
concentration range ranging from very low to high aqueous phase concentrations. The model must also have the ability to account for various interactions with other species in a multi-component aqueous electrolyte solution. It is also of significant importance for the model to have published values in the literature for its model parameters. If this is not the case, it will mean that extensive experimental work will have to be performed to evaluate the model parameters for each species present in the RIP systems of interest to this dissertation.

\subsection{OVERVIEW OF INDUSTRIAL PROCESSES IN AN AQUEOUS ELECTROLYTE SYSTEM ENVIRONMENT}

In the past several years, interest in the fundamental understanding of aqueous phase electrolyte equilibria has grown significantly in the hydrometallurgical industry. This is especially the case for the liquid-solid equilibrium condition that exists between a weak or strong aqueous electrolyte solution in contact with an ore containing a valuable species that needs to be leached and recovered by adsorption. The adsorbent can be contacted directly with the ore in the leaching circuit, of which the Carbon-in-Pulp (CIP) process for the recovery of gold is a well known example. Similar Resin-in-Pulp (RIP) processes exist which employ the use of highly gold-selective resins in a multi component aqueous electrolyte solution/slurry mixture. In the above-mentioned processes there exist two multi phase equilibrium conditions which can influence the overall recovery of the gold (or valuable species), i.e. the ore/solution and solution/adsorbent equilibrium condition. The activity of the gold species in the aqueous electrolyte solution will influence its equilibrium distribution between the ore and the adsorbent.

It is therefore important to have a fundamental understanding of the factors influencing the activity of each particular species of interest in an aqueous electrolyte solution so that its equilibrium distribution between the different phases can be predicted and its recovery optimised. 
The above mentioned process is only one of several important hydrometallurgical processes, which needs to be understood and analysed in a much more fundamental way. This is important so that the engineer can optimise the process at a molecular level, which in turn will result in higher value added end products. Further examples of hydrometallurgical processes, where the prediction of the species activity in a multicomponent aqueous electrolyte solution is of importance to optimisation and design, include

1. The recovery of pollutants from waste water and effluent process streams with the use of adsorbents such as activated carbon or species selective resins, or by the precipitation of the pollutant species where the activities of the species in solution will determine the stability of the formed precipitate.

The simultaneous adsorption of organic pollutants from aqueous wastewater solutions on activated carbon was studied by Fritz and Schluender (1974), who stated that equilibrium adsorption information (activity coefficients) of the system is required for the design of such purification facilities. The decontamination of wastewater, containing $\mathrm{Sr}$ and $\mathrm{Cs}$, with the use of chabazite zeolites was studied by Perona (1993) and later by Robinson et al. (1994). Perona (1993) used the Wilson equation to predict the solid-phase activity coefficients of the adsorbed species in the Sr-Cs-Ca-Mg-Na multicomponent system to assist in the design of ion-exchange columns. The removal of dissolved heavy metal ions, such as $\mathrm{Pb}$ (II), $\mathrm{Cu}(\mathrm{II}), \mathrm{Ni}$ (II) and $\mathrm{Cd}(\mathrm{II})$, from contaminated water with non toxic competing ions, such as $\mathrm{Ca}^{+2}, \mathrm{Mg}^{+2}$ and $\mathrm{Na}^{+}$, with the use of polymeric chelating ion exchangers was studied by Sengupta (1992). Yoshida et al. (1990) studied the removal of diisopropanolamine, butylcellosolve and ethylcellosolve from the wastewater of an electrodeposition painting process, with the use of an $\mathrm{H}$-form strong acid ion exchanger. 
2. Desalination of seawater or brackish water. Vermeer et al. (1975) used a strong acid cation exchange resin, Dowex 50W-X12, for the desalination of brackish water in a column set-up where the major cations in the multicomponent concentrated aqueous electrolyte solution are $\mathrm{Na}^{+}, \mathrm{Mg}^{+2}, \mathrm{Ca}^{+2}$ with $\mathrm{H}^{+}$ions exchanged from the cation exchanger and $\mathrm{Cl}^{-}$ions as the neutralising anion.

3. The recovery of valuable species from seawater, which is present at extremely low concentrations, with the use of highly selective ion exchange resins. The recovery of uranium from seawater present at very low concentrations $\left(3.3 \times 10^{-6}\right.$ $\mathrm{kg}-\mathrm{U} / \mathrm{m}^{3}$ ) was studied by Tamon et al. (1990), with the development of hydrous titanium oxide and amidoxime resins.

4. Hydrometallurgical processes, which involve the treatment of raw ores or concentrates with aqueous electrolyte solutions that facilitate the dissolution reactions.

5. The recovery of valuable species in hydrometallurgical crystallisation processes, which involves the formation of sparingly soluble precipitates from multicomponent, supersaturated aqueous electrolyte solutions of these species. The stability of the precipitates that are formed is greatly influenced by the activities of the species remaining in the solution phase.

6. Ion exchange processes, where the attainable equilibrium loading of a particular species on a resin is influenced by its activity in the multicomponent aqueous electrolyte solution.

7. Specific ion electrodes. 


\subsection{BASIC THERMODYNAMIC RELATIONSHIPS}

The chemical potential of species $i$ in a multicomponent aqueous electrolyte solution is defined by Equation (2.13),

$$
\mu_{i} \quad=\mu_{i}^{o}+R T \ln a_{i}
$$

where $\mu_{i}^{0}$ is the chemical potential of species $i$ in the standard state and $a_{i}$ represents the activity of species $i$ in the solution. The standard state of species $i$ is usually chosen as the pure solute standard state, thus where the ionic fraction of species $i$ equals unity $\left(x_{i}=\right.$ 1). In an ideal bulk solution phase the different species do not influence one another. The different species therefore behave as if they are the only species present in the solution $\left(x_{i}=1\right)$, with their activities equal to their real concentrations in the solution. However, this is not the case for real electrolyte solutions, where definite interactions between the constituent ionic species exist. To model these interactions between the different ionic species, which result in the non-ideality of the solution, the activity of species $i$ is expressed as the product of its concentration and its activity coefficient, which represents the deviation from ideality, given by Equation (2.14),

$$
a_{i}=C_{i} \gamma_{i}^{c}
$$

where $C_{i}$ is the molarity and $\gamma_{i}^{c}$ the molar activity coefficient of species $i$ in the solution.

The value of the activity coefficient depends on the concentration units used to express the concentration of species $i$ in Equation (2.14), since the activity coefficient itself is dimensionless. The concentration of species $i$ can be expressed in various different concentration units, e.g. mole fraction $\left(x_{i}\right)$, molarity $\left(C_{i}\right)$ and molality $\left(m_{i}\right)$. If the activity defined in Equation (2.14) is substituted into Equation (2.13), the chemical potential of 
species $i$ in a multicomponent non-ideal aqueous electrolyte solution is obtained, given by Equation (2.15).

$$
\begin{aligned}
\mu_{i} & =\mu_{i}^{o}+R T \ln \left(C_{i} \gamma_{i}^{c}\right) \\
& =\mu_{i}^{o}+R T \ln \left(C_{i}\right)+R T \ln \left(\gamma_{i}^{c}\right)
\end{aligned}
$$

The activity and activity coefficient of species $i$ in a non-ideal, multicomponent aqueous electrolyte solution have now been defined by Equations (2.13) and (2.14). However, it is impossible for a real electrolyte solution to consist of only cations or anions, since electroneutrality must be maintained in all natural solutions, and we therefore need to define the mean or average activity coefficient.

Consider the dissolution of one mole of a strong electrolyte, $M_{v_{M}} X_{v_{X}}$, which completely dissociates when dissolved in one litre of water. The reaction is given by Equation (3.1),

$$
M_{v_{M}} X_{v_{X}(a q)} \rightarrow v_{M} M^{z_{M}}(a q)+v_{X} X^{z_{X}}(a q)
$$

where $v_{M}$ moles of cation species $M$ and $v_{\mathrm{X}}$ moles of anion species $X$ are formed for each mole of solute that dissolves. The chemical potential of the dissolved solute, $M_{v_{M}} X_{v_{X}}$, is equal to the sum of the chemical potentials of the total constituent ions, given by Equation (3.2).

$$
\mu\left(M_{v_{M}} X_{v_{X}}\right)=v_{M} \mu\left(M^{z_{M}}\right)+v_{X} \mu\left(X^{z_{X}}\right)
$$

Substituting Equation (2.15) for each of the constituent ions into Equation (3.2) and rearranging gives Equation (3.3), 


$$
\begin{gathered}
\mu\left(M_{v_{M}} X_{v_{X}}\right)=\left(v_{M} \mu^{0}\left(M^{z_{M}}\right)+v_{X} \mu^{0}\left(X^{z_{X}}\right)\right)+R T \ln \left(C_{M}^{v_{M}} C_{X}^{v_{X}}\right)+R T \ln \left(\gamma_{M}^{c v_{M}} \gamma_{X}^{c^{v_{X}}}\right) \\
=\mu^{0}\left(M_{v_{M}} X_{v_{X}}\right)+R T \ln \left(C_{M}^{v_{M}} C_{X}{ }^{v_{X}}\right)+R T \ln \left(\gamma_{ \pm}\left(M_{v_{M}} X_{v_{X}}\right)\right)^{v}
\end{gathered}
$$

where the chemical potential of the pure solute in its standard reference state is given by Equation (3.4).

$$
v_{M} \mu^{0}\left(M^{z_{M}}\right)+v_{X} \mu^{0}\left(X^{z_{X}}\right)=\mu^{0}\left(M_{v_{M}} X_{v_{X}}\right)
$$

The mean activity coefficient of the solute is given by Equation (3.5)

$$
\gamma_{ \pm}\left(M_{v_{M}} X_{v_{X}}\right)=\left(\gamma_{M}^{c^{v_{M}}} \gamma_{X}^{c^{v_{X}}}\right)^{\frac{1}{v}}
$$

where $v=v_{M}+v_{X}$, the stoichiometric number of moles of constituent ions in one mole of solute. The following generalised term for the mean activity coefficient of an ionic solute can be written upon its complete dissociation when dissolved in water, given by Equation (3.6)

$$
\gamma_{ \pm}=\left(\gamma_{c}{ }^{v_{c}} \gamma_{a}{ }^{v_{a}}\right)^{\frac{1}{v}}
$$

where the subscript $c$ and $a$ designates the cation and anion respectively, with

$$
\begin{aligned}
v & =v_{\text {cation }}+v_{\text {anion }} \\
& =v_{c}+v_{a}
\end{aligned}
$$

The ionic strength of an electrolyte solution, $I$, is defined by Equation (3.8), 


$$
I_{c}=\frac{1}{2} \sum_{i} C_{i} z_{i}^{2}
$$

where $C_{i}$ is the molarity of ion $i$ and $z_{i}$ is its valence. The ionic strength, $I$, can be based on different concentration units. In Equation (3.8) it is based on the molarity of species $i$ $\left(C_{i}\right.$, moles/litre), and called the molar ionic strength, $I_{c}$. The molal ionic strength, $I_{m}$, is based on the molality of ion $i\left(m_{i}\right.$, moles $/ \mathrm{kg}$ solvent), and defined by Equation (3.9),

$$
I_{m}=\frac{1}{2} \sum_{i} m_{i} z_{i}^{2}
$$

which is similar to Equation (3.8). From Equations (3.8) and (3.9) it becomes clear that it is important to state the concentration scale when the value of an ionic activity coefficient is calculated from experimental data, and reported in the literature. This will prevent it from being used with the wrong concentration scales of the ionic strength $I$.

Equation (3.10) gives the molality of an electrolyte solution containing only one symmetrical strong electrolyte as a function of the solution ionic strength $I$ (see Equation (A-8) in Appendix G).

$$
m^{0}=\frac{4 I}{\left(z_{M}{ }^{2}+z_{X}{ }^{2}\right)}
$$

A similar equation, Equation (3.11), holds when the electrolyte is unsymmetrical (see Equation (A-11) in Appendix G).

$$
\begin{aligned}
m^{0} & =-\frac{2 I}{z_{M} z_{X}} \\
& =\frac{2 I}{z_{M}\left|z_{X}\right|}
\end{aligned}
$$




\subsection{THERMODYNAMIC MODELS AVAILABLE FOR THE PREDICTION OF SINGLE STRONG ELECTROLYTE ACTIVITY COEFFICIENTS IN AQUEOUS SOLUTIONS}

Despite the availability of experimentally determined activity coefficients for many electrolyte solutions (Harned and Owen, 1958 and Robinson and Stokes, 1959), gathered by experimental measurements from which the activity coefficients were derived with existing models, there still exists a need for thermodynamically based estimation methods which could predict the value of activity coefficients fairly accurately over a wide concentration and composition range. The obvious reason for this is that there are a vast number of single and multi component electrolyte solutions of interest to the hydrometallurgical and chemical industry, which makes it practically impossible to cover all possible solution combinations over all the different concentration ranges with experimentally based methods.

All currently used equations, which predict the mean activity coefficients of species in aqueous electrolyte solutions as a function of the ionic strength of the solution, can be expressed as the sum of two terms. The first term is a Debye-Hückel type term and the second term can be called a correction term (Apelblat, 1993). The correction term is introduced to extend the range of concentrations over which the equations are valid by compensating for the assumptions and simplifications made in the derivation of the Debye-Hückel limiting law. The equations usually have the following form,

$$
\ln \gamma_{ \pm}=\ln \gamma_{ \pm D H}+\ln \gamma_{ \pm \text {correction }}
$$

where the first term has the form of the extended Debye-Hückel law, described by Equation (3.15), but with different values for the parameters of $B_{m}$ and $a_{i}$, the distance of closest approach between two ions in solution (Guggenheim and Stokes, 1969; Horvath, 1985 and Zemaitis et al., 1986). 


\subsubsection{The Debye-Hückel limiting law}

A significant advance in the prediction of activity coefficients for species in electrolyte solutions was made by Debye and Hückel, when they derived the Debye-Hückel equation which has been the cornerstone for the development of more recent activity coefficient models. The Debye-Hückel equation was derived by considering the interionic forces in a dilute electrolyte solution of a single strong electrolyte. The model development is shown completely by Zemaitis et al. (1986), which clearly indicates the relationship between the activity coefficient and the concentration of an electrolyte solution, first put forward by Lewis and Randall (1921).

The Debye-Hückel equation for the prediction of the mean molal activity coefficient of a strong electrolyte in a dilute aqueous electrolyte solution, as a function of the molal ionic strength (Equation 3.9), is defined by Equation (3.13)

$$
\log \left(\gamma_{ \pm}^{m}\right)=-A_{m}\left|z_{+} z_{-}\right| \sqrt{I_{m}}
$$

where the value of the Debye-Hückel parameter $A_{m}$ is given by Equation (3.14) (Pitzer, 1991)

$$
\begin{aligned}
& A_{m}=\frac{1}{3}\left(\frac{e}{\sqrt{4 \pi \varepsilon_{o} D k T}}\right)^{3} \sqrt{\frac{2 \pi d_{0} N_{A}}{1000}} \\
& =0.391 \pm 0.001
\end{aligned}
$$

with the values for the variables obtained from Christian and O'Reilly (1986) and Bueche (1986) as follows:

$$
N_{A}=\text { Avogadro's number }\left(6.0232 \times 10^{26} \mathrm{kmol}^{-1}\right)
$$




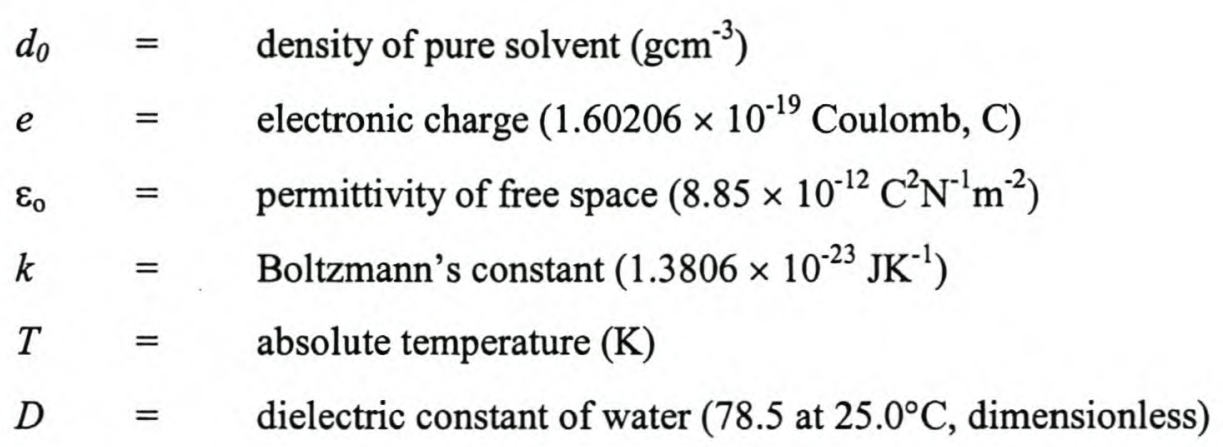

The Debye-Hückel limiting law gives reasonable estimates for the mean activity coefficient in dilute solutions only if the molal concentration of the solution is less than $0.001\left(I_{m}<0.001 \mathrm{~mol} \mathrm{~kg}^{-1}\right)$. This limitation is due to the assumptions made on the ionic atmosphere potential equation in the derivation of the Debye-Hückel limiting law (Zemaitis et al., 1986). The ions were represented by point charges with no restrictions on how closely they can approach one another in the ionic sphere, thus ignoring the fact that it is impossible for ions to infinitely approach one another.

In order to make the Debye-Hückel limiting law more applicable to higher ionic strengths, they introduced a factor, $a_{i}$, to account for the distance of closest approach between two ions in solution. The improved Debye-Hückel limiting law, which accounts for the mean distance of closest approach, was called the extended Debye-Hückel limiting law for the calculation of mean activity coefficients, given by Equation (3.15)

$$
\log \left(\gamma_{ \pm}^{m}\right)=-\frac{A_{m}\left|z_{+} z_{-}\right| \sqrt{I_{m}}}{1+B_{m} a_{i} \sqrt{I_{m}}}
$$

where, on a molal scale, the parameter $B_{m}$ is given by Equation (3.16) below. 


$$
\begin{aligned}
B_{m} & =\sqrt{\frac{8 \pi e^{2} N_{A} d_{0}}{1000 D k T}} \\
& =50.2916 \times 10^{8} \sqrt{\frac{d_{0}}{D T}}
\end{aligned}
$$

At $25^{\circ} \mathrm{C}$ the values for $A_{m}$ and $B_{m}$ were reported by several authors (Hamer, 1968; Hamer and Wu, 1972 and Staples and Nuttal, 1977 reported in Horvath, 1985) to be $0.5108 \mathrm{~kg}^{0.5}$ $\mathrm{mol}^{-0.5}$ and $0.3287 \times 10^{8} \mathrm{~kg}^{0.5} \mathrm{~mol}^{-0.5} \mathrm{~cm}^{-1}$ respectively. From Equations (3.14) and (3.16) it is evident that both $A_{m}$ and $B_{m}$ are temperature dependent variables. The value of $a_{i}$, accounting for the distance of closest approach between ions, was also reported by several investigators (Guggenheim and Stokes, 1969; Kielland, 1937; Pan, 1981 and Klotz, 1964).

\subsubsection{Bromley's correlation}

Bromley presented an equation to calculate the mean activity coefficient of ion pairs in strong aqueous electrolyte solutions with an ionic strength of up to $6\left(I_{m}=6\right)$, represented by Equation (3.17) (Bromley, 1973).

$$
\log \gamma_{ \pm}=-\frac{A_{m}\left|z_{+} z_{-}\right| \sqrt{I_{m}}}{1+a_{i} \sqrt{I_{m}}}+\frac{\left(0.06+0.6 B_{m}\right)\left|z_{+} z_{-}\right| I_{m}}{\left(1+\frac{1.5}{\left|z_{+} z_{-}\right|} I_{m}\right)^{2}}+B_{m} I_{m}
$$

$A_{m}$ is the Debye-Hückel constant for the activity coefficient and is defined by Equation (3.14), with a value of $0.511 \mathrm{~kg}^{0.5} \mathrm{~mol}^{-0.5}$. The value of the parameter $a_{i}$ is temperatureindependent and it varies according to the type of electrolyte (Horvath, 1985 and Zemaitis, 1986). Bromley calculated the value of $a_{i}$ for each salt valence type at $25^{\circ} \mathrm{C}$ from experimental data. Except for 3-1, 4-1 and 1-3 valence types, which gave $a_{i}$ values 
of 1.4, 1.6 and 1.4 respectively, all other types, including 1-1, 2-1, 1-2, 2-2, 3-2 and 1-4 gave $a_{i}$ values of $1.0 \pm 0.2$ (Bromley, 1973). The parameter $B_{m}$ is a function of temperature, which accounts for the ion interactions between the individual ions, represented by Equation (3.18). Bromley has shown that the $B_{m}$ values of the strong electrolytes can be approximated by the sum of the $B_{m}$ values of the individual constituent ions of the electrolyte. This additive quality of the individual constituent ions of an electrolyte is evident from Equation (3.18) (Bromley, 1973).

$$
B_{m}=B_{+}+B_{-}+\delta_{+} \delta_{-}
$$

A complete set of values for $a_{i}, B_{m}$ and $\delta$ at $25^{\circ} \mathrm{C}$ is given by Bromley for different electrolytes (Bromley, 1973; Horvath, 1985 and Zemaitis, 1986). Bromley's equation, Equation (3.17), is satisfactory for all strong electrolytes (nearly completely ionised), but it is not satisfactory for bivalent metal sulphates, sulphuric acid, and the zinc and cadmium halides, all of which are incompletely ionised (Bromley, 1973). Equation (3.17) should not be used for the prediction of the mean activity coefficients of strong electrolytes in aqueous solutions with an ionic strength of above 6 molal $\left(I_{m}=6\right)$, due to the exponential nature of Equation (3.17), which will result in an increasing error with increasing molality.

\subsubsection{Meissner's method}

Meissner and Tester (1972) showed that, in plotting the reduced activity coefficient, $\Gamma$, versus the ionic strength, a family of curves can be constructed. With a few exceptions, the curves usually do not cross; each curve remains between its neighbouring curves regardless of the electrolyte involved. All the curves converge at low ionic strengths and terminate at a value for $\Gamma$ of unity when the ionic strength is zero. Equation (3.19) defines the reduced activity coefficient $\Gamma$. 


$$
\Gamma=\left(\gamma_{ \pm}\right)^{\frac{1}{z_{+} \| z_{-} \mid}}
$$

The magnitude of the mean activity coefficient, $\gamma_{ \pm}$, of a single strong electrolyte in aqueous solution depends on its molality (total ionic strength of the solution), the charges of the electrolyte's constituent cation and anion and the temperature of the aqueous solution (Kusik and Meissner, 1973). Meissner and Tester (1972) proposed that, when the reduced activity coefficient, $\Gamma$, is plotted against the ionic strength, $I$, for various electrolytes at $25^{\circ} \mathrm{C}$, a family of curves form such that, given a single experimental value of $\gamma_{ \pm}$at a known ionic strength for an electrolyte, its value of $\gamma_{ \pm}$at any other ionic strength can be graphically predicted by using the family of curves. The data for most strong electrolytes fall onto this family of curves, including not only aqueous solutions derived from simple salts like sodium chloride, potassium nitrate, etc., but also hydrated salts and polybasic acids and their acid salts (Meissner and Peppas, 1973). Strong polybasic acids are best treated as 1-1 electrolytes when their second and third dissociation constants are small, while dibasic acids with large first and second dissociation constants are best treated as 1-2 electrolytes (Meissner and Peppas, 1973).

Refinements and expansion of the original method were done by Meissner and coworkers (Meissner and Kusik, 1972; Kusik and Meissner, 1973; Meissner, Kusik and Tester, 1972; Meissner and Kusik, 1973; Meissner and Peppas, 1973; Kusik and Meissner, 1978; Meissner and Kusik, 1979; Kusik, Meissner and Field, 1979). Useful methods for predicting the mean activity coefficient of a strong electrolyte in a multicomponent system and over a range of temperatures and ionic strengths were presented by Meissner and his co-workers over the years.

An empirical equation for representing the generalised isothermal family of curves was presented by Kusik and Meissner (1978). The empirical equation involves the parameter $q$, which has a different value for each electrolyte and each temperature, and is presented by Equation (3.20) 


$$
\Gamma^{0}=\left[1+B(1+0.1 I)^{q}-B\right] \Gamma^{*}
$$

where

$$
\begin{aligned}
& B=0.75-0.065 q \\
& \log _{10} \Gamma^{*}=\frac{-A_{m} \sqrt{I}}{1+C \sqrt{I}}=\frac{-5.107 \sqrt{I}}{1+C \sqrt{I}} \\
& C=1+0.055 q \exp \left(-0.023 I^{3}\right)
\end{aligned}
$$

By substituting $\Gamma^{*}$ from Equation (3.22) into Equation (3.20) and simplifying by using Equation (3.19), the mean activity coefficient of a strong electrolyte can be expressed as follows:

$$
\log \gamma_{ \pm}=\frac{\left(-A_{m}\left|z_{+} z_{-}\right| \sqrt{I}\right)}{(1+C \sqrt{I})}+\left|z_{+} z_{-}\right| \log \left[1+B(1+0.1 I)^{q}-B\right]
$$

where the first term of Equation (3.24) has the form of Debye-Hückel's model (Cisternas and Galleguillos, 1989).

\subsubsection{Temperature Effects}

Kusik and Meissner (1978) found that the isotherms of electrolytes at temperatures other than $25^{\circ} \mathrm{C}$ also fall onto the family of curves, and therefore remain in conformity with Equation (3.20) to Equation (3.23). They also found that an electrolyte's isotherm at $25^{\circ} \mathrm{C}$ usually does not coincide with its isotherms at other temperatures, except when $q=$ 1.7. On this reference curve the reduced activity coefficient $\Gamma^{0}$ is designated by $\Gamma_{\text {ref }}^{0}$ and 
it appears that in this case, when $q=1.7$, the reduced activity coefficient is independent of temperature, as represented by Equation (3.25).

$$
\left(\frac{\partial \Gamma^{0}}{\partial T}\right)_{q=1.7}=\left(\frac{\partial \Gamma_{r e f}^{0}}{\partial T}\right)=0
$$

Calculating an electrolyte's mean activity coefficient at any temperature $\mathrm{T}$ other than $25^{\circ} \mathrm{C}$, involves determining the location of the electrolyte's isotherm at the temperature $\mathrm{T}$ and $\Gamma_{25^{\circ} \mathrm{C}}^{0}$ for the electrolyte in question at an ionic strength of $I=10$. The quantity $\Gamma_{T}^{0}$ can be calculated with Equation (3.26) (Kusik and Meissner, 1978).

$$
\frac{\log \left(\frac{\Gamma_{T}^{0}}{\Gamma_{25^{\circ} C}^{0}}\right)_{I=10}}{T-25}=a \log \left(\Gamma_{25^{\circ} C}^{0}\right)_{I=10}+b
$$

We can obtain $\Gamma_{T}^{0}$ values at any other ionic strength, $I$, for the specific electrolyte at the relevant temperature $\mathrm{T}$, once the value of $\left(\Gamma_{T}^{0}\right)_{I=10}$ is known, calculated from Equation (3.20). By substituting the values of $I=10$ and $\left(\Gamma_{T}^{0}\right)_{I=10}$ into Equations (3.20) to (3.23) and calculating the new $q$ value, any new $\Gamma_{T}^{0}$ value can be calculated with Equation (3.20), which can be substituted into Equation (3.19) to solve for the mean molal activity coefficient, $\gamma_{ \pm}$, of the electrolyte. Kusik and Meissner (1978) also recognised that $\left(\Gamma^{0}\right)_{I=10}$ is almost linear in values of $q$, i.e. from $q=-2$ to $q=+7$, which resulted in Equation (3.27):

$$
\frac{q_{T}-q_{25}}{T-25}=a q_{25}+b^{*}
$$


where $\mathrm{T}$ is in degrees Centigrade. For most non-sulphuric electrolytes, $a=-0.005$ while $b=0$ and $b^{*}=0.0085$, because sulphuric acid does not obey the generalised correlations of Equations (3.20) to (3.23). For sulphuric electrolytes the constant $a=-0.0079$ and $b^{*}$ $=-0.0029$ (Kusik and Meissner, 1978).

A more convenient approximation of the effect of the temperature on the value of the reduced activity coefficient can be obtained by using Equation (3.28), which can be applied at any constant value of the ionic strength,

$$
\log \Gamma_{T}^{0}=(1.125-0.005 T) \log \Gamma_{25^{0} C}^{0}-(0.125-0.005 T) \log \Gamma_{r e f}^{0}
$$

where $\log \Gamma_{\text {ref }}^{0}$ is obtained from Equation (3.29) (Meissner and Peppas, 1973).

$$
\log \Gamma_{r e f}^{0}=-\frac{0.41 \sqrt{I}}{1+\sqrt{I}}+0.039 I^{0.92}
$$

The value of the temperature affected $q$ parameter, $q_{T}^{0}$, can be calculated from the value of the $q$ parameter at $25^{\circ} \mathrm{C}$ with the use of Equation (3.30) (Zemaitis et al., 1986).

$$
q_{T}^{0}=q_{25^{0} C}^{0}\left[1-\frac{0.0027(T-25)}{\left|z_{+} z_{-}\right|}\right]
$$

Cisternas and Galleguillos (1989) evaluated the effect of temperature on the activity coefficients of strong electrolytes in aqueous solutions, by studying the effect of temperature on the value of the Kusik-Meissner parameter $q$, defined in Equation (3.20). They studied twelve single electrolyte solutions, which included 66 isotherms of the mean activity coefficient $\gamma_{ \pm}$vs temperature for various total ionic strengths, and 933 experimental points. The value of $q$ for each isotherm of $\gamma_{ \pm}$vs temperature at a particular ionic strength $I$ was obtained using regression analysis by fitting Equation 
(3.20) to the experimental data and minimising the average deviation given by Equation (3.31).

$$
\text { average deviation }=\frac{1}{N} \sum\left[\left(\gamma_{ \pm \exp }-\gamma_{ \pm c a l}\right)^{2}\right]^{\frac{1}{2}}
$$

The Debye-Hückel constant $A_{m}$ in Equation (3.20) was treated as a temperature function as defined by Equation (3.14). Cisternas and Galleguillos (1989) found that Equations (3.27) and (3.30) did not represent the experimental evaluated $q$ parameters very well. Furthermore, the $q$ temperature dependence proved to be non-linear, opposite to the dependence indicated by Equations (3.27) and (3.30). Cisternas and Galleguillos (1989) proposed Equation (3.32) to predict $q$ parameters;

$$
q=a+b T+c T^{2}+d T^{3}
$$

where $\mathrm{T}$ is in degrees Kelvin. Experimentally evaluated values for the coefficients $a, b, c$ and $d$ are tabulated by Cisternas and Galleguillos (1989) for various strong electrolytes over a wide temperature and ionic strength range.

\subsubsection{Pitzer's method}

Pitzer and co-workers (Pitzer, 1973; 1975; 1977; Pitzer and Mayorga, 1973; 1974; Pitzer and Kim, 1974; Pitzer and Silvester, 1976; 1978; Pitzer, Roy and Silvester, 1977; Silvester and Pitzer, 1977; 1978; Pitzer, Peterson and Silvester, 1978; Pitzer and Pelper, 1980) developed an expression for the mean ionic activity coefficient of single ion pairs in aqueous electrolyte solutions by expanding the Debye-Hückel equation, using a virial expansion to account for ionic interactions. Terms were added to the existing equation to account for different ionic interactions that occur at low as well as higher ionic solution concentrations. The equation included a term which accounted for the effect of the ionic 
strength dependence short-range forces between species $i$ and $j$ in binary interactions as well as the effect of triple ion interactions, which may have a significant effect on the value of the activity coefficient at high ionic solution concentrations. Zemaitis et al. (1986) give a complete derivation of the Pitzer activity of a neutral electrolyte $M_{v_{M}} X_{v_{X}}$, represented by Equation (3.33), after simplifying the various ion interactions.

$$
\ln \gamma_{M X}=\left|z_{M} z_{X}\right| f^{\gamma}+m\left[\frac{2 v_{M} v_{X}}{v}\right] B_{M X}^{\gamma}+m^{2}\left[\frac{2\left(v_{M} v_{X}\right)^{3 / 2}}{v}\right] C_{M X}^{\gamma}
$$

The symbols $v_{M}$ and $v_{X}$ are the numbers of cations $M$ and anions $X$ respectively, with the parameter $f^{\gamma}$ defined as follows

$$
f^{\gamma}=-A_{\phi}\left[\frac{\sqrt{I}}{1+B_{m} \sqrt{I}}+\frac{2}{B_{m}} \ln \left(1+B_{m} \sqrt{I}\right)\right]
$$

where the parameter $A_{\phi}$ is the Debye-Hückel constant for the osmotic coefficient defined by Equation (3.37).

For electrolytes with one or both ions univalent, (1-1, 1-2, 2-1, 3-1, 4-1, 5-1 electrolytes)

$$
B_{M X}^{\gamma}=2 \beta_{M X}^{(0)}+\left(\frac{2 \beta_{M X}^{(1)}}{\alpha^{2} I}\right)\left[1-\left(1+\alpha \sqrt{I}-\frac{\alpha^{2} I}{2}\right) \exp (-\alpha \sqrt{I})\right]
$$

For higher valence type electrolytes such as 2-2, 3-3, 2-3, 4-2 electrolytes, 


$$
\begin{aligned}
B_{M X}^{\gamma} & =2 \beta_{M X}^{(0)}+\left(\frac{2 \beta_{M X}^{(1)}}{\alpha_{1}^{2} I}\right)\left[1-\left(1+\alpha_{1} \sqrt{I}-\frac{\alpha_{1}^{2} I}{2}\right) \exp \left(-\alpha_{1} \sqrt{I}\right)\right] \\
& +\left(\frac{2 \beta_{M X}^{(2)}}{\alpha_{2}^{2} I}\right)\left[1-\left(1+\alpha_{2} \sqrt{I}-\frac{\alpha_{2}^{2} I}{2}\right) \exp \left(-\alpha_{2} \sqrt{I}\right)\right] \\
A_{\phi} & =\frac{1}{3}\left(\frac{e}{\sqrt{D k T}}\right)^{3} \sqrt{\frac{2 \pi d_{0} N_{A}}{1000}} \\
v & =v_{M}+v_{X} \\
C_{M X}^{\gamma} & =\frac{3 C_{M X}^{\phi}}{2}
\end{aligned}
$$

where the superscripts $\gamma, \phi,(0),(1)$ and (2) are indices and not exponents. The following are constants used in Equations (3.35) to (3.36), with values as indicated

$$
\begin{array}{rll}
B_{m} & = & 1.2, \\
\alpha & = & 2.0, \\
\alpha_{1} & = & 1.4, \\
\alpha_{2} & = & 12 .
\end{array}
$$

The set of parameters, $\beta_{M X}^{(0)}, \beta_{M X}^{(1)}, \beta_{M X}^{(2)}, C_{M X}^{\phi}$, are called the Pitzer parameters and have a unique value for each electrolyte. The values of these Pitzer parameters for many different electrolytes are extensively tabulated in the literature.

The most important feature of the Pitzer equation is the recognition of an ionic strength dependence of the effect of short-range forces in binary interactions. Pitzer (1973) clearly showed that the short-range interaction of unlike charged ions becomes relatively much 
more important at low ionic strengths. Pitzer modified the second virial coefficients to include this feature, presented in Equations (3.35) and (3.36), where the principal contribution to $\beta_{M X}^{(1)}$ will come from the short-range interactions of unlike charged ions while the interactions of like and unlike charged ions will both contribute to $\beta_{M X}^{(0)}$ (Pitzer, 1973).

Pitzer's equations are able to predict the activity coefficient of strong electrolytes, within experimental error, to concentrations of several molal instead of $0.1 \mathrm{M}$ as was the case with Guggenheim's equation (Pitzer, 1973). Gugenheim followed Brфnsted's principle of specific interaction and excluded terms related to short-range forces between ions of like sign. Pitzer's principal suggestion made with Equation (3.33) is that the properties of electrolyte solutions can be expressed by an "electrostatic" term plus a virial coefficient series in which the virial coefficients may be functions of the ionic strength of the solution, (Pitzer, 1973). It is rather important to keep in mind that Pitzer's equations are derived for strong electrolytes which show no association, hence they are fully dissociated. However, Pitzer's equation for nonassociating electrolytes was able to satisfactorily predict the thermodynamic properties of solutes that showed some association without any modifications to the equations (Pitzer and Mayorga, 1973).

\subsubsection{Harvie and Weare model}

Harvie and Weare (1980) developed a chemical equilibrium model based on Pitzer's equations to calculate mineral solubilities in the $\mathrm{Na}-\mathrm{K}-\mathrm{Mg}-\mathrm{Ca}-\mathrm{Cl}-\mathrm{SO}_{4}-\mathrm{H}_{2} \mathrm{O}$ system at $25^{\circ} \mathrm{C}$. Kim and Frederick (1988(a)) fitted ion interaction parameters, used in the Harvie and Weare model, for single strong electrolytes from osmotic coefficient data at $25^{\circ} \mathrm{C}$ by using multiple regression analysis. The mean osmotic and mean ionic activity coefficients for single electrolyte solutions are given by Equation (3.40) and Equation (3.41) respectively, 


$$
\begin{aligned}
\phi=1+ & \frac{2}{\left(m_{M}+m_{X}\right)}\left[\frac{-A_{\phi} I^{3 / 2}}{1+b I^{1 / 2}}+m_{M} m_{X}\left(B_{M X}^{\phi}+Z C_{M X}\right)\right] \\
\ln \gamma_{M X}= & -\left|z_{M} z_{X}\right| A_{\phi}\left[\frac{I^{1 / 2}}{1+b I^{1 / 2}}+\frac{2}{b} \ln \left(1+b I^{1 / 2}\right)\right] \\
& +4 m\left[\frac{v_{M} v_{X}}{v}\right]\left[B_{M X}+\frac{I}{2} B_{M X}^{\prime}\right]+6 m^{2}\left[\frac{v_{M} v_{X}}{v}\right] v_{M} z_{M} C_{M X}
\end{aligned}
$$

In Equations (3.40) and (3.41), $m_{M}$ is the molality (mol $/ \mathrm{kg}$ of solvent) of a cation with charge $z_{M}$ corresponding to stoichiometric coefficient $v_{M}$. Similarly, the subscript $X$ refers to the anion of the single strong electrolyte $M X$, where the function $Z$ in Equation (3.40) is defined as,

$$
Z=\sum_{i} m_{i}\left|z_{i}\right|=2 \sum_{c} m_{c}\left|z_{c}\right|=2 \sum_{a} m_{a}\left|z_{a}\right|
$$

summed over all cations and/or anions.

$$
\begin{aligned}
& v=v_{M}+v_{X} \\
& A_{\phi}=\frac{1}{3}\left(\frac{e}{\sqrt{D k T}}\right)^{3} \sqrt{\frac{2 \pi d_{0} N_{A}}{1000}}
\end{aligned}
$$

The term $\mathrm{b}$ in Equations (3.40) and (3.41) is an empirical parameter equal to 1.2 at $25^{\circ} \mathrm{C}$ (Kim and Frederick, 1988(a)). The parameters $B_{M X}^{\phi}, B_{M X}$ and $B_{M X}^{\prime}$ which describe the interaction of pairs of oppositely charged ions represent measurable combinations of the second virial coefficients, defined as explicit functions of ionic strength by using the following equations: 


$$
\begin{aligned}
& B_{M X}^{\phi}=\beta_{M X}^{(0)}+\beta_{M X}^{(1)} e^{-\alpha_{1} I^{1 / 2}}+\beta_{M X}^{(2)} e^{-\alpha_{2} I^{1 / 2}} \\
& B_{M X}=\beta_{M X}^{(0)}+\beta_{M X}^{(1)} f\left(\alpha_{1} I^{1 / 2}\right)+\beta_{M X}^{(2)} f\left(\alpha_{2} I^{1 / 2}\right) \\
& B_{M X}^{\prime}=\frac{\beta_{M X}^{(1)} f^{\prime}\left(\alpha_{1} I^{1 / 2}\right)}{I}+\frac{\beta_{M X}^{(2)} f^{\prime}\left(\alpha_{2} I^{1 / 2}\right)}{I}
\end{aligned}
$$

where

$$
\begin{aligned}
& f(x)=\frac{2\left[1-(1+x) e^{-x}\right]}{x^{2}} \\
& f^{\prime}(x)=-\frac{2\left[1-\left(1+x+0.5 x^{2}\right) e^{-x}\right]}{x^{2}}
\end{aligned}
$$

For one or both ions in univalent type electrolytes the first two terms of Equations (3.45) and (3.46) and only the first term of Equation (3.47) are considered where $\alpha_{1}=2$. For higher valence type electrolytes, such as 2-2 electrolytes, all the terms in Equations (3.45), (3.46) and (3.47) are used and $\alpha_{1}=1.4$ and $\alpha_{2}=1$ (Kim and Frederick, 1988(a)). The short range interactions of ion triplets, which are only important at high solution concentrations, are accounted for by the third virial coefficients, $C_{M X}$, given by Equation (3.50)

$$
C_{M X}=\frac{C_{M X}^{\phi}}{2\left|z_{M} z_{X}\right|^{1 / 2}}
$$

where $C_{M X}^{\phi}$ is a fitted parameter. Ion interaction parameters for 304 single salts in aqueous solution have been fitted by Kim and Frederick (1988(a)) for Pitzer's equations. 


\subsection{THERMODYNAMIC MODELS AVAILABLE FOR THE PREDICTION OF SPECIES ACTIVITY COEFFICIENTS IN MULTICOMPONENT AQUEOUS ELECTROLYTE SOLUTIONS}

3.5.1 Bromley's method

Bromley also presented a method, Equation (3.51), by which the activity coefficient of the compound $M_{1} X_{1}$ in a multicomponent system can be calculated (Bromley, 1973):

$$
\begin{aligned}
\log \gamma_{ \pm, m, M_{1} X_{1}} & =-\frac{A_{m}\left|z_{M_{1}} z_{X_{1}}\right| \sqrt{I}}{1+\sqrt{I}}+\frac{v_{1} F_{1}}{v}+\frac{v_{2} F_{2}}{v} \\
& =-\frac{0.511\left|z_{M_{1}} z_{X_{1}}\right| \sqrt{I}}{1+\sqrt{I}}+\frac{\left|z_{M_{1}} z_{X_{1}}\right|}{\left|z_{M_{1}}\right|+\left|z_{X_{1}}\right|}\left[\frac{F_{1}}{\left|z_{M_{1}}\right|}+\frac{F_{2}}{\left|z_{M_{2}}\right|}\right]
\end{aligned}
$$

where

$$
\begin{aligned}
& F_{1}=\sum_{m=1}^{j} \bar{B}_{M_{1} X_{1}}\left(\bar{Z}_{M_{1} X_{m}}\right)^{2} m_{X_{m}} \\
& F_{2}=\sum_{n=1}^{i} \bar{B}_{M_{n} X_{1}}\left(\bar{Z}_{M_{n} X_{m}}\right)^{2} m_{X_{n}} \\
& \bar{Z}_{M_{n} X_{m}}=\frac{\left\lfloor\left|z_{M_{n}}\right|+\left|z_{X_{m}}\right|\right]}{2}
\end{aligned}
$$

the arithmetic average charge number of $M_{n} X_{m}$, 


$$
\bar{B}_{M_{1} X_{m}}=\frac{\left(0.06+0.6 B_{1, M_{1} X_{m}}\right) \cdot\left|z_{M_{1}} z_{X_{m}}\right|}{\left(1+\frac{1.5 I}{\left|z_{M_{1}} z_{X_{m}}\right|}\right)^{2}}+B_{1, M_{1} X_{m}}
$$

and the constant $B_{1, M_{1} X_{m}}$ being given by Equation (3.18). The above expressions ignore interactions between similarly charged species which Pitzer (1972) showed to be important in some univalent salt mixtures, as well as higher order interactions (Bromley,1973). For a complex electrolyte of $v$ ions in the solution, the mean activity coefficient is given by Equation (3.56)

$$
\log \gamma_{ \pm, m, M_{1} X_{1}}=-\frac{A_{m}\left(\sum_{i} v_{i} z_{i}^{2}\right) \sqrt{I}}{1+\sqrt{I}}+\frac{\sum_{i} v_{i} F_{i}}{v}
$$

where

$$
v=\sum_{i} v_{i}
$$

For a multicomponent aqueous electrolyte solution with numerous ions present, the $i$ ions refer only to those in the solution which arise from the salt whose activity coefficient is desired.

\subsection{2}

\section{The Lietzke-Stoughton (LS) method}

With the Lietzke-Stoughton (LS) method, the activity coefficient of a species in an aqueous electrolyte mixture containing a common ion, can be calculated according to Lietzke and Stoughton (1972). The empirical equation has the following form 


$$
\frac{1}{\left|z_{+, i} z_{-i}\right|} \log \gamma_{ \pm, i}=\frac{1}{\left|z_{+, i} z_{-, i}\right|} \log \gamma_{ \pm, i}^{0}+\sum_{\substack{j=1 \\ j \neq i}} \frac{Y_{j}}{2}\left[\frac{1}{\left|z_{+, j} z_{-, j}\right|} \log \gamma_{ \pm, j}^{0}-\frac{1}{\left|z_{+, i} z_{-, i}\right|} \log \gamma_{ \pm, i}^{0}\right]
$$

where $\gamma_{ \pm, i}$ is the mean activity coefficient of the $i$ 'th component in the multicomponent solution. $\gamma_{ \pm, i}^{0}$ and $\gamma_{ \pm, j}^{0}$ are the mean activity coefficients of the $i$ 'th and $j$ 'th components in a binary solution of which the ionic strength is equal to the ionic strength of the mixture. $Y_{j}=\left(I_{j} /\right)$, where $I_{j}$ is the ionic strength due to the presence of compound $j$, and $I$ the overall ionic strength of the multicomponent solution. The values of the activity coefficients $\gamma_{ \pm, i}^{0}$ and $\gamma_{ \pm, j}^{0}$ can be calculated with the use of one of the other methods for estimating mean activity coefficients of species in binary aqueous electrolyte solutions.

The osmotic coefficient of the solution containing $n$ electrolytes is given by Equation (3.59) (Lietzke and Stoughton, 1974)

$$
\phi=\frac{\sum_{j=1}^{n} v_{j} m_{j} \phi_{j}^{0}}{\sum_{j=1}^{n} v_{j} m_{j}}
$$

where $\phi_{j}^{0}$ is the osmotic coefficient of the binary system containing the $j$ 'th electrolyte with the same ionic strength as that of the multicomponent solution mixture. The molal concentration of electrolyte $j$ in the mixture is given by $m_{j}$. 
Meissner and Kusik (1978) presented a revised model for calculating the reduced activity coefficient of an electrolyte in a multicomponent aqueous electrolyte solution. In mixed solutions the cations $i$ are identified with the odd subscripts 1, 3, 5 etc., and the anions $j$ with the even subscripts $2,4,6$ etc. Using this notation, the reduced activity coefficient of electrolyte $i j$ in a mixed aqueous solution is obtained from Equation (3.60),

$$
\begin{aligned}
\log \Gamma_{i j}= & \frac{z_{i}}{z_{i}+z_{j}} \frac{\left(V_{i 2} I_{2} \log \Gamma_{i 2}^{0}+V_{i 4} I_{4} \log \Gamma_{i 4}^{0}+\ldots\right)}{I} \\
& +\frac{z_{j}}{z_{i}+z_{j}} \frac{\left(V_{j 1} I_{1} \log \Gamma_{j 1}^{0}+V_{j 3} I_{3} \log \Gamma_{j 3}^{0}+\ldots\right)}{I}
\end{aligned}
$$

where

$V_{i j}=\frac{\left(z_{i}+z_{j}\right)^{2}}{2 z_{i} z_{j}} \quad$ a weighting factor

$I_{n}=\frac{m_{n} z_{n}{ }^{2}}{2} \quad$ ionic strength of ion $n$

$I=\frac{1}{2} \sum_{n} m_{n} z_{n}^{2} \quad$ total ionic strength of the solution

$\Gamma_{i j}^{0}$ represents the reduced activity coefficient of electrolyte $i j$ in a pure solution at the same temperature and total ionic strength $I$ of the multicomponent aqueous electrolyte solution. The water activity for the mixed electrolyte solution, $\left(a_{w}\right)_{m i x}$, can be calculated 
from the pure solution activities of water, at the total ionic strength and temperature of the mixed solution with Equation (3.64) (Kusik and Meissner, 1978):

$$
\log \left(a_{w}\right)_{m i x}=\sum_{i} \sum_{j} W_{i j} \log \left(a_{w}^{0}\right)_{i j}+r
$$

where,

$\left(a_{w}^{0}\right)_{i j} \quad$ is the water activity of a pure solution of electrolyte $i j$

$i \quad$ odd numbers denoting cations

$j \quad$ even numbers denoting anions

$W_{i j}=X_{i} Y_{j}\left[\frac{\left(z_{i}+z_{j}\right)^{2}}{z_{i} z_{j}}\right]\left(\frac{I_{c}}{I}\right)\left(\frac{I_{a}}{I}\right)$

$X_{i}=\frac{I_{i}}{I_{c}}, \quad$ cationic fraction

$Y_{j}=\frac{I_{j}}{I_{a}}, \quad$ anionic fraction

$I_{c}=\frac{1}{2} \sum_{i} m_{i} z_{i}^{2} \quad$ cationic strength

$I_{a}=\frac{1}{2} \sum_{j} m_{j} z_{j}^{2}$ anionic strength 
The residue term $r$ in Equation (3.64) is zero for similarly charged electrolytes, and it was generally found to have a very small value when the electrolytes are dissimilarly charged, so that it can therefore usually be neglected (Kusik and Meissner, 1978). Meissner (1980) also presented another method for calculating the reduced activity coefficient of an electrolyte in a mixed electrolyte solution by calculating a $q$ parameter for the mixture. The new $q$ parameter, $q_{i j \text { mix }}$, is used to calculate the reduced activity coefficient of the electrolyte $i j$ by replacing $q$ in Equations (3.20) to (3.23) with $q_{i j \text { mix }}$, defined by Equation (3.70),

$$
q_{i j \operatorname{mix}}=\frac{\left(I_{1} q_{1 j}^{0}+I_{3} q_{3 j}^{0}+\ldots\right)}{I}+\frac{\left(I_{2} q_{i 2}^{0}+I_{4} q_{i 4}^{0}+\ldots\right)}{I}
$$

where $q_{i j}^{0}$ is the Meissner $q$ parameter for electrolyte $i j$ in a pure solution at the same temperature and total ionic strength as that of the mixed electrolyte solution.

\subsubsection{Pitzer's equation}

Pitzer and co-workers (see paragraph 3.4.4 for references) developed an expression for the mean ionic activity coefficient of an electrolyte in a mixed electrolyte solution using a virial expansion to account for different ionic interactions.

Using a similar method of combining the virial coefficients (which are not individually measurable) as was done to obtain Equation (3.33), the equation for the mean activity coefficient of electrolyte $M_{v_{M}} X_{v_{X}}$ in a multicomponent solution is given by Equation (3.71) below. 


$$
\begin{aligned}
\ln \gamma_{M X}=\left|z_{M^{\prime}} z_{X}\right| f^{\gamma}+\frac{2 v_{M}}{v} \sum_{a} m_{a}\left[B_{M a}+\left(\sum m_{c} z_{c}\right) C_{M a}+\frac{v_{X}}{v_{M}} \theta_{X a}\right] \\
+\frac{2 v_{X}}{v} \sum_{c} m_{c}\left[B_{c X}+\left(\sum m_{c} z_{c}\right) C_{c X}+\frac{v_{M}}{v_{X}} \theta_{M c}\right] \\
+\sum_{c} \sum_{a} m_{c} m_{a}\left[\left|z_{M^{\prime}} z_{X}\right| B_{c a}^{\prime}+\frac{1}{v}\left(2 v_{M^{\prime}} z_{M} C_{c a}+v_{M} \psi_{M c a}+v_{X} \psi_{c a X}\right)\right] \\
+\frac{1}{2} \sum_{c<c^{\prime}} m_{c} m_{c^{\prime}}\left[\frac{v_{X}}{v} \psi_{c c^{\prime} X}+\left|z_{M^{\prime}} z_{X}\right| \theta_{c c^{\prime}}\right] \\
+\frac{1}{2} \sum_{a<a^{\prime}} m_{a} m_{a^{\prime}}\left[\frac{v_{M}}{v} \psi_{M a a^{\prime}}+\left|z_{M} z_{X}\right| \theta_{a a^{\prime}}\right]
\end{aligned}
$$

In Equation (3.71) the subscripts $M, c$ and $c$ ' represent cations. Similarly, the subscripts $X, a$ and $a$ ' refer to anions. The designations

$$
\sum_{c<c} \sum_{c} \text { and } \quad \sum_{a<a^{\prime}}
$$

in Equation (3.71) mean the sum over all distinguishable pairs of dissimilar cations or anions with

$$
f^{\gamma}=-A_{\phi}\left[\frac{\sqrt{I}}{1+B_{m} \sqrt{I}}+\frac{2}{B_{m}} \ln \left(1+B_{m} \sqrt{I}\right)\right]
$$

For electrolytes with one or both ions univalent, (1-1, 1-2, 2-1, 3-1, 4-1, 5-1 electrolytes) 


$$
B_{i j}=\lambda_{i j}+\left|\frac{z_{j}}{2 z_{i}}\right| \lambda_{i i}+\left|\frac{z_{i}}{2 z_{j}}\right| \lambda_{i j}
$$

hence

$$
B_{M X}=\beta_{M X}^{(0)}+\frac{2 \beta_{M X}^{(1)}}{\alpha^{2} I}[1-(1+\alpha \sqrt{I}) \exp (-\alpha \sqrt{I})]
$$

and with

$$
B_{i j}^{\prime}=\lambda_{i j}^{\prime}+\left|\frac{z_{j}}{2 z_{i}}\right| \lambda_{i i}^{\prime}+\left|\frac{z_{i}}{2 z_{j}}\right| \lambda_{i j}^{\prime}
$$

hence

$$
B_{M X}^{\prime}=\frac{2 \beta_{M X}^{(1)}}{\alpha^{2} I^{2}}\left[-1+\left(1+\alpha \sqrt{I}+\frac{\alpha^{2} I}{2}\right) \exp (-\alpha \sqrt{I})\right]
$$

For higher valence type electrolytes such as 2-2, 3-3, 2-3, 4-2, etc. electrolytes

$$
\begin{aligned}
B_{M X}= & \beta_{M X}^{(0)}+\frac{2 \beta_{M X}^{(1)}}{\alpha_{1}{ }^{2} I}\left[1-\left(1+\alpha_{1} \sqrt{I}\right) \exp \left(-\alpha_{1} \sqrt{I}\right)\right] \\
& +\frac{2 \beta_{M X}^{(2)}}{\alpha_{2}{ }^{2} I}\left[1-\left(1+\alpha_{2} \sqrt{I}\right) \exp \left(-\alpha_{2} \sqrt{I}\right)\right]
\end{aligned}
$$




$$
\begin{aligned}
B_{M X}^{\prime}= & \frac{2 \beta_{M X}^{(1)}}{\alpha_{1}^{2} I^{2}}\left[-1+\left(1+\alpha_{1} \sqrt{I}+\frac{\alpha_{1}^{2} I}{2}\right) \exp \left(-\alpha_{1} \sqrt{I}\right)\right] \\
& +\frac{2 \beta_{M X}^{(2)}}{\alpha_{2}^{2} I^{2}}\left[-1+\left(1+\alpha_{2} \sqrt{I}+\frac{\alpha_{2}^{2} I}{2}\right) \exp \left(-\alpha_{2} \sqrt{I}\right)\right] \\
C_{i j}= & \frac{C_{i j}^{\phi}}{2 \sqrt{z_{+} z_{-}}} \\
C_{i j}^{\phi=} & \frac{3}{\sqrt{v_{+} v_{-}}}\left[v_{+} \Lambda_{l i j}+v_{-} \Lambda_{i j j}\right] \\
\theta_{i j}= & \lambda_{i j}-\frac{z_{j}}{2 z_{i}} \lambda_{i i}-\frac{z_{i}}{2 z_{j}} \lambda_{j j} \\
\theta_{i j}^{\prime}= & \frac{\partial \theta_{i j}}{\partial I} \\
\psi_{i j k}= & 6 \Lambda_{i j k}-\frac{3 z_{j}}{z_{i}} \Lambda_{i j}-\frac{3 z_{i}}{z_{j}} \Lambda_{j j k}
\end{aligned}
$$

Pitzer and Kim (1974) noted that the $\beta^{(0)}, \beta^{(1)}, \beta^{(2)}$ and $C^{\phi}$ terms have the greatest effect on the value of the calculated activity coefficient and that the $\psi$ and $\theta$ terms contribute little or nothing to the end result. Equations (3.79), (3.80) and (3.81) represent the double and triple ion interactions between the different ions in a multicomponent electrolyte solution (Zemaitis et al., 1986). 
With the RWR-method (Reilly et al., 1971) the mean activity coefficient of an electrolyte in a multicomponent electrolyte solution can be calculated. The general equation gives the osmotic and activity coefficient for a multicomponent mixture in terms of the osmotic and activity coefficients of the pure binary electrolyte solutions, at the same ionic strength as that of the multicomponent mixture, and interactions between different pairs of electrolytes (Reilly et al., 1971). The RWR-method is therefore used in combination with other activity coefficient models, from which predicted values for the pure binary electrolyte activity and osmotic coefficients can be obtained. According to Reilly et al. (1971), two levels of approximation are available with the equations. In the first level only data on single-salt solutions are used and in the second level, data on the common ion mixtures of the electrolytes are added to the data used in the first level. A complete derivation of the general equations for the prediction of the activity and osmotic coefficients is given by Reilly et al. (1971) in their paper, who applied it to two types of mixtures: (1) mixtures of two salts with a common ion ( $\mathrm{MX}-\mathrm{NX}-\mathrm{H}_{2} \mathrm{O}$ system) and (2) mixtures with two ions without a common ion ( $\mathrm{MX}-\mathrm{NY}-\mathrm{H}_{2} \mathrm{O}$ system).

\subsubsection{The $\mathrm{MX}-\mathrm{NX}-\mathrm{H}_{2} \mathrm{O}$ system}

In a solution mixture formed by adding $y \mathrm{~kg}$ of solvent containing the salt $M X$ to (1-y) $\mathrm{kg}$ of solvent containing the salt $N X$ at constant ionic strength, the molal concentrations of the two cations $M$ and $N$, and the anion $X$ are given by Equations (3.82), (3.83) and (3.84), respectively.

$$
m_{M}=\frac{2 I y}{z_{M}\left(z_{M}-z_{X}\right)}
$$




$$
\begin{aligned}
& m_{N}=\frac{2 I(1-y)}{z_{N}\left(z_{N}-z_{X}\right)} \\
& m_{X}=-\frac{2 I y}{z_{X}\left(z_{M}-z_{X}\right)}-\frac{2 I(1-y)}{z_{X}\left(z_{N}-z_{X}\right)}
\end{aligned}
$$

where $z_{M}$ and $z_{N}$ are positive and $z_{X}$ negative.

When Equations (3.82), (3.83) and (3.84) are substituted into the general equation and simplified, Equations (3.85) and (3.86) are obtained which give the mean molal activity coefficients of electrolytes $M X$ and $N X$ respectively,

$$
\begin{aligned}
\ln \gamma_{ \pm M X}= & \ln \gamma_{ \pm M X}^{0}+(1-y)\left[1-\phi_{M X}^{0}-\frac{z_{M}}{z_{N}}\left(1-\phi_{N X}^{0}\right)\right]- \\
& \frac{z_{M} z_{X}(1-y) I}{2}\left[g_{M N}^{X}+y I \frac{\partial\left(g_{M N}^{X}\right)}{\partial I}\right]
\end{aligned}
$$

and

$$
\begin{aligned}
\ln \gamma_{ \pm N X}= & \ln \gamma_{ \pm N X}^{0}+y\left[1-\phi_{N X}^{0}-\frac{z_{N}}{z_{M}}\left(1-\phi_{M X}^{0}\right)\right]- \\
& \frac{z_{N} z_{X} y I}{2}\left[g_{M N}^{X}+(1-y) I \frac{\partial\left(g_{M N}^{X}\right)}{\partial I}\right]
\end{aligned}
$$

where $\gamma_{ \pm M X}^{0}$ and $\gamma_{ \pm N X}^{0}$ are the mean molal activity coefficients of the pure electrolytes $M X$ and $N X$ respectively, at the same ionic strength $I$ as that of the mixture. The parameter $g_{M N}^{X}$ describes the excess free energy of mixing of $M$ and $N$ in the presence of 
$X$, which is the parameter describing the interactions between the electrolytes $M X$ and $N X$. In order to achieve high precision values for the activity coefficients, especially in the case of concentrated electrolyte solutions, it is necessary to take into account the parameters describing the interactions among the different electrolytes in the multicomponent system. Unfortunately the excess free energy of mixing of many common ion electrolyte mixtures is not available in the literature, and consequently the last terms involving this parameter are discarded from Equations (3.85) and (3.86) at low solution ionic strengths (Reilly et al., 1971).

\subsubsection{The $\mathrm{MX}-\mathrm{NY}-\mathrm{H}_{2} \mathrm{O}$ system}

The trace activity coefficient of the salt $M X$ in a solution of the salt $N Y$ is given by Equation (3.87),

$$
\begin{aligned}
\frac{\left(z_{M}-z_{X}\right)}{z_{M} z_{X}} \ln \gamma_{ \pm M X}^{\text {trace }}= & \frac{\left(z_{M}-z_{Y}\right)}{z_{M} z_{Y}}\left(1-\phi_{M Y}^{0}+\ln \gamma_{ \pm M Y}^{0}\right)+\frac{\left(z_{N}-z_{X}\right)}{z_{N} z_{X}}\left(1-\phi_{N X}^{0}+\ln \gamma_{ \pm N X}^{0}\right) \\
& -\frac{\left(z_{N}-z_{Y}\right)}{z_{N} z_{Y}}\left(1-\phi_{N Y}^{0}+\ln \gamma_{ \pm N Y}^{0}\right)-\frac{\left(z_{M}-z_{X}\right)}{z_{N} z_{Y}}\left(1-\phi_{N Y}^{0}\right) \\
& -\frac{I}{2}\left[\left(z_{M}-z_{Y}\right) g_{M N}^{Y}+\left(z_{N}-z_{X}\right) g_{X Y}^{N}\right]
\end{aligned}
$$

which is similar to Equations (3.85) and (3.86). For low ionic strength solutions the last term of Equation (3.87) can be discarded as discussed previously for Equations (3.85) and (3.86). Equations (3.85), (3.86) and (3.87) are particularly useful to determine the activity coefficient of a sparingly soluble solid in an aqueous electrolyte solution in order to calculate its equilibrium solubility from the solubility product of the solid. 


\subsection{OVERVIEW OF EXISTING ACTIVITY COEFFICIENT MODELS}

The thermodynamic properties of aqueous electrolyte solutions have been extensively investigated in the past several years, both experimentally and theoretically, due to the need for a better understanding of aqueous chemistry. This was necessary in order to supply the engineer with the appropriate design tools needed to optimise chemical and hydrometallurgical processes. The methods for calculating activity and osmotic coefficients of aqueous electrolyte solutions which were reported in the literature before 1960 are of historical interest only, since they were all developed for very dilute single component systems. Because of this they had very limited practical application value, which resulted in the development of new expressions. From this chapter it is evident that many methods have been proposed by several investigators for the prediction of activity coefficients for both strong and weak electrolytes in single and multicomponent electrolyte solutions.

The relationship between the activity coefficient and the concentration of an aqueous electrolyte solution was first put forward by Lewis and Randall (1921). Following on the work of Lewis and Randall, the equation of Debye and Hückel was of great importance, and which has since been the basis of more recent models. Consequently, most of the currently used models, which predict activity and osmotic coefficients of species in aqueous electrolyte solutions as a function of the solution ionic strength, have the form of Equation (3.10). The first term is usually a Debye-Hückel type term, taking into account the "electrostatic" interactions, while the second term is a correction term that takes into account the ionic interactions in more concentrated solutions. The GuggenheimScatchard equation, reported by Pitzer (1973), had considerable success in predicting activity coefficients in solutions up to 0.1 molar strength, where the correction term accounted for the net effect of various short range forces between the ions of the electrolyte. The equations of Bromley (1973), and Pitzer and Mayorga (1973), are classical examples where the correction term is a virial coefficient series as a function of ionic strength. 
The model of Lietzke and Stoughton (1972) abandoned the Bronsted principle, and included terms to account for the short-range interactions of ions of like sign (Lietzke and Stoughton, 1972 and Pitzer, 1973).

The activity coefficient model of Reilly, Wood and Robinson (1971) was derived from the excess free energy of the mixed electrolyte, while Cruz and Renon $(1978 ; 1979)$ proposed a model to calculate the activity coefficients of partially or weakly dissociated electrolytes in aqueous solutions. They included parameters in the correction term of Equation (3.10) to account for the ion-ion, ion-molecule and molecule-molecule interactions in the multicomponent aqueous solutions. Of similar interest is the model of Chen and co-workers (Chen et al., 1979), who presented an extended form of Pitzer's equation to predict the activity coefficients of both ionic and molecular solutes in aqueous electrolyte systems.

Meissner and Tester (1972) proposed a one parameter equation for the reduced activity coefficient as a function of the ionic strength which results in the formation of a family of curves. Meissner and Tester (1972) showed that, with a few exceptions, the curves usually do not cross one another and proposed that a graphical prediction of the activity coefficient can be made. The Debye-Hückel limiting law recognises the distance of closest approach ( $a_{i}$ in Equation (3.15)) in the calculation of the electrostatic energy of the distribution of ions but ignores the kinetic effect of the hard core on the activity coefficient and other properties (Pitzer, 1973). To account for this effect, Card and Valleau (1970) used a Monte Carlo simulation to calculate the osmotic coefficient for 1-1 electrolytes up to about $1 \mathrm{M}$. They used the radial distribution of ions around a given ion obtained from Boltzmann's law, with the interaction energy given by the product of the charge on one ion and the average electrical potential surrounding the other ion (Pitzer, 1973). 
The properties of the models discussed above could be summarised as follows:

1. Debye-Hückel limiting law — an equation using one parameter per ion pair and it is for very dilute electrolyte solutions only. Useful in the very dilute range when no experimental data on the activity coefficient of the desired species are available.

2. The Bromley equation _ _ an equation using one parameter per ion pair and fits activity coefficient data in the low to medium concentration range satisfactorily. The equation ignores interactions between like charged species, which become important in the higher concentration region.

3. The Meissner equation _ - an equation using one parameter per ion pair and it fits the reduced activity coefficient data from dilute to moderately high concentrations satisfactorily. The equation should be used only for systems for which experimental data are available to verify the validity of the $q$-parameter used, since curve cross-overs on the plot of the reduced activity coefficient versus the ionic strength are a possibility.

4. The Pitzer equation - $\quad$ an equation using three to four parameters per ion pair, one parameter for each like charged ion pair and one ternary parameter for high concentration interaction. The accuracy of the Pitzer equation to predict activity and osmotic coefficients over a wide concentration range has been verified by many investigators. Extensively tabulated values for the parameters of many electrolyte solutions are available in the literature.

5. Harvie and Weare model - model based on Pitzer's equation to calculate mineral solubilities in multicomponent aqueous electrolyte solutions over a wide concentration range by predicting the activity coefficients of the species. The accuracy is claimed to be higher than that of the Pitzer equation.

6. Lietzke-Stoughton model - an empirical equation for the prediction of the activity and osmotic coefficients of each electrolyte in multicomponent aqueous electrolyte solutions containing a common ion. It uses the activity coefficients of the pure constituent electrolytes at the same ionic strength as that 
of the multicomponent electrolyte solution, which can be obtained from one of the other methods, such as the Pitzer equation.

7. Reilly-Wood-Robinson - an equation for the prediction of activity coefficients in multicomponent aqueous electrolyte solutions based on the thermodynamics of mixed electrolytes. It uses activity and osmotic coefficients of the pure constituent electrolytes of the same ionic strength as that of the multicomponent solution, which can be obtained from one of the other methods. It is particularly useful for the prediction of the activity coefficient of a sparingly soluble solid in an aqueous solution in order to calculate its equilibrium solubility.

\subsection{SUMMARY}

In this chapter only the more recent models for the calculation of activity coefficients in aqueous electrolyte solutions were outlined, keeping in mind the need for practical applicability to real non-ideal solutions. Considerations to keep in mind when choosing an activity coefficient model for the purposes of the synthesis of the consolidated equilibrium model for a RIP slurry mixture are:

1. The model should have the ability to accurately model a species activity coefficient in a multicomponent aqueous electrolyte solution over a substantial concentration range. This should preferably be achieved by the model with only one set of the model parameters involved.

2. The model should have a sound thermodynamic basis to ensure that it will be able to account for the various higher order electrolytic interactions between various species in the aqueous phase.

3. Values for the model parameters for the various electrolyte systems of interest to this dissertation and in general should be available from the literature. This is to ensure that no extensive experimental evaluations of the required model parameters are needed for the purpose of this dissertation. 
4. It will also be useful if the accuracy of the model has been verified by various researchers in the literature for different aqueous electrolyte systems over a wide range of aqueous phase concentrations of the species.

For the above requirements the activity coefficient model of Pitzer proved to be the most useful and comprehensive. Although the model equations for the Pitzer model seem to be exhaustive, it is one of the few models accounting for higher order electrolytic interactions between species in aqueous electrolyte solutions. The model also has the ability to model the activity coefficient of a species over a significant aqueous phase concentration range with a single set of model parameters. This model feature is required for a RIP slurry mixture, due to the fact that the solution phase ionic strength increases significantly during equilibrium attainment of the RIP slurry system. The Pitzer model is also very flexible in that some of the model parameters may be excluded at low solution phase concentrations without impairing on the model accuracy. This feature enables the user to simplify the model equations significantly when the high solution phase concentration region is not of interest to the specific system under investigation. A further advantage of the Pitzer model is that extensive sources of tabulated data for the model parameters are available from the literature, and researchers are continually contributing to the existing set of model parameters as new combinations of aqueous phase electrolyte systems are under continual investigation. 


\section{CHAPTER 4}

\section{GENERAL CONSIDERATIONS ON ION-EXCHANGE RESINS AND ION-EXCHANGE EQUILIBRIA}

The earliest reference to ion exchange is found in the Holy Bible. Moses succeeded in preparing drinking water from brackish water of Marah by an ion-exchange technique, (Exodus 15: 23-25). Later in history Aristotle stated that sea water loses part of its salt content when percolating through certain sands. In 1850 Thompson and Way, two English chemists, noticed that ammonium sulphate was transformed into calcium sulphate after percolation through soil, thus an early example of cation exchange (De Dardel et al., 1989). In 1903, Harm and Rumpler, two German chemists, prepared the first synthetic industrial ion exchanger. In 1905, Gans softened water for the first time by passing it through a column filled with aluminosilicate, which could be regenerated with a sodium chloride solution. In 1935, Adams and Holmes produced the first synthetic cation exchangers by polycondensation of phenol with formaldehyde and a polyamine, respectively. They discovered that crushed phonographic records exhibit ion-exchange properties. The study of this effect led to the synthesis of organic ion-exchange resins with much better properties than previous products. In the same year, Liebknecht and Smit (De Dardel et al., 1989) discovered that a chemically and mechanically stable cation exchanger can be prepared by sulphonating certain types of coal. At present, sulphonated coal has been replaced by sulphonated polystyrene.

All of these new resins developed were improved by I.G. Farbenindustrie in Germany to give them better properties for specific application in industry. After World War II this development and improvement were continued by companies in the United States and England. Furthermore, the synthesis of organic resins made it possible to vary the 
properties of the ion exchangers for specific applications in chemical processing systems as well as supplementing these systems, such as distillation, adsorption and filtration.

Many industrial plants all over the world are using this technology today that range from decontamination of water for nuclear systems, recovery of metals in feed and waste streams, decontamination of process effluent streams, separation of rare earths and using ion-exchange resins as catalysis of organic reactions.

\subsection{OBJECTIVES OF THIS CHAPTER}

Modern synthetic ion-exchangers differ considerably from the first natural exchangers used and are manufactured in such a wide variety, each with its own unique properties. Some sort of introduction to these properties and factors influencing them is essential for anyone interested in modelling these systems. It is therefore the objective of this chapter to briefly discuss the fundamental principles concerning ion-exchangers that give rise to their specific equilibrium properties for a given set of physical conditions. This behaviour of ion-exchange resins is of utmost importance and needs to be considered in the mathematical modelling of the ion-exchange equilibria when incorporated into the consolidated equilibrium model for the Resin-in-Pulp (RIP) slurry mixture system represented by Figure 1.1. The mathematical models for the simulation of ion-exchange equilibria are discussed in detail in Chapter 5 of this dissertation and utilise the concepts discussed in this chapter.

It is also the purpose of this chapter to introduce various definitions that will be used in the rest of this dissertation. The most important of these definitions is that of the ionexchange capacity as discussed in paragraph 4.2 .3 below, which is of the utmost importance in the modelling of the ion-exchange equilibrium behaviour. The phenomena of "electrolytic sorption" is also discussed below and has an influence on the "true capacity" of an ion exchange resin, which justifies further consideration. 


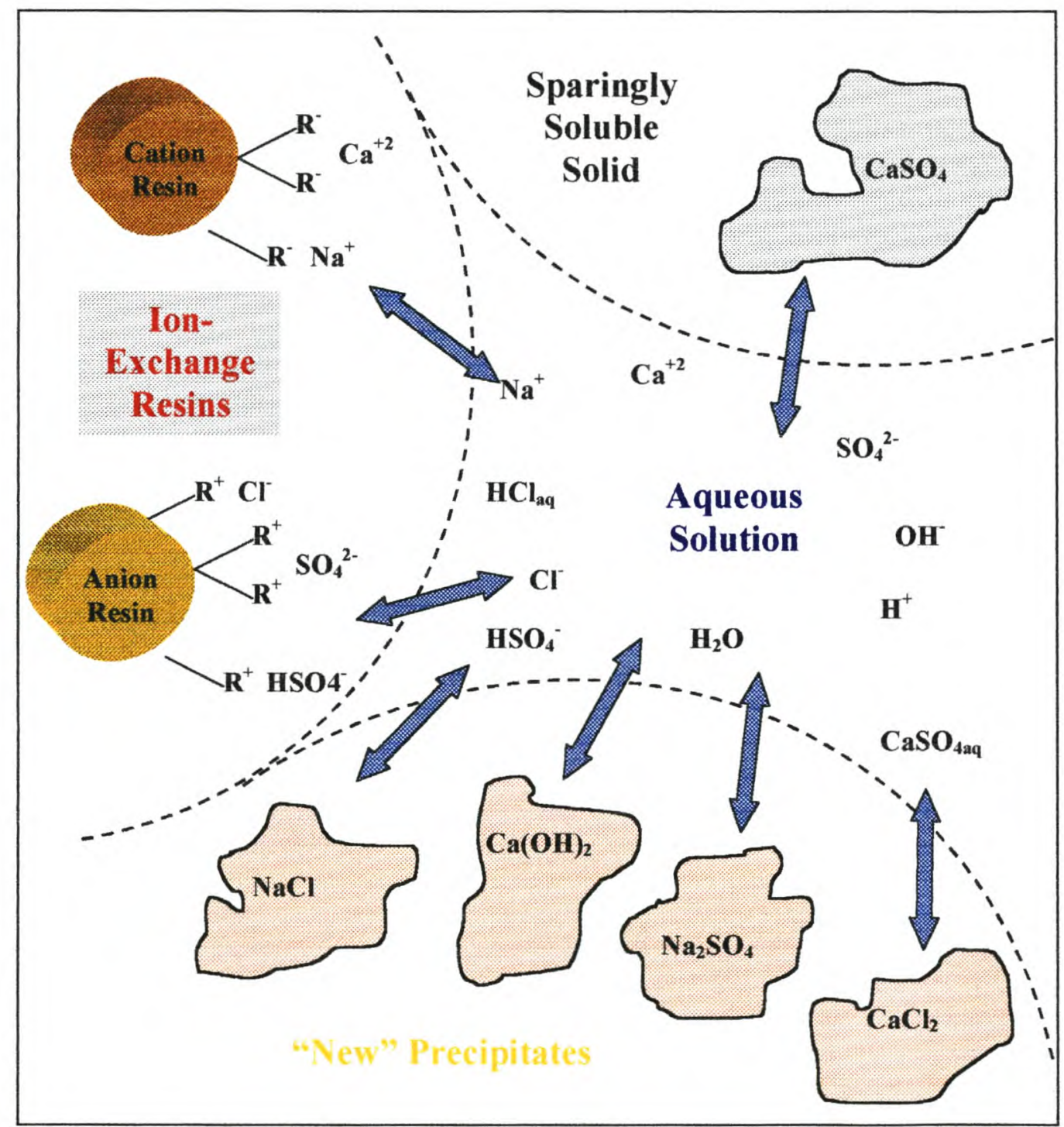

Figure 4.1 Ion-exchange resin phase equilibrium considerations for the dissolution of sparingly soluble solids of a Resin-in-Slurry mixture of $\mathrm{CaSO}_{4}$ with a cation and anion exchange resin 


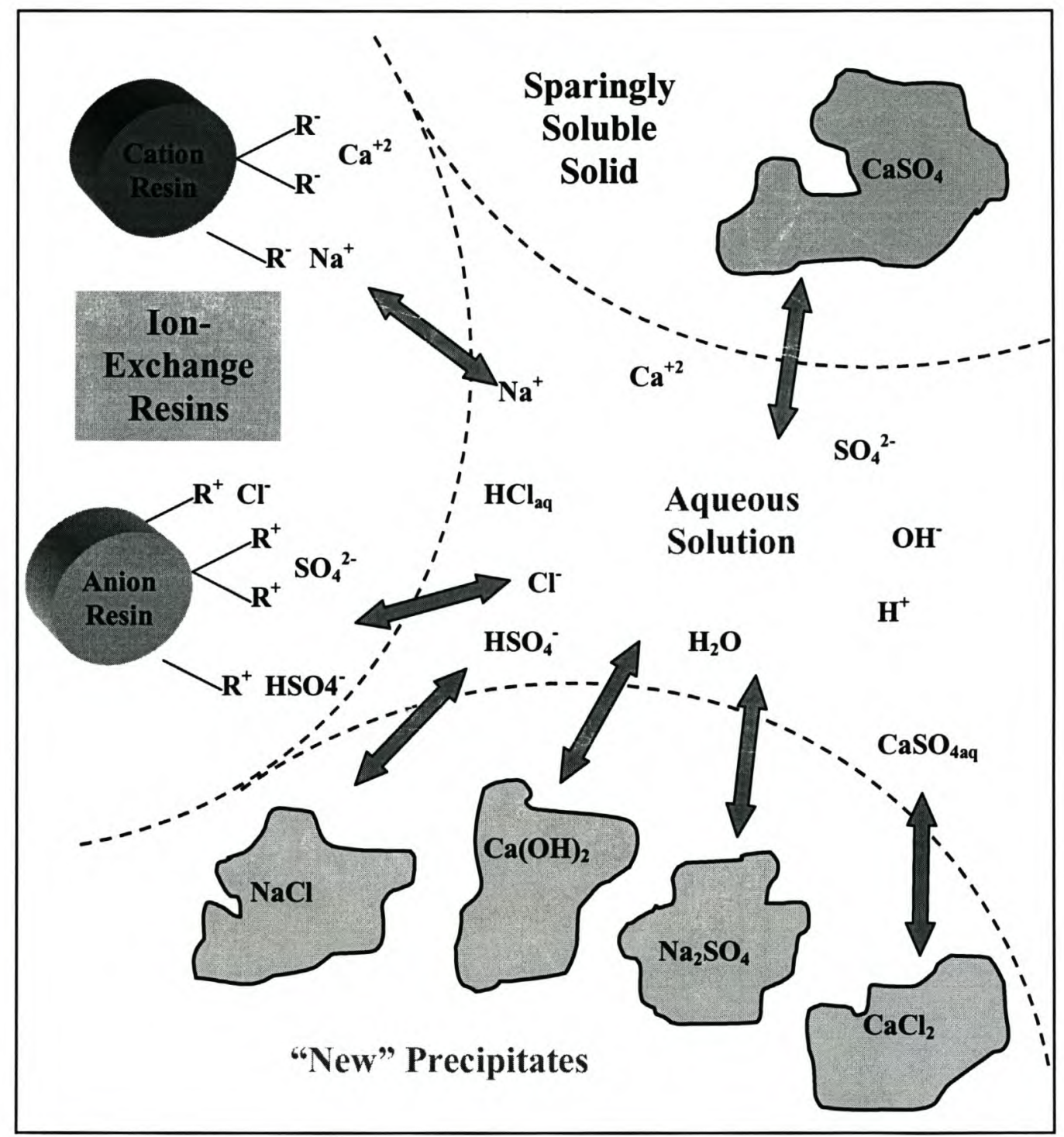

Figure 4.1 Ion-exchange resin phase equilibrium considerations for the dissolution of sparingly soluble solids of a Resin-in-Slurry mixture of $\mathrm{CaSO}_{4}$ with a cation and anion exchange resin 
A significant amount of experimental test work was performed for the purposes of this dissertation in order to verify the existence of electrolytic sorption for a RIP slurry mixture and to quantify the effect thereof. The results of the experimental test work on the electrolytic sorption phenomena are presented and discussed in detail in Chapter 8 of this dissertation, with the discussion on general considerations regarding the issue given by paragraph 4.2 .3 and paragraph 4.2 .6 below.

The important phenomena of resin "swelling" are also discussed below. Resin swelling may have a significant effect on the amount of ion-exchange resin measured and we therefore require a "reference state" for the ion-exchange resin for the purposes of the experimental procedures followed in this dissertation. This issue is addressed in Chapter 7 of this dissertation with the general background on resin swelling, that necessitates the measures followed in Chapter 7, provided by paragraph 4.2.4.2 below.

It is further also the objective of this dissertation to define the ion-exchange reaction in terms of a reaction equation, represented by Equation 4.1 below. The format used in Equation 4.1 will form the standard for reference to an ion-exchange reaction for the purposes of this dissertation.

The focus of this chapter in the synthesis of the consolidated equilibrium model for a Resin-in-Pulp slurry mixture is represented by Figure 4.1, which is a derivation of Figure 1.1 showing all of the equilibrium conditions for a RIP slurry system. From Figure 4.1 it is evident that the focus is on the ion-exchange resins (represented as three dimensional cylinders) and the factors influencing the "internal" resin phase equilibrium conditions when compared with Figure 1.1. 


\subsection{ION-EXCHANGE PRINCIPLES}

\subsubsection{Definition of an ion exchanger}

An ion exchanger is an insoluble solid material with fixed ionogenic functional groups that carry exchangeable cations or anions. Ion exchangers with only cationic functional groups are called cation exchangers and can exchange cations for a stoichiometrically equivalent amount of any other cation or positively charged molecules such as complexes. Anion exchangers can exchange only anions for a stoichiometrically equivalent amount of any other anions or complexes with a negative sign. Ion exchangers that are able to exchange both cations and anions on the same solid exchange material are called amphoteric ion exchangers.

The general ion exchange reaction for the purpose of this dissertation is given by Equation (4.1);

$$
v_{A}\left[\left(R^{-}\right)_{z_{A}} A^{z_{A}}\right]+v_{B} B^{z_{B}} \leftrightarrow v_{B}\left[\left(R^{-}\right)_{z_{B}} B^{z_{B}}\right]+v_{A} A^{z_{A}}
$$

where the cation $B^{z_{B}}$ is exchanged for cation $A^{z_{A}}$ on the resin and the stoichiometric coefficients $v_{A}$ and $v_{B}$ are defined as follows

$$
\begin{array}{ll}
\text { IF } \quad & \left|z_{A}\right| \neq\left|z_{B}\right| \quad \text { Then } \\
& v_{A}=\left|z_{B}\right| \text { and } v_{B}=\left|z_{A}\right| \\
\text { ELSE } & v_{A}=v_{B}=1
\end{array}
$$

Equation (4.2) gives the dissociation reaction of the strong electrolyte $B E$, which completely dissociates to give cation $B^{z_{B}}$ and anion $E^{z_{E}}$, 


$$
\left\lfloor\left(B^{z_{B}}\right)_{v_{B^{\prime}}}\left(E^{z_{E}}\right)_{v_{E}}\right\rfloor_{(a q)} \leftrightarrow v_{B^{\prime}} B^{z_{B}}+v_{E} E^{z_{E}}
$$

where the stoichiometric coefficients $v_{E}$ and $v_{B^{\prime}}$ are defined in the same way as the coefficients $v_{A}$ and $v_{B}$, as follows:

$$
\begin{array}{ll}
\text { IF } \quad & \left|z_{E}\right| \neq\left|z_{B}\right| \quad \text { Then } \\
& v_{E}=\left|z_{B}\right| \text { and } v_{B^{\prime}}=\left|z_{E}\right| \\
\text { ELSE } & v_{E}=v_{B^{\prime}}=1
\end{array}
$$

Equation (4.3) is a stoichiometric combination of Equations (4.1) and (4.2) to include the anion $E^{z_{E}}$, but this form of the ion exchange reaction is usually not encountered in the literature.

$$
\frac{v_{B^{\prime}} v_{A}}{v_{B}}\left[\left(R^{-}\right)_{z_{A}} A^{z_{A}}\right]+\left[\left(B^{z_{B}}\right)_{v_{B}}\left(E^{z_{E}}\right)_{v_{E}}\right]_{(a q)} \leftrightarrow v_{B^{\prime}}\left[\left(R^{-}\right)_{z_{B}} B^{z_{B}}\right]+\frac{v_{B^{\prime}} v_{A}}{v_{B}} A^{z_{A}}+v_{E} E^{z_{E}}
$$

Therefore, for the purpose of this dissertation Equation (4.1) is used as a general representation of the ion exchange reaction and it implicitly includes the anion $E^{z_{E}}$, though not shown in the reaction itself.

The symbol $R$ represents a unit in the ion exchange matrix that contains one functional group where stoichiometric ion exchange can occur, with $z$ the valence of an ion. $B^{z_{B}}$ represents a cation and $E^{z_{E}}$ the anion, which is also the spectator ion and called the coion of the ion exchange reaction. According to the above discussion it is evident that Equation (4.1) represents a cation exchange reaction. In the Equation (4.1) the ion exchanger initially carries the cationic species $A^{z_{A}}$, which is exchanged for the cationic species $B^{z_{B}}$. The cation $B^{z_{B}}$ is called the counter ion initially in the solution phase and 
cation $A^{z_{A}}$ the counter ion initially in the resin phase. Since the sign of the valence of the co-ion $Y^{z_{Y}}\left(z_{Y}\right)$ differs from that of the counter ions $A^{z_{A}}$ and $B^{z_{B}}\left(z_{A}\right.$ and $z_{B}$ respectively), it does not participate in the actual ion exchange reaction. It is also clear that a stoichiometrically equivalent amount of the counter ions (ions of the same sign) are exchanged for one another, the quantities which are governed by the valences of the participating ionic species. The ion exchange process is thus actually an electrochemical process, and from Equation (4.1) it is also evident that it is assumed that the ion exchange reaction is a reversible process.

\subsubsection{Structures and properties of ion exchangers}

Modern synthetic ion exchangers are available in such a wide variety that the choice of a specific ion exchanger depends on the intended application of the exchanger and the required physical properties needed to perform satisfactorily in such an application. Because of this, it is almost impossible to give a lengthy discussion on all the industrially available ion exchange resins, each with its own structures. Since only strong base anion exchange resins and strong acid cation exchange resins were used in the experimental procedures for the purpose of this dissertation, the discussion will be focused on these general types of resins.

\subsubsection{Preparation}

Inorganic aluminosilicates were the first synthetic ion exchangers to be prepared. Synthetic organic ion exchangers have become the most widely used ion exchangers nowadays, since it can be prepared to meet pre-specified unique exchange and physical properties.

These organic ion exchangers have a three-dimensional, insoluble cross-linked organic matrix of hydrocarbon chains with fixed ionic groups called the "active sites", since it is 
these ionic groups that render the exchange characteristics to the ion exchanger. The resin should also be able to swell to a limited extent, which is controlled by the degree of cross-linking. Highly cross-linked resin matrices are mechanically very stable, but cannot swell. Subsequently the mobility of any counter ions in such highly cross-linked systems is so low that ion exchange no longer occurs. The degree of cross-linking therefore plays an important role in the resin properties, and can thus be controlled by controlling the degree of cross-linking.

There are two basic methods of preparation of organic ion exchangers, namely polycondensation and addition polymerisation. The process of polycondensation is a much more complex one, since the structure and hence the properties of the final product depends both on the experimental conditions and the composition of the reaction mixture whilst preparing the resin. Because of the above mentioned difficulties, polycondensation polymers have almost completely been replaced by addition polymers. There are three routes to follow during the preparation of addition polymers. Firstly, non-ionic monomers are polymerised and cross-linked to form the three-dimensional organic matrix; the fixed ionic groups are then introduced to lend the structure "exchange properties". Secondly, ionic monomeric electrolytes are polymerised and cross-linked. The ionic groups are thus present in the substrate and no further addition is required. Thirdly, the ionic groups are introduced during the polymerisation process of non-ionic monomers, and the linear polymers then cross-linked. Divinylbenzene is used to crosslink the linear polymer molecules.

\subsubsection{Cation exchangers}

The properties of an ion exchange resin are governed both by the structure of the organic matrix and by the type of fixed ionic groups. There are two basic ionic groups used in the preparation of cation exchangers with different acid strengths, i.e. strong-acid cation exchangers with sulphonic acid groups $\left(-\mathrm{SO}_{3}{ }^{-}\right)$and weak-acid cation resins with 
carboxylic acid groups (-COO-), (De Dardel et al., 1989). The dissociation constants of these ionic groups in an electrolyte solution depend on the structure of the organic matrix.

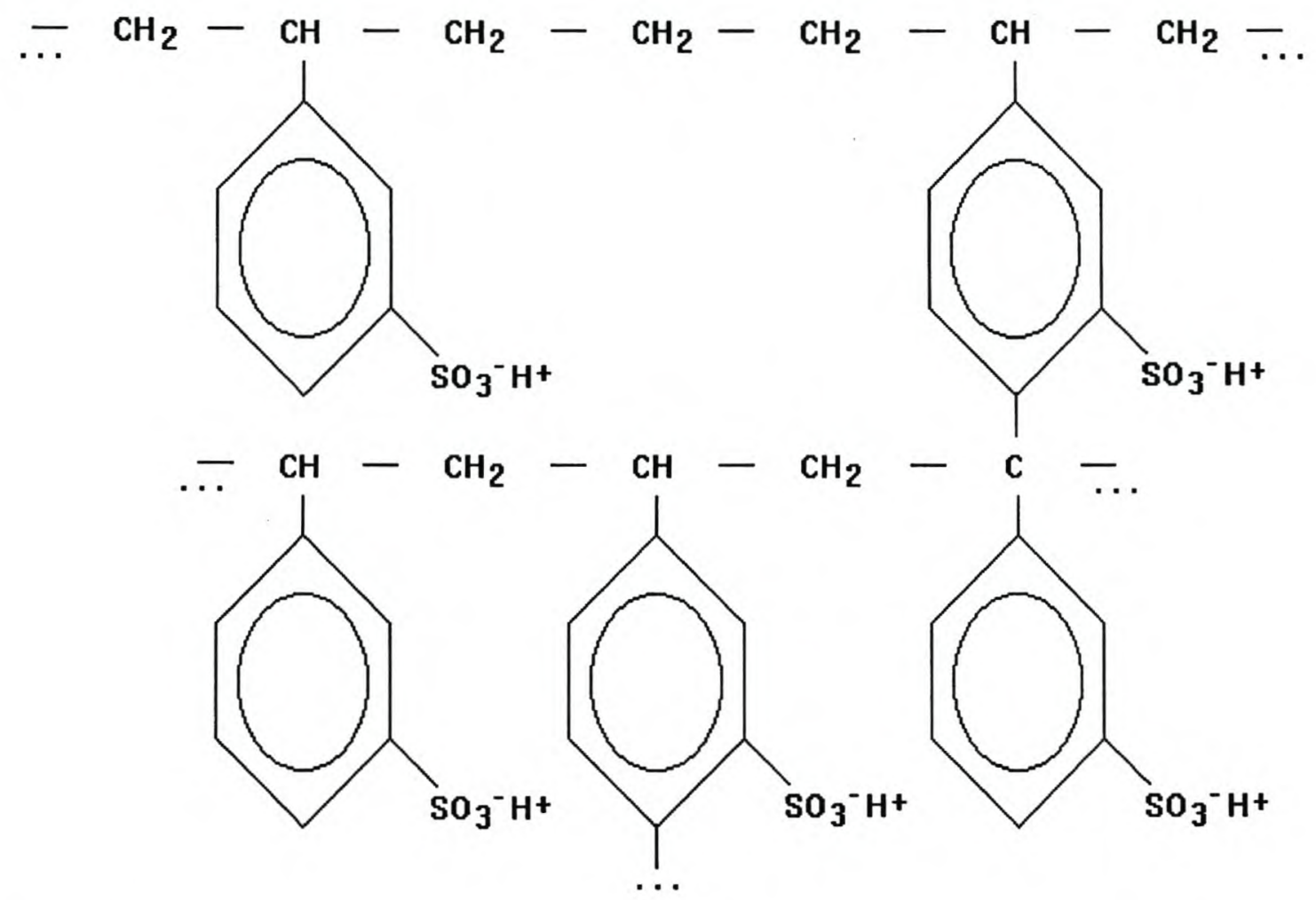

FIGURE 4.2 A synthetic strong-acid cation exchange resin with sulphonic functional groups $\left(-\mathrm{SO}_{3}{ }^{-}\right)$with a styrene-divinylbenzene polymer cross-linked matrix. The sulphonic acid groups are replaced by carboxylic acid groups (-COO') in the case of a weak-acid cation exchange resin.

Figure 4.2 shows a typical organic matrix of a strong acid cation exchanger constructed of polystyrene polymers cross-linked with divinylbenzene with sulphonic acid groups as the ionic groups introduced during preparation. The hydrogen ions are exchanged for counter ions during the ion exchange process. A weak-acid cation exchanger will have a similar organic matrix, but with the sulphonic acid groups replaced by carboxylic acid groups. The dissociation constants of the sulphonic acid groups are larger than that of the 
carboxylic acid groups, and will hence more readily exchange hydrogen ions for other counter ionic species than the carboxylic groups.

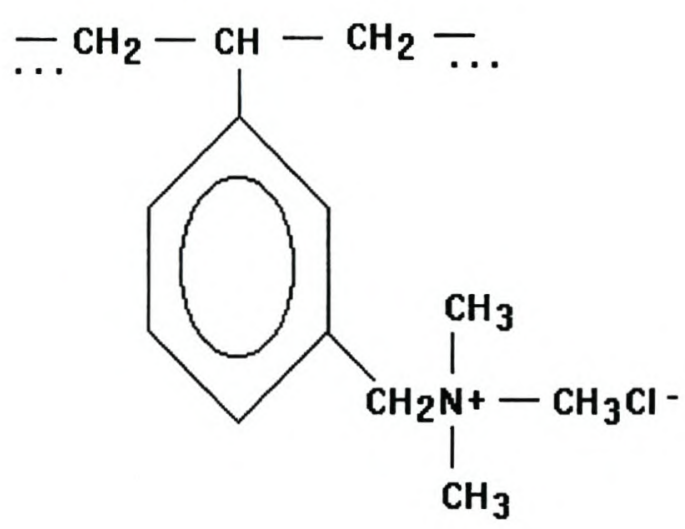

(A)

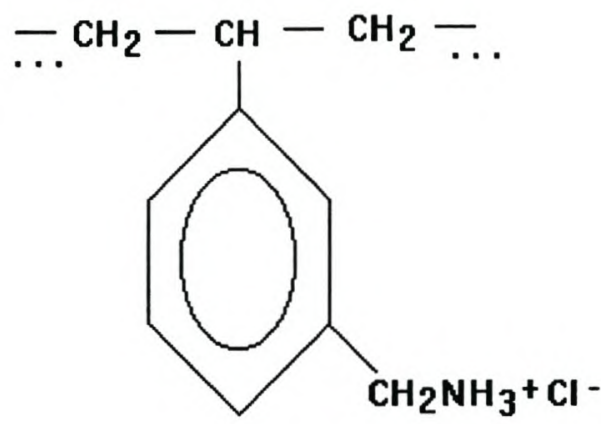

[B]

FIGURE 4.3 A typical synthetic organic anion exchange resin matrix constructed of polystyrene polymers cross-linked with divinylbenzene with basic ionic functional groups introduced by chloromethylation and treatment with (A) tertiary amino groups to form a strong-base anion exchange resin, and (B) with ammonia to form a weak-base anion exchange resin.

\subsubsection{Anion exchangers}

Anion exchangers with synthetic organic matrices are prepared similar to the cation exchangers, except for the introduction of the basic ionic groups which form the "active 
sites". Most of the anion exchangers are made of polystyrene polymers cross-linked with divinylbenzene (De Dardel et al., 1989). The basic ionic groups can be introduced to the matrix in different ways, of which chloromethylation of the polystyrene beads and subsequent treatment with ammonia, primary, secondary or tertiary alkyl amines are most common.

Weak-base anion exchangers are formed when the chloromethylated intermediate is treated with ammonia or with primary or secondary amines. Treatment with tertiary amines leads to the formation of strong-base anion exchangers, as shown by Figure 4.3.

\subsubsection{Amphoteric ion exchangers}

Ion exchange resins that can exchange for both cations and anions are called amphoteric ion exchangers. These resins contain both cationic and anionic functional groups. These resins are manufactured from conventional cation and anion resins where linear polycations or polyanions have been formed within the resin matrices via polymerisation.

\subsubsection{Gel-type ion-exchange resins}

The gel type resin is a polymer matrix constructed from polystyrene and then cross-linked with divinylbenzene to make it completely insoluble in any organic solvent or acid. These resin types do not contain any true porosity and any ion to be exchanged for a counter ion on the resin must diffuse through the gel structure to the exchange sites ("active sites"). The size of the ion that can migrate through the polystyrene DVB gel structure is often referred to as the apparent porosity of the resin, and is limited by the inter-molecular distances. Even in very low cross-linked gel-type resins, the apparent porosity is usually no greater than 40 Angstrom units. These styrene divinylbenzene type resins date back to 1947 , and are in operation in hundreds of thousands of installations the world over. 
Two of the most common problems encountered in the use of ion-exchange resins are mechanical stresses imposed by plants operating at extreme conditions and resin fouling by natural organic acids. In order to cope with these problems, resins with a high degree of cross-linking and channel-like artificial open pores up to 1500 Angstrom units in diameter were invented. When manufacturing these resins, the polymer is artificially expanded by the additional addition of a non-polymerisable compound that is soluble in the monomer. This results in a tough, rigid sponge-like ball having large discrete pores as well as a gel-type structure. These large discrete pores mean that high molecular weight ions and complexes can be more completely removed from electrolyte solutions and more completely eluted during regeneration of the resin beads.

The network of channels in a macroporous resin is filled with free water, known as the pore liquid. In the gel-type resins there is much less free pore liquid due to the much smaller diameter channels. Once inside the resin, ions to be exchanged have a much smaller distance to travel before they encounter an active group ("active site"): ca. $100 \mathrm{~nm}$ in macroporous resins and up to $500 \mu \mathrm{m}$ in gel resins (De Dardel et al., 1989). Ion exchange in macroporous resins is thus faster than in gel resins.

\subsubsection{Capacity of an ion exchanger}

The capacity of an ion exchanger is one of its most important characteristics. The ion exchanger itself can be considered to be a true electrolyte solution, with a reservoir of exchangeable counter ions, with properties similar to that of such a solution, the main difference being the restriction of movement of the free ionic species in the pore liquid and the fixed functional groups impaired by the retractive forces of the cross-linked network. The counter ion content of the ion exchanger is given by the amount of the fixed functional groups where exchange between two counter ions can occur. The 
capacity of an ion exchanger is thus influenced by factors that have an influence on the amount of counter ions that can be exchanged.

If the ion exchange process is viewed as a stoichiometrical process, it means that only a stoichiometrically equivalent amount of ionic species are exchanged between the bulk electrolyte solution and the inside of the ion exchanger. This means that counter ion $B^{z_{B}}$ can diffuse into the ion exchanger and be exchanged for another counter ion $A^{z_{A}}$, only if counter ion $A^{z_{A}}$ diffuses out of the exchanger into the bulk solution simultaneously. This is necessary to maintain electroneutrality inside the ion exchanger. Thus the counter ion content of the ion exchanger is a constant depending only on the amount of functional groups present inside the exchanger and is independent of the particle size and shape. This constant counter ion content is called the ion exchange capacity of the ion exchanger and is the number of ionogenic functional groups per specified amount of ion exchanger. This simple definition for the capacity of an ion exchanger for a particular species is not sufficient, since the ion exchange resin does not totally exclude the sorption of co-ions from the external electrolyte solution. The ion exchange process itself is dependent on the chemical composition of the external electrolyte solution, the solution phase concentrations of the particular species as well as the physical conditions under which the ion exchange reaction occurs, such as temperature and pressure.

There are many different definitions for the capacity of an ion exchanger and the definition used depends on the purpose of it, whether it will be used for numerical calculations or for characterising different ion exchange materials from synthetic materials to natural clays. The ion exchange capacity definition refers to the capacity of an ion exchanger devoided of all the free, unbounded sorbed electrolytes. Counter ions taken up by sorption alone, which did not "participate" in active ion exchange itself is not included in this definition. The sorption capacity of the ion exchanger refers to the amount of electrolyte species that are adsorbed per unit volume of ion exchange material by the ion exchanger without participating in actual ion exchange at the functional group sites inside the ion exchanger. Species adsorbed in this manner must therefore be present 
in the pore liquid of the ion exchanger. The overall sorption capacity of an ion exchange resin, for a given set of physical conditions, is equal to the sum of the ion exchange capacity plus the sorption capacity of the ion exchanger.

The overall sorption capacity of a particular species from a multicomponent electrolyte solution at equilibrium is called the equilibrium loading of the particular species on the ion exchange resin and is strongly dependent on the physical conditions of the system, of which the external solution phase concentration of the species, the degree of swelling of the resin matrix and the temperature are the most important.

Extensive experimental test work has been performed for the purposes of this dissertation to verify the existence of electrolytic sorption for the aqueous phase solution concentration ranges of interest to the RIP slurry mixture. The results of these tests are presented in Chapter 8 and discussed in more detail. From Figure 8.2 and Figure 8.4 it is evident that $\mathrm{Na}^{+}$ions are adsorbed by the anion-exchange resin from the bulk aqueous phase solution. This is only possible if the $\mathrm{Na}^{+}$ions is absorbed as an electrolyte molecule associated with one of the solution anions, as discussed in detail in paragraph 4.2.6. Typically the electrolytic sorption of species accounted for less than $2 \%$ of the overall sorption capacity of the ion-exchange resin.

For the purposes of this dissertation the capacity of the ion-exchange resin will be assumed as the overall sorption capacity of the resin. The effect of electrolytic sorption is therefore ignored in the interpretation of the experimental results, but the reader should take note of this fact. The amount of electrolytic sorption may become significant to the interpretation of the experimental results depending on the physical amounts of resin and solution used in the test work itself. If very large amounts of resin are used per unit volume of the RIP slurry mixture the cumulative amount of a specific species that may be removed for the aqueous phase solution due to electrolytic sorption may become significant. The amounts of ion-exchange resin used per unit volume of the aqueous phase solution in the experimental test work performed for the purposes of this 
dissertation prevented electrolytic sorption from having a significant influence on the experimental results.

\subsubsection{Parameters influencing the equilibrium loading of species on ion-exchange resins}

\subsubsection{Solution phase concentration of species}

There exists an equilibrium distribution of each particular species present between the external liquid phase (bulk phase) and the internal pore liquid phase for a given set of physical conditions. If the external liquid phase concentration of a particular species is changed, the internal pore liquid concentration of that species will change according to the existing equilibrium condition, which will then change the overall number of counter ions taken up by sorption and hence the overall sorption capacity of the ion exchanger. At very low species concentrations the exchange is usually stoichiometric in nature, meaning that a stoichiometrically equivalent amount of counter ions are exchanged for one another. When equilibrium is attained at high liquid bulk phase concentrations, the ion exchange process becomes non stoichiometric in that stoichiometrically more counter ions, initially in the bulk phase, are exchanged for counter ions initially saturating the resin in stoichiometric accordance with the number of functional groups present.

\subsubsection{Swelling of the ion-exchange resins}

Ion exchange resins swell in water and polar solvents, but only to a limited degree. It is evident from Figure 4.2 that a typical resin is built from units carrying the functional ionogenic groups. The interior of the ion exchange resin can therefore be viewed as a highly concentrated electrolyte solution, of which the functional groups have a tendency to dilute themselves by surrounding themselves with polar solvents (water), a process 
which is called solvation. However, in ion exchange resins the units carrying the functional groups are cross-linked. The resin can therefore be viewed as an electrolyte solution of which the movement of its functional groups is restricted.

This "degree of restriction" will have a profound effect on the capability of the functional groups to be solvated by the polar solvent, since it will restrict the increase in the interior pore volume of the resin caused by swelling during solvent uptake, and hence the number of solvent molecules that can enter the interior of the ion exchange resin. The more cross-linked the resin matrix is, the more restricted are the movements of the functional groups and the less solvent can be absorbed.

When the ion exchange resin swells, the matrix is stretched and consequently exerts a "pressure" on the internal pore liquid brought about by the elastic, retractive forces of the resin matrix. This results in an osmotic pressure difference between the internal pore liquid and the external electrolyte solution, which is called the swelling pressure of the ion exchange resin. Swelling equilibrium is attained when the tendency of solvent uptake is balanced by the opposing forces of the resin matrix.

The extent of swelling depends on many physical parameters, of which the following are the most important (Helfferich, 1962):

\section{i. $\quad$ Nature of Solvent}

Polar solvents (water) interact more strongly with the fixed functional ionogenic and polar groups inside the resin and are less likely to be "expelled" from the resin phase due to the retractive forces imposed by the resin matrix than is the case for non-polar solvents (Helfferich, 1962). 


\section{ii. $\quad$ Degree of cross-linking}

The more cross-linked the resin matrix is, the more restricted are the movements of the functional groups and the less solvent can be absorbed (Harland, 1994). Jones et al. (1993) studied the equilibrium loading of amino acids and dipeptides on sulphonated polystyrene-divinylbenzene cation exchange resins of varying degree of crosslinking. These resins were highly hydrated, and at a low degree of cross-linking (low \% DVB) the attainable equilibrium loading of the species increases with solute hydrophobicity (Helfferich, 1962). On the other hand, at high degrees of cross-linking the attainable equilibrium loading was smaller for the larger molecules, because of the fact that steric hindrances prevented a full utilisation of the exchange capacity that is observed for small inorganic cations.

\section{iii. $\quad$ Nature of fixed ionic groups (functional groups)}

The electrostatic forces between the fixed ions and the polar solvents depend on the degree of dissociation of the fixed ionic groups. The more dissociated the functional groups are the more strongly will the solvent interact with fixed groups and the more can the resin consequently swell. In the case of strong base anion and strong acid cation exchange resins the functional groups are fully ionised. This is not the case for weak base anion and weak acid cation exchange resins, since the degree of ionisation depends on the solution $\mathrm{pH}$, (Helfferich, 1962). Swelling in the case of strong base anion and strong acid cation exchange resins is therefore usually more profound than in the case of the "weak" resins.

iv $\quad$ Ion exchange resin capacity

A high-capacity ion exchange resin contains functional group ions in higher concentrations. It will therefore need more pore liquid to solvate the higher concentration 
of ions that results in more pronounced swelling than in the case of low-capacity ion exchange resins (Helfferich, 1962).

v. $\quad$ Nature of the counter ion

The ion-exchange process is one that is governed by electrostatic interactions. The effect of the counter ion on resin swelling is complex and can be described in terms of its "Ionic Potential", which is defined by Equation (4.4) as the ratio of its electrochemical valence to the crystallographic ionic radius,

$$
\text { Ionic Potential }=\frac{z}{r}
$$

The size and solvation tendency of the counter ion inside the ion exchange resin is a function of its "Ionic Potential" and the degree of cross-linking of the exchanger phase.

In moderately to highly cross-linked resins the solvent is primarily present in the form of solvation shells, hence the resin phase will expand when a counter ion is replaced by another one with a larger solvation shell, which is proportional to its "Ionic Potential". However, in the case of very highly cross-linked resins, solvation may remain incomplete and the uptake of counter ions with a low tendency towards solvation (small "Ionic Potential") may be favoured.

In the case of weakly cross-linked resins the internal "pore liquid" contains solvent in the form of hydration shells as well as large amounts of "free" solvent (i.e., solvent not in the form of solvation shells). The number of counter ions exchanged during a stoichiometric ion exchange reaction is dependent on the valence of the counter ion, since equivalent amounts of each counter ion are exchanged for one another. The number of counter ions adsorbed in the resin phase during an ion exchange reaction is therefore cut in half when univalent ions are exchanged for bivalent counter ions from the external electrolyte 
solution, which will reduce the amount of solvent adsorbed. The valence of the counter ion is therefore, as a rule, the most important factor for swelling in weakly cross-linked resins when considering the contribution of the counter ions (Helfferich, 1962).

\section{vi. Ion-pair formation and association inside the resin phase}

Swelling of the resin phase is reduced when counter ions and the fixed functional groups associate or form complexes. This is especially the case for chelating ion exchange resins as well as "weakly dissociated" resins, such as a weak acid cation and weak base anion exchange resins. The fixed functional groups of weak acid cation exchange resins in the $\mathrm{H}^{+}$form are less dissociated than in the alkali-ion form, which means that less "free" hydrogen counter ion species are present in the pore liquid that need to be solvated by the solvent. Consequently less amounts of the solvent are needed and adsorbed by the ion exchanger, which limits the swelling of the ion exchanger (Helfferich, 1962).

\section{vii. Concentration of the external electrolyte solution}

An increase in the ionic strength of the external electrolyte solution will decrease the osmotic pressure difference between the external solution and the internal pore liquid of the resin phase. This reduces the driving force for the uptake of solvent by the resin phase. Ion exchange resins will therefore swell to a much more appreciable extent in very dilute aqueous electrolyte solutions than in medium to highly concentrated solutions (Harland, 1994).

\subsubsection{Phase-boundary potentials and the electric double layer (Donnan potential)}

When two phases are in contact with one another, there exists a difference in their electric potential, irrespective of whether they are in equilibrium or not (Helfferich, 1962). This 
electric potential difference between the phases is called the phase-boundary potential, and in the case of ion exchangers it is called the Donnan potential. Consider a cation exchange resin containing no sorbed electrolyte solution, placed in a dilute electrolyte solution, which means that the only cations present in the resin are the ones fixed to the functional groups. The capacity of a typical strong acid cation exchange resin is 2.0 eq moles per litre of resin (De Dardel et al., 1989), which is a much higher cation concentration than in the dilute electrolyte solution. The concentration of the mobile anions is again much higher in the dilute electrolyte solution than in the cation exchange resin itself, which only contains anion groups fixed to the polymer matrix forming the active sites for the cations. If the ionic species carried no electric charges, which implies non-electrolyte adsorption, any considerable concentration differences would be levelled out by diffusion.

Since ion exchange reactions involve the migration of ionic species between the bulk electrolyte solution and the inside of the resin beads, they involve the transfer of electrically charged fluxes. Diffusion of the cations from the higher cation concentrated resin beads into the lower cation concentrated solution, and the diffusion of the mobile anions from the higher anion (mobile) concentrated solution into the lower anion (mobile) concentrated resin beads will result in the accumulation of a net positive charge in the solution and a net negative charge in the ion exchanger (De Dardel et al., 1989). Migration of only the first few ions is sufficient to build up a strong enough electric field between the two phases which will pull the cations back into the "net negatively charged" ion exchanger and the anions back into the "net positively charged" solution. An equilibrium is therefore established between the two phases where the retarding force of the electric field on the diffusing ionic species equals the concentration driving force in magnitude, but in an opposite direction.

Because of these potential differences the co-ions are largely prevented from entering the ion exchange resins and thus prevent the internal co-ion concentration from rising beyond an equilibrium value which is much smaller than the external solution concentration. 
This partial exclusion of the co-ions from the inside of the ion exchange resin is called Donnan exclusion (Harland, 1994). This unequal equilibrium distribution of the mobile ionic species gives rise to the already mentioned potential difference, which is called the Donnan potential (Helfferich, 1962). The fixed charges (functional groups) in the ion exchanger are electrically balanced by the counter ions which are in excess of the co-ions, largely excluded due to the Donnan potential. Electroneutrality therefore requires that these counter ions cannot diffuse out of the resin matrix without being replaced by an electrically equivalent amount of counter ions from the solution.

The electric potential and the concentrations of the ions change gradually rather then stepwise from one bulk phase to the other (Helfferich, 1962). The potential and concentration gradients exist in a narrow region on either side of the phase boundary, called the electrical double layer with a thickness in the order of a few hundred Angstrom units or less.

\subsubsection{Parameters influencing electrolyte sorption by ion-exchange resins}

Ion-exchange equilibria and sorption behaviour of strong electrolytes are more complex and quite different from that of weak and non-electrolytes, because of the electric charges carried by the ions of a strong electrolyte. The co-ions of a strong electrolyte are subject to electrostatic forces (present as the Donnan-phase boundary potential) arising from the fixed ionic groups (repelling forces) and counter ions (attracting forces) inside the resin. Because of this, there are considerable concentration differences for the co-ions between the external electrolyte solution and the internal pore liquid of the ion-exchanger. If the ions have very little or no electric charge, such as weak or non-electrolytes, their concentration difference between the external solution and internal pore liquid would be levelled out by diffusion to a much larger extent than for strong electrolytes.

Electrolyte sorption is best described in terms of the distribution of the co-ion, since electrolyte uptake and co-ion uptake are stoichiometrically equivalent because of the 
electroneutrality requirement and no co-ions are present in the ion-exchanger prior to sorption (Helfferich, 1962). The co-ions are partially excluded from the inside of the ionexchange resin due to the presence of the Donnan potential, which consequently partially excludes the electrolyte as well.

A fundamental knowledge of electrolyte sorption and the parameters influencing it, is of practical importance in understanding and predicting ion exchange equilibria. This is especially true for macroporous ion-exchange resins with their large internal pore volumes, which allows significant electrolyte sorption under favourable physical conditions. The sorption of unwanted electrolyte species from multicomponent electrolyte solutions can result in the formation of precipitates inside the resin pores. These precipitates may significantly retard the kinetics of the ion-exchange reaction as well as the equilibrium distribution of the species between the external solution and the ion-exchanger. During elution of the pregnant resin phase, the blocked pores may result in incomplete recovery of the sorbed species due to the inability of the eluant to properly penetrate the blocked pores. Unwanted sorbed electrolytes are also flushed from the pore volumes of highly selective, macro-porous ion-exchange resins during elution, which gives rise to contaminated product streams that need further refinement.

There are various parameters limiting the extent to which the concentration differences of the co-ions, and hence the electrolyte, can be levelled out between the external solution and internal pore liquid. A qualitative discussion, based on the Donnan concept, is given by Helfferich (1962).

\subsubsection{Capacity, degree of cross-linking and external solution concentration}

The co-ions are partially excluded from the resin phase due to the Donnan potential difference. The larger the Donnan potential difference is between the resin and the external solution, the stronger is the exclusion of the co-ions and hence the electrolyte from the inside of the ion-exchanger. The equilibrium distribution of the counter-ions 
between the resin and external solution phase is attained when the Donnan potential balances the tendency of the counter-ions to diffuse out of the resin phase and into the external solution. The Donnan potential is greater when the concentration difference between the ion-exchanger and the external solution is larger, hence the Donnan potential increases with decreasing external and increasing internal counter-ion concentration, and so does the degree of electrolyte sorption.

High capacity, highly cross-linked ion-exchange resins have a higher internal counter ion concentration and consequently the efficiency of electrolyte exclusion increases with decreasing external solution concentration and with increasing capacity and degree of cross-linking of the ion-exchanger (Helfferich, 1962).

\subsubsection{Ionic valences of species}

The force with which an electric field acts on an ion is proportional to the "Ionic Potential", defined by Equation (4.4). The Donnan potential required to balance the tendency of the counter ion to diffuse out of the resin phase into the external solution is smaller when the valence of the counter ion is higher. The smaller Donnan potential will consequently result in less effective electrolyte exclusion from the resin phase. If the valence of the co-ions is higher, a given Donnan potential will exclude the co-ions more effectively. Consequently, electrolyte exclusion is more efficient with counter ions of low valence and co-ions of high valence (Helfferich, 1962).

\subsubsection{Ion-pair formation and association inside the resin phase}

Ion-pair formation and association between the counter ions and the fixed ionic groups localise the counter ions in the ion exchanger and thus reduce the Donnan potential and the efficiency of electrolyte exclusion. This is especially true for chelating ion exchange resins as well as weak acid cation and weak basic anion exchange resins. Weak acid 
cation exchange resins in the $\mathrm{H}^{+}$form are very little ionised as compared with the alkaliion forms, and consequently do not exclude acids very effectively.

More extreme cases of ion-pair formation are encountered when multivalent counter ions associate strongly with the fixed ionic groups. In such cases the rules for Donnan exclusion of the co-ions may even be reversed, when the counter-ions are bound strongly by the fixed functional groups which may cause a cation exchange resin to behave like an anion exchange resin. Phenomena of this kind are the rule with cation exchangers containing trivalent or quadrivalent counter ions (Helfferich, 1962). Strong interactions between the co-ion and the fixed functional groups may also occur which provides a "driving force" for co-ion uptake and thus counteracts electrolyte exclusion from the resin phase. Complex formation between the exchanged counter ions, initially saturating the ion exchange resin, and the co-ions can also provide an additional "driving force" for coion uptake by forming complexes with the same valence signs as the counter ions.

\subsubsection{Temperature and pressure}

Specific sorption of species decreases with increasing temperature, which can be attributed to various effects of the increased temperature on resin swelling, solvation, ionisation of the functional groups, ion-pair formation, etc. An increase in the pressure of the system has very little effect on the ion-exchange process. This may be explained if it is considered that ion-exchange usually occurs without much change in the volume of the total system (ion-exchanger and aqueous solution). It should further be considered that the pressure difference between the pore liquid of the ion-exchange resin and the external electrolyte solution (called the swelling pressure) is typically several tens of atmospheres in magnitude (Helfferich, 1962). The external pressure on the ion-exchange system therefore also needs to be in the same order of magnitude as the swelling pressure before having an effect on the ion-exchange process. 


\subsection{SUMMARY}

From the above discussions it followed that the definition of the equilibrium capacity of an ion-exchange resin for the purposes of this dissertation is defined as the overall sorption capacity of the exchanger. The overall sorption capacity of an ion exchange resin is equal to the sum of the ion exchange capacity (depends on the number of functional groups) plus the sorption capacity (known as electrolytic sorption) of the ion exchanger. It is shown experimentally that electrolytic sorption exists for the ionexchange resins used in the experimental test work performed for the purposes of this dissertation (Chapter 8).

The effect of resin swelling on the ion-exchange equilibrium capacity has also been discussed in detail and because of this a standard reference state of measurement for ionexchange resins is defined in Chapter 7. Typically the standard states are the $\mathrm{Na}^{+}$ionic form for cation exchangers and the $\mathrm{Cl}^{-}$ionic form for anion exchangers.

The discussions above on important aspects influencing the ion-exchange equilibrium capacity give the reader a better understanding of the complexity of the system and the various parameters influencing the ion-exchange capacity for a given set of physical parameters. It is evident and intuitive from the above discussions that the ion-exchange resin phase may behave in a highly non-ideal manner. It is therefore of significant importance from a modelling point of view to be able to account for these non-idealities in a mathematical way. Any model attempting to model the equilibrium behaviour of an ion-exchange resin should therefore account for these non-idealities. This is usually done in the form of resin phase activity coefficients, which is discussed in more detail in Chapter 5. In Chapter 5 that follows a detailed discussion on the various ion-exchange equilibrium models available in the literature is presented together with the formulation of the equilibrium model to be used in the consolidated equilibrium model for the RIP slurry mixture system. 


\section{CHAPTER 5}

\section{EXISTING METHODS FOR THE PREDICTION OF MULTICOMPONENT ION-EXCHANGE EQUILIBRIA}

Ion-exchange adsorption has established itself as an effective, low cost purification and separation technique in the industry (Scholl et al., 1991). Knowledge of multicomponent ion-exchange adsorption equilibria is therefore of great practical importance, which is used in the design of ion-exchange adsorption equipment. Since these ion-exchange processes usually operate over a wide range of physical conditions, experimental determination of all possible multicomponent adsorption equilibria requires significant expenditure of time and equipment.

Because of this practical implication, the need for a useful method of predicting multicomponent ion-exchange equilibria from single or binary equilibrium data was identified, which leads to the development of various mathematical models. A successful and useful model should be capable of accurately predicting the resin phase composition, which is in contact with a solution phase of known composition.

A high priority requirement of any multicomponent equilibrium model is its applicability to a variety of systems, with a minimum amount of required experimental data (Haub et al., 1986). In the past, several methods (consisting of numerous ion-exchange models) have been proposed to predict multicomponent equilibria between ion-exchangers and solutions, which were mainly concerned with the distribution of different competing ionic species between the ion-exchanger and the solution phase. 


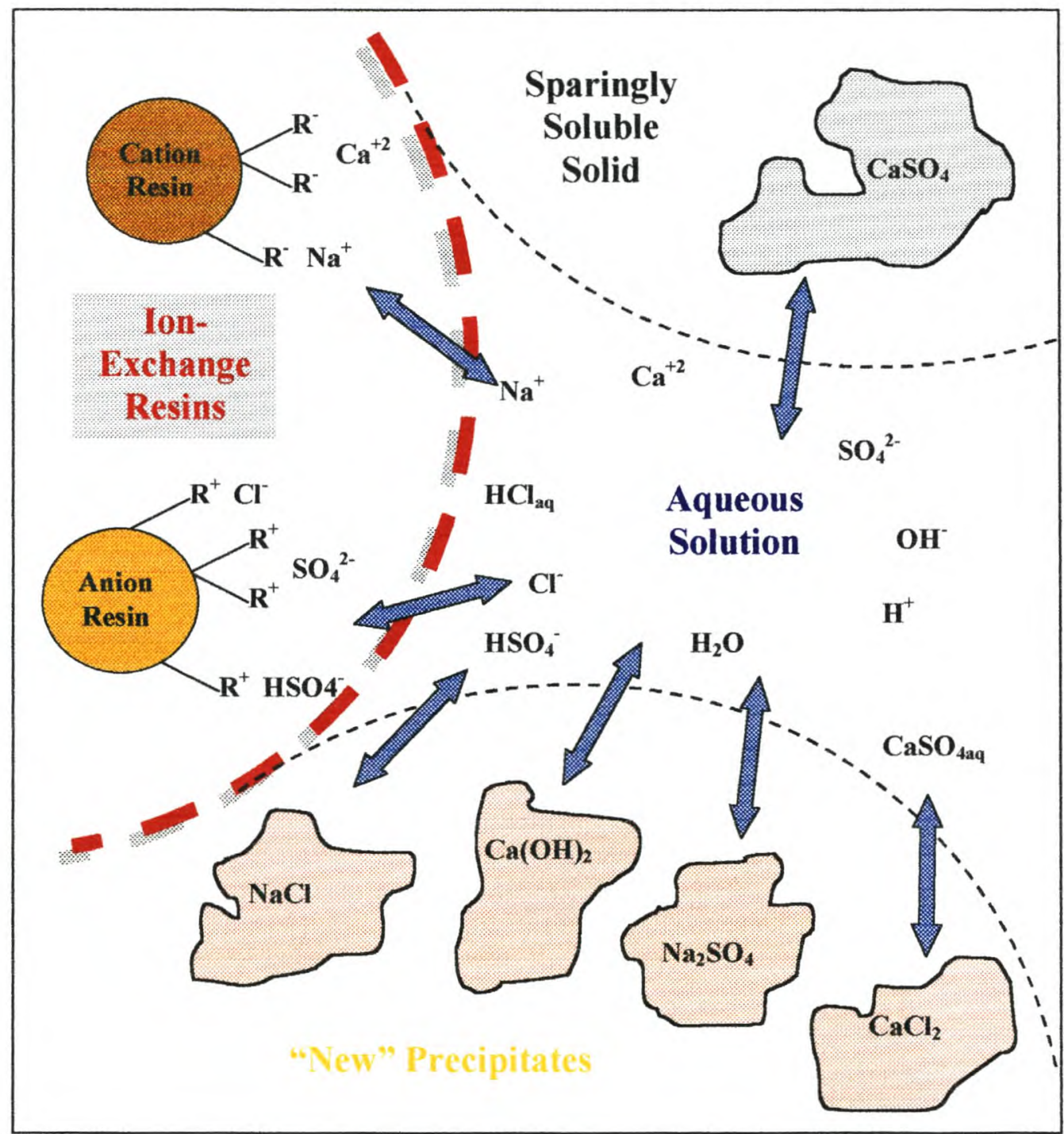

Figure 5.1 Resin / aqueous phase equilibrium considerations for the dissolution of sparingly soluble solids for a Resin-in-Slurry mixture of $\mathrm{CaSO}_{4}$ with a cation and anion exchange resin 


\subsection{OBJECTIVES OF THIS CHAPTER}

Figure 5.1 is a schematic representation of the various equilibrium conditions existing in a Resin-in-Pulp (RIP) slurry mixture. By comparing Figure 5.1 with Figure 1.1 it is evident that the focus of this chapter is concerned with the ion-exchange resin / aqueous phase equilibrium condition, which is indicated by the bold dashed line in Figure 5.1. Chapter 4 focussed on the "internal" resin equilibrium conditions and the various parameters influencing ion-exchange equilibrium, which forms part of the resin / aqueous phase equilibrium condition to be investigated in this chapter. The concepts introduced in Chapter 4 will therefore be used in this chapter to investigate the resin / aqueous phase equilibrium condition in more detail. Chapter 3 covered the various techniques available to model aqueous phase solutions and the non-idealities associated with it, by means of species activity coefficient predictions. This forms the other end of the resin / aqueous phase equilibrium condition, which will also be required in the investigation of this chapter. It is therefore evident that the concepts on the various equilibrium conditions as discussed in Chapter 3 and Chapter 4 form the basis for the investigation into the resin / aqueous phase equilibrium condition to be discussed in this chapter.

It is also the objective of this dissertation to give an overview on the various models available in the literature to model ion-exchange equilibria. The models that will be considered in this chapter fall roughly into two categories, i.e. empirical models and thermodynamic based models. The latter of the two types are the models based on a more fundamental approach that also consider various factors such as species non-idealities in the resin phase itself.

Various definitions for equilibrium constants will also be defined it this chapter for the purposes of this dissertation. These definitions will also be used in the synthesis of the consolidated equilibrium model for the RIP slurry mixture system. The type of ionexchange equilibrium model to be used in the consolidated equilibrium model will have 
to conform to several requirements. The most important of these will be the ability to account for non-idealities in the ion-exchange resin phase, as it became evident from the discussions in Chapter 4 that the resin phase may be a highly non-ideal phase. The model also needs to be able to model the ion-exchange equilibrium conditions over a wide range of solution phase concentrations. This is important due to the fact the RIP slurry mixture may cause the solution ionic strength to increase substantially in the process of equilibrium attainment. The model should preferably be able to this with only one set of model parameters that is valid over the entire solution phase concentration range.

\subsection{GENERAL CONSIDERATIONS ON THE HISTORICAL DEVELOPMENT OF ION-EXCHANGE EQUILIBRIUM MODELS}

Most of the initial attempts to describe ion-exchange equilibria consisted of empirical and semi-empirical equations.

In recent years a more fundamental approach was followed, which led to the development of several models, based on a more thermodynamic approach, which is the appropriate means of describing ion-exchange equilibria.

The effects of electrolyte and solvent adsorption / desorption by the resin phase received little attention when the first attempts were made to model ion-exchange equilibria. The effect of electrolytic sorption on ion-exchange equilibria is still regarded as insignificant by numerous modern investigators (de Lucas Martinez et al., 1994). In the development of this type of equilibrium models, it is implicitly assumed that the resin phase only contains fixed ionic groups and bound counter ions, which is hardly the case. Porous ionexchangers can also adsorb solvents and electrolytes from the solution phase in contact with it, and the importance of this were realised when the first organic ion-exchange resins were invented and synthesised. This lead to the development of various thermodynamically based models accounting for electrolyte and solvent adsorption (Gaines and Thomas, 1953; Novosad and Myers, 1982 and Hogfeldt, 1984, 1988, 1989). 
Vermeer and co-workers (Vermeer et al., 1975) noted that a strong interaction exists between the liquid and resin phases. When a $6 \mathrm{~N} \mathrm{HCl}$ brine solution was passed through an ion-exchange column, it was found that the average outlet concentration of the brine was approximately $3 \mathrm{~N}$. This dilution is caused by Donnan uptake and by resin shrinkage, which expels interstitial pore liquid that causes dilution. The importance and magnitude of solvent and electrolyte adsorption in modern ion-exchange resins is further illustrated with the development of solvent impregnated resins (Cote et al., 1990). These types of resins were developed out of a need for ion-specific resins, due to a lack of suitable technology required for the chemical functionalisation of the polymeric supports (adding functional groups to the resin backbone structure).

Ion-exchange equilibria and selectivity are also very dependent on the ionic strength of the competing species in both the external solution and resin phase (Marton and Inczedy, 1988). This is the result of ionic and molecular interactions existing in multicomponent concentrated electrolyte solutions. These interactions lead to non-idealities, which need to be incorporated into a successful equilibrium model, usually in the form of species activity coefficients. The importance and applicability of species ionic strength in modern ion-exchange equilibria are clearly illustrated with some chelating ion-exchange polymers. Sengupta and Zhu (1992) have identified a speciality chelating polymer, which exhibits a significant increase in metal-ion selectivity at acidic $\mathrm{pH}$ with an increase in the ionic strength of the external aqueous solution phase. A representative equilibrium model should therefore be capable of accounting for chemical speciation in both the solution and resin phase, which is largely influenced by the species ionic strength.

From the above discussion it is evident that there exists numerous types of ion-exchange equilibrium models, considering various interactions and non-idealities. Deciding which model best represents a specific exchange case depends on the amount of modelling detail required to obtain a desired degree of prediction accuracy, which varies from case to case. 
It is therefore the objective of this chapter to discuss the most prominent ion-exchange equilibrium models used in the literature and to identify the ones that are in good agreement with experimental results.

\subsection{EMPIRICAL AND SEMI-EMPIRICAL ADSORPTION MODELS}

A wide variety of empirical equations are available from the literature for the modelling of species adsorption onto solids, such as activated carbon and ion-exchange resins. Only the most prominent and widely used equations will be discussed in this section.

Fritz and Schluender (1974) proposed a general empirical equation for the calculation of adsorption equilibria of organic solutes in aqueous solution onto activated carbon as represented by Equation (5.1),

$$
q_{i}=\frac{a_{i 0} C_{i}^{b_{i 0}}}{c_{i}+\sum_{j=1}^{n} a_{i j} C_{i}^{b_{i j}}}
$$

where $\mathrm{q}_{\mathrm{i}}$ is the amount of solute $i$ adsorbed per unit weight of solid at equilibrium concentration $C_{i}$ in a solution containing n solutes. Clover et al. (1990) modelled the binary adsorption of gold and zinc cyanides onto a strong base anion-exchange resin, using Equation (5.1). Fritz and Schluender (1974) used Equation (5.1) to model the competitive adsorption of p-nitrophenol and phenol onto activated carbon. They found that the mutual interference of the two solutes on one another was very different, even though the adsorbed amounts of both solutes from the pure solution were about the same order of magnitude. There was only weak competition in the adsorptive capacity o pnitrophenol in the presence of phenol, whereas the uptake of phenol was very much reduced by the addition of p-nitrophenol. Chemical interactions and competition effects of multicomponent systems of this nature between different solutes are complicated, and can become problematic to predict with empirical equations. Equations of this type are 
either too simplified to describe the complexity of a multicomponent isotherm or too mathematically complicated to be used in practice, since a different empirical fit is usually needed for different total solution concentrations (McKay and Al Duri, 1989).

Equation (5.1), as presented by Fritz and Schluender (1974), includes some well-known relationships as special cases. For a single component system, Equation (5.1) reduces to Equation (5.2),

$$
q_{i}=\frac{a_{i 0} C_{1}^{b_{i 0}}}{c_{i}+a_{i 1} C_{1}^{b_{i 0}-1}}
$$

which reduces to the Redlich-Peterson expression for a single component system when $\mathrm{c}_{\mathrm{i}}$ $=1$ and $b_{i 1}=\left(b_{i 0}-1\right)$, represented by Equation (5.3). Radke and Prausnitz (1972) also used this adsorption isotherm.

$$
q_{i}=\frac{a_{i 0} C_{1}^{b_{i 0}}}{1+a_{i 1} C_{1}^{b_{i 0}-1}}
$$

For $b_{i 0}=b_{i j}=c_{i}=1$, Equation (5.1) reduces to the multicomponent Langmuir adsorption isotherm, represented by Equation (5.4).

$$
q_{i}=\frac{a_{i 0} C_{i}}{1+\sum_{j=1}^{n} a_{i} C_{i}}
$$

Yoshida et al. (1990) successfully modelled the equilibrium adsorption of three different amine paints, from a multicomponent electrodeposition wastewater, onto a hydrogenform ion-exchange resin, using a Langmuir isotherm. The isotherm was then used to predict the breakthrough curves for the adsorption of each component from a resin column. 
The Freundlich adsorption isotherm, represented by Equation (5.5), yields from Equation (5.2) as a special case when the parameter $c_{i}$ is identically zero.

$$
q_{i}=\frac{a_{10} C_{1}^{b_{10}-b_{11}}}{a_{11}}
$$

Tamon and co-workers (Tamon et al., 1990) successfully used a Freundlich type adsorption isotherm to predict the multicomponent adsorption equilibria of uranium from seawater onto an amidoxime resin. McKay and Al Duri (1989) studied the multicomponent adsorption of three basic dye systems and the mathematical modelling thereof. The empirical Freundlich adsorption isotherm proved to be most accurate in predicting the isotherms for the bisolute systems compared with the predictions of the Langmuir adsorption and the Redlich-Peterson relationship.

Various other researchers have also used the Freundlich isotherm with great success in the modelling of adsorption systems for various species. This isotherm has also been used to model the diffusion kinetics of various adsorption processes (Gutsche and Yoshida et al., 1994; Higashi et al., 1963; Ruthven and Derrah, 1972; Gutsche et al., 1985; Kapoor and Yang, 1991).

There are several other empirical and semi-empirical models available in the literature. Very few of these models are applicable to the ion-exchange adsorption process, which is best described by the use of thermodynamic based models. For the purposes of this dissertation no further detailed discussion of the other empirical equations will be presented here.

\subsection{THERMODYNAMIC BASED EQUILIBRIUM MODELS}

The sorption behaviour of strong electrolytes is quite different from that of weak and nonelectrolytes when adsorbed by ion-exchange resins. Strong electrolytes are subject to the 
electrostatic forces arising from the presence of the fixed ionic groups on the polymer matrix of the ion-exchange resin. Since this thesis is mainly concerned with the sorption of strong electrolytes, very little attention will be given to the effect of non-electrolytes on the exchange equilibrium. Ion-exchange equilibrium data are usually best described in terms of the sorption isotherms and distribution coefficients. The sorption isotherm of a particular ion-exchanger describes the dependence of the equilibrium loading of a particular species in the ion-exchanger on the concentration of the species in the external solution for a given set of physical parameters, such as temperature and pressure.

A general stoichiometric equation for the sorption of ions between a solution phase and an ion-exchange resin phase is given by Equation (5.6),

$$
v_{A}\left[\left(R^{-}\right)_{z_{A}} A^{z_{A}}\right\rfloor+v_{B} B^{z_{B}} \longleftrightarrow v_{B}\left[\left(R^{-}\right)_{z_{B}} B^{z_{B}}\right\rfloor+v_{A} A^{z_{A}}
$$

where $R$ represents the solid polymer resin matrix and $z_{A}$ and $z_{B}$ are the valences of the ionic species and $B^{z_{B}}$ respectively. Only ions $A^{z_{A}}$ are initially present in the ionexchanger and ions $B^{z_{B}}$ in the external solution. The stoichiometric coefficients $v_{A}$ and $v_{B}$ are defined as follows:

$$
\begin{array}{ll}
\text { IF } \quad & \left|z_{A}\right| \neq\left|z_{B}\right| \quad \text { Then } \\
& v_{A}=\left|z_{B}\right| \text { and } v_{B}=\left|z_{A}\right| \\
\text { ELSE } & v_{A}=v_{B}=1
\end{array}
$$

Equation (5.6) can be represented in a simplified form by Equation (5.7),

$$
z_{B} R A+z_{A} B \leftrightarrow z_{A} R B+z_{B} A
$$


Where $R A$ and $R B$ represent the presence of species $A^{z_{A}}$ and $B^{z_{B}}$ in the ion-exchanger phase respectively. At equilibrium the condition is denoted by Equation (5.8), which is analogous to Equation (2.12) of Chapter 2 of this dissertation.

$$
z_{B} \mu_{R A}+z_{A} \mu_{B}=z_{A} \mu_{R B}+z_{B} \mu_{A}
$$

The chemical potential of a species in aqueous solution can be thermodynamically described in terms of its solution phase activity, $a_{i}$. The chemical potential of species $i$ in a multicomponent mixture is defined by Equation (5.9) in terms of its activity $a_{i}$, as

$$
\mu_{i}=\mu_{i}^{o}+R T \ln \left(a_{i}\right)
$$

Where $\mu_{i}^{o}$ is the reference chemical potential or the standard chemical potential of an arbitrarily chosen standard state. In an ideal solution, where the components in the multicomponent solution do not influence one another, the activities of the components are equal to their concentrations. In a real electrolyte solution the activity of a component is not equal to its concentration, due the non-ideal behaviour caused by the interactions between the different components. The activity of a particular species, behaving nonideally, is expressed as a product of its concentration and a term representing the deviation from ideality at the given concentration, represented by Equation (5.10).

$$
a_{i}=C_{i} \gamma_{i}
$$

$C_{i}$ is the molar solution phase concentration and $\gamma_{i}$ the molar solution phase activity coefficient of species $i$. For ideal bulk solution phase conditions the activity coefficients of all the dissolved ionic species are equal to unity, hence the activity of a particular species is equal to its solution phase concentration. This is usually the case for dilute aqueous electrolyte solutions, where ideal behaviour of the dissolved ionic species in the solution phase is assumed. Substituting Equation (5.10) and Equation (5.9) into Equation 
(5.8) gives the general expression for the ion-exchange equilibrium reaction, defined by Equation (5.11)

$$
\begin{aligned}
& z_{B}\left(\mu_{R A}^{0}+R T \ln \left(C_{R A} \mu_{R A}\right)\right)+z_{A}\left(\mu_{B}^{0}+R T \ln \left(C_{B} \mu_{B}\right)\right)= \\
& z_{A}\left(\mu_{R B}^{0}+R T \ln \left(C_{R B} \gamma_{R B}\right)\right)+z_{B}\left(\mu_{A}^{0}+R T \ln \left(C_{A} \gamma_{A}\right)\right)
\end{aligned}
$$

Equation (5.11) can be simplified to Equation (5.12).

$$
z_{B} \mu_{R A}^{0}+z_{A} \mu_{B}^{0}-z_{A} \mu_{R B}^{0}-z_{B} \mu_{A}^{0}=R T \ln \left(\frac{\left(C_{R B} \gamma_{R B}\right)^{z A}\left(C_{A} \gamma_{A}\right)^{z B}}{\left(C_{R A} \gamma_{R A}\right)^{z B}\left(C_{B} \gamma_{B}\right)^{z A}}\right)
$$

The partial molar Gibbs free energy, $\overline{G_{i}^{0}}$, is also known and defined as the chemical potential, $\mu_{i}^{0}$, at the same arbitrarily chosen standard state. Tabulations of the partial molar Gibbs free energy are available in the form of tabulations of $\Delta G_{f}^{0}$, which represents the free energy when one gram-formula weight of the substance is formed, isothermally at the indicated temperature of the standard state (Zemaitis et al., 1986). Equation (5.12) can be simplified to Equation (5.13) by substituting the partial molar Gibbs free energy for the reference chemical potential of each particular species at the reference conditions.

$$
\frac{\left[z_{B} \Delta G_{f R A}^{0}+z_{A} \Delta G_{f B}^{0}-\left(z_{A} \Delta G_{f R B}^{0}+z_{B} \Delta G_{f A}^{0}\right)\right]}{R T}=\ln \left(\frac{\left(C_{R B} \gamma_{R B}\right)^{z A}\left(C_{A} \gamma_{A}\right)^{z B}}{\left(C_{R A} \gamma_{R A}\right)^{z B}\left(C_{B} \gamma_{B}\right)^{z A}}\right)
$$

The true thermodynamic equilibrium constant for the ion-exchange reaction given by Equation (5.6), is therefore defined as: 


$$
K_{A B}=\exp \left(\frac{z_{B} \Delta G_{f R A}^{0}+z_{A} \Delta G_{f B}^{0}-\left(z_{A} \Delta G_{f R B}^{0}+z_{B} \Delta G_{f A}^{0}\right)}{R T}\right)
$$

Substituting Equation (5.14) into Equation (5.13) and simplifying gives the expression for the thermodynamic equilibrium constant of the ion-exchange reaction in terms of the species concentration and activity coefficients in the solution and resin phase, given by Equation (5.15)

$$
K_{A B}=\left(\frac{\left(C_{R B} \gamma_{R B}\right)^{z A}\left(C_{A} \gamma_{A}\right)^{z B}}{\left(C_{R A} \gamma_{R A}\right)^{z B}\left(C_{B} \gamma_{B}\right)^{z A}}\right)
$$

The equilibrium constant, $\mathrm{K}_{\mathrm{AB}}$, for the ion-exchange reaction may therefore be calculated from the Gibbs free energy change for the exchange reaction from Equation (5.14) if the values for the individual or overall Gibbs free energy changes are known.

Existing models using stoichiometry and separation factors to predict multicomponent ion-exchange equilibria fall into three main classes. Models of the first type assume that the entire system behaves ideally, i.e. the activity coefficients of all the components in the system in both the resin and solution phase are taken equal to unity. Equilibrium models of the second type assume that any other counter ions present in the multicomponent system do not affect the equilibrium condition between exchanging counter ions, i.e. there exists no ionic or electrostatic interactions between exchanging ions and other counter ions. This assumption may be a good approximation for the external solution phase at low ionic concentrations, but does not hold well for the resin phase in equilibrium with this solution phase, for a number of reasons. Firstly, the total resin phase equilibrium ionic concentration is much higher than the total solution phase concentration, and is roughly equal to the resin phase exchange capacity. Secondly, the swelling effects, induced by the other counter ions on the resin matrix, are affecting the capacity of the ionexchanger to a significant extent. Equilibrium models of the third type do not make any 
of the above assumptions for any of the two phases in the system and should therefore be more accurate in predicting the equilibrium behaviour.

\subsubsection{The ion-exchange isotherm}

The simplest way in which ion-exchange equilibria can be characterised is by means of the graphical ion-exchange isotherm, which covers all possible experimental conditions (total solution concentration, equivalent ionic fraction of each species, etc.) at a given temperature. The ion-exchange isotherm shows the equivalent ionic fraction, $y_{A}$, of the counter ion $A^{z_{A}}$ in the ion-exchange resin as a function of the equivalent fraction of $A^{z_{A}}$, $x_{A}$, in the solution for a specific set of experimental conditions. The equivalent ionic fraction, $x_{i}$, of species $i$ is defined as

$$
x_{i}=\frac{\left|z_{i}\right| m_{i}}{\sum_{k}\left|z_{k}\right| m_{k}}
$$

where the summation is carried out over all the counter ion species $\mathrm{k}$ which includes species $i$, where $m_{i}$ represents the molality and $z_{i}$ the electrochemical valence of species $i$.

\subsubsection{Ion-exchange affinity and selectivity represented by the separation factor}

Ion-exchange selectivity is defined as the preference an ion-exchanger has for one counter ion compared with another one. The preference of the ion-exchanger for a specific counter ionic species can be expressed by the separation factor

$$
\alpha_{B}^{A}=\frac{\bar{C}_{A} C_{B}}{\bar{C}_{B} C_{A}}=\frac{\overline{x_{A} x_{B}}}{\overline{x_{B} x_{A}}}
$$


where $A^{z_{A}}$ and $B^{z_{B}}$ are the two counter ionic species, $x$ the ionic fraction and quantities with bars refer to properties inside the ion-exchanger bead.

The ion-exchanger has a greater affinity for $B^{z_{B}}$ compared with species $A^{z_{A}}$ if the value of $\alpha_{A}^{B}$ is larger than unity and prefers $A^{z_{A}}$ if the value of $\alpha_{A}^{B}$ is less than unity. There are various physical causes for this preference of an ion-exchanger for one counter ionic species compared with another. One of the most important factors is the effect of electrostatic interactions between different competing ions.

The ion-exchange process itself is largely governed by electrostatic interactions between the different competing ions, and these ions and the fixed functional groups of the polymer matrix. Ions in aqueous solutions are hydrated, the degree of which is dependent on their "Ionic Potential", defined as the ratio of their valence to their ionic radius (Equation (5.18)).

$$
\text { IonicPotential }=\frac{z}{r}
$$

The degree of hydration of a specific ionic species is therefore proportional to its valence $\mathrm{z}$, and inversely proportional to its ionic radius $r$. The greater the value of the ionic potential, the stronger are the electrostatic forces between the species and the fixed functional groups (opposite electrostatic charges), hence the higher the selectivity for the specific species.

\subsubsection{Ion-exchange equilibrium represented by equilibrium constants}

Klein et al. (1967) proposed the following equilibrium model, represented by Equation (5.19), for the binary exchange reaction described by Equation (5.6), assuming that the entire system behaves ideally. 


$$
K_{A}^{B}=\left(\frac{x_{A}}{y_{A}}\right)^{v_{A}}\left(\frac{y_{B}}{x_{B}}\right)^{v_{B}}
$$

where $x_{i}$ and $y_{i}$ are the liquid and resin phase mole fractions of species $i$ respectively. The equilibrium coefficient, $K_{A}^{B}$, is simply the definition of the reaction equilibrium constant for an ideal system. The value of the equilibrium coefficient is taken to be constant at constant
i) system temperature and pressure,
ii) total solution phase ionic concentration, I, and
iii) solution phase composition (number of different species)

for the same type of ion-exchanger, whereas the reaction equilibrium constant is a function of temperature only.

Vermeer et al. (1975) modelled the ion-exchange equilibria for the ternary system of $\mathrm{H}^{+}$$\mathrm{Na}^{+}-\mathrm{Ca}^{+2}$ in a $0.1 \mathrm{~N}$ and $5 \mathrm{~N} \mathrm{HCl}$ regenerant solution with the use of Equation (5.19). The developed equilibrium model for this cation-exchange system was used to study the column behaviour in a desalination process with $\mathrm{HCl}$ as a regenerant.

Novasad and Myers (1982) developed a thermodynamic model for ion-exchange equilibrium adsorption by defining a surface excess parameter that accounts for electrolyte sorption, which incorporates the "selectivity" term defined by Equation (5.19). They used the proposed model to predict the adsorption of $\mathrm{HNO}_{3}$ onto a weak base anionexchange resin, Amberlyst A21. 


\subsubsection{The ion-exchange selectivity coefficient}

Kataoka and Yoshida (1980) proposed a model of the second type that accounted for the non-idealities in the solution phase but which assumed fully ideal behaviour of the species in the resin phase. They successfully modelled various ternary ion-exchange equilibrium systems using a modified form of Equation (5.20). Models of this type incorporate the effect of the solution phase non-idealities by using the selectivity coefficient $K_{A}^{B}$,

$$
\begin{aligned}
K_{A}^{B} & =\left(\frac{a_{A}}{y_{A}}\right)^{v_{A}}\left(\frac{y_{B}}{a_{B}}\right)^{v_{B}} \\
& =\left(\frac{C_{A}}{y_{A}}\right)^{v_{A}}\left(\frac{y_{B}}{C_{B}}\right)^{v_{B}} \frac{\gamma_{A}^{v_{A}}}{\gamma_{B}^{v_{B}}}
\end{aligned}
$$

where $a_{i}$ and $y_{i}$ represent the solution phase activity and resin phase mole fraction of species $i$ respectively.

The selectivity coefficient is constant and independent of composition when the liquid and resin phases are both ideal, or when the non-idealities in the two phases cancel (Vermeer et al., 1975). It is often experienced that the selectivity coefficient is dependent on the resin phase composition. This dependence is a consequence of the ionic and molecular interactions that exist in the concentrated electrolyte solutions inside the resin phase (Marton and Inczedy, 1988). Marton and Inczedy (1988) also showed that, when a suitable model for the concentrated electrolyte resin solution is introduced into a formal thermodynamic derivation of the selectivity coefficient, a theoretical equation can be obtained for the composition dependence of the selectivity coefficient.

Haub and Foutch (1986) modelled mixed-bed ion-exchange equilibria and kinetics with the use of a selectivity coefficient at concentrations approaching the dissociation of water, 
taking into consideration factors such as the dissociation of water, the ratio of cationic to anionic resins, differing resin exchange rates as well as differing resin capacities. Manning and Meisheimer (1983) modelled binary and ternary ion-exchange equilibria for a perfluorosulphonic acid membrane using the selectivity coefficient. Kataoka and Yoshida (1980) also successfully modelled various ternary ion-exchange equilibria systems with the use of a selectivity coefficient, as defined by Equation (5.20).

\subsubsection{The ion-exchange thermodynamic equilibrium constant}

Sengupta and Paul (1985) defined the true thermodynamic equilibrium constant for the ion-exchange reaction (Equation (5.21)) when the species in both the resin and solution phase behave non-ideally,

$$
\begin{aligned}
K_{A}^{B} & =\left(\frac{a_{A}}{\overline{a_{A}}}\right)^{v_{A}}\left(\overline{\frac{a_{B}}{a_{B}}}\right)^{\gamma_{B}} \\
& =\left(\frac{C_{A}}{y_{A}}\right)^{v_{A}}\left(\frac{y_{B}}{C_{B}}\right)^{v_{B}}\left(\frac{\gamma_{A}}{\overline{\gamma_{A}}}\right)^{\gamma_{A}}\left(\overline{\frac{\gamma_{B}}{\gamma_{B}}}\right)^{\nu_{B}}
\end{aligned}
$$

where $a_{i}$ and $\overline{a_{i}}$ represent the chemical activities of the ionic species in the external solution and resin respectively.

Perona (1993) modelled the ion-exchange sorption of $\mathrm{Sr}$ and $\mathrm{Cs}$ from wastewater onto chabazite zeolites using the thermodynamic equilibrium constant of Equation (5.21) for the five component system of Sr-Cs-Ca-Mg-Na. Perona (1993) also applied Equation (5.21) successfully to the different binary, ternary and quaternary systems comprising the five component system. Mehablia et al. (1994) developed a model for the prediction of multicomponent ion-exchange equilibria from binary systems, which used the thermodynamic equilibrium constant obtained from the Gaines and Thomas (1953) approach. The model was successfully applied to the binary and ternary systems of $\mathrm{H}^{+}$, 
$\mathrm{Na}^{+}, \mathrm{K}^{+}$and $\mathrm{Ca}^{+2}$. Allen and Addison (1990) predicted the ion-exchange equilibria of various ternary ion-exchange systems from measured binary equilibrium data using the thermodynamic equilibrium constant (Equation (5.21)) together with the Wilson equation in which the Hala constraint was incorporated. De Lucas Martinez et al. (1993) used the thermodynamic equilibrium constant to successfully predict most of the binary ionexchange equilibria for different combinations of the systems of $\mathrm{Ca}^{+2}, \mathrm{Mg}^{+2}, \mathrm{~K}^{+}, \mathrm{Na}^{+}$and $\mathrm{H}^{+}$on Amberlite IR-120.

Elprince and Babcock (1975), Shallcross et al. (1988), Allen et al. (1989) and Melis et al. (1995) are some of the other numerous investigators who used the thermodynamic equilibrium constant in various forms to model equilibria in various multicomponent ionexchange electrolyte systems.

Model predictions of ion-exchange equilibria using the thermodynamic equilibrium constant described by Equation (5.21) are strongly dependent on the values used for the solution and resin phase activity coefficients. Various models have been proposed in the literature with which the activity coefficients of the species in the solution and resin phases can be evaluated. Chapter 3 covered most of the prominent solution phase activity coefficient models currently available for the prediction of aqueous solution phase activity coefficients of electrolytes in multicomponent systems.

Simple models to predict the activity coefficients of ionic species in the solution phase in an ion-exchange system often use the equations based upon the Debye-Hückel method. Smith and Woodburn (1978) and Chakravarti and Fritzsch (1988) described the solution phase activity coefficients of species of aqueous electrolyte solutions in an ion-exchange system with an extended form of the Debye-Hückel equation, first proposed by Guggenheim (1935). Pitzer $(1979 ; 1991)$ proposed a model for the estimation of the activity coefficients of single ionic species in a multicomponent aqueous electrolyte solution, which incorporates terms that relate to both binary and ternary interactions between the ions, as well as a Debye-Hückel electrostatic term. Shallcross et al. (1988) 
and Mehablia et al. (1994) showed that the Pitzer ion-interaction model could accurately predict the non-idealities in the aqueous solution phase by calculating the activity coefficients for the different ionic species in an ion-exchange system.

\subsection{MODEL PREDICTIONS OF THE SOLUTION PHASE ACTIVITY COEFFICIENTS}

The sorption behaviour of strong electrolytes is quite different from that of weak and nonelectrolytes when adsorbed by ion exchange resins. Strong electrolytes are subject to the terms that relate to both binary and ternary interactions between the ions as well as a Debye-Hückel electrostatic term. Simple models to predict the activity coefficients of ionic species in the solution phase in an ion exchange system therefore often use the equations based upon the Debye-Hückel method. Smith and Woodburn (1978) and Chakravarti and Fritzsch (1988) described the solution phase activity coefficients of species of aqueous electrolyte solutions in an ion exchange system with an extended form of the Debye-Hückel equation, first proposed by Guggenheim (1935). Pitzer (1979; 1991) proposed a model for the estimation of the activity coefficients of single ionic species in a multicomponent aqueous electrolyte solution which incorporates terms that relate to both binary and ternary interactions between the ions as well as a Debye-Hückel electrostatic term. Shallcross et al. (1988) and Mehablia et al. (1994) have shown that the Pitzer ion-interaction model can accurately predict the non-idealities in the aqueous solution phase by calculating the activity coefficients for the different ionic species in an ion exchange system.

The Pitzer equation has various terms that take into account the various interactions between the different ions in an aqueous electrolyte solution. For the purposes of this dissertation the Pitzer equation has been separated into its various parts and a detailed breakdown of the equation is shown in Appendix $\mathrm{C}$ of this dissertation. The equation has been defined for various types of aqueous electrolyte systems of different compositions. The aqueous system is typically defined as MX-NY systems, where $\mathrm{M}$ and $\mathrm{N}$ are two 
different cations and $\mathrm{X}$ and $\mathrm{Y}$ two different anions. The detailed equations for the systems MX-NY, MX-NX and MX-MY have been derived from the general Pitzer equation describing the single anion and cation activity coefficient, given by Equations (4) and (5) of Appendix C.

The detailed equations have been derived for the system MX-NY, described by Equations (57) to (60) of Appendix C. This system contains two different cations and two different anions in solution. The system MX-NX is described by Equations (61) to (63) in Appendix C. This system contains two different cations but only one anion. The system MX-MY is described by Equations (64) to (66) in Appendix C. This system contains only one cation and two different anions.

The "BRAC" term found in Equations (57) to (66) of Appendix C is an abbreviation for "Bracket". The "BRAC" terms are defined by Equation (45) to Equation (56) of Appendix $C$. The " $B$ " and " $C$ " terms used in the "BRAC" equations are defined by Equation (31) to Equation (44) of Appendix C. This sequential breakdown of the Pitzer terms enables the user to easily construct the Pitzer equation for an aqueous electrolyte solution of specific composition.

\subsection{MODEL PREDICTIONS OF THE RESIN PHASE ACTIVITY COEFFICIENTS}

During an ion-exchange reaction, the ionic strength of both the external solution phase and internal resin phase does not remain constant as a consequence of ionic and molecular interactions (Marton and Inczedy, 1988). The resin phase should always be viewed as a concentrated electrolyte solution, with non-idealities in the solid phase that are similar to those encountered in concentrated electrolyte solutions. This suggests that the non-idealities in the solid resin phase may be described by ionic-solution theory, to the extent that it has been developed for highly concentrated solution phases (Vermeer et al., 1975). 
The resin phase activity coefficients for an ion-exchange system have been successfully modelled by several workers (Smith and Woodburn (1978); Vazquez Una et al. (1985); Chakravarti and Fritzsch (1988) and Shallcross et al. (1988)) using the model developed by Wilson (1964) for the excess Gibbs free energy.

Prausnitz et al. (1967) successfully applied the Wilson equation to vapour-liquid equilibria, which makes use of the excess Gibbs free energy of the system. The excess Gibbs energy is defined as the difference between the Gibbs free energy of the actual mixture, and the same mixture considered to be ideal under the same physical conditions (temperature, pressure and composition), as represented by Equation (5.22):

$\Delta G^{E}=G\left(\right.$ actual mixture $\left.T, P, N_{j}\right)-G\left(\right.$ ideal mixture $\left.T, P, N_{j}\right)$

The Wilson equation has the second advantage that its original development was as an athermal solution theory, thus making it especially applicable to ion-exchange calculations since heats of reaction in ion-exchange are almost always small (Allen et al., 1989). For the resin phase, the Wilson equation is defined as,

$$
\frac{\Delta G^{E}}{R T}=\sum_{i=1}^{M} y_{m i} \ln \left(\sum_{j=1}^{M} \Lambda_{i j} y_{m i}\right)
$$

where $y_{m i}$ is the mole fraction of species $i$ in the resin phase, $M$ the number of exchanging counter-ion species and $\Lambda_{i j}$ are the Wilson binary interaction parameters, defined such that $\Lambda_{i j}=1$ when $i=j$ and $\Lambda_{i j}>0$ when $i \neq j$. For an ideal resin phase $\Lambda_{i j}$ $=\Lambda_{j i}$ for all $i$ and $j$ and any deviation of the parameters from unity is an indication of the non-ideality of the resin phase. Differentiation of Equation (5.23) with respect to $n_{i}$, the number of moles of species $i$ in the resin phase, yields Equation (5.24) from which the resin phase activity coefficient can be calculated. 


$$
\ln \left(\overline{\gamma_{i}}\right)=1-\ln \left(\sum_{j=1}^{M} y_{m j} \Lambda_{i j}\right)-\sum_{k=1}^{M}\left(\frac{y_{m k} \Lambda_{k i}}{\sum_{j=1}^{M} y_{m j} \Lambda_{k j}}\right)
$$

With Equation (5.24) the resin phase activity coefficient of species $i, \overline{\gamma_{i}}$, can be calculated given that the Wilson binary interaction coefficients, $\Lambda_{i j}$, are known for the ion-exchange system.

For a single binary system Equation (5.24) reduces to Equations (5.25) and (5.26) for species 1 and 2 respectively.

$$
\begin{aligned}
& \ln \bar{\gamma}_{1}=1-\ln \left(y_{1}+y_{2} \Lambda_{12}\right)-\left(\frac{y_{1}}{y_{1}+y_{2} \Lambda_{12}}+\frac{y_{2} \Lambda_{21}}{y_{1} \Lambda_{21}+y_{2}}\right) \\
& \ln \overline{\gamma_{2}}=1-\ln \left(y_{1} \Lambda_{21}+y_{2}\right)-\left(\frac{y_{1} \Lambda_{12}}{y_{1}+y_{2} \Lambda_{12}}+\frac{y_{2}}{y_{1} \Lambda_{21}+y_{2}}\right)
\end{aligned}
$$

Elprince and Babcock (1975); Smith and Woodburn (1978); Shallcross et al. (1988); Allen et al. (1989); Allen and Addison (1990) and Mehablia et al. (1992) all used a method to calculate the values for the Wilson binary interaction coefficients, along with the value of the thermodynamic equilibrium constant $K_{A}^{B}$, from a single binary system by defining an equilibrium quotient, $\lambda_{A}^{B}$, for each ion-exchange reaction as:

$$
\lambda_{A}^{B}=\left(\frac{y_{B}}{\gamma_{B} C_{B}}\right)^{v_{B}}\left(\frac{\gamma_{A} C_{A}}{y_{A}}\right)^{v_{A}}
$$


Where $C_{i}$ is the solution phase concentration for species $i, q_{i}$ the equivalent mole fraction of species $i$ in the resin phase and $\gamma_{i}$ the solution phase activity coefficient of species $i$. The equilibrium quotient is related to the equilibrium constant by

$$
\lambda_{A}^{B}=K_{A}^{B} \frac{\bar{\gamma}_{A}^{v_{A}}}{\bar{\gamma}_{B}^{v_{B}}}
$$

Taking the natural logarithms of Equation (5.28) on both sides yields

$$
\ln \left(\lambda_{A}^{B}\right)=\ln \left(K_{A}^{B}\right)+v_{A} \ln \left(\overline{\gamma_{A}}\right)-v_{B} \ln \left(\overline{\gamma_{B}}\right)
$$

For the binary system containing only species $A^{z_{A}}$ and $B^{z_{B}}$ the resin phase activity coefficients, as described by the Wilson equation (Equations (5.24) to (5.26)), is as follows

$$
\ln \left(\overline{\gamma_{A}}\right)=1-\ln \left(y_{A}+y_{B} \Lambda_{A B}\right)-\left(\frac{y_{A}}{y_{A}+y_{B} \Lambda_{A B}}+\frac{y_{B} \Lambda_{B A}}{y_{A} \Lambda_{B A}+y_{B}}\right)
$$

And

$$
\ln \left(\overline{\gamma_{B}}\right)=1-\ln \left(y_{A} \Lambda_{B A}+y_{B}\right)-\left(\frac{y_{A} \Lambda_{A B}}{y_{A}+y_{B} \Lambda_{A B}}+\frac{y_{B}}{y_{A} \Lambda_{B A}+y_{B}}\right)
$$

Substitution of the Wilson equation for species $A^{z_{A}}$ and $B^{z_{B}}$, Equations (5.30) and (5.31), into Equation (5.29) yields Equation (5.32) containing three unknown parameters, the thermodynamic equilibrium constant and the two interaction parameters. 


$$
\begin{aligned}
\ln \lambda_{A B}=\ln K_{A}^{B}+v_{A}\left[1-\ln \left(y_{A}+y_{B} \Lambda_{A B}\right)-\left(\frac{y_{A}}{y_{A}+y_{B} \Lambda_{A B}}+\frac{y_{B} \Lambda_{B A}}{y_{A} \Lambda_{B A}+y_{B}}\right)\right] \\
-v_{B}\left[1-\ln \left(y_{A} \Lambda_{B A}+y_{B}\right)-\left(\frac{y_{A} \Lambda_{A B}}{y_{A}+y_{B} \Lambda_{A B}}+\frac{y_{B}}{y_{A} \Lambda_{B A}+y_{B}}\right)\right]
\end{aligned}
$$

Rearranging Equation (5.32) yields Equation (5.33). The form of Equation (5.33) was used in the modelling of the Resin-in-Pulp (RIP) slurry mixture system as described in the consolidated model in Chapter 6 of this dissertation.

$$
\begin{aligned}
\ln \left(\lambda_{A}^{B}\right)= & \ln \left(K_{A}^{B}\right)+\left(v_{A}-v_{B}\right) \\
& -v_{A} \ln \left(y_{A}+\Lambda_{A B}\left(1-y_{A}\right)\right)+v_{B} \ln \left(y_{A} \Lambda_{B A}+1-y_{A}\right) \\
& -\frac{y_{A}\left(v_{A}-v_{B} \Lambda_{A B}\right)}{y_{A}+\Lambda_{A B}\left(1-y_{A}\right)}-\frac{\left(1-y_{A}\right)\left(v_{A} \Lambda_{B A}-v_{B}\right)}{y_{A} \Lambda_{B A}+1-y_{A}}
\end{aligned}
$$

A search procedure is used to fit the three parameters to the equilibrium data that minimise the sum of squares of the deviations between experimental equilibrium quotients (Equation (5.27)) and predicted equilibrium quotients (Equation (5.33)). With the binary interaction parameters known, the resin phase activity coefficients of the species can be calculated from Equations (5.30) and (5.31).

Several workers using the Wilson equation have successfully modelled the resin phase activity coefficients for various ion-exchange systems. Smith and Woodburn (1978) modelled the ternary system $\mathrm{Cl}^{-}-\mathrm{NO}_{3}{ }^{-}-\mathrm{SO}_{4}{ }^{2-}$ on Amberlite IRA 400 using the model developed by Wilson (1964) for the excess Gibbs free energy. Mehablia et al. (1992) modelled the resin phase non-idealities for the ternary system $\mathrm{K}^{+}-\mathrm{Na}^{+}-\mathrm{H}^{+}$with $\mathrm{Cl}^{-}$using the Wilson equation, while the solution phase non-idealities were accounted for with the Pitzer model. Shallcross et al. (1988) followed essentially the same method as Smith and 
Woodburn in modelling the ternary system $\mathrm{Ca}^{+2}-\mathrm{Mg}^{+2}-\mathrm{Na}^{+}$on Amberlite 252; others included Vaquez Una et al. (1988) and Allen et al. (1990).

\subsection{CHOICE OF THE OBJECTIVE FUNCTION}

The values for the fitted binary interaction parameters and the thermodynamic equilibrium constant, whilst fitting the experimental data very well, are very sensitive to slight changes in the data. To minimise this effect of the data on the fitted parameters, various non-linear least-squares regression algorithms were used by the above mentioned researchers. Mehablia et al. (1994) fitted values for the three parameters by minimising the objective function $F$, defined as

$$
F=\sum_{i=1}^{N}\left(\frac{\lambda_{i}^{\exp }-\lambda_{i}^{f i t}}{\lambda_{i}^{\exp }}\right)^{2}
$$

Where $\mathrm{N}$ is the number of experimental data points and $\lambda_{i}^{\exp }$ is calculated from Equation (5.27) and $\lambda_{i}^{\text {fit }}$ is calculated from Equation (5.33). Various forms of Equation (5.34) are found in the literature. Smith and Woodburn (1978); Shallcross et al. (1988); Perona (1993) and Mehablia et al. (1994) used an objective function of the form as in Equation (5.34). Mehablia et al. (1992) used a modified version of Equation (5.34). The objective function of Equation (5.34) was slightly modified to the following form, represented by Equation (5.35).

$$
F=\frac{\sum\left[x_{i}\left(1-x_{i}\right) y_{i}\left(1-y_{i}\right)\right]^{2}\left(\frac{\lambda_{i}^{\exp }-\lambda_{i}^{f i t}}{\lambda_{i}^{\exp }}\right)^{2}}{\sum\left[x_{i}\left(1-x_{i}\right) y_{i}\left(1-y_{i}\right]^{2}\right.}
$$

Each data point is weighted according to where it falls on the binary equilibrium isotherm. The use of weighting recognises that when one of the phase compositions 
approaches an extreme (i.e. $x_{i} \rightarrow 0, x_{i} \rightarrow 1, y_{i} \rightarrow 0$ or $y_{i} \rightarrow 1$ ) then the experimental error associated with the data point will be much higher (Mehablia et al., 1994). This modified form of the objective was used due to the fact that it became evident that the quality and accuracy of the experimental data have a significant effect on the values of the parameters as calculated from Equation (5.33). Various other researchers (Nagahama et al. (1971); Kaliaguine and Ramalho (1972); Brinkman et al. (1974); Hiranuma and Honma (1975); Tao and Ceplecha (1986) and Jianmin et al. (1989)) have also studied the effect of different optimisation techniques and functions on the values of the calculated Wilson parameters, known as the resin phase activity coefficients for the purposes of this dissertation.

Perona (1993) modelled the ion-exchange equilibria for the five component system consisting of Sr-Cs-Ca-Mg-Na. The Wilson equation was used to model the resin phase non-idealities, but a different search procedure was used to fit the parameters of the Wilson model to the experimental data. Perona (1993) found that the search procedure used by the above-mentioned investigators to obtain the Wilson interaction parameters was not successful for the present five component system. It was found that the experimental values for the equilibrium quotients passed through a maximum when plotted against equivalent fraction in the solid phase. Theoretically calculated values for the equilibrium quotient could not be matched to the experimental values on both sides of the maximum, and the following objective function was used instead, defined as

$$
F=\frac{\sum_{i=1}^{N}\left(\frac{C_{i}^{\exp }-C_{i}^{\text {pred }}}{C_{i}^{\exp }}\right)^{2}}{N}
$$

where an iterative procedure was used to calculate the Wilson interaction parameters.

From the above discussion it is evident that the values of the estimated Wilson parameters depend upon the objective function which is used in the optimisation 
procedure. Brinkman et al. (1974) noted that by using the parameters estimated from binary data using a chosen objective function did not produce the best sum of squares of errors in a ternary system for the same objective function. Brinkman et al. (1974) studied the effect of different objective functions on the values of the Wilson parameters for binary systems, and how these results affect the prediction of the behaviour of ternary systems. Four different objective functions were used and it was concluded that there are no unique estimates of the Wilson parameters; they depend on the objective function used for evaluation. Jianmin et al. (1990) stated that the flexibility and symmetry of the Wilson equation imply that comparably good results can be obtained even though the choice of an objective function may be changed. Tao et al. (1986) also stated that the flexibility and symmetry of the different paired interaction parameters enhance the usefulness of the Wilson equation. Brinkman et al. (1974) extended their above mentioned investigation to that of binary and ternary systems employing the Hala constraint. It was found that the inclusion of the Hala constraint produced Wilson parameters, which predict the ternary system better than those without using the constraint for the three binary systems investigated. Nagahama et al. (1971) stated that when a large number of data points are available, a non-linear least-squares technique coupled with an objective function should be preferred to any other technique.

\subsection{SUMMARY}

It is evident from the above discussion that various models were used in the past by several researchers to model ion-exchange equilibria. The ones that proved to be most successful and applicable over a wide range of conditions (i.e. different solution concentrations and compositions) were the models with model parameters independent of the resin phase and solution phase composition. Models of this type are the thermodynamic based models, which outperformed the traditional empirical and semiempirical models, such as the Freundlich, Langmuir and Redlich-Peterson adsorption isotherms. 
From Chapter 4 it was also evident that ion-exchange equilibria are complex phenomena and influenced by various factors. One of the most important factors were the solution phase concentration and composition that strongly influence resin shrinking and swelling, which has a significant effect on the resin capacity and hence equilibrium loading. It can therefore be expected that empirical and semi-empirical models with model parameters that are not independent of composition will have difficulty to model ion-exchange equilibria over a wide range of conditions. From the above it is also evident that the resin phase itself can be viewed as a concentrated electrolyte solution, with non-idealities associated with it. The importance of the resin phase non-ideality was recognised by various researchers who incorporated it into the thermodynamic models.

It should also be mentioned that models based on statistical thermodynamics have been used by various researchers. Ruthen (1971) proposed the first statistical thermodynamic model for single component adsorption by replacing the configuration integrals with simplified expressions containing Henry's coefficients and molar volume. The model was later extended to binary adsorption equilibria (Ruthen et al., 1973). Due to underlying assumptions, the theory was applied successfully only to the adsorption of non-polar molecules of uniform size onto structured adsorbents such as zeolites. The model was later modified to account for the effect of polarisable species (Ruthen et al., 1985). Morbidelli et al. (1988) reduced Ruthen's model further by introducing subsystems containing a maximum of two adsorbate molecules. The configuration integrals of alike species were then fitted from single component data. A statistical thermodynamic theory for the adsorption of nitrogen and argon on carbon surfaces was developed by Heer (1971), using a grand canonical ensemble to describe monolayer adsorption.

Due to the computational intensity associated with these methods in modelling relatively simple adsorption systems (non-polar adsorption on highly structured adsorbents), and given the inherent complexities associated with ion-exchange equilibria (highly 
electrostatic driven adsorption), it was decided to not study these models in too much detail.

From the above discussion on various equilibrium models, it was decided that the most appropriate ion-exchange equilibria models for the purposes of this dissertation (studying the general fundamentals of ion-exchange dissolution of sparingly soluble species) are the thermodynamic models taking into account the non-idealities of both the resin and solution phases. 


\section{CHAPTER 6}

\section{COMPUTATIONAL PROCEDURES FOR THE CONSOLIDATED EQUILIBRIUM MODEL}

The previous chapters discussed the various equilibrium interactions and modelling techniques thereof that are of interest to the synthesis of the consolidated equilibrium model for a Resin-in-Pulp (RIP) slurry mixture system. In a typical RIP slurry mixture there are several equilibrium conditions between the different sparingly soluble, aqueous and ion-exchange resin phases. All of these equilibrium conditions will be discussed in more detail below with mathematical equations representing the various reactions. This chapter will deal with the formulation and synthesis of the consolidated equilibrium model for such a RIP slurry mixture system, making use of the various topics discussed in Chapter 1 to 5 . Chapter 7 will then deal with experimental procedures followed in the collection of experimental data used to estimate model parameters for the various RIP systems considered in this dissertation, while Chapters 8 to 11 will present the experimental results and model simulations for the RIP systems.

From Figure 1.1 in Chapter 1 it is evident that the consolidated equilibrium model needs to be able to account for various different scenarios that may be encountered depending on the system properties, i.e.

i) number of different types of ion-exchange resins (cation and or anion resins),

ii) initial resin ionic forms (valence of initial counter-ions present in the resin phases)

iii) amounts of the various phases, i.e. the volume of the solution, the volume of resins used and the amount of the sparingly soluble used,

iv) system extensive properties such as temperature

v) and the valences of the various species present in the various combinations of the different phases 
All of the above mentioned parameters will be included in the consolidated equilibrium model for the RIP slurry mixture system and the derivation thereof explained in this chapter. The derivation of the consolidated equilibrium model is performed by considering the various equilibrium conditions between the different phases and formulating appropriate mass balance equations as well as electroneutrality balances for the RIP system. All of these equations are shown below in more detail.

There are also several assumptions made in the synthesis of the consolidated equilibrium model for the RIP slurry mixture system. These assumptions are described in more detail below. It is important that the reader have a good understanding of the implications of these assumptions for the validity of the consolidated equilibrium model for various RIP system configurations that may be encountered. In order to understand the limitations of the assumptions it is necessary for the reader to have a good understanding of the detailed equations derived to describe the thermodynamic equilibrium conditions between the various phases (resin, aqueous solution and sparingly soluble phase) for different properties (valences and concentrations) of the species involved. The derivation of some of these equations is showed in more detail in Appendix B of this dissertation. It will become evident from these equations that the solubility and recovery of the sparingly soluble solid depend significantly on both the ion-exchange thermodynamic equilibrium constant and the solubility product (equilibrium constant) of the solid. Both of these constants depend on the activities of the species in the aqueous solution and resin phases as well as their valences.

\subsection{OBJECTIVES OF THIS CHAPTER}

The various phases involved in a typical Resin-in-Slurry mixture system have been discussed in detail in Chapter 1 and were schematically represented in Figure 1.1 of Chapter 1. The subsequent Chapters 2 to 5 have each discussed in more detail the various equilibrium conditions existing between the various phases and also discussed 
mathematical models that may be used to describe these equilibrium conditions. It will therefore be the objective of this chapter to combine all of these individual phase models into a single consolidated equilibrium model for the RIP slurry mixture system. The interfacing of the various models will be derived in this chapter and also the model equation solution methodology.

It is evident form the discussions of Chapters 1 to 5 that various model parameters need to be acquired form the literature and experimental work to be able to solve the mathematical equations as proposed in the various chapters. In order to ensure the consistency of the model parameters used as well as verifying the thermodynamic data obtained from various literature sources a SQL data base has been designed and populated with the data from the literature and the experimental work performed in this dissertation for the purpose of consistent model parameter estimations. This ensures that all model parameters used in the various individual models comprising the consolidated model are the same for the individual models where needs be. The structure of the database is also discussed in more detail in this chapter because of its importance to the solution of the model equations for the consolidated equilibrium model. The data base also enables the user of the model equations to extract the necessary model parameters required in a fast and efficient manner.

This chapter will further discuss in detail the mathematical procedures followed to solve the model equations of the consolidated equilibrium model. This procedure is discussed in detail and represented in schematic format for the purposes of this dissertation. The user of the models will therefore be able to trace the model calculations in detail and modify them with ease for the various RIP slurry mixtures systems of interest. 


\subsection{DEFINITION OF THE VARIOUS PHASES CONSIDERED IN THE CONSOLIDATED EQUILIBRIUM MODEL FOR A RIP SLURRY MIXTURE}

For the purposes of this dissertation the various phases of interest to the consolidated equilibrium model will be defined in this section and will be used according to the definitions in the synthesis of the consolidated equilibrium model for the RIP slurry mixture system. In order to do this a set of equations will be formulated representing a typical RIP slurry mixture system. The notation for the various phases and phase species will be used in the derivations of the consolidated model.

From Figure 1.1 (Chapter 1) it is evident that there are two types equilibrium interfaces between different phases and an additional two types of "internal phase equilibrium" considerations for a typical RIP slurry mixture system. These equilibrium conditions are defined as follows for the purposes of this dissertation.

i) The sparingly soluble solid / aqueous phase equilibrium condition (as discussed in Chapter 2 of this dissertation),

ii) The ion-exchange resin / aqueous phase equilibrium condition (as discussed in Chapter 5 of this dissertation),

iii) The "internal" aqueous phase equilibrium conditions that determine chemical speciation in the aqueous phase (as discussed in chapter 3 of this dissertation) and

iv) The "internal" resin phase composition equilibrium condition that determines the equilibrium condition between the "internal" ion-exchange resin pore liquid and the functional groups on the resin backbone (as discussed in Chapter 4 of this dissertation) 


\subsubsection{The dissolution reaction for the sparingly soluble solid}

To formulate the definitions of the various equilibrium conditions between the various phases as defined above more clearly, it is necessary to view the mathematical equations representing these equilibrium conditions more closely. The first reaction of interest is the dissociation reaction of a sparingly soluble solid BY in an aqueous slurry solution as given by Equation (6.1),

$$
\left[\left(B^{z_{B}}\right)_{v_{B}}\left(Y^{z_{Y}}\right)_{v_{Y}}\right]_{S} \stackrel{K_{s p}}{\longleftrightarrow} v_{B} B^{z_{B}}+v_{Y} Y^{z_{Y}}
$$

Where $v_{B}$ and $v_{Y}$ represent the number of moles of the cation $B$ and anion $Y$ that are formed when one mole of the sparingly solid completely dissolves.

As mentioned, the chemical composition of the Resin-in-Pulp (RIP) solution phase is changed during equilibrium attainment through the ion-exchange reaction, with the introduction of new chemical species that were initially restricted to the resin phase. This shift in the solution phase composition can alter the solubility of the sparingly soluble solid, which is a function of the solubility product constant for the species. The solubility of the cation, $B^{z_{B}}$, can be expressed as a function of the solubility product constant and the solution phase activity coefficients, represented in Equation (6.2).

$$
S=\left(\frac{K_{s p}}{\left[v_{B} \gamma_{B}\right]^{v_{B}}\left[\begin{array}{ll}
v_{Y} \gamma_{Y} \\
v^{v_{Y}}
\end{array}\right.}\right)^{\frac{1}{v_{B}+v_{Y}}}
$$

Equation (6.2) is derived in Chapter 2, Equation (2.34). If the solution phase behaves ideally the solubility for various types of sparingly soluble solids, as a function of the solubility product, is given by Table 2.2 . 
It is evident that the solubility $S$ of the cation must change with variations in its solution phase activity coefficient, $\gamma_{B}$, since the solubility product, $K_{s p}$, is constant for a given set of physical conditions, i.e. temperature, etc. The shift in electrolyte composition of the RIP solution phase with the introduction of alien species will inevitably change the solution phase activity coefficient of the cation. Natural multicomponent electrolyte solutions behave non-ideally, which are represented by the deviation in the value of the solution phase activity coefficients from unity. A decrease in the value of the activity coefficient of the cation in Equation (6.2), mathematically corresponds to a larger value in $S$ which relates to an increase in the solution phase concentration of the cation. This increase provides an additional mass transfer driving force for the sorption of the cation by the ion-exchanger.

However, an increase in the solution phase concentration of the cation $B^{z_{B}}$ is accompanied by an increase in the solution phase concentration of the anion $Y^{z_{Y}}$, which, according to Le Chatelier's principle will shift the dissolution reaction to the left. This shift in the equilibrium condition, activated by an increase in the concentration of the ion common to the equilibrium reaction, is called the common ion effect.

6.2.1.1 General considerations on the mathematical representation of the common-ion effect on the solubility of the sparingly soluble solid

The decline in the solubility of the sparingly soluble solid due to the common ion effect is represented by Equation (6.3), where the solution phase concentration of species $Y^{z_{Y}}$ has increased with $\mathrm{m}$ moles/litre.

$$
K_{s p}=\left[v_{B} S \gamma_{B}\right]^{v_{B}}\left[\left(v_{Y} S+m\right) \gamma_{Y}\right]^{\nu_{Y}}
$$

There are many possibilities to compensate for the common ion effect, which in principle involves the chemical transformation of the anion species $Y^{z_{Y}}$ to disguise it for the 
dissolution reaction involving the cation. This transformation can be effected with the use of a proper counter ion species, $A^{z_{A}}$, initially saturating the ion-exchange resin. If the anion species $Y^{z_{Y}}$ is the conjugate base of a weak acid, the solubility of the cation can be significantly enhanced if the cation exchange resin is initially used in the hydrogen ionic form. The exchanged hydrogen ions will form a weak acid with the anion $Y^{z_{Y}}$, represented by Equation (6.4),

$$
\left[\left(B^{z_{B}}\right)_{v_{B}}\left(Y^{z_{Y}}\right)_{v_{Y}}\right]_{S}+v_{Y} H^{+} \stackrel{K_{a}}{\longleftrightarrow} v_{B} B^{z_{B}}+v_{Y} H Y^{\left(z_{Y}+1\right)}
$$

With the enhanced solubility product constant given by Equation (6.5).

$$
K_{s p}=\frac{\left(a_{B}\right)^{v_{B}}\left(a_{H Y}\right)^{v_{Y}}}{\left(a_{H}\right)^{\nu_{Y}}}=\frac{K_{s p}}{\left(K_{a}\right)^{v_{a}}}
$$

It is evident that the smaller the value of the dissociation constant of the weak acid is, the larger the value of the enhanced solubility product will be.

Another possibility to counteract the common ion effect involves the precipitation of the anion species $Y^{z_{Y}}$ with the exchanged counter ion species $A^{z_{A}}$. This option will only be viable if electrolyte sorption by the ion-exchanger is virtually non-existent, especially towards the anion $Y^{z_{Y}}$. The obvious reason for this is the possibility of precipitation within the ion-exchanger pores, which will severely retard the sorption kinetics. Complete Donnan-exclusion of electrolytes holds extremely well for gel-type resins of moderately to high degrees of cross-linking, in which case precipitation can be used. In the case of macroporous ion-exchange resins, electrolyte sorption can be as much $2 \%$ of the total ionic species content inside the resin phase. Typical experimental results on these phenomena, gathered for the purposes of this dissertation, are presented in Chapter 8. If the pore liquid concentration of anion $Y^{z_{Y}}$ is high enough, precipitation might be triggered which render this possibility non-applicable. 
The solubility of the cation can be enhanced significantly with the use of RIP slurries employing mixtures of cation and anion exchange resins. There exists an optimum value for the ratio of the amounts of each of the resins used. The principal objective is to minimise the value of $\mathrm{m}$ in Equation (6.3). To do this, we must be able to quantitatively predict the distribution of the different species between the three phases (ore/solution/resin) for a multi-component mixture.

\subsubsection{The cation exchange reaction for the sorption of the dissolved cation species of the sparingly soluble solid}

The second reaction is the general ion-exchange reaction for the sorption of the dissolved cation of the sparingly soluble solid, ion $B^{z_{B}}$, onto a cation exchange resin initially in the ionic form containing counter ion $A^{z_{A}}$. The general expression for the sorption of the cation $B^{z_{B}}$ by the ion-exchanger, initially saturated with species $A^{z_{A}}$, is given in Equation (6.6).

$$
z_{B}\left[\left(R^{-}\right)_{z_{A}} A^{z_{A}}\right]+z_{A} B^{z_{B}} \stackrel{K_{A}^{B}}{\longleftrightarrow} z_{A}\left[\left(R^{-}\right)_{z_{B}} B^{z_{B}}\right]+z_{B} A^{z_{A}}
$$

Equation (6.6) reduces to different equations depending on the values of $z_{A}$ and $z_{B}$, the valences of the species. The thermodynamic equilibrium constant for the ion-exchange reaction is given by Equation (6.7),

$$
K_{A}^{B}=\frac{\left(y_{B} \bar{\gamma}_{B}\right)^{z_{A}}\left(C_{A} \gamma_{A}\right)^{z_{B}}}{\left(y_{A} \bar{\gamma}_{A}\right)^{z_{B}}\left(C_{B} \gamma_{B}\right)^{z_{A}}}
$$

Where $y_{i}$ and $C_{i}$ represents the resin phase mole fraction and solution phase concentration of species $i$ respectively. 


\subsubsection{The anion exchange reaction for the sorption of the dissolved anion species of the sparingly soluble solid}

The third reaction of interest is the general ion-exchange reaction for the sorption of the dissolved anion of the sparingly soluble solid, ion $Y^{z_{Y}}$, onto an anion exchange resin initially in the ionic form containing counter ion $E^{z_{E}}$, as given by Equation (6.8).

$$
z_{Y}\left[\left(R^{+}\right)_{z_{E}} E^{z_{E}}\right]+z_{E} Y^{z_{Y}} \stackrel{K_{E}^{Y}}{\longleftrightarrow} z_{E}\left[\left(R^{+}\right)_{z_{Y}} Y^{z_{Y}}\right]+z_{Y} E^{z_{E}}
$$

The thermodynamic equilibrium constant for the anion exchange reaction is given by Equation (6.9),

$$
K_{E}^{Y}=\frac{\left(y_{Y} \bar{\gamma}_{Y}\right)^{z_{E}}\left(C_{E} \gamma_{E}\right)^{z_{Y}}}{\left(y_{E} \bar{\gamma}_{E}\right)^{z_{Y}}\left(C_{Y} \gamma_{Y}\right)^{z_{E}}}
$$

For resin-in-pulp mixtures containing either a cation or an anion exchange resin only, the simultaneous dissolution and sorption reaction, that represents the overall process, can be found by the stoichiometric combination of the appropriate dissolution reaction, represented by Equations (6.1), and the appropriate ion exchange reaction, represented by Equation (6.6) or (6.8).

The various combinations of the concentration units for the different species may then also be expressed in terms of the solubility product, represented by Equation (6.2), and the thermodynamic equilibrium constants for the ion-exchange reaction, represented by Equations (6.7) or (6.9). 
Table 6.1 Thermodynamic dissolution coefficients for different resin-in-pulp mixtures containing a cation exchange resin only.

\begin{tabular}{|c|c|c|c|c|}
\hline $\begin{array}{c}\text { Dissolution } \\
\text { Reaction }\end{array}$ & $\begin{array}{c}\text { Cation } \\
\text { Exchange } \\
\text { Reaction } \\
\end{array}$ & $K_{s p}$ & $K_{A}^{B}$ & $K_{\text {diss }}$ \\
\hline$\left|z_{B}\right|=\left|z_{Y}\right|$ & $\begin{array}{c}\left|z_{B}\right|>\left|z_{A}\right|, \\
\left|z_{B}\right| /\left|z_{A}\right|= \\
\text { integer }\end{array}$ & $\left(a_{B}\right)\left(a_{Y}\right)$ & $\frac{\left(\overline{a_{B}}\right)\left(a_{A}\right)^{\frac{z_{B}}{z_{A}}}}{\left(\overline{a_{A}}\right)^{\frac{z_{B}}{z_{A}}}\left(a_{B}\right)}$ & $K_{s p} K_{A}^{B}$ \\
\hline$\left|z_{B}\right|=\left|z_{Y}\right|$ & $\begin{array}{c}\left|z_{\mathrm{B}}\right|>\left|\mathrm{z}_{\mathrm{A}}\right| \\
\left|\mathrm{z}_{\mathrm{B}}\right| /\left|\mathrm{z}_{\mathrm{A}}\right| \neq \\
\text { integer } \\
\text { or } \\
\left|\mathrm{z}_{\mathrm{A}}\right|>\left|\mathrm{z}_{\mathrm{B}}\right| \\
\left|\mathrm{z}_{\mathrm{A}}\right| /\left|\mathrm{z}_{\mathrm{B}}\right| \neq \\
\text { integer }\end{array}$ & $\left(a_{B}\right)\left(a_{Y}\right)$ & $\frac{\left(\overline{a_{B}}\right)^{z_{A}}\left(a_{A}\right)^{z_{B}}}{\left(\overline{a_{A}}\right)^{z_{B}}\left(a_{B}\right)^{z_{A}}}$ & {$\left[K_{s p}\right]^{z_{A}} K_{A}^{B}$} \\
\hline$\left|z_{B}\right|=\left|z_{Y}\right|$ & $\begin{array}{c}\left|z_{A}\right|>\left|z_{B}\right|, \\
\left|z_{A}\right| /\left|z_{B}\right|= \\
\text { integer }\end{array}$ & $\left(a_{B}\right)\left(a_{Y}\right)$ & $\frac{\left(\overline{a_{B}}\right)^{\frac{z_{A}}{z_{B}}}\left(a_{A}\right)}{\left(\overline{a_{A}}\right)\left(a_{B}\right)^{\frac{z_{A}}{z_{B}}}}$ & {$\left[K_{s p}\right]^{\frac{z_{A}}{z_{B}}} K_{A}^{B}$} \\
\hline$\left|z_{B}\right|=\left|z_{Y}\right|$ & $\left|z_{B}\right|=\left|z_{A}\right|$ & $\left(a_{B}\right)\left(a_{Y}\right)$ & $\frac{\left(\overline{a_{B}}\right)\left(a_{A}\right)}{\left(\overline{a_{A}}\right)\left(a_{B}\right)}$ & $K_{s p} K_{A}^{B}$ \\
\hline$\left|z_{B}\right| \neq\left|z_{Y}\right|$ & $\left|z_{B}\right|=\left|z_{A}\right|$ & $\left(a_{B}\right)^{z_{Y}}\left(a_{Y}\right)^{z_{B}}$ & $\frac{\left(\overline{a_{B}}\right)\left(a_{A}\right)}{\left(\overline{a_{A}}\right)\left(a_{B}\right)}$ & $K_{s p}\left[K_{A}^{B}\right]^{z_{Y}}$ \\
\hline$\left|z_{B}\right| \neq\left|z_{Y}\right|$ & $\begin{array}{c}\left|z_{B}\right|>\left|z_{A}\right|, \\
\left|z_{B}\right| /\left|z_{A}\right|= \\
\text { integer }\end{array}$ & $\left(a_{B}\right)^{z_{Y}}\left(a_{Y}\right)^{z_{B}}$ & $\frac{\left(\overline{a_{B}}\right)\left(a_{A}\right)^{\frac{z_{B}}{z_{A}}}}{\left(\overline{a_{A}}\right)^{\frac{z_{B}}{z_{A}}}\left(a_{B}\right)}$ & $K_{s p}\left[K_{A}^{B}\right]^{z_{Y}}$ \\
\hline$\left|z_{B}\right| \neq\left|z_{Y}\right|$ & $\begin{array}{c}\left|z_{\mathrm{B}}\right|>\left|z_{\mathrm{A}}\right| \\
\left|\mathrm{z}_{\mathrm{B}}\right| /\left|\mathrm{z}_{\mathrm{A}}\right| \neq \\
\text { integer } \\
\text { or } \\
\left|\mathrm{z}_{\mathrm{A}}\right|>\left|\mathrm{z}_{\mathrm{B}}\right|, \\
\left|\mathrm{z}_{\mathrm{A}}\right| /\left|\mathrm{z}_{\mathrm{B}}\right| \neq \\
\text { integer } \\
\end{array}$ & $\left(a_{B}\right)^{z_{Y}}\left(a_{Y}\right)^{z_{B}}$ & $\frac{\left(\overline{a_{B}}\right)^{z_{A}}\left(a_{A}\right)^{z_{B}}}{\left(\overline{a_{A}}\right)^{z_{B}}\left(a_{B}\right)^{z_{A}}}$ & {$\left[K_{s p}\right]^{z_{A}}\left[K_{A}^{B}\right]^{z_{Y}}$} \\
\hline$\left|z_{B}\right| \neq\left|z_{Y}\right|$ & $\begin{array}{c}\left|z_{A}\right|>\left|z_{B}\right|, \\
\left|z_{A}\right| /\left|z_{B}\right|= \\
\text { integer }\end{array}$ & $\left(a_{B}\right)^{z_{Y}}\left(a_{Y}\right)^{z_{B}}$ & $\frac{\left(\overline{a_{B}}\right)^{\frac{z_{A}}{z_{B}}}\left(a_{A}\right)}{\left(\overline{a_{A}}\right)\left(a_{B}\right)^{\frac{z_{A}}{z_{B}}}}$ & {$\left[K_{s p}\right]^{\frac{z_{A}}{z_{B}}}\left[K_{A}^{B}\right]^{z_{Y}}$} \\
\hline
\end{tabular}


Table 6.2 Thermodynamic dissolution coefficients for different resin-in-pulp mixtures containing an anion exchange resin only.

\begin{tabular}{|c|c|c|c|c|}
\hline $\begin{array}{c}\text { Dissolution } \\
\text { Reaction }\end{array}$ & $\begin{array}{c}\text { Anion } \\
\text { Exchange } \\
\text { Reaction } \\
\end{array}$ & $K_{s p}$ & $K_{E}^{Y}$ & $K_{\text {diss }}$ \\
\hline$\left|z_{B}\right|=\left|z_{Y}\right|$ & $\begin{array}{c}\left|z_{Y}\right|>\left|z_{E}\right| \\
\left|z_{Y}\right| /\left|z_{E}\right|= \\
\text { integer }\end{array}$ & $\left(a_{B}\right)\left(a_{Y}\right)$ & $\frac{\left(\overline{a_{Y}}\right)\left(a_{E}\right)^{\frac{z_{Y}}{z_{E}}}}{\left(\overline{a_{E}}\right)^{\frac{z_{Y}}{z_{E}}}\left(a_{Y}\right)}$ & $K_{s p} K_{E}^{Y}$ \\
\hline$\left|z_{B}\right|=\left|z_{Y}\right|$ & $\begin{array}{c}\left|z_{Y}\right|>\left|z_{E}\right| \\
\left|z_{Y}\right| /\left|z_{E}\right| \neq \\
\text { integer } \\
\text { or } \\
\left|z_{E}\right|>\left|z_{Y}\right| \\
\left|z_{E}\right| /\left|z_{Y}\right| \neq \\
\text { integer } \\
\end{array}$ & $\left(a_{B}\right)\left(a_{Y}\right)$ & $\frac{\left(\overline{a_{Y}}\right)^{z_{E}}\left(a_{E}\right)^{z_{Y}}}{\left(\overline{a_{E}}\right)^{z_{Y}}\left(a_{Y}\right)^{z_{E}}}$ & {$\left[K_{s p}\right]^{z_{E}} K_{E}^{Y}$} \\
\hline$\left|z_{B}\right|=\left|z_{Y}\right|$ & $\begin{array}{c}\left|z_{E}\right|>\left|z_{Y}\right| \\
\left|z_{E}\right| /\left|z_{Y}\right|= \\
\text { integer }\end{array}$ & $\left(a_{B}\right)\left(a_{Y}\right)$ & $\frac{\left(\overline{a_{Y}}\right)^{\frac{z_{E}}{z_{Y}}}\left(a_{E}\right)}{\left(\overline{a_{E}}\right)\left(a_{Y}\right)^{\frac{z_{E}}{z_{Y}}}}$ & {$\left[K_{s p}\right]^{\frac{z_{E}}{z_{Y}}} K_{E}^{Y}$} \\
\hline$\left|z_{B}\right|=\left|z_{Y}\right|$ & $\left|z_{Y}\right|=\left|z_{E}\right|$ & $\left(a_{B}\right)\left(a_{Y}\right)$ & $\frac{\left(\overline{a_{Y}}\right)\left(a_{E}\right)}{\left(\overline{a_{E}}\right)\left(a_{Y}\right)}$ & $K_{s p} K_{E}^{Y}$ \\
\hline$\left|z_{B}\right| \neq\left|z_{Y}\right|$ & $\left|z_{Y}\right|=\left|z_{E}\right|$ & $\left(a_{B}\right)^{z_{Y}}\left(a_{Y}\right)^{z_{B}}$ & $\frac{\left(\overline{a_{Y}}\right)\left(a_{E}\right)}{\left(\overline{a_{E}}\right)\left(a_{Y}\right)}$ & $K_{s p}\left[K_{E}^{Y}\right]^{z_{B}}$ \\
\hline$\left|z_{B}\right| \neq\left|z_{Y}\right|$ & $\begin{array}{c}\left|z_{Y}\right|>\left|z_{E}\right| \\
\left|z_{Y}\right| /\left|z_{E}\right|= \\
\text { integer }\end{array}$ & $\left(a_{B}\right)^{z_{Y}}\left(a_{Y}\right)^{z_{B}}$ & $\frac{\left(\overline{a_{Y}}\right)\left(a_{E}\right)^{\frac{z_{Y}}{z_{E}}}}{\left(\overline{a_{E}}\right)^{\frac{z_{Y}}{z_{E}}}\left(a_{Y}\right)}$ & $K_{s p}\left[K_{E}^{Y}\right]^{z_{B}}$ \\
\hline$\left|z_{B}\right| \neq\left|z_{Y}\right|$ & $\begin{array}{c}\left|z_{Y}\right|>\left|z_{E}\right| \\
\left|z_{Y}\right| /\left|z_{E}\right| \neq \\
\text { integer } \\
\text { or } \\
\left|z_{E}\right|>\left|z_{Y}\right| \\
\left|z_{E}\right| /\left|z_{Y}\right| \neq \\
\text { integer }\end{array}$ & $\left(a_{B}\right)^{z_{Y}}\left(a_{Y}\right)^{z_{B}}$ & $\frac{\left(\overline{a_{Y}}\right)^{z_{E}}\left(a_{E}\right)^{z_{Y}}}{\left(\overline{a_{E}}\right)^{z_{Y}}\left(a_{Y}\right)^{z_{E}}}$ & {$\left[K_{s p}\right]^{z_{E}}\left[K_{E}^{Y}\right]^{z_{B}}$} \\
\hline$\left|\mathrm{z}_{\mathrm{B}}\right| \neq\left|\mathrm{z}_{\mathrm{Y}}\right|$ & $\begin{array}{c}\left|z_{E}\right|>\left|z_{Y}\right| \\
\left|z_{E}\right| /\left|z_{Y}\right|= \\
\text { integer }\end{array}$ & $\left(a_{B}\right)^{z_{Y}}\left(a_{Y}\right)^{z_{B}}$ & $\frac{\left(\overline{a_{Y}}\right)^{\frac{z_{E}}{z_{Y}}}\left(a_{E}\right)}{\left(\overline{a_{E}}\right)\left(a_{Y}\right)^{\frac{z_{E}}{z_{Y}}}}$ & {$\left[K_{s p}\right]^{\frac{z_{E}}{z_{Y}}}\left[K_{E}^{Y}\right]^{z_{B}}$} \\
\hline
\end{tabular}


When the various equations are combined stoichiometrically the simultaneous dissolution and sorption reaction for the sparingly soluble solid by the ion-exchange resins may be formulated, represented by equation (6.10).

$\frac{z_{A}}{z_{B}}\left[\left(B^{z_{B}}\right)_{z_{Y}}\left(Y^{z_{Y}}\right)_{z_{B}}\right]_{S}+z_{Y}\left[\left(R^{-}\right)_{z_{A}} A^{z_{A}}\right] \stackrel{K_{\text {diss }}}{\longleftrightarrow} \frac{z_{A} z_{Y}}{z_{B}}\left[\left(R^{-}\right)_{z_{B}} B^{z_{B}}\right]+z_{Y} A^{z_{A}}+z_{A} Y^{z_{Y}}$

Equation (6.10) is one of the many general cases that may be encountered, depending on the values of the species valence in Equations (6.1), (6.7) and (6.9). The scenario represented by Equation (6.10) is the last entry case for Table 6.1, which has been derived in Appendix B of this dissertation. Similar to the reaction equilibrium constants for the dissolution reaction (solubility product) and the ion-exchange reactions (thermodynamic equilibrium constants) an equilibrium constant may also be formulated for the combined reaction represented by Equation (6.10), which is shown in Table 6.1. This combined reaction equilibrium constant will be referred to as the "Thermodynamic dissolution constant" for the purposes of this dissertation.

From the derivation of Equation (6.10) in Appendix B it is evident that all the equations participating in the overall dissolution and sorption process must be written in a complete and simplified stoichiometric form. This means that all of the stoichiometric coefficients present in the final composite reaction equation must be integers. This means that the overall thermodynamic dissolution constant of a particular resin-in-pulp slurry mixture is a function of the solubility product of the sparingly soluble solid, the thermodynamic equilibrium constant for the ion exchange reactions and the valences of the species present, which strongly depends on the initial ionic form of the resin.

There are therefore several forms for the thermodynamic dissolution constant. The various forms for the overall thermodynamic dissolution constant for the various RIP 
slurry mixtures are derived in Appendix B of this dissertation and represented by Tables 6.1 and 6.2. The different scenarios include the following:

i) RIP slurry mixture systems containing a cation exchange resin only for different ionic forms of the cations exchange resin (various counter-ions with different valences),

ii) RIP slurry mixture system containing an anion exchange resin only for different forms of the anion exchange resin (various counter ions with different valences),

iii) RIP slurry mixtures containing a mixture of both cation and anion exchange resin for different ionic forms of both resins.

Table 6.1 and Table 6.2 show the solubility product for the sparingly soluble solid, the ion-exchange thermodynamic equilibrium constant and also the thermodynamic dissolution constant for RIP slurry mixtures containing ionic species of various valences. Both Tables 6.1 and 6.2 are only for the scenario where one sparingly soluble solid is present with either only a cation or only an anion exchange resin in the slurry mixture. From Figure 1.1 in Chapter 1 it was evident that various "new precipitates' may form as a result of the ion-exchange reactions. This may result in a scenario where more than one sparingly soluble solid may be present in the RIP slurry mixture at equilibrium attainment. This will mean that the equations as derived in Appendix B of this dissertation will have to be expanded to include the extra precipitate species. To derive these equations is not fairly simple and the procedure followed in Appendix B should enable the user of these equations to easily expand them to more complex scenarios.

\subsection{MODEL ASSUMPTIONS USED IN THE SYNTHESIS OF THE CONSOLIDATED EQUILIBRIUM MODEL FOR THE RIP SLURRY MIXTURE SYSTEM}

The following are some of the basic assumptions made in the synthesis of the consolidated equilibrium model for the RIP slurry mixture system. The consolidated 
equilibrium model is based on the basic assumption that all of the equilibrium equations occurring between the various phases of interest are fully reversible reactions. This assumption holds fairly well for all of the phases considered under the conditions considered in this dissertation. Below are the assumptions applicable to the various species in the various phases at equilibrium.

1. It is assumed that the equilibrium constituent ion concentrations of a sparingly soluble solid in an aqueous electrolyte solution are maintained due to equal and opposite dissolution and crystallisation rates. It is therefore assumed that the equilibrium dissolution reaction is a reversible process, as discussed in Chapter 2 (paragraphs 2.1 and 2.2).

2. It is assumed that the ion-exchange reaction is a thermodynamically reversible process, the extent of which is governed by the value of the thermodynamic equilibrium constant. This assumption is valid as long as no completely irreversible ion-pair formation or association exists between the counter and coions and the ions of the fixed functional groups inside the ion-exchange resin. This assumption is not completely valid for chelating ion-exchange resins, since in these cases there exist definite chemical reactions that result in the formation of new ionic species. To model these type of systems a similar approach to completely reversible ion-exchange reactions can be followed, provided that the thermodynamic equilibrium constants of the different chemical reactions are taken into account, which dictate the degree of reversibility of each separate reaction.

3. The behaviour of all of the ionic species in the solution and resin phases is assumed to be non-ideal. This non-ideal behaviour is accounted for by the introduction of the solution and resin phase activity coefficients to the equations describing the thermodynamic equilibrium constants of the different reactions. These activity coefficients are predicted with thermodynamic models available from the literature as discussed in Chapter 3 and Chapter 5. 
4. In the case of a multi-component aqueous RIL electrolyte solution, which is in equilibrium with both the resin and precipitate phase, it is assumed that the coions will only influence the solution phase activity coefficients of the counter ions and not their resin phase activity coefficients. The reasoning is that the co-ions are largely excluded from the internal resin phase due to the Donnan potential. This assumption is valid for most practical cases. The validity of this assumption depends on the extent to which the amount of species adsorbed compares with the total solution phase concentration and whether the amount absorbed causes any internal reactions not accounted for by the model. From paragraph 7.5.2 (Chapter 7) of this dissertation it is evident that this assumption is not completely valid. This is evident from the experimental data presented in paragraph 7.5.2 and the discussions in paragraphs 4.2 .3 to 4.2 .6 (Chapter 4). The assumption is still a good first approximation and the experimental data show that the concentration of the co-ions inside the ion-exchanger is in the order of a magnitude smaller than that of the counter-ions. Provided that there are no ion-pair formation or association between the co-ions and the ions of the fixed functional groups, the model should be able to satisfactorily predict the ion-exchange equilibrium constant. Actually, it is the activities of the co-ions inside the ion-exchanger that will be mostly affected by the presence of the counter ions and not vice versa.

5. It is assumed that the effect of the resin swelling pressure on the equilibrium distribution of the species between the internal pore liquid of the resin and the external electrolyte solution is indirectly accounted for in the values of the thermodynamic equilibrium constants. The effect is therefore accounted for in the regression analysis from experimental data obtained for the equilibrium isotherms over the whole range of the species ionic strengths of interest. 


\subsection{EQUILIBRIUM MASS AND NEUTRALITY BALANCE FOR A RIP SLURRY MIXTURE SYSTEM}

The following equations represent a typical mass balance and electroneutrality balance for a RIP slurry mixture system containing a cation exchange resin and a single sparingly soluble solid. The dissolution reaction of the sparingly soluble solid BY (cation species $B^{z_{B}}$ and anion species $Y^{z_{P}}$ ) is represented by Equation (6.1) above. The ion-exchange reaction between the dissolved cations of the sparingly soluble solid and the cation exchange resin's counter ions $A^{z_{1}}$ is represented by Equation (6.6) above. The notation for the various ions as represented by Equations (6.1) and (6.6) will be used in the equations below.

Initially all of the dissolved cation species $B^{z_{B}}$ are in the aqueous solution phase and all of the counter cation species $A^{z_{A}}$ are present in the cation exchange resin phase, hence Equation (6.4) to Equation (6.7) hold as mass balance equations at the beginning of the equilibrium attainment process for the RIP slurry mixture system.

\subsubsection{Set the initial resin phase conditions:}

The resin fractional loading of species $A^{z_{A}}$ on the cation exchange resin at the start of the equilibrium attainment process is unity. The resin has only species $A^{z_{A}}$ loaded on it, consuming the complete resin capacity.

$$
y_{A, 0}=1
$$

Where the subscript 0 refers to the beginning of the equilibrium attainment process. The resin fractional loading of species $B^{z_{B}}$ on the cation exchange resin at the start of the equilibrium attainment process is given by Equation (6.12). At this stage there are no species $B^{z_{B}}$ present on the cation exchange resin. 


$$
y_{B, 0}=0
$$

\subsubsection{Set the initial solution phase conditions:}

The initial solution phase concentration of species $A^{z_{A}}$ in the aqueous phase at the beginning of the equilibrium attainment process is given by Equation (6.13). No counter ion species $A^{z_{A}}$ is present in the solution phase at this stage of the process.

$$
C_{A, 0}=0
$$

All of the dissolved species $B^{z_{B}}$ of the sparingly soluble solid is present in the solution phase at the beginning of the equilibrium attainment process. The concentration of the cation species $B^{z_{B}}$ relates to the anion species $Y^{z_{Y}}$ of the sparingly soluble solid according to the stoichiometric dissolution reaction represented by Equation (6.14). Equation (6.14) is obtained from an electroneutrality balance performed for the aqueous phase solution. The equivalent number of moles of cations must be equal to the equivalent number of anions to preserve electroneutrality in the solution.

$$
\left|z_{B}\right| C_{B, 0}=\left|z_{Y}\right| C_{Y, 0}
$$

From Equation (6.14) the value of the concentration of species $B^{z_{B}}$ at the start of the equilibrium attainment process may be calculated from Equation (6.15), after re-arranging Equation (6.14).

$$
C_{B, 0}=\frac{\left|z_{Y}\right| C_{Y, 0}}{\left|z_{B}\right|}
$$

\subsubsection{Mass balance equation for species $A^{z_{A}}$ between the solution and the resin phase}


The equilibrium concentration of the counter ion species $A^{z_{A}}$ may be obtained from a component mass balance between the solution and resin phases. The mass balance equation represents the distribution of species $A^{z_{A}}$ between the ion-exchange and solution phases. In Equation (6.16) it is assumed that the total number of equivalent moles (eq moles) of species $A^{z_{A}}$ stays constant in the RIP slurry mixture system during the equilibrium attainment process.

Total number eq moles at start $=$ Total number eq moles at equilibrium

The total number of equivalent moles of species $A^{z_{A}}$ at any given stage of the equilibrium process is equal to the equivalent number of moles in the aqueous solution phase together with the total number of equivalent moles in the resin phase.

Equation (6.17) shows the distribution of species $A^{z_{A}}$ between the solution and the resin phase at the start of the equilibrium attainment process for the RIP slurry mixture.

Total number eq moles at start $=\quad$ number eq moles in Solution at start +

Number eq moles in Resin at start

$$
=V \cdot C_{A, 0} \cdot\left|z_{A}\right|+Q \cdot D P R V \cdot y_{A, 0}
$$

Equation (6.18) represents the equilibrium distribution of species $A^{z_{A}}$ between the solution and the resin phase for the RIP slurry mixture. 
number eq moles in Resin at equilibrium

$$
=V \cdot C_{A, e} \cdot\left|z_{A}\right|+Q \cdot D P R V \cdot y_{A, e}
$$

The subscript $e$ in Equation (6.18) represents the equilibrium condition. In Equations (6.17) and (6.18) the following nomenclature is applicable:

i) $\quad V=$ aqueous phase solution volume in litres

ii) $Q=$ Resin phase capacity in equivalent moles per litre $D P R V$

iii) $\quad D P R V=$ Densely packed resin volume in litres

With the other parameters as defined in the previous chapters. Substituting Equations (6.11), (6.13), (6.17) and (6.18) into Equation (6.16) and upon re-arrangement gives Equation (6.19), which represents the equilibrium solution phase concentration of species $A^{z_{1}}$.

$$
C_{A, e}=\frac{Q D P R V\left(1-y_{A, e}\right)}{\left|z_{A}\right| V}
$$

From Equation (6.19) the value of the equilibrium concentration of species $A^{z_{A}}$ may be calculated if the value of the equilibrium resin loading of species $A^{z_{A}}$ on the ionexchanger is known. For the case of binary ion-exchange between the two cations, Equation (6.20) holds all the time for the resin phase.

$$
y_{A}+y_{B}=1
$$

Substituting Equation (6.20) into Equation (6.19) gives Equation (6.21), which gives the equilibrium solution phase concentration of species $A^{z_{A}}$ as a function of the equilibrium resin loading of species $B^{z_{B}}$. 


$$
C_{A, e}=\frac{Q D P R V y_{B, e}}{\left|z_{A}\right| V}
$$

\subsubsection{Mass balance equation for species $B^{z_{B}}$ between the solution and the resin phase}

At equilibrium, the solution phase concentration of the species $B^{z_{B}}$ and $Y^{z_{Y}}$ may be obtained from Equations (6.23) and (6.24) respectively. Equation (6.22) is obtained from an electroneutrality balance for the aqueous phase with no other electrolyte species present except species $B^{z_{B}}, Y^{z_{y}}$ and $A^{z_{A}}$.

$$
\left|z_{B}\right| C_{B, e}+\left|z_{A}\right| C_{A, e}=\left|z_{Y}\right| C_{Y, e}
$$

From Equation (6.22) the equilibrium concentration of species $B^{z_{B}}$ may be calculated if the concentrations of the other species are available. Equation (6.22) may be re-arranged to give Equation (6.23).

$$
C_{B, e}=\frac{\left|z_{Y}\right| C_{Y, e}-\left|z_{A}\right| C_{A, e}}{\left|z_{B}\right|}
$$

\subsubsection{Calculate the total number of moles of the solid that have dissolved}

The total number moles that dissolved at equilibrium may be calculated from the total number of moles of species $B^{z_{B}}$ present in the aqueous solution and resin phase at equilibrium attainment. Equation (6.24) below gives the number of equivalent moles of species $B^{z_{B}}$ in the aqueous solution and resin phase at equilibrium.

Total number eq moles at equilibrium $=$ number eq moles in Solution at equilibrium + 


$$
\begin{aligned}
& \text { number eq moles in Resin at equilibrium } \\
= & V \cdot C_{B, e} \cdot\left|z_{B}\right|+Q \cdot D P R V \cdot y_{B, e}
\end{aligned}
$$

Where the following nomenclature is applicable:

i) $V=$ aqueous phase solution volume in litres

ii) $Q=$ Resin phase capacity in equivalent moles per litre $D P R V$

iii) $\quad D P R V=\quad$ Densely packed resin volume in litres

The number of moles of species $B^{z_{B}}$ may be obtained by dividing the equivalent number of moles of species $B^{z_{B}}$ (obtained from Equation (6.24)) by its valence, as represented in equation (6.25) below.

$$
\begin{aligned}
\text { Number Moles of species } B^{z_{B}}= & \frac{\text { Number equivalent moles of species } B^{z_{B}}}{\left|z_{B}\right|} \\
& =V \cdot C_{B, e}+\frac{Q \cdot D P R V \cdot y_{B, e}}{\left|z_{B}\right|}
\end{aligned}
$$

From Equation (6.1) it follows that for every mole of the sparingly soluble solid that dissolves, $v_{B}$ moles of species $B^{z_{B}}$ and $v_{Y}$ moles of species $Y^{z_{Y}}$ are formed as a result of the dissolution reaction. The total number of moles of the sparingly soluble solid that dissolved may be calculated from Equation (6.1), represented by Equation (6.26) below.

Number Moles of Dissolved Solid $=\frac{\text { Number moles of species } B^{z_{B}}}{v_{B}}$

Substituting Equation (6.25) into Equation (6.26) gives Equation (6.27) from which the total number of moles of the sparingly soluble solid that dissolved may be calculated. 
Number Moles of Dissolved Solid $=\frac{V \cdot C_{B, e}}{v_{B}}+\frac{Q \cdot D P R V \cdot y_{B, e}}{v_{B}\left|z_{B}\right|}$

\subsubsection{Mass balance equations for species $Y^{z_{Y}}$}

If it is assumed that no electrolytic sorption of species $Y^{z_{Y}}$ by the cation resin phase occurs its equilibrium solution phase concentration may be calculated from the number of moles of the sparingly soluble solid that have dissolved upon equilibrium attainment. From Equation (6.1) it follows that for every mole of the sparingly soluble solid that dissolves, $v_{B}$ moles of species $B^{z_{B}}$ and $v_{Y}$ moles of species $Y^{z_{Y}}$ is formed. The number of moles of species $Y^{z_{Y}}$ at equilibrium in the aqueous solution phase may therefore be calculated from Equation (6.28) below.

Number moles of species $Y^{z_{Y}}=v_{Y} \times \quad$ Number Moles of Dissolved Solid (6.28)

Substituting Equation (6.27) into Equation (6.28) it follows that the number of moles of species $Y^{z_{Y}}$ per unit volume of solution (concentration) is given by

$$
C_{Y, e}=\frac{v_{Y} V C_{B, e}}{v_{B}}+\frac{v_{Y} Q D P R V y_{B, e}}{v_{B}\left|z_{B}\right|}
$$

When calculating the new solubility, $S$, of the sparingly soluble solid that will dissolve for the current concentration of species $Y^{z_{Y}}$ in solution, Equation (6.3) must be used with the value of $m$, representing the total number of moles of species $Y^{z_{Y}}$ that is associated with the exchanged resin species $A^{z_{A}}$. The combination of species $Y^{z_{Y}}$ and $A^{z_{A}}$ form the electrolyte $A Y$, which will lower the solubility of the sparingly soluble solid due to the common ion effect. The value of $m$ may be obtained from Equation (6.30). 


$$
\begin{aligned}
m & =\frac{\left|z_{A}\right| C_{A}}{\left|z_{Y}\right|} \\
& =C_{Y, \text { associated with } A^{z_{A}}}
\end{aligned}
$$

The value of the new solubility, $S$, for the sparingly soluble solid may be calculated from Equation (6.31).

$$
K_{s p}=\left[v_{B} S \gamma_{B}\right]^{v_{B}}\left[\left(v_{Y} S+m\right) \gamma_{Y}\right]^{v_{Y}}
$$

The value of S may then be solved from Equation (6.31) and the value of the solubility product $K_{s p}$ for the sparingly soluble solid. From Equation (6.31) it is also evident that the subscript $e$ has been dropped from Equation (6.29) before inserting it into Equation (6.3) to produce Equation (6.31). The reason for this is that the true equilibrium concentrations are only obtained after Equation (6.31) have been solved and that the new equilibrium concentration for species $Y^{z_{Y}}$ will be the sum of the value produced by Equation (6.29) and the value of $S$ in Equation (6.31). The detailed solution methodology that is followed when solving the model equations by means of iterative calculations is explained later in this chapter.

\subsubsection{Modifying the thermodynamic equilibrium constant for the cation exchange resin}

The thermodynamic equilibrium constant for the cation exchange reaction may be modified by substituting the values for the equilibrium concentrations for the various species as derived above into Equation (6.7). Substituting Equations (6.20) and (6.23) 
into Equation (6.7) and dropping the subscripts $e$, gives Equation (6.32), which represents the form of the thermodynamic equilibrium constant used in the model equations.

$$
K_{A}^{B}=\frac{\left(y_{B} \overline{\gamma_{B}}\right)^{z_{A}}\left(\frac{Q \cdot D P R V}{\left|z_{A}\right| V} y_{B} \gamma_{A}\right)^{z_{B}}}{\left(\left(1-y_{B}\right) \overline{\gamma_{A}}\right)^{z_{B}}\left(C_{B} \gamma_{B}\right)^{z_{A}}}
$$

The consolidated model for the RIP slurry mixture consists of Equations (6.21), (6.23), (6.31) and (6.32). These Equations have to be solved by means of an iterative calculation. The detailed mathematical procedures used to perform these calculations are described in detail in this chapter. It is evident from the mentioned equations that both the species aqueous phase activity coefficients as well as the resin phase activity coefficients are required to perform these calculations. The sections below give the detailed Pitzer and Wilson equations used in the calculations of these activity coefficients for the aqueous solution and resin phases respectively.

\subsection{CAlCUlation OF THE SOLUTION PHASE ACTIVITY COEFFICIENTS USED IN THE EQUILIBRIUM CALCULATIONS}

One of the first principles the reader may argue with is that the solution phase concentration of the sparingly soluble species is extremely low. Hence in the synthesis of the consolidated model for the RIP slurry mixture system the modelling of the solubility and recovery of the sparingly soluble species by ion-exchange should not require extensive non-ideal aqueous phase calculations in the form of activity coefficient calculations. It may be argued that at such low solution phase concentrations the aqueous phase should behave ideally. Although it is true that the aqueous phase concentration of the constituent ions of the sparingly soluble solid is extremely low, it should be kept in mind that the solution phase composition may change considerably upon equilibrium attainment. This results in the presence of various co-ions (initially in the ion-exchanger 
phases) present at fairly high solution phase concentrations provided that significant ionexchange has occurred. From the activity coefficient models (discussed in Chapter 3 ) it may be shown that the activity (extent of non-ideal behaviour) of the more concentrated species is not affected by the presence of the dilute species to the same degree than the activity of the dilute species is influenced by the more concentrated species. In other words, the more concentrated species have a more significant effect on the activities of the dilute species than vice versa. Because of the fact that the species of interest to the consolidated RIP slurry mixture model is the more dilute species, it is necessary for the model to account for any non-ideal behaviour of the dilute species that may be imposed on the more concentrated co-ion species resulting from the ion-exchange reactions.

Secondly, one should kept in mind that as the ion-exchange reactions in the RIP slurry mixture progress towards equilibrium attainment the ionic strength of the aqueous phase increases steadily. This phenomenon is a result of the fact that as more and more of the sparingly soluble solid dissolves more and more ion-exchange occurs that causes the aqueous phase concentration of the counter-ions (initially in the resin phase) to increase. A significantly strong electrolyte solution may eventually be formed after sufficient ionexchange has occurred. The once extremely low ionic strength of the aqueous phase may become significantly concentrated, which warrants the inclusion of an aqueous phase activity coefficient model to account for any non-ideal behaviour in the solution.

Another consideration to justify the inclusion of an aqueous phase activity coefficient model is the nature and shape of the ion-exchange equilibrium isotherm curve. From Chapter 8 it will become evident that typical ion-exchange isotherms may have extremely sharp "wave" fronts. This is evident when the resin phase equilibrium loading is plotted against the equilibrium solution phase concentration for a particular species. An extremely steep curve is observed in the very low solution phase concentration region. This steep curves results in a scenario that for a small change in the solution phase concentration of the particular species, a significant change in the resin equilibrium loading for the species may be observed. The consolidated equilibrium model for the RIP 
slurry mixture should therefore be able to model the most minute changes in aqueous phase concentration of the particular species as a function of the solution phase composition to be able to accurately predict the resin phase equilibrium loading. In other words, the consolidated equilibrium model should ensure that the $\mathrm{x}$-axis position (equilibrium solution phase concentration) on the isotherm curve is estimated as accurately as possible in order to ensure that the associated resin phase loading ( $y$-axis of the isotherm curve) is obtained as accurately as possible.

When one considers the above arguments it is evident that a very reliable and proven aqueous phase activity coefficient model, such as the Pitzer model, is required in the synthesis of the consolidated equilibrium model for the RIP slurry mixture system. The shape of the equilibrium curve may also change significantly, as is evident from Figure (8.15) to Figure (8.19) of Chapter 8 of this dissertation. The observed behaviour of the equilibrium isotherms trends for the same ion-exchange reaction disqualifies a more empirical approach such as the Freundlich isotherm (discussed in Chapter 5) from being used in the consolidated equilibrium model for the RIP system. The isotherm model needs to have a more thermodynamic approach in order to 'de-couple' the non-ideal aqueous phase behaviour from the model characteristics that need to represent the equilibrium resin phase isotherm. This 'de-coupling' process of the thermodynamic equilibrium isotherm from the non-ideal behaviour in the aqueous phase warrants the inclusion of thermodynamic principles to account for the observed behaviour. The importance of this therefore also warrants the detailed investigation into the numerous aqueous phase activity coefficient models investigated in Chapter 3 of this dissertation.

From the above discussion the choice of the inclusion of an aqueous phase activity coefficient model in the consolidated equilibrium model for the RIP slurry mixture system is evident. From Chapter 3 of this dissertation it followed that the Pitzer model for the prediction of aqueous phase activity coefficients was identified as the most suitable model for inclusion in the synthesis of the consolidated equilibrium model for the RIP slurry mixture system. 
The detailed equations for the Pitzer model were discussed in Chapter 3. These equations have been formulated for the various RIP slurry systems of interests to this dissertation and are shown in more detail below. In the equations below the importance of the various terms in the Pitzer model equations for the purposes of this dissertation is also discussed and the equations are reduced to simple mathematical expressions as used in the model equations of the consolidated equilibrium model for the RIP slurry mixture system. The Pitzer equations as discussed in Chapter 3 will be repeated below for the notation where MX, NX, MY and NY represent four different electrolytes in the aqueous phase solution. The terms $\mathrm{M}$ and $\mathrm{N}$ refer to the cations and the terms $\mathrm{X}$ and $\mathrm{Y}$ to the anions in the electrolytes. The different combinations between the four electrolytes mentioned are sufficient to cover the various electrolyte combinations that will be encountered in the RIP slurry mixture's aqueous phase for the purposes of this dissertation. The Species M and $\mathrm{N}$ can therefore be any cations in the RIP system. It may represent the constituent ions of the sparingly soluble solid or the counter-ions of the ion-exchange resin phases for the cation resin. Similarly the anions X and Y may represent the constituent ions of the sparingly soluble solid in the RIP slurry mixture system or the counter-ions of the anion exchange resins.

The various combinations of any two of the possible four electrolytes mentioned may include the following systems:

i) The MX-MY or NX-NY system with only one cation (M or N) and two anions (X and $\mathrm{Y})$,

ii) The MY-NY or MX-NX system with two cations (M and N) and only one anion (Y or $\mathrm{X})$,

iii) The MX-NY or My-NX system containing two cations ( $\mathrm{M}$ and $\mathrm{N}$ ) and two anions (X and $\mathrm{Y}$ ) 
The type of systems described in paragraph (i) and (ii) above may be encountered where only one type of ion-exchange resin (either cation or anion) is added to the RIP slurry mixture containing only one sparingly soluble solid. The type of system described in paragraph (iii) is encountered when both a cation and anion exchange resin is added to a RIP slurry mixture system containing only one sparingly soluble solid. This type of system will be referred to as a mixed resin bed slurry system. The Pitzer activity coefficient models for both of the different types of systems are shown in detail below. In the Equations below the terms "BRAC" refer to bracketed combinations of the various Pitzer parameters. The detailed equations and derivation of the "BRAC" terms as used below are shown in Appendix $\mathrm{C}$ of this dissertation. Appendix $\mathrm{C}$ also gives some background on the Pitzer parameters for unsymmetrical mixing that may occur in mixed electrolytes.

\subsubsection{Pitzer equations for the MX-NY electrolyte system.}

The single-ion activities for the mixed electrolyte system MX-NY are defined in terms of the above equations as follows.

$$
\begin{aligned}
\ln \gamma_{M}= & \left(z_{M}^{2}\right) f^{\gamma}+\left(m_{Y}\right) B R A C 1+\left(m_{X}\right) B R A C 3+\left(m_{N}\right) B R A C 5 \\
& +\left(z_{M}^{2}\right) B_{S U M}+\left(z_{M}\right) C_{S U M}+B R A C 7+\left(z_{M}^{2}\right) B R A C 8+\left(z_{M}^{2}\right) B R A C 9 \\
\ln \gamma_{N}= & \left(z_{N}^{2}\right) f^{\gamma}+\left(m_{Y}\right) B R A C 2+\left(m_{X}\right) B R A C 4+\left(m_{M}\right) B R A C 5 \\
& +\left(z_{N}^{2}\right) B_{S U M}+\left(z_{N}\right) C_{S U M}+B R A C 11+\left(z_{N}^{2}\right) B R A C 8+\left(z_{N}^{2}\right) B R A C 9 \\
\ln \gamma_{X}= & \left(z_{X}^{2}\right) f^{\gamma}+\left(m_{M}\right) B R A C 3+\left(m_{N}\right) B R A C 4+\left(m_{Y}\right) B R A C 6 \\
& +\left(z_{X}^{2}\right) B_{S U M}+\left(z_{X}\right) C_{S U M}+B R A C 10+\left(z_{X}^{2}\right) B R A C 9+\left(z_{X}^{2}\right) B R A C 8
\end{aligned}
$$




$$
\begin{aligned}
\ln \gamma_{Y}= & \left(z_{Y}^{2}\right) f^{\gamma}+\left(m_{M}\right) B R A C 1+\left(m_{N}\right) B R A C 2+\left(m_{X}\right) B R A C 6 \\
& +\left(z_{Y}^{2}\right) B_{S U M}+\left(z_{Y}\right) C_{S U M}+B R A C 12+\left(z_{Y}^{2}\right) B R A C 9+\left(z_{Y}^{2}\right) B R A C 8
\end{aligned}
$$

\subsubsection{Pitzer equations for the MX-NX electrolyte system.}

$$
\begin{aligned}
\ln \gamma_{M}= & \left(z_{M}^{2}\right) f^{\gamma}+\left(m_{X}\right) B R A C 3+\left(m_{N}\right) B R A C 5 \\
& +\left(z_{M}^{2}\right) B_{S U M}+\left(z_{M}\right) C_{S U M}+\left(z_{M}^{2}\right) B R A C 9 \\
\ln \gamma_{N}= & \left(z_{N}^{2}\right) f^{\gamma}+\left(m_{X}\right) B R A C 4+\left(m_{M}\right) B R A C 5 \\
& +\left(z_{N}^{2}\right) B_{S U M}+\left(z_{N}\right) C_{S U M}+\left(z_{N}^{2}\right) B R A C 9 \\
\ln \gamma_{X}= & \left(z_{X}^{2}\right) f^{\gamma}+\left(m_{M}\right) B R A C 3+\left(m_{N}\right) B R A C 4 \\
& +\left(z_{X}^{2}\right) B_{S U M}+\left(z_{X}\right) C_{S U M}+B R A C 10+\left(z_{X}^{2}\right) B R A C 9
\end{aligned}
$$

6.5.3 Pitzer equations for the MX-MY electrolyte system.

$$
\begin{aligned}
\ln \gamma_{M}= & \left(z_{M}^{2}\right) f^{\gamma}+\left(m_{X}\right) B R A C 3+\left(m_{Y}\right) B R A C 1 \\
& +\left(z_{M}^{2}\right) B_{S U M}+\left(z_{M}\right) C_{S U M}+B R A C 7+\left(z_{M}^{2}\right) B R A C 8 \\
\ln \gamma_{X}= & \left(z_{X}^{2}\right) f^{\gamma}+\left(m_{M}\right) B R A C 3+\left(m_{Y}\right) B R A C 6 \\
& +\left(z_{X}^{2}\right) B_{S U M}+\left(z_{X}\right) C_{S U M}+\left(z_{X}^{2}\right) B R A C 8
\end{aligned}
$$




$$
\begin{aligned}
\ln \gamma_{Y}= & \left(z_{Y}^{2}\right) f^{\gamma}+\left(m_{M}\right) B R A C 1+\left(m_{X}\right) B R A C 6 \\
& +\left(z_{Y}^{2}\right) B_{S U M}+\left(z_{Y}\right) C_{S U M}+\left(z_{Y}^{2}\right) B R A C 8
\end{aligned}
$$

\subsection{CALCULATIONS OF THE THERMODYNAMIC EQUILIBRIUM CONSTANT FOR THE ION-EXCHANGE REACTION AND THE RESIN PHASE ACTIVITY COEFFICIENTS}

In Chapter 5 of this dissertation the equations for the calculation of the thermodynamic equilibrium constant $K_{A}^{B}$, represented by Equation (6.7), for the ion-exchange reaction as well as the resin phase activity coefficients have been shown in detail. The resin phase activity coefficients have been modelled successfully by several workers. (Smith and Woodburn (1978); Vazquez Una et al. (1985), Chakravarti et al. (1988) and Shallcross et al. (1988)) using the model developed by Wilson (1964) for the excess Gibbs free energy.

Equations (6.43) and (6.44) show the Wilson equation expanded for species $A^{z_{A}}$ and $B^{z_{B}}$ on the ion-exchange resin. From the discussions in paragraph 6.4 of this chapter it is evident that it is assumed that only species $B^{z_{B}}$ and $A^{z_{A}}$ participate in the ion-exchange reaction and that none of species $Y^{z_{Y}}$ enters the ion-exchange resin as a result of electrolytic sorption.

$$
\begin{aligned}
& \ln \left(\overline{\gamma_{A}}\right)=1-\ln \left(y_{A}+y_{B} \Lambda_{A B}\right)-\left(\frac{y_{A}}{y_{A}+y_{B} \Lambda_{A B}}+\frac{y_{B} \Lambda_{B A}}{y_{A} \Lambda_{B A}+y_{B}}\right) \\
& \ln \left(\overline{\gamma_{B}}\right)=1-\ln \left(y_{A} \Lambda_{B A}+y_{B}\right)-\left(\frac{y_{A} \Lambda_{A B}}{y_{A}+y_{B} \Lambda_{A B}}+\frac{y_{B}}{y_{A} \Lambda_{B A}+y_{B}}\right)
\end{aligned}
$$


The thermodynamic equilibrium quotient was also defined in Chapter 5 of this dissertation. It followed that the equilibrium quotient, $\lambda_{A}^{B}$, for each ion-exchange reaction is represented by Equation (5.27)

$$
\lambda_{A}^{B}=\left(\frac{y_{B}}{\gamma_{B} C_{B}}\right)^{v_{B}}\left(\frac{\gamma_{A} C_{A}}{y_{A}}\right)^{\nu_{A}}
$$

From experimental data all of the model parameters on the right hand side of Equation (5.27) can be calculated or directly measured. These parameters include $C_{i}$, the solution phase concentration for species $i, q_{i}$ the equivalent mole fraction of species $i$ in the resin phase which is calculated from a mass balance and $\gamma_{i}$ the solution phase activity coefficient of species $i$, which is calculated from the equations as presented in paragraphs 6.5.1 to 6.5 .3 above.

From Chapter 5 it follows that after substituting the Wilson equations for species $A^{z_{A}}$ and $B^{z_{B}}$ into the equation for the equilibrium quotient and rearranging, Equation (6.45) is obtained by expanding Equation (5.32).

$$
\begin{aligned}
\ln \left(\lambda_{A}^{B}\right)= & \ln \left(K_{A}^{B}\right)+\left(v_{A}-v_{B}\right) \\
& -v_{A} \ln \left(y_{A}+\Lambda_{A B}\left(1-y_{A}\right)\right)+v_{B} \ln \left(y_{A} \Lambda_{B A}+1-y_{A}\right) \\
& -\frac{y_{A}\left(v_{A}-v_{B} \Lambda_{A B}\right)}{y_{A}+\Lambda_{A B}\left(1-y_{A}\right)}-\frac{\left(1-y_{A}\right)\left(v_{A} \Lambda_{B A}-v_{B}\right)}{y_{A} \Lambda_{B A}+1-y_{A}}
\end{aligned}
$$

An optimisation procedure is used to fit the three unknown parameters in Equation (6.45) to the experimental data. The three unknown parameters are

i) The thermodynamic equilibrium constant $K_{A}^{B}$, 
ii) The Wilson interaction parameter $\Lambda_{A B}$ and

iii) The Wilson interaction parameter $\Lambda_{B A}$.

Appendix D of this dissertation shows a detailed calculation and optimisation of the above unknown parameters in Equation (6.45) from experimental data. The programming code for the calculation is shown in MATHCAD 6.0 for explanatory purposes. Once the values of the unknown parameters have been calculated they may be used in Equations (6.43) and (6.44) to calculate the resin phase activity coefficients as used in Equation (6.32) of this dissertation. Equation (6.32) forms part of the set of model equations describing the consolidated equilibrium for the RIP slurry mixture system.

\subsection{DETAILED ITERATIVE SOLUTION PROCEDURE FOLLOWED TO SOLVE THE CONSOLIDATED MODEL EQUATIONS}

During the equilibrium modelling of the RIP slurry mixture, equilibrium exists between the precipitate/solution and resin/solution phases in the aqueous slurry mixture. Transfer of the electrolyte species from the precipitate and resin phases to the solution phase is governed by the equilibrium constants, i.e. the solubility product and thermodynamic equilibrium constant respectively. Mathematically this results in a set of equations, consisting of two equilibrium and one mass balance equation for each of the species that must be solved simultaneously.

An iterative procedure can be used to solve these equations where $\mathrm{j}, \mathrm{n}$ and $\mathrm{k}$ represent the current calculation step in each of the three different proposed iteration procedures.

$$
\begin{array}{ll}
\text { Set } & j=1, \\
\text { Set } & n=1, \\
\text { Set } & k=1
\end{array}
$$


1. Ideal solution and resin phase behaviour for all of the species is assumed for initial calculations. Set $\gamma_{i, j}=\bar{\gamma}_{i, j}=1$ for all $i$ and calculate the solubility $S_{j}$ from Equation (6.46), which is Equation (6.2) with $\gamma_{B}=\gamma_{Y}=1$.

$$
S_{j}=\left(\frac{K_{s p}}{\left[v_{B}\right]^{v_{B}}\left[v_{Y}\right]^{v_{Y}}}\right)^{\frac{1}{v_{B}+v_{Y}}}
$$

Calculate $C_{B, j}$ and $C_{Y, j}$ from Equations (6.47) and (6.48) according to the definition of the solubility, $S$, described by Equation (6.2).

$$
\begin{aligned}
& C_{B, j}=v_{B} S_{j} \\
& C_{Y, j}=v_{Y} S_{j}
\end{aligned}
$$

2. Calculate $y_{B, j}$ from Equation (6.49) with the current values of $\gamma_{i, j}, \bar{\gamma}_{i, j}, C_{B, j}$. Calculate the new values for $y_{A, j}, C_{A, j}$ and $C_{B, j}$ from Equations (6.50), (6.51) and (6.52) with the newly calculated value of $y_{B, j}$. Equations (6.50) and (6.51) are obtained from a mass balance performed for species $A^{z_{A}}$ over the resin and solution phase. Equation (6.52) is obtained from an electroneutrality balance for the aqueous phase solution with the concentration of species $B^{z_{B}}$ on the left-hand side of the equation.

$$
K_{A, j}^{B}=\frac{\left(y_{B, j} \bar{\gamma}_{B, j}\right)^{z_{A}}\left(\frac{Q \cdot D P R V}{V\left|z_{A}\right|} y_{B, j} \gamma_{A, j}\right)^{z_{B}}}{\left(\left(1-y_{B, j} \overline{\gamma_{A, j}}\right)^{z_{B}}\left(C_{B, j} \gamma_{B, j}\right)^{z_{A}}\right.}
$$




$$
\begin{aligned}
& y_{A, j}=\left(1-y_{B, j}\right) \\
& C_{A, j}=\frac{Q \cdot D P R V y_{B, j}}{\left|z_{A}\right| V} \\
& C_{B, j}=\frac{\left|z_{Y}\right| C_{Y, j}-\left|z_{A}\right| C_{A, j}}{\left|z_{B}\right|}
\end{aligned}
$$

3. Calculate $m_{j}$, which is the number of moles per litre of solution of the anion $Y^{z_{y}}$ associated with the exchanged cation $A^{z_{A}}$. From the discussions in paragraph 6.4.7 of this chapter it is evident that the amount of the electrolyte $A Y$ needs to be calculated to estimate its common-ion effect on the solubility of the sparingly soluble solid. This amount is given by Equation (6.53).

$$
m_{j}=\frac{\left|z_{A}\right| C_{A, j}}{\left|z_{Y}\right|}
$$

4. Calculate the new value for the solubility of the precipitate, $S_{n e w, j}$, from Equation (6.54) with the current values of $\gamma_{i, j}, \bar{\gamma}_{i, j}$ and $m_{j}$ and then calculate $C_{B \text { new }, j}$ and $C_{Y \text { new }, j}$ from Equations (6.55) and (6.56). These new concentration values are closer to the true equilibrium values than the previous calculated values without the common-ion effect included.

$$
\begin{aligned}
& K_{s p}=\left[v_{B} S_{\text {new }, j} \gamma_{B, j}\right]^{v_{B}}\left[\left(v_{Y} S_{n e w, j}+m_{j}\right) \gamma_{Y, j}\right]^{v_{Y}} \\
& C_{B \text { new }, j}=v_{B} S_{\text {new }, j} \\
& C_{Y \text { new }, j}=v_{Y} S_{\text {new }, j}
\end{aligned}
$$


5. Calculate $\xi$ with Equation (6.57)

$$
\xi=\left|\frac{C_{Y \text { new }, j}-C_{Y, j}}{C_{Y \text { new }, j}}\right|
$$

6. Check for convergence in the values of all of the solution phase species concentrations of by checking for convergence in the solution phase concentration of only species $Y^{z_{Y}}$. This can be done due to the electroneutrality balance that exists between all of the solution phase species, i.e. $C_{Y, j}$ is a function of the solution phase concentrations of species $A^{z_{A}}$ and $B^{z_{B}}$.

(6a) If $\xi \geq 0.00001$

$\underline{\text { Set }}$

$$
\begin{aligned}
& S_{j+1}=S_{\text {new }, j+1}=0 \\
& C_{B, j+1}=C_{B \text { new }, j} \\
& C_{Y, j+1}=C_{Y \text { new }, j} \\
& \gamma_{i, j+1}=\gamma_{i, j} \\
& \bar{\gamma}_{i, j+1}=\overline{\gamma_{i, j}} \\
& j=j+1
\end{aligned}
$$

Return to step 2 .

(6b) If $\xi<0.00001$

$\underline{\text { Set }}$

$$
\begin{aligned}
& S_{j+1}=S_{\text {new }, j+1}=0 \\
& C_{B, n}=C_{B \text { new }, j}
\end{aligned}
$$




$$
\begin{aligned}
& C_{Y, n}=C_{Y \text { new }, j} \\
& m_{n}=m_{j} \\
& \overline{\gamma_{i, n}}=\bar{\gamma}_{i, j} \\
& j=j+1
\end{aligned}
$$

Go to step 7 .

The objective of the iteration procedure up to this point was to assume ideal solution and resin phase conditions (no activity coefficient calculations) and to obtain a first approximation of the equilibrium concentrations. A new iteration is started in step 7 with the current solution phase concentrations of all of the species, but assuming non-ideal conditions do exist in both the solution and resin phases. In the iterations following step 7 the solution phase activity coefficients of the different species are considered in the calculations.

7. With all of the solution phase concentrations known, calculate the ionic strength of the solution, $I_{c, n}$.

$$
I_{c, n}=\frac{1}{2} \sum_{i} z_{i}^{2} C_{i, n}
$$

8. Calculate the solution phase activity coefficients, $\gamma_{i, n}$, of all of the species present with an appropriate activity coefficient model, as discussed in paragraph 6.5 of this chapter. There are various combinations of the activity coefficient model "BRAC" equations possible as presented in paragraph 6.5. The applicable set of equations needs to be derived from the equations as set out in Appendix $\mathrm{C}$ of this dissertation. This procedure is not difficult due to the fact that all of the Pitzer equations are compressed into the defined "BRAC" terms, which makes the derivation of the required equations less tedious. 
9. Calculate a new value for the solubility of the precipitate, $S_{n}$, from Equation (6.59) with the current values of $\gamma_{i, n}$ and $\bar{\gamma}_{i, n}$ and then calculate $C_{B \text { new }, n}$ and $C_{Y \text { new }, n}$ from Equations (6.60) and (6.61).

$$
\begin{aligned}
& K_{s p}=\left[v_{B} S_{\text {new }, n} \gamma_{B, n}\right]^{v_{B}}\left[\left(v_{Y} S_{n e w, n}+m_{n}\right) \gamma_{Y, n}\right]^{v_{Y}} \\
& C_{B \text { new }, n}=v_{B} S_{n} \\
& C_{Y \text { new }, n}=v_{Y} S_{n}
\end{aligned}
$$

10. Calculate $\xi$ with Equation (6.62)

$$
\xi=\left|\frac{C_{Y \text { new }, n}-C_{Y, n}}{C_{Y \text { new }, n}}\right|
$$

11. Check for convergence in the values of the solution phase concentrations, after the introduction of the solution phase activity coefficients, by checking for convergence in the value of the solution phase concentration of species $Y^{z_{Y}}$.

(11a) If $\xi \geq 0.00001$

$\underline{\text { Set }}$

$$
\begin{aligned}
& C_{B, j}=C_{B \text { new }, n} \\
& C_{Y, j}=C_{Y \text { new }, n} \\
& \bar{\gamma}_{i, j}=\bar{\gamma}_{i, n} \\
& \gamma_{i, j}=\gamma_{i, n}
\end{aligned}
$$




$$
n=n+1
$$

Start from step 2 with the current values of the parameters

(11b) If $\xi<0.00001$

$\underline{\text { Set }}$

$$
\begin{aligned}
& C_{B, k}=C_{\text {Bnew }, n} \\
& C_{Y, k}=C_{Y \text { new }, n} \\
& \gamma_{i, k}=\gamma_{i, n} \\
& y_{i, k}=y_{i, j} \\
& n=n+1
\end{aligned}
$$

Go to step 12 .

A new iteration is started in step 12 with the current solution phase concentrations and solution phase activity coefficients for all of the species. In the iterations following step 12 the resin phase activity coefficients of the two counter ion species are considered in the calculations.

12. Calculate the resin phase activity coefficients of the two counter ion species with Equations (6.63) and (6.64). In these equations the only model parameters required are the Wilson interaction parameters as discussed in paragraph 6.6 of this dissertation.

$\ln \bar{\gamma}_{A, k}=1-\ln \left(y_{A, k}+y_{B, k} \Lambda_{A B, k}\right)-\left(\frac{y_{A, k}}{y_{A, k}+y_{B, k} \Lambda_{A B, k}}+\frac{y_{B, k} \Lambda_{B A, k}}{y_{A, k} \Lambda_{B A, k}+y_{B, k}}\right)$ 


$$
\ln \bar{\gamma}_{B, k}=1-\ln \left(y_{A, k} \Lambda_{B A, k}+y_{B, k}\right)-\left(\frac{y_{A, k} \Lambda_{A B, k}}{y_{A, k}+y_{B, k} \Lambda_{A B, k}}+\frac{y_{B, k}}{y_{A, k} \Lambda_{B A, k}+y_{B, k}}\right)
$$

13. Calculate $y_{B, k}$ from Equation (6.65), which is obtained by substituting Equations (6.66) and (6.67) into the expression for the thermodynamic equilibrium constant of the ion-exchanger, with the current values of $\gamma_{i, k}$ and $\bar{\gamma}_{i, k}$. Calculate $y_{A, k}$ and $C_{A, k}$ from Equations (6.66) and (6.67), which is obtained from a mass balance performed for species $A^{z_{A}}$ over the resin and solution phase respectively.

$$
\begin{aligned}
K_{A, k}^{B}= & \frac{\left(y_{B, k} \bar{\gamma}_{B, k}\right)^{z_{A}}\left(\frac{Q \cdot D P R V}{V\left|z_{A}\right|} y_{B, k} \gamma_{A, k}\right)^{z_{B}}}{\left(\left(1-y_{B, k} \overline{\gamma_{A, k}}\right)^{z_{B}}\left(C_{B, k} \gamma_{B, k}\right)^{z_{A}}\right.} \\
y_{A, k} & =\left(1-y_{B, k}\right) \\
C_{A, k} & =\frac{Q \cdot D P R V y_{B, k}}{\left|z_{A}\right| V} \\
C_{B, k} & =\frac{\left|z_{Y}\right| C_{Y, k}-\left|z_{A}\right| C_{A, k}}{\left|z_{B}\right|}
\end{aligned}
$$

14. Calculate $m_{k}$, the number of moles per litre of solution of the anion $Y^{z_{r}}$ associated with the exchanged cation $A^{z_{A}}$. This is obtained from an 
electroneutrality mass balance performed on the solution phase, given by Equation (6.69).

$$
m_{k}=\frac{\left|z_{A}\right| C_{A, k}}{\left|z_{Y}\right|}
$$

15. Calculate the new value for the solubility of the precipitate, $S_{\text {new }, k}$, from Equation (6.70) with the current values of $\gamma_{i, k}$ and $\bar{\gamma}_{i, k}$ and then calculate $C_{B \text { new }, k}$ and $C_{Y \text { new }, k}$ from Equations (6.71) and (6.72).

$$
\begin{aligned}
& K_{s p}=\left[v_{B} S_{\text {new }, k} \gamma_{B, k}\right]^{v_{B}}\left[\left(v_{Y} S_{\text {new }, k}+m_{k}\right) \gamma_{Y, k}\right]^{v_{Y}} \\
& C_{B \text { new }, k}=v_{B} S_{\text {new }, k} \\
& C_{Y \text { new }, k}=v_{Y} S_{\text {new }, k}
\end{aligned}
$$

16. Calculate $\xi$ with Equation (6.73)

$$
\xi=\left|\frac{C_{Y \text { new }, k}-C_{Y, k}}{C_{Y \text { new }, k}}\right|
$$

17. Check for convergence in the values of the solution phase concentrations, after the introduction of the resin phase activity coefficients, by checking for convergence in the value of the solution phase concentration of species $Y^{z_{Y}}$.

(17a) If $\xi \geq 0.00001$ 


$$
\begin{aligned}
& C_{B, j}=C_{B \text { new }, k} \\
& C_{Y, j}=C_{Y \text { new }, k} \\
& \bar{\gamma}_{i, j}=\bar{\gamma}_{i, k} \\
& \gamma_{i, j}=\gamma_{i, k} \\
& k=k+1
\end{aligned}
$$

Start from step 2 with the current values of the parameters

(17b) If $\xi<0.00001$

If the iteration is completed the current set of values for all of the parameters is the true equilibrium values according to the consolidated equilibrium model for the RIP slurry mixture system.

From the iterative procedure above it is evident that the first set of calculations is performed assuming ideal conditions in both the solution and resin phases. Once the calculations have converged by assuming ideal conditions the non-idealities in both the resin and solution phase are introduced by means of the activity coefficient calculations. The iteration steps of the first part of the procedure are then repeated until convergence is obtained for all of the species solution phase concentrations.

\subsection{THERMODYNAMIC DATA BASE CONSTRUCTED FOR USE IN THE CONSOLIDATED EQUILIBRIUM MODEL FOR THE RIP SLURRY MIXTURE SYSTEM}


Various sources in the literature exist that supply values for the Pitzer interaction parameters for various aqueous electrolyte systems. Many of these literature sources are mentioned in Chapter 3. Due to this a detailed SQL 7.0 database has been created in which the Pitzer parameters from the different literature sources are stored.

Table 6.3 Detailed Pitzer parameters for various electrolyte species as used in above detailed equations at $25^{\circ} \mathrm{C}$, selected from the database.

\begin{tabular}{|c|c|c|c|c|c|c|c|}
\hline Species_1 & Species_2 & beta_0 & beta_1 & Beta_2 & C_phi & Temperature & max_m \\
\hline $\mathrm{Ag}<+>$ & NO3<-> & $-8.56 \bar{E}-02$ & $2.50 \mathrm{E}-03$ & NULL & 5.91E-03 & 298.15 & 6 \\
\hline $\mathrm{K}<+>$ & NO3<-> & $-8.18 \mathrm{E}-02$ & $5.05 \mathrm{E}-02$ & NULL & 7.09E-03 & 298.15 & 1 \\
\hline $\mathrm{Rb}<+>$ & NO3<-> & $-8.17 \mathrm{E}-02$ & -0.03175 & NULL & $6.24 \mathrm{E}-03$ & 298.15 & 1 \\
\hline$K<+>$ & NO3<-> & $-8.16 \mathrm{E}-02$ & 4.94E-02 & NULL & 0.0066 & 298.15 & 3.8 \\
\hline $\mathrm{Na}<+>$ & $\mathrm{H} 2 \mathrm{AsO} 4<->$ & $-8.00 \mathrm{E}-02$ & 0.35866 & NULL & $2.27 \mathrm{E}-02$ & 298.15 & 1 \\
\hline$R b<+>$ & NO3<-> & $-7.89 \mathrm{E}-02$ & -0.0172 & NULL & $5.29 \mathrm{E}-03$ & 298.15 & 4.5 \\
\hline $\mathrm{Na}<+>$ & HPO4<2-> & $-7.77 E-02$ & 1.954 & NULL & $5.54 \mathrm{E}-02$ & 298.15 & 1 \\
\hline Cs<+> & NO3<-> & $-7.58 \mathrm{E}-02$ & $-6.69 E-02$ & NULL & NULL & 298.15 & 1.4 \\
\hline $\mathrm{Ag}<+>$ & NO3<-> & -0.07102 & -0.16793 & NULL & $3.22 \mathrm{E}-03$ & 298.15 & 1 \\
\hline $\mathrm{NH} 4<+>$ & H2PO4<-> & $-7.04 \mathrm{E}-02$ & -0.4156 & NULL & $6.69 \mathrm{E}-03$ & 298.15 & 3.5 \\
\hline $\mathrm{K}<+>$ & H2PO4<-> & $-6.78 E-02$ & -0.1042 & NULL & NULL & 298.15 & 1.8 \\
\hline $\mathrm{K}<+>$ & H2PO4<-> & $-6.74 \mathrm{E}-02$ & -0.1036 & NULL & -0.000435 & 298.15 & 1 \\
\hline $\mathrm{K}<+>$ & $\mathrm{H} 2 \mathrm{AsO} 4<->$ & $-5.84 E-02$ & $6.26 \mathrm{E}-02$ & NULL & NULL & 298.15 & 1.2 \\
\hline $\mathrm{Na}<+>$ & H2PO4<-> & -0.0533 & $3.96 \mathrm{E}-02$ & NULL & $7.95 \mathrm{E}-03$ & 298.15 & 6 \\
\hline $\mathrm{Na}<+>$ & $\mathrm{BO} 2<->$ & -0.05289 & -0.10888 & NULL & $1.50 \mathrm{E}-02$ & 298.15 & 1 \\
\hline $\mathrm{Na}<+>$ & $\mathrm{B}(\mathrm{OH}) 4<->$ & $-5.26 \mathrm{E}-02$ & 0.1104 & NULL & 0.0154 & 298.15 & 4.5 \\
\hline $\mathrm{Pb}<2+>$ & NO3<-> & -0.0482 & 0.38 & NULL & 0.01005 & 298.15 & 2 \\
\hline $\mathrm{Na}<+>$ & $\mathrm{H} 2 \mathrm{PO} 4<->$ & $-4.75 E-02$ & $-7.59 \mathrm{E}-02$ & NULL & $6.59 \mathrm{E}-03$ & 298.15 & 1 \\
\hline $\mathrm{Na}<+>$ & H2AsO4<-> & $-4.42 \mathrm{E}-02$ & 0.2895 & NULL & NULL & 298.15 & 1.2 \\
\hline $\mathrm{Ba}<2+>$ & NO3<-> & $-4.37 \mathrm{E}-02$ & 1.11778 & NULL & NULL & 298.15 & 1 \\
\hline $\mathrm{Ba}<2+>$ & NO3<-> & $-4.30 \mathrm{E}-02$ & 1.07 & NULL & NULL & 298.15 & 0.4 \\
\hline $\mathrm{NH} 4<+>$ & HPO4<2-> & $-4.25 E-02$ & -0.69871 & NULL & $5.27 \mathrm{E}-03$ & 298.15 & 1 \\
\hline $\mathrm{NH} 4<+>$ & $\mathrm{HCO} 3<->$ & $-3.80 \mathrm{E}-02$ & $7.00 \mathrm{E}-02$ & NULL & NULL & 298.15 & 0.7 \\
\hline $\mathrm{Na}<+>$ & BF4<-> & $-2.60 \mathrm{E}-02$ & -0.10084 & NULL & $1.71 \mathrm{E}-03$ & 298.15 & 1 \\
\hline $\mathrm{Na}<+>$ & BF4<-> & -0.0252 & 0.1824 & NULL & $2.10 \mathrm{E}-03$ & 298.15 & 6 \\
\hline $\mathrm{Na}<+>$ & HPO4<2-> & $-2.17 E-02$ & 1.24472 & NULL & 0.00726 & 298.15 & 1 \\
\hline $\mathrm{Na}<+>$ & BrO3<-> & $-2.05 E-02$ & 0.191 & NULL & $5.90 \mathrm{E}-03$ & 298.15 & 2.5 \\
\hline $\mathrm{NH} 4<+>$ & NO3<-> & -0.0154 & 0.112 & NULL & $-3.00 \mathrm{E}-05$ & 298.15 & 6 \\
\hline $\mathrm{NH} 4<+>$ & NO3<-> & $-1.48 \mathrm{E}-02$ & 0.13826 & NULL & 0.00029 & 298.15 & 1 \\
\hline
\end{tabular}

Table 6.4 Thermodynamic properties stored for various species in the SQL database for use in model equations. Properties shown are those at $25^{\circ} \mathrm{C}(298.15$ $\mathrm{K}$ ) as selected from the database. 


\begin{tabular}{|c|c|c|c|c|c|c|}
\hline ID & Species_Name & Type & Valence & dG & dH & S \\
\hline 1 & $\mathrm{H} 2 \mathrm{O}$ & Neutral & 0 & -237290.9655 & -285937.1781 & 69.93228723 \\
\hline 2 & $\mathrm{H}<+>$ & Cation & 1 & 0 & 0 & -6.978 \\
\hline 4 & $\mathrm{Na}<+>$ & Cation & 1 & -261982.671 & -239991.6863 & 54.40971334 \\
\hline 5 & $\mathrm{~K}<+>$ & Cation & 1 & -282712.0196 & -251938.8685 & 97.43396882 \\
\hline 14 & $\mathrm{Mg}<2+>$ & Cation & 2 & -454904.1825 & -466971.642 & -148.6371456 \\
\hline 15 & $\mathrm{Ca}<2+>$ & Cation & 2 & -553789.0933 & -543017.7973 & -67.10424 \\
\hline 17 & $\mathrm{Ba}<2+>$ & Cation & 2 & -560885.6 & -537821.9 & -11.31918 \\
\hline 22 & $\mathrm{Cu}<2+>$ & Cation & 2 & 65642.13008 & 65337.7 & -119.35692 \\
\hline 26 & $\mathrm{~Pb}<2+>$ & Cation & 2 & -24296.72 & -1652.36 & -5.0505 \\
\hline 44 & $\mathrm{Al} 3+>$ & Cation & 3 & -485304.6316 & -531482.4 & -342.9106133 \\
\hline 51 & $\mathrm{~F}<->$ & Anion & -1 & -278889.744 & -332777.0667 & -6.836293333 \\
\hline 52 & $\mathrm{Cl}<->$ & Anion & -1 & -131285.6121 & -167084.4065 & 61.75841775 \\
\hline 58 & $\mathrm{NO3<->}$ & Anion & -1 & -111359.876 & -207521.0293 & 153.3366667 \\
\hline 59 & $\mathrm{OH}<->$ & Anion & -1 & -157371.7464 & -230138.7987 & -3.820585333 \\
\hline 61 & $\mathrm{HCO}<->$ & Anion & -1 & -587236.2027 & -692017.1907 & 99.49282667 \\
\hline 71 & $\mathrm{CO}<2->$ & Anion & -2 & -528174.2387 & -677231.544 & -41.70432 \\
\hline 92 & $\mathrm{CO} 2$ & Neutral & 0 & -386237.084 & -413487.26 & 119.32454 \\
\hline 95 & $\mathrm{SO} 2$ & Neutral & 0 & -300808.7514 & -323087.9196 & 162.07958 \\
\hline 97 & $\mathrm{Al}(\mathrm{NO}) 3$ & Neutral & 0 & -820000 & -1154700 & 117.6 \\
\hline 103 & $\mathrm{AlCl} 3$ & Neutral & 0 & -877567.3 & -1027080.26 & 152.3 \\
\hline 105 & $\mathrm{Ba}(\mathrm{OH}) 2$ & Neutral & 0 & -875212.468 & -995426.784 & -4.2 \\
\hline 108 & $\mathrm{BaCl} 2$ & Neutral & 0 & -822973.1 & -871234.728 & 122.6 \\
\hline 112 & $\mathrm{Ca}(\mathrm{OH})<+>$ & Cation & 1 & -718636.78 & $\mathrm{NULL}$ & $\mathrm{NULL}$ \\
\hline 113 & $\mathrm{Ca}(\mathrm{OH}) 2$ & Neutral & 0 & -869098.284 & -1002598.261 & -74.51252 \\
\hline 115 & $\mathrm{CaCl2}$ & Neutral & 0 & -816858.9067 & -876839.9907 & 59.83562 \\
\hline 128 & $\mathrm{H} 2$ & Neutral & 0 & 17584.56 & -4186.8 & 57.77784 \\
\hline 130 & $\mathrm{H} 2 \mathrm{CO} 3$ & Neutral & 0 & -623562.428 & -699710.187 & 188.5728667 \\
\hline 132 & $\mathrm{H} 2 \mathrm{SO} 4$ & Neutral & 0 & -744877.398 & -902290.86 & 20.09832 \\
\hline 134 & $\mathrm{HCl}$ & Neutral & 0 & -131155.9684 & -167111.1251 & 56.16285333 \\
\hline & & & & &
\end{tabular}

The database also contains thermodynamic data for the electrolytes of interest and approximately 450 species are listed in the database. The database is used to extract and verify the data required for the model parameters, sourced from several different literature sources, before it is used in the programming code.

In Table 6.3 the partial contents of various data base tables collected with a select query are shown. In the table below "Species_1" and "Species_2" represent different cationic or anionic species respectively. The Pitzer interaction parameters $\beta_{I, J}^{(0)}, \beta_{I, J}^{(1)}, \beta_{I, J}^{(2)}$ and $C_{I, J}^{\phi}$ are represented by "beta_0", "beta_1", "beta_2" and "C_phi" respectively. The 
Pitzer interaction parameters listed in the Table 6.3 are those at $25^{\circ} \mathrm{C}(298.15 \mathrm{~K})$. The term "max_m" refers to the maximum molality at which the parameters hold.

As mentioned above, various other thermodynamic parameters are also stored in the database. These parameters include the species valence, Gibbs free energy $(\mathrm{J} / \mathrm{mol})$, entropy (J/mol.K), etc. for the different species. These parameters are also used in the above equations as described in this dissertation. Table 6.4 gives a selected query from this database.

\subsection{SUMMARY}

In this chapter the model equations for the consolidated equilibrium model for a Resin-inPulp (RIP) slurry mixture system have been derived from various thermodynamic models describing the equilibrium distribution of the species between the various phases. In summary the set of modelling equations for the consolidated equilibrium model consists of:

i) Two mass balance equations for each species describing the distribution of the species between the aqueous and resin phases,

ii) An electroneutrality balance equation for each species in the aqueous solution phase,

iii) An equation for each species describing the equilibrium distribution between the aqueous and solution phase (thermodynamic equilibrium constant for the ionexchange reaction) and

iv) An equation for each species describing the equilibrium distribution between the aqueous and the solid precipitate phases (Solubility product equation).

Additional to these equations there are two more sets of equations describing the nonideality of both the solution and resin phases. These model equations include, 
v) The Pitzer aqueous solution activity coefficient model for each species predicting its activity coefficient and

vi) The Wilson model predicting the species resin phase activity coefficients.

All of the above mentioned model equations are solved simultaneously with an iterative procedure described in this chapter. The nature and structure of the set of model equations for the consolidated equilibrium model may differ significantly from one RIP slurry system to another, depending on the type of ion-exchange resins used (cation an/or anion exchange resin) and the species valences.

The case study for the model equations as derived in this chapter was for the case of a sparingly soluble solid with only one type of ion-exchange resin present (cation exchange resin). The formation of no other possible precipitates, as schematically represented by Figure 1.1 in Chapter 1 of this dissertation, was considered. In Chapters 8 to 11 of this dissertation these equations will be expanded to account for all of these possibilities and will be studied for the RIP slurry mixture systems under investigation in each of these chapters.

From the discussions in the beginning of this chapter it also became evident that the nature of the resin equilibrium isotherm curve has a significant effect on the model calculations. This is due to the fact that the typical isotherm curve has a very "steep" front in the very low solution phase concentration region, which is of particular interest to this dissertation. The quality of the experimental data collected in the experimental tests, performed for the purposes of this dissertation, is therefore of significant importance. The values for the thermodynamic model parameters used are also of critical importance. To ensure the maximum accuracy and consistency in the use of these thermodynamic model parameters, as obtained from the literature, a SQL7 database was designed and populated with thermodynamic data from various literature sources. The structure of the database is briefly discussed above, but will be done in more detail in Chapter 8 to 11 
when the data from the database are used in solving the set of consolidated equilibrium model equations.

Another important feature of the consolidated equilibrium model for the RIP slurry mixture system is the fact that the calculation of the thermodynamic equilibrium constant for the ion-exchange reaction is de-coupled from the set of modelling equations. The calculation of the thermodynamic equilibrium constant for the ion-exchange reaction is described in detail in paragraph 6.6 of this chapter.

In Chapter 8 a detailed discussion on the experimental results for the resin / solution interface will be conducted. This discussion will form the basis for all of the calculations performed in the subsequent chapters, together with the proposed consolidated model as presented in this chapter. From the discussions above it followed that the thermodynamic equilibrium constant for the ion-exchange reaction is de-coupled from the consolidated equilibrium model by estimating the values of this parameter separately. This concept was discussed in paragraph 6.6 of this chapter. Before continuing with the consolidated equilibrium model calculations in Chapters 9 to 11 the objective of Chapter 8 will be to provide the necessary information and concepts on the thermodynamic equilibrium constant. This will be done for the various RIP slurry mixture systems of interest to this dissertation. 


\section{CHAPTER 7}

\section{EXPERIMENTAL PROCEDURES AND ANALYSES}

\subsection{PREPARATION OF ION EXCHANGE RESINS FOR USE IN KINETIC AND EQUILIBRIUM EXPERIMENTS}

Industrial grade Duolite resins [Manufactured by Rohm \& Haas Co., supplied by ACIX / NCP Ltd., Germiston, South Africa] were used in all experiments during this study. The virgin resin, as received from the suppliers, in either 25 or 50 litre sealed plastic bags is hardly fit for use in any experimental procedure where the aim is to obtain accurate and reproducible results at very low solution phase concentrations of the species of interest. The resin particles used were carefully selected since the rates of ion exchange and sorption equilibrium depended strongly on particle shape, size and composition. The ionexchange resin in its bulk form as received from the suppliers includes numerous broken, cracked and non-spherical particles. In the case of macroreticular resins (macro-porous resins) the composition of the particles also differs significantly with regard to their internal porosity. This is an important feature of newly acquired macroreticular resin and needs further discussion to highlight the utmost importance of good resin preparation procedures.

Macroreticular ion exchange resins have been developed due to the need for ion exchangers having particular mechanical properties such as higher porosities and special internal geometric forms for certain applications. Macroreticular ion exchange resins are formed by introducing an organic solvent to the reaction mixture containing the monomers, which is a good solvent for the monomers but a poor solvent for the polymer matrix formed, as the monomers polymerise to form the polymer resin matrix. The added solvent occupies space in the reaction mixture that could have been filled with monomers participating in the polymerisation process. Consequently no polymerisation occurs in 
this occupied space region. The resin polymer matrix is then formed around this region occupied by the added solvent.

As the polymerisation process proceeds, the solvent is squeezed out by the growing polymer matrix and later washed from the beads resulting in spherical beads with wide internal pores. It is obvious that the manner, in which the solvent is introduced to the reaction mixture containing the monomers, will greatly influence the final internal polymer matrix structure. Many resin beads, as received from the suppliers, end up being completely or partially hollow on the inside, although they seem exactly the same as the other denser resin particles. These large internal cavities in the resin beads greatly reduce their exchange capacity, due to active sites being lost that are fixed to the polymer matrix that could have filled the cavity. It is clear that in order to ensure reproducible experimental results the "internally deformed" resin beads must be separated from the bulk of denser particles.

In order to achieve all of the above mentioned the following experimental procedure was followed to obtain and fully prepare a batch of resin particles with uniformly distributed characteristics.

\subsubsection{Initial resin batch washing}

It is necessary to thoroughly wash the resin with de-mineralised water prior to any further handling. This is done in order to remove any chemical substances, excess electrolyte solutions and organic solvents (used to create the macropore structures in the case of macroreticular resins) from the resin beads. This washing procedure is performed and repeated during the batch preparation procedure, with 15 to 20 litres of resin per batch. Initially the effluent water will be very foamy and varying in colour depending on the type of resin (gel-type, macroreticular, cation or anion) washed. 
Only distilled water should be used throughout the whole washing procedure. During sorption of ions onto the resin, the configuration around each active group fixed to the polymer matrix changes since the adsorbed ion has a different size and hydration layer than the displaced ion. The resin bead may, therefore, swell or contract appreciably during the exchange reaction, which can cause a total reversible swelling and volume change of up to $20 \%$ in the resin beads. It is clear that in order to prevent any resin beads from swelling or contracting during the initial washing procedure only soft water should be used. The resin is washed until the effluent water becomes clear and foam free and thus all of the above mentioned substances have been removed from the resin beads.

Table 7.1 Conventional screen and constructed square surface screen sizes used for screening the resin particles into different size fractions.

\begin{tabular}{|c|c|}
\hline Conventional & Constructed \\
\hline$+1180 \mu \mathrm{m}$ & $+1200 \mu \mathrm{m}$ \\
\hline $1180 \mu \mathrm{m}$ & $1200 \mu \mathrm{m}$ \\
\hline $1000 \mu \mathrm{m}$ & $1000 \mu \mathrm{m}$ \\
\hline $850 \mu \mathrm{m}$ & $900 \mu \mathrm{m}$ \\
\hline $710 \mu \mathrm{m}$ & $711 \mu \mathrm{m}$ \\
\hline $600 \mu \mathrm{m}$ & $572 \mu \mathrm{m}$ \\
\hline $500 \mu \mathrm{m}$ & $451 \mu \mathrm{m}$ \\
\hline$-500 \mu \mathrm{m}$ & $-451 \mu \mathrm{m}$ \\
\hline
\end{tabular}

\subsubsection{Sizing the resin particles by screening into distinct size fractions}

Most resin manufacturers screen and bag their resins partially dried. When the resin beads are fully water-swollen they become slightly larger, another reason why the beads are washed with de-mineralised water prior to screening, thus to allow them to become fully swollen. After the initial washing procedure the resin beads were wet screened into distinct size fractions. The screening process can be very time consuming, depending on 
the amount of resin that needs to be screened, when using conventional laboratory screens with a typical diameter of about $20 \mathrm{~cm}$.

To reduce the screening time needed, large square surface area screens $(45 \mathrm{~cm} \times 45 \mathrm{~cm} \times$ $6 \mathrm{~cm}$ high) were made from high quality stainless steel wire cloth of the appropriate aperture size melted into a square PVC sized frame. The screens fitted into a rectangular PVC water bath $(55 \mathrm{~cm} \times 75 \mathrm{~cm} \times 20 \mathrm{~cm}$ deep $)$ and were partially submerged when the resin was added on top of the screen.

Standard industrial grade resins contain particles with diameters ranging from $300 \mu \mathrm{m}$ to $1200 \mu \mathrm{m}$. Coarser or finer grades are also available, but are not commonly used in industry due to their hydrodynamic behaviour in counterflow systems. The resin beads always have a range of particle sizes rather than a uniform size, which are determined by the manufacturing process variables. For industrial use approximately $80 \%$ of the resin particles fall in the size range $500 \mu \mathrm{m}$ to $1000 \mu \mathrm{m}$. This is a compromise between the speed of the ion exchange reaction (which is greater with small resin beads) and the hydrodynamic behaviour of the particles in high flow rate process streams (which require coarse particles to minimise the head loss). Table 7.1 shows the different screen sizes used in the screening procedures for the conventional and constructed square surface screens.

\subsubsection{Final washing and particle selection in a fluidised column set-up}

After screening the resin particles into the distinct size fractions, further washing of a particular size fraction was carried out in a fluidised column set-up as shown in Figure 7.1 .

The inside diameter of the glass columns was $40 \mathrm{~mm}$ and the length, from above the glass sinter to the exit port at the top of each column was $90 \mathrm{~cm}$. The columns were connected in series so that the effluent stream from column number one was used as the inlet stream 
to column number two, which was repeated with columns two and three, and three and four. The effluent stream from each column could also be drained directly into a container by the opening or shutting of valves. A Watson and Marlow no. 503S variable speed peristaltic pump with Marprene tubing was used to pump the solution from the reservoir container upwards through column number one.

The fluidised resin beds were used to perform the particle selection process. Each of the glass columns was filled with approximately 0.75 litres of resin. The ion-exchange resins were thoroughly washed in a fluidised bed for two reasons:

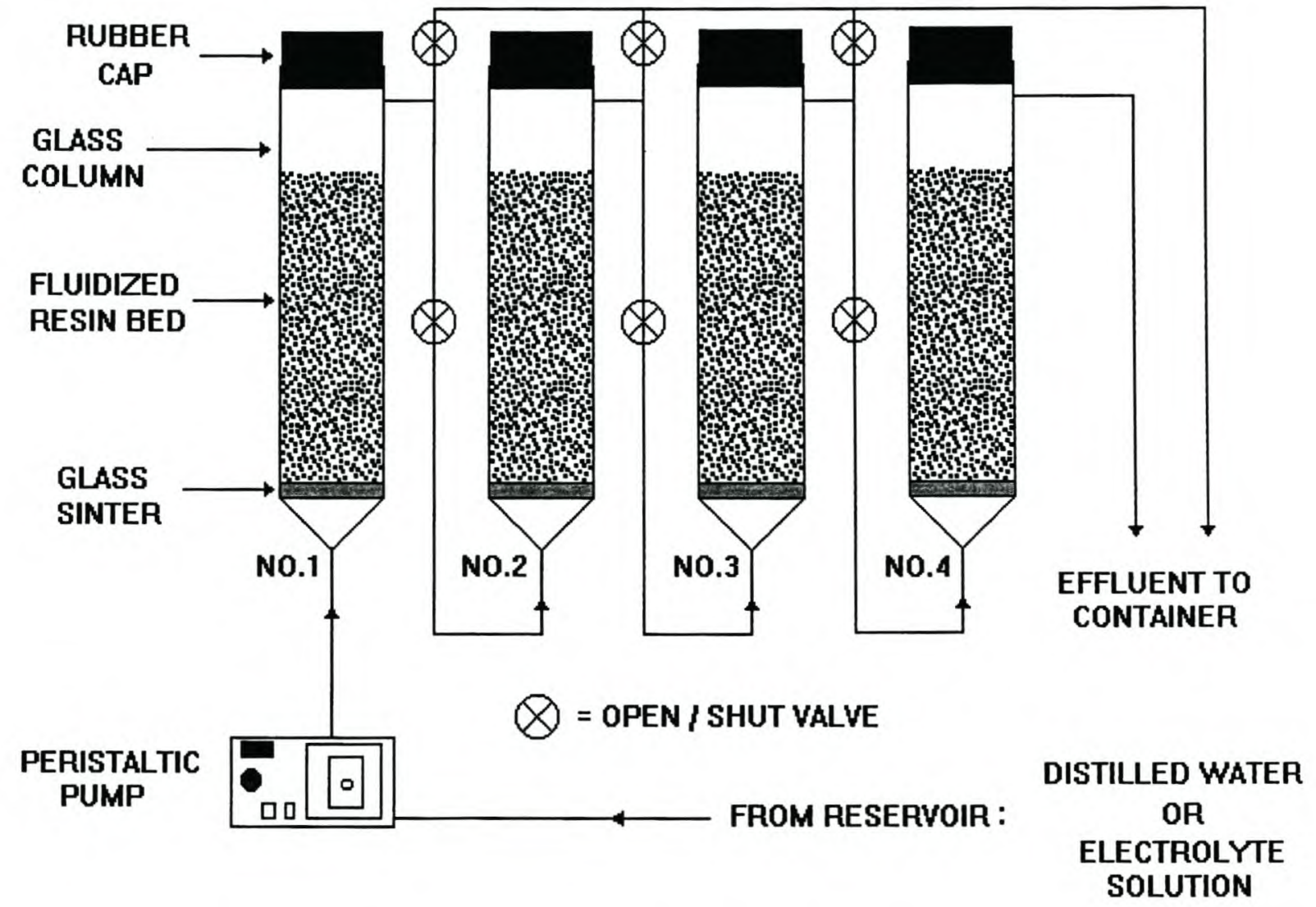

Figure 7.1 A schematic diagram of the column set-up used to convert the functional groups of a specific size fraction of the ion exchanger to the desired ionic form. 
Firstly to remove the last traces of unwanted chemical substances such as solvents and free ionic species, which could not be achieved completely during batch washing. Secondly, but more importantly, to allow the resin particles to be separated into different zones according to their physical properties.

To achieve this desired physical separation, 25 litres of distilled water was pumped through the columns at a constant flowrate ( 8 litres per hour) which easily allowed a fixed bed expansion of between $30 \%$ and $40 \%$. The broken, half split, hollow (less densely) and deformed (small non-spherical pieces) resin particles accumulated in approximately the top $2 \%$ of the fluidised bed. Any undersized resin particles present in the particular size fraction, due to unwanted displacement during the screening procedure, also reported to this zone. These unwanted particles were then removed by continually increasing the upward flowrate of the distilled water through each column successively (starting with column number one) until almost all the unwanted particles reported to the effluent stream where they were flushed away. The only unwanted particles that could not be selected and removed this way, were the perfect spherical particles of appropriate size with fine cracks and flaws in their structures.

\subsubsection{Converting the resin matrix functional groups to a specific ionic form}

As described earlier, the configuration around each active group in the resin changes during ion exchange because the adsorbed ion generally has a different size and hydration layer compared to the displaced ion. The resin bead may therefore swell or contract to an appreciable extent during the ion exchange reaction, which results in stresses in the polymer matrix. These intense forces on the polymer matrix are better known as osmotic forces and can produce local pressures of several thousand kilo pascal.

The resin was transformed to the desired ionic form by fluidisation using 20 litres ( 7 bed volumes per column) of a two normal strength solution ( $2 \mathrm{~N}$ solution) of the desired ion at 
a constant flowrate of 4 litres per hour. The immense osmotic forces associated with such concentrated electrolyte solutions caused fragmentation of any resin bead with a flaw in its structure. The broken particles reported to the top of the fluidised beds. Table 7.2 shows the chemicals used for the different ionic conversions.

Table 7.2 Chemicals used to convert the ion exchange resins to a specific ionic form. (All chemicals were of analytical reagent grade.)

\begin{tabular}{|c|c|}
\hline Cationic Resin Form & Chemical \\
\hline $\mathrm{R}^{-} H^{+}$ & $\mathrm{HCl}$ \\
\hline $\mathrm{R} \mathrm{Na}^{+}$ & $\mathrm{NaCl}$ \\
\hline $\mathrm{R}^{-} \mathrm{K}^{+}$ & $\mathrm{KCl}$ \\
\hline$\left(\mathrm{R}^{-}\right)_{2} \mathrm{Cu}^{+2}$ & $\mathrm{CuSO}$ \\
\hline$\left(\mathrm{R}_{3}^{-}\right)_{3} \mathrm{Al}^{+3}$ & $\mathrm{Al}\left(\mathrm{NO}_{3}\right)_{3}$ \\
\hline Anionic Resin Form $^{+}$ & $\mathbf{C h e m i c a l}$ \\
\hline $\mathrm{R}^{+} \mathrm{Cl}^{-}$ & $\mathrm{NaCl}$ \\
\hline $\mathrm{R}^{+} \mathrm{NO}_{3}^{-}$ & $\mathrm{NaNO}$ \\
\hline $\mathrm{R}^{+} \mathrm{OH}^{-}$ & $\mathrm{NaOH}$ \\
\hline
\end{tabular}

\subsubsection{Removal of excess electrolyte solution by washing with distilled water}

After the resin was fully converted to a specific ionic form it was washed with distilled water in the fluidised bed set-up until no more free ionic species could be measured in the effluent stream of column number four. This usually required 50 litres of distilled water being pumped through the four columns connected in series, at a flowrate of 4 litres per hour. This resulted in a fixed bed expansion of between $20 \%$ and $30 \%$, depending on the density of the newly converted resin, which was necessary for the mass transfer processes to be efficient. Cation resins are also much denser than anion resins and consequently need larger flowrates to achieve similar bed expansions. 
The resin beads that fragmented when washed with the strong electrolyte solution were also removed from the top of the fluidised bed by increasing the flowrate of the distilled water until it reported to the effluent stream. The physical properties of the resin particles left after this final preparation stage had a very narrow distribution range in their density, structure and size.

\subsection{PREPARATION OF ION EXCHANGE RESINS AND CARBON SAMPLES FOR THE DETERMINATION OF TRACE ELEMENTS BY ATOMIC ABSORPTION SPECTROPHOTOMETRY}

The method described in this section is essentially for the determination of trace elements in activated carbon, ion exchange resins and other similar organic matrices. Dissolution method 1 (as described in paragraph 7.2.1.5 in this section) is the preferred method for the determination of gold and some base metals, but it is unsuitable for silver. Dissolution method 2 is used for silver, and can also be used for gold and certain base metals. It is however, more time consuming than method 1. Dissolution method 3 is suitable for $\mathrm{Ca}, \mathrm{Mg}, \mathrm{K}, \mathrm{Pb}, \mathrm{Mn}, \mathrm{Na}, \mathrm{Ni}$ and $\mathrm{Fe}$. In Table 7.3, the concentration range and background matrix for each analyte are presented.

\subsubsection{Preparation procedure}

The analyses for ionic species adsorbed onto activated carbon and ion exchange resins can give rise to a number of experimental difficulties. This section presents an outline that can be followed to overcome these difficulties and achieve accurate and reproducible results.

There are five basic steps in the resin sample preparation procedure, i.e.
i. Washing
ii. Drying 
iii. Pulverising
iv. Ashing of the dried resin sample
v. Dissolution of the ashed sample to liberate ionic species.

\subsubsection{Washing of the resin sample}

The resin sample obtained from the reactor must firstly be washed thoroughly with distilled water to remove all excess electrolyte solution from the resin bead pores and interstitial spaces, since this electrolyte solution still contains free unbound counter ions. This preliminary washing of the resin sample will ensure that only the exchanged, fixed counter ions are left in the beads, and hence no over determination of the actual amount of counter ions exchanged will be made.

This washing procedure becomes even more important when a macro reticular (macroporous) ion-exchanged resin is used, since these resins have pore diameters of up to $1500 \stackrel{\circ}{A}$. Much more electrolyte solution will penetrate these macro-pores, containing free unbound ionic species. Clogging and fouling of ion exchange resins are a known fact.

Penetration of the macro-pores on the resin bead surface by finely dispersed particles is also a possibility, depending on the particle size distribution of the solids. Hence, if the macro-porous resin sample has been in contact with a finely dispersed ore, there is a distinct possibility that the very fine particles have penetrated into the macro-pores. These particles may also contain ionic species, which can influence the end result of the analysis.

To remove these fine particles, the resin should be washed thoroughly to ensure accurate results. When macro-porous anion exchangers are used with an ore containing silicates, the problem of fouling is enhanced. When using such systems, special care should be taken in choosing the experimental conditions to limit the fouling of the resin. 
Table 7.3 Methods and background solutions needed to analyse for the different species.

\begin{tabular}{|c|c|c|c|}
\hline Method & $\begin{array}{c}\text { Dissolution } \\
\text { Element }\end{array}$ & Calibration Range & Matrix \\
\hline Method 1 & $\mathrm{Cu}$ & $0.5 \mathrm{ppm} \rightarrow 6 \quad \mathrm{ppm}$ & $10 \% \mathrm{HCl}$ or $10 \% \mathrm{HNO}_{3}$ \\
\hline Method 1 or 2 & Co & $0.25 \mathrm{ppm} \rightarrow 2 \quad \mathrm{ppm}$ & $\begin{array}{c}10 \% \mathrm{HNO}_{3} \text { or } 40 \% \mathrm{HCl} \text { with } \\
1 \% \mathrm{KNO}_{3}\end{array}$ \\
\hline Method 1 or 2 & $\mathrm{Au}$ & $0.1 \mathrm{ppm} \rightarrow 10 \mathrm{ppm}$ & $30 \% \mathrm{HCl} \quad 10 \% \mathrm{HNO}_{3}$ \\
\hline Method 2 or 3 & $\overline{\mathrm{Ag}}$ & $0.2 \mathrm{ppm} \rightarrow 5 \quad \mathrm{ppm}$ & $40 \% \mathrm{HCl}$ \\
\hline Method 2 or 3 & $\mathrm{~Pb}$ & $1.0 \mathrm{ppm} \rightarrow 12 \mathrm{ppm}$ & $40 \% \mathrm{HCl}$ or $10 \% \mathrm{HNO}_{3}$ \\
\hline Method 3 & $\mathrm{Ca}$ & $0.2 \mathrm{ppm} \rightarrow 3 \mathrm{ppm}$ & $10 \% \mathrm{HNO}_{3} \quad 1 \% \mathrm{KNO}_{3}$ \\
\hline Method 3 & $\mathrm{Mg}$ & $0.2 \mathrm{ppm} \rightarrow 2.5 \mathrm{ppm}$ & $10 \% \mathrm{HNO}_{3} \quad 1 \% \mathrm{La}\left(\mathrm{NO}_{3}\right)_{3}$ \\
\hline Method 3 & $\mathrm{~K}$ & $0.1 \mathrm{ppm} \rightarrow 0.8 \mathrm{ppm}$ & $\begin{array}{c}10 \% \mathrm{HNO}_{3} \text { or } 10 \% \mathrm{HCl} \text { with } \\
1 \% \mathrm{La}\left(\mathrm{NO}_{3}\right)_{3}\end{array}$ \\
\hline Method 3 & $\mathrm{Fe}$ & $1.0 \mathrm{ppm} \rightarrow 30 \mathrm{ppm}$ & $\begin{array}{c}10 \% \mathrm{HNO}_{3} \text { or } 40 \% \mathrm{HCl} \text { with } \\
1 \% \mathrm{KNO}_{3}\end{array}$ \\
\hline Method 3 & $\mathrm{Mn}$ & $\begin{array}{l}0.2 \mathrm{ppm} \rightarrow 2.5 \mathrm{ppm} \\
10 \mathrm{ppm} \rightarrow 150 \mathrm{ppm}\end{array}$ & $10 \% \mathrm{HNO}_{3}$ with $1 \% \mathrm{KNO}_{3}$ \\
\hline Method 3 & $\mathrm{Na}$ & $0.25 \mathrm{ppm} \rightarrow 2.5 \mathrm{ppm}$ & $10 \% \mathrm{HNO}_{3} \quad 1 \% \mathrm{La}\left(\mathrm{NO}_{3}\right)_{3}$ or \\
\hline & & & $10 \% \mathrm{HNO}_{3} 0.2 \% \mathrm{KHphtalate}$ \\
\hline Method 3 & $\mathrm{Ni}$ & $1 \mathrm{ppm} \rightarrow 12 \mathrm{ppm}$ & $10 \% \mathrm{HNO}_{3} \quad 1 \% \mathrm{KNO}_{3}$ \\
\hline Method 3 & $\mathrm{Zn}$ & $0.1 \mathrm{ppm} \rightarrow 1.2 \mathrm{ppm}$ & $10 \% \mathrm{HNO}_{3}$ with $1 \% \mathrm{KNO}_{3}$ \\
\hline Method 3 & $\mathrm{Al}$ & $40 \mathrm{ppm} \rightarrow 200 \mathrm{ppm}$ & $\begin{array}{c}10 \% \mathrm{HCl} \text { or } 10 \% \mathrm{HNO}_{3} \text { with } \\
1 \% \mathrm{KNO}_{3}\end{array}$ \\
\hline
\end{tabular}

The importance of proper washed resin samples is evident from the above discussion, since insufficient or no washing can result in inaccurate results. Over estimation of the actual amount of counter ionic species adsorbed onto the resin matrix may result, leading to significant errors in the case of low resin coverage by the desired species. 
Quantitatively:

A $10-20 \mathrm{ml}$ free wet settled volume (FWSV) resin sample should be washed with 300 $500 \mathrm{ml}$ of distilled water in a small fluidised column at a flowrate of $15-25 \mathrm{ml} / \mathrm{min}$ if the resin has only been in contact with clear, particle free electrolyte solutions. If a column is not available, it can be done in a CSTR or by shaking the sample by hand with $100-200$ $\mathrm{ml}$ of distilled water, repeating this procedure three or more times with fresh distilled water. It is also preferred that the sample is shaken by hand if fines are clogging the surface pores, since this method results in the enhanced removal of the fines when compared with fluidisation.

\subsubsection{Drying of the resin sample}

The washed resin sample is air dried in an oven for 3 hours at $110^{\circ} \mathrm{C}$ before ashing. This is to ensure that most of the pore liquid evaporates, which should at this stage of the preparation only be distilled water, and that no "steam pockets" are formed during the ashing of the resin sample at more elevated temperatures. If any distilled water is left inside the resin beads or in the bulk resin sample on the bead surfaces, it will result in "steam explosions" as steam pockets are formed rapidly at ashing temperatures of 800 $1000^{\circ} \mathrm{C}$. This will result in the sample being displaced from the ashing crucible and thus will result in inaccurate results.

\subsubsection{Pulverising the dried resin sample}

The dried resin sample is then pulverised before ashing to ensure complete degradation of the resin polymer matrix. If the dried resin sample is ashed in the non-pulverised form, the time needed for complete ashing increases and the centre of the beads is often not completely ashed. This results in incomplete dissolution and inaccurate results. Care should be taken not to contaminate the sample during pulverising. The maximum amount 
of the pulverised sample possible should be recovered from this processing step for further analyses.

\subsubsection{Drying and ashing of the crushed resin sample}

This processing step is very important in the preparation procedure of the samples, since incomplete ashing will result in incomplete dissolution and inaccurate results. There are two important factors affecting the ashing step, i.e. the choice of a suitable crucible that can withstand the elevated temperatures and the method of sample introduction to the elevated temperatures.

Ashing of a carbon or anion exchange resin, which has only been in contact with a clear electrolyte solution, should be performed in a porcelain crucible of which the gloss is still in a good condition. This is to ensure that none of the ionic species is adsorbed into the walls of the crucible, since porcelain has a fine porous structure. Platinum crucibles should be used for resin samples that have been in contact with ore slurries containing silicates, since hydrofluoric acid is required in the treatment of these ashed samples. The second important factor in ashing the samples is the method of sample introduction. The samples should be placed in the furnace at $60^{\circ} \mathrm{C}$ and ashed by gradually increasing the temperature to between $800-1000^{\circ} \mathrm{C}$. The resin sample should be ashed until a white residue is obtained. Darker coloured residues usually indicate incomplete ashing.

Quantitatively:

(a) Dry the crushed resin samples and the reference sample in an air oven for 3 hours at $110^{\circ} \mathrm{C}$.

(b) Cool the dried samples in a desicator and transfer 1.0 gram of sample to a suitable silica or porcelain crucible $(100-200 \mathrm{ml})$. A separate dish of 1.0 gram of reference standard is prepared as well. Place the dishes in a cold muffle furnace and set the 
temperature to between $800-1000{ }^{\circ} \mathrm{C}$. The samples are left in the furnace for 48 hours to completely ash. Toxic gases may result from the ashing procedure, and an extractor fan should be used to remove the gases from the furnace. The crucible should be covered with a non-reacting porous lid to prevent any displacement of the sample from the crucible during the ashing period, but allowing for sufficient air to reach the sample to ensure complete ashing.

NOTE: The reference standard is a resin sample of which the exact analyte element composition is known. It is treated under the same experimental conditions as the other resin samples while preparing the batch of samples for analyte element determination.

(c) Remove the dishes from the muffle furnace after 48 hours, cover with watch glasses and allow cooling.

\subsubsection{Dissolution of the ashed resin sample}

The ashed resin residue is transferred to a platinum crucible and dissolved in an acid solution, followed by boiling the solution until the entire ashed sample is dissolved completely. This can be done by allowing the residue and solution mixture to percolate at the boiling point of the acid solution until the mixture becomes clear when the entire solid residue has dissolved. A clear yellowish solution is obtained with complete dissolution. The clear solution obtained is then allowed to cool and transferred to a volumetric flask, which is then filled to volume. This solution is then analysed for the ionic species of interest.

Quantitatively:

For a $1 \mathrm{~g}$ pulverised resin sample, follow after complete ashing: 


\section{Method 1}

For the determination of $\mathrm{Au}, \mathrm{Cu}$ and $\mathrm{Co}$.

(a) Transfer the ashed resin residue to a $125 \mathrm{ml}$ Phillips beaker. Wash the silica or porcelain dish with aqua regia. Cover the beaker with a watch glass, place on a hot plate and allow to reflux for fifteen minutes or more until all of the residue dissolves.

(b) Wash and remove the watch glasses. Evaporate the solution carefully to near dryness.

(c) Add $2 \mathrm{ml}$ of aqua regia, warm slightly and transfer to a $25 \mathrm{ml}$ volumetric flask. Make up to volume with an acid mixture of $35 \% \mathrm{HCl}, 5 \% \mathrm{HNO}_{3}$ and $60 \% \mathrm{H}_{2} \mathrm{O}$.

\section{Method 2}

For the determination of $\mathrm{Ag}, \mathrm{Au}, \mathrm{Cu}, \mathrm{Co}$ and $\mathrm{Pb}$

(a) Transfer the ashed resin residue to a $250 \mathrm{ml}$ Teflon beaker. Add $10 \mathrm{ml} \mathrm{HNO}_{3}$ and 10 $\mathrm{ml} \mathrm{HClO} 4$. Heat, slowly at first, on a hot plate and cover the beaker with a watch glass. Allow percolating at the boiling point of the acid mixture for $\sim 10$ minutes. Remove the lid and fume until the volume is reduced to $\sim 2$ or $3 \mathrm{ml}$.

NOTE: In the case of $\mathrm{Au}$ determination the $\mathrm{HNO}_{3}$ is replaced with aqua regia. The Teflon beaker should be covered with a lid at first since the presence of $\mathrm{HCl}$ in $\mathrm{HClO}_{4}$ causes a strong reaction. Remove the lid and fume until the volume is reduced to $\sim 2$ or $3 \mathrm{ml}$.

(c) Add $\sim 6 \mathrm{ml}$ of distilled water (aqua regia in case of $\mathrm{Au}$ ) and boil for 10 minutes. Fume to near dryness.

(d) Add $8 \mathrm{ml} \mathrm{HCl}$ and $2 \mathrm{ml} \mathrm{HNO}_{3}$ and heat the beaker with a lid on for 5 minutes. 
(d) Transfer the solution to a $25 \mathrm{ml}$ volumetric flask, rinsing the beaker with distilled water. Dilute to volume with distilled water.

\section{Method 3}

For the determination of $\mathrm{Ag}, \mathrm{Al}, \mathrm{Ca}, \mathrm{Mg}, \mathrm{K}, \mathrm{Na}, \mathrm{Fe}, \mathrm{Mn}, \mathrm{Ni}, \mathrm{Pb}, \mathrm{Co}$ and $\mathrm{Zn}$.

Platinum is preferred to Teflon when analysing for the alkali elements, because the volatilisation of the last traces of perchloric acid is facilitated. It is necessary to expel the perchloric acid to prevent the formation of insoluble perchlorates.

(a) Transfer the ashed resin residue to a platinum dish. Wash the silica or porcelain dish with $10 \mathrm{ml} \mathrm{HNO}_{3}$ and $10 \mathrm{ml} \mathrm{HClO}_{4}$. Cover the platinum dish with a Teflon lid (not watch glass) and place on a hot plate. Heat, slowly at first, and allow percolating at the boiling point of the acid mixture for 10 minutes.

(b) Remove and wash the lid and fume until the volume is reduced to $\sim 2$ or $3 \mathrm{ml}$.

(c) Cool the solution and add $5 \mathrm{ml} \mathrm{HClO}_{4}$ and $10 \mathrm{ml} \mathrm{HF}$.

(d) Take to near dryness. Add $3 \mathrm{ml} \mathrm{HNO}_{3}$ and bake dry. Care should be taken not to ignite the residue.

(e) Add $3 \mathrm{ml} \mathrm{HNO}_{3}$, heat slightly and transfer to a $25 \mathrm{ml}$ volumetric flask. Dilute to volume after adding appropriate de-ionising agent shown in Table 7.3.

NOTE: In the case of $\mathrm{Fe}$ and $\mathrm{Mn}$ determinations $\mathrm{HCl}$ must be used in place of $\mathrm{HNO}_{3}$ to dissolve the salts in step (d) of Method 3.

\subsubsection{6}

Measurement

Make all further dilutions with the appropriate matrix solution so that the absorbence of the analyte elements falls within the range of the calibration standards. The solution can now be analysed for the desired cationic species using an Atomic Absorption 
Spectrophotometer (Varian AA-1275 series) or an ICP Emission Spectrometer (Varian Liberty 200).

\subsubsection{Reagents}

All chemicals used are of analytical reagent grade to avoid any contamination. All glassware is rinsed with warm $50 \%$ aqua regia and then with distilled water. Teflon and platinum equipment are cleaned with $40 \% \mathrm{HCl}$. The following reagents were used:

(1) Hydrochloric acid 37\%, Merck.

(2) Nitric Acid 65\%, Merck.

(3) Perchloric Acid $70-72 \%$, Merck.

(4) Hydrofluoric-Acid 50\%, Merck.

(5) Aqua regia: mix three volumes of hydrochloric acid with one volume of nitric acid.

(6) Potassium nitrate solution, $[100 \mathrm{~g} / 1]$. Dissolve $10 \mathrm{~g} \mathrm{KNO}_{3}$ in $100 \mathrm{ml}$ distilled water.

(7) Lanthanum solution, $[10 \mathrm{~g} / 1]$. Dissolve $31.2 \mathrm{~g} \mathrm{La}\left(\mathrm{NO}_{3}\right)_{3}$ in $100 \mathrm{ml}$ distilled water.

(8) Caesium solution, $[20 \mathrm{~g} / 1]$. Dissolve $3 \mathrm{~g} \mathrm{CsNO}_{3}$ in $100 \mathrm{ml}$ distilled water.

(9) Potassium hydrogen phthalate solution, [20g/1]. Dissolve $2 \mathrm{~g} \mathrm{C}_{8} \mathrm{H}_{5} \mathrm{KO}_{4}$ in $100 \mathrm{ml}$ distilled water.

\subsection{CALCULATION OF PARAMETERS NEEDED IN KINETIC AND EQUILIBRIUM PROCESS MODELLING}

The effective capacity of an ion exchanger, which can be considered as a reservoir of exchangeable counter ions, and the behaviour of the fixed ionic groups under different physical conditions are some of its most important characteristics. The total counter ion content of a given ion exchange resin is equal to the total amount of fixed charges that must be balanced by the counter ions, which is constant for a given ion exchanger. From 
a practical point of view it is therefore important to express this total counter ion content (effective capacity) in useful terms which will reflect its independence from variables such as particle shape, size and the nature of the counter ion balancing the ion exchanger's content of fixed charges. To satisfy this objective the capacity of the ion exchanger must be characterised in a quantitative manner, which means that the exact amount of ion exchange material must be specified. Due to the importance of this matter, many different authors have different concepts of expressing the effective capacity of an ion exchanger under a given set of physical parameters, and consequently many different definitions and units have been used which leads to considerable confusion. In the light of the above it is therefore the objective of this section to define the exact amount of ion exchange material that is present in a measured volume of ion exchange resin.

Besides the need to define and measure the effective capacity of an ion exchanger, other important properties are also dependent on the exact amount of ion exchange material measured. One such property of a measured volume of ion exchange resin beads of a specific particle size distribution is the total surface area available for mass transfer, which must be known to perform any mass transfer calculations.

\subsubsection{Experimental procedure}

The following experimental procedure is proposed to calculate the specific amount of ion exchange material in a measured volume of ion exchange resin beads of particular particle diameter, $d_{p}$. It is assumed that the experimental preparation procedure for ion exchange resins, as outlined in section 7.1 of this chapter, has been followed. This will ensure a narrow distribution of the physical properties of the resin particles (density, structure and size) and it can be assumed that the resin beads are perfect spheres.

Figure 7.2 is a conceptual representation of a measured volume of ion exchange resin beads in the measuring beaker. The volume of resin beads can be measured as either a 
free wet settled volume of resin beads (FWSV) or as a densely packed resin volume (DPRV).

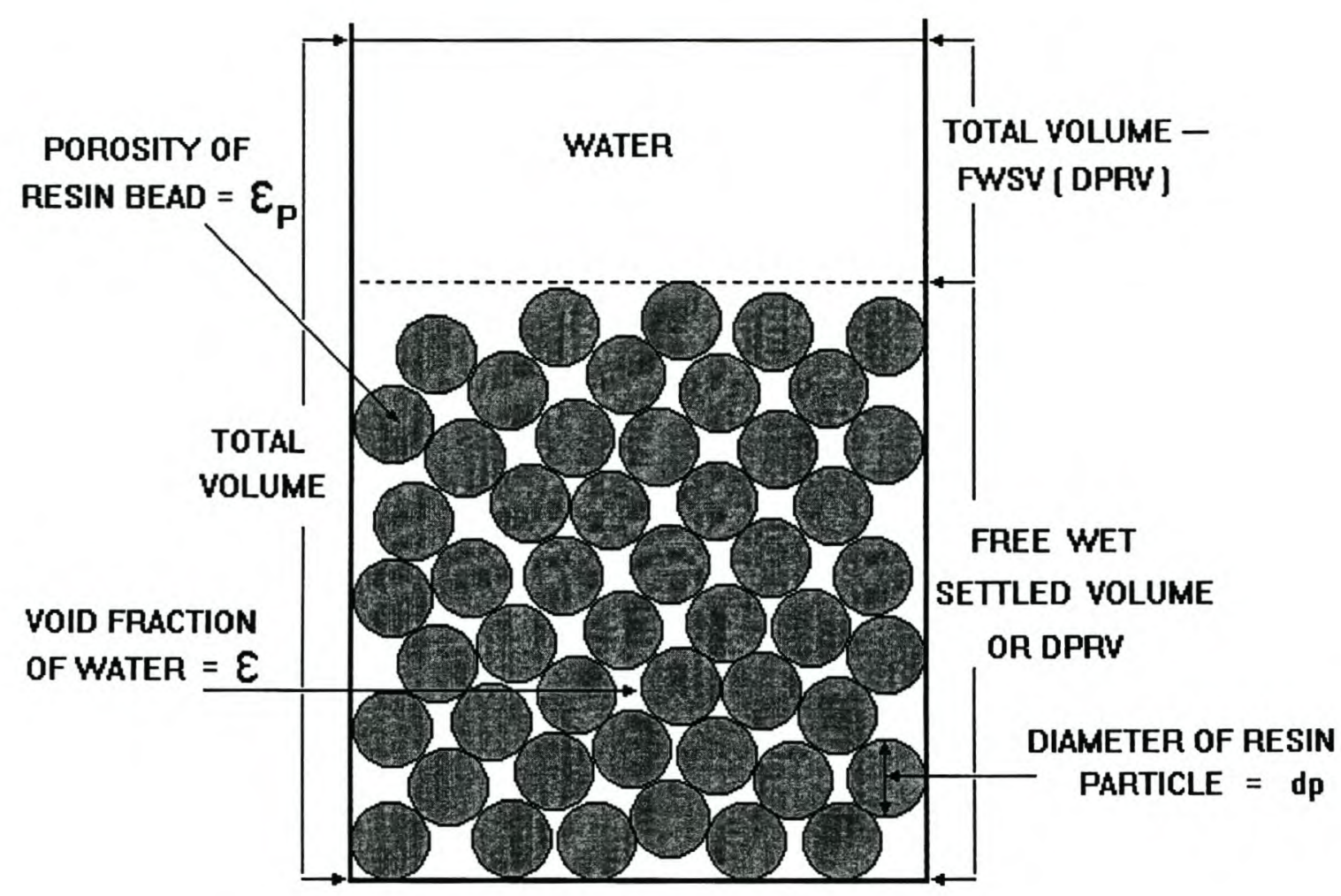

Figure 7.2 Conceptual diagram of a volume of measured resin beads of uniform particle size in a volumetric flask filled to volume with distilled water.

\section{Nomenclature for Figure 7.2}

$d_{p} \quad$ Diameter of the resin bead particle

DPRV Densely packed resin volume. This is the volume of resin when allowed to settle as densely as possible by tapping the measuring beaker until no more consolidation is observed.

FWSV Free Wet Settled Volume. This is the volume of resin when allowed to settle freely under the force of gravity in water at standard conditions. 


$\begin{array}{ll}M & \text { Total mass } \\ M_{R} & \text { Mass of resin matrix } \\ M_{L} & \text { Mass of water } \\ V_{R} & \text { Volume of resin matrix } \\ V_{W} & \text { Volume of water } \\ \varepsilon & \text { Volume fraction of water in a FWSV (or DPRV) of resin of particle size } \\ d_{p} & \\ \varepsilon_{p} & \text { Volume fraction of water in a single resin bead of particle size } d_{p} \text {, porosity } \\ \rho_{R} & \text { The density of the resin matrix excluding the water content } \\ \rho_{R w} & \text { liquid } \\ \rho_{w} & \text { The density of water }\end{array}$

- A free wet settled volume (FWSV) of resin is measured when the resin beads are allowed to settle freely and only under the force of gravity in the measuring beaker at the prevailing physical conditions. The physical properties of the resin beads, such as density and particle size, have a very definite effect on the FWSV of resin measured. Accurate and reproducible results are only obtainable if the amount of resin to be measured is large enough. This method of measuring works well when more than $5 \mathrm{ml}$ of resin needs to be measured. The length and volume capacity of the measuring beaker must also be sufficient to allow the resin beads to settle relatively freely and undisturbed from one another.

- A densely packed resin volume (DPRV) is the volume of resin when the beads are allowed to settle as densely as possible by tapping the measuring beaker until no more consolidation is observed. This method is the preferred one when measuring relatively small amounts of resin $(<5 \mathrm{ml})$ since it is not influenced strongly by the physical properties of the resin beads such as density. 
The measured volume of ion exchange resin is added to a volumetric flask, which is then carefully filled to volume with distilled water. The total mass of the volumetric flask with its contents is then measured accurately on a four decimal laboratory scale. This mass is then noted against the volume of ion exchange resin present in the flask. Part of the distilled water is decanted from the volumetric flask and the volume of resin in the flask is increased by adding another measured amount of resin. The flask is again filled to volume and the total mass measured. This mass is then noted against the new accumulative resin volume. This procedure is then repeated by adding a specific premeasured amount of ion exchange resin to the flask, which is then filled to volume and weighed. The mass of the empty dry volumetric flask is also measured and subtracted from the set of masses obtained from the above procedure. A 100-ml glass volumetric flask and a Sartorius laboratory scale were used in all the measurements. The volume of the resin in the flask was increased by $10-\mathrm{ml}$ increments after each measurement.

\subsubsection{Calculation of the total surface area}

The following equations are used with the experimental data to calculate the total surface area and the specific volume of the resin beads for any size distribution.

The volume of a perfect sphere of diameter dp is given by Equation (7.1)

$$
V=\frac{\pi}{6}\left(d_{p}\right)^{3}
$$

The surface area of a perfect sphere of diameter dp is given by Equation (7.2)

$$
A=\pi\left(d_{p}\right)^{2}
$$

The total surface area for mass transfer can be calculated by multiplying the number of beads present in a measured amount of ion exchange resin with the surface area of one 
bead. The total number of resin beads $\mathrm{N}$ that are present in the measured volume of ion exchange resin can be calculated, given by Equation (7.3), if the specific volume of resin beads and the volume of one resin bead (Equation 7.1) are known,

$$
\begin{aligned}
N= & \frac{\text { Total Specific Volume }}{\text { Volume of one Bead }} \\
& =\frac{6(1-\varepsilon) F W S V}{\pi\left(d_{p}\right)^{3}}
\end{aligned}
$$

where $\varepsilon$ represents the volumetric fraction of water in the measured volume of ion exchange resin. In Equation (7.3) the resin was measured as a free wet settled volume, which can be replaced with a densely packed volume if preferred.

The total surface area, Equation (7.4), can now be calculated using Equation (7.3) and Equation (7.2),

$$
\begin{aligned}
A_{\text {tot }} & =N \times A \\
& =\frac{6(1-\varepsilon) F W S V}{d_{p}}
\end{aligned}
$$

To calculate the number of resin beads (Equation 7.3) and the total surface area (Equation 7.4) we need to calculate the value of $\varepsilon$, the volumetric fraction of water in a given volume of measured resin with particles of uniform diameter $d_{p}$. The value of $\varepsilon$ can be calculated from the experimental data using the following equations:

Calculation of $\varepsilon$, the volumetric fraction of water in a measured volume of ion exchange resin. 
The total mass of the measuring beaker's content with a specific amount of ion exchange resin in it is given by Equation (7.5),

$$
M=M_{R}+M_{L}
$$

which is equal to the sum of the mass of the resin beads and the water in the beaker. The mass of the resin beads, $M_{R}$, can be calculated from the specific volume of ion exchange resin and its true wet density. The resin beads have an internal porosity $\varepsilon_{\mathrm{p}}$. The pores of the resin beads are filled with pore liquid, which is water in this case, that also contributes to the total mass of the measured volume of ion exchange resin as represented by Equation (7.6).

$$
\begin{aligned}
M_{R} & =(1-\varepsilon) F W S V \rho_{R w} \\
& =(1-\varepsilon)\left(1-\varepsilon_{p}\right) F W S V \rho_{R}+(1-\varepsilon) \varepsilon_{p} F W S V \rho_{w}
\end{aligned}
$$

The mass of the water in the beaker (Equation 7.7), excluding the pore liquid of the resin beads, is equal to the sum of the mass of the interstitial water in the volume of measured resin and the mass of the column of water above the measured volume of resin as represented in Figure 7.3.1.

$$
M_{L}=\varepsilon F W S V \rho_{w}+\left(V_{T}-F W S V\right) \rho_{w}
$$

Substituting Equations (7.6) and (7.7) into Equation (7.5) gives Equation (7.8), which represents the total mass of the measuring beaker's contents.

$$
\begin{aligned}
M \quad & (1-\varepsilon)\left(1-\varepsilon_{p}\right) F W S V \rho_{R}-(1-\varepsilon)\left(1-\varepsilon_{p}\right) F W S V \rho_{W}+V_{T} \rho_{W} \\
& =(1-\varepsilon)\left(1-\varepsilon_{p}\right)\left(\rho_{R}-\rho_{w}\right) F W S V+V_{T} \rho_{W}
\end{aligned}
$$


In Equation (7.8) the only unknown constant is $\varepsilon$ and the variables are M and FWSV. Equation (7.8) can be fitted on the experimental data, obtained from the experimental procedure described in paragraph 7.3.1, with a regression technique to calculate the best value of $\varepsilon$ which is needed in Equations (7.3) and (7.4) to calculate the number of resin beads and the total surface area of a measured volume of ion exchange resin respectively.

A graphical plot of M (y-axis) versus FWSV (x-axis) will give a straight line, which will cut the $y$-axis at $\mathrm{V}_{\mathrm{T}} \rho_{\mathrm{w}}$ with a gradient equal to

$$
\text { gradient }=(1-\varepsilon)\left(1-\varepsilon_{p}\right)\left(\rho_{R}-\rho_{w}\right)
$$

from which $\varepsilon$ can be calculated. The relationship between the density, $\rho_{R}$, and the true wet density, $\rho_{\mathrm{Rw}}$, of the resin phase is given by Equation (7.10),

$$
\rho_{R}=\frac{\rho_{R w}-\varepsilon_{p} \rho_{w}}{\left(1-\varepsilon_{p}\right)}
$$

which can be substituted into Equation (7.9) and simplified to give the gradient as a function of the true wet density of the resin phase, represented by Equation (7.11).

$$
\text { gradient }=(1-\varepsilon)\left(\rho_{R w}-\rho_{w}\right)
$$

With regression analysis the value of $\varepsilon$ can be calculated from Equations (7.9) or (7.11) by obtaining the best possible fit for the gradient of the straight line running through experimental data points. With $\varepsilon$ known, the actual amount of the ion exchange material present in a measured volume of resin beads can be calculated with the use of Equation (7.12),

$$
V_{R}=(1-\varepsilon) F W S V
$$


which is used as the effective resin volume in which the loading of a particular species on the resin can be expressed that will be independent of properties such as particle size.

\subsubsection{Calculation of the volume fraction and resin density for the resins used in experiments}

The resin volume fraction and densities were calculated from experimental data for the different cation and anion exchange resins used in the experiments. Experimental data were collected in order to calculate these parameters, which are shown in Table 7.4 to Table 7.26 in Appendix A of this dissertation.

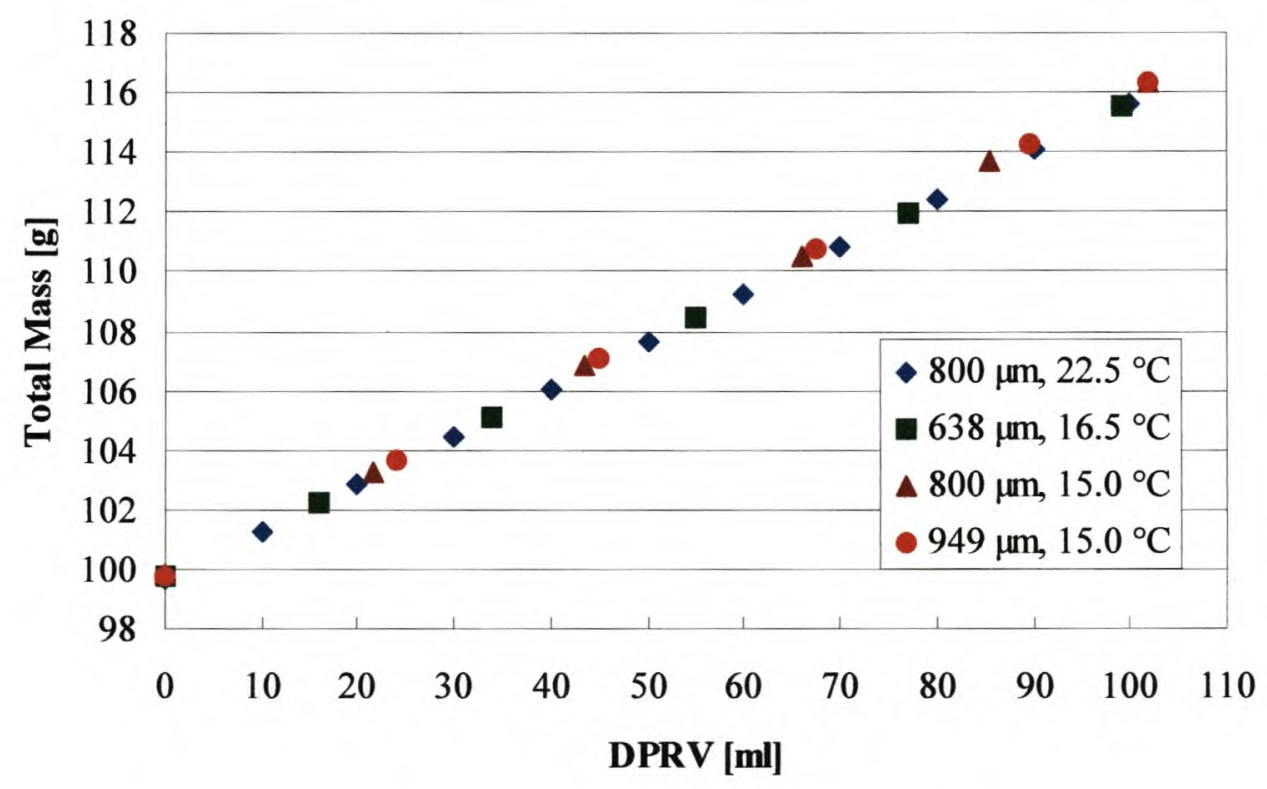

Figure 7.3 Experimental data for the cation exchange resin $\mathrm{C} 26$ in the $\mathrm{Na}^{+}$ionic form, for various resin sizes and water temperatures.

The weighting measurements were performed for different resin size fractions of the same resin in the same ionic form. Various ionic forms of the cation and anion exchange resin 
were used. The experiments were also performed for various temperatures ranging from $15^{\circ} \mathrm{C}$ to $25^{\circ} \mathrm{C}$, to study the effect that relatively small temperature deviations $\left( \pm 5^{\circ} \mathrm{C}\right)$ from the average ambient conditions of $20^{\circ} \mathrm{C}$ will have on the resin measuring technique.

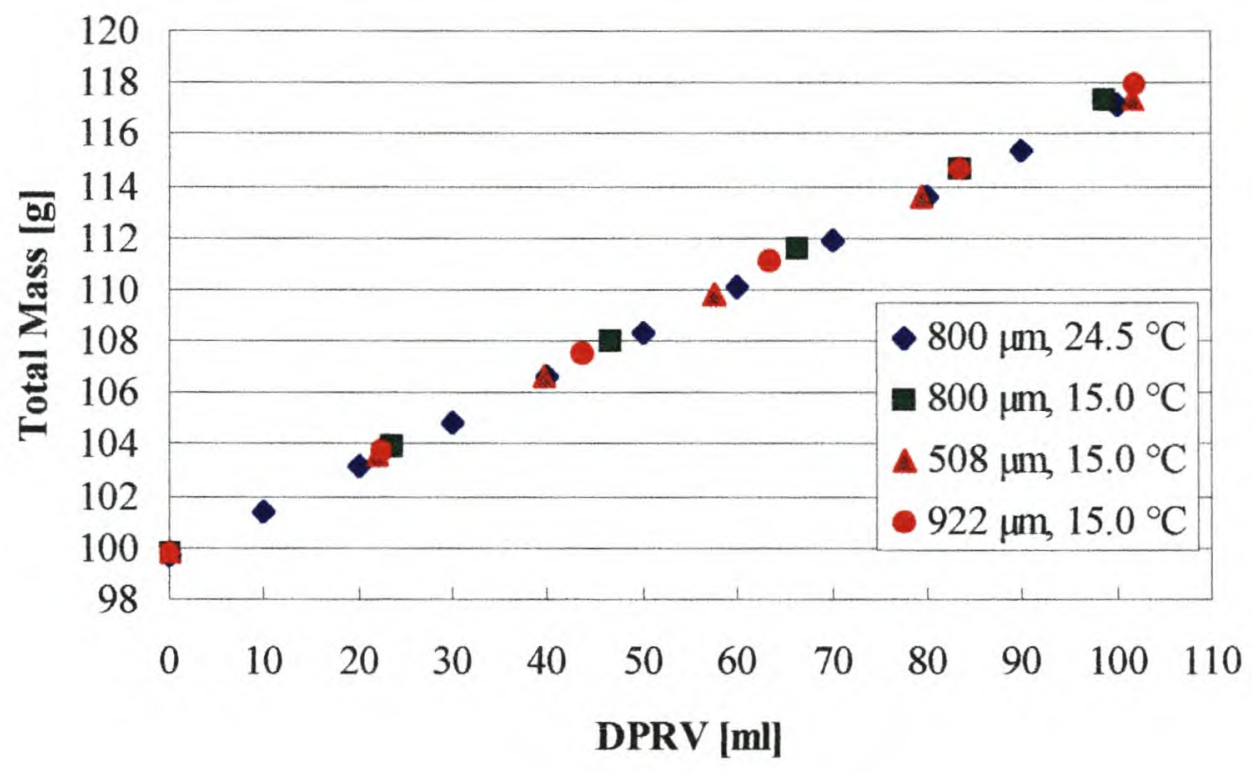

Figure 7.4 Experimental data for the cation exchange resin $\mathrm{C} 26$ in the $\mathrm{K}^{+}$ionic form, for various resin sizes and water temperatures.

The resin measuring and weighting procedure as discussed in paragraph 7.3.1 was followed. Equation (7.11) was then used to calculate the volumetric fraction of water in a measured volume of ion-exchange resin. All the resin volumes measured were as DPRV (densely packed resin volume). A value of $\varepsilon=0.319$ gave the best fit for all of the experimental data shown in Table 7.4 to Table 7.26 in Appendix A of this dissertation. The resin densities were then calculated for the different ionic forms of the cation and anion resins used. These values were then used in Equation (7.6) to calculate the true wet mass of resin used in each experiment. None of the resin samples used in the experimental procedures therefore required any drying to obtain a repeatable resin mass that may be used as reference for the amount of resin used. It should also be noted that 
the density of an ion-exchange resin varies for different ionic forms. It is therefore important to refer to the specific ionic form of the resin when a measured quantity of resin is reported in the literature.

From the experiments it was found that small deviations from the ambient temperature had very little effect on the measuring procedure. It was also found that the density of the used resins for a specific ionic did not vary with particle size, which indicates that the resin samples used in the experiments were properly prepared and classified with the resin preparation procedure as discussed in this Chapter.

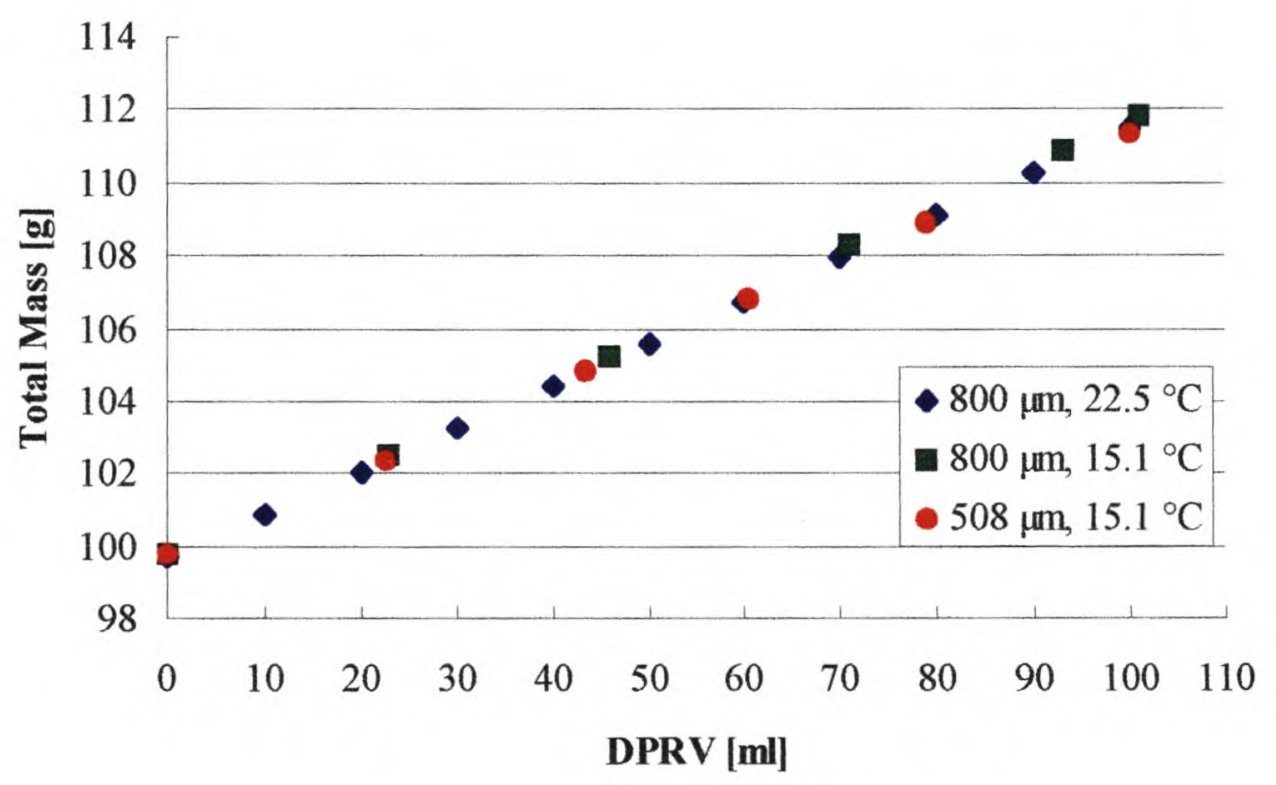

Figure 7.5 Experimental data for the cation exchange resin $\mathrm{C} 26$ in the $\mathrm{H}^{+}$ionic form, for various resin sizes and water temperatures.

From Figure 7.3 it is evident that the experimental data points for the different size fractions and water temperatures used for the same cation exchange resin $\mathrm{C} 26$ in the $\mathrm{Na}^{+}$ ionic form, lies on the same straight line described by Equation (7.8). It is therefore 
evident that neither the resin size fraction nor the water temperature has any significant influences on the proposed measuring technique, as stated above.

From Figure 7.4 the same trend is evident for the cation exchange resin $\mathrm{C} 26$ in the $\mathrm{K}^{+}$ ionic form. The experimental data for the three different resin size fractions and two different water temperatures lie on the same straight line as was the case when the cation resin was the $\mathrm{Na}^{+}$ionic form. Figure 7.5 shows the experimental data for the same cation exchange resin in the $\mathrm{H}^{+}$ionic form.

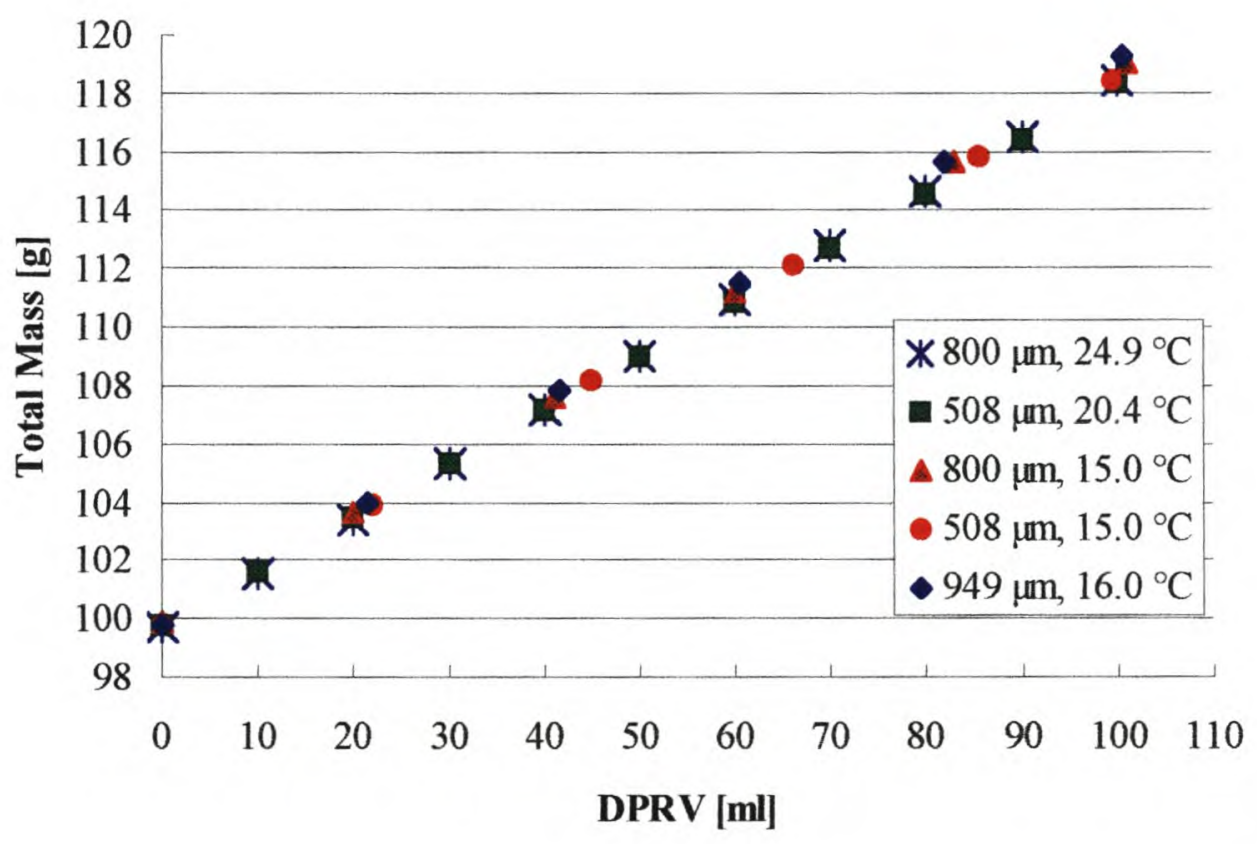

Figure 7.6 Experimental data for the cation exchange resin $\mathrm{C} 26$ in the $\mathrm{Cu}^{+2}$ ionic form, for various resin sizes and water temperatures.

When the cation resin is in a higher valence ionic state, the same experimental observations are made. Figures 7.6 and 7.7 show the straight line plots of the experimental data for the cation exchange resin $\mathrm{C} 26$ in the bivalent $\mathrm{Cu}^{+2}$ and tri-valent $\mathrm{Al}^{+3}$ ionic form respectively. It is evident from these curves that no significant deviation 
from the straight line is observed when the cation exchanger is in a higher valence ionic form.

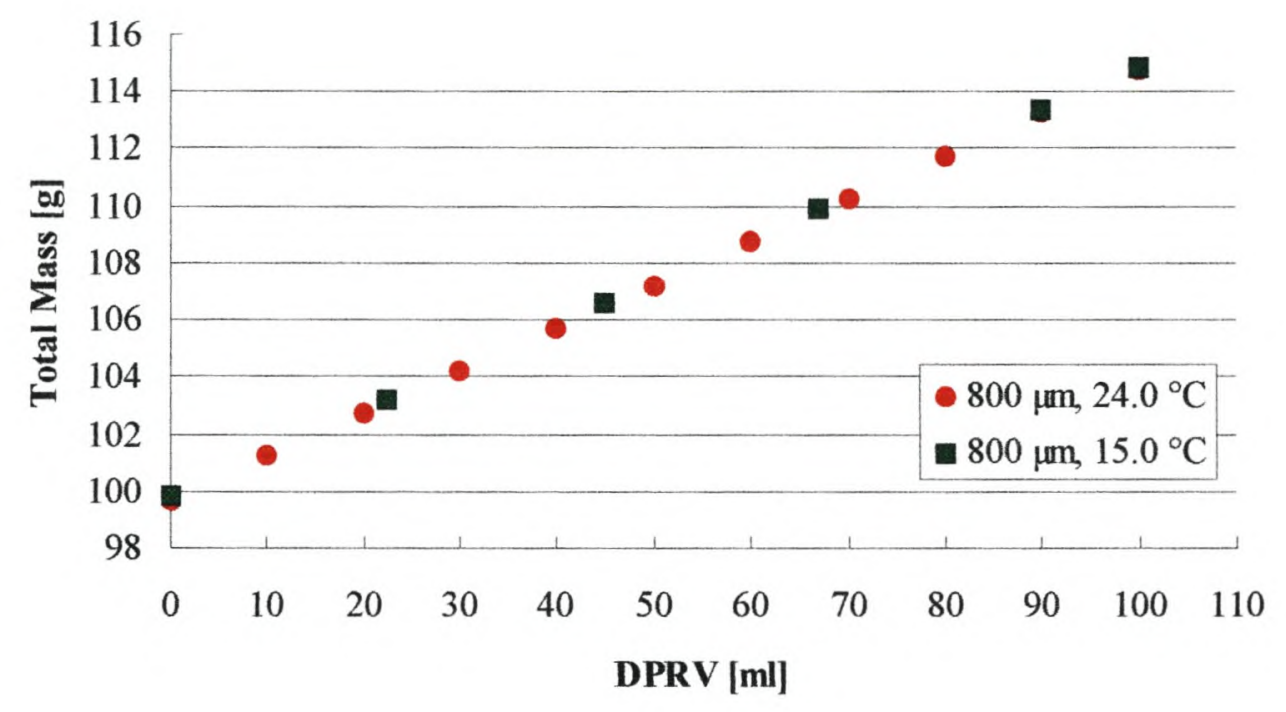

Figure 7.7 Experimental data for the cation exchange resin $\mathrm{C} 26$ in the $\mathrm{Al}^{+3}$ ionic form, for various resin sizes and water temperatures.

Figures 7.8, 7.9 and 7.10 show the experimental data for the anion exchange resin A161 in the $\mathrm{Cl}^{-}, \mathrm{NO}^{-}$and $\mathrm{OH}^{-}$ionic form respectively. The proposed resin measuring and weighting technique shows the same straight line trends, with the different curves on top of one another, as was the case for the cation exchange resin C26.

From Figures 7.3 to 7.10 it is evident that the gradient of the various lines (Equation 7.11) differ for both the cation exchange and anion exchange resin as the resin ionic form of the resin varies. 


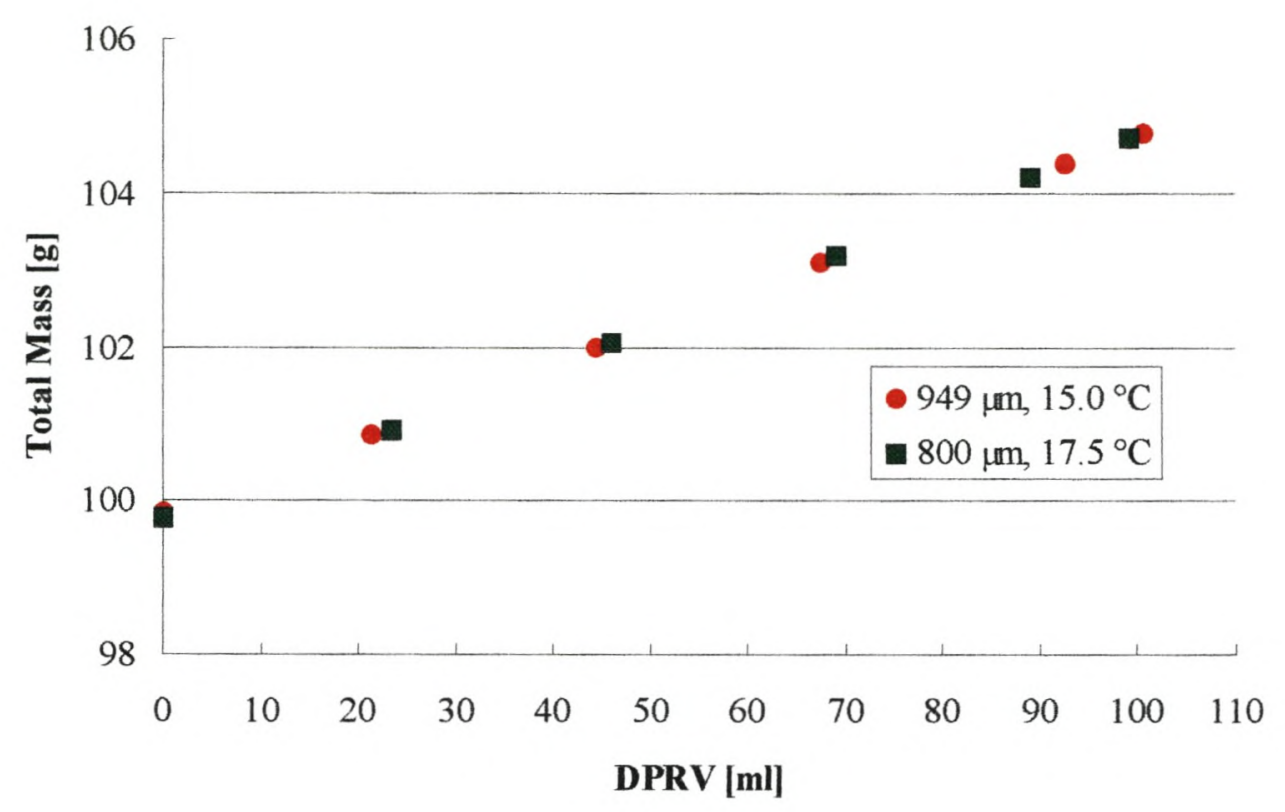

Figure 7.8 Experimental data for the anion exchange resin $\mathrm{A} 161$ in the $\mathrm{Cl}^{-}$ionic form, for various resin sizes and water temperatures.

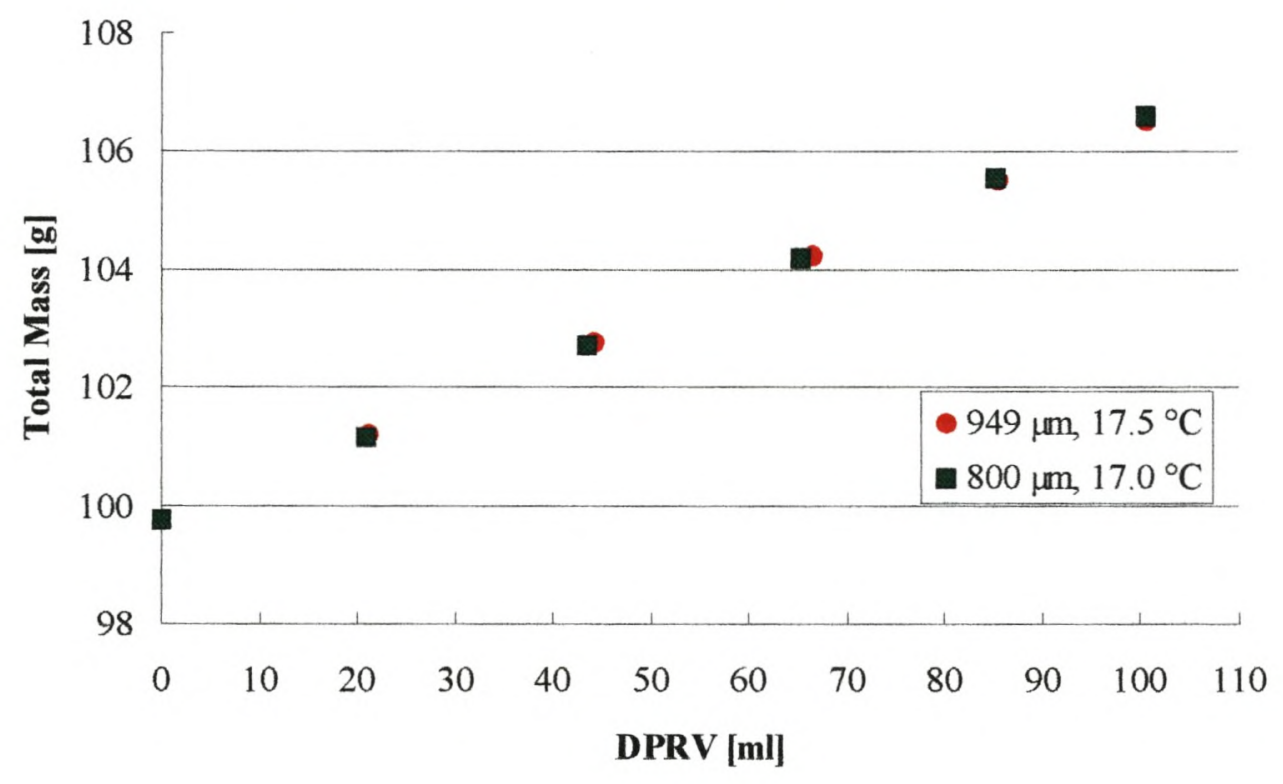

Figure 7.9 Experimental data for the anion exchange resin $\mathrm{A} 161$ in the $\mathrm{NO}_{3}{ }^{-}$ionic form, for various resin sizes and water temperatures. 


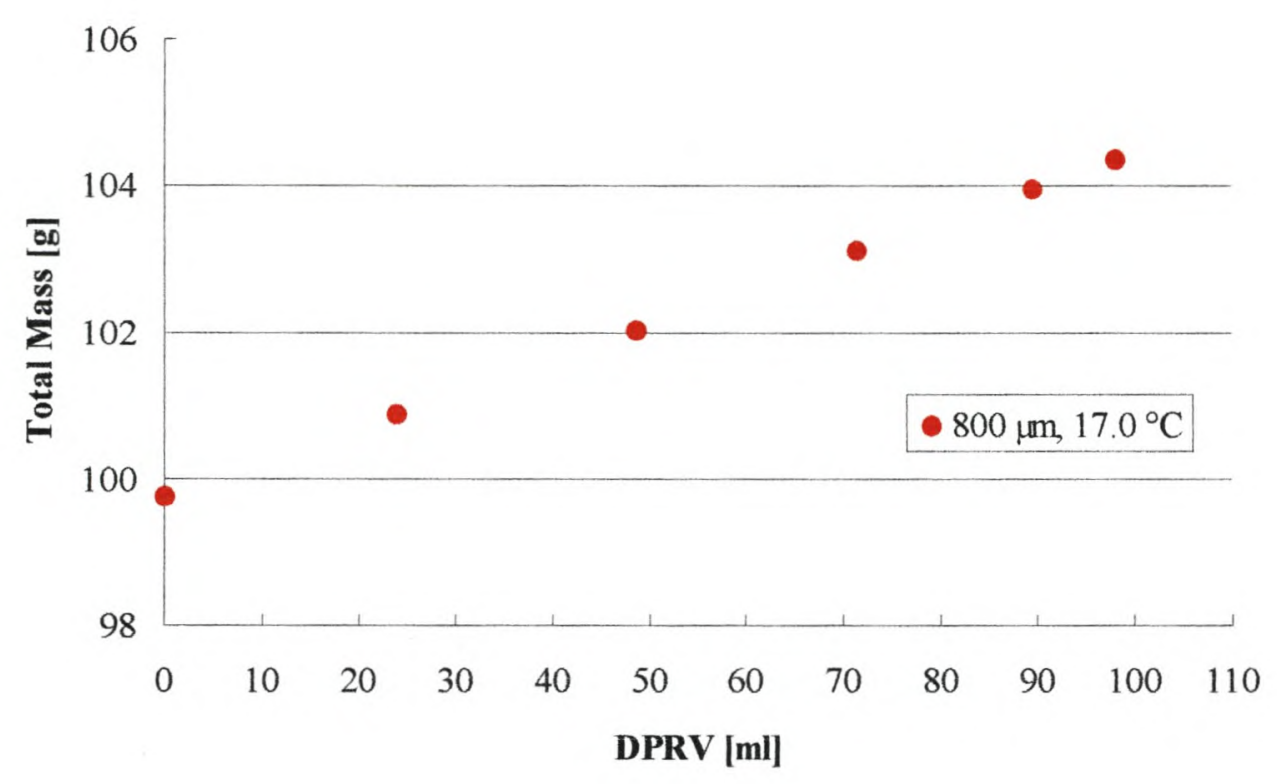

Figure 7.10 Experimental data for the anion exchange resin Al61 in the $\mathrm{OH}^{-}$ionic form.

The variance in the gradients of the lines is caused by a variation in the true wet density of the resins as a function of the resin ionic form. The true wet densities for the various resin ionic forms have been calculated using Equation (7.11). The values for the different ionic forms are shown in Figure 7.11 in descending order.

It is evident from Figure (7.11) that the cation exchange resin is much denser than the anion exchange resin. The cation exchange resin $\mathrm{C} 26$ in the $\mathrm{Cu}^{+2}$ ionic form has the highest density, with the anion exchange resin $\mathrm{A} 161$ in the $\mathrm{OH}^{-}$form having the lowest density. 


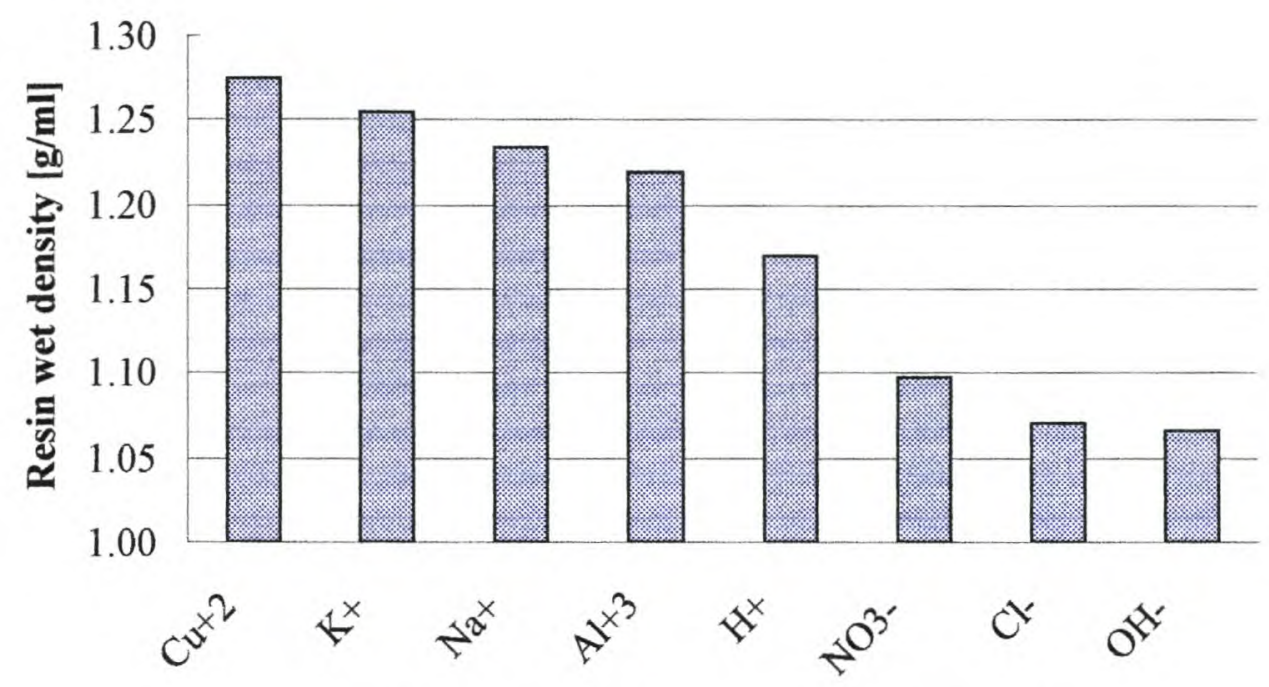

Cation (C26) and Anion (A161) resin ionic form

Figure 7.11 Experimentally determined data for the true wet densities of the cation exchange (C26) and anion exchange (A161) resin for different ionic forms.

\subsection{EXPERIMENTAL PROCEDURES FOLLOWED IN EQUILIBRIUM AND KINETIC EXPERIMENTS}

\subsubsection{Ion-exchange equilibrium experiments with aqueous electrolyte solutions and slurries of sparingly soluble solids}

Equilibrium experiments were performed in one litre, high-density PVC plastic bottles. PVC bottles were used because the alkaline earth metal ions such as sodium, potassium and to a lesser extent calcium and magnesium are present in substantial quantities in ordinary glassware, such as glass bottles, from where they can leach into aqueous solutions in contact with the glass. Initial test work was performed in ordinary glass bottles. It was found that significant contamination of both the resin and aqueous phase samples occurred. Although the concentration levels of the contaminants were extremely 
low it was picked up in the analysis due to the fact that the experiments were performed with sparingly soluble solids, which resulted in very low solution phase concentrations of the dissolved cations. Only a very small amount of alkaline metal ions, leaching from the glass, is needed to compete to a significant extent with the cations of the low soluble solid for sorption by the ion exchange resin.

Table 7.27 Sparingly soluble solids used in experimental procedures.

\begin{tabular}{|c|c|c|}
\hline Chemical Substance & Chemical Formula & Assay \% \\
\hline Aluminium hydroxide & $\mathrm{Al}(\mathrm{OH})_{3}$ & 96 \\
\hline Barium Carbonate & $\mathrm{BaCO}_{3}$ & 98.5 \\
\hline Barium Sulphate & $\mathrm{BaSO}_{4}$ & 96 \\
\hline Calcium Carbonate & $\mathrm{CaCO}_{3}$ & 99.5 \\
\hline Calcium Fluoride & $\mathrm{CaF}_{2}$ & 98 \\
\hline Calcium Sulphate & $\mathrm{CaSO}_{4} \cdot 2 \mathrm{H}_{2} \mathrm{O}$ & 98.5 \\
\hline Ferrous Sulphide & $\mathrm{FeS}_{2}$ & $29(\mathrm{~S})$ \\
\hline Lead Carbonate & $\mathrm{PbCO}_{3}$ & 98 \\
\hline Lead Chromate & $\mathrm{PbCrO}_{4}$ & 98 \\
\hline Lead Sulphate & $\mathrm{PbSO}_{4}$ & 98.5 \\
\hline Lead Sulphide & $\mathrm{PbS}_{2}$ & 98 \\
\hline Magnesium Hydroxide & $\mathrm{Mg}(\mathrm{OH})_{2}$ & 95 \\
\hline Strontium Carbonate & $\mathrm{SrCO}_{3}$ & 99 \\
\hline Zinc Sulphide & $\mathrm{ZnS}$ & 98 \\
\hline
\end{tabular}

This problem of metal ion contamination can be successfully eliminated to a large extent using high quality borosilicate glassware. Glassware of this quality is very expensive and was economically not feasible for the purposes of the test work required for this dissertation, which required hundreds of equilibrium experiments to be performed. 
A weighted mass of solid was added with a measured amount of ion exchange resin into a one litre PVC bottle with a specific amount of distilled water. The bottle was then sealed and rolled on open rollers to allow the resin/slurry mixture to obtain complete equilibrium. The bottles were rolled at $60 \mathrm{rpm}$ for a period ranging from two weeks to one month depending on the solubility of the solid, the more insoluble the solid the longer the mixing time. When equilibrium was reached the solution and resin phases were separated from the solid phase using a Millipore filter and a laboratory screen respectively. Only the solution and the resin phases were analysed for the species present.

The solution phase contains the counter ions of the cation and/or anion exchange resin, and the dissolved ions from the solid that were in equilibrium with the resin phase. An Atomic Absorption Spectrophotometer (Varian AA-1275 series) or an ICP Emission Spectrometer (Varian Liberty 200) was used to analyse for the cation content of the solution phase. The anion analyses were performed using a computer controlled ion chromatograph (Dionex Series 4500I). The resin phase analyses were performed using the experimental procedure outlined in paragraph 7.2. A mass balance was then performed on the three phases (Solid / Solution / Resin) to calculate the distribution of a particular ionic species between them. 


\section{CHAPTER 8}

\section{RESULTS FOR THE SOLUTION RESIN SYSTEM}

In the discussions of Chapter 6 it was mentioned that the estimation of the thermodynamic equilibrium coefficient $K_{A}^{B}$ for the ion-exchange reaction was de-coupled from the set of model equations for the consolidated equilibrium model for the Resin-inPulp (RIP) slurry mixture system. In paragraph 6.6 of Chapter 6 the mathematical equations and procedure were discussed in more detail on how to calculate the value of $K_{A}^{B}$ and the binary Wilson interaction parameters between the resin species. It was also mentioned that the format of the set of model equations for the consolidated equilibrium model strongly depends on the species valences and the number of "new" precipitates, as shown in Figure (1.1) of Chapter 1, that are formed during the dissolution reaction. The importance of electrolytic sorption was also discussed and the derivation of the set of model equations in paragraph 6.4 of Chapter 6 assumed that no electrolytic sorption of the anion species $Y^{z_{Y}}$ occurred by the cation exchange reaction.

It is therefore evident from the above discussion that the estimation of the thermodynamic equilibrium coefficient $K_{A}^{B}$ is of significant importance to the accuracy of the consolidated equilibrium model for the RIP slurry mixture system. The validity of the assumption to ignore electrolytic sorption in the ion-exchange reaction needs to be considered as well. It is a well-known fact that electrolytic sorption does occur as discussed in detail in paragraph 4.2.6 of Chapter 4 of this dissertation. In most cases the contribution of electrolytic sorption is ignored and considered part of the overall sorption capacity (defined in paragraph 4.2.3, Chapter 4) of the ion-exchange resin. When following this approach the value of the equilibrium coefficient $K_{A}^{B}$ is calculated from the experimental data and includes the value of the electrolytic sorption component. This 
was the approach that was eventually followed in this dissertation and it will be discussed in more detail below.

\subsection{OBJECTIVES OF THIS CHAPTER}

In this chapter the experimental data for the equilibrium condition between the resin phase and aqueous solution phase will be discussed in more detail. Electrolytic sorption is also considered, as calculated for the experimental data. General conclusions are drawn on the trends that the electrolytic sorption shows with increasing or decreasing amounts of ion-exchange resin per unit volume of the aqueous phase solution. It is therefore one of the objectives of this chapter to look into the extent to which electrolytic sorption exists for the experimental configurations used in the experimental procedures followed in this dissertation. Experimental data for all of the resin / solution equilibrium curves of interest to this dissertation are shown in Figures (8.5) to (8.14). This includes both the cation and anion exchange reactions. The shape of the equilibrium isotherms, as represented in Figures (8.5) to (8.14), gives a good indication of the nature of the isotherms encountered in the RIP slurry mixture systems of interest to this dissertation.

A further objective of this chapter is to consider the general trends that the equilibrium isotherms follow as a function of the various system parameters. This is of significant importance due to the fact that the typical resin isotherm curves have an extremely steep curve in the low solution phase concentration region. The effect of the species valences on the ion-exchange isotherms is also studied in more detail. From the derivation of the set of model equations for the consolidated equilibrium model, paragraph 6.4 of Chapter 6 , it is evident that the species valences and stoichiometric coefficients feature significantly in all of the derived equations. This is primarily due to the fact that any ionexchange process maintains electroneutrality in both the aqueous and resin phase as discussed in detail in Chapter 4 of this dissertation. 
A detailed calculation of the equilibrium coefficient $K_{A}^{B}$ and Wilson binary interaction parameters is also performed and the results discussed in this chapter. The detailed model equations used in the calculation of the equilibrium coefficient $K_{A}^{B}$ are shown in Appendix D of this dissertation. The equations used are those derived in Chapter 6 of this dissertation. From this discussion it will become evident that the equilibrium quotient $\lambda_{A}^{B}$ curve, as defined by Equation (6.45) in Chapter 6, may have various forms for the same ion-exchange reaction at different total solution phase concentrations. These

differences between the equilibrium quotient $\lambda_{A}^{B}$ curves for the same ion-exchange reaction emphasise the importance of a sound thermodynamic approach in the modelling of the equilibrium coefficient $K_{A}^{B}$ for the ion-exchange reaction, as discussed in detail in Chapter 5 of this dissertation. It is therefore an objective of this chapter to introduce the reader to this phenomenon and the pitfalls associated with it in the context of the set of model equations for the consolidated equilibrium model for the RIP slurry mixture system.

\subsection{EXPERIMENTAL TEST WORK ON ELECTROLYTIC SORPTION IN THE DETERMINATION OF BINARY ION-EXCHANGE EQUILIBRIUM ISOTHERMS}

From the discussions in Chapters 5 and 6 it become evident that in order to successfully model ion-exchange equilibria over a wide range of species concentrations it is necessary to account for non-idealities in both the solution and resin phases. The Pitzer model has proved to be very accurate in modelling solution phase non-idealities by means of species activity coefficients, with experimental data available form the literature for numerous electrolyte species over wide concentration ranges. The Wilson model has been used with success by several workers to calculate the resin phase activity coefficients. It is therefore proposed that this method is suitable for the purposes of this dissertation and a similar approach is followed in the modelling of various ion-exchange equilibrium isotherms. 
In order to do this, experimental data have been collected for various electrolyte systems over concentrations ranges applicable to the modelling of sparingly soluble solids in aqueous electrolyte solutions as done in this dissertation. Table (8.1) and Table (8.2) gives a summary of the number of experimental data points collected for various binary ion-exchange equilibrium isotherms for cation and anion exchange respectively. The maximum concentration ranges in ppm at the start of the ion-exchange reactions are also given as well as the various temperatures at which these experimental data points were collected. Not all of the experiments were performed in a temperature-controlled bath, hence the distribution in the temperature ranges for the various isotherms.

Table 8.1 Extent of the number of experimental data points for binary ion-exchange equilibrium isotherms between different cations with different anions as co-ions for various concentration and temperature ranges.

\begin{tabular}{|l|l|l|l|l|l|}
\hline \multicolumn{2}{|c|}{ Cation } & Anion & $\begin{array}{c}\text { Number of } \\
\text { Data Points }\end{array}$ & $\begin{array}{c}\text { Concentration } \\
\text { Range [ppm] }\end{array}$ & $\begin{array}{c}\text { Temperature } \\
{ }^{\circ} \mathrm{C}\end{array}$ \\
\hline $\mathrm{Al}^{+3}$ & $\mathrm{H}^{+}$ & $\mathrm{NO}_{3}^{-}$ & 24 & 200 & $20.5^{\circ} \mathrm{C}$ \\
\hline $\mathrm{Al}^{+3}$ & $\mathrm{Na}^{+}$ & $\mathrm{NO}_{3}^{-}$ & 40 & 200 & $18.0^{\circ} \mathrm{C}, 20.5^{\circ} \mathrm{C}$ \\
\hline $\mathrm{Al}^{+3}$ & $\mathrm{~K}^{+}$ & $\mathrm{NO}_{3}^{-}$ & 24 & 200 & $20.5^{\circ} \mathrm{C}$ \\
\hline $\mathrm{Ba}^{+2}$ & $\mathrm{H}^{+}$ & $\mathrm{Cl}^{-}$ & 40 & 1100 & $19.8^{\circ} \mathrm{C}, 22.5^{\circ} \mathrm{C}$ \\
\hline $\mathrm{Ba}^{+2}$ & $\mathrm{Na}^{+}$ & $\mathrm{Cl}^{-}$ & 40 & 1100 & $19.8^{\circ} \mathrm{C}, 22.5^{\circ} \mathrm{C}$ \\
\hline $\mathrm{Ba}^{+2}$ & $\mathrm{~K}^{+}$ & $\mathrm{Cl}^{-}$ & 40 & 1100 & $19.8^{\circ} \mathrm{C}, 22.5^{\circ} \mathrm{C}$ \\
\hline $\mathrm{Ba}^{+2}$ & $\mathrm{Cu}^{+2}$ & $\mathrm{Cl}^{-}$ & 40 & 1100 & $19.8^{\circ} \mathrm{C}, 22.5^{\circ} \mathrm{C}$ \\
\hline $\mathrm{Ba}^{+2}$ & $\mathrm{Al}^{+3}$ & $\mathrm{Cl}^{-}$ & 40 & 1100 & $19.8^{\circ} \mathrm{C}, 22.5^{\circ} \mathrm{C}$ \\
\hline $\mathrm{Ca}^{+2}$ & $\mathrm{H}^{+}$ & $\mathrm{Cl}^{-}$ & 23 & 1000 & $20.5^{\circ} \mathrm{C}$ \\
\hline $\mathrm{Ca}^{+2}$ & $\mathrm{Na}^{+}$ & $\mathrm{Cl}^{-}$ & 39 & 1000 & $18.0^{\circ} \mathrm{C}, 20.5^{\circ} \mathrm{C}$ \\
\hline $\mathrm{Ca}^{+2}$ & $\mathrm{~K}^{+}$ & $\mathrm{Cl}^{-}$ & 23 & 1000 & $20.5^{\circ} \mathrm{C}$ \\
\hline $\mathrm{Ca}^{+2}$ & $\mathrm{Cu}^{+2}$ & $\mathrm{Cl}^{-}$ & 24 & 1000 & $20.5^{\circ} \mathrm{C}$ \\
\hline $\mathrm{Ca}^{+2}$ & $\mathrm{Al}^{+3}$ & $\mathrm{Cl}^{-}$ & 24 & 1000 & $20.5^{\circ} \mathrm{C}$ \\
\hline
\end{tabular}




\begin{tabular}{|l|l|l|l|l|l|}
\hline $\mathrm{Mg}^{+2}$ & $\mathrm{H}^{+}$ & $\mathrm{Cl}^{-}$ & 23 & 610 & $18.0^{\circ} \mathrm{C}$ \\
\hline $\mathrm{Mg}^{+2}$ & $\mathrm{~K}^{+}$ & $\mathrm{Cl}^{-}$ & 24 & 610 & $18.0^{\circ} \mathrm{C}$ \\
\hline $\mathrm{Mg}^{+2}$ & $\mathrm{Na}^{+}$ & $\mathrm{Cl}^{-}$ & 40 & 610 & $18.0^{\circ} \mathrm{C}$ \\
\hline $\mathrm{Mg}^{+2}$ & $\mathrm{Cu}^{+2}$ & $\mathrm{Cl}^{-}$ & 24 & 610 & $18.0^{\circ} \mathrm{C}$ \\
\hline $\mathrm{Mg}^{+2}$ & $\mathrm{Al}^{+3}$ & $\mathrm{Cl}^{-}$ & 24 & 610 & $18.0^{\circ} \mathrm{C}$ \\
\hline $\mathrm{Pb}^{+2}$ & $\mathrm{H}^{+}$ & $\mathrm{NO}_{3}^{-}$ & 40 & 1120 & $18.0^{\circ} \mathrm{C}, 19.8^{\circ} \mathrm{C}$ \\
\hline $\mathrm{Pb}^{+2}$ & $\mathrm{Na}^{+}$ & $\mathrm{NO}_{3}^{-}$ & 39 & 1120 & $18.0^{\circ} \mathrm{C}, 19.8^{\circ} \mathrm{C}$ \\
\hline $\mathrm{Pb}^{+2}$ & $\mathrm{~K}^{+}$ & $\mathrm{NO}_{3}^{-}$ & 40 & 1120 & $18.0^{\circ} \mathrm{C}, 19.8^{\circ} \mathrm{C}$ \\
\hline $\mathrm{Pb}^{+2}$ & $\mathrm{Cu}^{+2}$ & $\mathrm{NO}_{3}^{-}$ & 40 & 1120 & $18.0^{\circ} \mathrm{C}, 19.8^{\circ} \mathrm{C}$ \\
\hline $\mathrm{Pb}^{+2}$ & $\mathrm{Al}^{+3}$ & $\mathrm{NO}_{3}^{-}$ & 40 & 1120 & $18.0^{\circ} \mathrm{C}, 19.8^{\circ} \mathrm{C}$ \\
\hline $\mathrm{Sr}^{+2}$ & $\mathrm{Na}^{+}$ & $\mathrm{Cl}^{-}$ & 16 & 750 & $18.0^{\circ} \mathrm{C}$ \\
\hline $\mathrm{Zn}^{+2}$ & $\mathrm{Na}^{+}$ & $\mathrm{NO}_{3}^{-}$ & 20 & 520 & $18.0^{\circ} \mathrm{C}, 19.0^{\circ} \mathrm{C}$ \\
\hline $\mathrm{Zn}^{+2}$ & $\mathrm{~K}^{+}$ & $\mathrm{NO}_{3}{ }^{-}$ & 6 & 180 & $19.0^{\circ} \mathrm{C}$ \\
\hline $\mathrm{Zn}^{+2}$ & $\mathrm{H}^{+}$ & $\mathrm{NO}_{3}^{-}$ & 6 & 180 & $19.0^{\circ} \mathrm{C}$ \\
\hline
\end{tabular}

Table 8.2 Extent of the number of experimental data points for binary ion-exchange equilibrium isotherms between different anions with different cations as co-ions for various concentration and temperature ranges.

\begin{tabular}{|l|l|l|l|l|l|}
\hline \multicolumn{2}{|c|}{ Anion } & Cation & $\begin{array}{c}\text { Number of } \\
\text { Data Points }\end{array}$ & $\begin{array}{c}\text { Concentration } \\
\text { Range [ppm] }\end{array}$ & $\begin{array}{c}\text { Temperature } \\
{ }^{\circ} \mathrm{C}\end{array}$ \\
\hline $\mathrm{CO}_{3}{ }^{2-}$ & $\mathrm{Cl}^{-}$ & $\mathrm{Na}^{+}$ & 41 & 950 & $17.5^{\circ} \mathrm{C}, 19.0^{\circ} \mathrm{C}$ \\
\hline $\mathrm{CO}_{3}{ }^{2}$ & $\mathrm{NO}_{3}{ }^{-}$ & $\mathrm{Na}^{+}$ & 22 & 850 & $19.0^{\circ} \mathrm{C}$ \\
\hline $\mathrm{CO}_{3}{ }^{2}$ & $\mathrm{OH}^{-}$ & $\mathrm{Na}^{+}$ & 22 & 850 & $19.0^{\circ} \mathrm{C}$ \\
\hline $\mathrm{CrO}_{4}{ }^{2-}$ & $\mathrm{Cl}^{-}$ & $\mathrm{Na}^{+}$ & 16 & 390 & $18.0^{\circ} \mathrm{C}$ \\
\hline $\mathrm{F}^{-}$ & $\mathrm{Cl}^{-}$ & $\mathrm{Na}^{+}$ & 60 & 510 & $17.0^{\circ} \mathrm{C}, 15.0^{\circ} \mathrm{C}$ \\
\hline $\mathrm{F}^{-}$ & $\mathrm{Cl}^{-}$ & $\mathrm{NH}_{4}^{+}$ & 16 & 122 & $18.0^{\circ} \mathrm{C}$ \\
\hline $\mathrm{F}^{-}$ & $\mathrm{NO}_{3}^{-}$ & $\mathrm{Na}^{+}$ & 30 & 510 & $15.0^{\circ} \mathrm{C}$ \\
\hline $\mathrm{F}$ & $\mathrm{Cl}^{-}$ & $\mathrm{Na}^{+}$ & 10 & 50 & $17.0^{\circ} \mathrm{C}$ \\
\hline
\end{tabular}




\begin{tabular}{|l|l|l|l|l|l|}
\hline $\mathrm{F}^{-}$ & $\mathrm{Cl}^{-}$ & $\mathrm{Na}^{+}$ & 10 & 50 & $25.5^{\circ} \mathrm{C}$ \\
\hline $\mathrm{F}^{-}$ & $\mathrm{Cl}^{-}$ & $\mathrm{Na}^{+}$ & 10 & 50 & $35.0^{\circ} \mathrm{C}$ \\
\hline $\mathrm{F}^{-}$ & $\mathrm{Cl}^{-}$ & $\mathrm{Na}^{+}$ & 10 & 50 & $44.7^{\circ} \mathrm{C}$ \\
\hline $\mathrm{F}^{-}$ & $\mathrm{Cl}^{-}$ & $\mathrm{Na}^{+}$ & 10 & 50 & $55.9^{\circ} \mathrm{C}$ \\
\hline $\mathrm{F}^{-}$ & $\mathrm{NO}^{-}$ & $\mathrm{Na}^{+}$ & 10 & 50 & $15.5^{\circ} \mathrm{C}$ \\
\hline $\mathrm{F}^{-}$ & $\mathrm{NO}_{3}^{-}$ & $\mathrm{Na}^{+}$ & 10 & 50 & $24.5^{\circ} \mathrm{C}$ \\
\hline $\mathrm{F}^{-}$ & $\mathrm{NO}_{3}{ }^{-}$ & $\mathrm{Na}^{+}$ & 10 & 50 & $35.0^{\circ} \mathrm{C}$ \\
\hline $\mathrm{F}^{-}$ & $\mathrm{NO}_{3}{ }^{-}$ & $\mathrm{Na}^{+}$ & 10 & 50 & $45.0^{\circ} \mathrm{C}$ \\
\hline $\mathrm{F}^{-}$ & $\mathrm{NO}_{3}{ }^{-}$ & $\mathrm{Na}^{+}$ & 10 & 50 & $55.0^{\circ} \mathrm{C}$ \\
\hline $\mathrm{HCO}_{3}{ }^{-}$ & $\mathrm{Cl}^{-}$ & $\mathrm{Na}^{+}$ & 6 & 313 & $19.0^{\circ} \mathrm{C}$ \\
\hline $\mathrm{HCO}_{3}{ }^{-}$ & $\mathrm{NO}^{-}$ & $\mathrm{Na}^{+}$ & 24 & 1032 & $19.0^{\circ} \mathrm{C}$ \\
\hline $\mathrm{OH}^{-}$ & $\mathrm{Cl}^{-}$ & $\mathrm{Na}^{+}$ & 24 & 266 & $22.0^{\circ} \mathrm{C}$ \\
\hline $\mathrm{OH}^{-}$ & $\mathrm{NO}_{3}{ }^{-}$ & $\mathrm{Na}^{+}$ & 24 & 266 & $22.0^{\circ} \mathrm{C}$ \\
\hline $\mathrm{SO}_{4}{ }^{2-}$ & $\mathrm{Cl}^{-}$ & $\mathrm{Na}^{+}$ & 66 & 2400 & $18.0^{\circ} \mathrm{C}, \quad 17.5^{\circ} \mathrm{C}$, \\
\hline $\mathrm{SO}_{4}{ }^{2-}$ & $\mathrm{NO}_{3}{ }^{-}$ & $\mathrm{Na}^{+}$ & 46 & 2400 & $18.5^{\circ} \mathrm{C}$ \\
\hline $\mathrm{SO}_{4}{ }^{2-}$ & $\mathrm{OH}^{-}$ & $\mathrm{Na}^{+}$ & 46 & 2400 & $23.0^{\circ} \mathrm{C}, 18.5^{\circ} \mathrm{C}$ \\
\hline $\mathrm{SO}_{4}{ }^{2-}$ & $\mathrm{Cl}^{-}$ & $\mathrm{Na}^{+}$ & 10 & 50 & $23.0^{\circ} \mathrm{C}, 18.5^{\circ} \mathrm{C}$ \\
\hline $\mathrm{SO}_{4}{ }^{2-}$ & $\mathrm{Cl}^{-}$ & $\mathrm{Na}^{+}$ & 10 & 50 & $17.5^{\circ} \mathrm{C}$ \\
\hline $\mathrm{SO}_{4}{ }^{2-}$ & $\mathrm{Cl}^{-}$ & $\mathrm{Na}^{+}$ & 10 & 50 & $24.5^{\circ} \mathrm{C}$ \\
\hline $\mathrm{SO}_{4}{ }^{2-}$ & $\mathrm{Cl}^{-}$ & $\mathrm{Na}^{+}$ & 10 & 50 & $34.9^{\circ} \mathrm{C}$ \\
\hline $\mathrm{SO}_{4}{ }^{2-}$ & $\mathrm{Cl}^{-}$ & $\mathrm{Na}^{+}$ & 10 & 50 & $54.0^{\circ} \mathrm{C}$ \\
\hline
\end{tabular}

During these experiments a detailed study was also performed to measure the amount of electrolytic sorption that occurred for each of the isotherms. This was done by measuring the solution phase concentration of the co-ion species for each experimental data point at the start of each equilibrium experiment and also at equilibrium attainment. The difference between these two concentrations is an indication of the amount of electrolyte species that is adsorbed by the resin phase, but which does not actively participate in the ion-exchange reaction at the active sites on the resin phase. The purpose of this exercise 
was to determine whether electrolyte sorption is of any great significance at the very low solution phase concentrations encountered when modelling the adsorption of sparingly soluble solids from electrolyte solutions onto ion-exchange resins is the objective of this dissertation. The results of these studies are discussed in more detail below.

The Pitzer activity coefficient model was used to calculate the solution phase activity coefficients for the various electrolyte species as shown in Table (8.1) and Table (8.2). The calculated activity coefficients were used in Equation (6.45) of chapter 6 to calculate the equilibrium quotient for the various ion-exchange isotherms. The Pitzer interaction parameters used in the calculation of the species activity coefficients as described in the detailed equations of Appendix C, are shown in Table (C.1) of appendix C.

\subsubsection{Electrolytic sorption of co-ionic species at equilibrium as observed during the experimental determination of binary ion-exchange equilibrium isotherms}

The parameters influencing the electrolytic sorption of species by ion-exchange resins was discussed in detail in Chapter 4, paragraph 4.2.6. of this dissertation. From this discussion it is evident that there are various parameters influencing the degree to which electrolytic sorption will take place during ion-exchange reactions. As mentioned above, a detailed study was performed to determine whether electrolyte sorption is of any significance for the concentration ranges of interest in this dissertation or not. Electrolytic sorption may become important in modelling the solubility and sorption of sparingly soluble solids by ion-exchangers. This is especially true when this type of sorption results in the formation of precipitates inside the ion-exchange resin. The adsorbed species of the electrolyte may form a precipitate with one of the sparingly soluble solid's dissolved ions when the correct concentration range is attained, depending on the value of the solubility product of the precipitate formed. 
The amount of electrolytic sorption was measured by monitoring the concentration of the co-ions of the exchange reaction. If mathematical terms for the co-ions were included in the ion-exchange reaction represented by Equation (6.6) of Chapter 6, it has the form as represented by Equation (8.1),

$$
\frac{v_{B^{\prime}} v_{A}}{v_{B}}\left[\left(R^{-}\right)_{z_{A}} A^{z_{A}}\right]+\left[\left(B^{z_{B}}\right)_{v_{B}}\left(E^{z_{E}}\right)_{v_{E}}\right]_{(a q)} \leftrightarrow v_{B^{\prime}}\left[\left(R^{-}\right)_{z_{B}} B^{z_{B}}\right]+\frac{v_{B^{\prime}} v_{A}}{v_{B}} A^{z_{A}}+v_{E} E^{z_{E}}
$$

where

$$
\text { IF } \begin{aligned}
\left|z_{A}\right| & \neq\left|z_{B}\right| \quad \text { Then } \\
v_{A} & =\left|z_{B}\right| \text { and } \quad v_{B}=\left|z_{A}\right|
\end{aligned}
$$$$
\text { ELSE } \quad v_{A}=v_{B}=1
$$

and

$$
\text { IF } \begin{aligned}
\left|z_{E}\right| & \neq\left|z_{B}\right| \quad \text { Then } \\
v_{E} & =\left|z_{B}\right| \text { and } \quad v_{B^{\prime}}=\left|z_{E}\right|
\end{aligned}
$$

ELSE

$$
v_{E}=v_{B^{\prime}}=1
$$

Equation (8.1) is the same as Equation (4.3) as derived in Chapter 4 of this dissertation. Species $E^{z_{E}}$ represents the co-ion species associated with species $B^{z_{B}}$. The left-hand side of Equation (8.1) represents the scenario where initially only species $A^{z_{A}}$ was present in the ion-exchanger and only species $B^{z_{B}}$ and $E^{z_{E}}$ were present in the solution phase. Equation (8.1) also assumes that no electrolytic sorption has occurred, hence all of species $E^{z_{E}}$ stays in the solution phase. If any of species $E^{z_{E}}$ were adsorbed by the ionexchange resin phase, electrolytic sorption would have occurred. Both species $E^{z_{E}}$ and 
the active sites inside the resin have valences of the same sign; hence they repel one another. Species $E^{z_{E}}$ could therefore only be adsorbed by the resin phase if it represents itself as a "neutral" electrolyte in the form of the electrolyte $B E$ or $A E$. When adsorption of this "neutral" electrolyte occurs, it is referred to as electrolytic sorption for the purposes of this dissertation.

A general equation for the representation of electrolytic sorption of species $E^{z_{E}}$ as electrolyte $B E$, of which the dissociation is given as

$$
\left\lfloor\left(B^{z_{B}}\right)_{v_{B^{\prime}}}\left(E^{z_{E}}\right)_{v_{E}}\right\rfloor_{(a q)} \leftrightarrow v_{B^{\prime}} B^{z_{B}}+v_{E} E^{z_{E}}
$$

may therefore be defined as follows,

$$
\begin{aligned}
\frac{v_{B^{\prime}} v_{A}}{v_{B}}\left[\left(R^{-}\right)_{z_{A}} A^{z_{A}}\right]+\left[\left(B^{z_{B}}\right)_{v_{B}}\left(E^{z_{E}}\right)_{v_{E}}\right]_{(a q)} \leftrightarrow \\
\\
(1-n) v_{B^{\prime}}\left[\left(R^{-}\right)_{z_{B}} B^{z_{B}}\right]+\left(\frac{v_{B}^{\prime} v_{A}}{v_{A}}-n v_{A}\right) A^{z_{A}}+ \\
(1-n) v_{E} E^{z_{E}}+n\left[\left(B^{z_{B}}\right)_{v_{B}^{\prime}}\left(E^{z_{E}}\right)_{v_{E}} l_{(a q)}\right.
\end{aligned}
$$

where $n$ is the fraction of the number of moles of species $E^{z_{E}}$ that is adsorbed by the resin as species $B E$. It is also possible that species $E^{z_{E}}$ is adsorbed by the resin phase as more than one electrolyte, i.e. as both electrolytes species $B E$ and $A E$.

Electrolytic sorption was therefore monitored for various cation-cation and anion-anion exchange equilibrium reactions and measured. The results of this method of obtaining 
experimental data is prone to experimental error due to the fact that minute concentration differences are measured for the co-ion, which is already at extremely low solution phase concentrations. The equilibrium isotherm data need to be collected at these extremely low solution phase concentrations due to the fact that the concentrations of the constituent ionic species of the sparingly soluble solid is present at the same order of magnitude of the concentrations. The electrolytic sorption data collected experimentally are therefore only suitable for interpretation of the trends at these low solution phase concentrations. It may further serve to make an assessment on the order of magnitude of the electrolytic sorption relative to the adsorption of the exchanging counter ionic species actively participating in the exchange reaction.

\subsubsection{Experimental data on electrolyte sorption for binary ion-exchange reactions}

During anion exchange reactions the co-ion or spectator ion is a cation species. Various electrolytic sorption curves have been collected for the numerous binary anion exchange isotherms as listed in Table (8.2) above.

Figure (8.1) shows the fraction of the initial solution phase concentration of the $\mathrm{Na}^{+}$ions participating in electrolytic sorption at equilibrium for the binary anion exchange reaction between $\mathrm{F}^{-}$and $\mathrm{Cl}^{-}$for Duolite A161, a macroreticular anion exchange resin.

The initial solution phase concentration of the $\mathrm{Na}^{+}$ions varies from $120 \mathrm{ppm}$ to $617 \mathrm{ppm}$, which represents the very low solution phase concentrations encountered when sparingly soluble solids dissociate in aqueous solutions. From Figure (8.1) it is evident that electrolytic sorption does occur at these low solution phase concentrations as can be seen from the fact that the ratio $\frac{C_{0}-C_{e}}{C_{0}}$ is not constant. 


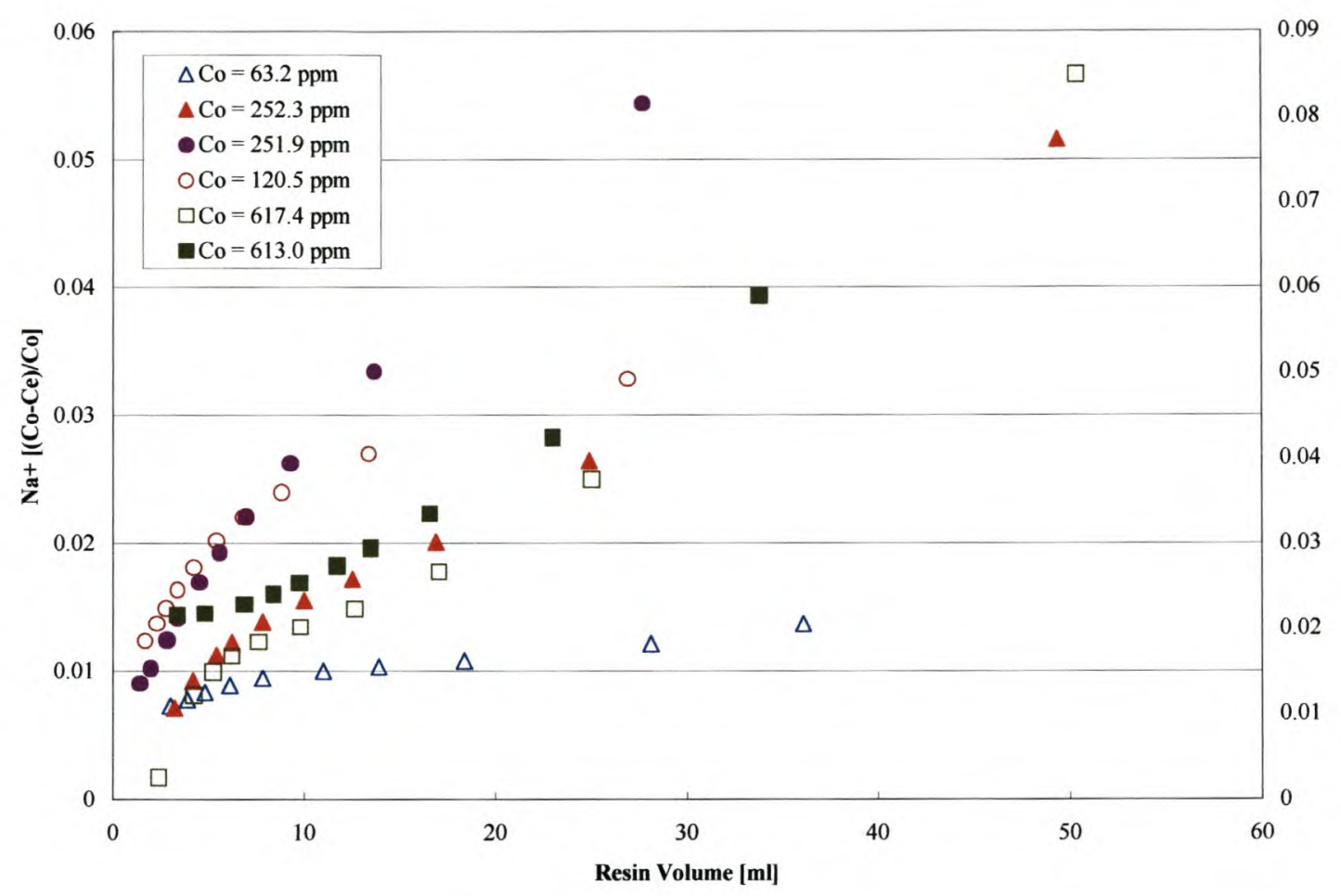

Figure 8.1 Equilibrium electrolyte adsorption of $\mathrm{Na}^{+}$ions by a macroreticular anion exchange resin, Duolite A161, for the binary anion exchange reaction between $\mathrm{F}^{-}$and $\mathrm{Cl}^{-}$.

From Figure (8.1) it is also evident that with an increase in the volume of resin present per unit volume of solution for the same initial solution phase concentration of the co-ion $\left(\mathrm{Na}^{+}\right.$ion) the amount of co-ion adsorbed increases. This may be explained by a simple mass balance equation. The amount of resin in this mass balance equation increases while the volume of the solution phase stays constant. This trend is evident for all of the initial solution phase concentrations as displayed in Figure (8.1). This is as expected due to the fact that an increase in resin volume per unit volume of solution means an increase in the interstitial pore volume of the resin phase, which facilitates electrolytic sorption as discussed in Chapter 4. 


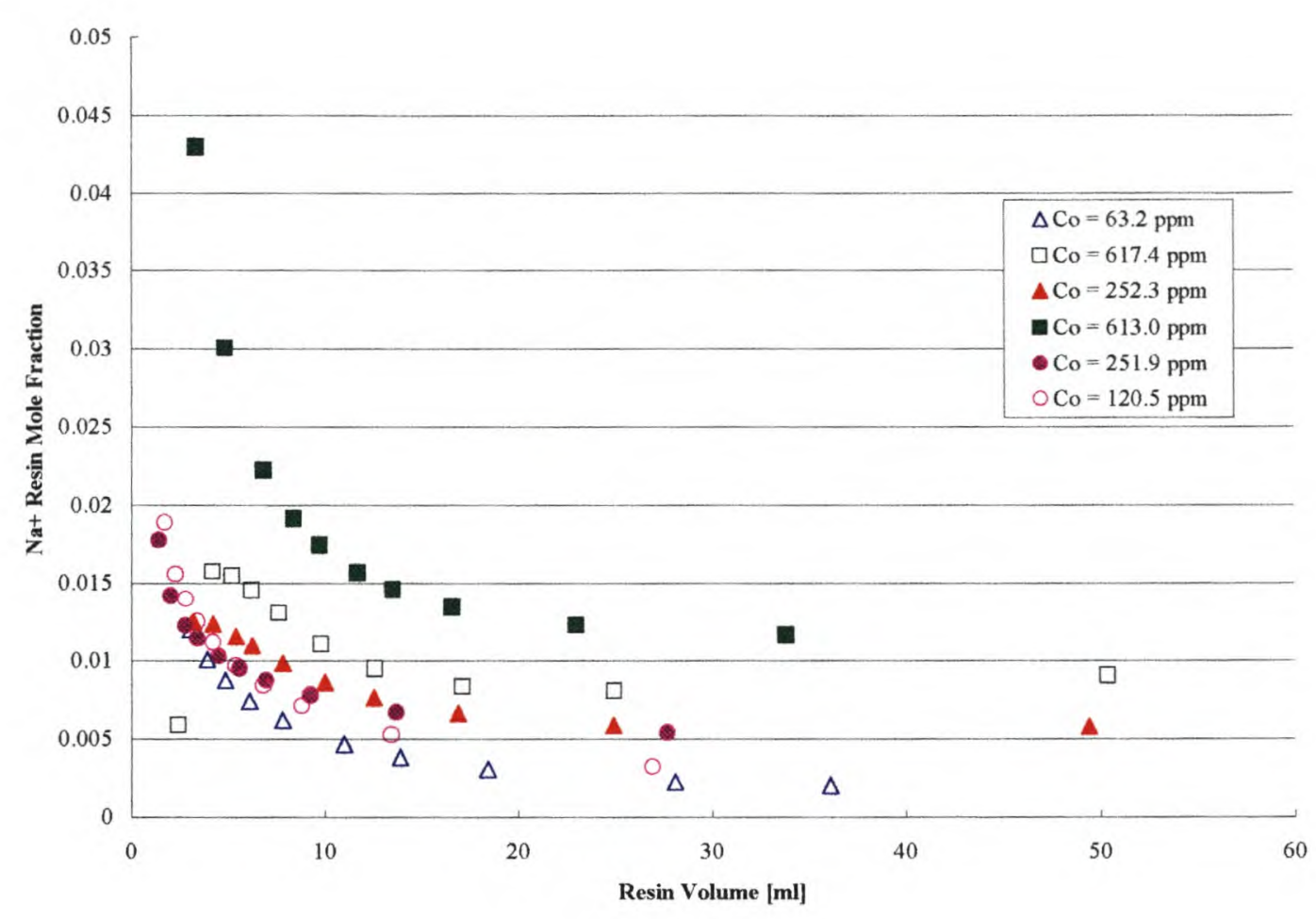

Figure 8.2 Equilibrium electrolyte adsorption of $\mathrm{Na}^{+}$ions by a macroreticular anion exchange resin, Duolite A161, for the binary anion exchange reaction between $\mathrm{F}^{-}$and $\mathrm{Cl}^{-}$expressed as a resin phase mole fraction of the capacity of the anion exchange resin.

Figure (8.2) shows the electrolytic sorption of the $\mathrm{Na}^{+}$ions, as displayed in Figure (8.1), expressed in different units. In Figure (8.2) the y-axis represents the amount of the $\mathrm{Na}^{+}$ ions adsorbed as a mole fraction of the available anion resin capacity. Although the adsorbed $\mathrm{Na}^{+}$ions do not actively participate in the anion exchange reaction occurring on the active sites of the resin, Figure (8.2) does facilitate in explaining the order of magnitude of the extent of electrolytic sorption of the co-ion relative to the actual ionexchange reaction. The ions participating in electrolytic sorption do not consume any of the anion exchange capacity and therefore the y-axis of Figure (8.2) is not theoretically correct. The y-axis is expressed as a mole fraction of the anion-exchange resin capacity. If the co-ion species were to actively participate in the ion-exchange reaction it would 
occupy on average less than 2 percent of the total exchange capacity of the anion exchange resin. It should be kept in mind that the data used in the calculation of the trends in Figures (8.1) and (8.2) are prone to some experimental inaccuracy. This is due to the extremely low solution phase concentration of the species of interest and the experimental limitations in accurately analysing such low solution phase concentrations.

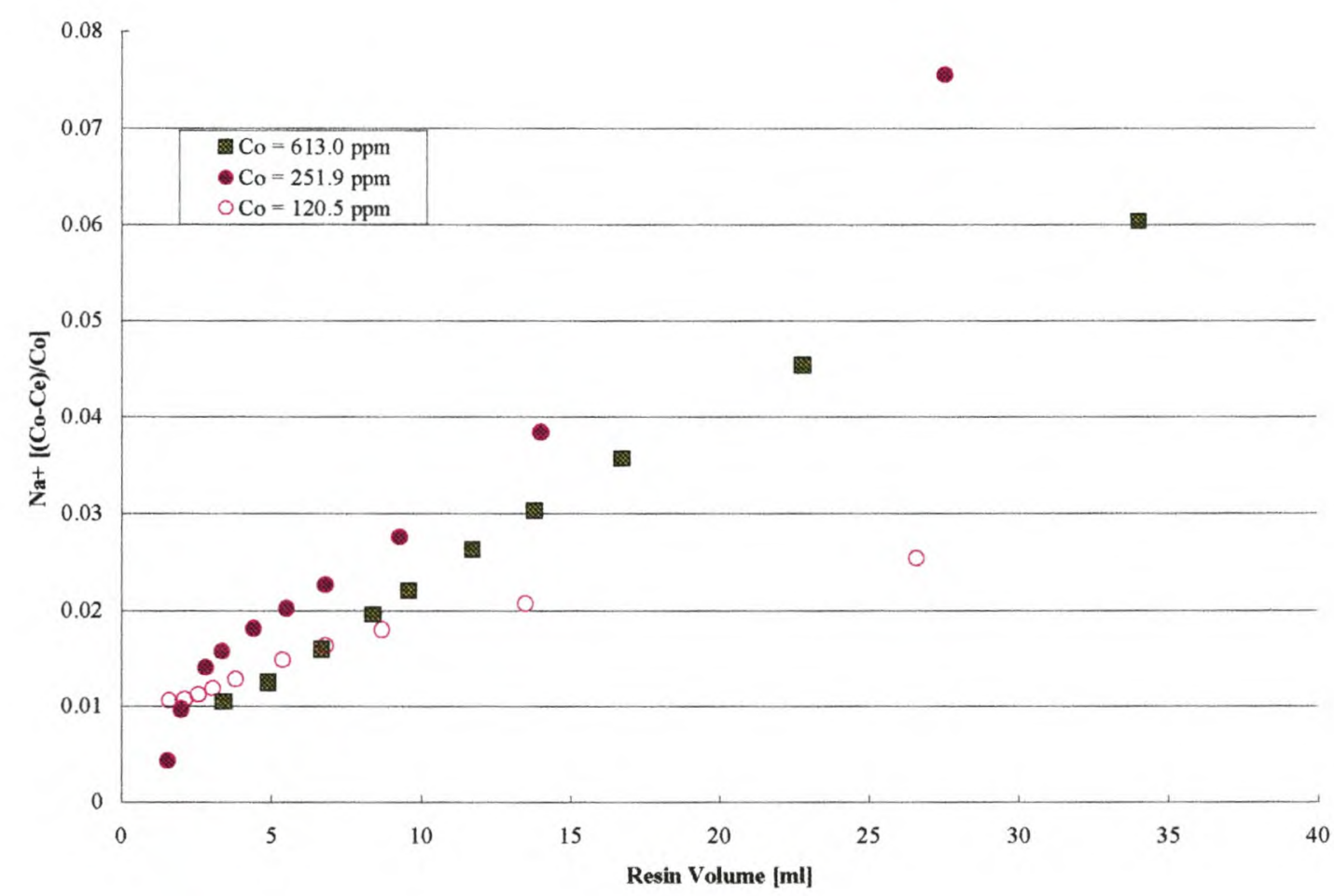

Figure 8.3 Equilibrium electrolyte adsorption of $\mathrm{Na}^{+}$ions by a macroreticular anion exchange resin, Duolite A161, for the binary anion exchange reaction between $\mathrm{F}^{-}$and $\mathrm{NO}_{3}^{-}$.

Figure (8.1) is similar to Figure (8.2) in that it shows the fraction of the initial solution phase concentration of the $\mathrm{Na}^{+}$ions that participate in electrolytic sorption at equilibrium for the binary anion exchange reaction between $\mathrm{F}$ and $\mathrm{NO}_{3}{ }^{-}$for Duolite $\mathrm{A} 161$. It is evident that electrolytic sorption also occurred for these binary anion exchange reactions. The initial solution phase concentration of the $\mathrm{Na}^{+}$ions varies from $120 \mathrm{ppm}$ to $613 \mathrm{ppm}$. 
The amount of $\mathrm{Na}^{+}$ions adsorbed is similar to that in Figure (8.1). As mentioned previously the experimental data at this low solution phase concentrations are prone to experimental error and this should be kept in mind when interpreting the results.

From Figure (8.1) and Figure (8.2) the effect of experimental deviations is evident for the two cases where the initial solution phase concentration of the $\mathrm{Na}^{+}$ions is equal to 613.0 ppm and $617.4 \mathrm{ppm}$, and $252.3 \mathrm{ppm}$ and $251.9 \mathrm{ppm}$. Two sets of independent experiments were performed for the two concentration regions, approximately $615 \mathrm{ppm}$ and $251 \mathrm{ppm}$. It is evident from Figure (8.1) and Figure (8.2) that significant deviations exist between the trend lines of the $613.0 \mathrm{ppm}$ and $617.4 \mathrm{ppm}$ curves and the $252.3 \mathrm{ppm}$ and $251.9 \mathrm{ppm}$ curves. The experiments for these two sets of curves were performed at the same temperature with the same prepared batch of resin (according to the procedure as described in Chapter 6). Both sets of curves show the trends, which clearly indicate that electrolytic sorption does occur.

From Figure (8.4) it is evident that the mole fraction anion-exchange capacity consumed by the $\mathrm{Na}^{+}$co-ions, if they were actively participating in the exchange reaction with the resin active sites, would have been less than 2 percent on average for the concentration ranges of interest. These values representing electrolytic sorption of the co-ions for the anion exchange reaction between $\mathrm{F}^{-}$and $\mathrm{NO}_{3}{ }^{-}$are similar to the values displayed in Figure (8.2) for the binary anion exchange reaction between $\mathrm{F}^{-}$and $\mathrm{Cl}^{-}$for the same initial concentration ranges of the $\mathrm{Na}^{+}$ions.

From the above discussion it is evident that electrolytic sorption of the co-ions does occur at low solution phase concentrations but only to such an extent that it only represents one or two percent of the total ion-exchange sorption of binary ion-exchange reactions. It is therefore decided that it is not necessary to model these interactions for the successful modelling of ion-exchange equilibria in general at low solution phase concentrations. 
Instead of modelling the effect of electrolytic sorption as an occurrence, it is considered for the purposes of this dissertation as part of the overall sorption capacity of the ionexchange reaction as discussed in detail in Chapter 4 of this dissertation. The contribution of the electrolytic sorption to the overall loading of exchanged species on the ion-exchange resin is treated as additional ion-exchange capacity. This treatment of electrolytic sorption is shown in paragraph 8.5 below, where the value of the equilibrium quotient was calculated from the actual measured values in the experiments that included the effect of the electrolytic sorption. No adjustments in the measured values were made in order to account for the amount of electrolytic sorption that occurred.

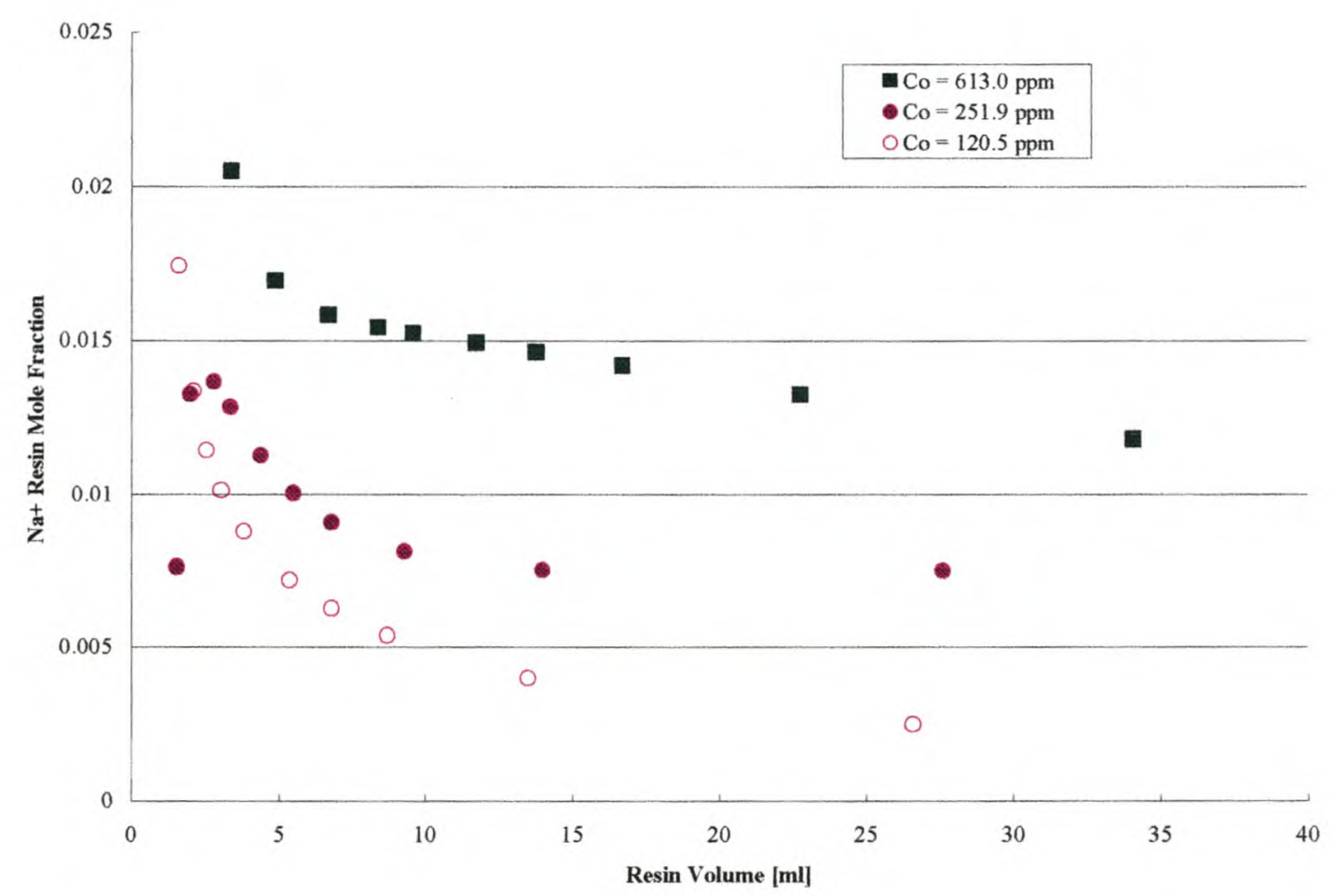

Figure 8.4 Equilibrium electrolyte adsorption of $\mathrm{Na}^{+}$ions by a macroreticular anion exchange resin, Duolite A161, for the binary anion exchange reaction between $\mathrm{F}$ and $\mathrm{NO}_{3}{ }^{-}$expressed as a resin phase mole fraction of the capacity of the anion exchange resin. 


\subsection{EXPERIMENTAL DATA FOR THE RESIN / SOLUTION PHASE ISOTHERMS FOR THE ANION-EXCHANGE REACTIONS OF INTEREST TO THIS DISSERTATION}

In the sections below the experimental data for all of the anion exchange reactions of interest to this dissertation are shown in Figures (8.5) to (8.9). The data shown were collected experimentally and are used in Chapters 9 to 11 for the various RIP slurry mixture systems investigated. The anions of interest are $\mathrm{F}^{-}, \mathrm{SO}_{4}{ }^{2-}, \mathrm{OH}^{-}, \mathrm{CO}_{3}{ }^{2-}$ and $\mathrm{HCO}^{-}$ and the counter ions are $\mathrm{Cl}^{-}, \mathrm{NO}_{3}{ }^{-}$and $\mathrm{OH}^{-}$. Various combinations of the above mentioned anions are possible in the RIP slurry mixture systems investigated in Chapters 9 to 11 .

\subsubsection{Experimental data for binary ion-exchange equilibrium isotherms for the anion exchange reaction between $\mathrm{F}^{-}$and $\mathrm{NO}_{3}{ }^{-}$and $\mathrm{F}^{-}$and $\mathrm{Cl}^{-}$}

The legends in Figures (8.5) to (8.14) indicate two properties for each individual equilibrium isotherm. The symbol Co represents the total solution phase concentration of the exchanging species of interest in ppm present at the start of the ion-exchange reaction. The second property shown by the legend in each of the Figures (8.5) to (8.14) is the counter ion species symbol. This counter ion species is initially present only in the resin phase. The equilibrium isotherm for each of the Figures (8.5) to (8.14) is therefore for the exchange reaction between the species indicated on both the $y$-axis and $x$-axis of each figure and the species indicated by the legend.

Figure (8.5) shows the binary ion-exchange isotherms for the anion exchange reactions between $\mathrm{F}^{-}$and $\mathrm{NO}_{3}{ }_{3}$ and $\mathrm{F}^{-}$and $\mathrm{Cl}^{-}$. The isotherms were determined experimentally for different initial $\mathrm{F}^{-}$concentrations ranging from approximately $50 \mathrm{ppm}$ to $500 \mathrm{ppm}$. It is evident from Figure (8.5) that all of the isotherms for the $\mathrm{Cl}^{-}$exchange overlap with one another, except for the $50 \mathrm{ppm}$ isotherm. It is also evident that reasonable experimental reproducibility was obtained for the $208 \mathrm{ppm}$ and $>500 \mathrm{ppm}$ isotherms for the $\mathrm{Cl}^{-}$ 
exchange. For each of the two $\mathrm{Cl}^{-}$exchange isotherms the experiments were repeated for different volumes of ion-exchange resins and slightly different initial solution phase concentrations of the $\mathrm{F}^{-}$ions (208.2 ppm and $208.5 \mathrm{ppm} ; 510.2 \mathrm{ppm}$ and $\left.506.6 \mathrm{ppm}\right)$. The anion exchange resin used was Duolite A161, a macroreticular strong base anion exchange resin. The $\mathrm{Cl}^{-}$exchange isotherms for Figure (8.5) were collected at the temperatures of $17.0^{\circ} \mathrm{C}$ and $15.0^{\circ} \mathrm{C}$ as indicated in Table (8.2) for the $\mathrm{F}^{-}-\mathrm{Cl}^{-}-\mathrm{Na}^{+}$system.

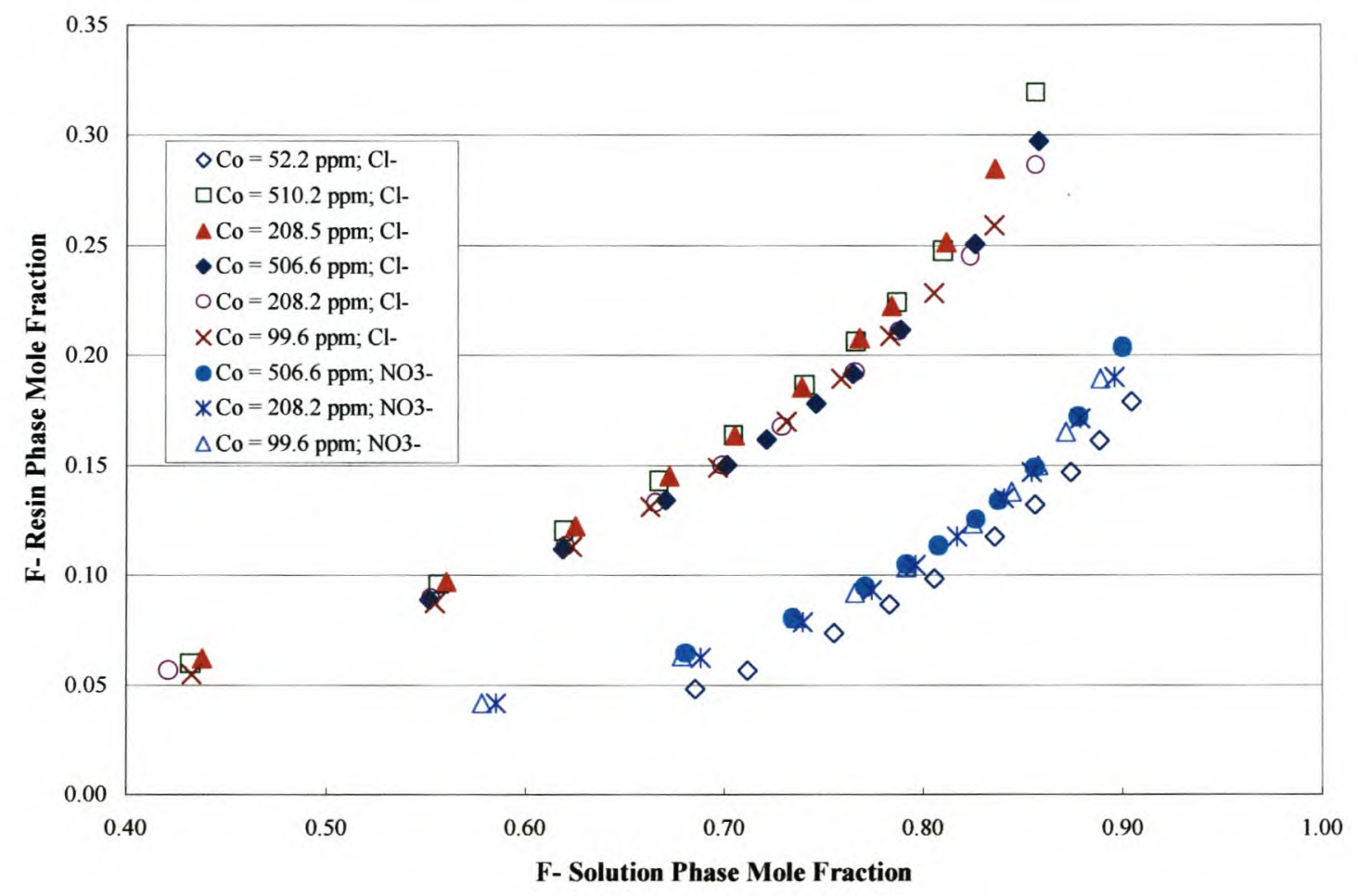

Figure 8.5 Equilibrium solution and resin phase mole fractions for the ion-exchange reaction between $\mathrm{F}^{-}$and $\mathrm{Cl}^{-}$and $\mathrm{F}^{-}$and $\mathrm{NO}_{3}{ }^{-}$on a macroreticular strong base anion exchange resin Duolite A161. Data obtained experimentally for different initial $\mathrm{F}^{-}$concentrations as indicated by the legend.

Figure (8.5) also shows the binary ion-exchange isotherms for the anion exchange reactions between $\mathrm{F}^{-}$and $\mathrm{NO}_{3}^{-}$. The isotherms were determined experimentally for different initial $\mathrm{F}^{-}$concentrations ranging from approximately $100 \mathrm{ppm}$ to $506 \mathrm{ppm}$. 
It is evident from Figure (8.5) that all of the $\mathrm{NO}_{3}{ }^{-}$exchange isotherms also overlap with one another, which indicates that the thermodynamic equilibrium constant for the binary exchange reaction is fairly independent of solution phase concentration for the concentration range of interest.

8.3.2 Experimental data for binary ion-exchange equilibrium isotherms for the anion exchange reaction between $\mathrm{SO}_{4}{ }^{2-}$ and $\mathrm{Cl}^{-}, \mathrm{SO}_{4}{ }^{2-}$ and $\mathrm{NO}_{3}{ }^{-}$and $\mathrm{SO}_{4}{ }^{2-}$ and $\mathrm{OH}^{-}$

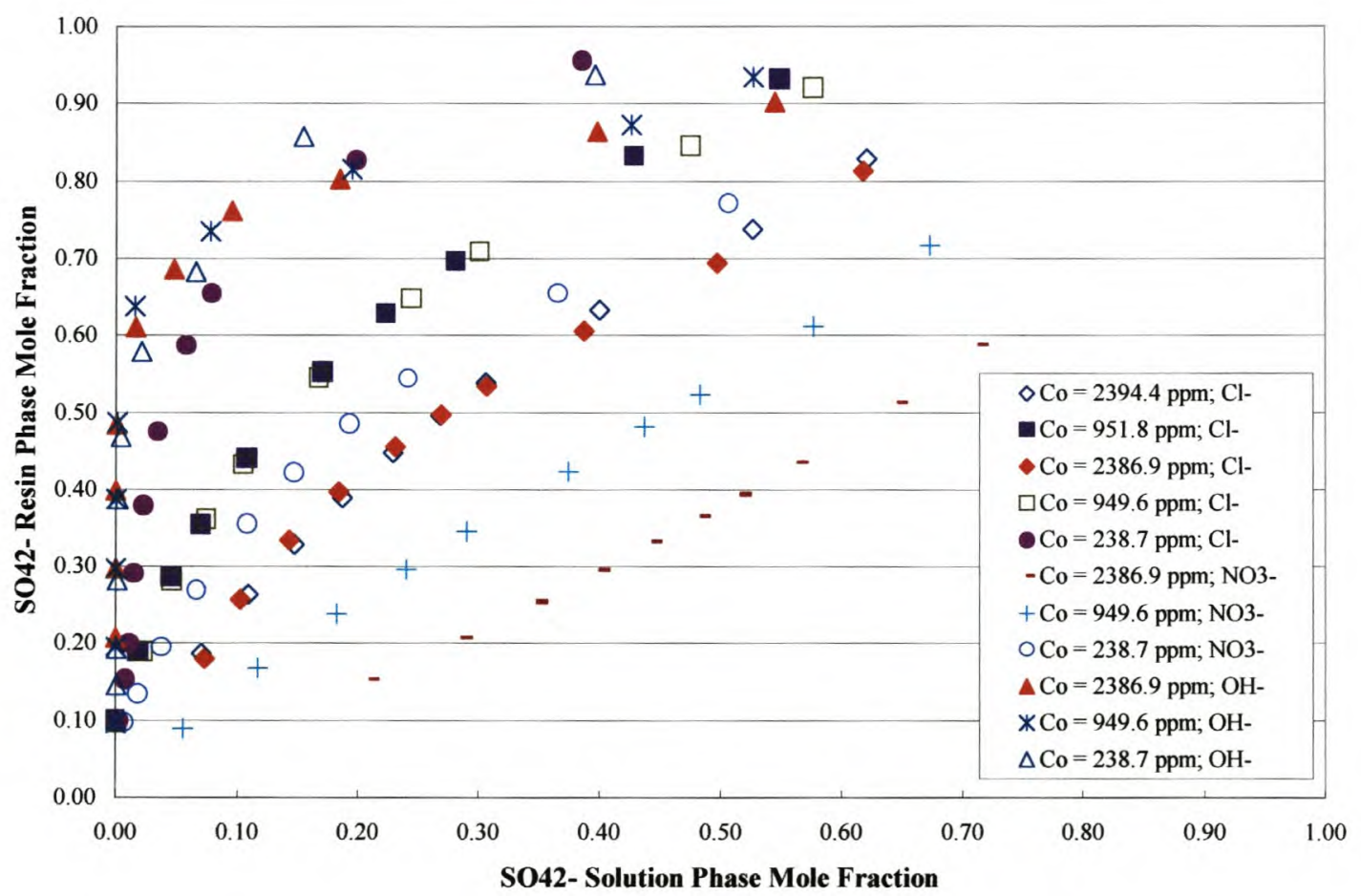

Figure 8.6 Equilibrium solution and resin phase mole fractions for the ion-exchange reaction between $\mathrm{SO}_{4}{ }^{2-}$ and $\mathrm{Cl}^{-}, \mathrm{SO}_{4}{ }^{2-}$ and $\mathrm{NO}_{3}{ }^{-}$and $\mathrm{SO}_{4}{ }^{2-}$ and $\mathrm{OH}^{-}$on a macroreticular strong base anion exchange resin Duolite A161. Data obtained experimentally for different initial $\mathrm{SO}_{4}{ }^{2-}$ concentrations as indicated by the legend. 
The $\mathrm{NO}_{3}{ }^{-}$exchange isotherms for Figure (8.5) were collected at the temperature of $15.0^{\circ} \mathrm{C}$ (as indicated by Table (8.2) for the $\mathrm{F}^{-}-\mathrm{NO}_{3}{ }^{-}-\mathrm{Na}^{+}$system).

\subsubsection{Experimental data for binary ion-exchange equilibrium isotherms for the anion exchange reaction between $\mathrm{OH}^{-}$and $\mathrm{NO}_{3}{ }^{-}$and $\mathrm{OH}^{-}$and $\mathrm{Cl}^{-}$}

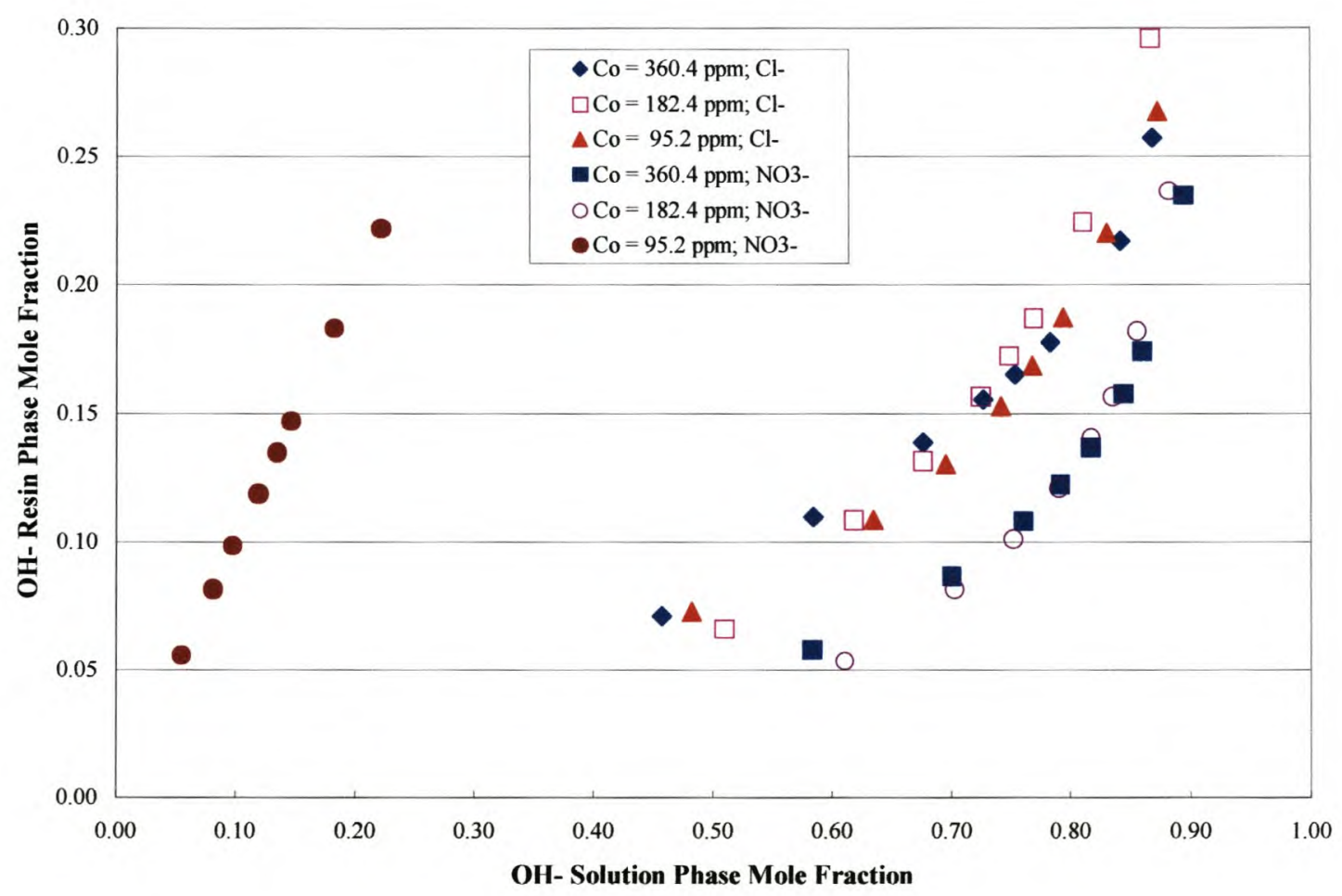

Figure 8.7 Equilibrium solution and resin phase mole fractions for the ion-exchange reaction between $\mathrm{OH}^{-}$and $\mathrm{NO}_{3}^{-}$and $\mathrm{OH}^{-}$and $\mathrm{Cl}^{-}$on a macroreticular strong base anion exchange resin Duolite A161. Data obtained experimentally for different initial $\mathrm{NaOH}$ concentrations, of which the initial $\mathrm{Na}^{+}$concentration is indicated by the legend.

The $\mathrm{SO}_{4}{ }^{2-}$ exchange isotherms for Figure (8.6) were collected at the temperatures of $17.5^{\circ} \mathrm{C}, 18.0^{\circ} \mathrm{C}$ and $18.5^{\circ} \mathrm{C}$ for the $\mathrm{SO}_{4}{ }^{2-}-\mathrm{Cl}^{-}-\mathrm{Na}^{+}$system; $18.5^{\circ} \mathrm{C}$ and $23.0^{\circ} \mathrm{C}$ for the 
$\mathrm{SO}_{4}{ }^{2}-\mathrm{NO}_{3}{ }^{-}-\mathrm{Na}^{+}$system and $18.5^{\circ} \mathrm{C}$ and $23.0^{\circ} \mathrm{C}$ for the $\mathrm{SO}_{4}{ }^{2-}-\mathrm{OH}^{-}-\mathrm{Na}^{+}$system (as indicated by Table (8.2)).

The $\mathrm{OH}^{-}$exchange isotherms for Figure (8.7) were collected at the temperature of $22.0^{\circ} \mathrm{C}$ for the $\mathrm{OH}^{-}-\mathrm{NO}_{3}{ }^{-}-\mathrm{Na}^{+}$system and $22.0^{\circ} \mathrm{C}$ for the $\mathrm{OH}^{-}-\mathrm{Cl}^{-}-\mathrm{Na}^{+}$system (as indicated by Table (8.2)).

8.3.4 Experimental data for binary ion-exchange equilibrium isotherms for the anion exchange reaction between $\mathrm{CO}_{3}{ }^{2-}$ and $\mathrm{Cl}^{-}$and $\mathrm{CO}_{3}{ }^{2-}$ and $\mathrm{NO}_{3}{ }^{-}$

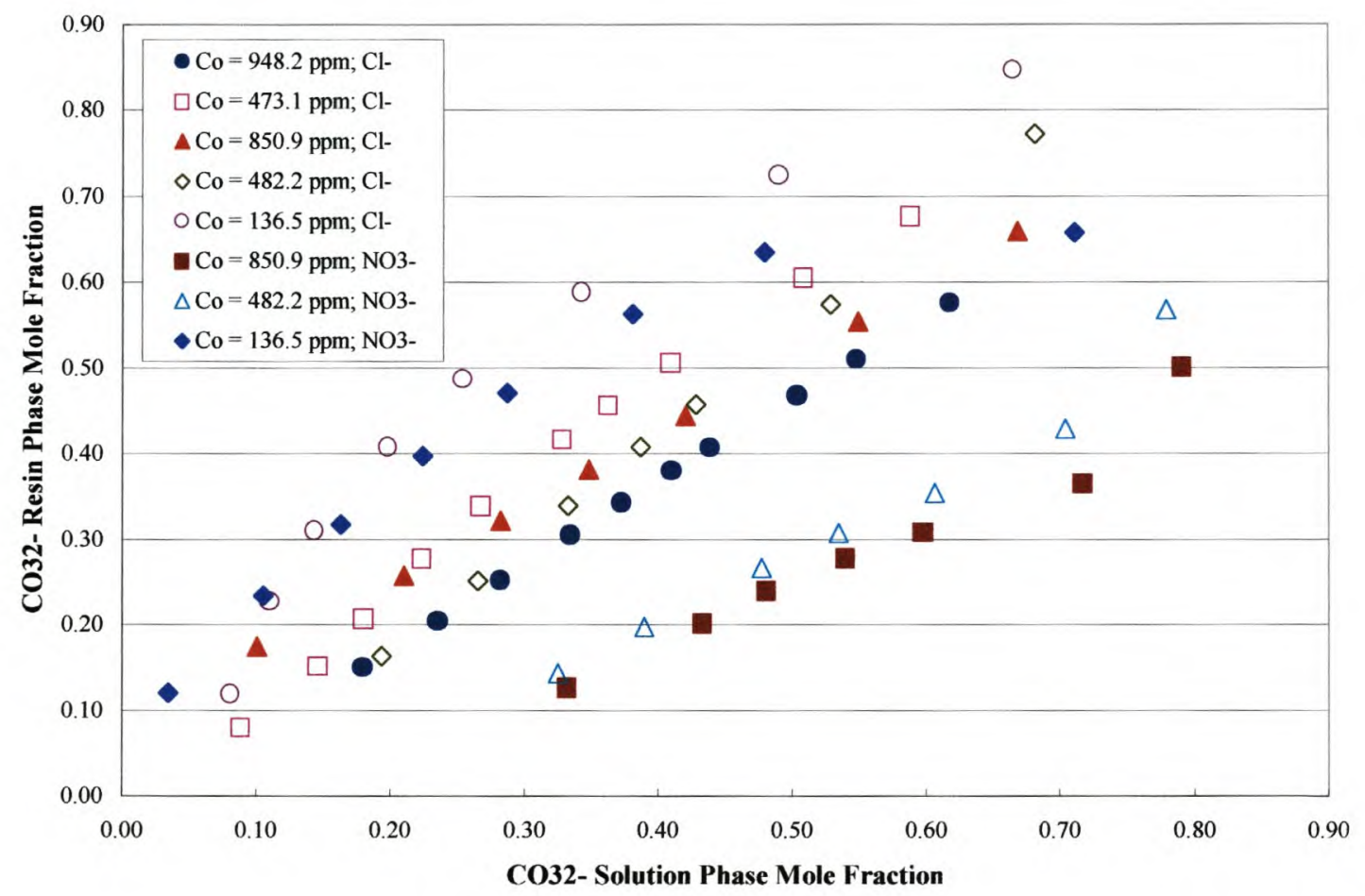

Figure 8.8 Equilibrium solution and resin phase mole fractions for the ion-exchange reaction between $\mathrm{CO}_{3}{ }^{2-}$ and $\mathrm{Cl}^{-}$and $\mathrm{CO}_{3}{ }^{2-}$ and $\mathrm{NO}_{3}{ }^{-}$on a macroreticular strong base anion exchange resin Duolite A161. Data obtained experimentally for different initial $\mathrm{CO}_{3}{ }^{2-}$ concentrations as indicated by the legend. 
The $\mathrm{CO}_{3}{ }^{2-}$ exchange isotherms for Figure (8.8) were collected at the temperature of $19.0^{\circ} \mathrm{C}$ for the $\mathrm{CO}_{3}{ }^{2-}-\mathrm{NO}_{3}{ }^{-}-\mathrm{Na}^{+}$system and $19.0^{\circ} \mathrm{C}$ for the $\mathrm{CO}_{3}{ }^{2-}-\mathrm{Cl}^{-}-\mathrm{Na}^{+}$(as indicated by Table (8.2)).

8.3.5 Experimental data for binary ion-exchange equilibrium isotherms for the anion exchange reaction between $\mathrm{HCO}_{3}{ }^{-}$and $\mathrm{Cl}^{-}$and $\mathrm{HCO}_{3}{ }^{-}$and $\mathrm{NO}_{3}{ }^{-}$

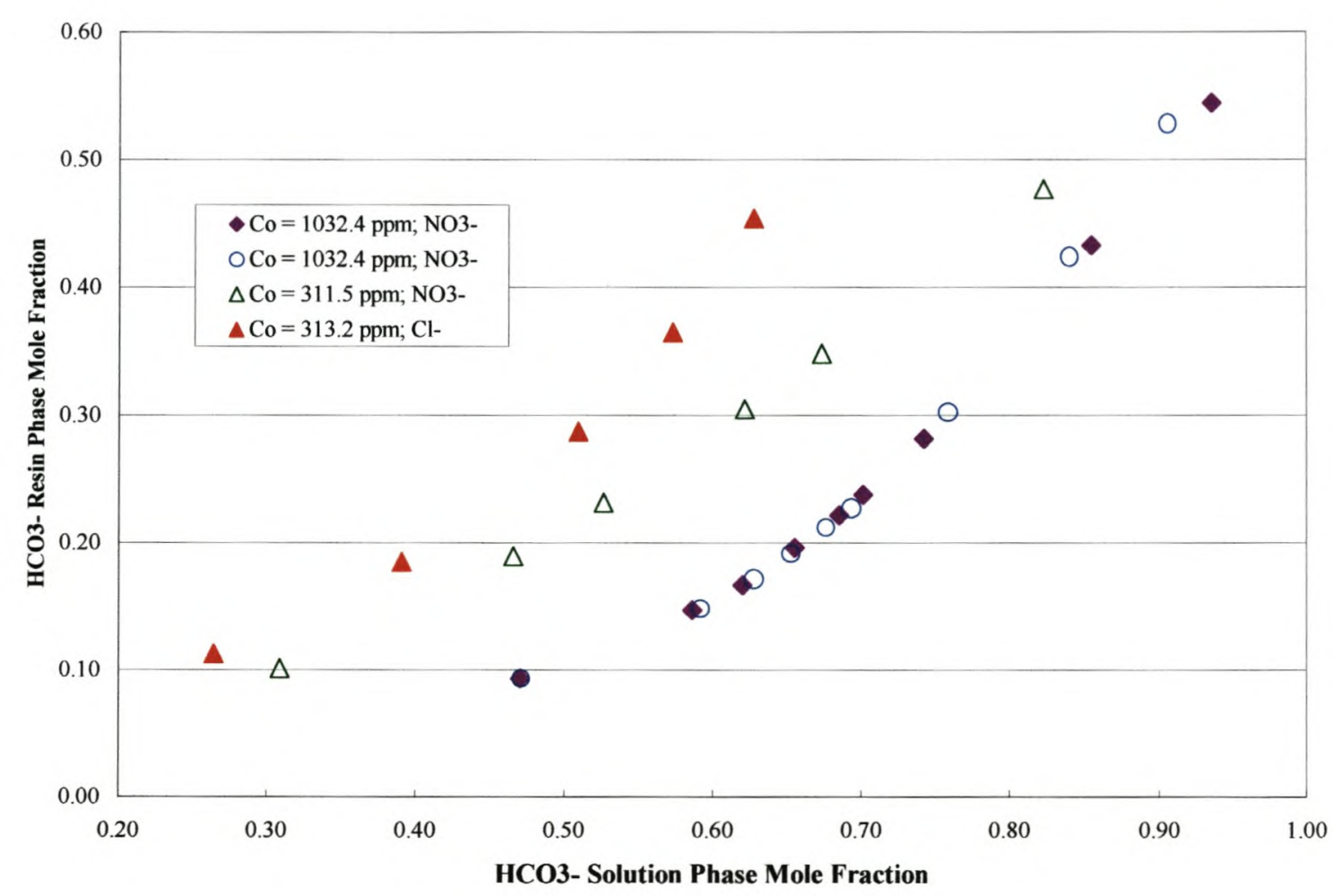

Figure 8.9 Equilibrium solution and resin phase mole fractions for the ion-exchange reaction between $\mathrm{HCO}_{3}{ }^{-}$and $\mathrm{Cl}^{-}$and $\mathrm{HCO}_{3}{ }^{-}$and $\mathrm{NO}_{3}{ }^{-}$on a macroreticular strong base anion exchange resin Duolite A161. Data obtained experimentally for different initial $\mathrm{HCO}_{3}{ }^{-}$concentrations as indicated by the legend. 
The $\mathrm{HCO}_{3}{ }^{-}$exchange isotherms for Figure (8.9) were collected at the temperature of $19.0^{\circ} \mathrm{C}$ for the $\mathrm{HCO}_{3}{ }^{-}-\mathrm{NO}_{3}{ }^{-}-\mathrm{Na}^{+}$system and $19.0^{\circ} \mathrm{C}$ for the $\mathrm{HCO}_{3}{ }^{-}-\mathrm{Cl}^{-}-\mathrm{Na}^{+}$(as indicated by Table (8.2)).

\subsection{EXPERIMENTAL DATA FOR THE RESIN / SOLUTION PHASE ISOTHERMS FOR CATION-EXCHANGE REACTIONS}

Figures (8.10) to (8.14) show the experimental data for the various cation exchange reactions of interest to this dissertation. The cations considered are $\mathrm{Mg}^{+2}, \mathrm{Ca}^{+2}, \mathrm{Ba}^{+2}$, $\mathrm{Pb}^{+2}$ and $\mathrm{Al}^{+3}$ and the counter-ions on the resin phases $\mathrm{H}^{+}, \mathrm{Na}^{+}$and $\mathrm{K}^{+}$. Various combinations of the cations mentioned above are considered in the experimental results for which data are shown in Figures (8.10) to (8.14).

\subsubsection{Experimental data for binary ion-exchange equilibrium isotherms for the cation exchange reaction between $\mathrm{Mg}^{+2}$ and $\mathrm{H}^{+} ; \mathrm{Mg}^{+2}$ and $\mathrm{Na}^{+} ; \mathrm{Mg}^{+2}$ and $\mathrm{K}^{+}$; $\mathrm{Mg}^{+2}$ and $\mathrm{Cu}^{+2}$ and $\mathrm{Mg}^{+2}$ and $\mathrm{Al}^{+3}$}

Figure (8.10) shows the ion-exchange isotherms for the exchange reaction between $\mathrm{Mg}^{+2}$ and $\mathrm{H}^{+} ; \mathrm{Mg}^{+2}$ and $\mathrm{Na}^{+} ; \mathrm{Mg}^{+2}$ and $\mathrm{K}^{+} ; \mathrm{Mg}^{+2}$ and $\mathrm{Cu}^{+2}$ and $\mathrm{Mg}^{+2}$ and $\mathrm{Al}^{+3}$ on the macroreticular strong acid cation exchange resin Duolite C26. The equilibrium isotherms were determined for the divalent-monovalent $\left(\mathrm{Mg}^{+2}\right.$ with $\mathrm{H}^{+} ; \mathrm{Na}^{+}$and $\left.\mathrm{K}^{+}\right)$; divalentdivalent $\left(\mathrm{Mg}^{+2}\right.$ for $\left.\mathrm{Cu}^{+2}\right)$ and divalent-trivalent $\left(\mathrm{Mg}^{+2}\right.$ and $\left.\mathrm{Al}^{+3}\right)$ exchange reactions. The same experiments were repeated for the other divalent cations of interest $\left(\mathrm{Ca}^{+2}, \mathrm{Ba}^{+2}\right.$ and $\mathrm{Pb}^{+2}$ ), which are as shown in Figure (8.11) to Figure (8.13) respectively.

It is evident from these figures that there is an increase in the selectivity of the ionexchange resin for an ionic species with an increase in valence of the species, as expected. This trend can clearly be seen from Figure (8.10) to Figure (8.13). The resin mole fraction for the cations of interest (y-axis in Figure (8.10) to Figure (8.13) ) has the highest equilibrium values for the divalent-monovalent exchange reactions between the 
cation of interest $\left(\mathrm{Mg}^{+2}, \mathrm{Ca}^{+2}, \mathrm{Ba}^{+2}\right.$ and $\left.\mathrm{Pb}^{+2}\right)$ and the monvalent cations $\mathrm{H}^{+} ; \mathrm{Na}^{+}$and $\mathrm{K}^{+}$ and the lowest values for the divalent-trivalent exchange reaction between the cations of interest and the trivalent cation $\mathrm{Al}^{+3}$. The divalent-divalent exchange isotherms with divalent cation $\mathrm{Cu}^{+2}$ lie in between the monovalent and trivalent isotherm curves.

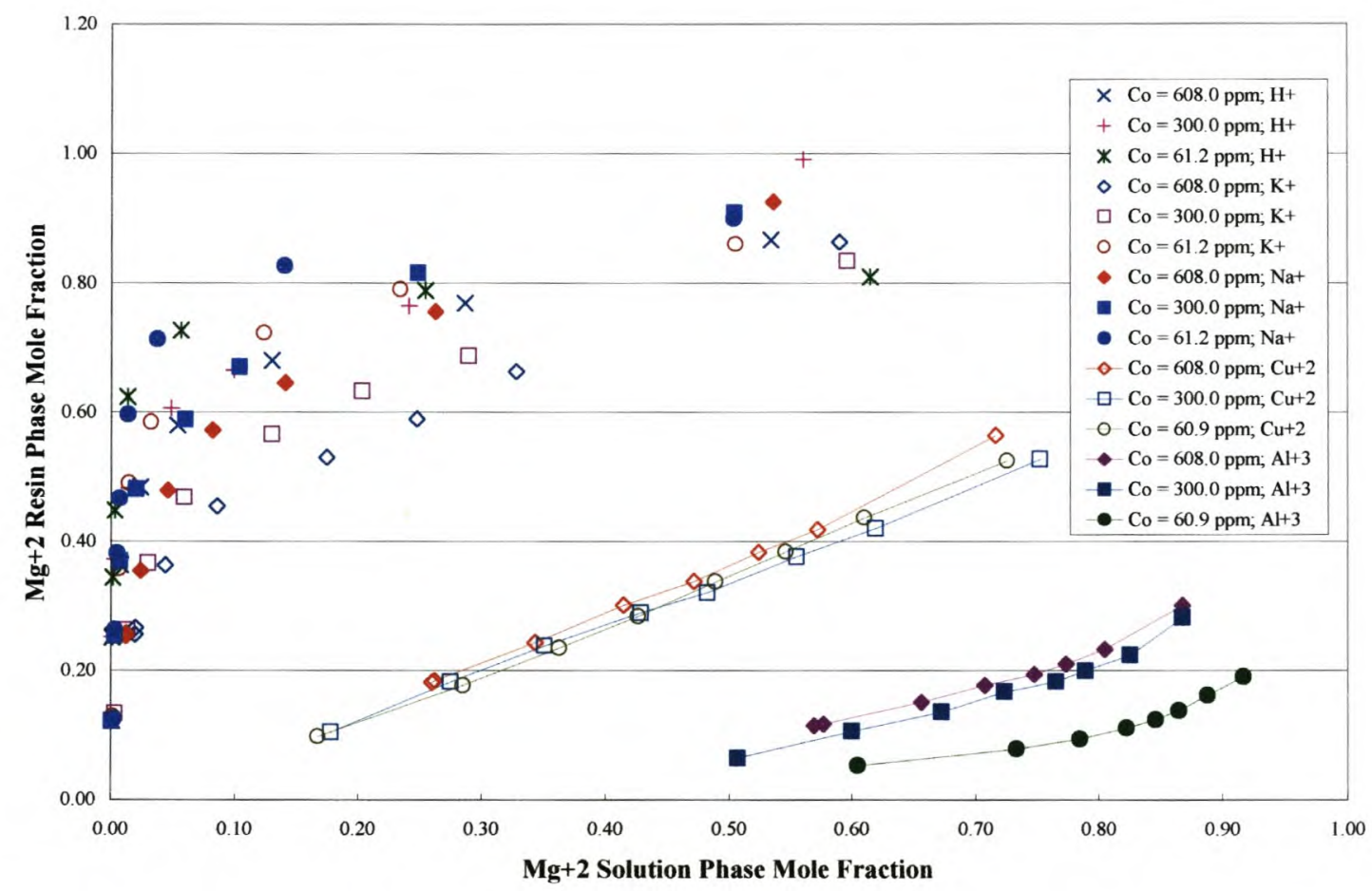

Figure 8.10 Equilibrium solution and resin phase mole fractions for the ion-exchange reaction between $\mathrm{Mg}^{+2}$ and $\mathrm{H}^{+} ; \mathrm{Mg}^{+2}$ and $\mathrm{Na}^{+} ; \mathrm{Mg}^{+2}$ and $\mathrm{K}^{+} ; \mathrm{Mg}^{+2}$ and $\mathrm{Cu}^{+2}$ and $\mathrm{Mg}^{+2}$ and $\mathrm{Al}^{+3}$ on a macroreticular strong acid cation exchange resin Duolite C26. Data obtained experimentally for different initial $\mathrm{Mg}^{+2}$ concentrations as indicated by the legend. 
8.4.2 Experimental data for binary ion-exchange equilibrium isotherms for the cation exchange reaction between $\mathrm{Ca}^{+2}$ and $\mathrm{H}^{+} ; \mathrm{Ca}^{+2}$ and $\mathrm{Na}^{+} ; \mathrm{Ca}^{+2}$ and $\mathrm{K}^{+}$; $\mathrm{Ca}^{+2}$ and $\mathrm{Cu}^{+2}$ and $\mathrm{Ca}^{+2}$ and $\mathrm{Al}^{+3}$

It is further evident from Figures (8.10) to (8.13) that the largest sensitivity of the equilibrium isotherms for the initial solution phase concentration for a specific exchange reaction occurs for the divalent-monovalent and divalent-trivalent exchange reactions. The equilibrium isotherms for these exchange reactions show the biggest trend away from one another for the various initial solution phase concentrations of the cations of interest.

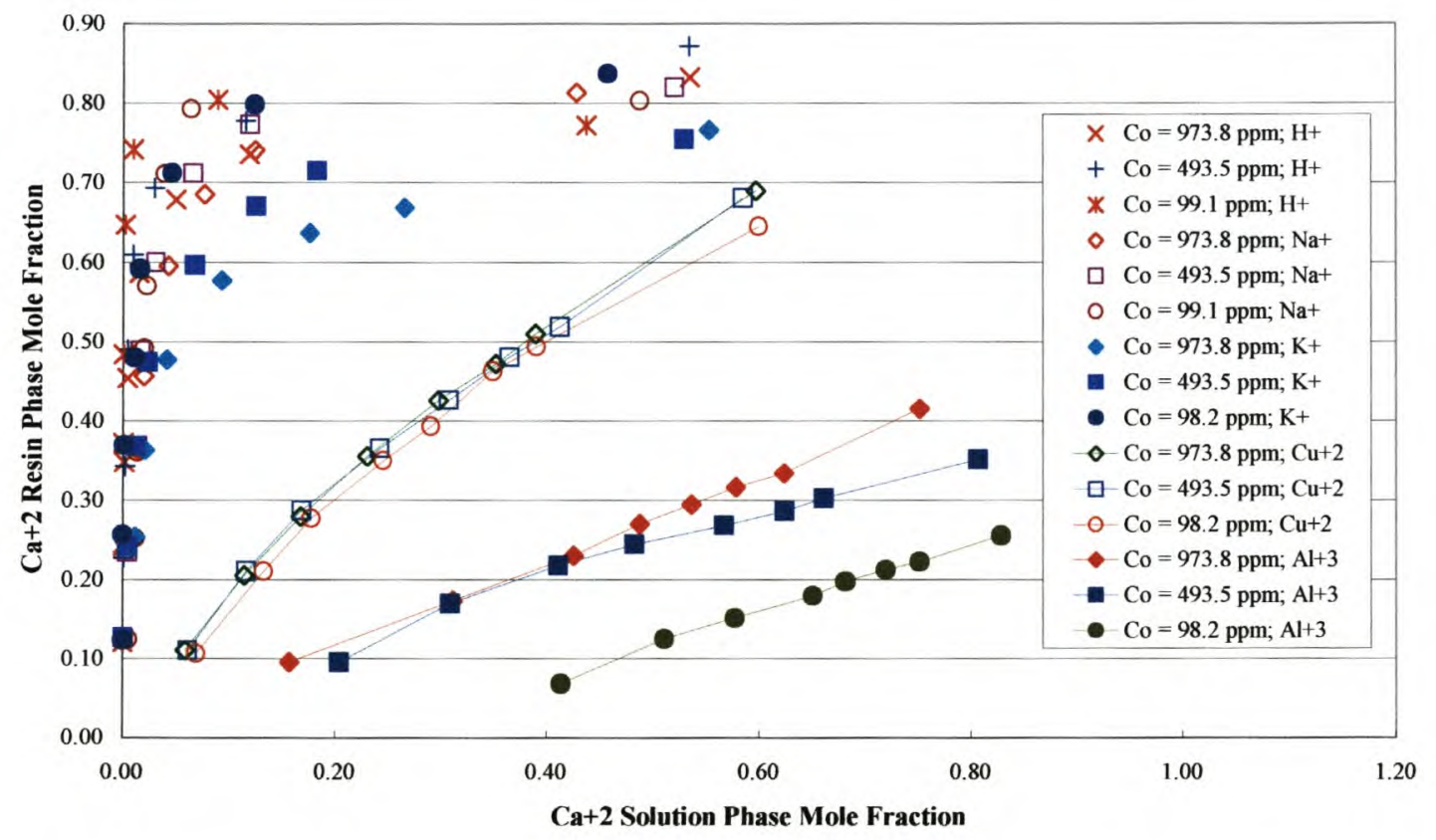

Figure 8.11 Equilibrium solution and resin phase mole fractions for the ion-exchange reaction between $\mathrm{Ca}^{+2}$ and $\mathrm{H}^{+} ; \mathrm{Ca}^{+2}$ and $\mathrm{Na}^{+} ; \mathrm{Ca}^{+2}$ and $\mathrm{K}^{+} ; \mathrm{Ca}^{+2}$ and $\mathrm{Cu}^{+2}$ and $\mathrm{Ca}^{+2}$ and $\mathrm{Al}^{+3}$ on a macroreticular strong acid cation exchange resin Duolite C26. Data obtained experimentally for different initial $\mathrm{Ca}^{+2}$ concentrations as indicated by the legend. 
The divalent-divalent isotherms for the exchange reaction between the cations of interest and the divalent $\mathrm{Cu}^{+2}$ ions are very close to one another and show less sensitivity for the initial solution phase concentration. These isotherms fall mostly on top of one another, while a wider concentration dependent spread exists between the isotherms for the divalent-monovalent and divalent-trivalent exchange reactions.

\subsubsection{Experimental data for binary ion-exchange equilibrium isotherms for the cation exchange reaction between $\mathrm{Ba}^{+2}$ and $\mathrm{H}^{+} ; \mathrm{Ba}^{+2}$ and $\mathrm{Na}^{+} ; \mathrm{Ba}^{+2}$ and $\mathrm{K}^{+}$; $\mathrm{Ba}^{+2}$ and $\mathrm{Cu}^{+2}$ and $\mathrm{Ba}^{+2}$ and $\mathrm{Al}^{+3}$}

Another phenomenon evident from Figures (8.10) to (8.13) is the effect of the total solution phase concentration (represented by the initial solution phase concentration of the exchanging species given in ppm by the legend on each figure).

If studied carefully it is evident that the resin takes up more of the species of the higher valence as the total cation solution phase concentration decreases. The resin phase therefore becomes more selective for the higher valence species at lower solution phase concentrations of the exchanging species (De Dardel and Arden, 1989). This phenomenon resulted in the observed spread between the various isotherms for the divalent-monovalent and divalent-trivalent exchange reactions as discussed above.

For the divalent-trivalent exchange reaction between the divalent cations $\mathrm{Mg}^{+2}, \mathrm{Ca}^{+2}$, $\mathrm{Ba}^{+2}$ and $\mathrm{Pb}^{+2}$ and the trivalent cation $\mathrm{Al}^{+3}$ (shown in Figure (8.10) to Figure (8.13) respectively), it is evident that the isotherms for the lowest solution phase concentration of the divalent cation lie below the intermediate concentration isotherm, which in turn lies below the high solution phase concentration isotherm. It is therefore evident that the lower the solution phase concentration, the lower the resin phase mole fraction of the divalent cation, and the higher the solution phase concentration the higher the resin phase mole fraction for the divalent cation. This trend is evident for the studied cases and 
confirms the expected result that the resin phase will take up more of the higher valence ion at lower solution phase concentrations, which in this case is the $\mathrm{Al}^{+3}$ cation.

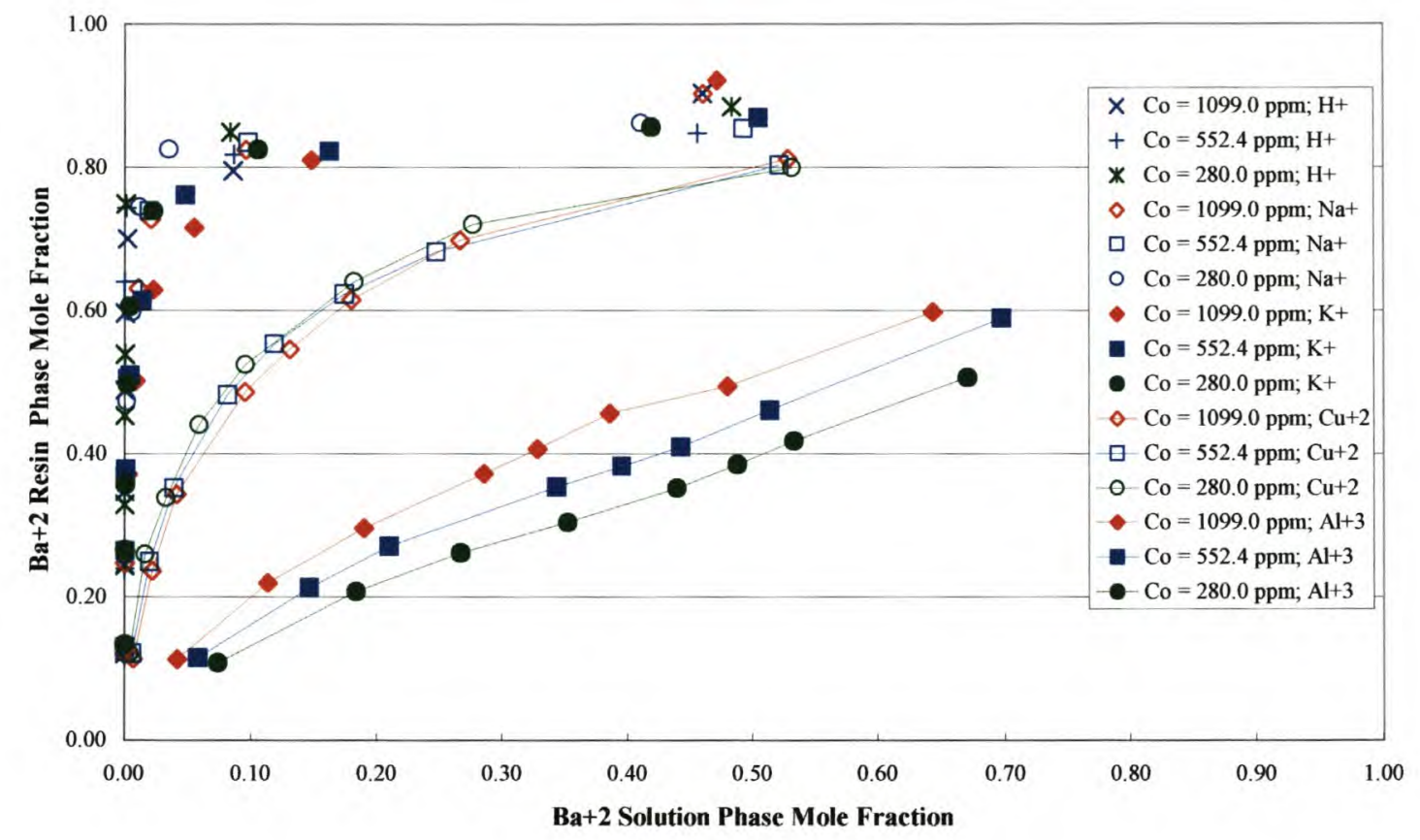

Figure 8.12 Equilibrium solution and resin phase mole fractions for the ion-exchange reaction between $\mathrm{Ba}^{+2}$ and $\mathrm{H}^{+} ; \mathrm{Ba}^{+2}$ and $\mathrm{Na}^{+} ; \mathrm{Ba}^{+2}$ and $\mathrm{K}^{+} ; \mathrm{Ba}^{+2}$ and $\mathrm{Cu}^{+2}$ and $\mathrm{Ba}^{+2}$ and $\mathrm{Al}^{+3}$ on a macroreticular strong acid cation exchange resin Duolite C26. Data obtained experimentally for different initial $\mathrm{Ba}^{+2}$ concentrations as indicated by the legend.

The same trend is evident when the divalent-monovalent isotherms are studied for the exchange reaction between the cations $\mathrm{Mg}^{+2}, \mathrm{Ca}^{+2}, \mathrm{Ba}^{+2}$ and $\mathrm{Pb}^{+2}$ and the monovalent cations $\mathrm{Na}^{+}$and $\mathrm{K}^{+}$(shown in Figure (8.10) to Figure (8.13) respectively). For these cases the isotherms for the lowest solution phase concentration lie above the medium and high solution phase isotherms. This indicates that the resin takes up more of the divalent cations than the monovalent cations initially in the resin phase, which also confirms the expected result that the resin phase take up more of the higher valence species as the total solution phase concentration of the species decreases. This trend is especially evident 
from Figure (8.10) for the exchange reaction between divalent $\mathrm{Mg}^{+2}$ cation and the monovalent cations $\mathrm{Na}^{+}$and $\mathrm{K}^{+}$.

8.4.4 Experimental data for binary ion-exchange equilibrium isotherms for the cation exchange reaction between $\mathrm{Pb}^{+2}$ and $\mathrm{H}^{+} ; \mathrm{Pb}^{+2}$ and $\mathrm{Na}^{+} ; \mathrm{Pb}^{+2}$ and $\mathrm{K}^{+}$; $\mathrm{Pb}^{+2}$ and $\mathrm{Cu}^{+2}$ and $\mathrm{Pb}^{+2}$ and $\mathrm{Al}^{+3}$

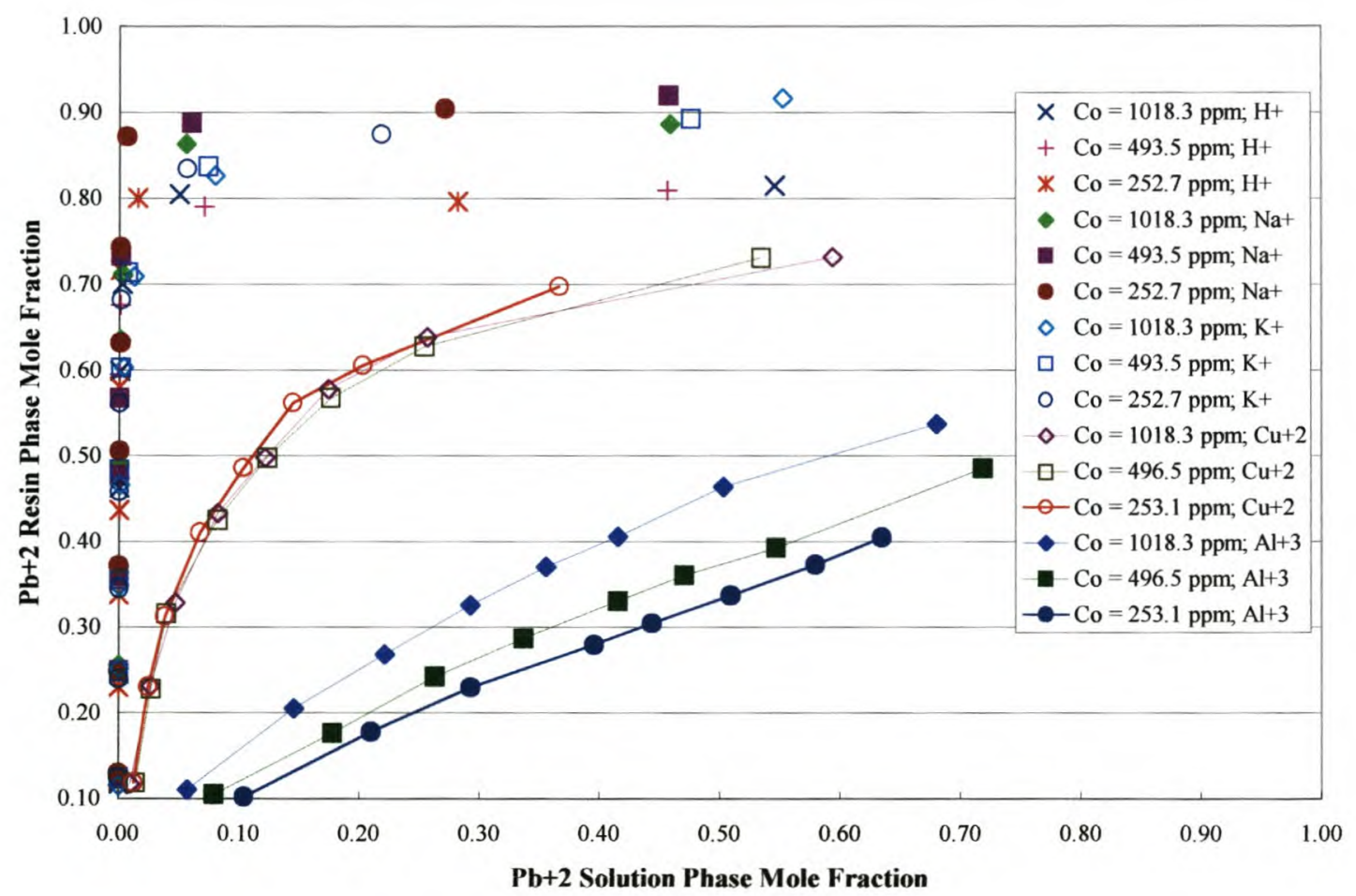

Figure 8.13 Equilibrium solution and resin phase mole fractions for the ion-exchange reaction between $\mathrm{Pb}^{+2}$ and $\mathrm{H}^{+} ; \mathrm{Pb}^{+2}$ and $\mathrm{Na}^{+} ; \mathrm{Pb}^{+2}$ and $\mathrm{K}^{+} ; \mathrm{Pb}^{+2}$ and $\mathrm{Cu}^{+2}$ and $\mathrm{Pb}^{+2}$ and $\mathrm{Al}^{+3}$ on a macroreticular strong acid cation exchange resin Duolite C26. Data obtained experimentally for different initial $\mathrm{Pb}^{+2}$ concentrations as indicated by the legend.

8.4.5 Experimental data for binary ion-exchange equilibrium isotherms for the cation exchange reaction between $\mathrm{Al}^{+3}$ and $\mathrm{H}^{+} ; \mathrm{Al}^{+3}$ and $\mathrm{Na}^{+}$and $\mathrm{Al}^{+3}$ and $\mathrm{K}^{+}$ 


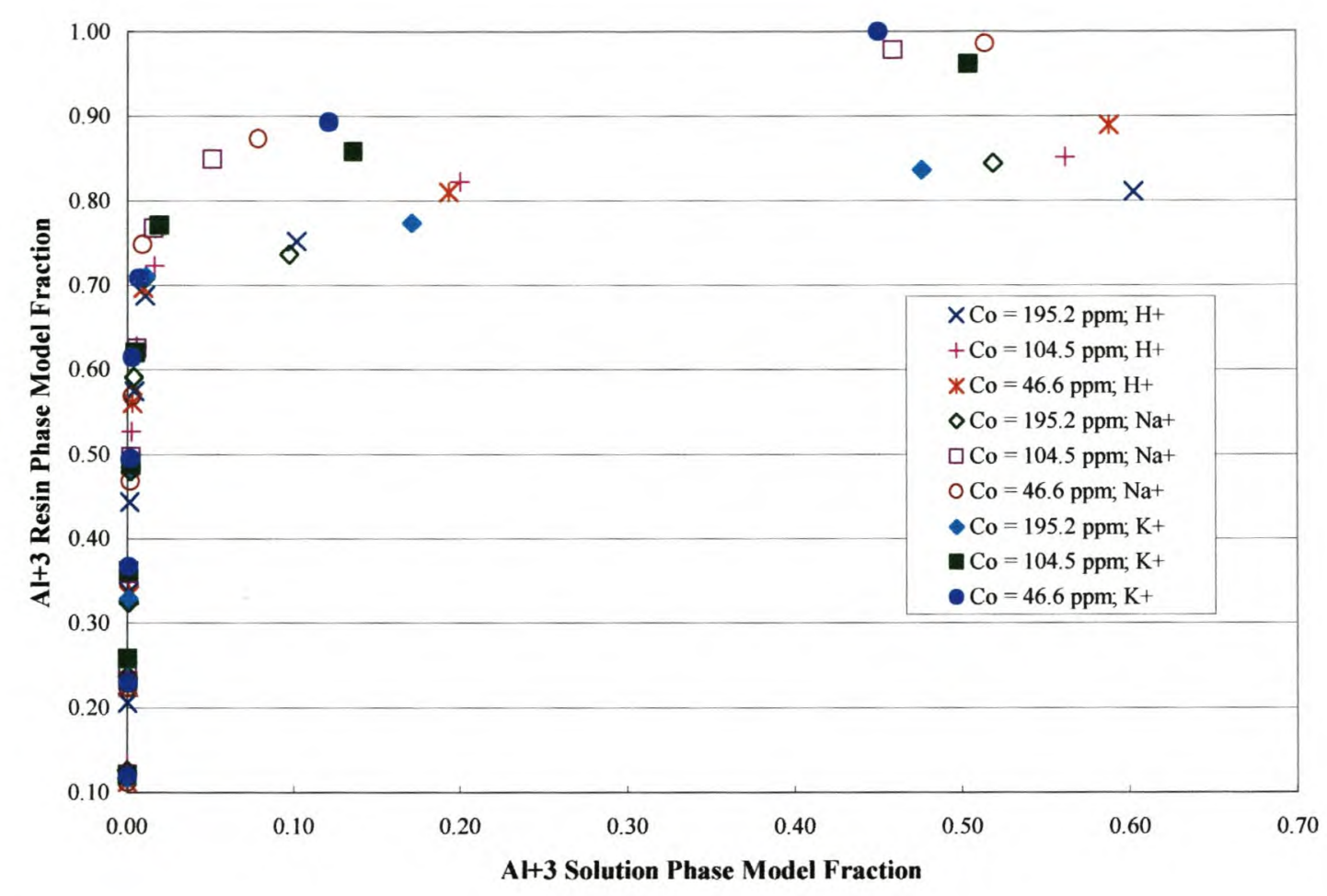

Figure 8.14 Equilibrium solution and resin phase mole fractions for the ion-exchange reaction between $\mathrm{Al}^{+3}$ and $\mathrm{H}^{+} ; \mathrm{Al}^{+3}$ and $\mathrm{Na}^{+}$and $\mathrm{Al}^{+3}$ and $\mathrm{K}^{+}$on a macroreticular strong acid cation exchange resin Duolite C26. Data obtained experimentally for different initial $\mathrm{Al}^{+3}$ concentrations as indicated by the legend.

\subsection{MODEL CALCULATIONS TO DETERMINE THE THERMODYNAMIC EQUILIBRIUM CONSTANT FOR AN ION-EXCHANGE REACTION}

The results of a model calculation, as performed for the anion exchange reaction between fluorine and chlorine, are shown below as calculated using the techniques discussed in Appendix C (Pitzer Equations), Appendix D (Pitzer sample calculation) and Appendix E (Optimisation routine for estimating parameters). Figures (8.15) to (8.18) show the model fit of the experimentally determined equilibrium quotient for the exchange 
reaction. It is evident from these figures that various shapes for the equilibrium quotient exist as the total solution concentration varies for the initial fluorine content. The parabolic shape of some of these curves makes it difficult to estimate the parameters from the experimental data. This problem is of significant importance and from the literature it is evident that various researchers have acknowledged this fact. The regression of the parameters for $\mathrm{K}_{\mathrm{AB}}$ and the resin phase activity coefficients from the experimental data poses a significant difficulty from a parameter estimation point of view. There are several reasons for this. A significant contributor to this difficulty proved to be the sensitivity of the parameter estimation technique to experimental error and the nature in which the objective function's surface plot behaves (Mehablia et al., 1992; Perona, 1993; Allen et al., 1989; Martinez et al., 1994). This difficulty is posed by the nature of the surface of the objective function described by Equation (5.35), Chapter 5. Various researchers have followed different procedures in ensuring a more stable and reliable fit of the parameters by de-coupling the simultaneous optimisation of these parameters (Mehablia et al., 1994).

For the reasons as discussed above a detailed investigation into a reliable and robust optimisation technique was launched. The Differential Evolution (DE) optimisation technique was identified as one with the ability to find the global optimum of various objective functions with a complex surface with many local minima. The availability of a robust optimisation routine such as the $\mathrm{DE}$ technique is therefore useful in ensuring that the true global minimum is obtained for the objective function and hence the best possible values for the parameter $\mathrm{K}_{\mathrm{AB}}$ and the resin phase activity coefficients.

Table (8.3) to Table (8.6) below show some of the experimental and model predictions of the equilibrium quotient for the exchange reaction between $\mathrm{F}^{-}$and $\mathrm{Cl}^{-}$on the anionexchange reaction Duolite A161 for various initial solution phase concentrations of the $\mathrm{F}^{-}$ ion. The counter ion in the reaction is $\mathrm{Na}^{+}$. It is evident that the model as described by Equations (5.27) to Equation (5.33) in Chapter 5 (with detailed equation descriptions given by Appendix C, Appendix D and Appendix E) fits the experimental data 
satisfactorily. Correlation coefficients for the model predictions range from 0.87 to 0.99 . The experimental error associated with the lower solution phase concentration data is more significant and hence that error associated with the model fit to this data is also more significant.

Table 8.3 Experimentally determined and model prediction values of the equilibrium quotient for the anion-exchange reaction between $\mathrm{F}^{-}$and $\mathrm{Cl}^{-}$as a function of the equilibrium fractional loading of $\mathrm{F}^{-}$for an initial solution phase concentration of $52.19 \mathrm{ppm} \mathrm{F}^{-}$.

\begin{tabular}{|c|c|c|}
\hline $\mathrm{F}^{-}(\mathrm{Co})=$ & 52.19 & ppm \\
\hline $\mathrm{Na}^{+}(\mathrm{Co})=$ & 63.16 & ppm \\
\hline $\mathbf{K}_{\mathrm{AB}}=$ & 0.015 & \\
\hline Resin_Act_Coeff_FCl = & 4.19 & \\
\hline Resin_Act_Coeff_CIF = & 0.0001 & \\
\hline Resin Type = & Duolite A161 & \\
\hline Correlation $=$ & 0.987119 & \\
\hline $\begin{array}{c}\text { Resin Loading } \\
\text { Fractional } \\
\mathbf{q}_{\mathrm{e}}\left(\mathbf{F}^{-}\right)\end{array}$ & $\begin{array}{c}\text { Experimental } \\
\text { Equil Quotient } \\
-1{ }^{*} \mathbf{L n}\left(\mathbf{K}_{\mathrm{FCl}}^{\prime} \mathbf{E x p}\right)\end{array}$ & $\begin{array}{c}\text { Model Pred } \\
\text { Equil Quotient } \\
-1 *^{*} \text { Ln(K'FCl_Mod) }\end{array}$ \\
\hline 0.049 & 3.741 & 3.744 \\
\hline 0.058 & 3.694 & 3.690 \\
\hline 0.075 & 3.664 & 3.631 \\
\hline 0.088 & 3.616 & 3.614 \\
\hline 0.101 & 3.609 & 3.611 \\
\hline 0.121 & 3.616 & 3.623 \\
\hline 0.136 & 3.634 & 3.641 \\
\hline 0.151 & 3.660 & 3.665 \\
\hline 0.166 & 3.690 & 3.690 \\
\hline 0.185 & 3.735 & 3.724 \\
\hline
\end{tabular}

Tables 8.3 to 8.6 contain the values for the equilibrium quotient as calculated from the experimental data (column 2 of the table), and values for the equilibrium quotient predicted by the model (column 3 of the table) as a function of the fractional resin phase loading of the $\mathrm{F}^{-}$species on the anion-exchange resin (column 1 of the table). 
Table 8.4 Experimentally determined and model prediction values of the equilibrium quotient for the anion-exchange reaction between $\mathrm{F}^{-}$and $\mathrm{Cl}^{-}$as a function of the equilibrium fractional loading of $\mathrm{F}^{-}$for an initial solution phase concentration of $208.17 \mathrm{ppm} \mathrm{F}^{-}$.

\begin{tabular}{|c|c|c|}
\hline $\mathbf{F}^{-}(\mathrm{Co})=$ & 208.17 & Ppm \\
\hline $\mathrm{Na}^{+}(\mathrm{Co})=$ & 251.91 & Ppm \\
\hline $\mathbf{K}_{\mathrm{AB}}=$ & 0.064 & \\
\hline Resin_Act_Coeff_FCl = & 2.15 & \\
\hline Resin_Act_Coeff_CIF $=$ & 0.05 & \\
\hline Resin $=$ & Duolite A161 & \\
\hline Correlation $=$ & 0.9984 & \\
\hline $\begin{array}{c}\text { Resin Fractional Loading } \\
\text { Fractional } \\
\mathrm{q}_{\mathrm{e}}(\mathbf{F})\end{array}$ & $\begin{array}{c}\text { Experimental } \\
\text { Equil Quotient } \\
-\mathbf{- 1}{ }^{*} \mathbf{L n}\left(\mathbf{K}_{\mathrm{FCL}}^{\prime} \mathbf{E x p}\right)\end{array}$ & $\begin{array}{c}\text { Model Pred } \\
\text { Equil Quotient } \\
-1 * \text { Ln(K'/KC_Mod) }\end{array}$ \\
\hline 0.060 & 2.437 & 2.442 \\
\hline 0.093 & 2.487 & 2.479 \\
\hline 0.117 & 2.508 & 2.505 \\
\hline 0.137 & 2.524 & 2.525 \\
\hline 0.155 & 2.539 & 2.542 \\
\hline 0.172 & 2.555 & 2.558 \\
\hline 0.198 & 2.579 & 2.581 \\
\hline 0.217 & 2.597 & 2.597 \\
\hline 0.252 & 2.629 & 2.626 \\
\hline 0.295 & 2.658 & 2.659 \\
\hline
\end{tabular}

The heading of each of Tables 8.3 to 8.6 also contains the value for the thermodynamic equilibrium constant for the exchange reaction (row 3 in table heading) as well as the resin phase activity coefficients for the binary interaction between $\mathrm{F}^{-}$and $\mathrm{Cl}^{-}$(rows 4 and 5 in table heading). The initial solution phase concentration for the $\mathrm{F}^{-}$and $\mathrm{Na}^{+}$ions (rows 1 and 2 in table heading) is shown as well as the model correlation (row 7 in table heading) with the experimental data. 
Tables 8.3 to 8.6 show the values for four different initial solution phase concentrations of the $\mathrm{F}^{-}$and $\mathrm{Na}^{+}$ions. The concentration ranges for the initial $\mathrm{F}^{-}$concentration are approximately 52 ppm, 208 ppm, 100 ppm and 510 ppm.

Table 8.5 Experimentally determined and model prediction values of the equilibrium quotient for the anion-exchange reaction between $\mathrm{F}^{-}$and $\mathrm{Cl}^{-}$as a function of the equilibrium fractional loading of $\mathrm{F}^{-}$for an initial solution phase concentration of 510.23 ppm F.

\begin{tabular}{|c|c|c|}
\hline $\mathrm{F}^{-}(\mathrm{Co})=$ & 510.23 & $\mathrm{ppm}$ \\
\hline $\mathrm{Na}^{+}(\mathrm{Co})=$ & 617.43 & ppm \\
\hline $\mathbf{K}_{\mathbf{A B}}=$ & 0.075 & \\
\hline Resin_Act_Coeff_FCl = & 1.88 & \\
\hline Resin_Act_Coeff_CIF = & 0.53 & \\
\hline Resin $=$ & Duolite A161 & \\
\hline Correlation $=$ & 0.99337 & \\
\hline $\begin{array}{c}\text { Resin Fractional Loading } \\
\text { Fractional } \\
\mathbf{q}_{\mathrm{e}}(\mathbf{F}) \\
\end{array}$ & $\begin{array}{c}\text { Experimental } \\
\text { Equil Quotient } \\
-1 * \operatorname{Ln}\left(\mathbf{K}_{\text {FCL_Exp }}^{\prime}\right)\end{array}$ & $\begin{array}{c}\text { Model Pred } \\
\text { Equil Quotient } \\
-1 * \text { Ln(K'FCL_Mod) }\end{array}$ \\
\hline 0.064 & 2.397 & 2.396 \\
\hline 0.100 & 2.422 & 2.419 \\
\hline 0.125 & 2.443 & 2.434 \\
\hline 0.148 & 2.431 & 2.448 \\
\hline 0.169 & 2.457 & 2.461 \\
\hline 0.193 & 2.474 & 2.474 \\
\hline 0.213 & 2.488 & 2.485 \\
\hline 0.232 & 2.500 & 2.495 \\
\hline 0.256 & 2.514 & 2.507 \\
\hline 0.322 & 2.531 & 2.539 \\
\hline
\end{tabular}

Table (8.6) shows the experimental and model values for an initial $\mathrm{F}^{-}$concentration of $100 \mathrm{ppm}$. Both the equilibrium quotient curves for the lower solution phase concentration of $\mathrm{F}^{-}$show the parabolic nature as is evident from the data of Tables 8.3 and 8.6 as represented by Figures (8.15) and (8.16) respectively. This makes the optimal model parameter estimations more difficult, which is also more dependent on the quality 
of the experimental data at these lower solution concentrations. In order to minimise the experimental error the procedures as described in Chapter 7 of this dissertation were followed.

Table 8.6 Experimentally determined and model prediction values of the equilibrium quotient for the anion-exchange reaction between $\mathrm{F}^{-}$and $\mathrm{Cl}^{-}$as a function of the equilibrium fractional loading of $\mathrm{F}^{-}$for an initial solution phase concentration of $99.56 \mathrm{ppm} \mathrm{F}^{-}$.

\begin{tabular}{|c|c|c|}
\hline $\mathrm{F}^{-}(\mathrm{Co})=$ & 99.56 & ppm \\
\hline $\mathrm{Na}^{+}(\mathrm{Co})=$ & 120.48 & ppm \\
\hline $\mathbf{K}_{\mathrm{AB}}=$ & 0.061 & \\
\hline Resin_Act_Coeff_FCl = & 3.14 & \\
\hline Resin_Act_Coeff_CIF $=$ & 0.13 & \\
\hline Resin $=$ & Duolite A161 & \\
\hline Correlation $=$ & 0.98755 & \\
\hline $\begin{array}{c}\text { Resin Fractional Loading } \\
\text { Fractional } \\
\mathbf{q}_{\mathrm{e}}(\mathbf{F})\end{array}$ & $\begin{array}{c}\text { Experimental } \\
\text { Equil Quotient } \\
-1{ }^{*} \text { Ln( } \mathbf{K}_{\mathrm{FCl}}^{\prime} \text { Exp) }\end{array}$ & 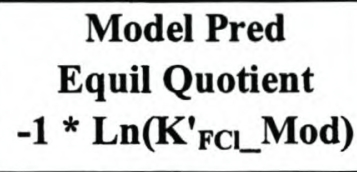 \\
\hline 0.057 & 2.539 & 2.544 \\
\hline 0.090 & 2.533 & 2.525 \\
\hline 0.116 & 2.530 & 2.525 \\
\hline 0.135 & 2.531 & 2.531 \\
\hline 0.154 & 2.537 & 2.539 \\
\hline 0.176 & 2.547 & 2.552 \\
\hline 0.196 & 2.560 & 2.566 \\
\hline 0.216 & 2.576 & 2.580 \\
\hline 0.236 & 2.596 & 2.596 \\
\hline 0.268 & 2.631 & 2.623 \\
\hline
\end{tabular}

The nature of the experimental data and the model predictions are clearly illustrated by Figures (8.15) to Figures (8.18) below. 


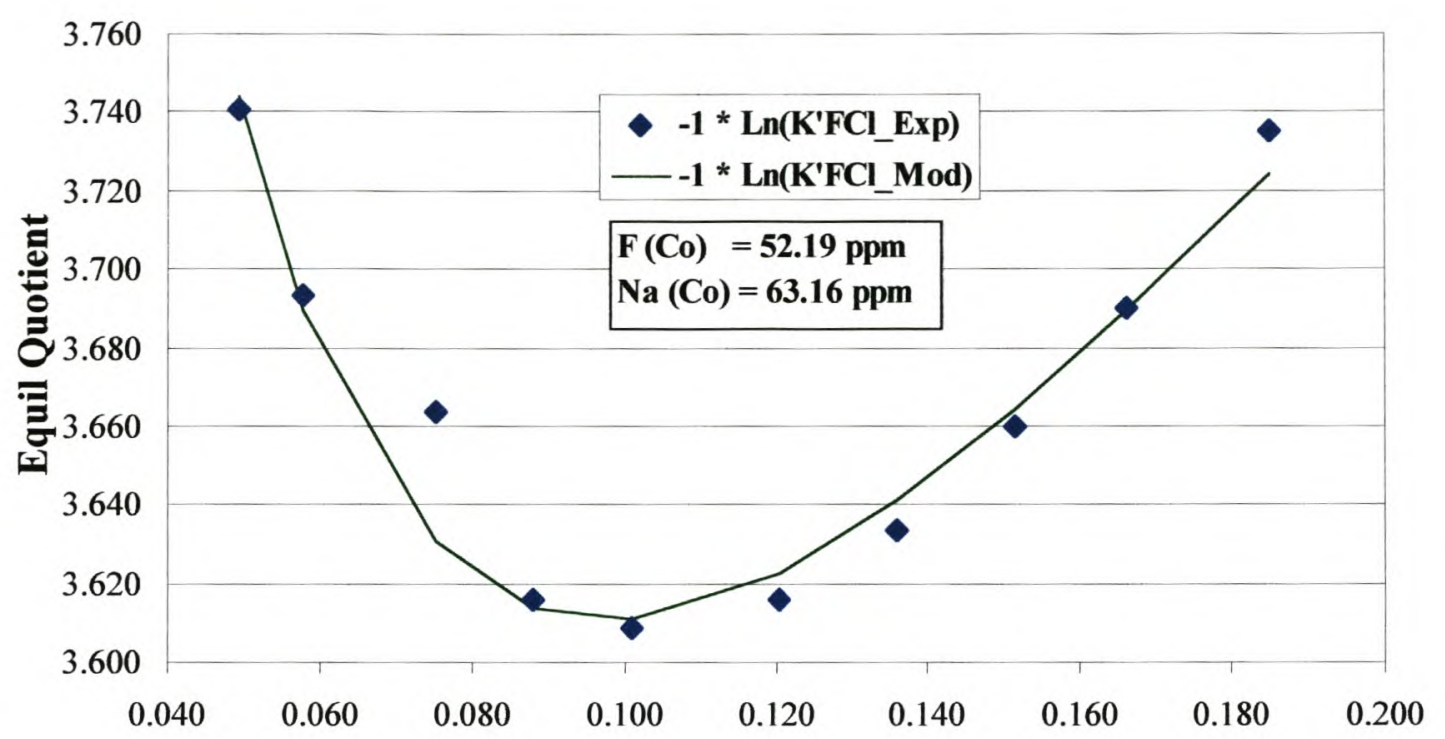

$F^{-}$Equilibrium Resin Loading, qe

Figure 8.15 Experimental and model values for the equilibrium quotient for the exchange reaction between $\mathrm{F}^{-}$and $\mathrm{Cl}^{-}$, with $\mathrm{Co}\left(\mathrm{F}^{-}\right)$of $52 \mathrm{ppm}$.

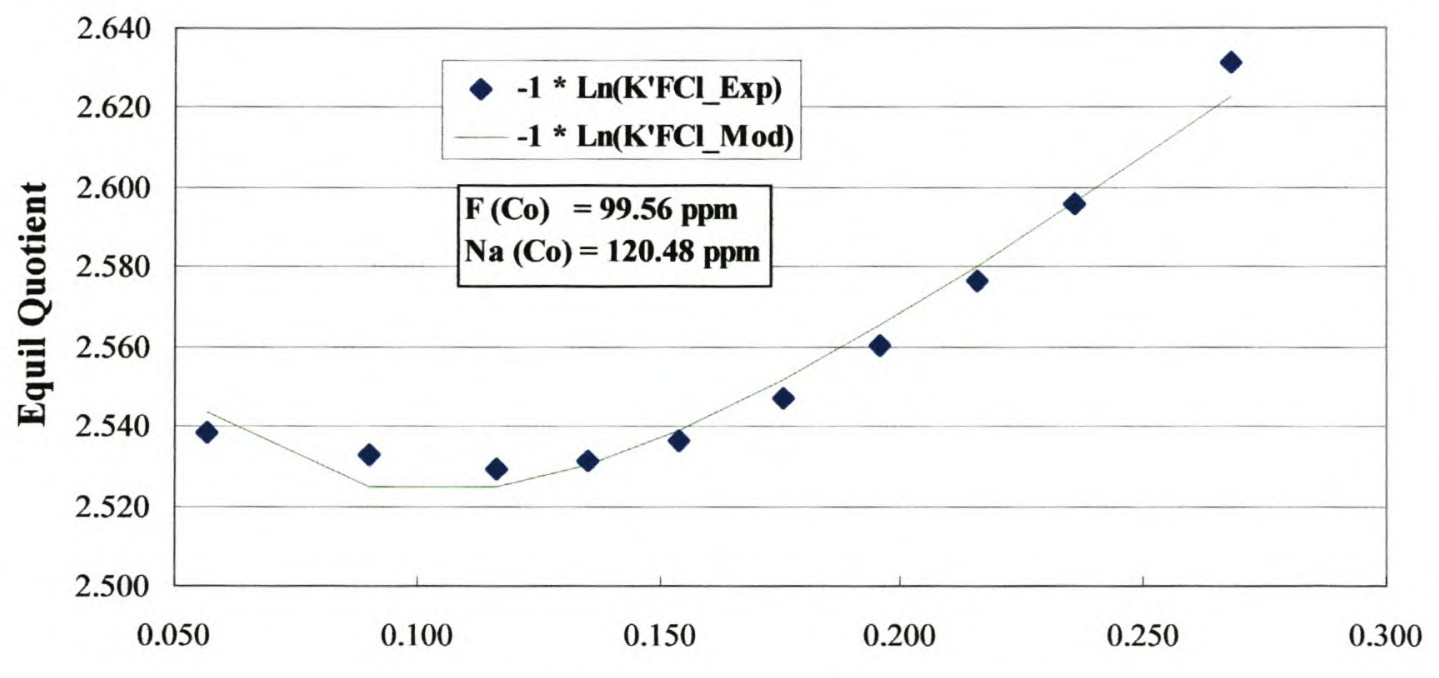

F' Equilibrium Resin Loading, qe

Figure 8.16 Experimental and model values for the equilibrium quotient for the exchange reaction between $\mathrm{F}^{-}$and $\mathrm{Cl}^{-}$, with $\mathrm{Co}\left(\mathrm{F}^{-}\right)$of $99.5 \mathrm{ppm}$. 


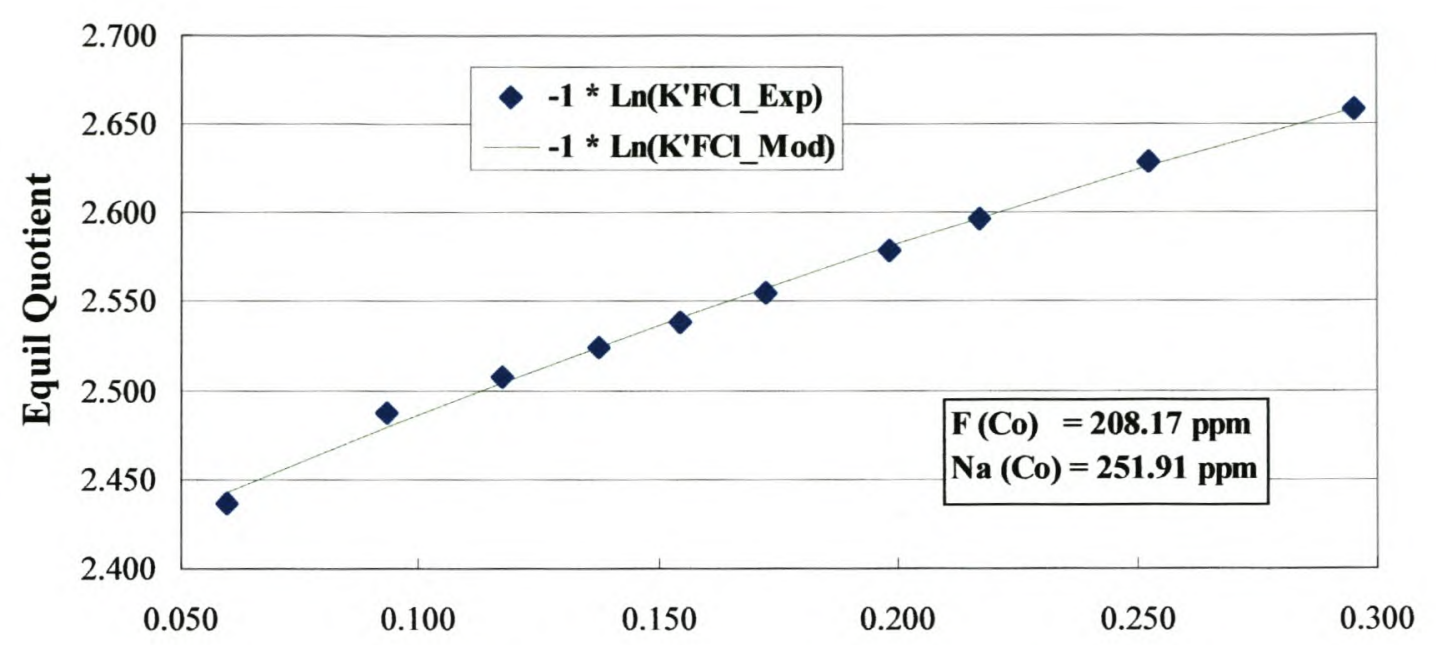

F$^{-}$Equilibrium Resin Loading, qe

Figure 8.17 Experimental and model values for the equilibrium quotient for the exchange reaction between $\mathrm{F}^{-}$and $\mathrm{Cl}^{-}$, with $\mathrm{Co}\left(\mathrm{F}^{-}\right)$of $208 \mathrm{ppm}$.

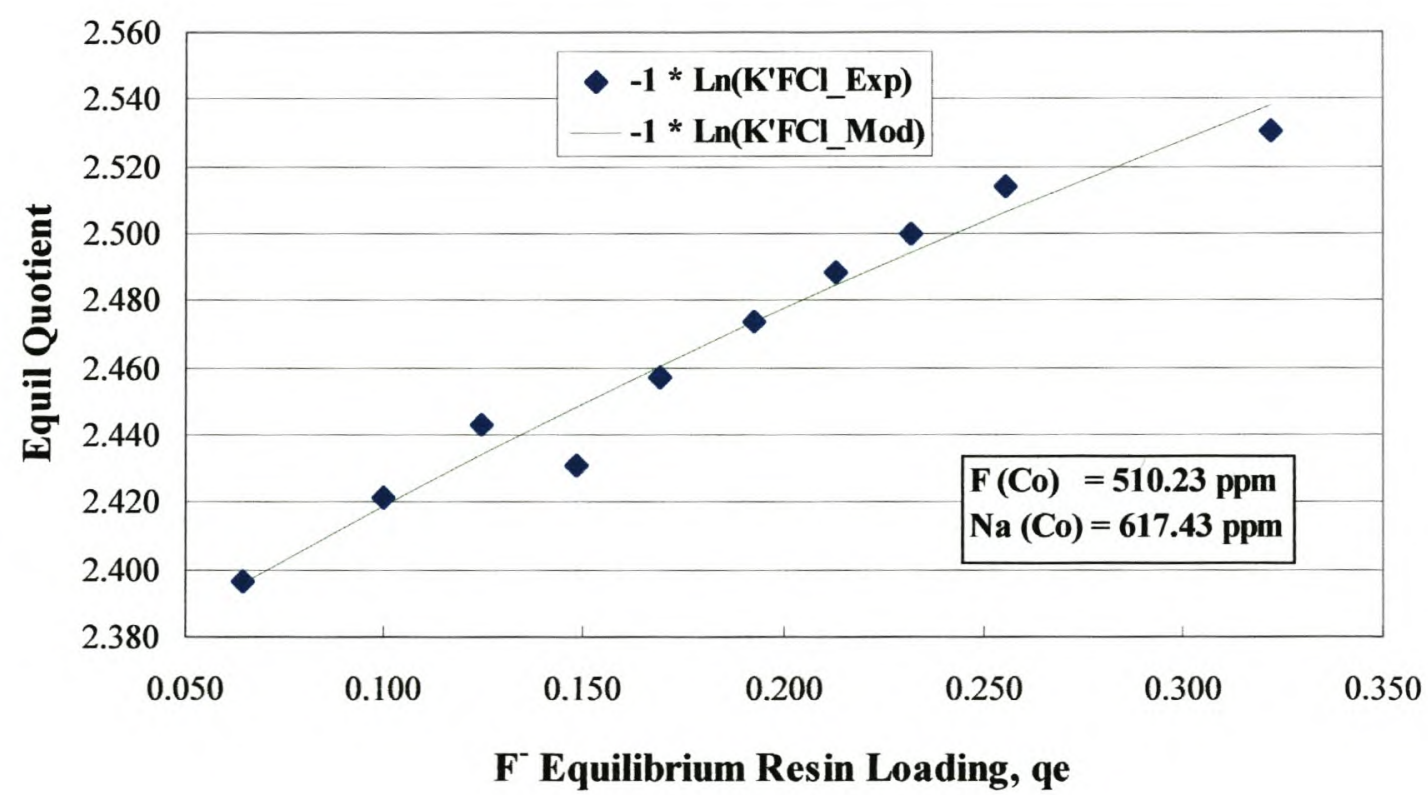

Figure 8.18 Experimental and model values for the equilibrium quotient for the exchange reaction between $\mathrm{F}^{-}$and $\mathrm{Cl}^{-}$, with $\mathrm{Co}\left(\mathrm{F}^{-}\right)$of $510 \mathrm{ppm}$. 
The importance of a good model fit for the parameters of $K_{A}^{B}$ and the resin phase interaction parameters, which describe the solution / resin equilibrium condition, to the performance of the consolidated equilibrium model for the RIP slurry mixture system was discussed in Chapter 6 and at the beginning of this chapter.

From the discussions and Figures (8.5) to (8.14) it was evident that the resin / solution isotherm has a very steep wave front in the low solution phase concentration region. This is especially true for the ion-exchange reactions where the counter-ion initially in the resin phase is of the monovalent type ions. The accuracy of the model predictions of the steep wave type isotherms has a significant effect on the accuracy of the consolidated equilibrium model for the RIP slurry mixture system. This is due to the fact that for a relatively small change in the solution phase concentration of the particular species a significant change in resin phase equilibrium loading may occur. Because of this phenomenon the user needs to ensure that the model parameters for $K_{A}^{B}$ and the Wilson resin phase interaction parameters are estimated as accurately as possible.

Table 8.7 Summary results for the model prediction of the thermodynamic equilibrium constant for the anion-exchange reaction between $\mathrm{F}^{-}$and $\mathrm{Cl}^{-}$ with $\mathrm{Na}^{+}$as the co-ionic species for various initial solution phase concentrations of $\mathrm{F}^{-}$.

\begin{tabular}{|c|c|c|c|c|c|c|}
\hline $\begin{array}{l}\text { F Co } \\
\text { Ppm }\end{array}$ & $\begin{array}{c}\mathrm{Na}^{+} \mathrm{Co} \\
\text { ppm }\end{array}$ & $\overline{\mathbf{K}_{\text {CI_F }}}$ & $\begin{array}{c}\text { Activity } \\
\text { Coeff } \\
\text { FCl }\end{array}$ & $\begin{array}{c}\text { Activity Coeff } \\
\text { CIF } \\
\end{array}$ & $\begin{array}{l}\text { Anion } \\
\text { Resin }\end{array}$ & $\begin{array}{c}\text { Model } \\
\text { Correlation }\end{array}$ \\
\hline 52.19 & 63.16 & 0.015 & 4.19 & 0.0001 & Duolite A161 & 0.987119 \\
\hline 99.56 & 120.48 & 0.061 & 3.14 & 0.13 & Duolite A161 & 0.98755 \\
\hline 208.17 & 251.91 & 0.064 & 2.15 & 0.05 & Duolite A161 & 0.9984 \\
\hline 208.52 & 252.34 & 0.075 & 1.72 & 0.61 & Duolite A161 & 0.99067 \\
\hline 510.23 & 617.43 & 0.075 & 1.88 & 0.53 & Duolite A161 & 0.99337 \\
\hline 506.57 & 613.01 & 0.072 & 1.80 & 0.55 & Duolite A161 & 0.87923 \\
\hline
\end{tabular}


It is evident from Table (8.7), which shows the summary results for the model prediction correlation of the thermodynamic equilibrium constant for the exchange reaction between $\mathrm{F}^{-}$and $\mathrm{Cl}^{-}$, that good model fits are obtained for the entire solution phase concentration range. The value of $\mathrm{K}_{\mathrm{Cl}_{-} \mathrm{F}}$ of 0.015 for the low solution phase concentration of $52 \mathrm{ppm} \mathrm{F}^{-}$ deviates significantly from the average value of approximately 0.07 for all of the concentration ranges. This deviation may be caused by experimental data that are prone to experimental analysis error at the very low solution phase concentrations. The limitations of accurate analysis of trace concentrations of species in aqueous solutions at extremely low solution concentrations are of great significance to the contents to this dissertation. This justifies the detailed experimental procedures followed for the preparation of samples as described in Chapter 6 of this dissertation.

The effect of electrolytic sorption of the aqueous species by the ion-exchanger should also be kept in mind when analysing the model results. Experimental data on electrolytic sorption relevant to this dissertation are presented and discussed in paragraph 8.2.

\subsection{SUMMARY}

From the above discussion it is evident that the value of the equilibrium quotient for the ion-exchange reaction may have various forms as shown in Figures (8.15) to (8.18). The value of the equilibrium quotient is related to the value of the thermodynamic equilibrium constant $K_{A}^{B}$ as described by Equation (5.28) in Chapter 5 of this dissertation. It is therefore evident that the contribution of the non-idealities in the resin phase is of significant importance to the calculation of the thermodynamic equilibrium constant $K_{A}^{B}$. This may be concluded from the various shapes of the equilibrium quotient curves as represented by Figures (8.15) and (8.18) and the fact that no resin phase non-idealities are considered in the calculation of the equilibrium quotient as represented by Equation (5.27) of Chapter 5 . 
The effect of the resin phase activity coefficients is therefore one of the contributing factors to the difference in shape of the various equilibrium quotient curves as represented by Figures (8.15) to (8.18). The only difference between the equations for the equilibrium quotient and the thermodynamic equilibrium constant for the ion-exchange reaction is the inclusion of the resin phase activity coefficient terms in the equation for the thermodynamic equilibrium constant for the ion-exchange reaction.

From Figures (8.1) to (8.4) it is evident that electrolytic sorption does occur for the ionexchange reactions of interest. The amount of electrolytic sorption that occurs is a function of the physical properties of the system, i.e. the amount of ion-exchange resin per litre of aqueous solution containing the exchanging species. This is evident from Figures (8.1) and (8.3). Equation (8.3) is a mathematical representation for the reaction of electrolytic sorption that may occur for the cation exchange reaction represented. Cation species $B^{z_{B}}$ of the sparingly soluble solid is exchanged for cation species $A^{z_{A}}$ on the resin phase, with anion species $E^{z_{E}}$ of the sparingly soluble solid participating in electrolytic sorption. In Equation (8.3) $n$ moles of species $E^{z_{E}}$ participate in electrolytic sorption. From the discussions in this chapter it is evident that up to $2 \%$ of the "equivalent" exchange capacity of the ion-exchange resin may be as a result of electrolytic sorption. This means that the overall exchange capacity (defined in Chapter 4 of this dissertation) may be $2 \%$ higher than the actual amount of active sites available for the ion-exchange resin phase. There are several ways in which the contribution of the electrolytic sorption on the ion-exchange reaction may be accounted for. For the purposes of this dissertation it was decided to treat the contribution of electrolytic sorption as "additional" exchange capacity. This means that the value for the thermodynamic equilibrium constant $K_{A}^{B}$ is estimated from the actual experimental values for the total exchange that took place as presented in Figures (8.15) to (8.18). In these figures the value for the equilibrium quotient was calculated from the total amount of species that were adsorbed by the ion-exchange resin, which is the "actual" exchange plus the contribution of the electrolytic sorption. For the relatively low solution phase concentrations of interest to this dissertation and the small amount of ion-exchange resins 
used per litre of slurry solution it is a fair approximation as is evident from Figures (8.1) and (8.3). These figures show a decrease in the total amount of electrolytic sorption with a decrease in the amount of ion-exchanger present, which is expected and easily explained by a mass balance.

The values for the various thermodynamic equilibrium constants $K_{A}^{B}$ of interest to this dissertation will be discussed in detail in each of the following chapters when various RIP slurry mixture systems will be investigated. For each of these systems the effect of electrolytic sorption on the overall ion-exchange capacity for each of the ion-exchange reactions of interest will be investigated. Conclusions on the validity of the above assumption regarding electrolytic sorption will then be drawn in more detail for each RIP system investigated. 


\section{CHAPTER 9}

\section{RESULTS FOR THE BIVALENT-MONOVALENT SLURRY RESIN SYSTEM}

In Chapter 6 in this dissertation the mathematical model for the consolidated equilibrium model for a typical Resin-in-Pulp (RIP) slurry mixture system was formulated and proposed. From the proposed model it is evident that typically three different phases are encountered in a RIP slurry mixture system as addressed, i.e. the ion-exchange resin, the aqueous solution and sparingly soluble precipitate phases. The equilibrium conditions in all of these phases are modelled using different equilibrium models to account for the distribution of species between them and non-idealities encountered in them. From the proposed model it was also evident that the calculation of the thermodynamic equilibrium constant $K_{A}^{B}$ for the resin / solution phase equilibrium condition was de-coupled from the consolidated RIP slurry mixture system model. In order to do this, extensive experimental test work was performed on the resin / solution system for various ionexchange reactions from which the value of the thermodynamic equilibrium constant $K_{A}^{B}$ was calculated. The resin / solution systems investigated were those that are of importance to the different RIP slurry mixture systems investigated. The experimental results of the tests performed were presented in Chapter 8 of this dissertation. From the results of these tests the value of the thermodynamic equilibrium constant $K_{A}^{B}$ will be calculated for each of the relevant ion-exchange reactions encountered in the different RIP slurry mixture systems studied. These thermodynamic equilibrium constant $K_{A}^{B}$ values will then be used in the consolidated equilibrium model for the applicable RIP slurry mixture system. 
In order to formulate the consolidated equilibrium model as presented in Chapter 6 of this dissertation, various RIP slurry mixture systems were investigated, as given in Table 9.1 below.

Table 9.1 Various Resin-in-Pulp slurry mixture systems studied experimentally for different ionic forms of the cation and anion exchange resin.

\begin{tabular}{|c|c|c|}
\hline Sparingly Soluble Solid & $\begin{array}{c}\text { Cation Exchange Resin } \\
\text { Ionic Form }\end{array}$ & $\begin{array}{c}\text { Anion Exchange Resin } \\
\text { Ionic Form }\end{array}$ \\
\hline $\mathrm{Al}(\mathrm{OH})_{3}$ & $\mathrm{H}^{+}, \mathrm{Na}^{+}, \mathrm{K}^{+}$ & $\mathrm{Cl}^{-}, \mathrm{NO}_{3}{ }^{-}$ \\
\hline $\mathrm{BaCO}_{3}$ & $\mathrm{H}^{+}, \mathrm{Na}^{+}, \mathrm{K}^{+}$ & $\mathrm{Cl}^{-}, \mathrm{NO}_{3}{ }^{-}$ \\
\hline $\mathrm{BaF}_{2}$ & $\mathrm{Na}^{+}, \mathrm{K}^{+}, \mathrm{Cu}^{+2}, \mathrm{Al}^{+3}$ & $\mathrm{NO}_{3}^{-}$ \\
\hline $\mathrm{BaSO}_{4}$ & $\mathrm{H}^{+}, \mathrm{Na}^{+}, \mathrm{K}^{+}, \mathrm{Cu}^{+2}, \mathrm{Al}^{+3}$ & $\mathrm{Cl}^{-}, \mathrm{NO}_{3}^{-}$ \\
\hline $\mathrm{CaF}_{2}$ & $\mathrm{H}^{+}, \mathrm{Na}^{+}, \mathrm{K}^{+}, \mathrm{Cu}^{+2}, \mathrm{Al}^{+3}$ & $\mathrm{Cl}^{-}, \mathrm{NO}_{3}^{-}$ \\
\hline $\mathrm{CaSO}_{4}$ & $\mathrm{H}^{+}, \mathrm{Na}^{+}, \mathrm{K}^{+}, \mathrm{Cu}^{+2}, \mathrm{Al}^{+3}$ & $\mathrm{Cl}^{-}, \mathrm{NO}_{3}{ }^{-}, \mathrm{OH}^{-}$ \\
\hline $\mathrm{CuS}$ & $\mathrm{H}^{+}, \mathrm{Na}^{+}, \mathrm{K}^{+}$ & $\mathrm{NO}_{3}^{-}$ \\
\hline FeS & $\mathrm{H}^{+}, \mathrm{Na}^{+}, \mathrm{K}^{+}$ & $\mathrm{Cl}^{-}, \mathrm{NO}_{3}^{-}$ \\
\hline $\mathrm{MgF}_{2}$ & $\mathrm{H}^{+}, \mathrm{Na}^{+}, \mathrm{K}^{+}, \mathrm{Cu}^{+2}, \mathrm{Al}^{+3}$ & $\mathrm{Cl}^{-}, \mathrm{NO}_{3}^{-}$ \\
\hline $\mathrm{Mg}(\mathrm{OH})_{2}$ & $\mathrm{H}^{+}, \mathrm{Na}^{+}, \mathrm{K}^{+}$ & $\mathrm{Cl}^{-}, \mathrm{NO}_{3}^{-}$ \\
\hline $\mathrm{PbCO}_{3}$ & $\mathrm{H}^{+}, \mathrm{Na}^{+}, \mathrm{K}^{+}$ & $\mathrm{NO}_{3}^{-}$ \\
\hline $\mathrm{PbF}_{2}$ & $\mathrm{H}^{+}, \mathrm{Na}^{+}, \mathrm{K}^{+}, \mathrm{Cu}^{+2}, \mathrm{Al}^{+3}$ & $\mathrm{NO}_{3}^{-}$ \\
\hline $\mathrm{PbS}$ & $\mathrm{H}^{+}, \mathrm{Na}^{+}, \mathrm{K}^{+}$ & $\mathrm{NO}_{3}^{-}$ \\
\hline $\mathrm{PbSO}_{4}$ & $\mathrm{H}^{+}, \mathrm{Na}^{+}, \mathrm{K}^{+}, \mathrm{Cu}^{+2}, \mathrm{Al}^{+3}$ & $\mathrm{Cl}^{-}, \mathrm{NO}_{3}^{-}, \mathrm{OH}^{-}$ \\
\hline $\mathrm{ZnS}$ & $\mathrm{H}^{+}, \mathrm{Na}^{+}, \mathrm{K}^{+}$ & $\mathrm{Cl}^{-}, \mathrm{NO}_{3}^{-}$ \\
\hline $\mathrm{MgF}_{2}$ and $\mathrm{CaF}_{2}$ & $\mathrm{Na}^{+}, \mathrm{K}^{+}, \mathrm{Cu}^{+2}, \mathrm{Al}^{+3}$ & $\mathrm{Cl}^{-}, \mathrm{NO}_{3}^{-}$ \\
\hline $\begin{array}{l}\mathrm{MgCO}_{3} \text { and } \mathrm{CaCO}_{3} \\
\text { (Vredendal ore body) }\end{array}$ & $\mathrm{H}^{+}, \mathrm{Na}^{+}, \mathrm{K}^{+}, \mathrm{Cu}^{+2}, \mathrm{Al}^{+3}$ & $\mathrm{Cl}^{-}, \mathrm{NO}_{3}^{-}$ \\
\hline
\end{tabular}

Table 9.1 is a combination of the various sparingly soluble solids used for the experimental purposes as represented by Table 7.27 of Chapter 7 and the various ionic 
forms of the cation and anion exchange resins used as represented by Table 7.2 of Chapter 7. Different combinations of the RIP slurry mixture systems as given by Table 9.1 were studied in the form of "mixed bed" resin systems. For the purposes of this dissertation a "mixed bed" of resins will refer to a system where both a cation and anion exchange resin are present in the RIP slurry mixture system.

These mixed bed RIP slurry mixture systems were used to counter act the common ion effect as discussed in paragraph 2.7 of Chapter 2 and paragraph 6.2.1 of Chapter 6. The objective of the mixed bed RIP slurry mixture systems is therefore to counter act the build-up of the constituent ions of the sparingly soluble solid in the aqueous phase, which will decrease the solubility of the solid. Various combinations of the mixed bed resin system were also investigated by combining different ionic form cation resins with different ionic form anion exchange resins. The experimental and consolidated equilibrium model results for these systems will also be presented in this chapter and Chapters 10 to 11 .

As mentioned above the synthesis of the consolidated equilibrium model for the RIP slurry mixture system, as presented in Chapter 6 of this dissertation, was based on the experimental results obtained for the various RIP slurry mixture systems studied. When designing the various RIP slurry mixture system experimental test work it is useful to consider a typical RIP slurry mixture system as a special case of the resin / solution system. The RIP slurry mixture system differs from the true resin / solution system in that the total solution phase concentration of the counter in the "RIP system" (consider only the resin and solution phase concentrations) continually changes as more of the sparingly soluble solid dissolves. This means that RIP slurry mixture system is similar to the resin / solution system, except for the changing total solution phase concentration if the presence of the sparingly soluble is ignored for the purposes of this discussion.

From discussions in Chapter 5 and 6 it is evident that any ion-exchange process is in essence an electrochemical exchange process of electrolyte species. For all of these 
electrochemical exchange processes electroneutrality must be maintained in both the resin and aqueous phase. Because of this the valence of the electrolyte species involved in the ion-exchange process is of significant importance in dictating the exchange of electrochemical equivalent amounts of each species for one another. As mentioned above the RIP slurry mixture system is also an ion-exchange system in which electroneutrality must be maintained at all times. The valences of the species in the RIP slurry mixture systems will therefore also play an important role in the equilibrium process, as is the case for a true resin / solution equilibrium system.

Keeping this in mind it is clear that the experimental tests for the RIP slurry mixture systems must be designed in such a way that various combinations of species with different valences are present in the same system. From Table 9.1 it is evident that the experimental tests performed for the various RIP slurry mixture systems were designed to maximise the different combinations of species valences present in the same RIP slurry mixture system. In order to do this various ionic forms of the cation exchange resin were used, i.e. the monovalent forms in $\mathrm{H}^{+}, \mathrm{Na}^{+}$and $\mathrm{K}^{+}$, the bivalent form in $\mathrm{Cu}^{+2}$ and the trivalent form in $\mathrm{Al}^{+3}$. It is also evident from Figures (8.10) to (8.13) that the resin / solution tests were performed for similar aqueous phase compositions to obtain representative values for the thermodynamic equilibrium constant for the various ionexchange reactions. Resin / solution equilibrium isotherms were determined experimentally for the exchange reactions between various bivalent cations $\left(\mathrm{Mg}^{+2}, \mathrm{Ca}^{+2}\right.$, $\mathrm{Ba}^{+2}$ and $\mathrm{Pb}^{+2}$ ) and monovalent counter-ions $\left(\mathrm{H}^{+}, \mathrm{K}^{+}\right.$and $\left.\mathrm{Na}^{+}\right)$. Similar isotherms were determined for the exchange reaction between the same bivalent cations and the bivalent cation $\mathrm{Cu}^{+2}$ and the trivalent cation $\mathrm{Al}^{+3}$. These equilibrium isotherms are all required for use in the consolidated equilibrium model for the various RIP slurry mixture systems given by Table 9.1 .

From Table 9.1 it is evident that the various RIP slurry mixture systems investigated for the purposes of this may be divided into several categories depending on the valence of 
the cation of the sparingly soluble solid and the valence of the counter-ion in the cation exchange resin. The categories are as follows:

i) Bivalent-monovalent slurry resin systems (discussed in this Chapter)

ii) Bivalent-bivalent slurry resin systems (discussed in Chapter 10)

iii) Bivalent-trivalent slurry resin systems (discussed in Chapter 11)

In each of these categories there are various RIP slurry mixture systems for which experimental data have been collected and studied for the purposes of the synthesis of the consolidated equilibrium model. Many of these systems are similar and therefore only some of them will be discussed in each of the following chapters for the purposes of this dissertation.

\subsection{OBJECTIVES OF THIS CHAPTER}

It is the objective of this chapter to study the consolidated equilibrium model for a bivalent-monovalent RIP slurry mixture system. From Table 9.1 it is evident that various sparingly soluble solids were used to study the bivalent-monovalent type RIP slurry mixture system. The systems that will be investigated in this chapter are as follows:

i) Slurry resin systems of $\mathrm{PbSO}_{4}$ with cation exchange resins in the $\mathrm{Na}^{+}, \mathrm{K}^{+}$and $\mathrm{H}^{+}$ ionic form.

ii) Slurry resin systems for $\mathrm{CaSO}_{4}$ with cation exchange resins in the $\mathrm{Na}^{+}, \mathrm{K}^{+}$and $\mathrm{H}^{+}$ ionic form.

It is further the objective of this chapter to calculate the thermodynamic equilibrium constant $K_{A}^{B}$ for the various resin / solution equilibrium systems as presented in Chapter 8 of this dissertation that is applicable to the $\mathrm{PbSO}_{4}$ and $\mathrm{CaSO}_{4} \mathrm{RIP}$ slurry mixture systems investigated. The thermodynamic equilibrium constants for the exchange reactions between the bivalent cations $\mathrm{Pb}^{+2}$ and $\mathrm{Ca}^{+2}$ and the monovalent ions $\mathrm{Na}^{+}, \mathrm{K}^{+}$ 
and $\mathrm{H}^{+}$will be calculated. The thermodynamic equilibrium constants for the exchange reactions between the $\mathrm{SO}_{4}{ }^{2-}$ anion and the $\mathrm{NO}_{3}{ }^{-}$and $\mathrm{Cl}^{-}$ion also need to be calculated as it is required in the consolidated equilibrium model for the RIP slurry mixture systems. The experimental data for the equilibrium isotherms for these anion-anion exchange reactions were also discussed in Chapter 8 of this dissertation.

The values of the solution phase activity coefficients for all of the species involved in the resin / solution equilibrium systems will be calculated using the Pitzer model. The values for the resin phase activity coefficients are also calculated as obtained from the Wilson interaction parameters, as discussed in Chapter 6 of this dissertation. Due to the fact that the total solution phase concentration (ionic strength) of the RIP slurry mixture systems varies significantly the value of the thermodynamic equilibrium constant $K_{A}^{B}$ will be calculated for various solution phase concentrations. The ionic strength of the RIP system typically varies with the different amounts of the ion-exchange resins used in the RIP slurry mixture system.

The change in the solubility of the sparingly soluble solid with the change of the solution phase composition will also be investigated. This will be done by calculating the solubility for the constituent ions of the sparingly soluble solid for various aqueous phase compositions. The calculated values will then be compared with data available from the literature where available for the different sparingly soluble solids presented in Table 9.1. The results of these calculations are used in the consolidated equilibrium model for the RIP slurry mixture system.

Before discussing the model results for the $\mathrm{PbSO}_{4}$ and $\mathrm{CaSO}_{4} \mathrm{RIP}$ slurry mixture system investigated in this chapter it is important to consider general trends as observed from the experimental data collected for the $\mathrm{PbSO}_{4} \mathrm{RIP}$ slurry mixture system. This will be of significant value in interpreting the model results for the various RIP slurry mixture systems that will be investigated in the following Chapters 10 to 12 . To interpret the model results it is important to revisit the concepts as defined in Chapter 6 of this 
dissertation on the basis of the experimental results obtained for the experimental procedures followed as described in Chapter 7 of this dissertation.

\subsection{GENERAL MECHANISTIC CONSIDERATIONS FOR THE SIMULTANEOUS DISSOLUTION AND SORPTION REACTION OF $\mathrm{PbSO}_{4}$ IN A RIP SLURRY MIXTURE SYSTEM}

Figure (8.13) in Chapter 8 of this dissertation shows the equilibrium isotherms for the adsorption of $\mathrm{Pb}^{+2}$ ions on the cation exchange resin Duolite $\mathrm{C} 26$ for various initial ionic forms. The different exchange reactions are between the $\mathrm{Pb}^{+2}$ ions and the $\mathrm{H}^{+}, \mathrm{Na}^{+}, \mathrm{K}^{+}$, $\mathrm{Cu}^{+2}$ and $\mathrm{Al}^{+3}$ cations. Figure (8.13) also shows the isotherms for various solution phase concentrations. Figure (9.1) shows a selected number of isotherms of Figure (8.13) for a specific solution phase concentration. It is evident that these isotherms have very steep wave fronts, which are typical for modern synthetic ion-exchangers. This clearly indicates that substantially high resin loadings of the $\mathrm{Pb}^{+2}$ ions may be obtained for very low solution phase concentrations of the $\mathrm{Pb}^{+2}$ ions, even though Duolite $\mathrm{C} 26$ is a relatively non-selective cation exchange resin. This phenomenon of high resin loading of a species for relatively low solution phase concentrations and the effect thereof on the RIP slurry mixture system have been discussed in Chapters 6 and 8. In the case of resins specifically designed to be selective towards a particular species, these equilibrium isotherms can become much more rectangular in shape for the sorption of the specific ion. With resins of this type, near maximum loadings can be obtained for the desired species with much smaller solution phase concentrations of the species of interest in the presence of other competing species.

It is a well-documented fact that the selectivity of an ion-exchange resin for a particular species increases with an increase in the valence of that species, which will result in a higher electrolytic charge density of the species. This is evident from Figure (9.1), which shows a significant decrease in the sorption of the $\mathrm{Pb}^{+2}$ ions with an increase in the valence of the counter ion initially saturating the cation exchange resin. 


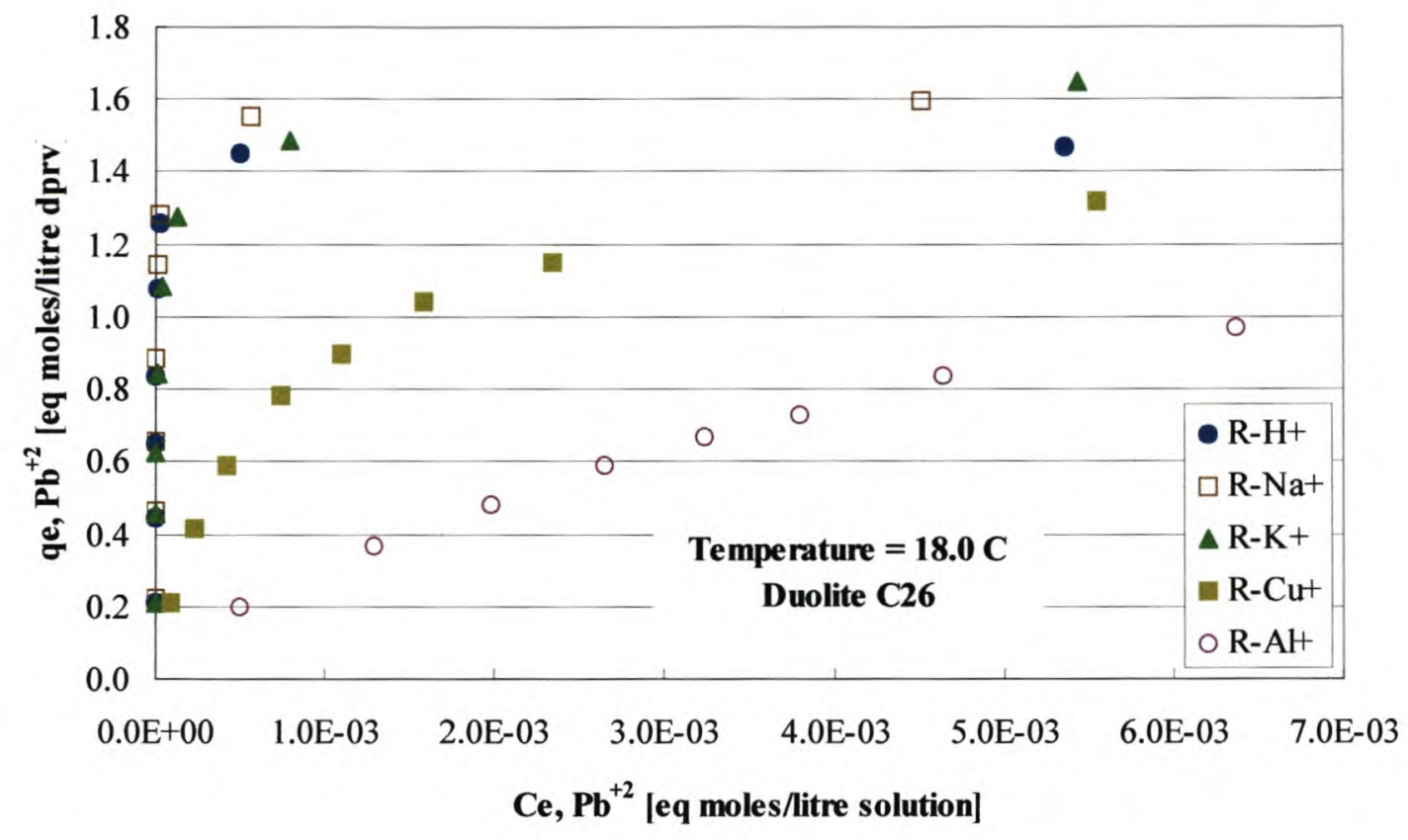

Figure 9.1 Equilibrium isotherms for the adsorption of $\mathrm{Pb}^{+2}$ ions by a strong acid cation exchange resin, Duolite $\mathrm{C} 26$, from a clear aqueous $\mathrm{Pb}\left(\mathrm{NO}_{3}\right)_{2}$ solution for different initial cationic forms of the resin at $18.0^{\circ} \mathrm{C}$.

From Figure (9.1) it can be seen that the isotherm for the binary counter-ion $\mathrm{Cu}^{+2}$ is less steep than that of the monovalent counter-ions $\mathrm{H}^{+}, \mathrm{Na}^{+}$and $\mathrm{K}^{+}$. The isotherm for the ternary counter-ion $\mathrm{Al}^{+3}$ is in turn less steep than that of the bivalent counter-ion $\mathrm{Cu}^{+2}$. This is especially true for the low solution phase concentration range of the $\mathrm{Pb}^{+2}$ ions, which is the solution phase concentration region of interest to the consolidated equilibrium model for the $\mathrm{PbSO}_{4}$ RIP slurry mixture system.

It is further evident from Figure (9.1) that there is very little difference in the isotherms for the various monovalent counter-ions $\mathrm{H}^{+}, \mathrm{Na}^{+}$and $\mathrm{K}^{+}$. The trends in Figure (9.1) emphasise the fact that most ion-exchange processes are very dependent on the electrochemical valence of the species participating in the reactions due to the fact that 
electroneutrality must be maintained in the phases at all times. This phenomenon can be used to extract species from sparingly soluble solids with the use of ion-exchange resins if there exists a significant difference in the charge density of the constituent ion of the sparingly soluble solid and the counter ion in the ion-exchange resin phase.

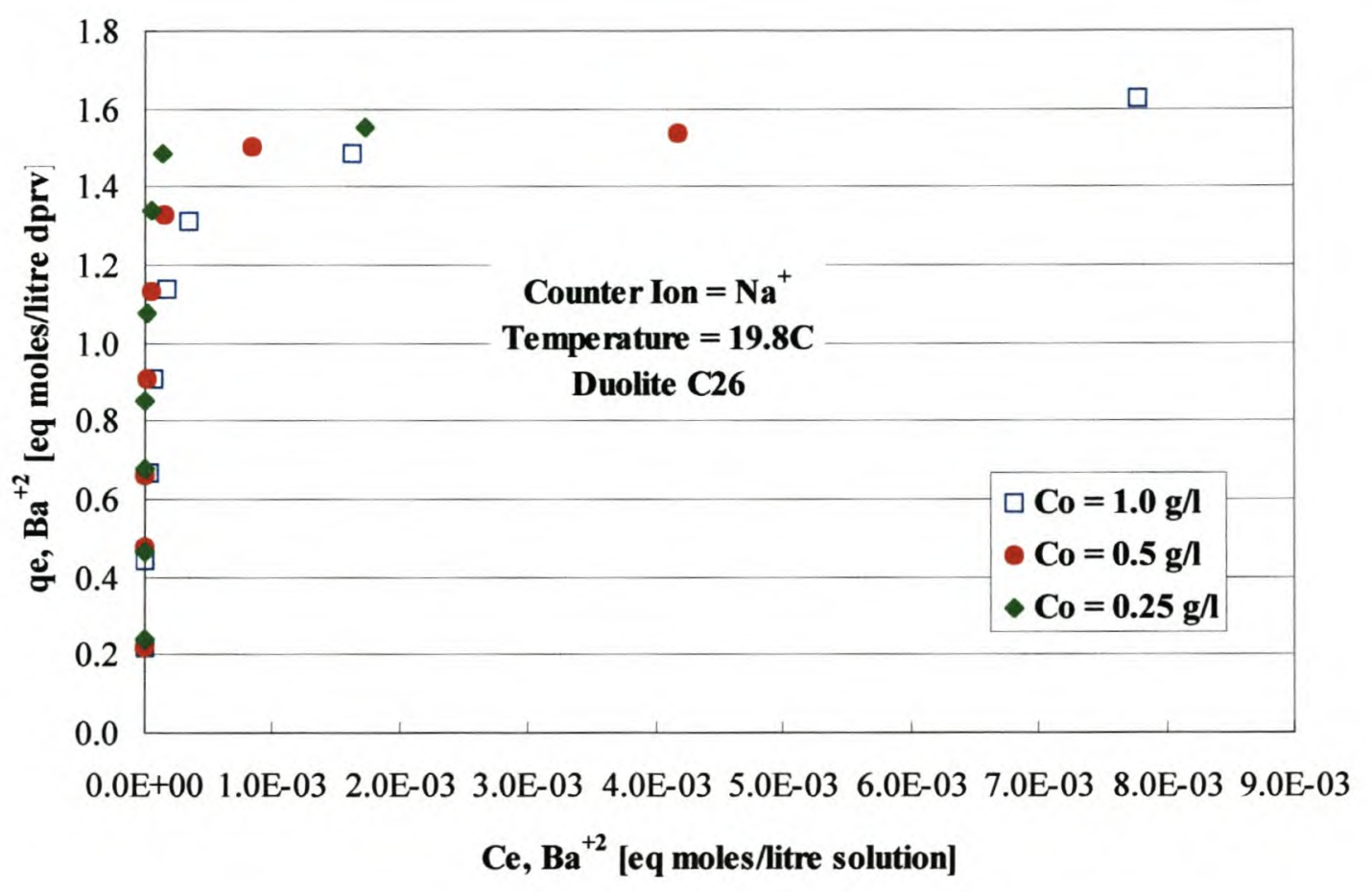

Figure 9.2 Equilibrium isotherms at different total solution concentrations for the adsorption of $\mathrm{Ba}^{+2}$ ions by Duolite $\mathrm{C} 26$, saturated with $\mathrm{Na}^{+}$ions, from a clear aqueous $\mathrm{BaCl}_{2}$ solution at $19.8^{\circ} \mathrm{C}$.

As discussed above and in Chapter 6 of this dissertation it was evident that the total solution phase concentration (ionic strength) of the RIP slurry mixture system changes as the equilibrium attainment process progresses. This mean that the thermodynamic equilibrium constants $K_{A}^{B}$ for the various exchange reactions need to be collected for various total solution phase concentrations as required for the consolidated equilibrium model for the RIP slurry mixture system. The behaviour of the equilibrium isotherms for 
various solution phase concentrations is of significant importance to the consolidated equilibrium model.

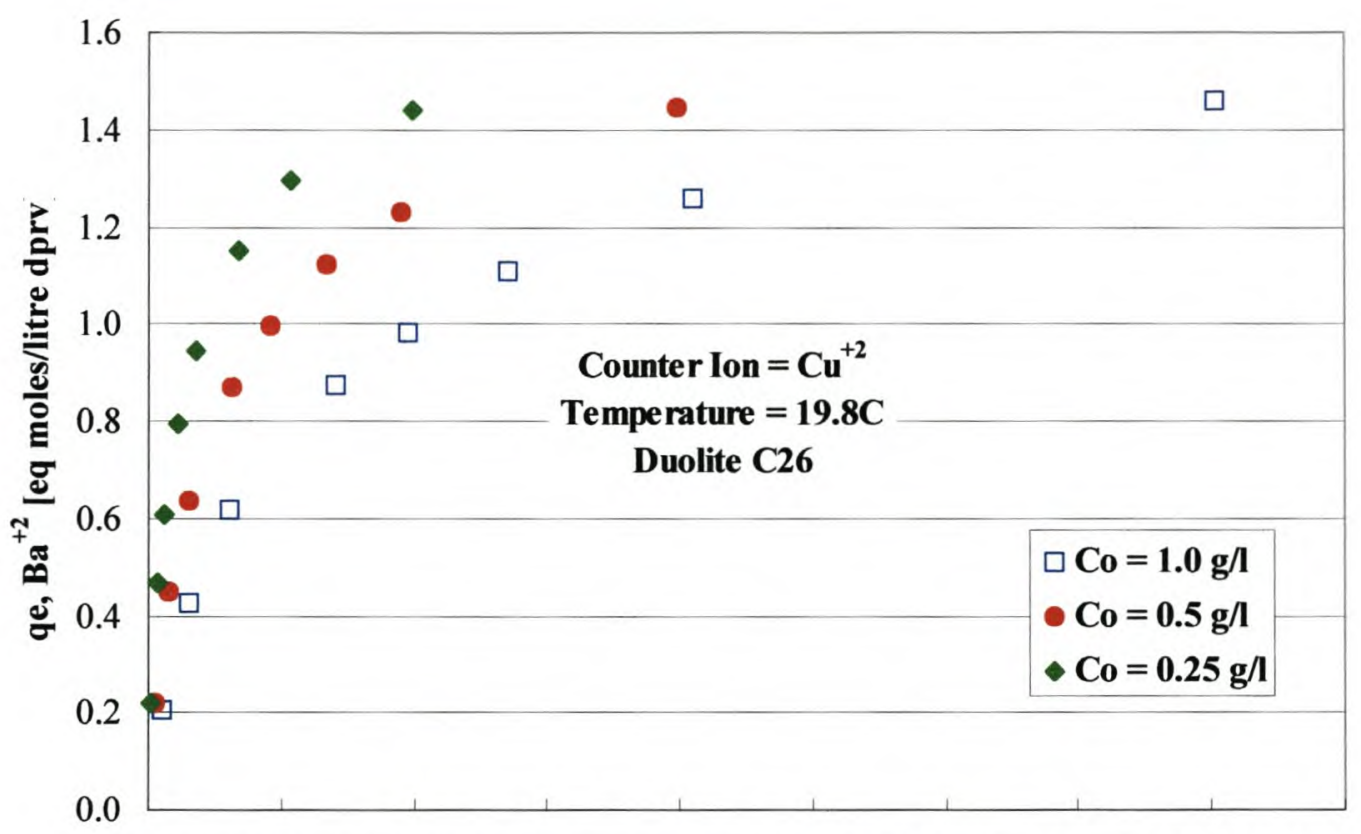

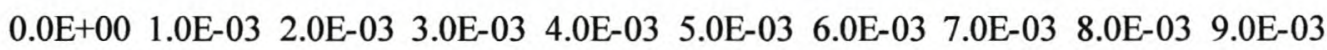

$\mathrm{Ce}, \mathrm{Ba}^{+2}$ [eq moles/litre solution]

Figure 9.3 Equilibrium isotherms at different total solution concentrations for the sorption of $\mathrm{Ba}^{+2}$ ions by Duolite $\mathrm{C} 26$, saturated with $\mathrm{Cu}^{+2}$ ions, from a clear aqueous $\mathrm{BaCl}_{2}$ solution at $19.8^{\circ} \mathrm{C}$.

Figures (9.2) to (9.4) illustrate the effect of the total solution ionic strength for the exchange reaction between the cation $\mathrm{Ba}^{+2}$ and the counter ions $\mathrm{Na}^{+}, \mathrm{Cu}^{+2}$ and $\mathrm{Al}^{+3}$ respectively for different total solution concentrations. From Figures (9.2) to (9.4) it is evident that different equilibrium isotherms exist for different total solution phase concentrations. The proposed model in Chapter 5 for the calculation of the thermodynamic equilibrium constant $\mathrm{KAB}$ for the various ion-exchange reactions should therefore be able to account for this behaviour. 


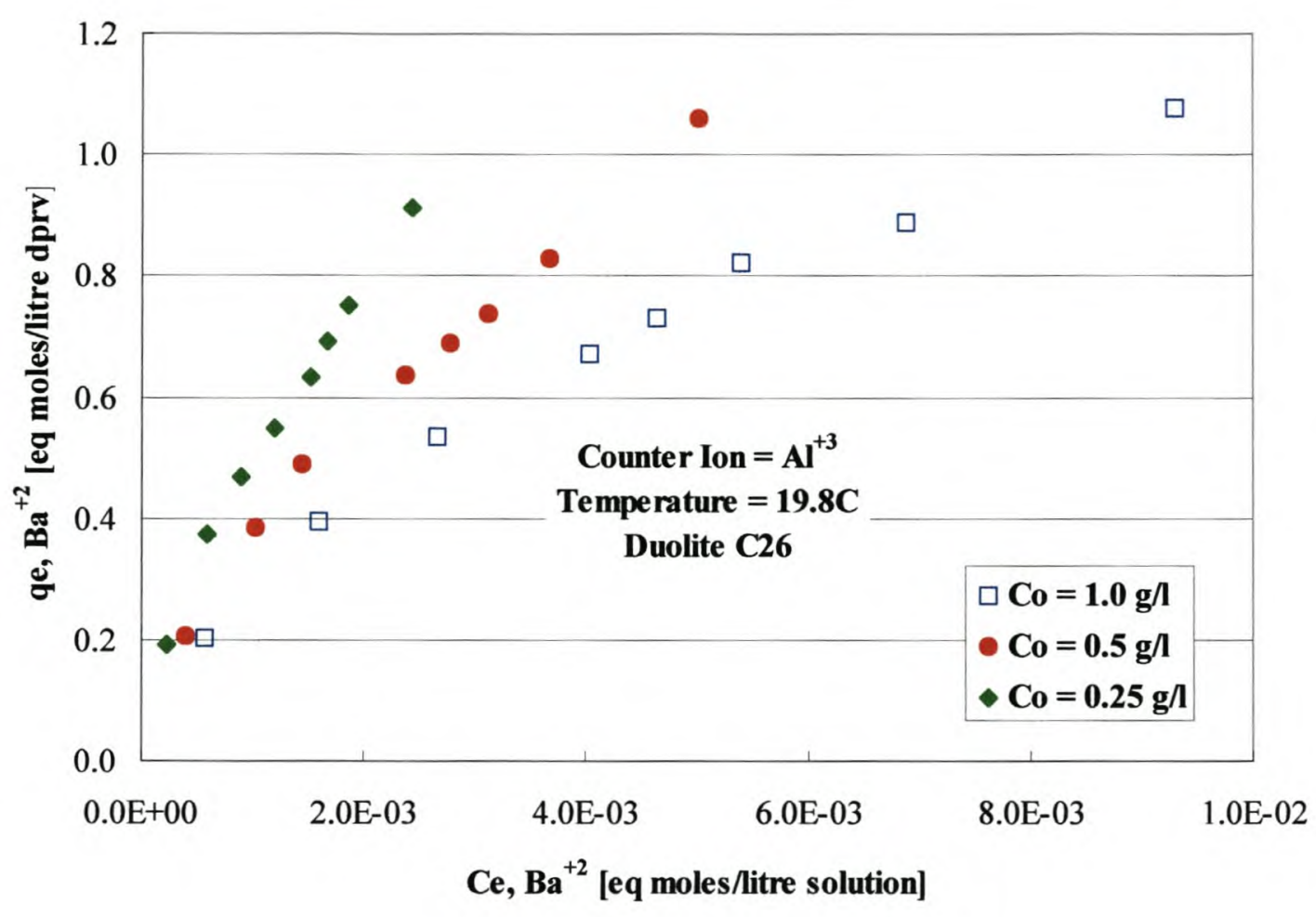

Figure 9.4 Equilibrium isotherms at different total solution concentrations for the sorption of $\mathrm{Ba}^{+2}$ ions by Duolite $\mathrm{C} 26$, saturated with $\mathrm{Al}^{+3}$ ions, from a clear aqueous $\mathrm{BaCl}_{2}$ solution at $19.8^{\circ} \mathrm{C}$.

As discussed in Chapter 6 of this dissertation it may be argued that the solution phase concentrations of the constituent ions of the sparingly soluble solid are relatively low and therefore only equilibrium isotherms for low total solution phase concentrations should be considered. It was evident from the discussion that relatively high total solution phase concentrations can be obtained due to the continual dissolution of the sparingly soluble solid as equilibrium is attained in the RIP slurry mixture system. Relatively high solution phase concentrations of the counter-ions can be obtained by simultaneously increasing the amount of the sparingly soluble solid and the ion-exchange resin in the RIP slurry mixture systems for a given volume of the aqueous phase solution. 


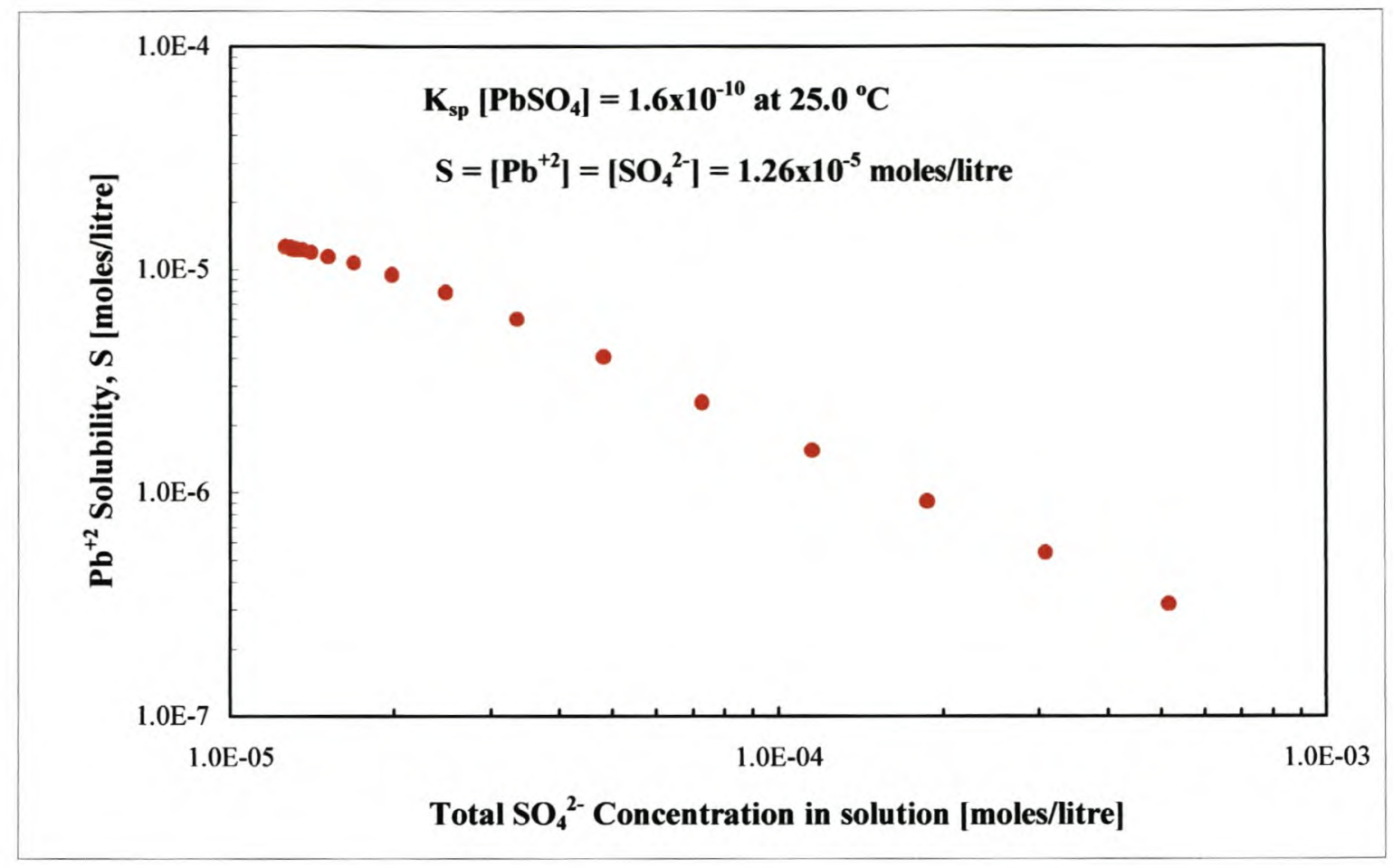

Figure 9.5 Decrease in the equilibrium solution concentration of $\mathrm{Pb}^{+2}$ ions in a pure $\mathrm{PbSO}_{4}$ slurry mixture with an increase in the $\mathrm{SO}_{4}{ }^{2-}$ concentration, common ion effect.

The solution phase concentration of the constituent ion of the sparingly soluble solid not participating in the ion-exchange reaction will also increase substantially as more of the solid dissolves, giving rise to the common ion effect discussed in earlier chapters. This increase in the total solution concentration changes both the resin and solution phase activities of the constituent ions of the sparingly soluble solid, which will inevitably change its solubility.

When a cation exchange resin is added to an aqueous slurry of the $\mathrm{PbSO}_{4}$ sparingly soluble solid the slightly dissolved traces of the $\mathrm{Pb}^{+2}$ constituent ions of the solid are adsorbed by the ion exchanger and replaced with counter ion species present in the resin phase. This ion exchange reaction results in a decrease in the solution concentration of the $\mathrm{Pb}^{+2}$ ions, which displaces the solid / liquid equilibrium condition. According to Le 
Chatelier's principle more of the $\mathrm{PbSO}_{4}$ will dissolve to restore the equilibrium concentration of the $\mathrm{Pb}^{+2}$ ions in solution, which will once again be adsorbed by the ionexchanger.

For each mole of $\mathrm{Pb}^{+2}$ ions dissolved from the $\mathrm{PbSO}_{4}$ solid, an equivalent number of moles of the $\mathrm{SO}_{4}{ }^{2-}$ ions accompany it in order to maintain electrical neutrality of the solution phase. The $\mathrm{SO}_{4}{ }^{2-}$ ions are largely excluded from the cation resin phase and are not removed from the solution phase. The consequence is a steady increase in its solution phase concentration as the cation exchange reaction proceeds. This will lead to a decrease in the solubility of the $\mathrm{PbSO}_{4}$ solid due to the common ion effect, as discussed above and in Chapter 6 of this dissertation.

The common ion effect described is evident from Figure (9.5), which shows a decrease in the solution phase concentration of the $\mathrm{Pb}^{+2}$ ions in a $\mathrm{PbSO}_{4}$ slurry mixture (containing no resin) as the solution phase concentration of the $\mathrm{SO}_{4}{ }^{2-}$ ions is increased with the addition of $\mathrm{Na}_{2} \mathrm{SO}_{4}$.

The same phenomenon is evident from Figure (9.6). Figure (9.6), which shows the equilibrium solution phase concentrations of the $\mathrm{Pb}^{+2}$ and $\mathrm{SO}_{4}{ }^{2-}$ ions in the $\mathrm{PbSO}_{4} \mathrm{RIP}$ slurry mixture for different amounts of the cation exchange resin at $19.0^{\circ} \mathrm{C}$. The ionexchange reaction between the $\mathrm{Pb}^{+2}$ ions and the various counter ions $\left(\mathrm{H}^{+}, \mathrm{Na}^{+}, \mathrm{K}^{+}, \mathrm{Cu}^{+2}\right.$ and $\mathrm{Al}^{+3}$ ) resulted in the formation of different amounts of the electrolytes $\mathrm{H}_{2} \mathrm{SO}_{4}$, $\mathrm{Na}_{2} \mathrm{SO}_{4}, \mathrm{~K}_{2} \mathrm{SO}_{4}, \mathrm{CuSO}_{4}$ and $\mathrm{Al}_{2}\left(\mathrm{SO}_{4}\right)_{3}$ for the different amounts of the cation exchange resin used. 


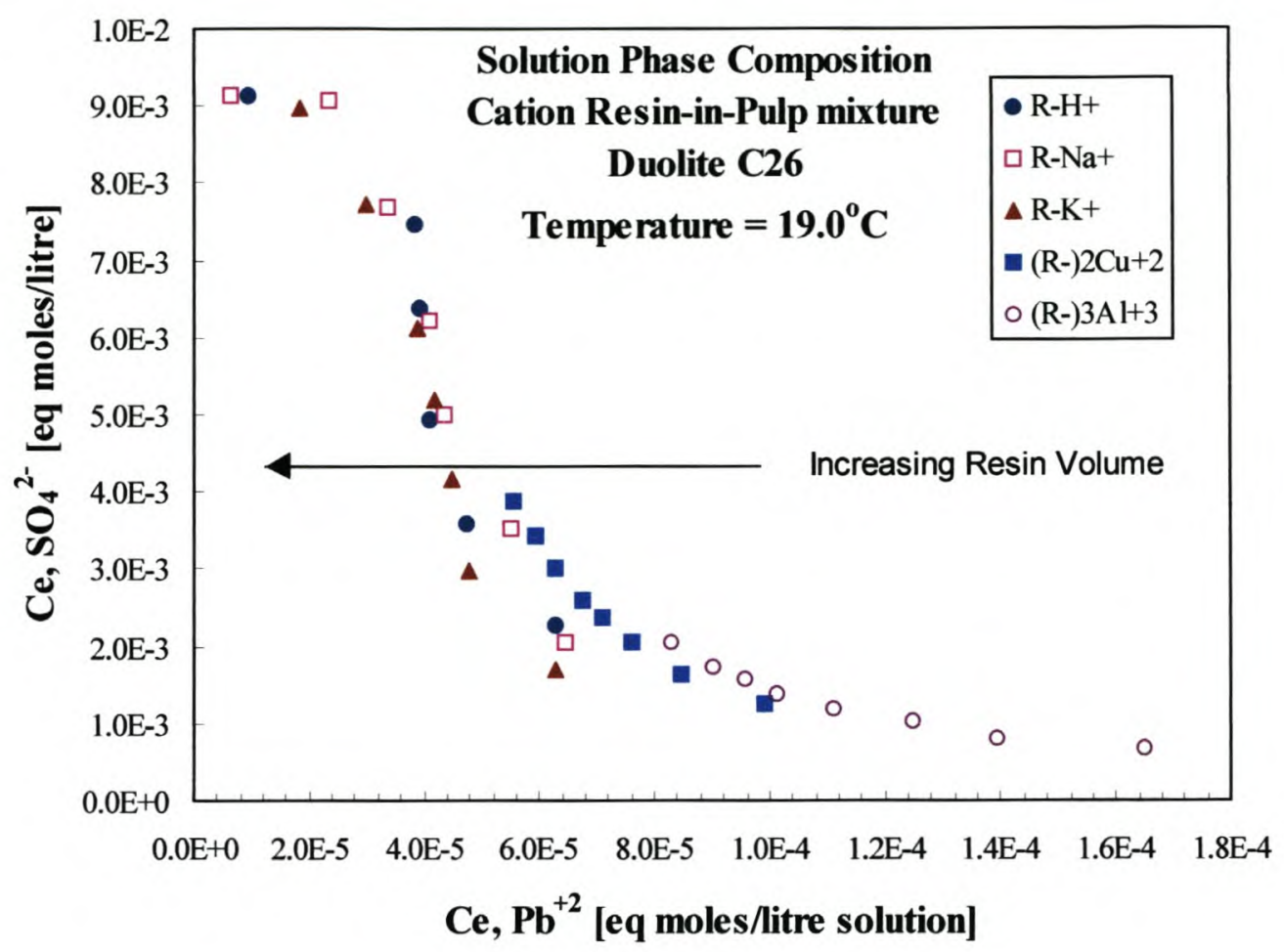

Figure 9.6 Equilibrium solution phase concentrations of $\mathrm{Pb}^{+2}$ and $\mathrm{SO}_{4}{ }^{2-}$ ions in an aqueous $\mathrm{PbSO}_{4}$ resin-in-pulp slurry mixture containing a strong acid cation exchange resin, Duolite C26, for different initial cationic forms of the resin at $19.0^{\circ} \mathrm{C}$.

It is evident from Figure (9.5) that the equilibrium concentration of the $\mathrm{Pb}^{+2}$ ions decreases as the solution phase concentration of the $\mathrm{SO}_{4}{ }^{2-}$ ions increases for the different amounts of the cation exchange resin used in the RIP slurry mixture system. This phenomenon is also clearly illustrated by Figure (9.7), which shows the equilibrium solution phase concentration of the $\mathrm{Pb}^{+2}$ ions that corresponds to the different volumes of the cation resin used in a one litre slurry mixture. 


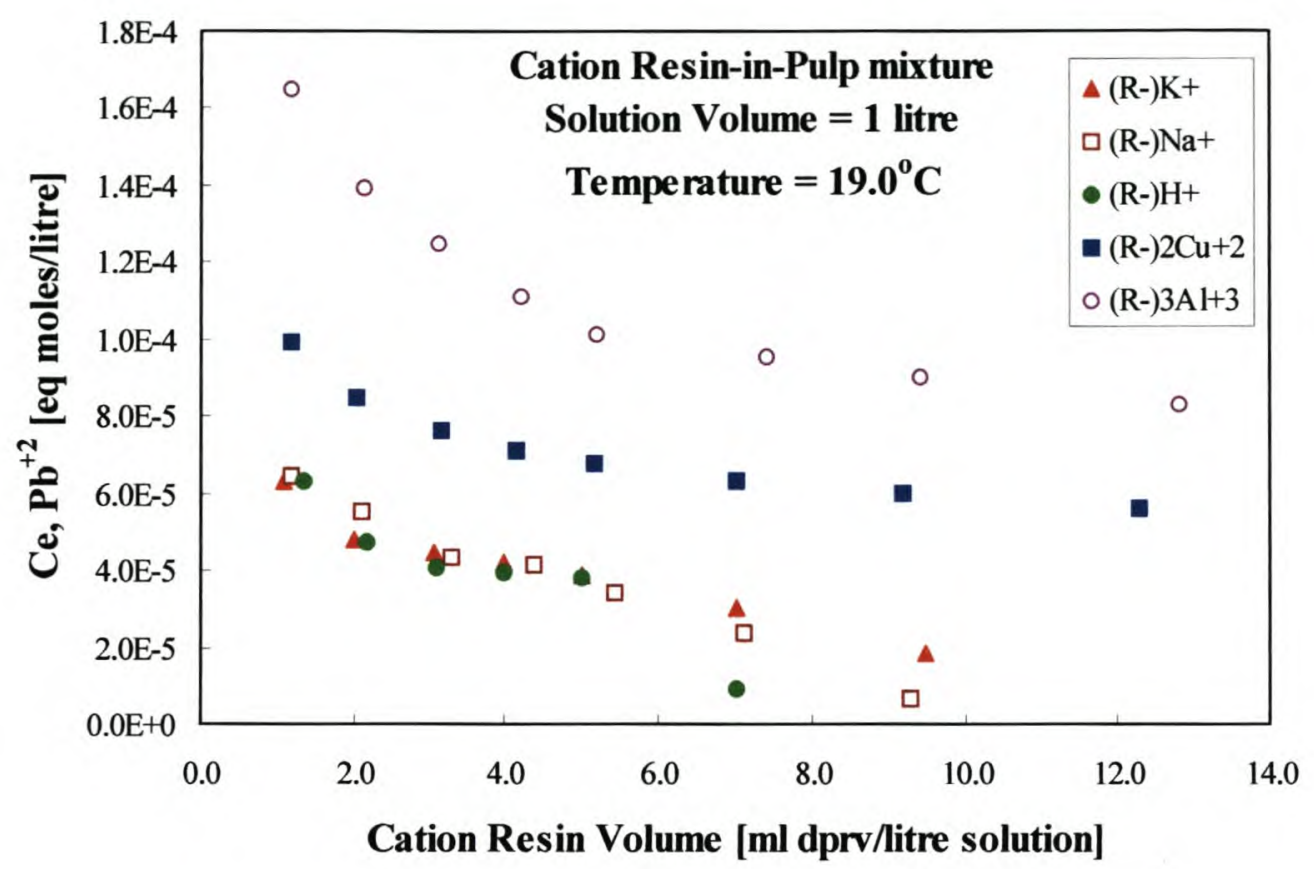

Figure 9.7 Equilibrium solution phase concentrations of $\mathrm{Pb}^{+2}$ ions, from an aqueous $\mathrm{PbSO}_{4}$ RIP slurry mixture as a function of the volume of resin added per litre of solution.

The decrease in the solution phase concentration of the $\mathrm{Pb}^{+2}$ ions will result in lower equilibrium resin loadings, as shown in Figure (8.13) of Chapter 8 and Figure (9.1). From Figure (8.13) it is evident that the higher the solution phase concentration of the $\mathrm{Pb}^{+2}$ ions is, the higher the corresponding equilibrium resin loading for the $\mathrm{Pb}^{+2}$ ions on the ion-exchange resin will be. It is therefore expected that the equilibrium resin loading of the $\mathrm{Pb}^{+2}$ ions in the $\mathrm{PbSO}_{4} \mathrm{RIP}$ slurry mixture will decrease with an increase in the amount of the cation exchange resin used, which results in higher solution phase concentrations of the $\mathrm{SO}_{4}{ }^{2-}$ ions. This expectation is clearly illustrated by Figure (9.7), which shows the equilibrium resin loading of the $\mathrm{Pb}^{+2}$ ions that corresponds to the different volumes of the cation exchange resin used in the RIP slurry mixture system. 


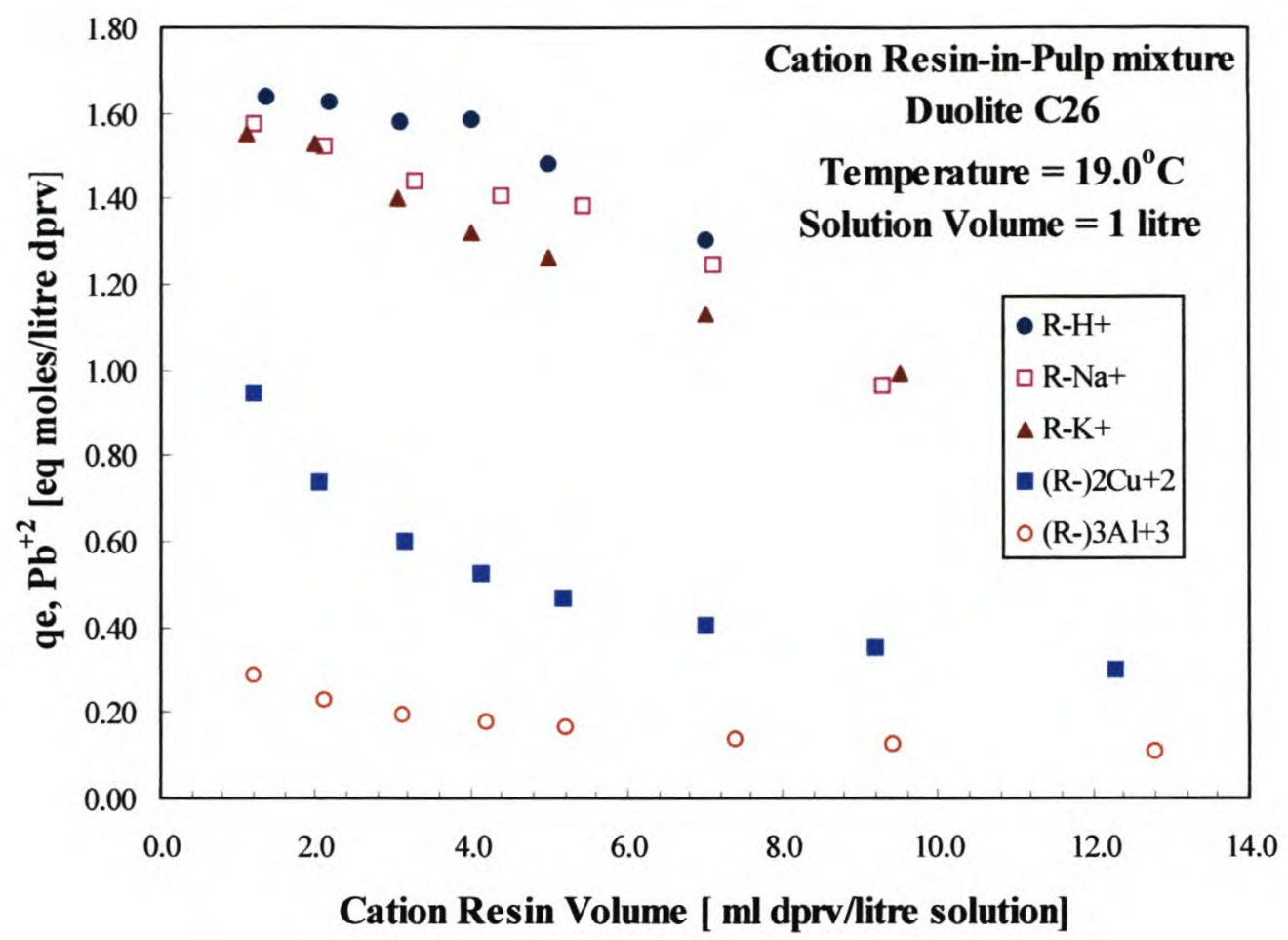

Figure 9.8 Equilibrium resin loading isotherms for the sorption of $\mathrm{Pb}^{+2}$ onto Duolite $\mathrm{C} 26$, from an aqueous $\mathrm{PbSO}_{4}$ RIP slurry mixture as a function of the volume of resin added per litre of solution.

When comparing Figures (9.6) and (9.7), it is evident that highest solution phase concentrations of the $\mathrm{Pb}^{+2}$ ions were obtained for the $\mathrm{Al}^{+3}$ form of the cation resin (Figure (9.6)), which corresponded to the lowest equilibrium loading obtained for the $\mathrm{Pb}^{+2}$ ions (Figure (9.7)). This was observed across the whole range of cation resin volumes used. The can easily be explained with Figures (8.13) and (9.1), which clearly shows lower equilibrium loadings of the $\mathrm{Pb}^{+2}$ ions for an increase in the valence of the counter ion. This is due to the higher selectivity of the ion-exchange resin for species with a higher electrochemical valence, as explained earlier. Comparing the solution phase concentrations for the $\mathrm{Pb}^{+2}$ ions in the $\mathrm{PbSO}_{4} \mathrm{RIP}$ system in Figure (9.6) with that of the resin / solution system in Figure (9.1), it is evident that the RIP slurry mixture system operates in the lower solution phase concentration region as stated earlier. 


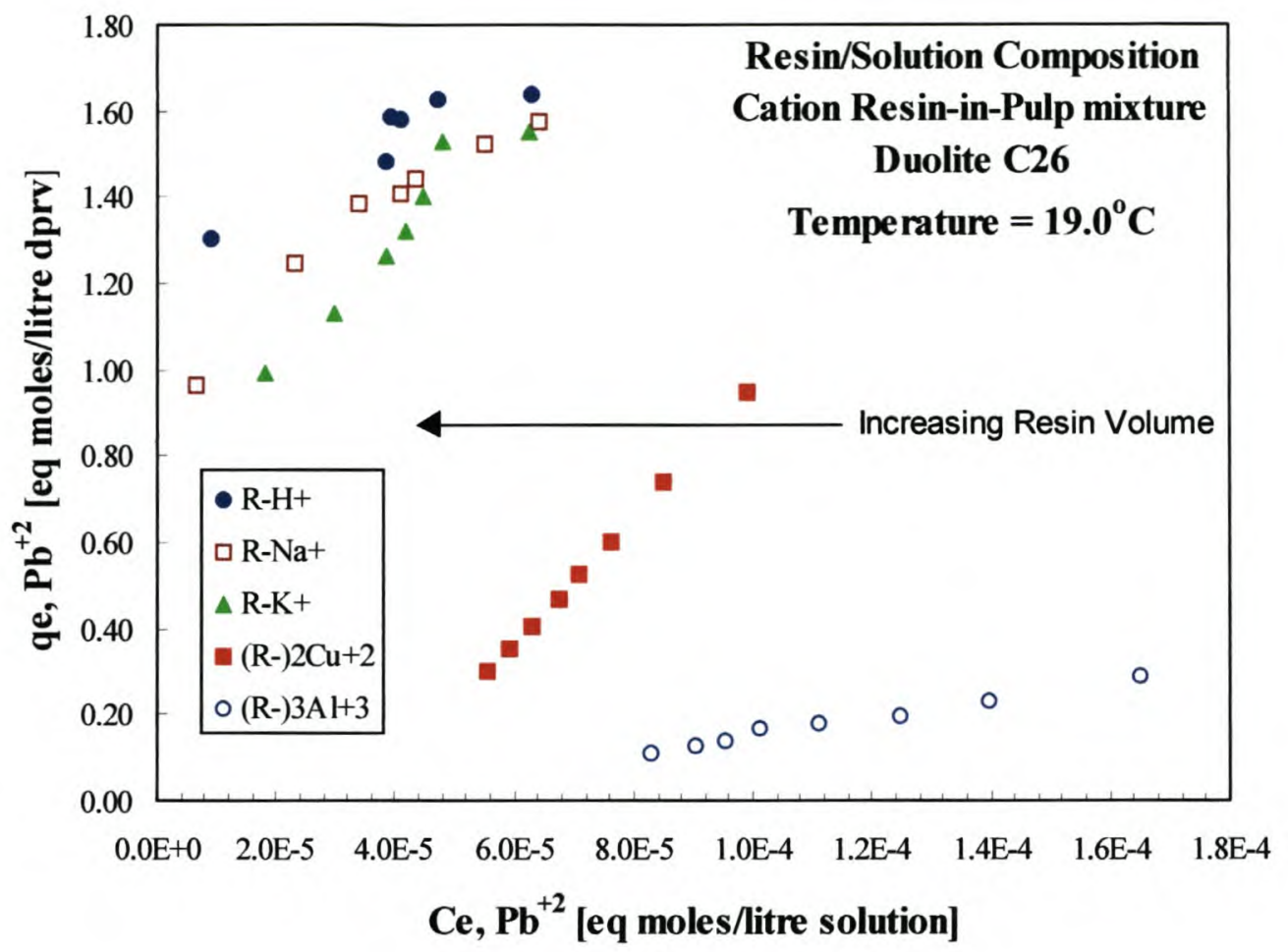

Figure 9.9 Resin/solution equilibrium loading isotherms for the sorption of $\mathrm{Pb}^{+2}$ ions onto Duolite $\mathrm{C} 26$, from a $\mathrm{PbSO}_{4}$ RIP slurry mixture for different initial ionic forms of the cation exchange resin at $19.0^{\circ} \mathrm{C}$.

The exchanged counter ions with the higher electrochemical valence $\left(\mathrm{Al}^{+3}>\mathrm{Cu}^{+2}>\mathrm{H}^{+}>\right.$ $\mathrm{K}^{+}>\mathrm{Na}^{+}$) influence the solubility of the sparingly soluble solid more strongly. As a rule of thumb, stronger ion-ion interactions are observed between ions of higher charge density. A larger electrochemical potential difference will exist between the mentioned counter cations and the $\mathrm{SO}_{4}{ }^{2-}$ ions, which will enhance the solubility of the $\mathrm{PbSO}_{4}$. The theoretical concepts of these electrochemical interactions and its influence on the solubility of the sparingly soluble solid have been discussed in detail in Chapter 2 of this dissertation. These interactions result in the solution becoming more non-ideal, which is represented by a deviation in the solution phase activity coefficients of the species from unity. This may result in a scenario where the common ion effect of the $\mathrm{SO}_{4}{ }^{2-}$ ions on the 
solubility of the $\mathrm{PbSO}_{4}$ solid is less noticeable for the higher valence counter ions such as $\mathrm{Al}^{+3}$ due to the formation of a strongly associating electrolyte with the $\mathrm{SO}_{4}{ }^{2-}$ ions. It may therefore be expected that the $\mathrm{PbSO}_{4}$ solid will remain more soluble in the aqueous solutions containing the $\mathrm{Al}^{+3}$ ions than would be the case for those with the monovalent counter ions $\mathrm{H}^{+}, \mathrm{Na}^{+}$and $\mathrm{K}^{+}$.

However, Figures (9.8) and (9.9) clearly indicate that much higher resin loadings of the $\mathrm{Pb}^{+2}$ ions are obtained with the cation resin in the monovalent ionic form compared to the bi- and trivalent forms. This suggest that the "enhancement" in the solubility of the $\mathrm{PbSO}_{4}$ solid for aqueous phase solutions containing the $\mathrm{Al}^{+3}$ and $\mathrm{Cu}^{+2}$ ions are outweighed by the selectivity of the cation resin for species of higher electrochemical valences. This means that the $\mathrm{Pb}^{+2}$ ions in the aqueous solution compete more favourable with the monovalent $\mathrm{H}^{+}, \mathrm{Na}^{+}$and $\mathrm{K}^{+}$ions than with the bivalent $\mathrm{Cu}^{+2}$ and trivalent $\mathrm{Al}^{+3}$ ions on the resin phase.

To minimise the common ion effect, a mixture of a cation and anion exchange resin (referred to as a "mixed bed" of resin for the purposes of this dissertation) may be used. The mixed bed of resin in the RIP slurry mixture system will simultaneously adsorb both the $\mathrm{Pb}^{+2}$ cations and $\mathrm{SO}_{4}{ }^{2-}$ anions, which will prevent a significant increase in the concentration of the any of these constituent ions as the $\mathrm{PbSO}_{4}$ solid is dissolved. Figures (9.10) and (9.11) show the attainable equilibrium loading of the $\mathrm{Pb}^{+2}$ ions on the cation exchange resin Duolite C26, when a mixed bed of the cation and anion resin is used in the RIP slurry mixture of $\mathrm{PbSO}_{4}$. For the equilibrium loading curves of Figure (9.10) the cation resin was initially in the $\mathrm{K}^{+}$ionic form and the anion resin, Duolite A161, in the $\mathrm{NO}_{3}{ }^{-}$ionic form. The equilibrium loading curves in Figure (9.11) are for the cation resin ionic form of $\mathrm{Al}^{+3}$ and the anion resin ionic form of $\mathrm{NO}_{3}^{-}$.

It is evident from both Figures (9.10) and (9.11) that the cation resin loading for the $\mathrm{Pb}^{+2}$ ions increases while the anion resin loading for the $\mathrm{SO}_{4}{ }^{2-}$ ions decreases with an increase in the ratio of the volumes displayed on the $\mathrm{x}$-axis. The $\mathrm{x}$-axis displays the ratio in 
volumes of the anion resin used relative to the volume of the cation resin used in the $\mathrm{PbSO}_{4}$ slurry mixture system. Different curves were constructed for different total volumes of the cation exchange resin.

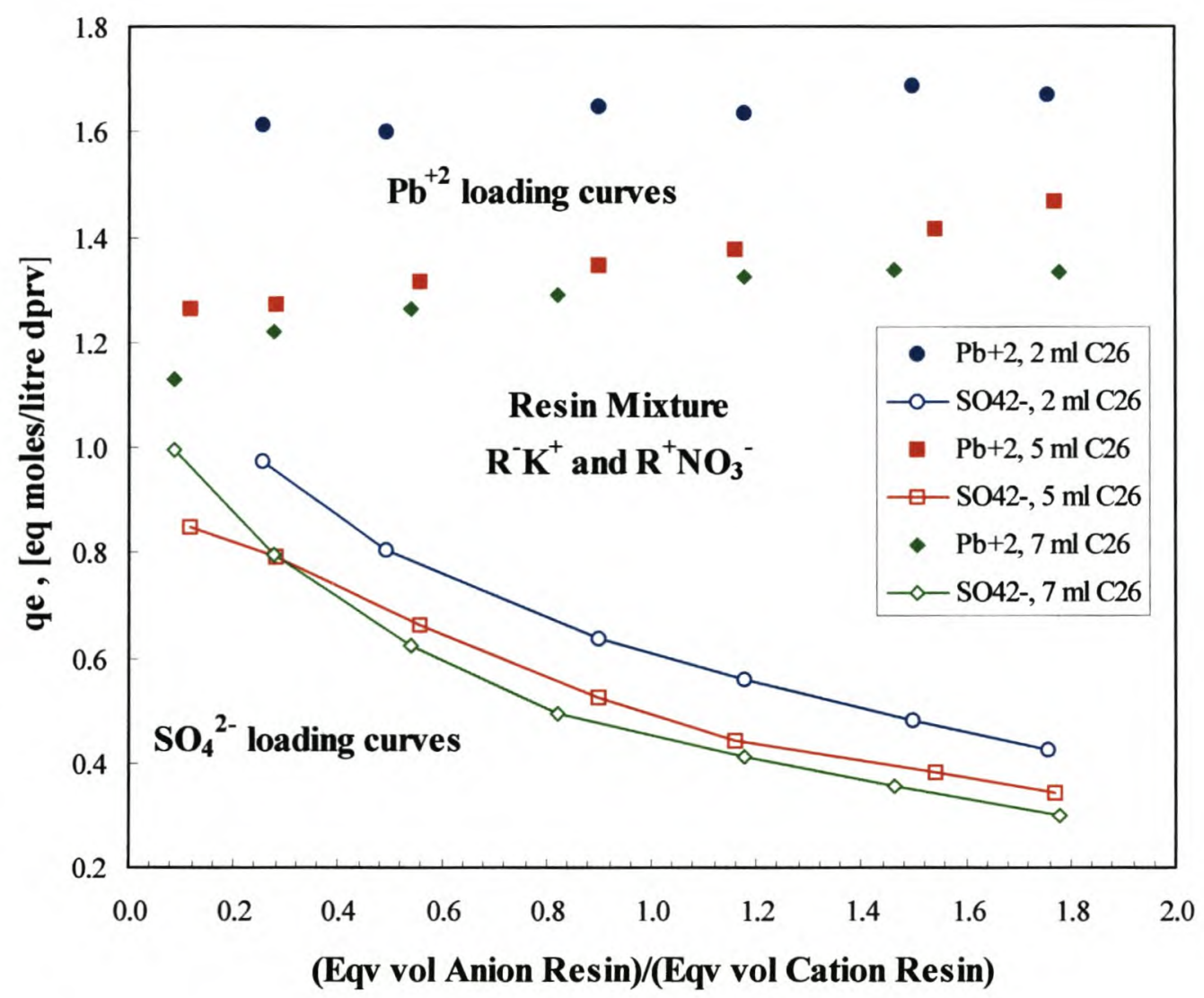

Figure 9.10 Equilibrium resin loading of $\mathrm{Pb}^{+2}$ ions onto Duolite $\mathrm{C} 26$, from an aqueous $\mathrm{PbSO}_{4}$ RIP slurry mixture containing the cation resin in the $\mathrm{K}^{+}$ionic form and the anion resin, Duolite $\mathrm{A} 161$, in the $\mathrm{NO}_{3}{ }^{-}$ionic form, as a function of the ratio of the equivalent volume of cation resin to equivalent volume of anion resin.

The decrease in the resin loading of the $\mathrm{Pb}^{+2}$ ions may be explained if it is considered that for a fixed amount of the cation exchange resin the solution phase concentration of the $\mathrm{SO}_{4}{ }^{2-}$ ions will be less for the larger volumes of the anion resin compared to the smaller 
volumes of anion resin used. The more of the anion exchange resin volume that is used, the more of the dissolved $\mathrm{SO}_{4}{ }^{2-}$ ions may be removed from the aqueous solution phase.. This will decrease the common ion effect of the $\mathrm{SO}_{4}{ }^{2-}$ ions on the solubility of the $\mathrm{PbSO}_{4}$. Because of this, more of the $\mathrm{PbSO}_{4}$ may dissolve resulting in higher than would have been solution phase concentrations of the $\mathrm{Pb}^{+2}$ ions. From Figures (9.1) and (8.13) of Chapter 8 it is evident that higher equilibrium resin loadings for the $\mathrm{Pb}^{+2}$ ions may be obtained in this way, which explains Figures (9.10) and (9.11).

Another important feature of the simultaneous dissolution and adsorption process in the RIP slurry mixture system is shown by Figure (9.12), which indicates that the total solution phase ionic strength $I$ for the RIP slurry mixture system increases with an increase in the volume of the cation exchange resin used. Figure (9.12) shows the solution phase concentrations of the $\mathrm{Pb}^{+2}, \mathrm{~K}^{+}$and $\mathrm{SO}_{4}{ }^{2-}$ ions as well as the total solution phase ionic strength $I$, defined by Equations (3.8) and (3.9) of Chapter 3 of this dissertation. This increase in the total solution phase ionic concentration of the system will influence the solution phase activities of the dissolved ions of the sparingly soluble solid, $\mathrm{PbSO}_{4}$. This results in a change in the activity coefficient of the $\mathrm{SO}_{4}{ }^{2-}$ anion, which may lead to either an increase or a decrease in the solubility of the sparingly soluble solid.

It is further evident from Figure (9.13), which shows the total solution molar ionic strength $I$ for the different initial ionic forms of the cation exchange resin, that there are significant differences in the solution phase ionic strength for the different ionic forms of the cation. It is evident that a steeper increase exists for the monovalent ionic forms as compared to bi- and trivalent forms. This indicates that more of the $\mathrm{PbSO}_{4}$ dissolved in the RIP slurry mixture systems containing the cation resin in the monovalent ionic form than that of the bivalent or trivalent ionic forms. This is as expected and a direct result of the cation exchange resin's higher selectivity for higher valence species. 


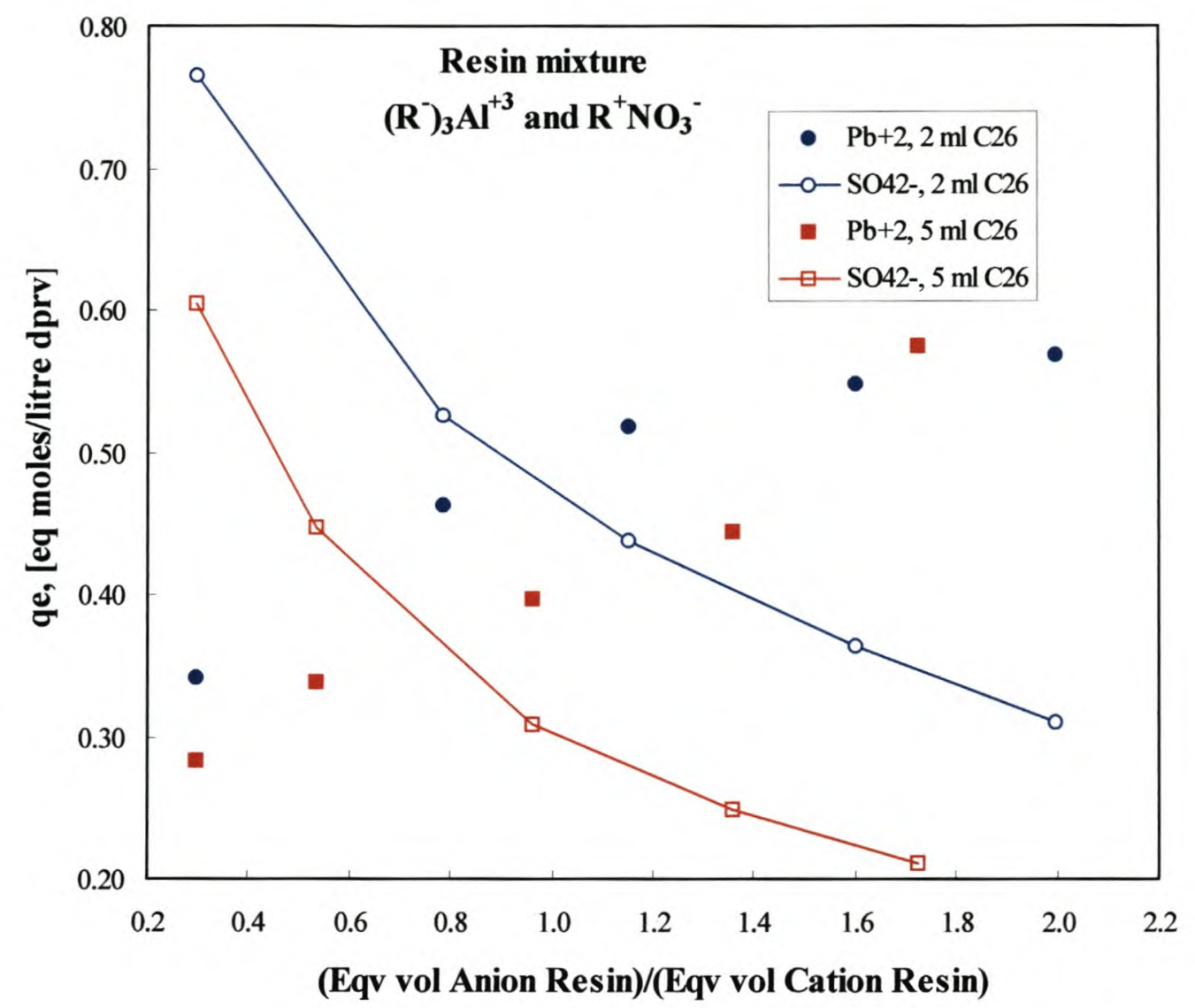

Figure 9.11 Equilibrium resin loading of $\mathrm{Pb}^{+2}$ ions onto Duolite $\mathrm{C} 26$, from an aqueous $\mathrm{PbSO}_{4}$ RIP slurry mixture containing the cation resin in the $\mathrm{Al}^{+3}$ ionic form and the anion resin, Duolite $\mathrm{A} 161$, in the $\mathrm{NO}_{3}{ }^{-}$ionic form, as a function of the ratio of the equivalent volume of cation resin to equivalent volume of anion resin.

The dissolved $\mathrm{Pb}^{+2}$ ions in the aqueous phase are more easily exchanged for the monovalent $\mathrm{H}^{+}, \mathrm{Na}^{+}$and $\mathrm{K}^{+}$ions than for the bivalent $\mathrm{Cu}^{+2}$ and trivalent $\mathrm{Al}^{+3}$ ions.

From Figure (9.13) it is also evident that an order of magnitude increase in the total solution phase ionic strength is observed for the RIP slurry mixture system with the cation exchange resin in the monovalent ionic forms. This associated increase in the total solution ionic strength with an increase in the total amount of resin added can be used to 
create concentrated electrolyte solutions that may influence the solubility of the sparingly soluble solid. These electrolyte solutions may be controlled to contain only relatively small amounts of the dissolved constituent ions of the sparingly soluble solid in the RIP slurry mixture by controlling the relative amounts of the cation and anion exchange resin used in the mixed bed. The solubility of the sparingly soluble solid may then be enhanced in this manner, which illustrates the flexibility of the RIP slurry mixture system as a recovery process for valuable species from sparingly soluble solids.

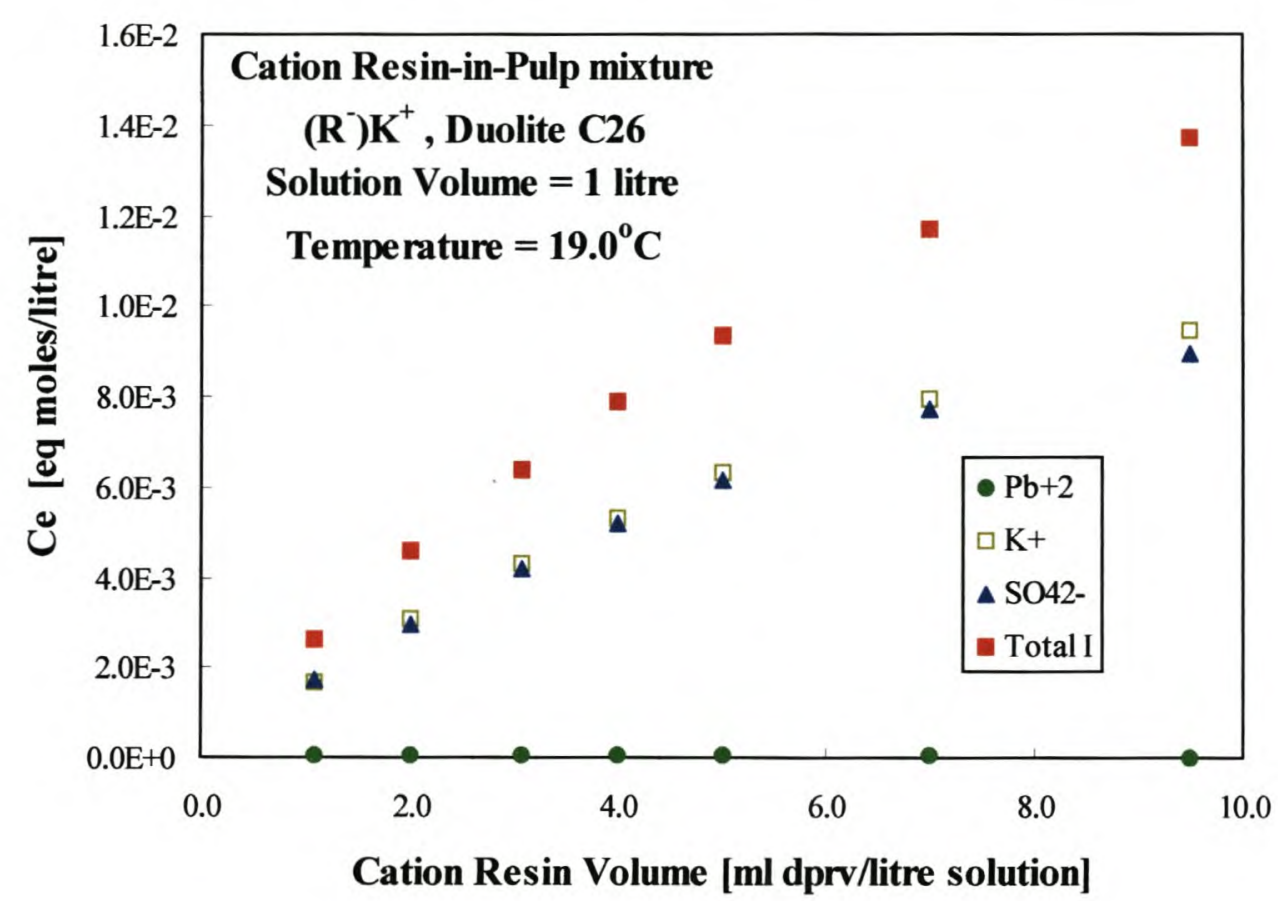

Figure 9.12 Total molar solution ionic strength I and equilibrium solution phase concentrations of $\mathrm{Pb}^{+2}, \mathrm{SO}_{4}{ }^{2-}$ and $\mathrm{K}^{+}$in an aqueous $\mathrm{PbSO}_{4}$ RIP slurry mixture containing Duolite C26 initially in the potassium ionic form ( $\left.\mathrm{R}^{-}\right)$ $\mathrm{K}^{+}$, as a function of the volume of resin added per litre of solution at $19.0^{\circ} \mathrm{C}$. 
In the modelling of the activities of the various species in the aqueous phase for the RIP slurry mixtures described above, the formation of various precipitates as well as the Pitzer ion interaction parameters for all possible species combinations need to be considered.

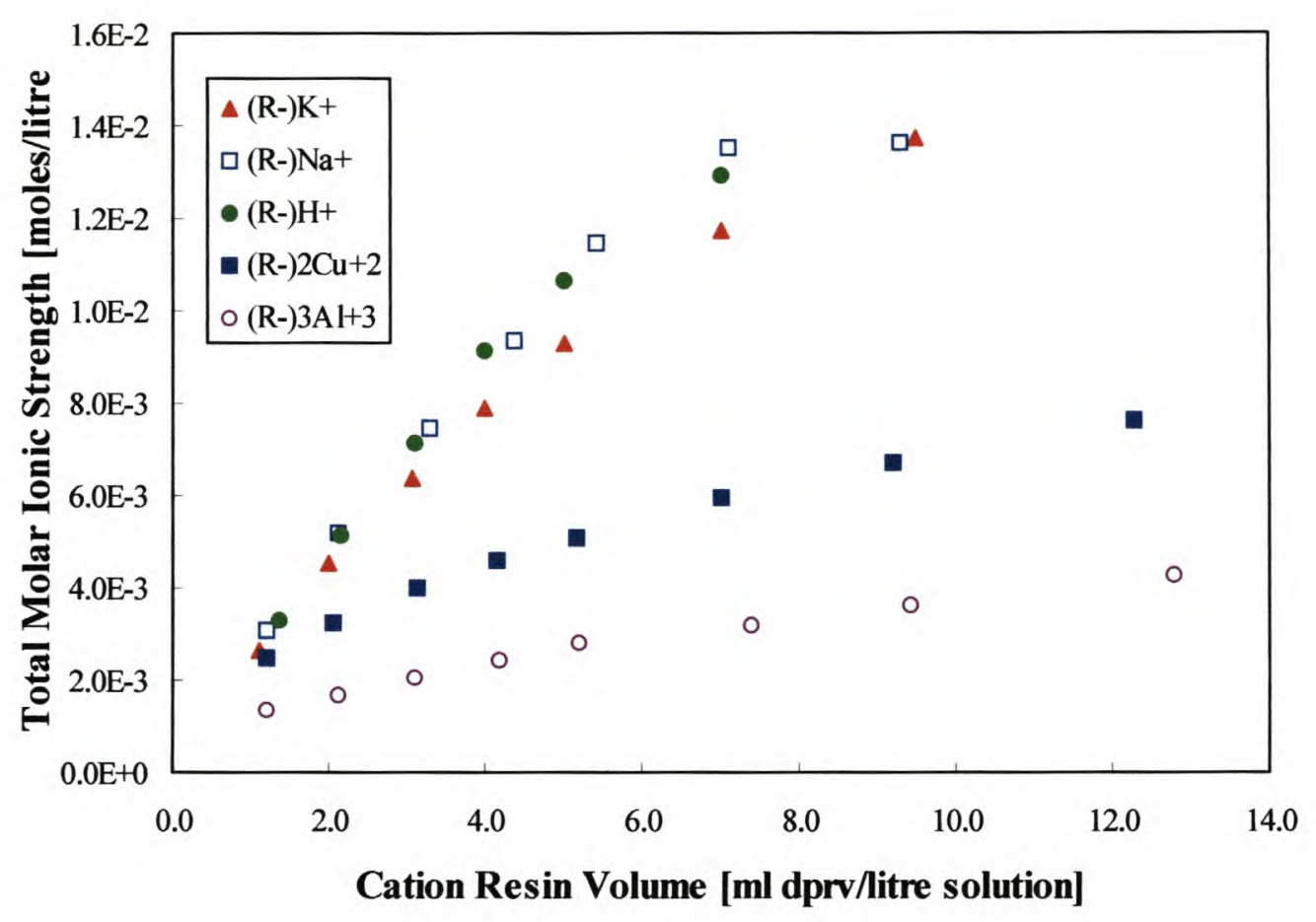

Figure 9.13 Total molar solution ionic strength $\mathrm{I}$ in an aqueous $\mathrm{PbSO}_{4} \mathrm{RIP}$ slurry mixture containing Duolite C26, for different initial ionic forms as a function of the volume of resin added per litre of solution at $19.0^{\circ} \mathrm{C}$.

The availability of the Pitzer model parameters in the literature will then dictate the extent to which the model may be solved for the non-idealities in the aqueous solution phase for the specific compositions. The availability of high quality thermodynamic data also becomes important for the consolidated equilibrium model. This includes thermodynamic data on the solubility products for the various species for the specified system temperature (all models have been solved at room temperature at $25^{\circ} \mathrm{C}$ ), values 
for the Pitzer model parameters and values for the Gibbs free energy of formation for all the species involved.

When collecting data for the Pitzer ion interaction parameters for the various ionic interactions of interest, it is of significant importance to verify the units of these parameters. By default the parameters are usually specified for use with species molal concentration units and not on a molar concentration unit basis.

Appendix $\mathrm{F}$ in this dissertation defines the difference between these two concentration units. In Chapter 3 most of the activity coefficient models discussed are for a molal concentration unit approach. At very low solution phase concentrations there is very little difference between the different approaches, but it can lead to significant errors in calculations when used at higher solution phase concentrations.

Due to the significant difference and discrepancies among literature sources as far as thermodynamic data is concerned an SQL7 data base was designed and populated with vast amounts of data from various literature sources. The data in the data base are used to benchmark the thermodynamic data from the various literature sources against one another before using it in the models. The data base has several front end applications developed in Visual Basic 6 and Borland $\mathrm{C}++$ that allow the insertion and extraction of the data from the data base. The contents of the data base have been discussed in Chapter 6 of this dissertation with tables of data shown as obtained by executing specific select queries on the data in the data base.

\subsection{CALCULATION OF THE RESIN THERMODYNAMIC EQUILIBRIUM CONSTANT FOR THE VARIOUS RESIN / SOLUTION SYSTEMS}

From paragraphs 6.4 and 6.5 of Chapter 6 it followed that the thermodynamic equilibrium constant $K_{A}^{B}$ and the Wilson interaction parameters $\Lambda_{A B}$ and $\Lambda_{B A}$ for the ion-exchange reaction are obtained from an optimisation routine. This is done by fitting the model 
equations, presented by Equations (6.43) to (6.45), to the experimental data for the resin / solution system under equilibrium. The experimental results for the various resin / solution equilibrium conditions have been presented in Chapter 8 of this dissertation.

In order to fit model Equations (6.43) to (6.45) to the experimental data, the value of the equilibrium quotient $\lambda_{A}^{B}$, represented by Equation (6.45), must first be calculated. This requires the calculation of the equilibrium resin fractional loading of the species and their solution phase activity coefficients. The solution phase activity coefficients are obtained from the Pitzer model. In order to ensure the consistency of all of the thermodynamic properties used for the various species in the calculations a thermodynamic data base in SQL7 has been constructed and populated with relevant data from various literature sources as discussed in paragraph 6.8 of Chapter 6 . Values for the Pitzer model parameters for the various resin / solution equilibrium conditions of interest were obtained from the data base and presented below in the calculation of the various $K_{A}^{B}$ values.

In the calculation of the various $K_{A}^{B}$ values for the different resin / solution systems the user needs to define the various species present in the aqueous phase. It was assumed in all of the calculations that the following species were always present in the aqueous phase,

i) $\mathrm{H}^{+}$ions present from the dissociation of water,

ii) $\mathrm{OH}^{-}$ions present from the dissociation of water,

iii) Aqueous $\mathrm{H}_{2} \mathrm{O}$ molecules,

iv) Aqueous dissolved $\mathrm{CO}_{2}$ molecules in equilibrium with the gas phase, which is air for the purposes of this dissertation,

v) $\mathrm{CO}_{3}{ }^{2-}$ ions present as a result of the dissolved aqueous $\mathrm{CO}_{2}$ molecules,

vi) $\mathrm{HCO}_{3}{ }^{-}$ions present as a result of the $\mathrm{CO}_{3}{ }^{2-}$ ions. 
The interaction between the above dissolved aqueous species and the counter ions participating in the ion-exchange reaction was considered. In some cases there are no Pitzer parameters available for these interactions from the literature. Due to the very dilute nature of all of these species in the aqueous solution the interactions were ignored if no model parameters for the Pitzer model were available from the literature. The composition of the gaseous phase was taken to be that of air at ambient conditions. All of the equilibrium experiments were performed at ambient conditions and exposed to a limited amount of air. Ambient conditions are considered to be a system temperature of $25^{\circ} \mathrm{C}$ and a system pressure of $101.325 \mathrm{kPa}$ for the purposes of this dissertation. The composition of the air was taken as follows:

i) Nitrogen $\left(\mathrm{N}_{2}\right)$ molecules at $78.09 \%$ by volume,

ii) Oxygen $\left(\mathrm{O}_{2}\right)$ molecules at $20.95 \%$ by volume,

iii) Carbon Dioxide $\left(\mathrm{CO}_{2}\right)$ at $0.03 \%$ by volume and

iv) Saturated with water vapour $\left(\mathrm{H}_{2} \mathrm{O}\right.$ molecules $)$.

The equilibrium distribution of these species between the vapour phase and the aqueous phase were calculated using a Gibbs free energy optimisation routine supplied by the CHEMAPP software of GGT-Technologies. From the equilibrium distribution of the gaseous phase species in the aqueous phase the concentrations of these species in the aqueous phase may be obtained and the Pitzer interaction parameters with the counter-ion species calculated. The effect of the gaseous phase species on the aqueous phase species is small due to the limited volume of air that were in contact with the aqueous phase solutions during the equilibrium experiments as described in Chapter 7 of this dissertation. All of the experiments were carried out in sealed plastic bottles with approximately $0.1 \mathrm{dm}^{3}$ air in contact with $1 \mathrm{dm}^{3}$ of the aqueous phase solution. Given the relatively low density of air at the ambient conditions the number of moles of the gaseous phase species was very low relative to the number of moles of the aqueous phase species. Nevertheless, the effect of the gaseous phase species was included in the calculations. 


\subsubsection{Calculation of the thermodynamic equilibrium constant $K_{A}^{B}$ for the bivalent- monovalent exchange reaction between $\mathrm{Ca}^{+2}$ and monovalent cations $\mathrm{H}^{+}, \mathrm{Na}^{+}$ and $\mathbf{K}^{+}$}

From paragraphs 6.5 and 6.6 of Chapter 6 it is evident that the first step in the calculation of the thermodynamic equilibrium constant for the ion-exchange reaction involves the calculation of the thermodynamic equilibrium quotient, represented by Equation (6.45). The solution phase activity coefficients for all of the participating species in the ionexchange reaction need to be calculated as well as the resin phase fractional loading of the species.

Tables 9.2, 9.4 and 9.5 represent the values of the Pitzer interaction parameters required to calculate the solution phase activity coefficients for the exchange reactions between $\mathrm{Ca}^{+2}$ and the monovalent cations $\mathrm{H}^{+}, \mathrm{Na}^{+}$and $\mathrm{K}^{+}$respectively. The values displayed in the Tables 9.2, 9.4 and 9.5 have been multiplied with gas constant $R$ with value of $8.31441 \mathrm{~kJ} / \mathrm{kmol} . \mathrm{K}$. It is common to encounter the values for the Pitzer interaction parameters in the literature multiplied by different factors. The user should take care to ensure that the correct "conversion" is done on the Pitzer parameter values before using it in any calculations. The values displayed in Tables 9.2, 9.4 and 9.5 have been multiplied with the gas constant $R$ for the purposes of this dissertation for use in the consolidated equilibrium model equations.

It is evident by comparing Table 9.2 with Tables 9.4 and 9.5 that the number of Pitzer parameters required to model a system with one additional cation increases significantly. The only difference between Table 9.2 and Tables 9.4 and 9.5 is the additional cation $\mathrm{Na}^{+}$ or $\mathrm{K}^{+}$respectively. Table 9.2 represents a system with only 2 cations, $\mathrm{Ca}^{+2}$ and $\mathrm{H}^{+}$, while Tables 9.4 ad 9.5 have the $\mathrm{Na}^{+}$and $\mathrm{K}^{+}$cation extra respectively. 
For large multi component aqueous systems with various cations and anions a significant number of interactions may be required to model the system's behaviour accurately. All of the required parameters may not be available from the literature and the user then needs to re-engineer the set of model equations to make do with the available parameters. The introduction of a large number of "independent" interaction parameters may also lead to increased inaccuracies in the calculations if the parameters used in the model equations were not obtained from experimental data sets representing the aqueous solution composition for which the calculations are performed. It is therefore clear that the utilisation of thermodynamic data obtained from different literature sources that are inconsistent with one another may easily be the single largest contributor to inaccurate model results. It is always preferable to use a set of Pitzer model parameters obtained from one literature source describing a specific aqueous phase system rather than "mixing" parameters from different literature sources describing the same aqueous system in order to obtain a "complete" set of interaction parameters.

To ensure maximum consistency for the Pitzer parameters used in the model equations the mentioned SQL7 data base was designed and populated with data from various literature sources. A comparison was performed between the parameter values of the various literature sources before using it in the model equations of the consolidated equilibrium model for the RIP slurry mixture system.

The results of the calculations performed to obtain the aqueous phase activity coefficients for the various aqueous phase systems are shown in Tables 9.3 to 9.10 for the ionexchange reactions between $\mathrm{Ca}^{+2}$ and the monovalent cations $\mathrm{H}^{+}$and $\mathrm{Na}^{+}$.

9.3.1.1 Calculation of the thermodynamic equilibrium constant $K_{H}^{\mathrm{Ca}}$ for the exchange reaction between $\mathrm{Ca}^{+2}$ and $\mathrm{H}^{+}$with $\mathrm{Cl}^{-}$as the co-ion

Table 9.2 represents the Pitzer interaction parameters used in the calculation of the aqueous phase activity coefficients for the species of the resin / solution system in the 
ion-exchange reaction between $\mathrm{Ca}^{+2}$ and $\mathrm{H}^{+}$with $\mathrm{Cl}^{-}$as the anion. In the calculations the formation of $\mathrm{OH}^{-}, \mathrm{CO}_{3}{ }^{2-}, \mathrm{HCO}_{3}{ }^{-}$and aqueous $\mathrm{CO}_{2}$ was considered. Table 9.2 gives only some of the Pitzer interaction parameters for the various interactions that were available from the literature.

Table 9.2 Values for the Pitzer model parameters $\beta^{(0)}, \beta^{(1)}, C^{\phi}, \phi$ and $\psi$ used in the calculation of the thermodynamic equilibrium constant $K_{H}^{\mathrm{Ca}}$ for the exchange reaction between $\mathrm{Ca}^{+2}$ and $\mathrm{H}^{+}$with $\mathrm{Cl}^{-}$as the co-ion. Parameters obtained from SQL7 data base. All Pitzer values shown are multiplied with the gas constant $R=8.31441 \mathrm{~kJ} / \mathrm{kmol} . \mathrm{K}$.

\begin{tabular}{|c|c|c|c|c|}
\hline Species A & Species B & Species C & $\begin{array}{c}\mathbf{R} * \text { Pitzer Parameter } \\
\mathbf{R}=\mathbf{8 . 3 1 4 4 1} \mathbf{~ k J} / \mathbf{k m o l} . \mathbf{K}\end{array}$ & Value \\
\hline $\mathrm{Ca}<2+>$ & $\mathrm{H}<+>$ & & $\mathrm{R} * \phi$ & $7.649 \mathrm{E}-01$ \\
$\mathrm{Ca}<2+>$ & $\mathrm{H}<+>$ & $\mathrm{Cl}<->$ & $\mathrm{R} * \psi$ & $-1.247 \mathrm{E}-01$ \\
$\mathrm{Ca}<2+>$ & $\mathrm{Cl}<->$ & & $\mathrm{R} * \beta^{(0)}$ & $2.627 \mathrm{E}+00$ \\
$\mathrm{Ca}<2+>$ & $\mathrm{Cl}<->$ & & $\mathrm{R} * \beta^{(1)}$ & $1.342 \mathrm{E}+01$ \\
$\mathrm{Ca}<2+>$ & $\mathrm{Cl}<->$ & & $\mathrm{R} * C^{\phi}$ & $-2.822 \mathrm{E}-03$ \\
$\mathrm{Ca}<2+>$ & $\mathrm{Cl}<->$ & $\mathrm{OH}<->$ & $\mathrm{R} * \psi$ & $-2.079 \mathrm{E}-01$ \\
$\mathrm{Ca}<2+>$ & $\mathrm{HCO} 3<->$ & & $\mathrm{R} * \beta^{(0)}$ & $3.324 \mathrm{E}+00$ \\
$\mathrm{Ca}<2+>$ & $\mathrm{HCO} 3<->$ & & $\mathrm{R} * \beta^{(1)}$ & $2.476 \mathrm{E}+01$ \\
$\mathrm{Cl}<->$ & $\mathrm{OH}<->$ & & $\mathrm{R} * \phi$ & $-4.157 \mathrm{E}-01$ \\
$\mathrm{Cl}<->$ & $\mathrm{CO} 3<2->$ & & $\mathrm{R} * \phi$ & $-1.663 \mathrm{E}-01$ \\
$\mathrm{Cl}<->$ & $\mathrm{HCO} 3<->$ & & $\mathrm{R} * \phi$ & $2.494 \mathrm{E}-01$ \\
$\mathrm{CO} 3<2->$ & $\mathrm{HCO} 3<->$ & & $\mathrm{R} * \phi$ & $-3.326 \mathrm{E}-01$ \\
$\mathrm{H}<+>$ & $\mathrm{Cl}<->$ & & $\mathrm{R} * \beta^{(0)}$ & $1.476 \mathrm{E}+00$ \\
$\mathrm{H}<+>$ & $\mathrm{Cl}<->$ & & $\mathrm{R} * \beta^{(1)}$ & $2.449 \mathrm{E}+00$ \\
$\mathrm{H}<+>$ & $\mathrm{Cl}<->$ & & $\mathrm{R} * C^{\phi}$ & $6.652 \mathrm{E}-03$ \\
$\mathrm{OH}<->$ & $\mathrm{CO} 3<2->$ & & $\mathrm{R} * \phi$ & $8.314 \mathrm{E}-01$ \\
\hline
\end{tabular}

The solution phase concentrations of the $\mathrm{CO}_{3}{ }^{2-}$ and $\mathrm{HCO}_{3}{ }^{-}$species are relatively low and were only considered to ensure that any precipitation of the $\mathrm{Ca}^{+2}$ ions as $\mathrm{CaCO}_{3}$ was taken into account. For all of the resin / solution equilibrium conditions investigated no 
precipitation of the $\mathrm{Ca}^{+2}$ ions as $\mathrm{CaCO}_{3}$ was identified. The notation of the species valences in Tables 9.2 to 9.5 is used in the SQL7 data base and given for reference purposes.

Table 9.3 shows the calculated values for the species solution phase activity coefficients as obtained with the values of the Pitzer parameters listed in Table 9.2.

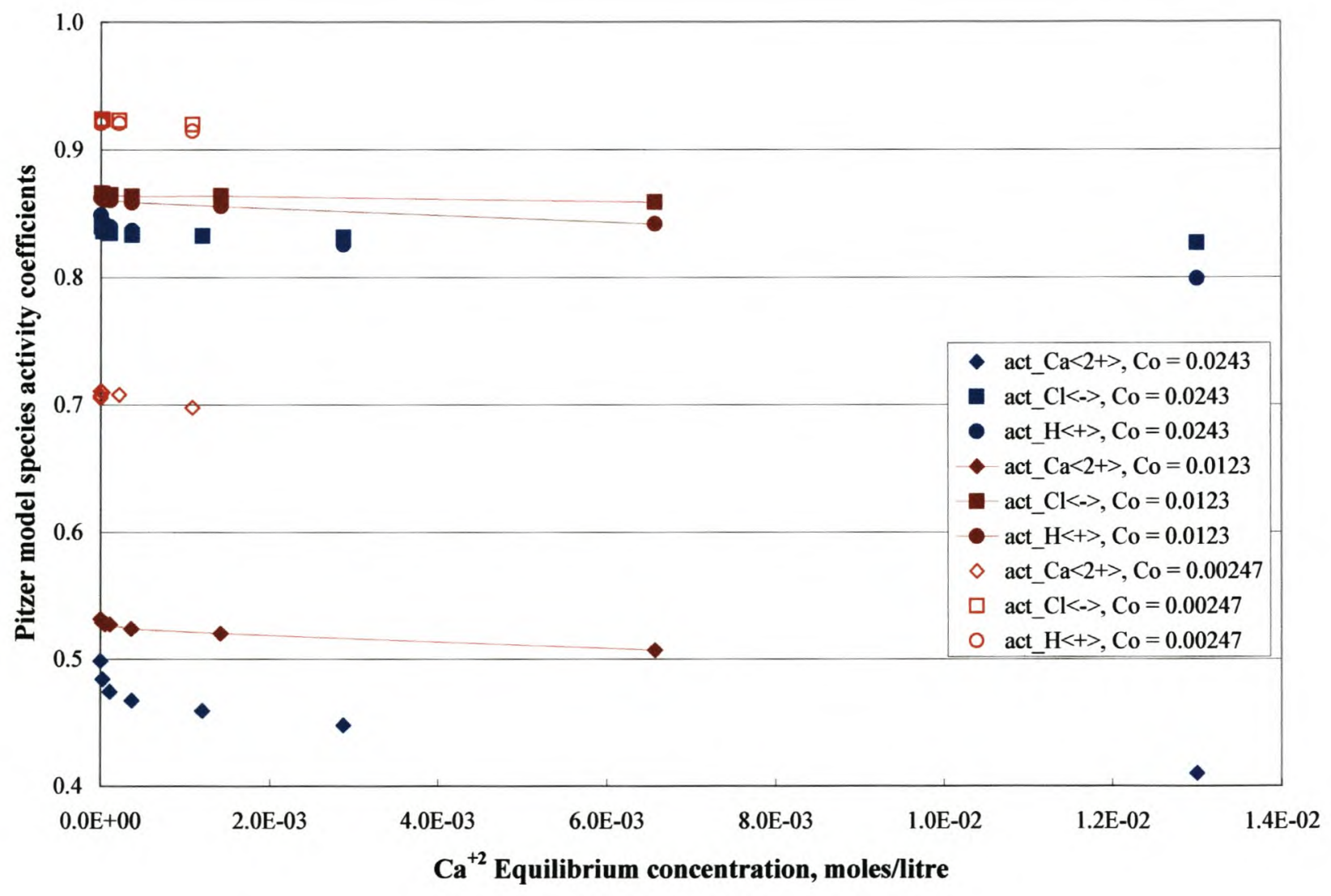

Figure 9.14 The Pitzer model activity coefficients for the aqueous phase species in the resin / solution system for the cation-exchange reaction between the cations $\mathrm{Ca}^{+2}$ and $\mathrm{H}^{+}$with $\mathrm{Cl}^{-}$anions for different total solution phase concentrations of the $\mathrm{Ca}^{+2}$ ions. 
The solution phase activities for the four species $\mathrm{Ca}^{+2}, \mathrm{Cl}^{-}, \mathrm{H}^{+}$and $\mathrm{OH}^{-}$are given in Table 9.3 for different initial solution phase concentrations of the $\mathrm{Ca}^{+2}$ species used in the resin / solution equilibrium experiments. It is evident from Table 9.3 that the $\mathrm{Ca}^{+2}$ species behaves highly non-ideal even at relatively low solution phase concentrations.

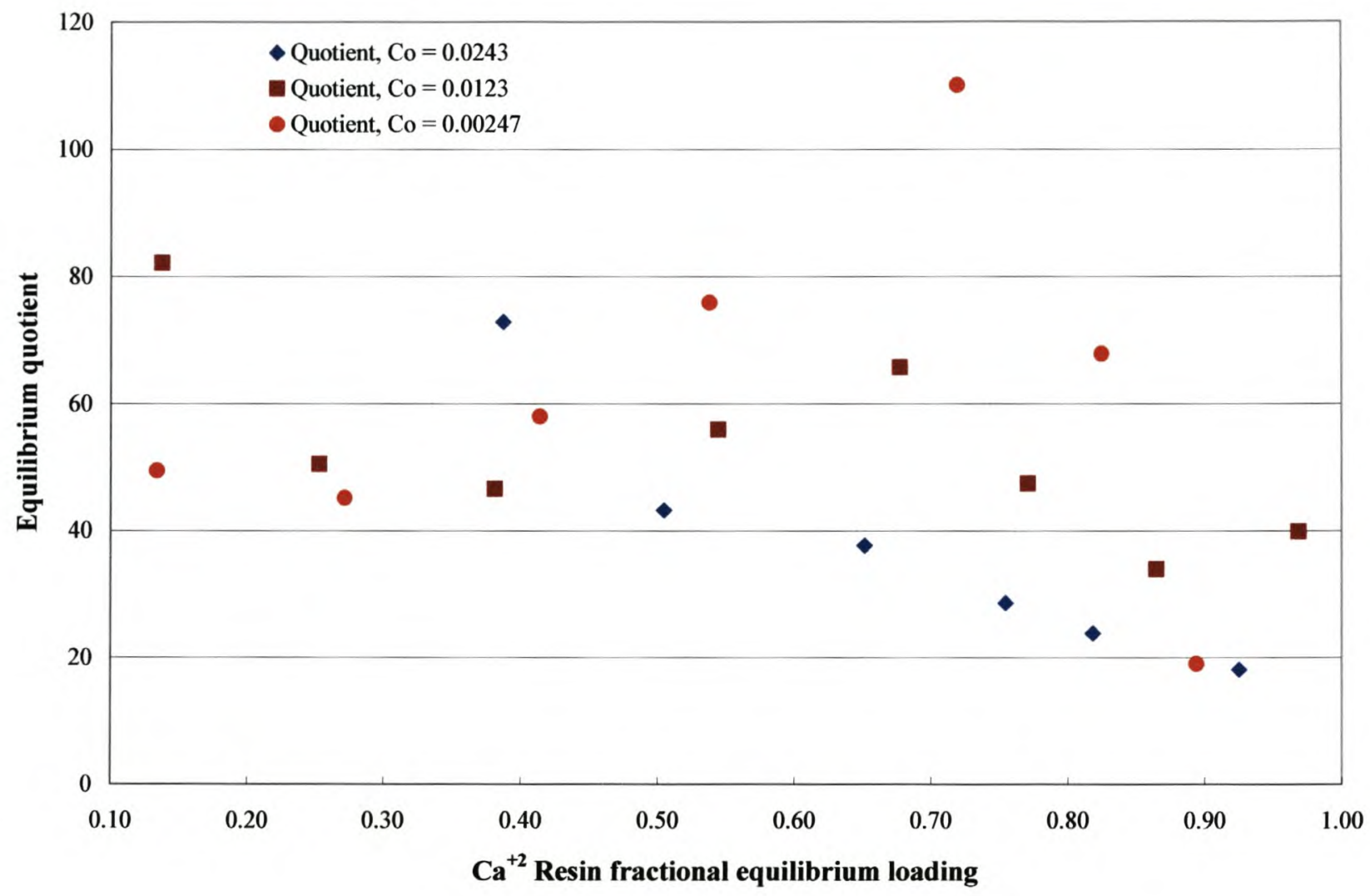

Figure 9.15 The equilibrium quotient calculated with the Pitzer model activity coefficients the resin / solution cation-exchange reaction between the cations $\mathrm{Ca}^{+2}$ and $\mathrm{H}^{+}$with anions $\mathrm{Cl}^{-}$.

It is further evident from Table 9.3 that the behaviour of the $\mathrm{Ca}^{+2}$ ions becomes more ideal as the initial solution phase concentration decreases from 0.0243 moles/litre to 0.00247 moles/litre. The value of the activity coefficient for the $\mathrm{Ca}^{+2}$ species increases from a value of approximately 0.5 to 0.7 respectively for the decrease in the initial 
solution phase concentration from 0.0243 to $0.00247 \mathrm{moles} / \mathrm{litre}$. The last two columns in Table 9.3 show the resin fractional loading for the $\mathrm{Ca}^{+2}$ species and the equilibrium quotient as calculated with Equation (6.45) of Chapter 6. Table 9.3 gives all of the required inputs for Equation (6.45).

Figure (9.14) is a graphical representation of Table 9.3 and shows the solution phase activity coefficients for $\mathrm{Ca}^{+2}, \mathrm{H}^{+}$and $\mathrm{Cl}^{-}$for the different $\mathrm{Ca}^{+2}$ equilibrium concentrations for the different resin / solution systems tested. It is evident from Figure (9.14) that the $\mathrm{Ca}^{+2}$ ions behave non-ideally, as is clear from the values for its activity coefficients. For all of the solution phase concentrations of interest the values stay below 0.75 . The importance of incorporating a suitable solution phase activity coefficient model into the consolidated equilibrium model is clear from Figure (9.14), which shows that even for the relatively low solution phase concentration region of interest to this dissertation significant non-ideal behaviour may be expected from all of the species.

It is further evident from Figure (9.14) that the activity coefficients for the $\mathrm{Cl}^{-}$and $\mathrm{Na}^{+}$ ions are significantly larger than that of the $\mathrm{Ca}^{+2}$ ions. This behaviour may be expected due to the fact that species with higher charge densities, which is typically the species with the larger electrochemical valences, tends to behave more non-ideally. This phenomenon was discussed in Chapter 3 of this dissertation.

Figure (9.15) shows the equilibrium quotient as calculated with Equation (6.45) in Chapter 6 of this dissertation. From Chapter 8 it was evident that various shapes may be encountered for the equilibrium quotient, as was evident from Figures (8.15) to (8.18) for the anion exchange reaction between $\mathrm{F}^{-}$and $\mathrm{Cl}^{-}$ions on the anion exchange resin Duolite A161. The shape of the curves as displayed in Figure (9.15) is strongly dependent on the values of the solution phase activity coefficients, as is evident from Equation (6.45) of Chapter 6. The values of the Pitzer interaction parameters used in the modelling equations are therefore of significant importance and justify any actions taken that ensures consistency of the parameter values used. For the purposes of this dissertation a 
SQL7 data base was developed that compares the values of the Pitzer interaction parameters obtained from the different literature sources with one another to check for significant deviations between the sources.

Table 9.3 Calculated solution phase activity coefficients, resin fractional loading of $\mathrm{Ca}^{+2}$ and equilibrium quotient for the cation-exchange reaction between $\mathrm{Ca}^{+2}$ and $\mathrm{H}^{+2}$ on Duolite $\mathrm{C} 26$.

\begin{tabular}{|c|c|c|c|c|c|c|c|c|c|c|}
\hline \multirow{2}{*}{$\begin{array}{c}\text { Resin } \\
\text { vol } \\
{[\mathrm{ml}]}\end{array}$} & \multirow{2}{*}{$\begin{array}{c}\text { Soln } \\
\text { vol } \\
{[\mathrm{ml}]}\end{array}$} & \multicolumn{3}{|c|}{ Equil concentration, $\mathrm{Ce}$} & \multicolumn{4}{|c|}{ Species activity coefficients } & \multirow{2}{*}{$\begin{array}{c}\text { Resin } \\
\text { loading } \\
\mathrm{Ca}<2+>\end{array}$} & \multirow{2}{*}{$\begin{array}{c}\text { Equil } \\
\text { quotient }\end{array}$} \\
\hline & & $\begin{array}{c}\mathrm{Ca}<2+> \\
{[\mathrm{mol} / \mathrm{l}]}\end{array}$ & $\begin{array}{l}\mathrm{Cl}<-> \\
{[\mathrm{mol} / \mathrm{l}]}\end{array}$ & $\begin{array}{l}\mathbf{H}<+> \\
{[\mathrm{mol} / \mathrm{l}]}\end{array}$ & $\mathrm{Ca}<2+>$ & $\mathbf{C l}<->$ & $\mathbf{H}<+>$ & OH<-> & & \\
\hline \multicolumn{11}{|c|}{$\mathrm{Ca}<2+>$} \\
\hline 25.1 & 50 & $2.50 \mathrm{E}-06$ & 53E-02 & $3.16 \mathrm{E}-02$ & & 39 & & & & \\
\hline 17.4 & 50 & 05 & & 3.63 & & & & & & \\
\hline 13.3 & 50 & $.12 \mathrm{E}-04$ & & & & & & & & \\
\hline 10.2 & 250 & 3.71E-04 & $6 \mathrm{E}-02$ & $4.17 \mathrm{E}-02$ & & 33 & & 01 & & \\
\hline 8.5 & 50 & $1.20 \mathrm{E}-03$ & -02 & 4.27 & & 32 & & 98 & & 89 \\
\hline 7.3 & 250 & 2.88 & & & & & & & & \\
\hline 3.4 & 50 & $1.30 \mathrm{E}-02$ & & & & & & & & \\
\hline \multicolumn{4}{|c|}{$\mathrm{Ca}<2+>$} & & \multicolumn{6}{|l|}{$[\mathrm{mol} / \mathrm{l}]$} \\
\hline 49.8 & 00 & $2.50 \mathrm{E}-06$ & 2 & $2.82 \mathrm{E}-02$ & 0530 & & & & & 31 \\
\hline 27.0 & 500 & 9.98E-06 & $8-02$ & $2.82 \mathrm{E}-02$ & & 866 & 62 & 44 & & 28 \\
\hline 17.9 & 500 & $2.50 \mathrm{E}-05$ & & 2.88 & & 66 & & & & 000 \\
\hline 12.5 & 500 & 5 & & 22 & & & & & & \\
\hline 10.0 & 500 & $1.16 \mathrm{E}-04$ & -02 & $2.88 \mathrm{E}-02$ & & 865 & & 42 & & 507 \\
\hline 8.6 & 500 & 3.63 . & & 02 & & 64 & & & & 640 \\
\hline 7.0 & 00 & 1.4 & & & & & & & & \\
\hline 3.3 & 00 & 6.58 & & 1.38 & & & & & & \\
\hline \multicolumn{4}{|c|}{$\mathrm{Ca}<2+>$} & $2.47 \mathrm{E}-03$ & \multicolumn{6}{|l|}{ [mol/l] } \\
\hline 20.5 & 00 & $2.50 \mathrm{E}-07$ & 4.8 & 7.59E-03 & & 923 & & 16 & & 239 \\
\hline 10.1 & 00 & 7.49E-07 & 4.8 & 7.41 & & 23 & 21 & 17 & 72 & 907 \\
\hline 6.6 & 1000 & $1.25 \mathrm{E}-06$ & $4.87 \mathrm{E}-03$ & $7.08 \mathrm{E}-03$ & & 0.924 & 22 & 18 & & 172 \\
\hline 5.1 & 1000 & $2.00 \mathrm{E}-06$ & $4.89 \mathrm{E}-03$ & $7.08 \mathrm{E}-03$ & & 0.924 & & & & 652 \\
\hline 3.8 & 1000 & $4.99 \mathrm{E}-06$ & $4.89 \mathrm{E}-03$ & $7.08 \mathrm{E}-03$ & & 0.924 & & & & 0580 \\
\hline 3.3 & 1000 & 2.37E-05 & $4.87 \mathrm{E}-03$ & $7.08 \mathrm{E}-03$ & & 0.924 & 0.922 & 0.918 & & 67.8176 \\
\hline 2.8 & 1000 & $2.20 \mathrm{E}-04$ & $4.88 \mathrm{E}-03$ & 6.61E-03 & & 0.923 & 0.921 & & & 679 \\
\hline 1.8 & 1000 & $1.08 \mathrm{E}-03$ & $4.92 \mathrm{E}-03$ & $4.68 \mathrm{E}-03$ & 0.698 & 0.920 & 0.915 & 0.912 & 0.859 & 1.0419 \\
\hline
\end{tabular}


The values of the Pitzer interaction parameters displayed in Table 9.2 for the $\mathrm{Ca}^{+2}-\mathrm{H}^{+}$ resin / solution system represent the "acceptable" parameters obtained from the literature with good agreement between the various literature sources.

9.3.1.2 Calculation of the thermodynamic equilibrium constant $K_{N a}^{\mathrm{Ca}}$ for the exchange reaction between $\mathrm{Ca}^{+2}$ and $\mathrm{Na}^{+}$with $\mathrm{Cl}$ as the co-ion

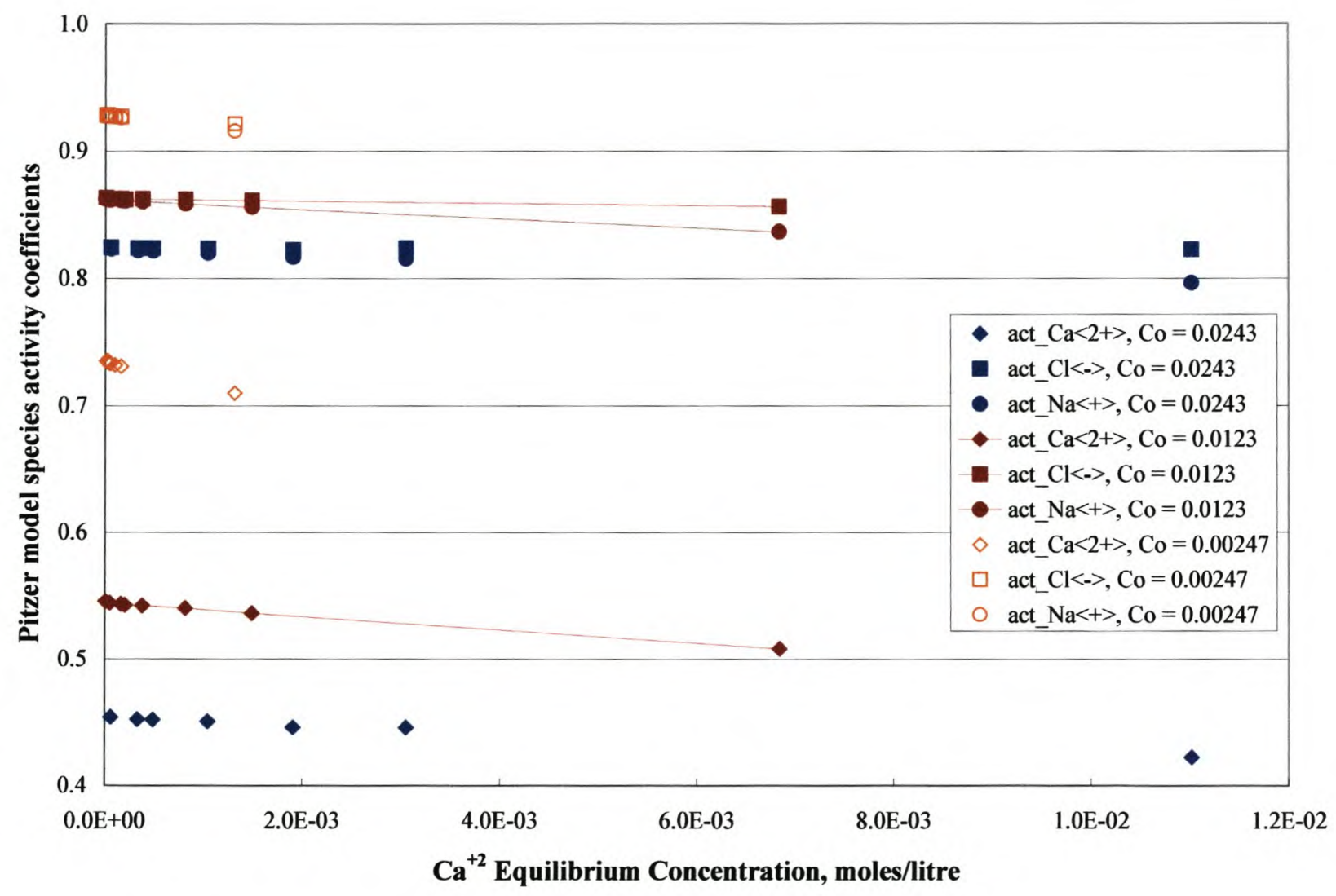

Figure 9.16 The Pitzer model activity coefficients for the aqueous phase species in the resin / solution system for the cation-exchange reaction between the cations $\mathrm{Ca}^{+2}$ and $\mathrm{Na}^{+}$with $\mathrm{Cl}^{-}$anions for different total solution phase concentrations of the $\mathrm{Ca}^{+2}$ ions. 
Table 9.4 represents the values of the Pitzer interaction parameters used in the calculation of the resin / solution equilibrium condition for the exchange reaction between $\mathrm{Ca}^{+2}$ and $\mathrm{Na}^{+}$ions.

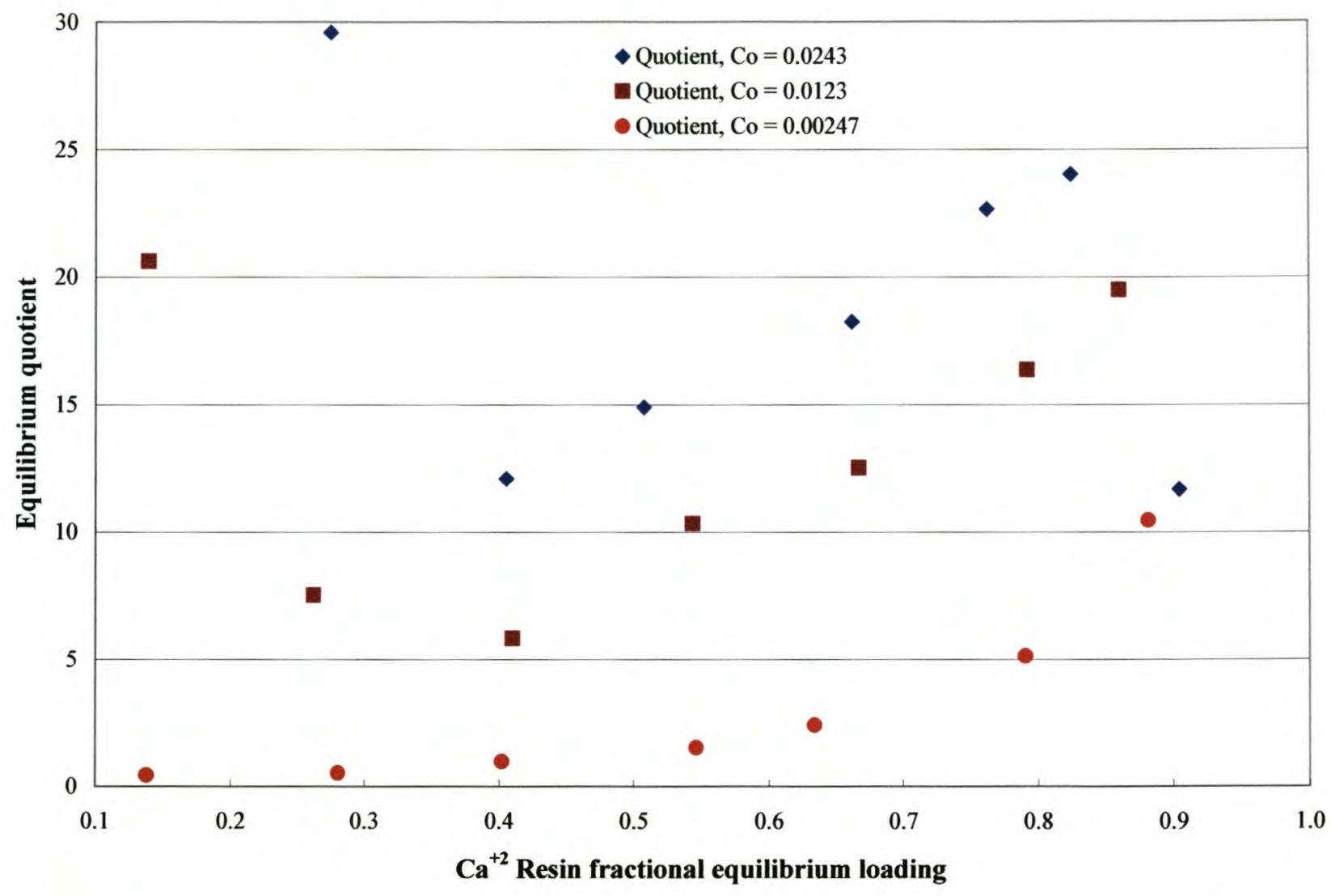

Figure 9.17 The equilibrium quotient calculated with the Pitzer model activity coefficients the resin / solution cation-exchange reaction between the cations $\mathrm{Ca}^{+2}$ and $\mathrm{Na}^{+}$with anions $\mathrm{Cl}^{-}$.

The number of interactions that needs to be considered in multiple aqueous phase solutions becomes significant if various species are present. For the purposes of the $\mathrm{Ca}^{+2}$ $-\mathrm{Na}^{+}$resin / solution system the three different cations $\mathrm{Ca}^{+2}, \mathrm{Na}^{+}$and $\mathrm{H}^{+}$were present in the solution phase with the anions $\mathrm{Cl}^{-}, \mathrm{OH}^{-}, \mathrm{CO}_{3}{ }^{2-}$ and $\mathrm{HCO}_{3}{ }^{-}$. The calculated values for the aqueous phase activity coefficients are shown by Figure (9.16). It is evident that 
similar behaviour exists for the species in the $\mathrm{Ca}^{+2}-\mathrm{Na}^{+}$system as was the case for the $\mathrm{Ca}^{+2}-\mathrm{H}^{+}$system described in Figure (9.14).

It is clear from Figure (9.16) that the $\mathrm{Ca}^{+2}$ species behaves non-ideally with typical activity coefficient values of less than 0.75 . The value of 0.75 was calculated for the system with the lowest initial $\mathrm{Ca}^{+2}$ concentration of $0.00247 \mathrm{moles} / \mathrm{litre}$. As the initial solution phase concentration of the $\mathrm{Ca}^{+2}$ ions increases from 0.00247 to 0.0243 moles/litre the average activity coefficients decrease from 0.75 to 0.45 , which represents significant non-ideal behaviour of the $\mathrm{Ca}^{+2}$ ions.

Figure (9.17) gives the calculated equilibrium quotients for the ion-exchange reaction between $\mathrm{Ca}^{+2}$ and $\mathrm{Na}^{+}$for different initial concentrations of the $\mathrm{Ca}^{+2}$ ions. It is evident from Figure (9.17) that the data point at the end of each series deviates from the average trend line. This may be caused by experimental error due to the fact that the resin phase equilibrium loading approaches an extreme (Mehablia et al., 1994). To counteract this phenomenon the objective function used in the calculation of the thermodynamic equilibrium constant from the equilibrium quotient is modified according to Equation (5.35) in Chapter 5 of this dissertation. The values of the trend line end points displayed in Figure (9.17) will be weighted to a lesser extent in the calculation of the thermodynamic equilibrium constant with the use of the optimisation routine described in Appendix E of this dissertation.

It is evident when comparing the trend lines of Figures (9.15) and (9.17) with one another that different shapes for the equilibrium quotient exist between the $\mathrm{Ca}^{+2}-\mathrm{H}^{+}$and $\mathrm{Ca}^{+2}-$ $\mathrm{Na}^{+}$resin / solution system. These differences become more significant between various systems when the valence of the counter ion species is different as is the case for the $\mathrm{Ca}^{+2}-\mathrm{Cu}^{+2}$ and $\mathrm{Ca}^{+2}-\mathrm{Al}^{+3}$ systems discussed in the following chapters. 
Table 9.4 Values for the Pitzer model parameters $\beta^{(0)}, \beta^{(1)}, C^{\phi}, \phi$ and $\psi$ used in the calculation of the thermodynamic equilibrium constant $K_{N a}^{\mathrm{Ca}}$ for the exchange reaction between $\mathrm{Ca}^{+2}$ and $\mathrm{Na}^{+}$with $\mathrm{Cl}^{-}$as the co-ion. Parameters obtained from SQL7 data base. All Pitzer values shown are multiplied with the gas constant $R=8.31441 \mathrm{~kJ} / \mathrm{kmol} . \mathrm{K}$.

\begin{tabular}{|c|c|c|c|c|c|c|c|c|c|}
\hline $\begin{array}{c}\text { Species A } \\
\mathrm{Ca}<2+>\end{array}$ & $\begin{array}{c}\text { Species B } \\
\mathrm{Na}<+>\end{array}$ & Species C & $\begin{array}{c}\text { Parameter } \\
\mathrm{R}^{*} \phi\end{array}$ & $\begin{array}{c}\text { Value } \\
5.820 \mathrm{E}-01\end{array}$ & $\begin{array}{c}\text { Species A } \\
\mathrm{CO} 3<2->\end{array}$ & $\begin{array}{l}\text { Species B } \\
\mathrm{HCO} 3<->\end{array}$ & Species C & $\begin{array}{c}\text { Parameter } \\
\mathrm{R}^{*} \phi\end{array}$ & $\begin{array}{c}\text { Value } \\
-3.326 \mathrm{E}-01\end{array}$ \\
\hline $\mathrm{Ca}<2+>$ & $\mathrm{Na}<+>$ & $\mathrm{Cl}<->$ & $\mathrm{R}^{*} \psi$ & $-5.820 \mathrm{E}-02$ & $\mathrm{Na}<+>$ & $\mathrm{Cl}<->$ & & $\mathrm{R}^{*} \beta^{(0)}$ & $6.361 \mathrm{E}-01$ \\
\hline $\mathrm{Ca}<2+>$ & $\mathrm{H}<+>$ & & $\mathrm{R} * \phi$ & 7.649E-01 & $\mathrm{Na}<+>$ & $\mathrm{Cl}<->$ & & $\mathrm{R} * \beta^{(1)}$ & $2.215 \mathrm{E}+00$ \\
\hline $\mathrm{Ca}<2+>$ & $\mathrm{H}<+>$ & $\mathrm{Cl}<->$ & $\mathrm{R}^{*} \psi$ & $-1.247 \mathrm{E}-01$ & $\mathrm{Na}<+>$ & $\mathrm{Cl}<->$ & & $\mathrm{R} * C^{\phi}$ & $1.056 \mathrm{E}-02$ \\
\hline $\mathrm{Ca}<2+>$ & $\mathrm{Cl}<->$ & & $\mathrm{R}^{*} \beta^{(0)}$ & $2.627 \mathrm{E}+00$ & $\mathrm{Na}<+>$ & $\mathrm{Cl}<->$ & $\mathrm{OH}<->$ & $\mathrm{R} * \psi$ & $-4.989 \mathrm{E}-02$ \\
\hline $\mathrm{Ca}<2+>$ & $\mathrm{Cl}<->$ & & $\mathrm{R}^{*} \beta^{(1)}$ & $1.342 \mathrm{E}+01$ & $\mathrm{Na}<+>$ & $\mathrm{Cl}<->$ & $\mathrm{CO} 3<2->$ & $\mathrm{R} * \psi$ & $7.067 \mathrm{E}-02$ \\
\hline $\mathrm{Ca}<2+>$ & $\mathrm{Cl}<->$ & & $\mathrm{R} * C^{\phi}$ & $-2.822 \mathrm{E}-03$ & $\mathrm{Na}<+>$ & $\mathrm{Cl}<->$ & $\mathrm{HCO} 3<->$ & $\mathrm{R}^{*} \psi$ & $-1.247 \mathrm{E}-01$ \\
\hline $\mathrm{Ca}<2+>$ & $\mathrm{Cl}<->$ & $\mathrm{OH}<->$ & $\mathrm{R} * \psi$ & $-2.079 \mathrm{E}-01$ & $\mathrm{Na}<+>$ & $\mathrm{OH}<->$ & & $\mathrm{R} * \beta^{(0)}$ & $7.184 \mathrm{E}-01$ \\
\hline $\mathrm{Ca}<2+>$ & $\mathrm{HCO} 3<->$ & & $\mathrm{R} * \beta^{(0)}$ & $3.324 \mathrm{E}+00$ & $\mathrm{Na}<+>$ & $\mathrm{OH}<->$ & & $\mathrm{R} * \beta^{(1)}$ & $2.104 \mathrm{E}+00$ \\
\hline $\mathrm{Ca}<2+>$ & $\mathrm{HCO} 3<->$ & & $\mathrm{R} * \beta^{(1)}$ & $2.476 \mathrm{E}+01$ & $\mathrm{Na}<+>$ & $\mathrm{OH}<->$ & & $\mathrm{R} * C^{\phi}$ & $3.658 \mathrm{E}-02$ \\
\hline $\mathrm{Cl}<->$ & $\mathrm{OH}<->$ & & $\mathrm{R} * \phi$ & $-4.157 \mathrm{E}-01$ & $\mathrm{Na}<+>$ & $\mathrm{OH}<->$ & $\mathrm{CO} 3<2->$ & $\mathrm{R} * \psi$ & $-1.413 \mathrm{E}-01$ \\
\hline $\mathrm{Cl}<->$ & $\mathrm{CO} 3<2->$ & & $\mathrm{R} * \phi$ & $-1.663 \mathrm{E}-01$ & $\mathrm{Na}<+>$ & $\mathrm{CO} 3<2->$ & & $\mathrm{R} * \beta^{(0)}$ & $3.012 \mathrm{E}-01$ \\
\hline $\mathrm{Cl}<->$ & $\mathrm{HCO} 3<->$ & & $\mathrm{R} * \phi$ & $2.494 \mathrm{E}-01$ & $\mathrm{Na}<+>$ & $\mathrm{CO} 3<2->$ & & $\mathrm{R} * \beta^{(1)}$ & $1.255 \mathrm{E}+01$ \\
\hline $\mathrm{H}<+>$ & $\mathrm{Cl}<->$ & & $\mathrm{R} * \beta^{(0)}$ & $1.476 \mathrm{E}+00$ & $\mathrm{Na}<+>$ & $\mathrm{CO} 3<2->$ & & $\mathrm{R} * C^{\phi}$ & $4.321 \mathrm{E}-02$ \\
\hline $\mathrm{H}<+>$ & $\mathrm{Cl}<->$ & & $\mathrm{R} * \beta^{(1)}$ & $2.449 \mathrm{E}+00$ & $\mathrm{Na}<+>$ & $\mathrm{CO} 3<2->$ & $\mathrm{HCO} 3<->$ & $\mathrm{R} * \psi$ & $1.663 \mathrm{E}-02$ \\
\hline $\mathrm{H}<+>$ & $\mathrm{Cl}<->$ & & $\mathrm{R} * C^{\phi}$ & $6.652 \mathrm{E}-03$ & $\mathrm{Na}<+>$ & $\mathrm{HCO} 3<->$ & & $\mathrm{R} * \beta^{(0)}$ & $2.328 \mathrm{E}-01$ \\
\hline $\mathrm{Na}<+>$ & $\mathrm{H}<+>$ & & $\mathrm{R}^{*} \phi$ & 2.993E-01 & $\mathrm{Na}<+>$ & $\mathrm{HCO} 3<->$ & & $\mathrm{R} * \beta^{(1)}$ & $3.658 \mathrm{E}-01$ \\
\hline $\mathrm{Na}<+>$ & $\mathrm{H}<+>$ & $\mathrm{Cl}<->$ & $\mathrm{R} * \psi$ & $-3.326 \mathrm{E}-02$ & $\mathrm{OH}<->$ & $\mathrm{CO} 3<2->$ & & $\mathrm{R} * \phi$ & $8.314 \mathrm{E}-01$ \\
\hline
\end{tabular}


Table 9.5 Values for the Pitzer model parameters $\beta^{(0)}, \beta^{(1)}, C^{\phi}, \phi$ and $\psi$ used in the calculation of the thermodynamic equilibrium constant $K_{K}^{\mathrm{Ca}}$ for the exchange reaction between $\mathrm{Ca}^{+2}$ and $\mathrm{K}^{+}$with $\mathrm{Cl}^{-}$as the co-ion. Parameters obtained from SQL7 data base. All Pitzer values shown are multiplied with the gas constant $R=8.31441 \mathrm{~kJ} / \mathrm{kmol} . \mathrm{K}$.

\begin{tabular}{|c|c|c|c|c|c|c|c|c|c|}
\hline Species A & Species B & Species C & Parameter & Value & Species A & Species B & Species C & Parameter & Value \\
\hline $\mathrm{Ca}<2+>$ & $\mathrm{K}<+>$ & & $\mathrm{R}^{*} \phi$ & $2.661 \mathrm{E}-01$ & $\mathrm{~K}<+>$ & $\mathrm{Cl}<->$ & & $\mathrm{R} * \beta^{(0)}$ & $4.020 \mathrm{E}-01$ \\
\hline $\mathrm{Ca}<2+>$ & $\mathrm{K}<+>$ & $\mathrm{Cl}<->$ & $\mathrm{R}^{*} \psi$ & $-2.079 \mathrm{E}-01$ & $\mathrm{~K}<+>$ & $\mathrm{Cl}<->$ & & $\mathrm{R} * \beta^{(1)}$ & $1.764 \mathrm{E}+00$ \\
\hline $\mathrm{Ca}<2+>$ & $\mathrm{H}<+>$ & & $\mathrm{R} * \phi$ & $7.649 \mathrm{E}-01$ & $\mathrm{~K}<+>$ & $\mathrm{Cl}<->$ & & $\mathrm{R} * C^{\phi}$ & $-6.984 \mathrm{E}-03$ \\
\hline $\mathrm{Ca}<2+>$ & $\mathrm{H}<+>$ & $\mathrm{Cl}<->$ & $\mathrm{R}^{*} \psi$ & $-1.247 \mathrm{E}-01$ & $\mathrm{~K}<+>$ & $\mathrm{Cl}<->$ & $\mathrm{OH}<->$ & $\mathrm{R} * \psi$ & $-6.652 \mathrm{E}-02$ \\
\hline $\mathrm{Ca}<2+>$ & $\mathrm{Cl}<->$ & & $\mathrm{R} * \beta^{(0)}$ & $2.627 \mathrm{E}+00$ & $\mathrm{~K}<+>$ & $\mathrm{Cl}<->$ & $\mathrm{CO} 3<2->$ & $\mathrm{R} * \psi$ & $3.326 \mathrm{E}-02$ \\
\hline $\mathrm{Ca}<2+>$ & $\mathrm{Cl}<->$ & & $\mathrm{R} * \beta^{(1)}$ & $1.342 \mathrm{E}+01$ & $\mathrm{~K}<+>$ & $\mathrm{OH}<->$ & & $\mathrm{R} * \beta^{(0)}$ & $1.079 \mathrm{E}+00$ \\
\hline $\mathrm{Ca}<2+>$ & $\mathrm{Cl}<->$ & & $\mathrm{R} * C^{\phi}$ & $-2.822 \mathrm{E}-03$ & $\mathrm{~K}<+>$ & $\mathrm{OH}<->$ & & $\mathrm{R} * \beta^{(1)}$ & $2.661 \mathrm{E}+00$ \\
\hline $\mathrm{Ca}<2+>$ & $\mathrm{Cl}<->$ & $\mathrm{OH}<->$ & $\mathrm{R}^{*} \psi$ & $-2.079 \mathrm{E}-01$ & $\mathrm{~K}<+>$ & $\mathrm{OH}<->$ & & $\mathrm{R} * C^{\phi}$ & 3.409E-02 \\
\hline $\mathrm{Ca}<2+>$ & $\mathrm{HCO} 3<->$ & & $\mathrm{R} * \beta^{(0)}$ & $3.324 \mathrm{E}+00$ & $\mathrm{~K}<+>$ & $\mathrm{OH}<->$ & $\mathrm{CO} 3<2->$ & $\mathrm{R} * \psi$ & $-8.314 \mathrm{E}-02$ \\
\hline $\mathrm{Ca}<2+>$ & $\mathrm{HCO} 3<->$ & & $\mathrm{R} * \beta^{(1)}$ & $2.476 \mathrm{E}+01$ & $\mathrm{~K}<+>$ & $\mathrm{CO} 3<2->$ & & $\mathrm{R} * \beta^{(0)}$ & $1.071 \mathrm{E}+00$ \\
\hline $\mathrm{Cl}<->$ & $\mathrm{OH}<->$ & & $\mathrm{R} * \phi$ & $-4.157 \mathrm{E}-01$ & $\mathrm{~K}<+>$ & $\mathrm{CO} 3<2->$ & & $\mathrm{R} * \beta^{(1)}$ & $1.192 \mathrm{E}+01$ \\
\hline $\mathrm{Cl}<->$ & $\mathrm{CO} 3<2->$ & & $\mathrm{R} * \phi$ & $-1.663 \mathrm{E}-01$ & $\mathrm{~K}<+>$ & $\mathrm{CO} 3<2->$ & & $\mathrm{R} * C^{\phi}$ & $4.145 \mathrm{E}-03$ \\
\hline $\mathrm{Cl}<->$ & $\mathrm{HCO} 3<->$ & & $\mathrm{R} * \phi$ & $2.494 \mathrm{E}-01$ & $\mathrm{~K}<+>$ & $\mathrm{CO} 3<2->$ & $\mathrm{HCO} 3<->$ & $\mathrm{R} * \psi$ & 9.977E-02 \\
\hline $\mathrm{H}<+>$ & $\mathrm{Cl}<->$ & & $\mathrm{R} * \beta^{(0)}$ & $1.476 \mathrm{E}+00$ & $\mathrm{~K}<+>$ & $\mathrm{HCO} 3<->$ & & $\mathrm{R} * \beta^{(0)}$ & $-8.896 \mathrm{E}-02$ \\
\hline $\mathrm{H}<+>$ & $\mathrm{Cl}<->$ & & $\mathrm{R} * \beta^{(1)}$ & $2.449 \mathrm{E}+00$ & $\mathrm{~K}<+>$ & $\mathrm{HCO} 3<->$ & & $\mathrm{R} * \beta^{(1)}$ & $3.974 \mathrm{E}-01$ \\
\hline $\mathrm{H}<+>$ & $\mathrm{Cl}<->$ & & $\mathrm{R} * C^{\phi}$ & 6.652E-03 & $\mathrm{OH}<->$ & $\mathrm{CO} 3<2->$ & & $\mathrm{R}^{*} \phi$ & $8.314 \mathrm{E}-01$ \\
\hline $\mathrm{K}<+>$ & $\mathrm{H}<+>$ & & $\mathrm{R}^{*} \phi$ & 4.157E-02 & $\mathrm{CO} 3<2->$ & $\mathrm{HCO} 3<->$ & & $\mathrm{R} * \phi$ & $-3.326 \mathrm{E}-01$ \\
\hline $\mathrm{K}<+>$ & $\mathrm{H}<+>$ & $\mathrm{Cl}<->$ & $\mathrm{R} * \psi$ & $-5.820 \mathrm{E}-02$ & & & & & \\
\hline
\end{tabular}


9.3.1.3 Calculation of the thermodynamic equilibrium constant $K_{K}^{C a}$ for the exchange reaction between $\mathrm{Ca}^{+2}$ and $\mathrm{K}^{+}$with $\mathrm{Cl}$ as the co-ion

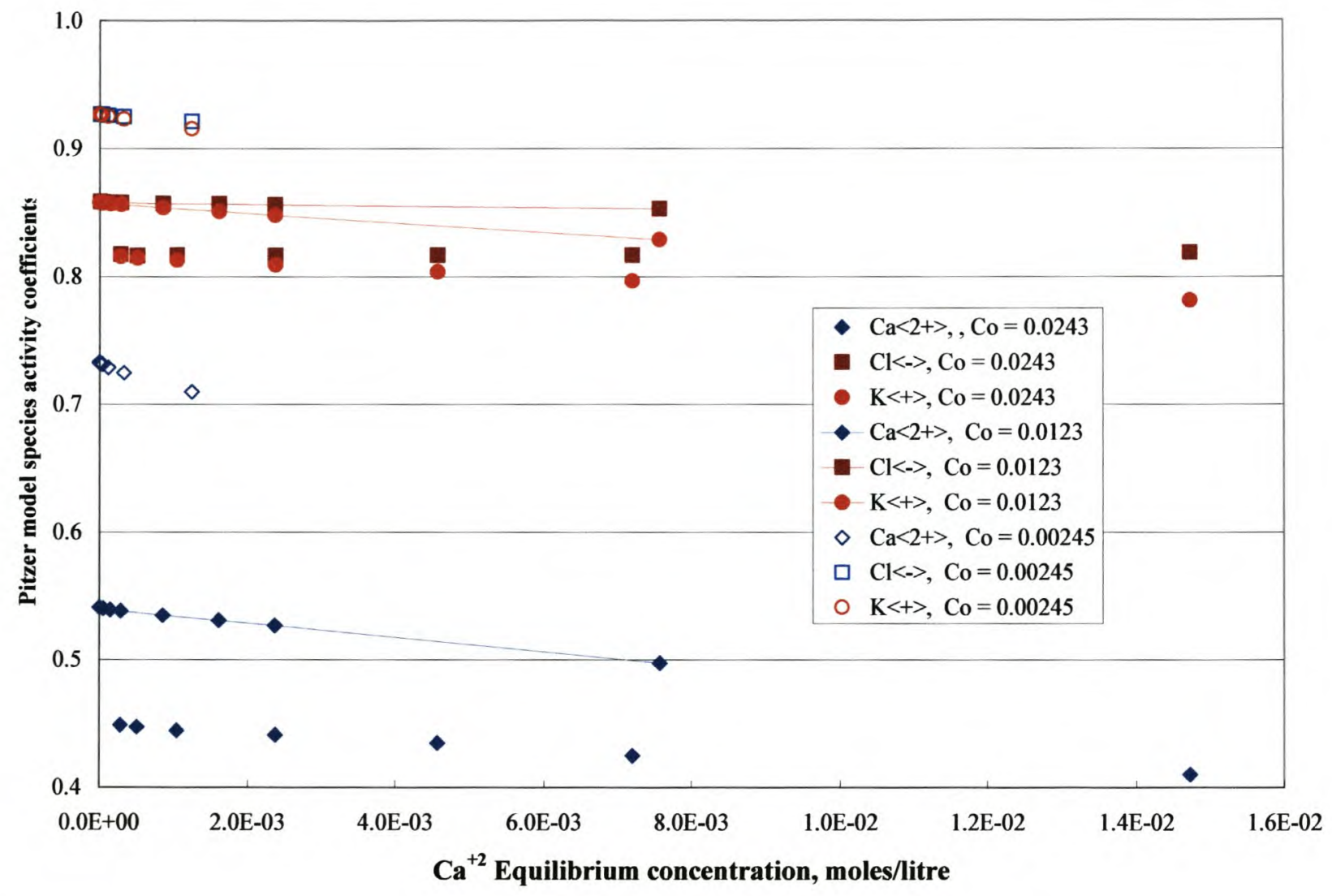

Figure 9.18 The Pitzer model activity coefficients for the aqueous phase species in the resin / solution system for the cation-exchange reaction between the cations $\mathrm{Ca}^{+2}$ and $\mathrm{K}^{+}$with $\mathrm{Cl}^{-}$anions for different solution phase concentrations of the $\mathrm{Ca}^{+2}$ ions.

Table 9.5 gives the Pitzer interaction parameters used in the calculation of the equilibrium quotient for the exchange reaction between $\mathrm{Ca}^{+2}$ and $\mathrm{K}^{+}$with $\mathrm{Cl}^{-}$as the anion species. The contents of Tables 9.4 and 9.5 are similar to one another. In Table 9.4 the $\mathrm{K}^{+}$ions were replaced with $\mathrm{Na}^{+}$with the new values for the Pitzer interaction parameters. The 
aqueous phase activity coefficients calculated with the Pitzer parameters in Table 9.5 are given by Figure (9.18). When comparing Figures (9.14), (9.16) and (9.18) it is evident that the same trends are displayed for all three of the monovalent ions $\mathrm{H}^{+}, \mathrm{Na}^{+}$and $\mathrm{K}^{+}$ respectively. In all of these figures it is evident that the $\mathrm{Ca}^{+2}$ ions behaves non-ideal even for the relatively low solution phase concentrations displayed in the figures.

The activity coefficients for all of the species decrease across the range with an increase in the equilibrium concentration of the $\mathrm{Ca}^{+2}$ ions, as expected. The values for the activity coefficients for the different species displayed in Figures (9.14), (9.16) and (9.18) are similar for the different resin / solution systems. This is expected due to the fact that all of the counter ion species are monovalent in nature and all of the systems are bivalentmonovalent in nature. It is clear from discussions in Chapters 4 and 5 that the ionexchange process is primarily an electrochemical process in which electroneutrality needs to be maintained in all of the phases, governed by the electrochemical valences of the species participating in the ion-exchange process. This explains the similarity between Figures (9.14), (9.16) and (9.18) mentioned above.

The calculated values for the equilibrium quotient of the $\mathrm{Ca}^{+2}-\mathrm{K}^{+}$resin / solution system are shown by Figure (9.19). It is evident that some of the end points of the series tend to deviate from the general trend for the particular series, as was the case in Figure (9.17).

When using the calculated values for the aqueous phase activity coefficients of the species and the values for the equilibrium quotients for the ion-exchange reaction, the value of the thermodynamic equilibrium constant for the exchange reaction may be obtained. With this value and the prediction of the solubility of the sparingly soluble solid the consolidated equilibrium model may be solved. 


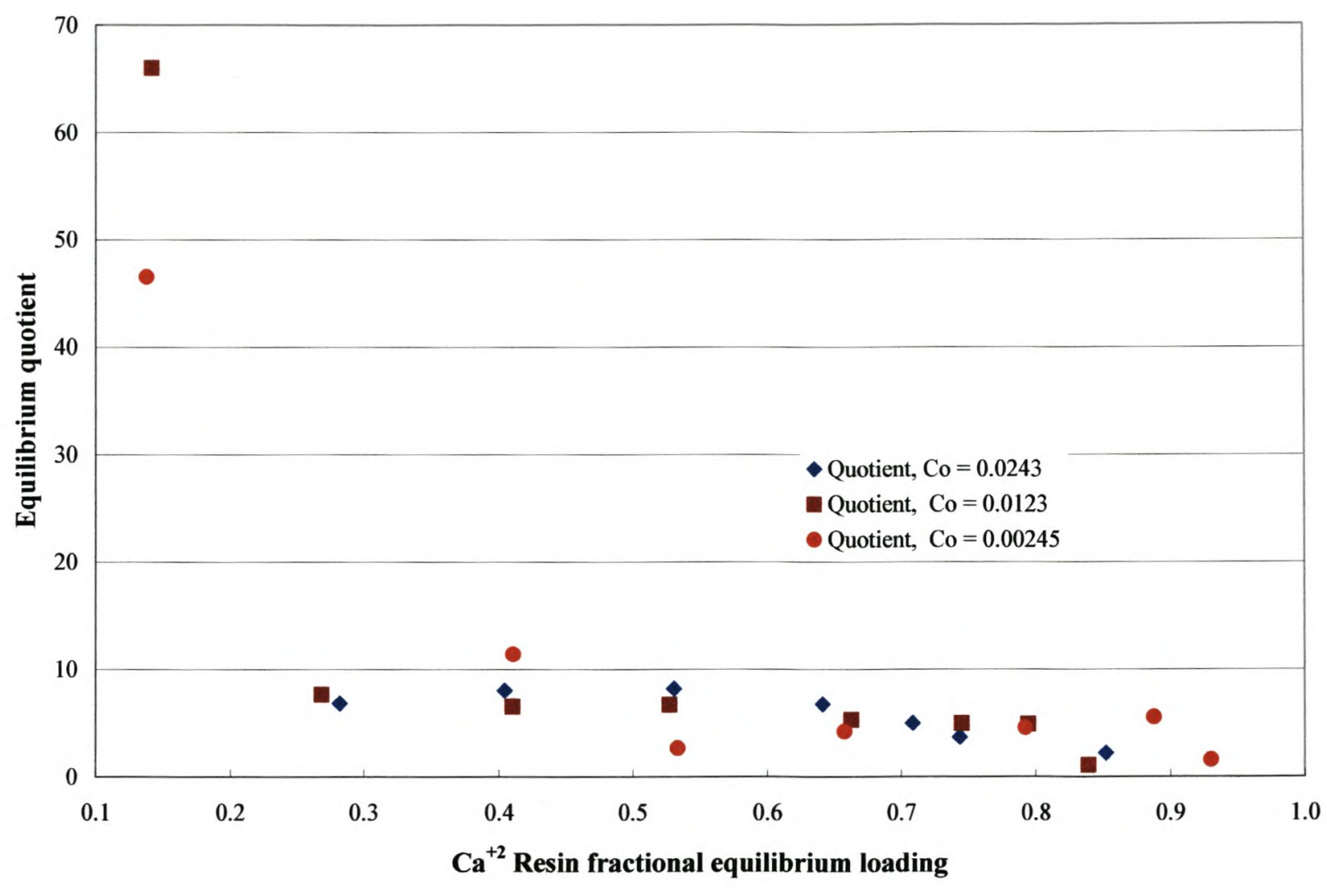

Figure 9.19 The equilibrium quotient calculated with the Pitzer model activity coefficients the resin / solution cation-exchange reaction between the cations $\mathrm{Ca}^{+2}$ and $\mathrm{K}^{+}$with anions $\mathrm{Cl}^{-}$.

The calculation of the solubility of the sparingly soluble solid also strongly depends on the aqueous phase activity coefficient calculations as performed above. It is therefore useful to consider the calculations for the solubility of the sparingly soluble solid for various aqueous phase solutions at this point due to its importance in the consolidated equilibrium model. 


\subsection{SOLUBILITY CALCULATIONS FOR THE SPARINGLY SOLUBLE SOLIDS}

As discussed in Chapter 4 of this dissertation there are several methods available to calculate the solubility of a sparingly soluble solid. The user may use the solubility product $K_{s p}$ of the sparingly soluble solid or make use of a Gibbs free energy minimisation method. The equations for both these techniques are presented in Chapter 4 of this dissertation.

The CHEMAPP software of GGT Technologies allows the use of the Gibbs free energy minimisation technique. In order to utilise this computational procedure the SQL7 data base discussed in Chapter 6 of this dissertation was extended to include the values of the Gibbs free energy of formation for various substances. The data base differentiates between the different phases of interest to the consolidated equilibrium model for the various RIP slurry mixture systems investigated. These phases are primarily the gaseous phase, aqueous phase and the various insoluble solid phases.

Irrespective of the technique used, the user still needs to calculate the aqueous phase activities of the species in the solution. From the discussions in Chapter 4 it is evident that these solution phase activity calculations are pivotal to the calculation of the species solubility in the aqueous phase. In paragraph 9.3 the Pitzer model parameters presented in Tables 9.2. 9.4 and 9.5 were specific to the calculation of the thermodynamic equilibrium constant for the different resin / solution equilibrium conditions. When these experiments were performed $\mathrm{CaCl}_{2}$ was used to determine the $K_{A}^{B}$ for the various exchange reactions between the $\mathrm{Ca}^{+2}$ ions and the $\mathrm{H}^{+}, \mathrm{Na}^{+}$and $\mathrm{K}^{+}$ions.

In the RIP slurry mixture systems of interest to this dissertation the $\mathrm{Ca}^{+2}$ ions were introduced in the form of various sparingly soluble solids. Table 7.27 in Chapter 7 shows the various forms of $\mathrm{Ca}^{+2}$ used. It included sparingly soluble solids of the form $\mathrm{CaCO}_{3}$, $\mathrm{CaSO}_{4}$ and $\mathrm{CaF}_{2}$. Extensive experimental test work was performed for all of these 
different sparingly soluble solids of the $\mathrm{Ca}^{+2}$ ion. For the purposes of this chapter we will only look into the $\mathrm{CaSO}_{4}$ RIP slurry mixture system.

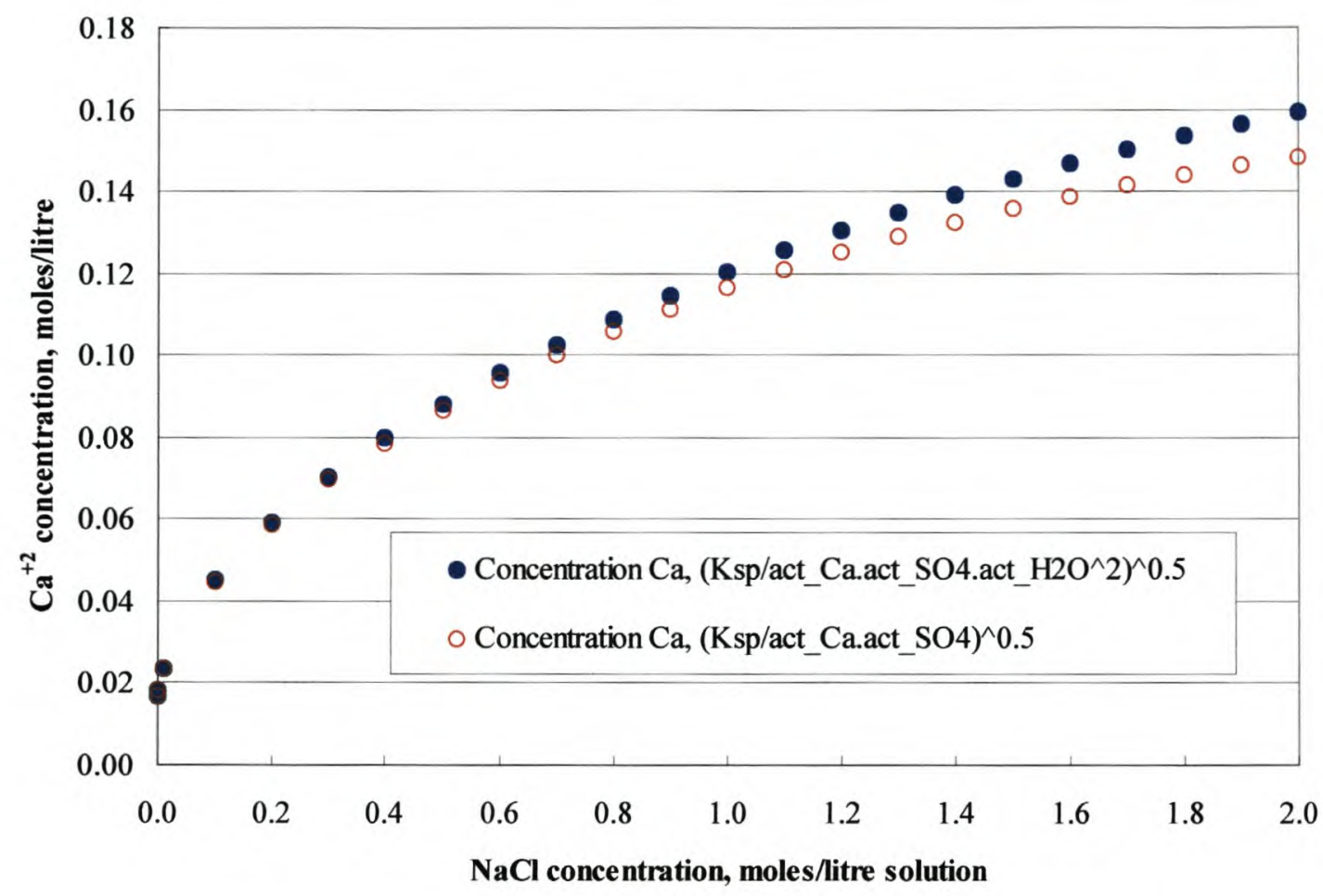

Figure 9.20 Calculated solubility of $\mathrm{CaSO}_{4} \cdot 2 \mathrm{H}_{2} \mathrm{O}$ in a $\mathrm{NaCl}$ aqueous electrolyte solution at $25^{\circ} \mathrm{C}$ and $101.325 \mathrm{kPa}$ pressure with the use of a Pitzer activity coefficient model.

In order to model the solubility of the sparingly soluble solid, new Pitzer model parameters are required that are different to those listed in Tables 9.2, 9.4 and 9.5. From Figure 1.1 in Chapter 1 it is evident that other sparingly soluble solids may be formed during the equilibrium attainment process in the RIP slurry mixture system. It is therefore necessary to consider the formation of all possible sparingly soluble solids for the concentration ranges of interest to the RIP slurry mixtures. The formation of "new precipitates" and the thermodynamic data required to model the RIP slurry mixture system are discussed in more detail below. 


\subsection{SOLUBILITY CALCULATONS FOR $\mathrm{CaSO}_{4}$ IN DIFFERENT AQUEOUS PHASE ELECTROLYTE SYSTEMS}

The solubility of $\mathrm{CaSO}_{4} \cdot 2 \mathrm{H}_{2} \mathrm{O}$ in a $\mathrm{NaCl}$ and $\mathrm{KCl}$ aqueous electrolyte solution was considered and calculated. Significant differences in the thermodynamic properties of species may exist in the literature, which is required for general solubility calculations. Linkson (1996) showed that great care should be taken in the selection of thermodynamic properties used in any thermodynamic calculation.

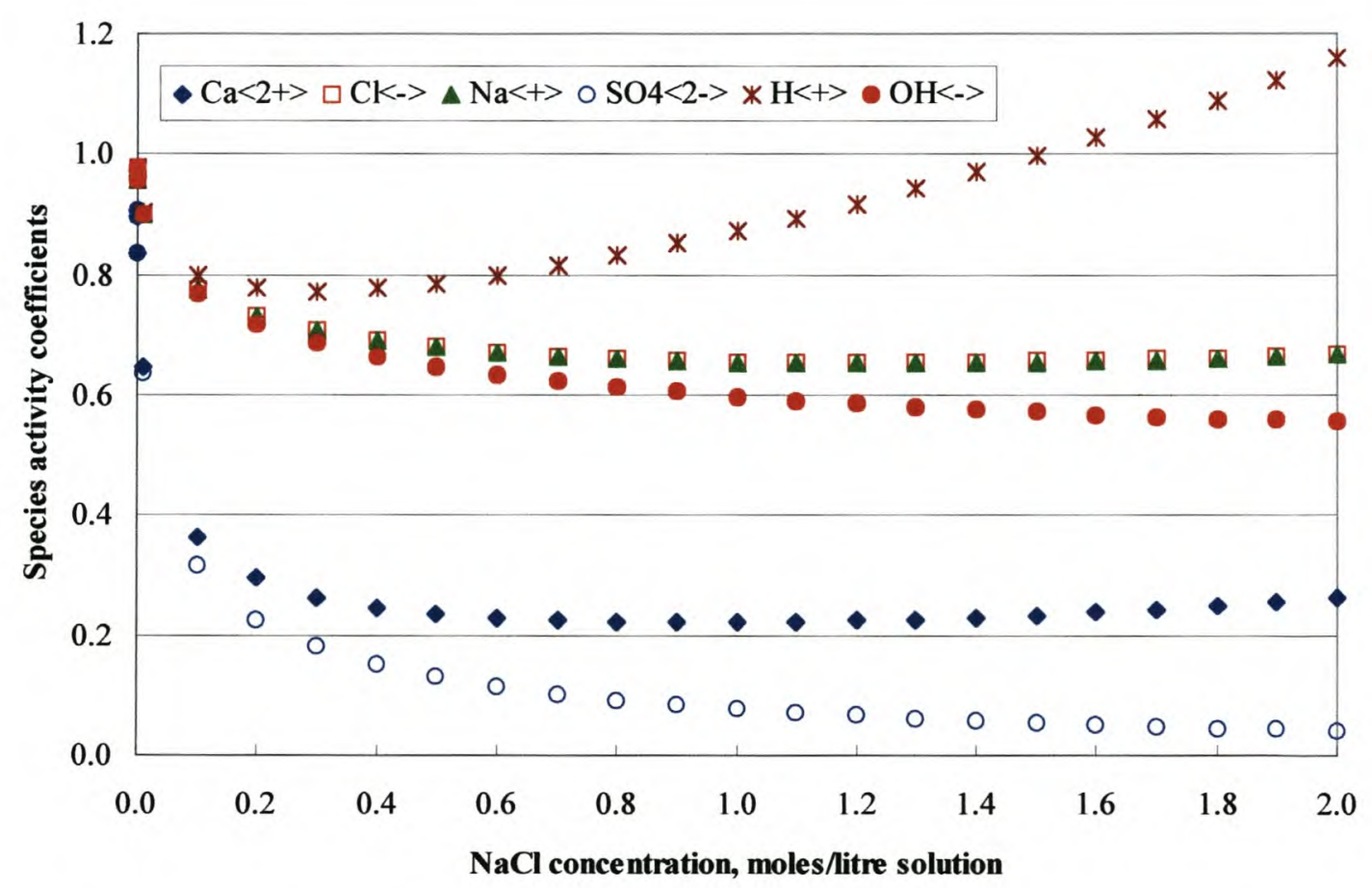

Figure 9.21 Calculated aqueous phase activity coefficients for the solubility of $\mathrm{CaSO}_{4} \cdot 2 \mathrm{H}_{2} \mathrm{O}$ in a $\mathrm{NaCl}$ aqueous electrolyte solution at $25^{\circ} \mathrm{C}$ and 101.325 $\mathrm{kPa}$ pressure with the use of a Pitzer activity coefficient model. 
In Chapter 11 of this dissertation it is shown that very different values for the solubility product $K_{s p}$ of the $\mathrm{CaSO}_{4} \cdot 2 \mathrm{H}_{2} \mathrm{O}$ precipitate may be obtained from the literature. The different values from the literature sources were compared with the value for the solubility product of the $\mathrm{CaSO}_{4} \cdot 2 \mathrm{H}_{2} \mathrm{O}$ precipitate as derived from the RIP slurry mixture system experiments performed for the purposes of this dissertation.

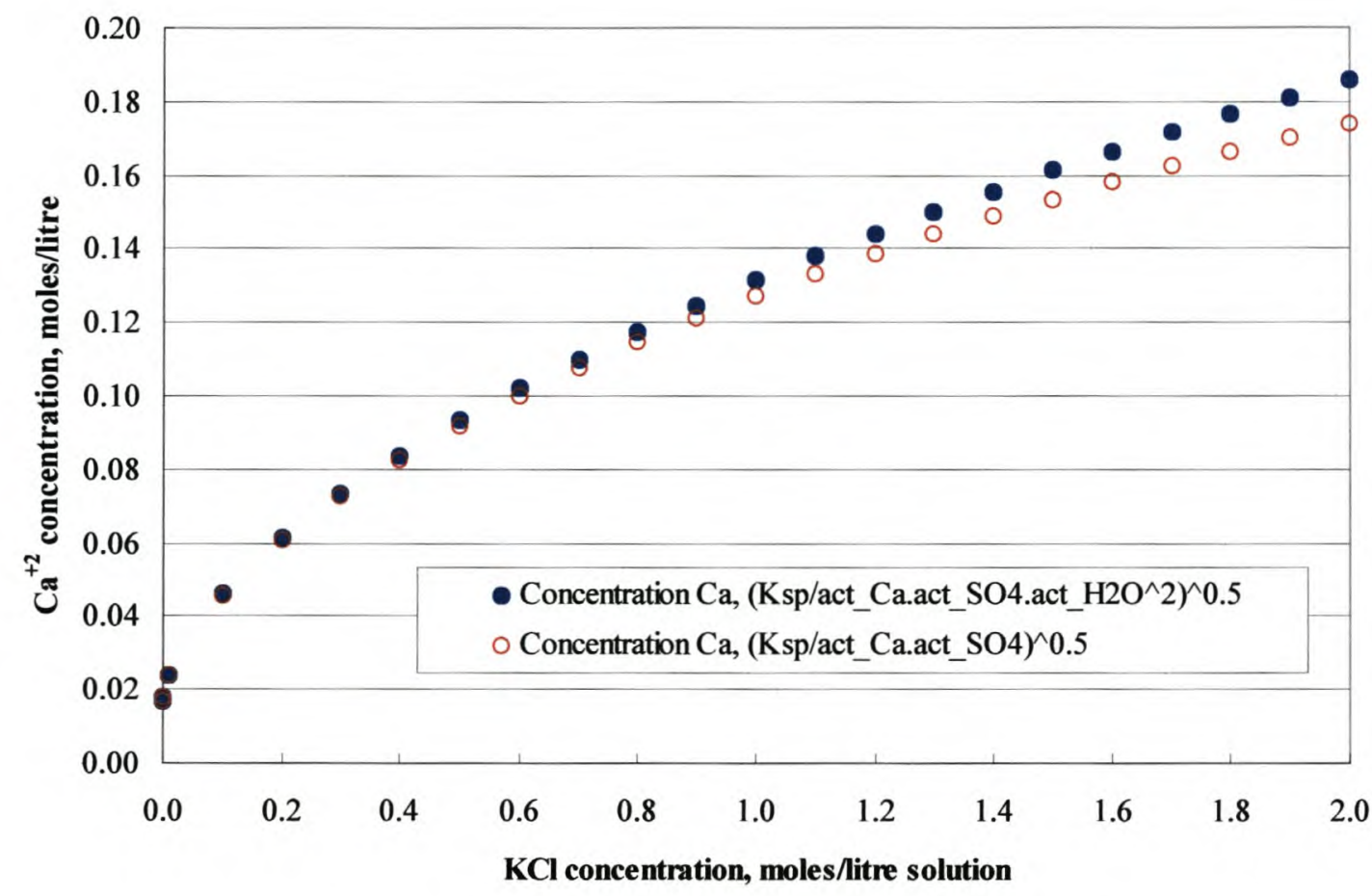

Figure 9.22 Calculated solubility of $\mathrm{CaSO}_{4} \cdot 2 \mathrm{H}_{2} \mathrm{O}$ in a $\mathrm{KCl}$ aqueous electrolyte solution at $25^{\circ} \mathrm{C}$ and $101.325 \mathrm{kPa}$ pressure with the use of a Pitzer activity coefficient model.

A $K_{s p}$ value of $2.31 \mathrm{E}-04$ was obtained from the experimental test work for the $\mathrm{CaSO}_{4} \cdot 2 \mathrm{H}_{2} \mathrm{O}$ precipitate, which correlated to within $98.6 \%$ of the value obtained from Zemaitis et al. (1986). This value was used in all of the solubility calculations performed for the $\mathrm{CaSO}_{4} \cdot 2 \mathrm{H}_{2} \mathrm{O}$ RIP slurry mixture system in this chapter and in Chapters 10 and 11 of this dissertation. 
The values for the activity coefficients and equilibrium concentrations of the species in the RIP slurry mixture were calculated as well as the activity of the water. In the calculations performed an aqueous slurry containing 2 moles of the precipitated $\mathrm{CaSO}_{4} \cdot 2 \mathrm{H}_{2} \mathrm{O}$ in one litre of water was considered to which the $\mathrm{NaCl}$ and $\mathrm{KCl}$ electrolyte were added. Figures (9.20) to (9.23) show the results of the simulations for the $\mathrm{NaCl}$ and $\mathrm{KCl}$ respectively. In the simulations the amount of water stayed constant at 55.5 moles, which is the number of moles of water molecules in one kilogram of water.

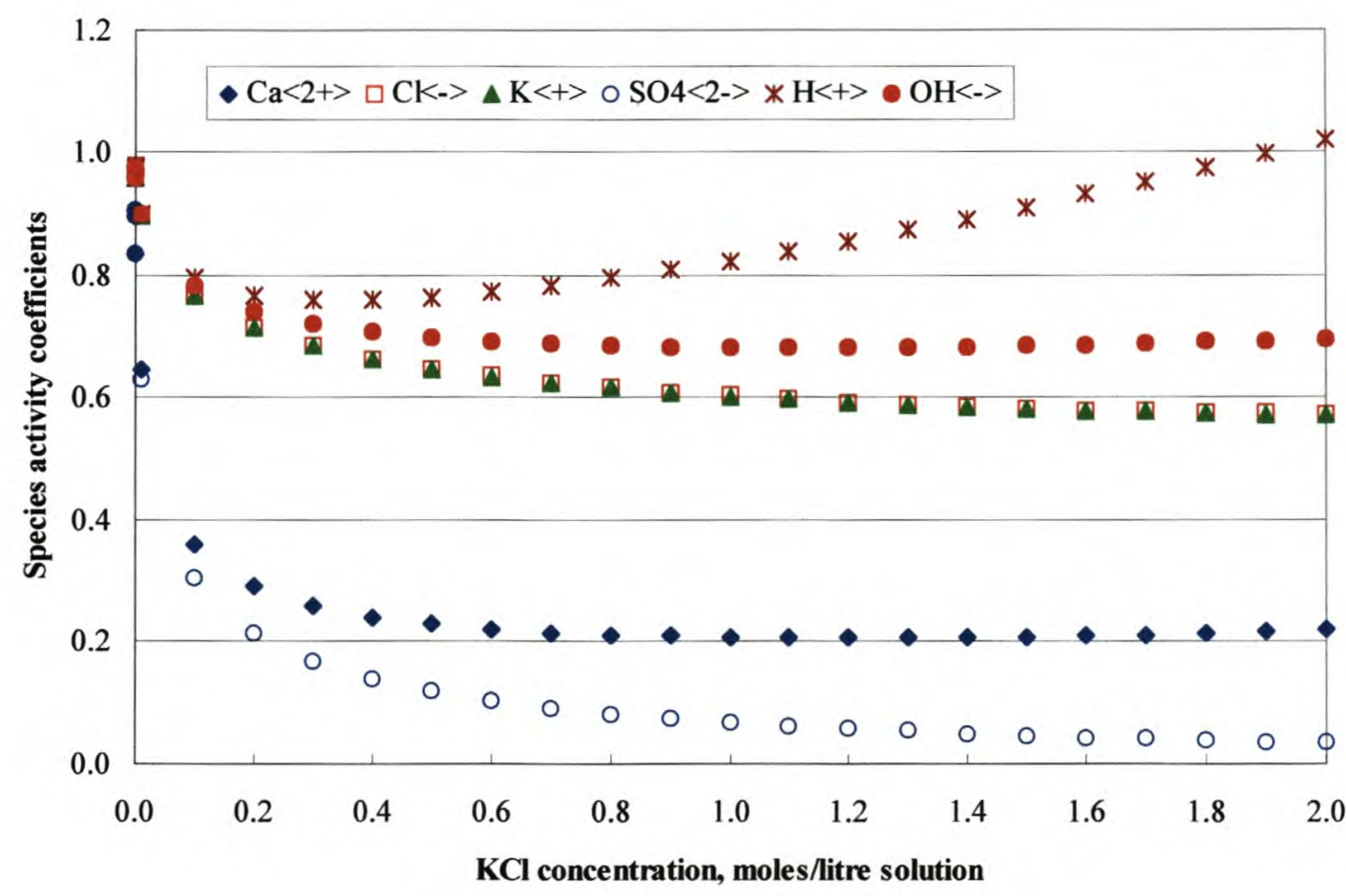

Figure 9.23 Calculated aqueous phase activity coefficients for the solubility of $\mathrm{CaSO}_{4} \cdot 2 \mathrm{H}_{2} \mathrm{O}$ in a $\mathrm{KCl}$ aqueous electrolyte solution at $25^{\circ} \mathrm{C}$ and 101.325 $\mathrm{kPa}$ pressure with the use of a Pitzer activity coefficient model.

Figures (9.20) and (9.22) give the saturation concentration of the $\mathrm{Ca}^{+2}$ ions in the solution as a function of the $\mathrm{NaCl}$ and $\mathrm{KCl}$ electrolyte concentration in the aqueous phases. It is 
evident from Figures (9.20) and (9.22) that the solubility of the $\mathrm{CaSO}_{4}$ increases with an increase in the $\mathrm{NaCl}$ and $\mathrm{KCl}$ molarity. The values of the Pitzer ion-interaction parameters used in these simulations are not valid beyond the 4 molar concentration limit for the electrolytes.

The simulations were therefore only performed for the low to moderate solution phase concentration regions, which is more typical of the aqueous phase concentrations in the RIP slurry mixture system of interest to this dissertation.

From Equation (2.35) in Chapter 2 (given below for reference) it is evident that the solubility of the $\mathrm{CaSO}_{4}$ precipitate will only increase if the solution phase activities of the $\mathrm{Ca}^{+2}$ (species $B$ ) and $\mathrm{SO}_{4}{ }^{2-}$ ions (species $Y$ ) decrease. The $K_{s p}$ value in Equation (2.35) is constant for constant temperature and pressure and hence the value of the solubility $S$ will only increase if the $K_{s p}$ value is divided by smaller values for the species activities.

$$
S=\left(\frac{K_{s p}}{\left[\gamma_{B}\right]\left[\gamma_{Y}\right]}\right)^{\frac{1}{2}}
$$

This therefore implies that the solution phase activity coefficients of the $\mathrm{Ca}^{+2}$ and $\mathrm{SO}_{4}{ }^{2-}$ species have to decrease, as is evident from Figures (9.21) and (9.23) for the $\mathrm{NaCl}$ and $\mathrm{KCl}$ electrolyte solutions respectively. The results derived from the experiments and used in the simulation compare well with data available from the literature (Zematis et al., 1986).

\subsection{CONSOLIDATED EQUILIBRIUM MODEL CALCULATIONS FOR THE $\mathrm{CaSO}_{4}$ RIP SLURRY MIXTURE SYSTEM}


In paragraph 9.2 the experimental data for the $\mathrm{PbSO}_{4}$ RIP slurry mixture system were discussed to provide some general background to the behaviour of RIP slurry mixture systems in general. From paragraph 9.2 it was evident that the obtained equilibrium curves for the RIP slurry mixture of $\mathrm{PbSO}_{4}$ followed expected trends according to the selectivity of the ion-exchange resin for species of higher electrochemical valences. For the purposes of the model development of this dissertation various RIP slurry mixture systems were used to verify the development of the consolidated equilibrium model for the RIP slurry mixture system in general. The systems investigated are given in Table 9.1 .

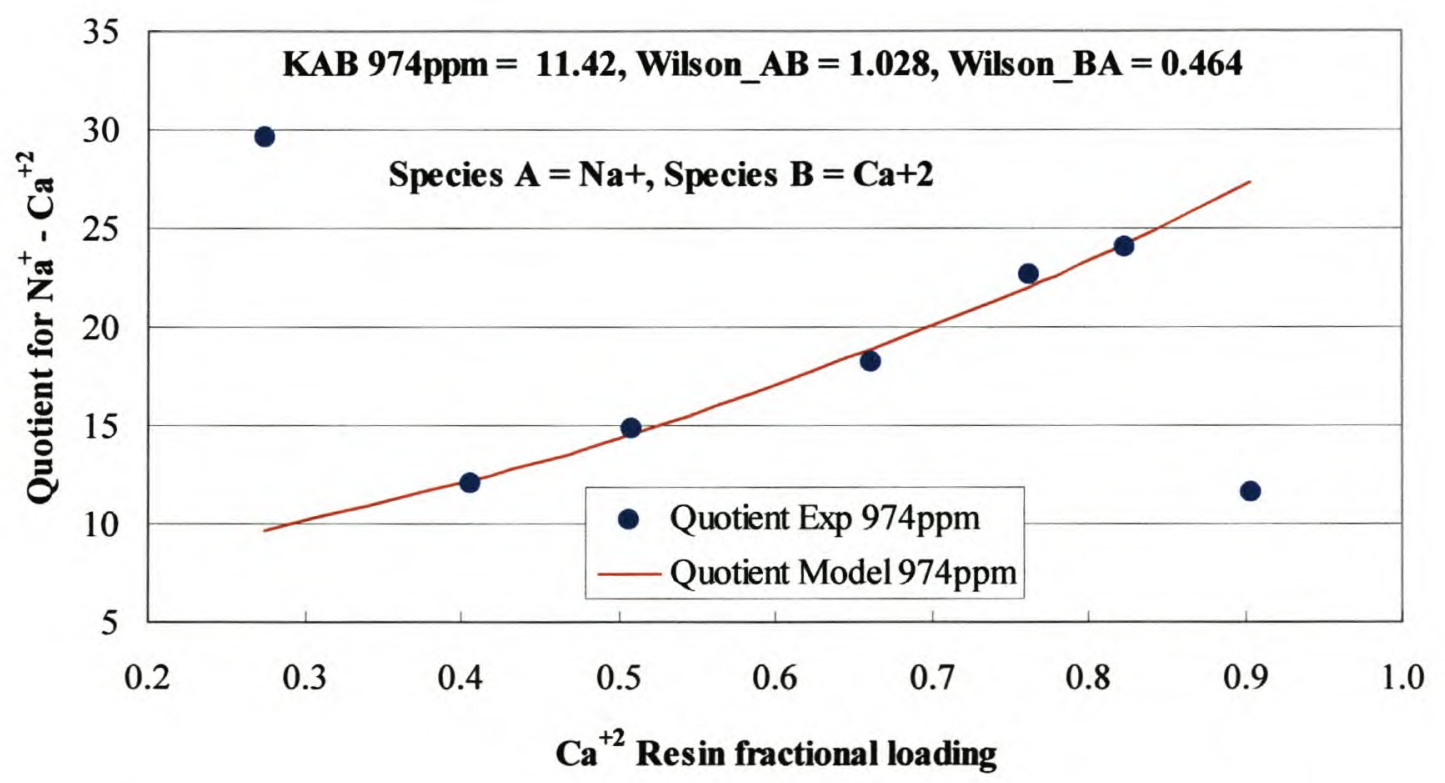

Figure 9.24 Model prediction of the equilibrium quotient for the exchange reaction between $\mathrm{Ca}^{+2}$ and $\mathrm{Na}^{+}$for a solution phase concentration of 0.0243 moles/litre.

For the purposes of this dissertation the general cation exchange resin Duolite C26 was used to perform the experimental tests for the RIP slurry mixture systems. This cation exchange resin has the sulphonic acid functional group structure as given by Figure 4.2 of 
Chapter 4. This particular structure is not chemically selective towards a specific cationic species used in the experiments of this dissertation.

The selectivity of the cation resin for the various cationic species is primarily based on the value of the species electrochemical valence as is evident from Figure (9.1). It is clear from Figure (9.1) that the equilibrium curves for the three monvalent species $\mathrm{H}^{+}, \mathrm{Na}^{+}$and $\mathrm{K}^{+}$lie on top of one another. The "general" trends of the equilibrium curves for the various bivalent-monovalent RIP slurry mixtures of Table 9.1 are therefore expected to be similar when the resin is used in the $\mathrm{H}^{+}, \mathrm{Na}^{+}$and $\mathrm{K}^{+}$ionic form.

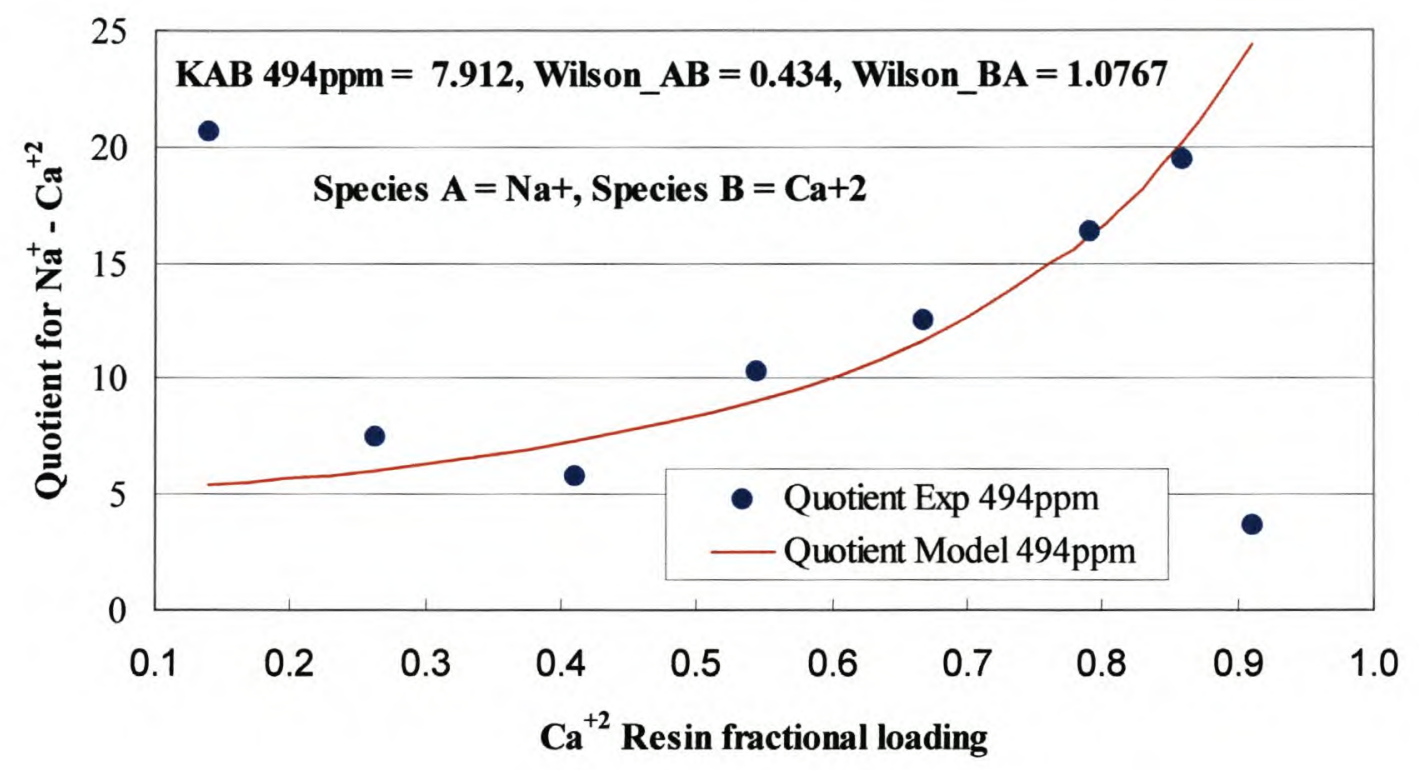

Figure 9.25 Model prediction of the equilibrium quotient for the exchange reaction between $\mathrm{Ca}^{+2}$ and $\mathrm{Na}^{+}$for a solution phase concentration of 0.0123 moles/litre.

It is further evident from Figure (9.1) that for the very dilute solution phase concentration region there is not much difference between the equilibrium curves for the various cation 
species with different chemical valences. The differences in equilibrium resin loading only become more evident at higher solution phase concentrations of the cation species.

Because of the fact that the solution phase concentrations of the cations species in the RIP slurry mixture systems are always very low it may be expected that there will not be significant differences between the various equilibrium curves for the cation resin in different ionic forms. This is partly evident from Figure (9.6), which indicates that for the $\mathrm{PbSO}_{4}$ RIP slurry mixture system the equilibrium curves for the different ionic resin forms lie practically on top of one another where the curves overlap.

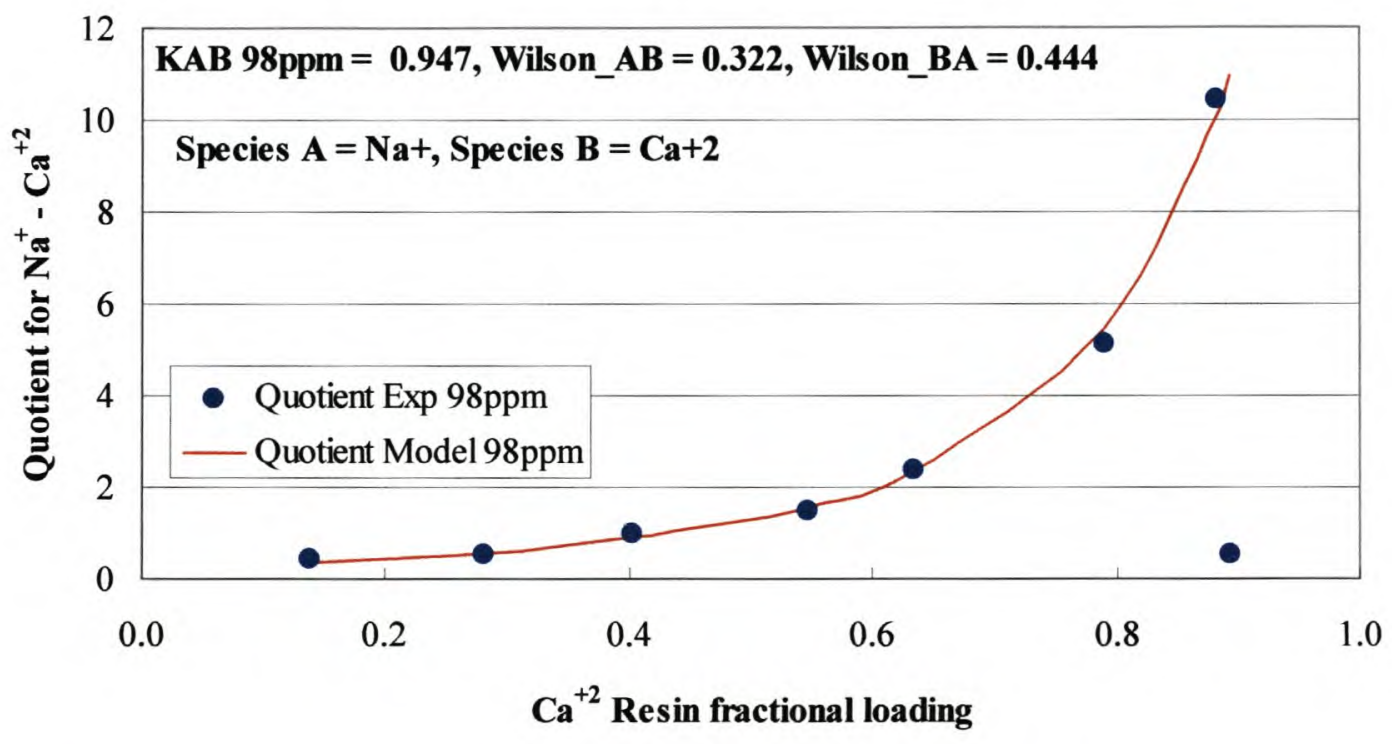

Figure 9.26 Model prediction of the equilibrium quotient for the exchange reaction between $\mathrm{Ca}^{+2}$ and $\mathrm{Na}^{+}$for a solution phase concentration of 0.0024 moles/litre.

It is evident from Figure (9.6) that the monovalent, bivalent and trivalent equilibrium curves for the $\mathrm{H}^{+}, \mathrm{Na}^{+}, \mathrm{K}^{+}, \mathrm{Cu}^{+2}$ and $\mathrm{Al}^{+3}$ curves form one "smooth" equilibrium curve. A particular point along this curve will move from right to left as the amount of the cation resin increases. The increase in the cation resin volume causes the solubility of the 
sparingly soluble solid to decrease as a result of the common-ion effect caused by the coion of the sparingly soluble solid as described in Chapter 4 of this dissertation. Different types of sparingly soluble solids with different solubility products will also cause the smooth equilibrium curve in Figure (9.6) to shift. The solubility of the sparingly soluble solid will move the position of the "smooth" equilibrium curve depending on the equilibrium concentration of the cation species in the solution. Because of this behaviour and the fact that the selectivity of the cation resin depends primarily on the species chemical valences the equilibrium calculations for the various RIP slurry mixture systems are very similar.

This chapter will therefore only focus on one of these systems. The monovalent-bivalent RIP slurry mixture system of $\mathrm{CaSO}_{4}$ with the cation exchange resin in the monovalent ionic forms of $\mathrm{H}^{+}, \mathrm{Na}^{+}$and $\mathrm{K}^{+}$will be considered. Chapters 10 and 11 will respectively consider the bivalent-bivalent and bivalent-trivalent systems.

The values for the model predictions of the equilibrium quotient for the bivalentmonovalent exchange reaction between $\mathrm{Ca}^{+2}$ and $\mathrm{Na}^{+}$are given by Figures (9.24) to (9.26). The values for the thermodynamic equilibrium constant and the Wilson interaction parameters are also given. It is evident from Figures (9.24) to (9.26) that there are experimental errors associated with the extreme boundary data points of the curves where the values of the resin fractional loading are close to zero or unity. Various researchers in the literature have identified the problem associated with the experimental data points when one of the phase compositions approaches an extreme, which causes an increase in the calculation error associated with the data point (Mehablia et al., 1994).

From Equation (5.27) of Chapter 5, given below, it is evident that the experimentally calculated value of the equilibrium quotient is the result of various measured and calculated parameters. A slight error in one of the data points may easily be amplified by the mathematical relationships it is used in as shown in Equation (5.27). 


$$
\lambda_{A}^{B}=\left(\frac{y_{B}}{\gamma_{B} C_{B}}\right)^{v_{B}}\left(\frac{\gamma_{A} C_{A}}{y_{A}}\right)^{\nu_{A}}
$$

Significant deviations from the trend line for the equilibrium quotient may therefore occur for relatively small experimental errors. This poses a difficulty in the collection of representative experimental data for the ion-exchange isotherms at the phase composition extremes to be used in the calculations of this dissertation. Data collected near the extreme end points of the resin phase composition are less useful in the determination of the model parameters and may cause substantial problems in the estimation of the model parameters with the optimisation routine as described in Appendix E of this dissertation.

By comparing the values for the equilibrium quotient of Figures (9.24) to (9.26) with one another it is evident that the equilibrium quotient curve becomes more non-linear as the total solution phase concentration of the $\mathrm{Ca}^{+2}$ ions decreases from approximately 0.0243 to $0.0024 \mathrm{moles} / \mathrm{litre}$. The value of the thermodynamic equilibrium quotient decreases from approximately 11.4 to 0.94 with the decrease in the solution phase concentration, as shown in Figure (9.27) below. The thermodynamic equilibrium constant may be viewed as an indication of the selectivity of the resin for a particular species. Equations (5.20) and (5.21) of Chapter 5 give the selectivity and thermodynamic equilibrium constant for an ion-exchange reaction respectively. By comparing Equations (5.20) with (5.21) it is evident that the two equations are related to one another. The thermodynamic equilibrium constant is a refined version of the selectivity coefficient for the exchange reaction between two species on an ion-exchange resin. The larger the value of the selectivity coefficient for a particular exchange reaction the more selective is the resin towards one particular species. A value close to unity for the thermodynamic equilibrium constant for an exchange reaction between two species with equivalent chemical valences will mean that the resin has equal affinity for both species. 


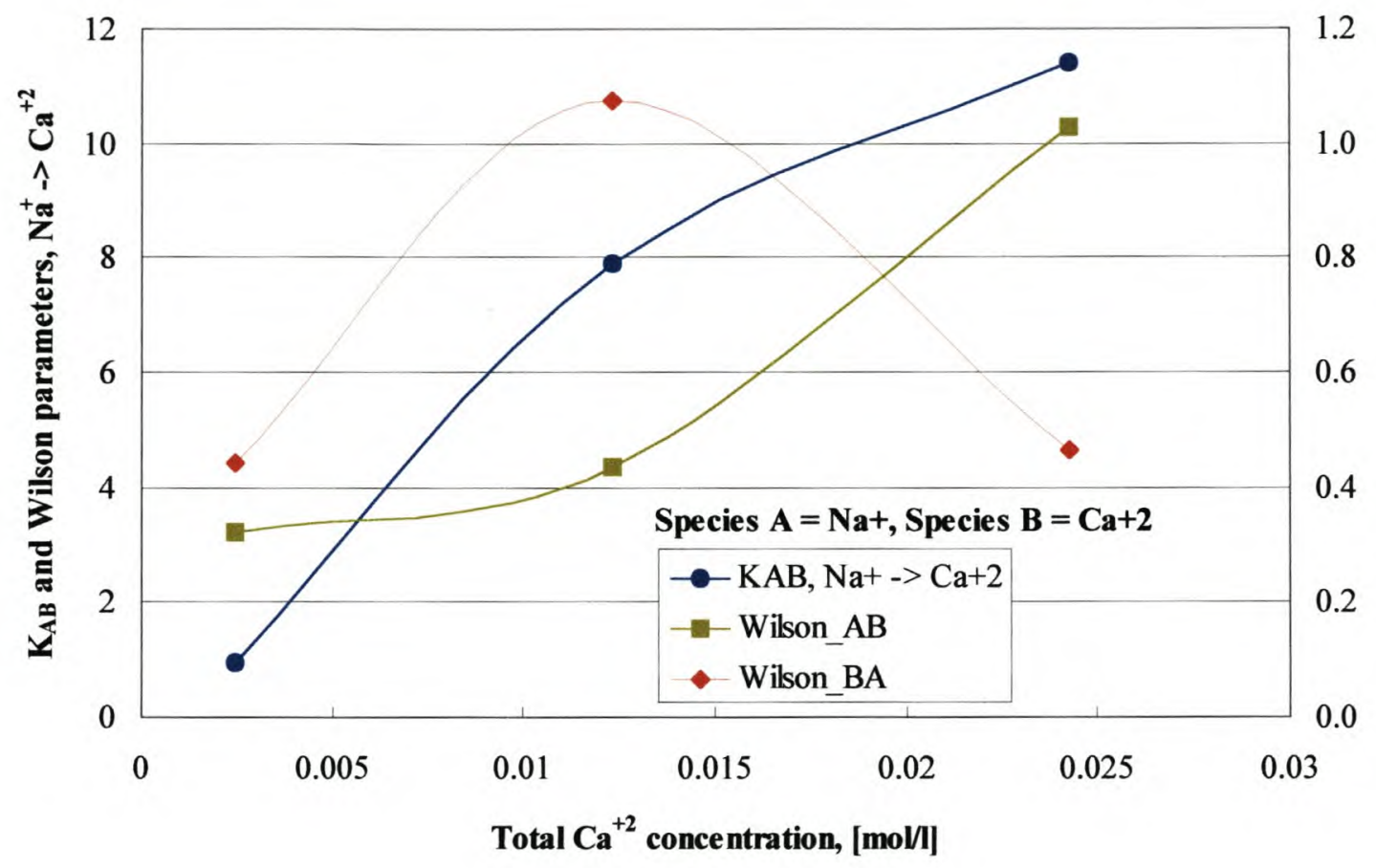

Figure 9.27 Thermodynamic equilibrium constant $\mathrm{K}_{\mathrm{NaCa}}$ and Wilson interaction parameters for the ion-exchange reaction between $\mathrm{Ca}^{+2}$ and $\mathrm{Na}^{+}$for different solution phase concentrations of the $\mathrm{Ca}^{+2}$ ions on Duolite $\mathrm{C} 26$.

It is further important to consider the sequence of species in the notation of the equilibrium constant. The value of $K_{A B}$ may differ substantially from the value of $K_{B A}$ where $A$ and $B$ represent the species participating in the exchange reaction. For the purposes of this dissertation the notation of the $K_{A B}$ values is done in such a manner that species $A$ is the species initially in the ion-exchange resin phase and species $B$ is initially in the solution phase at the start of the ion-exchange process.

From the above discussion on the thermodynamic equilibrium constant it is therefore evident that the decrease in the value of it for the exchange reaction between $\mathrm{Ca}^{+2}$ and $\mathrm{Na}^{+}$implies that the resin selectivity for the $\mathrm{Ca}^{+2}$ species over the $\mathrm{Na}^{+}$species decreases with decreasing total solution phase concentration of the $\mathrm{Ca}^{+2}$ species. 
Table 9.6 Calculated values for thermodynamic equilibrium constant and Wilson parameters for the exchange reaction between $\mathrm{Ca}^{+2}$ and $\mathrm{Na}^{+}$ions on Duolite C26.

\begin{tabular}{|c|c|c|c|c|c|c|c|c|}
\hline $\begin{array}{c}\text { Species } \\
\mathbf{A}\end{array}$ & $\begin{array}{c}\text { Species } \\
\mathbf{B}\end{array}$ & $\begin{array}{c}\text { Species } \\
\mathbf{C}\end{array}$ & $K_{A}^{B}$ & $\begin{array}{c}\text { Wilson } \\
\Lambda_{A B}\end{array}$ & $\begin{array}{c}\text { Wilson } \\
\Lambda_{B A}\end{array}$ & $\begin{array}{c}\text { Objective } \\
\text { Function } \\
\text { Value }\end{array}$ & $\begin{array}{c}\text { Total } \\
\mathbf{C a}^{+2} \\
\mathbf{m o l} / \text { litre }\end{array}$ & $\mathbf{N}$ \\
\hline $\mathrm{Na}^{+}$ & $\mathrm{Ca}^{+2}$ & $\mathrm{Cl}^{-}$ & 0.801 & 0.3398 & $1.5 \mathrm{E}-08$ & 0.3284 & $\mathrm{All}$ & 23 \\
$\mathrm{Na}^{+}$ & $\mathrm{Ca}^{+2}$ & $\mathrm{Cl}^{-}$ & 11.420 & 1.0284 & 0.4643 & 0.0023 & 0.0243 & 7 \\
$\mathrm{Na}^{+}$ & $\mathrm{Ca}^{+2}$ & $\mathrm{Cl}^{-}$ & 7.912 & 0.4343 & 1.0761 & 0.1225 & 0.0123 & 8 \\
$\mathrm{Na}^{+}$ & $\mathrm{Ca}^{+2}$ & $\mathrm{Cl}^{-}$ & 0.947 & 0.3216 & 0.4444 & 0.0212 & 0.0024 & 8 \\
\hline
\end{tabular}

In the calculation of the values of the thermodynamic equilibrium constant and Wilson interaction parameters the objective function as described by Equation (5.35) was used. The results for these calculations are given by Table 9.6, which also gives the value of the objective function for the listed values of $K_{A}^{B}$ and the Wilson parameters $\Lambda_{A B}$ and $\Lambda_{B A}$.

Table 9.7 Calculated values for thermodynamic equilibrium constant and Wilson parameters for the exchange reaction between $\mathrm{Ca}^{+2}$ and $\mathrm{K}^{+}$ions on Duolite C26.

\begin{tabular}{|c|c|c|c|c|c|c|c|c|c|}
\hline $\begin{array}{c}\text { Species } \\
\text { A }\end{array}$ & \begin{tabular}{|c} 
Species \\
B
\end{tabular} & $\begin{array}{c}\text { Species } \\
\text { C }\end{array}$ & $K_{A}^{B}$ & $\begin{array}{c}\text { Wilson } \\
\Lambda_{A B}\end{array}$ & $\begin{array}{c}\text { Wilson } \\
\Lambda_{B A}\end{array}$ & $\begin{array}{l}\text { Objective } \\
\text { Function } \\
\text { Equation }\end{array}$ & $\begin{array}{c}\text { Objective } \\
\text { Function } \\
\text { Value }\end{array}$ & $\begin{array}{c}\text { Total } \\
\mathrm{Ca}^{+2} \\
\text { mol/litre }\end{array}$ & $\mathbf{N}$ \\
\hline$\overline{\mathrm{K}^{+}}$ & $\mathrm{Ca}^{+2}$ & $\mathrm{Cl}^{-}$ & 9.185 & 1.5617 & 1.8028 & $\bar{F} 2$ & 0.67136 & All & 23 \\
\hline $\mathrm{K}^{+}$ & $\mathrm{Ca}^{+2}$ & $\mathrm{Cl}^{-}$ & 9.144 & 0.6953 & 2.7075 & $\mathrm{~F} 2$ & 0.00571 & 0.0243 & 7 \\
\hline $\mathrm{K}^{+}$ & $\mathrm{Ca}^{+2}$ & $\mathrm{Cl}^{-}$ & 10.077 & 0.1658 & 6.0325 & $\mathrm{~F} 2$ & 0.12823 & 0.0123 & 8 \\
\hline $\mathrm{K}^{+}$ & $\mathrm{Ca}^{+2}$ & $\mathrm{Cl}^{-}$ & 5.377 & 0.3621 & 2.7615 & $\mathrm{~F} 2$ & 0.14434 & 0.0024 & 8 \\
\hline $\mathrm{K}^{+}$ & $\mathrm{Ca}^{+2}$ & $\mathrm{Cl}^{-}$ & 7.673 & 0.2834 & 3.5289 & F1 & 0.07155 & 0.0243 & 7 \\
\hline $\mathrm{K}^{+}$ & $\mathrm{Ca}^{+2}$ & $\mathrm{Cl}^{-}$ & 5.839 & 0.2398 & 4.1698 & F1 & 0.82197 & 0.0123 & 8 \\
\hline $\mathrm{K}^{+}$ & $\mathrm{Ca}^{+2}$ & $\mathrm{Cl}^{-}$ & 6.720 & 4.0201 & 0.2487 & F1 & 1.24640 & 0.0024 & 8 \\
\hline
\end{tabular}

The value of $\mathrm{N}$ in the last column gives the number of data points used in the model parameter estimation procedure described in Appendix $\mathrm{E}$ of this dissertation. For 
comparison the objective function in the form of Equation (5.34) was also used in the calculation of the thermodynamic equilibrium constant for the bivalent-monovalent exchange reaction be $\mathrm{Ca}^{+2}$ and $\mathrm{K}^{+}$, given in Table 9.7 below.

In Table 9.7 the objective function F2 represents Equation (5.35) and function F1 represents Equation (5.34). It is evident from the values of the thermodynamic equilibrium constant $K_{A}^{B}$ and the Wilson interaction parameters $\Lambda_{A B}$ and $\Lambda_{B A}$ that the choice of objective function has a significant influence on the outcome of the estimated model parameters. This poses a significant difficulty in the application of the consolidated equilibrium model to the RIP slurry mixture system results. As discussed in previous chapters it was evident that a relatively small change in any of the model parameters may cause a significant change in the model prediction. This is due to the steep nature of the equilibrium isotherm curve, as illustrated by Figure (9.1), and the fact that the RIP slurry mixture system operates in the very low solution phase concentration region for the constituent ions of the sparingly soluble solid.

From the values obtained for the Wilson interaction parameters the resin phase activity coefficients may be calculated with the use of Equations (5.30) and (5.31). From Equations (5.30) and (5.31) it is evident that the resin phase activity coefficient for a particular species is only a function of the resin fractional loading of that species on the ion-exchange resin and the Wilson interaction parameters. Figures $(9.28)$ to $(9.30)$ give the calculated values of the resin phase activity coefficients for both the $\mathrm{Na}^{+}$and $\mathrm{Ca}^{+2}$ ions for the exchange reaction between these two cations on Duolite C26 for different total solution phase concentrations of the $\mathrm{Ca}^{+2}$ ion. 


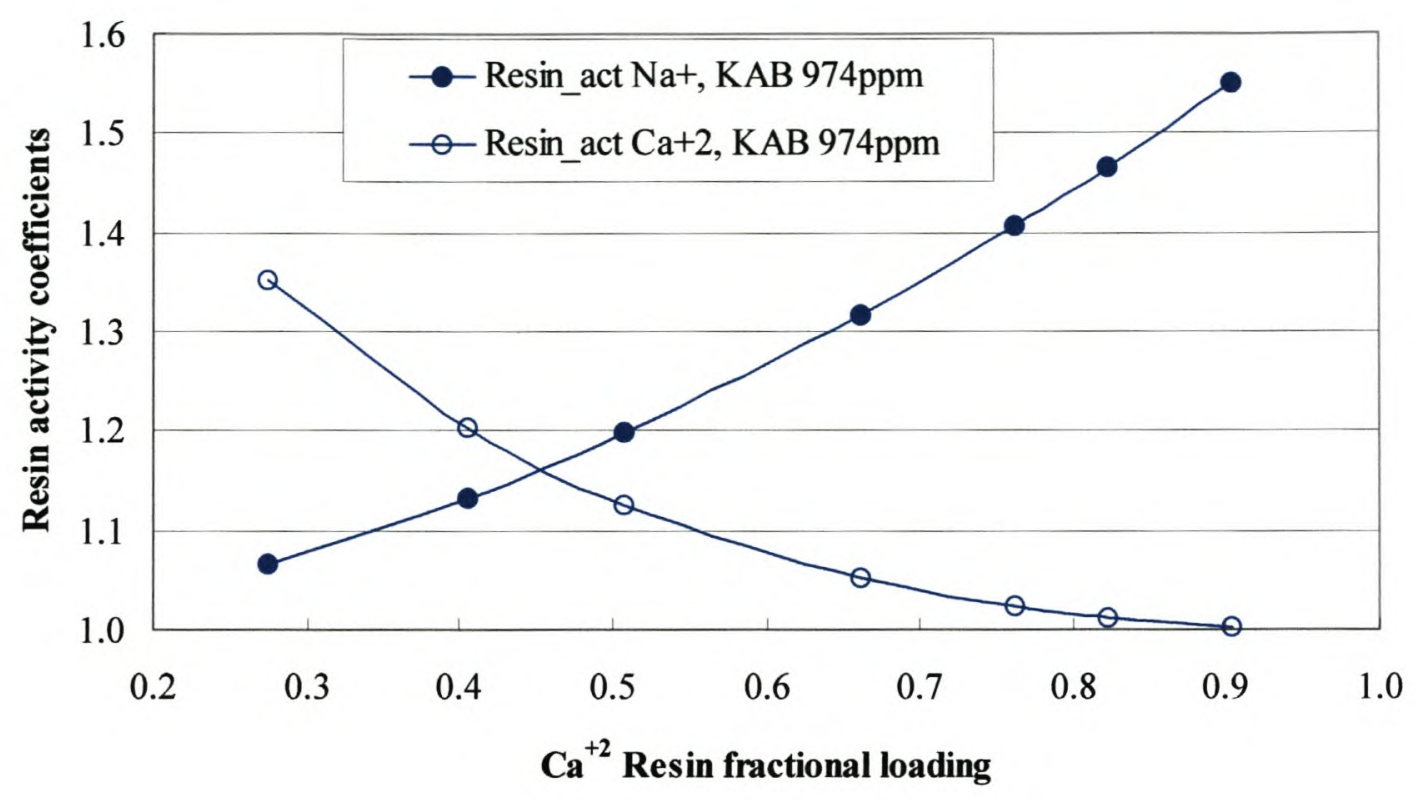

Figure 9.28 Resin activity coefficients for $\mathrm{Na}^{+}-\mathrm{Ca}^{+2}$ exchange at $974 \mathrm{ppm} \mathrm{Ca}{ }^{+2}$.

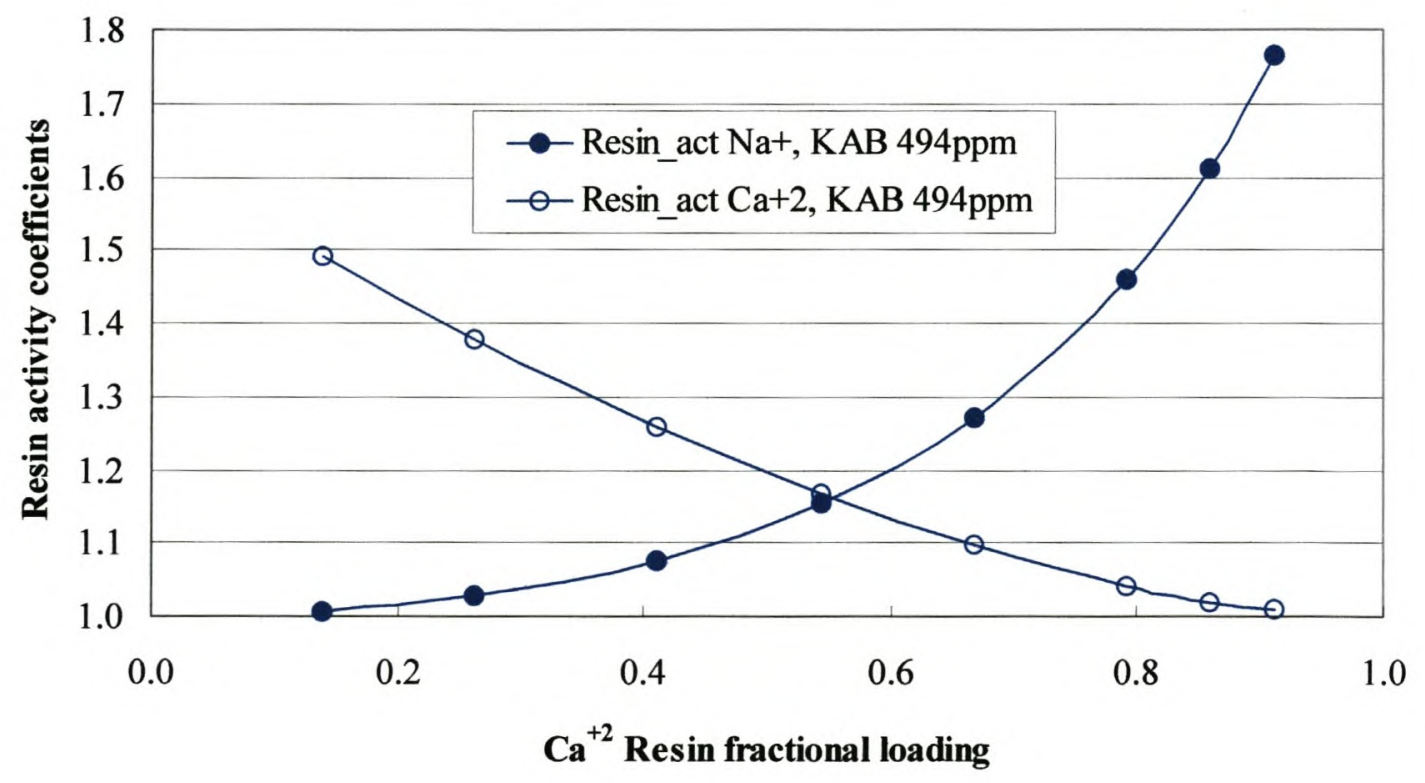

Figure 9.29 Resin activity coefficients for $\mathrm{Na}^{+}-\mathrm{Ca}^{+2}$ exchange at $494 \mathrm{ppm} \mathrm{Ca}^{+2}$. 


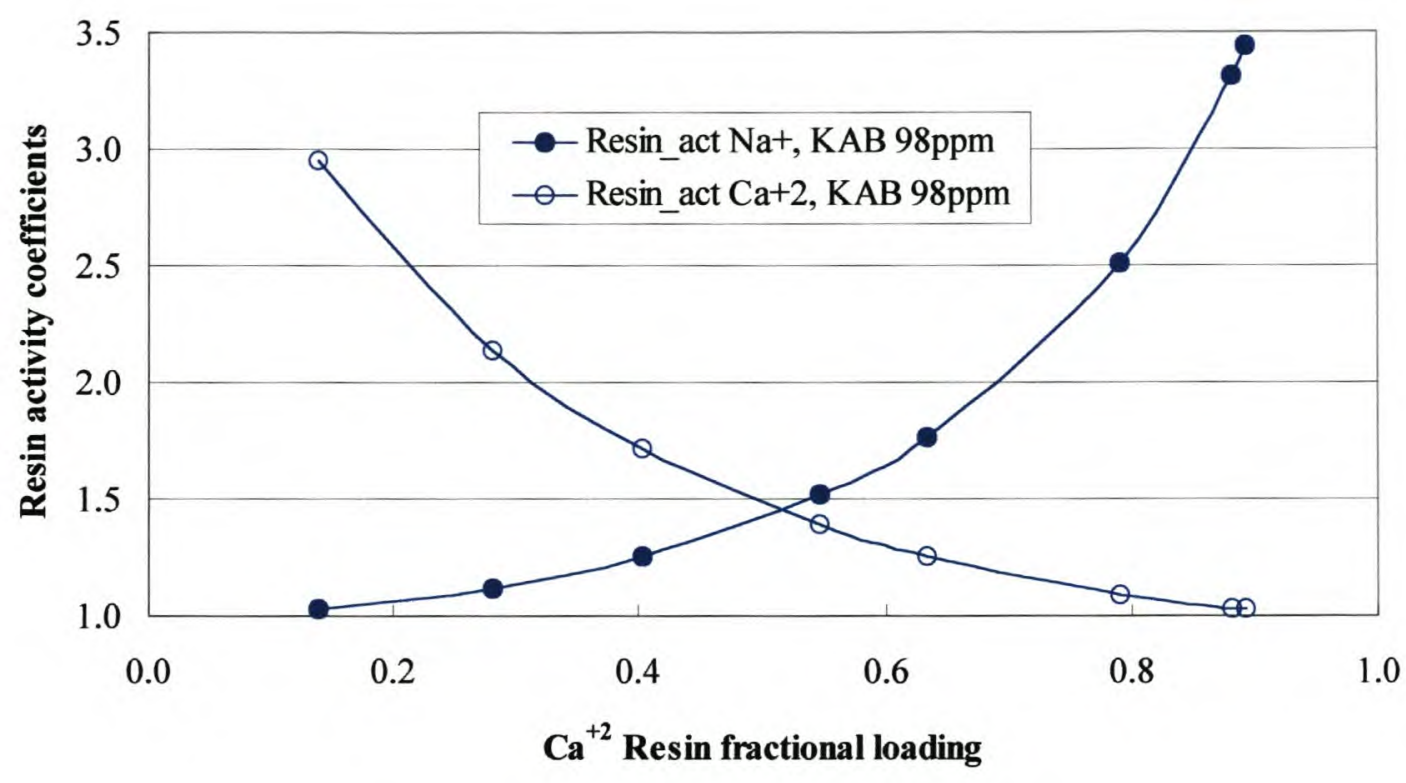

Figure 9.30 Resin activity coefficients for $\mathrm{Na}^{+}-\mathrm{Ca}^{+2}$ exchange at $98 \mathrm{ppm} \mathrm{Ca}{ }^{+2}$.

It is evident that for this particular exchange reaction the value of the resin phase activity coefficient of the $\mathrm{Ca}^{+2}$ ion decreases as its resin phase fractional loading increases. The same trend holds for the $\mathrm{Na}^{+}$ion if it is remembered that the sum total of the fractional loadings of the two cations equates to unity. It is further evident from Figures (9.28) to (9.30) that the values of the resin phase activity coefficients for both cations are greater than unity for the three different solution phase concentrations. The values as displayed in Figures (9.28) to (9.30) are used in the consolidated equilibrium model for the RIP slurry mixture system.

The calculated equilibrium quotient for various species may differ significantly, depending on the solution phase activity coefficients of the species as is evident from Equation (5.27). Significantly different values of the equilibrium quotient may be obtained for two ion-exchange systems with similar values for all of the model parameters in Equation (5.27) except the solution phase activity coefficients. The values of the solution phase activity coefficients depend strongly the values of the Pitzer 
parameters, which emphasise the important role of the SQL7 data base for using consistent and representative values for the Pitzer parameters obtained from the literature.

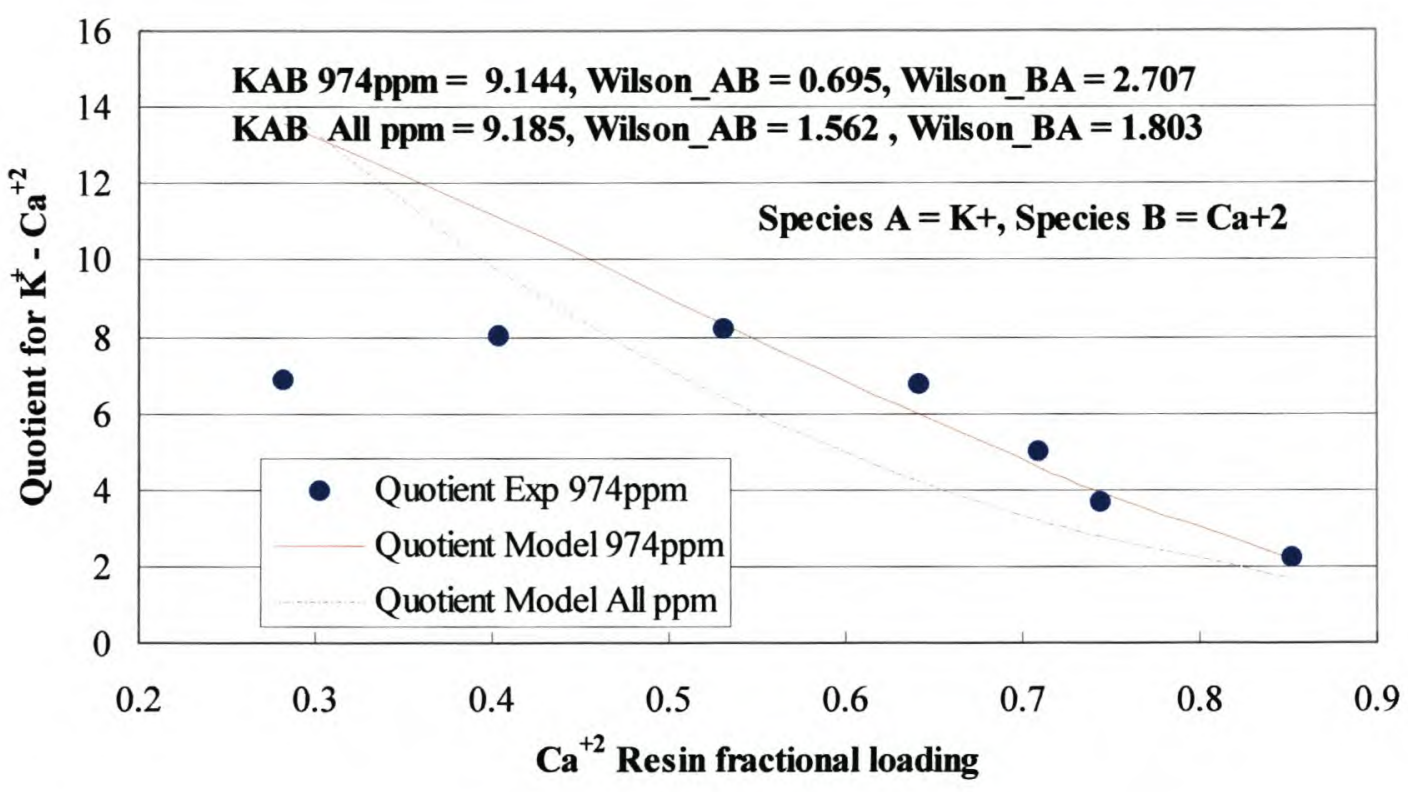

Figure 9.31 Model prediction of the equilibrium quotient for the exchange reaction between $\mathrm{Ca}^{+2}$ and $\mathrm{K}^{+}$for a solution phase concentration of 0.0243 moles/litre.

The thermodynamic equilibrium constant for the monovalent-bivalent exchange reaction between the $\mathrm{K}^{+}$and $\mathrm{Ca}^{+2}$ has been calculated for each individual data set for the different concentration ranges as well as for all of the data sets combined. The results of these calculations are given in Table 9.7. Values for $K_{A}^{B}, \Lambda_{A B}$ and $\Lambda_{B A}$ of 9.185, 1.562 and 1.803 have been obtained from the combined data set. From Figures (9.22) to (9.24) it is evident that a significant distribution in the values of $K_{A}^{B}$ for the exchange reaction between $\mathrm{Na}^{+}$and $\mathrm{Ca}^{+2}$ exists. The $K_{A}^{B}$ values for the between $\mathrm{K}^{+}$and $\mathrm{Ca}^{+2}$ do not show the same distribution. The values of the $K_{A}^{B}$ parameters for the $\mathrm{K}^{+}-\mathrm{Ca}^{+2}$ system is much closer together as shown in Table 9.7. 


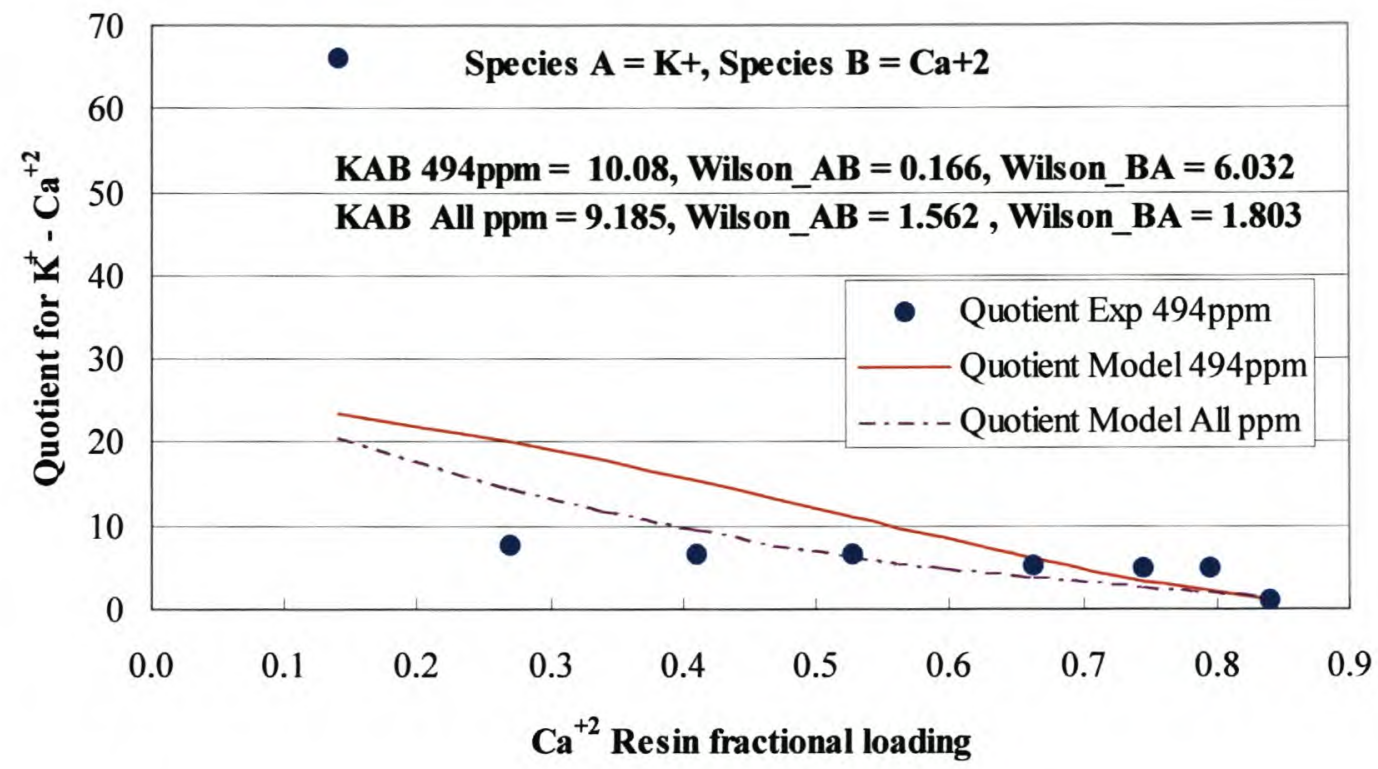

Figure 9.32 Model prediction of the equilibrium quotient for the exchange reaction between $\mathrm{Ca}^{+2}$ and $\mathrm{K}^{+}$for a solution phase concentration of 0.0123 moles/litre.

Figures (9.31) to (9.33) give the model prediction values and the experimentally calculated values for the equilibrium quotient for the different solution phase concentrations for the exchange reaction between $\mathrm{K}^{+}$and $\mathrm{Ca}^{+2}$. It is evident from Figures (9.31) to (9.33) that there are experimental errors associated with the extreme boundaries of the curves where the values of the resin fractional loading are close to zero or unity. This has been the same for the exchange reaction between $\mathrm{Na}^{+}$and $\mathrm{Ca}^{+2}$, as was evident from Figures (9.24) to (9.26). Experimental errors are associated with the data points when one of the phase compositions approaches an extreme (Mehablia et al., 1994). It is also evident by comparing Figures (9.24) to (9.26) with Figures (9.31) to (9.33) that the general trend lines for the model predicted values of the equilibrium quotient have opposite slopes. In Figures (9.24) to (9.26) the slope of the model predicted trend lines were positive, which showed an increase in the value of the equilibrium quotient with an 
increase in the value of the resin fractional loading of the $\mathrm{Ca}^{+2}$ ions on the ion-exchange resin. The opposite is observed for Figures (9.31) to (9.33).

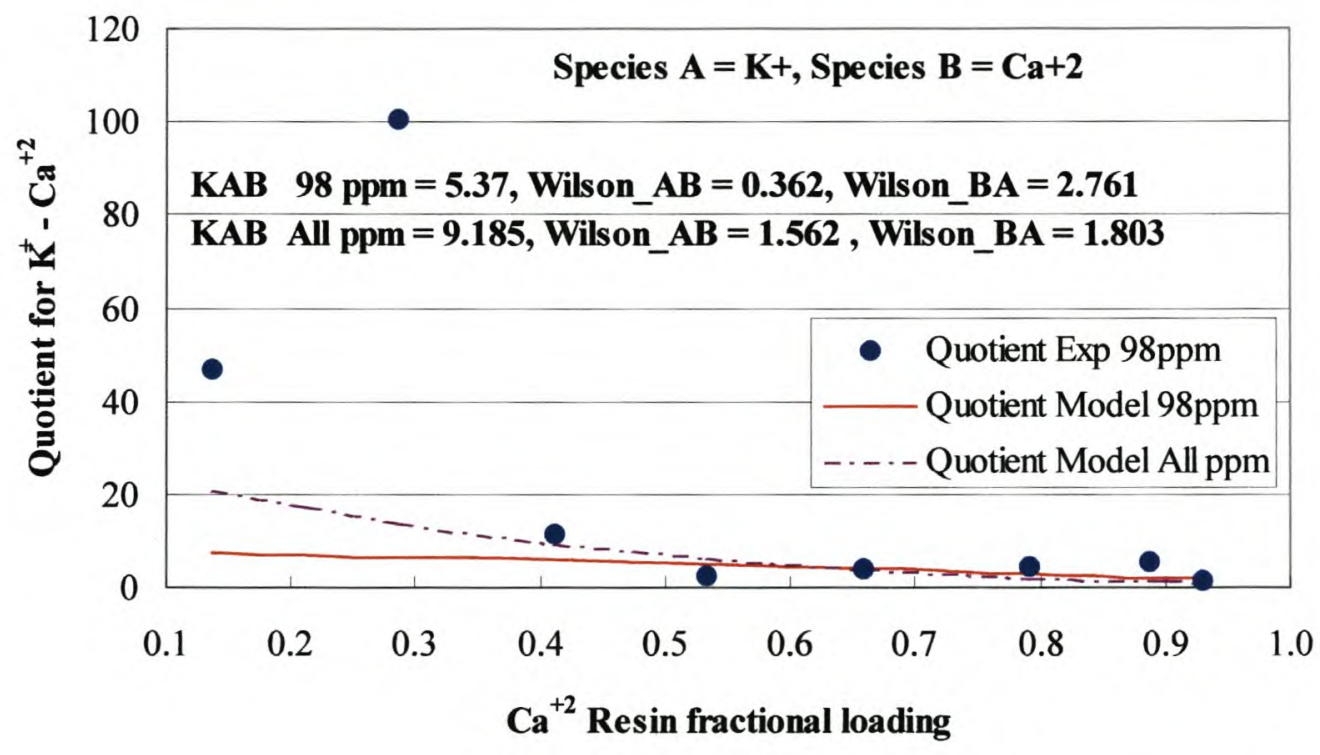

Figure 9.33 Model prediction of the equilibrium quotient for the exchange reaction between $\mathrm{Ca}^{+2}$ and $\mathrm{K}^{+}$for a solution phase concentration of 0.0024 moles/litre.

The values for the thermodynamic equilibrium quotients obtained from the optimisation routine are of the same order of magnitude for the two exchange reactions between $\mathrm{Na}^{+}$ and $\mathrm{Ca}^{+2}$, and $\mathrm{K}^{+}$and $\mathrm{Ca}^{+2}$. The main differences between the estimated values for the $K_{A}^{B}, \Lambda_{A B}$ and $\Lambda_{B A}$ parameters for the two exchange reactions lie in the values of the Wilson interaction parameters. 


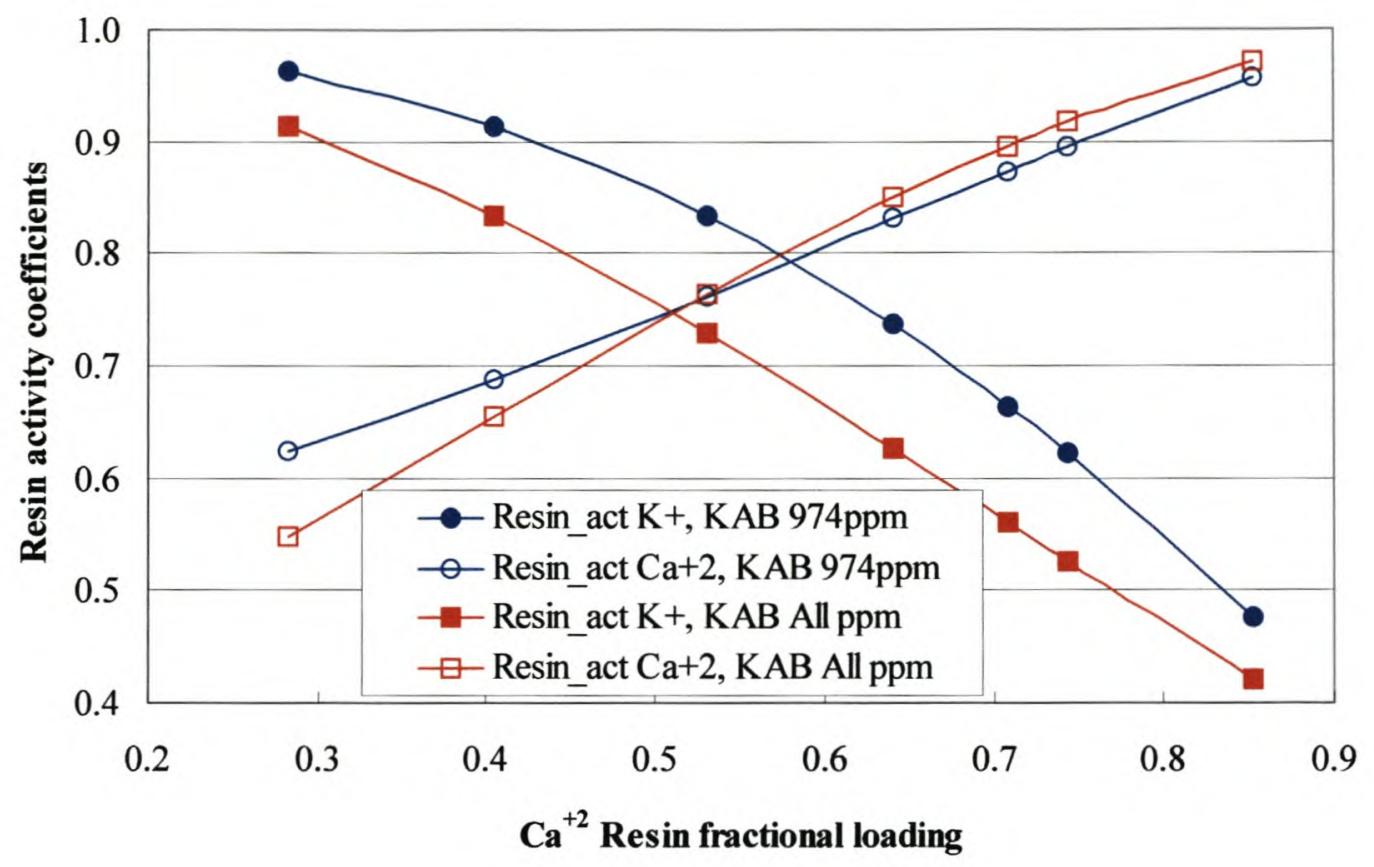

Figure 9.34 Resin activity coefficients for $\mathrm{K}^{+}-\mathrm{Ca}^{+2}$ exchange at $974 \mathrm{ppm} \mathrm{Ca}{ }^{+2}$.

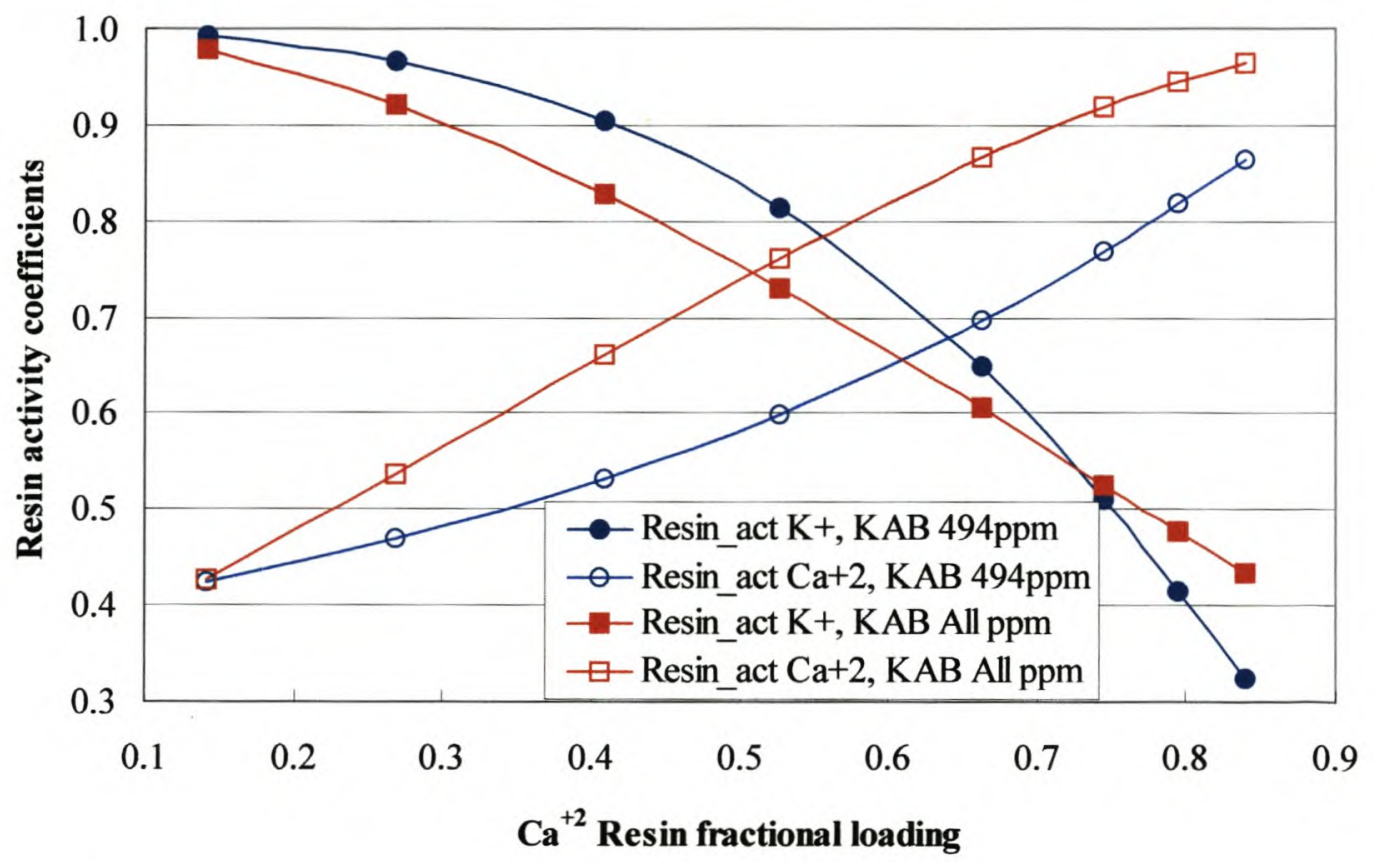

Figure 9.35 Resin activity coefficients for $\mathrm{K}^{+}-\mathrm{Ca}^{+2}$ exchange at $494 \mathrm{ppm} \mathrm{Ca}^{+2}$. 


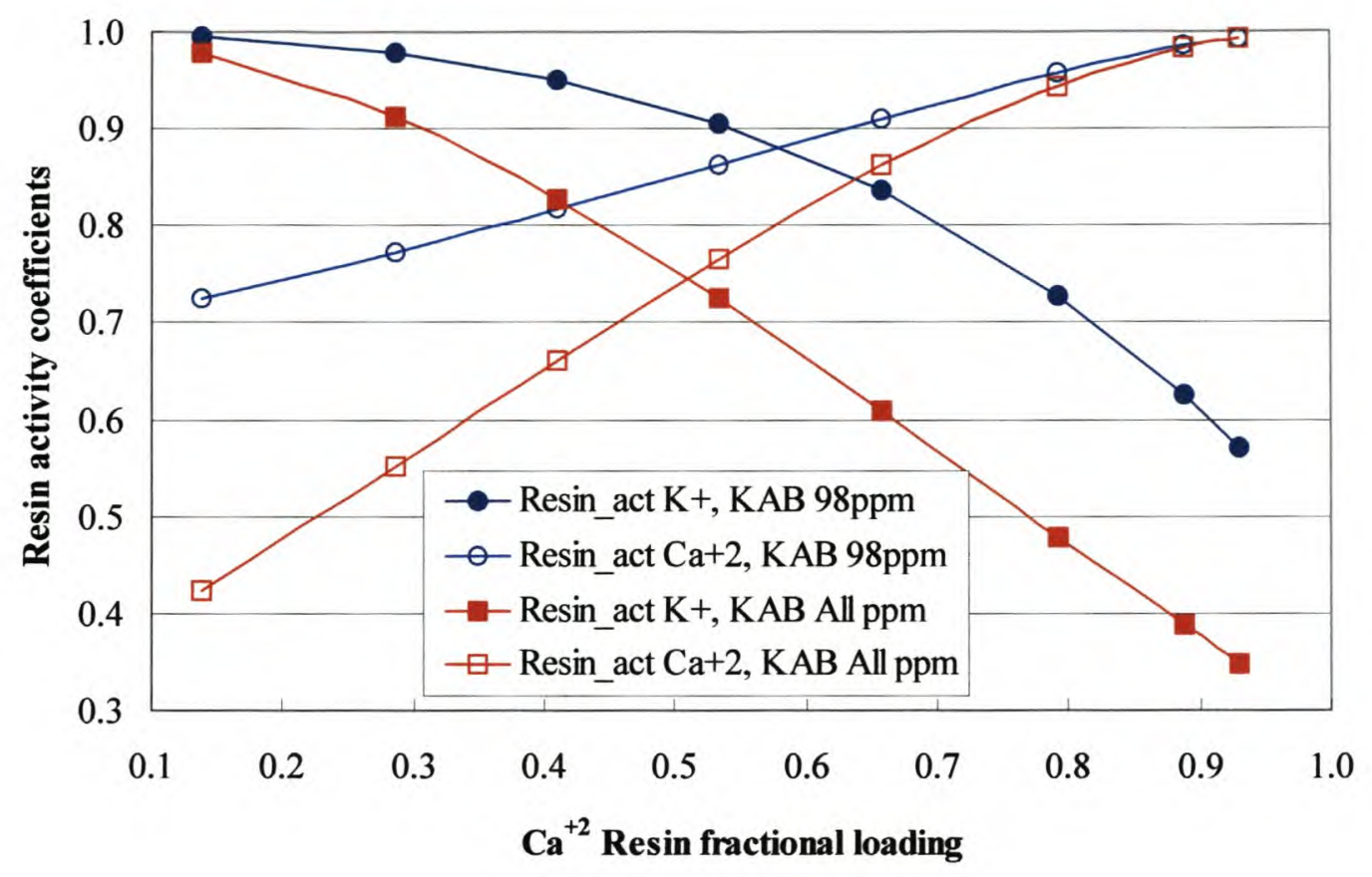

Figure 9.36 Resin activity coefficients for $\mathrm{K}^{+}-\mathrm{Ca}^{+2}$ exchange at $98 \mathrm{ppm} \mathrm{Ca} \mathrm{Ca}^{+2}$.

The values for the resin phase activity coefficients for the exchange reaction between $\mathrm{K}^{+}$ and $\mathrm{Ca}^{+2}$ are shown in Figures (9.34) to (9.36) for two different sets of the Wilson interaction parameters. The first set of parameters is obtained from the estimation based on each individual data set for a particular $\mathrm{Ca}^{+2}$ solution phase concentration and the other parameters set is obtained from the estimation based on the combined data set.

It is evident that significant differences between the different parameter sets may exist. This implies that the average $K_{A}^{B}$ value may not always be used to model the behaviour of the RIP slurry mixture system over wide concentration ranges of interest. It may be necessary to use the appropriate value of the $K_{A}^{B}$ parameter according to the value of the total solution phase concentration of the RIP slurry mixture system. It is evident from Figure (9.13) that the total solution phase concentration of a typical RIP slurry mixture system may vary substantially as the amount of the ion exchange resin varies. 
From Figures (9.28) to (9.30) it is evident that the calculated values of the resin phase activity coefficients for both the $\mathrm{Na}^{+}$and $\mathrm{Ca}^{+2}$ ions are greater than unity. From Figures (9.34) to $(9.36)$ the calculated values for the resin phase activity coefficients for the $\mathrm{K}^{+}$ and $\mathrm{Ca}^{+2}$ ions were less than unity. For the exchange reaction between $\mathrm{Na}^{+}$and $\mathrm{Ca}^{+2}$ ions the resin phase activity coefficient for the $\mathrm{Ca}^{+2}$ species decreases towards unity as the resin fractional loading of the $\mathrm{Ca}^{+2}$ species increases.

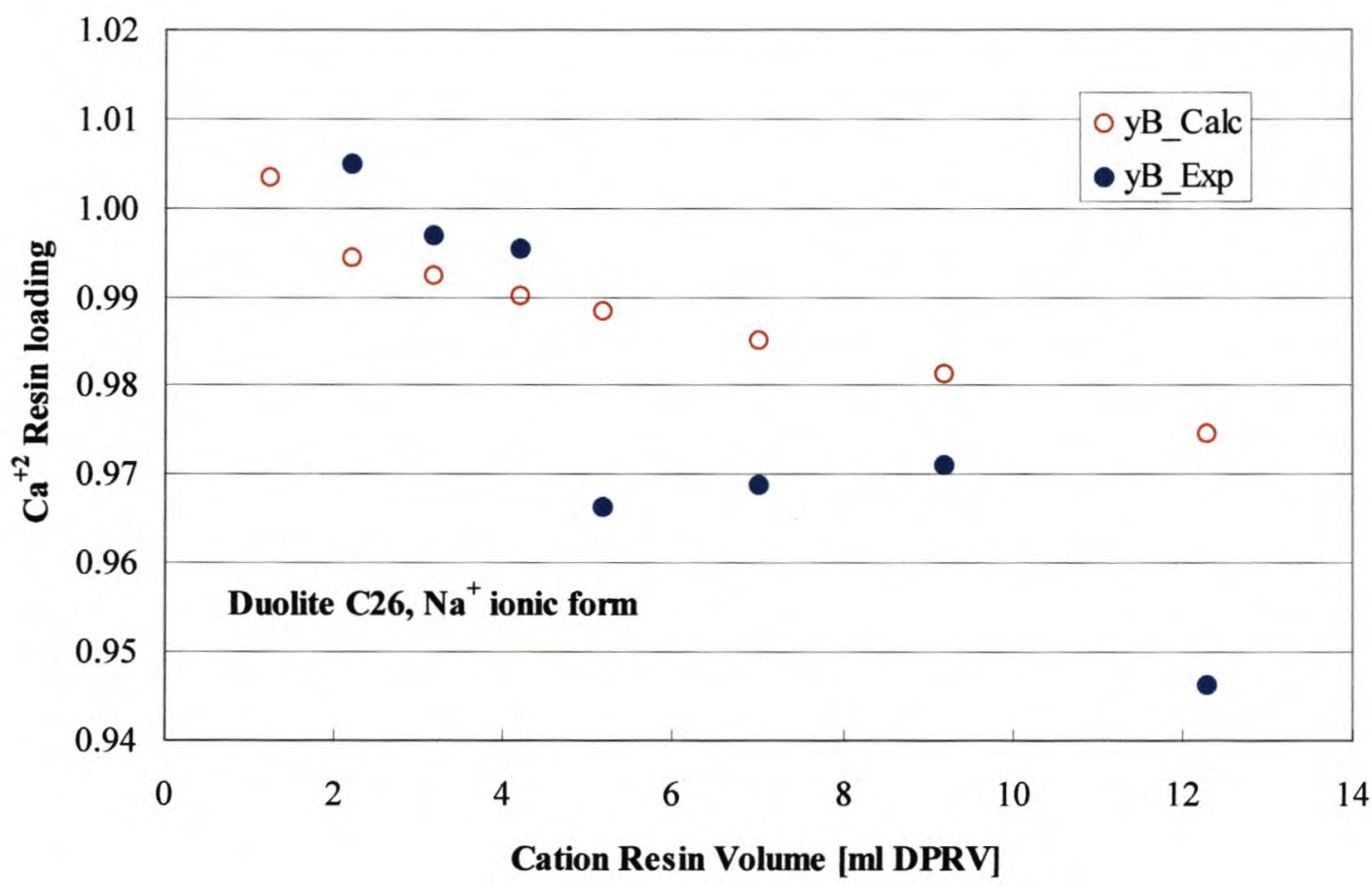

Figure 9.37 Model Prediction of the $\mathrm{Ca}^{+2}$ resin loading on the Cation exchange resin Duolite $\mathrm{C} 26$ for the $\mathrm{CaSO}_{4} \cdot 2 \mathrm{H}_{2} \mathrm{O}$ RIP slurry mixture system.

For the exchange reaction between $\mathrm{K}^{+}$and $\mathrm{Ca}^{+2}$ the resin phase activity coefficient for the $\mathrm{Ca}^{+2}$ species increases towards unity as the resin fractional loading of the $\mathrm{Ca}^{+2}$ species increases. The values for the resin phase activity coefficients as calculated with the estimated Wilson interaction parameters are used in the consolidated equilibrium model 
for the RIP slurry mixture system of $\mathrm{CaSO}_{4}$ with the cation exchange resin in the $\mathrm{Na}^{+}$and $\mathrm{K}^{+}$ionic form respectively.

The values for the resin phase activity coefficients displayed in Figures (9.34) to (9.36) were used in the consolidated equilibrium model calculations for the $\mathrm{CaSO}_{4} \cdot 2 \mathrm{H}_{2} \mathrm{O} \mathrm{RIP}$ slurry mixture system. Figure (9.37) gives the $\mathrm{Ca}^{+2}$ resin loading for the RIP slurry mixture system containing only a cation resin in the $\mathrm{Na}^{+}$ionic form. The results of the consolidated equilibrium model are given as well in Figure (9.37). The consolidated equilibrium model results were obtained from the model as presented in Chapter 6 with the values of the activity coefficients for the solution and resin phases as calculated above. The results in Figure (9.37) are typical of the consolidated equilibrium model for a bivalent-monovalent RIP slurry mixture system as described by Equation (9.1) below, which is obtained from Appendix B of this dissertation.

$$
\begin{aligned}
K_{\text {diiss }} & =\frac{\left(\overline{a_{B}}\right)\left(a_{A}\right)^{\frac{z_{B}}{z_{A}}}\left(a_{Y}\right)}{\left(\overline{a_{A}}\right)^{\frac{z_{B}}{z_{A}}}} \\
& =\left[\left(a_{B}\right)\left(a_{Y}\right)\right]\left[\frac{\left(\overline{a_{B}}\right)\left(a_{A}\right)^{\frac{z_{B}}{z_{A}}}}{\left(\overline{a_{A}}\right)^{\frac{z_{B}}{z_{A}}}\left(a_{B}\right)}\right] \\
& =K_{s p} K_{A}^{B}
\end{aligned}
$$

From Figure (9.8) a similar trend to that displayed in Figure (9.37) is evident for the resin loading of the $\mathrm{Pb}^{+2}$ ions on the cation exchange resin in the $\mathrm{Na}^{+}$ionic form. The units of the resin loading in Figure (9.8) are in equivalent moles per litre while the units in Figure (9.37) are displayed as a fractional loading. It is evident from Equation (9.1) that the thermodynamic dissolution constant $K_{\text {diss }}$ is dependent on various parameters relating to 
the RIP slurry mixture system configuration. The importance of the calculated activity coefficients for both the resin and solution phases is evident. The effect of the RIP slurry mixture system configuration is clearly evident from Table 6.1 of chapter 6 when comparing the expression for the thermodynamic dissolution constant $K_{\text {diss }}$ for the various systems with one another.

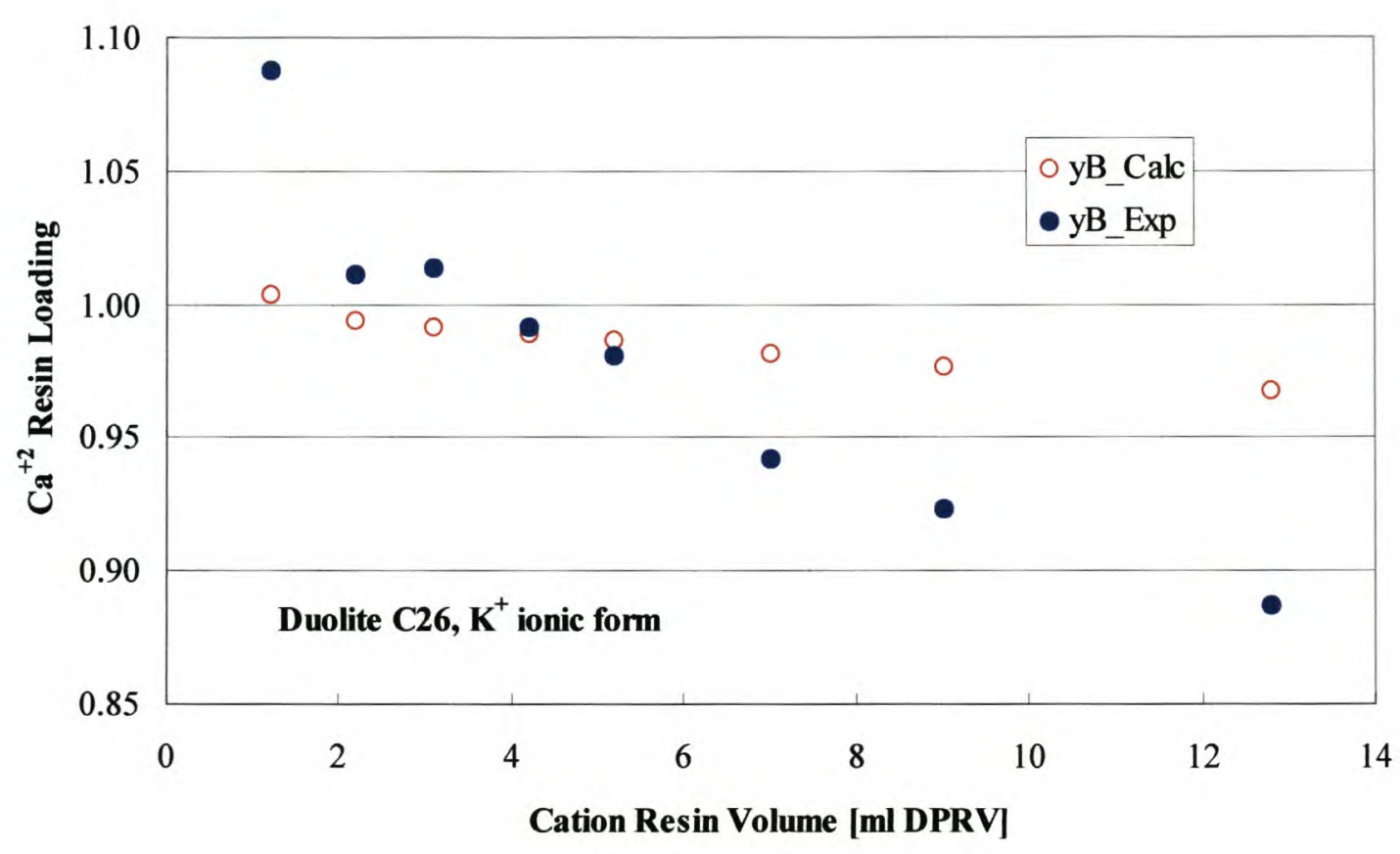

Figure 9.38 Model Prediction of the $\mathrm{Ca}^{+2}$ resin loading on the Cation exchange resin Duolite $\mathrm{C} 26$ for the $\mathrm{CaSO}_{4} \cdot 2 \mathrm{H}_{2} \mathrm{O}$ RIP slurry mixture system.

From Table 6.1 and Equation (9.1) it is evident that the calculated values of the activity coefficients are raised to various powers depending on the electrochemical valence of the species. Any inaccuracy in these calculations will therefore be amplified which may cause model deviations for the consolidated equilibrium model for the RIP slurry mixture system. The verification of the accuracy of the thermodynamic property values used in the calculations is therefore of significant importance. Difficulties in doing this for the Pitzer ion interaction model parameters are often experienced if very little data are 
available from the literature. This is usually the case for species of higher electrochemical valences.

The model results of the consolidated equilibrium model for the $\mathrm{Ca}^{+2}-\mathrm{K}^{+}$system is given by Figure (9.38), which gives the equilibrium resin loading of the $\mathrm{Ca}^{+2}$ ions for different volumes of the cation exchange resin in the $\mathrm{K}^{+}$ionic form. The trend lines in Figures (9.38) and (9.37) are similar as expected because of the fact that both are for a bivalent-monovalent RIP slurry mixture system. From Figures (9.37) and (9.38) it is evident that the model predictions differ slightly from the experimental data. This may be attributed to various factors including the quality of the thermodynamic data used in the calculations and the model assumption made in Chapter 6, paragraph 6.3. From Equation (9.1) it is evident that the value of the thermodynamic equilibrium constant for the ionexchange reaction is used to obtain the value of the thermodynamic dissolution constant. Figure (9.27) shows that the value of the thermodynamic equilibrium constant may vary significantly with a change in the total solution phase concentration. Part of the model deviations observed in Figures (9.37) and (9.38) may therefore be attributed to the value used of the thermodynamic equilibrium constant.

\subsection{SUMMARY}

From the above discussion of the model results it is evident that various thermodynamic parameters may have a significant influence on the model predictions of the various parts of the consolidated equilibrium model for a typical RIP slurry mixture. In the estimation of the values for the $K_{A}^{B}, \Lambda_{A B}$ and $\Lambda_{B A}$ parameters there are several difficulties that may cause inaccurate model predictions. The importance of these parameters in the consolidated equilibrium model predictions is evident from Table 6.1 of Chapter 6 of this dissertation. From Table 6.1 it follows that the estimated value of the thermodynamic equilibrium constant $K_{A}^{B}$ plays an important role in the value of the overall thermodynamic dissolution constant for the RIP slurry mixture system. 
The thermodynamic dissolution constant for different configurations of the RIP slurry mixture system have been defined and derived in Appendix B of this dissertation. Paragraph 2.1 in Appendix B is representative of the typical scenario that exists for the monovalent-bivalent exchange reaction in a RIP slurry mixture system of $\mathrm{CaSO}_{4}$ with cation resins in the $\mathrm{K}^{+}$and $\mathrm{Na}^{+}$ionic form. Equation (13) gives the value of the thermodynamic dissolution constant, which indicates the role of the thermodynamic equilibrium constant $K_{A}^{B}$ in the model predictions of the consolidated equilibrium model.

Another influence on the model predictions of the consolidated equilibrium model is the effect of experimental errors associated with data points when one of the phase compositions approaches an extreme (Mehablia et al., 1994). This was evident from the results for the calculated values of the equilibrium quotient from the experimental data presented in this chapter. As discussed, only a slight error in the experimental data at the phase extremes may cause a significant deviation in the calculated values of the equilibrium quotients and other model parameters. This is evident from Equation (5.27), which shows that the value of the equilibrium quotient as used in the objective function of the optimisation procedure is dependent on various experimentally measured and calculated values. A slight deviation in any one of the experimentally measured or calculated values is amplified by the powers in Equation (5.27). Experimental data collected near the phase boundary extremes are therefore less useful in the determination of the model parameters for the consolidated equilibrium model for the RIP slurry mixture system.

It was also found that the value of the thermodynamic equilibrium constant for the exchange reaction between $\mathrm{Na}^{+}$and $\mathrm{Ca}^{+2}$ decreased with a decrease in the total solution phase concentration of the $\mathrm{Ca}^{+}$ions. This is evident from Figure (9.27). Similar results were obtained in the literature by other researchers, of which Allen et al. (1989) summarised the results of various literature sources. From Allen et al. (1989) it is evident that the exchange reactions between $\mathrm{Ni}^{+2}$ and $\mathrm{Na}^{+}, \mathrm{Mn}^{+2}$ and $\mathrm{Na}^{+}$, and $\mathrm{Cu}^{+2}$ and $\mathrm{Na}^{+}$ showed similar trends for the decrease in the value of the thermodynamic equilibrium 
constant for a decrease in the total solution phase concentration. The solution phase concentrations for the various species of interest decreased from $1 \mathrm{~N}$ to $0.01 \mathrm{~N}$ while the values of the thermodynamic equilibrium constant decreased by an order of magnitude. The results in Allen et al. (1989) were obtained for various types of cation exchange resins, which indicates that this is a general trend for ion-exchange resins.

A similar trend was observed for the ion-exchange resin used in this dissertation. Figure (9.1) showed the equilibrium isotherms for the exchange reaction between $\mathrm{Pb}^{+2}$ ions and various monovalent, bivalent and trivalent cations. From Figure (9.1) it is evident that as the solution phase concentration of the $\mathrm{Pb}^{+2}$ ions decreases the difference between the various isotherms becomes less significant. This means that the cation exchange resin does not show significant differences in its selectivity towards the different species at low solution phase concentrations, which result in values of $K_{A}^{B}$ closer to unity for stoichiometrically equivalent species. This implies that the selectivity of the ionexchanger in a typical RIP slurry mixture system will cause less of a difference in the equilibrium isotherms for species of different electrochemical valences. This will result in a scenario where the equilibrium curves for the various RIP slurry mixture systems for species with different electrochemical valences will be closer together as was shown in Figure (9.6).

Another important influence on the predictions of the consolidated equilibrium model is the values of the thermodynamic properties used. In the calculation of the solubility of the sparingly soluble solid the values of the thermodynamic model parameters used are of paramount importance, as indicated by Linkson (1996). As discussed previously, a SQL7 data base was constructed and populated with thermodynamic data from various literature sources. The data in the data base from the various literature sources were then compared with one another to ensure consistency of the values used in the consolidated equilibrium model. 
In Chapter 10 the general case for the bivalent-bivalent RIP slurry mixture system will be discussed and modelled with the proposed consolidated equilibrium model. The general mechanistic considerations on the dissolution of a sparingly soluble solid in a RIP slurry mixture discussed in paragraph 9.2 will be used in Chapter 10 . 


\section{CHAPTER 10}

\section{RESULTS FOR THE BIVALENT-BIVALENT SLURRY RESIN SYSTEM}

From Figure (9.1) in Chapter 9 it is evident that various equilibrium isotherms exist for the exchange reaction between $\mathrm{Pb}^{+2}$ ions and the various monovalent; bivalent and trivalent species. From the discussions in Chapter 9 it was clear that for an increase in the electrochemical valence of the exchanging species the selectivity of the ionexchange resin for the specific species became more pronounced especially at higher solution phase concentrations. For the general low solution phase concentrations of the constituent ions of the sparingly soluble solid that exist in a typical Resin-in-Pulp (RIP) slurry mixture system the difference in selectivity of the ion exchange resin between species of different electrochemical valence is substantially less.

This results in a scenario of similar equilibrium isotherm curves for the thermodynamic dissolution constant of the RIP slurry mixture system for different ionic forms of the cation exchange resins. This was evident from Figure (9.6), which indicated that the equilibrium isotherm curves for the monovalent, bivalent and trivalent ionic forms of the cation exchange resin overlapped to some degree. It is therefore expected that the bivalent-bivalent RIP slurry mixture system will show similar trends to the equilibrium curves of monovalent-bivalent RIP slurry mixture system. The differences between the various RIP slurry mixture systems are accounted for by the electroneutrality and mass balance equations as derived in paragraph 6.4 of Chapter 6 of this dissertation. It is expected that these equations will highlight the differences between the various RIP systems to a greater extent than the equilibrium isotherm curves by means of the different values of the species valences used in the equations. 


\subsection{OBJECTIVES OF THIS CHAPTER}

The primary objective of this chapter is the calculation of the various model parameters from the experimental data as collected for the bivalent-bivalent RIP slurry mixture system. The thermodynamic parameters, as obtained from the constructed SQL7 data base, used in the model parameter calculations are given below for referencing to other literature sources the reader may whish to consult.

The general considerations for the dissolution of a sparingly soluble solid in the bivalent-bivalent RIP slurry mixture system will be investigated and the equations for the model parameters as derived in Chapter 6 will be fitted to the experimental data. From Table 9.1 in Chapter 9 it is evident that various bivalent-bivalent slurry mixture systems were investigated experimentally. The ionic form of the cation exchange resin used in the experiments was the $\mathrm{Cu}^{+2}$ ionic form. This ionic form was used due to the high solubility of the $\mathrm{Cu}^{+2}$ ion compared to other bivalent metal ions such $\mathrm{Ca}^{+2}$, $\mathrm{Mg}^{+2}, \mathrm{Ba}^{+2}$ and $\mathrm{Pb}^{+2}$ when used in the RIP slurry mixture system experiments containing anions such as the $\mathrm{SO}_{4}{ }^{2-}$ ion. $\mathrm{An}$ ionic form of the cation resin was required that would not form another precipitate with the constituent ion of the sparingly soluble solid at the prevalent solution phase concentrations of the RIP slurry mixture system. For the purposes of this chapter the $\mathrm{SO}_{4}{ }^{2-}$ ion is the possible ion of the sparingly soluble solid with which the $\mathrm{Cu}^{+2}$ ion may form a $\mathrm{CuSO}_{4}$ precipitate.

It is a further objective of this chapter to perform solubility calculations for the $\mathrm{CaSO}_{4}$ sparingly soluble solid in the various electrolyte solutions created in the RIP slurry mixture system. The Pitzer model parameters used in these calculations will be given for reference purposes. In the calculation of the solubility of the sparingly soluble solid all of the Pitzer model parameters may not necessarily be available. This is especially the case for the interaction parameters between the constituent ions of the sparingly soluble solid. The reason for the absence of Pitzer model parameters for sparingly soluble solids is the fact that the data available for the estimation of the parameters are solubility limited to dilute solutions (Pitzer, 1991).

In Chapter 11 of this dissertation it will be shown that the Pitzer model parameters may be estimated from the availability of other species' model parameters that have 
similar electrochemical valences. In the selection of the second virial coefficients Pitzer (1991) noted that there should be some relationship between the two parameters $\beta^{(0)}$ and $\beta^{(1)}$. It was found that there exists a general relationship between these two parameters for most electrolyte solutions but that the relationship is not an exact dependence (Pitzer, 1991).

The differential evolution optimisation routine, as described Appendix E of this dissertation, was used with settings for the parameters as shown in Table 10.4. These parameters include the initial population size, vector-scaling coefficient, number of generations, crossover probability and the estimation strategy for the routine. These parameters were kept constant for the various parameter estimations performed for the different sets of experimental data for the resin / solution data. A typical graph for the objective function described by Equation (5.35) will be given with the values of the parameters used for reference purposes. The optimisation procedure showed relatively fast convergence with good repeatability of the estimated model parameter values for successive independent runs. From the discussions in Appendix $\mathrm{E}$ it is evident that a random initialisation method is used to generate vectors of possible model values. This random procedure adds confidence to the estimated model parameter values as obtained from the optimisation routine given that good agreement exists between different sets of parameters obtained from independent successive estimations.

\subsection{GENERAL MECHANISTIC CONSIDERATIONS FOR THE DISSOLUTION AND SORPTION OF $\mathrm{CaSO}_{4}$ IN A BIVALENT- BIVALENT RIP SLURRY MIXTURE SYSTEM}

From Table 6.1 in Chapter 6 of this dissertation the thermodynamic dissolution constant for various RIP slurry mixture systems are given as a function of the solubility product and the thermodynamic equilibrium constant of the ion-exchange reaction. For the current RIP slurry mixture system of interest Equations (25) to (30) of Appendix B may be written as given below for the $\mathrm{CaSO}_{4} \cdot 2 \mathrm{H}_{2} \mathrm{O}$ RIP slurry mixture system. In the equations below the cation resin is in the $\mathrm{Cu}^{+2}$ ionic form and it is 
assumed that for the purpose of this dissertation the solution phase concentration of the $\mathrm{SO}_{4}{ }^{2-}$ ions is small enough to prevent the formation of a $\mathrm{CuSO}_{4}$ precipitate.

The dissolution reaction for the $\mathrm{CaSO}_{4}$ precipitate is given by Equation (10.1) below

$$
\|\left.\left(\mathrm{Ca}^{2+}\right)\left(\mathrm{SO}_{4}{ }^{2-}\right)\right|_{s} \stackrel{\mathrm{K}_{s p}}{\longleftrightarrow} \mathrm{Ca}^{2+}+\mathrm{SO}_{4}{ }^{2-}
$$

The solubility product for the $\mathrm{CaSO}_{4} \cdot 2 \mathrm{H}_{2} \mathrm{O}$ precipitate is defined by Equation (10.2) if the water activity is ignored,

$$
K_{s p}=\left(a_{-} \mathrm{Cu}\right)\left(a_{-} S \mathrm{~S}_{4}\right)
$$

with the solubility of the $\mathrm{Ca}^{+2}$ ions given by Table 2.2 of Chapter 2 as represented by Equation (10.3) below for a sparingly soluble solid dissolving in a stoichiometric oneto-one manner with ideal species behaviour.

$$
S=\left(K_{s p}\right)^{\frac{1}{2}}
$$

The general ion-exchange reaction with the cation exchange resin in the $\mathrm{Cu}^{+2}$ ionic form is given by Equation (10.4) below.

$$
\left[\left(R^{-}\right)_{2} \mathrm{Cu}^{2+}\right]+\mathrm{Ca}^{2+} \stackrel{K_{A}^{B}}{\longleftrightarrow}\left[\left(R^{-}\right)_{2} \mathrm{Ca}^{2+}\right]+\mathrm{Cu}^{2+}
$$

For the ion-exchange reaction above the thermodynamic equilibrium constant, as defined by Equation (5.21) of Chapter 5, may be written as follows.

$$
K_{A}^{B}=\frac{\left(\overline{a_{-} C a}\right)\left(a_{-} C u\right)}{\left(\overline{a_{-} C u}\right)\left(a_{-} C a\right)}
$$

By combining the dissolution reaction for the $\mathrm{CaSO}_{4}$ precipitate and the ion-exchange reaction between the dissolved $\mathrm{Ca}^{+2}$ ions and the $\mathrm{Cu}^{+2}$ ions on the cation exchange 
resin the simultaneous dissolution and sorption reaction for the RIP slurry mixture system may be obtained, given by Equation (10.6).

$\|\left.\left(\mathrm{Ca}^{2+}\right)\left(\mathrm{SO}_{4}{ }^{2-}\right)\right|_{s}+\left[\left(R^{-}\right)_{2} \mathrm{Cu}^{2+}\right] \stackrel{K_{\text {diss }}}{\longleftrightarrow}\left[\left(R^{-}\right)_{2} \mathrm{Ca}^{2+}\right]+\mathrm{Cu}^{2+}+\mathrm{SO}_{4}{ }^{2-}$

From Equation (10.6) the thermodynamic dissolution constant for the equilibrium condition in the RIP slurry mixture system may be derived as given by Equation (10.7) below,

$$
\begin{aligned}
& K_{\text {diss }}=\frac{\left(\overline{a_{-} C a}\right)\left(a_{-} C u\right)\left(a_{-} S O_{4}\right)}{\left(\overline{a_{-} C u}\right)} \\
& =\left[\left(a_{-} C a\right)\left(a_{-} S O_{4}\right)\right]\left[\frac{\left(\overline{a_{-} C a}\right)\left(a_{-} C u\right)}{\left.\overline{\left(a_{-} C u\right.}\right)\left(a_{-} C a\right)}\right] \\
& =K_{s p} K_{A}^{B}
\end{aligned}
$$

where $A$ represents $\mathrm{Cu}^{+2}$ and $B$ the $\mathrm{Ca}^{+2}$ species.

From Equation (10.7) the importance of the thermodynamic equilibrium constant for the ion-exchange reaction in the consolidated equilibrium model is evident. From the discussions in Chapter 9 it was evident that the value of the thermodynamic equilibrium constant for the ion-exchange reaction may vary substantially as the total solution phase concentration varies. The value of the $K_{\text {diss }}$ may therefore also vary for the RIP slurry mixture system. As discussed in the previous chapters it is known that the total solution phase concentration, or ionic strength, of the aqueous phase in the RIP slurry mixture system may vary substantially as the sparingly soluble solid is dissolved. This was evident from Figure (9.13) of Chapter 9, which showed the variation in the total ionic strength of the solution phase for various RIP slurry mixture configurations. This confirms the fact that the thermodynamic dissolution constant $K_{\text {diss }}$ for the ion-exchange reaction may change in the RIP slurry mixture system due to the observed phenomenon in the change of the value of the 
thermodynamic equilibrium constant $K_{A}^{B}$ with a change in the total solution phase concentration.

\subsection{CALCULATION OF THE THERMODYNAMIC EQUILIBRIUM CONSTANT $K_{A}^{B}$ FOR THE BIVALENT-BIVALENT RIP SLURRY MIXTURE SYSTEM BETWEEN $\mathrm{Ca}^{+2}$ AND $\mathrm{Cu}^{+2}$}

As discussed in Chapter 9 it followed that the thermodynamic equilibrium constant $K_{A}^{B}$ and the Wilson interaction parameters $\Lambda_{A B}$ and $\Lambda_{B A}$ for the ion-exchange reaction are estimated from experimental determined values of the equilibrium quotient. The optimisation routine described in Appendix E is used together with the objective function defined by Equation (5.35). The model equations for the thermodynamic equilibrium constant are given by Equations (6.43) to (6.45) of Chapter 6 of this dissertation.

The effect of the accuracy of the experimental data on the values of the estimated model parameters have also been discussed in Chapter 9 and it was shown that the objective function as defined by Equation (5.35) of Chapter 5 gave satisfactory results. Any inaccuracy associated with the experimental data may be amplified in the calculation of the value of the equilibrium quotient $\lambda_{A}^{B}$, represented by Equation (6.45).

From Equation (6.45) it is evident that various experimentally determined parameters and calculations are used in different mathematical relationships to obtain the value of the equilibrium quotient. It was also evident from the model predictions of the experimental data in Chapter 9 that experimental errors are associated with the data points when one of the phase compositions approaches an extreme. This phenomenon in the collection of ion-exchange isotherm data has been recognised by other researchers in the literature (Mehablia et al., 1994). The nature of the objective function given by Equation (5.35) is an attempt to minimise the effect of this phenomenon. In order to minimise the effect of inconsistent thermodynamic data from the literature on the model results the values used in the model equations were checked for consistency in the SQL7 data base as discussed in previous chapters. 
From Chapter 9 it was also evident that the presence of various species was considered in all of the aqueous phase calculations. These species were discussed in paragraph 9.3 of Chapter 9 and include $\mathrm{H}^{+}$ions, $\mathrm{OH}^{-}$ions, aqueous $\mathrm{H}_{2} \mathrm{O}$ molecules, aqueous dissolved $\mathrm{CO}_{2}$ molecules, $\mathrm{CO}_{3}{ }^{2-}$ ions and $\mathrm{HCO}_{3}{ }^{-}$ions present in the aqueous phase.

Table 10.1 Values for the Pitzer model parameters $\beta^{(0)}, \beta^{(1)}, C^{\phi}, \phi$ and $\psi$ used in the calculation of the thermodynamic equilibrium constant $K_{\mathrm{Cu}}^{\mathrm{Ca}}$ for the exchange reaction between $\mathrm{Ca}^{+2}$ and $\mathrm{Cu}^{+2}$ with $\mathrm{Cl}^{-}$as the co-ion. Parameters obtained from SQL7 data base. All Pitzer values shown are multiplied with the gas constant $R=8.31441 \mathrm{~kJ} / \mathrm{kmol} . \mathrm{K}$.

\begin{tabular}{|c|c|c|c|c|}
\hline Species A & Species B & Species C & $\begin{array}{l}\mathbf{R} * \text { Pitzer Parameter } \\
R=8.31441 \mathrm{~kJ} / \mathrm{kmol.K}\end{array}$ & Value \\
\hline $\mathrm{Ca}<2+>$ & $\mathrm{Cu}<2+>$ & \multirow{6}{*}{$\mathrm{Cl}<->$} & $\mathrm{R}^{*} \phi$ & $-4.639 \mathrm{E}-01$ \\
\hline $\mathrm{Ca}<2+>$ & $\mathrm{H}<+>$ & & $\mathrm{R}^{*} \phi$ & 7.649E-01 \\
\hline $\mathrm{Ca}<2+>$ & $\mathrm{H}<+>$ & & $\mathrm{R} * \psi$ & $-1.247 \mathrm{E}-01$ \\
\hline $\mathrm{Ca}<2+>$ & $\mathrm{Cl}<->$ & & $\mathrm{R} * \beta^{(0)}$ & $2.627 \mathrm{E}+00$ \\
\hline $\mathrm{Ca}<2+>$ & $\mathrm{Cl}<->$ & & $\mathrm{R} * \beta^{(1)}$ & $1.342 \mathrm{E}+01$ \\
\hline $\mathrm{Ca}<2+>$ & $\mathrm{Cl}<->$ & & $\mathrm{R} * C^{\phi}$ & $-2.822 \mathrm{E}-03$ \\
\hline $\mathrm{Ca}<2+>$ & $\mathrm{Cl}<->$ & \multirow[t]{14}{*}{$\mathrm{OH}<->$} & $\mathrm{R} * \psi$ & $-2.079 \mathrm{E}-01$ \\
\hline $\mathrm{Ca}<2+>$ & $\mathrm{HCO} 3<->$ & & $\mathrm{R} * \beta^{(0)}$ & $3.324 \mathrm{E}+00$ \\
\hline $\mathrm{Ca}<2+>$ & $\mathrm{HCO} 3<->$ & & $\mathrm{R} * \beta^{(1)}$ & $2.476 \mathrm{E}+01$ \\
\hline $\mathrm{Cl}<->$ & $\mathrm{OH}<->$ & & $\mathrm{R} * \phi$ & $-4.157 \mathrm{E}-01$ \\
\hline $\mathrm{Cl}<->$ & $\mathrm{CO} 3<2->$ & & $\mathrm{R}^{*} \phi$ & $-1.663 \mathrm{E}-01$ \\
\hline $\mathrm{Cl}<->$ & $\mathrm{HCO} 3<->$ & & $\mathrm{R}^{*} \phi$ & 2.494E-01 \\
\hline $\mathrm{CO} 3<2->$ & $\mathrm{HCO} 3<->$ & & $\mathrm{R}^{*} \phi$ & $-3.326 \mathrm{E}-01$ \\
\hline $\mathrm{Cu}<2+>$ & $\mathrm{Cl}<->$ & & $\mathrm{R}^{*} \beta^{(0)}$ & $2.466 \mathrm{E}+00$ \\
\hline $\mathrm{Cu}<2+>$ & $\mathrm{Cl}<->$ & & $\mathrm{R} * \beta^{(1)}$ & $1.157 \mathrm{E}+01$ \\
\hline $\mathrm{Cu}<2+>$ & $\mathrm{Cl}<->$ & & $\mathrm{R} * C^{\phi}$ & $-2.995 \mathrm{E}-01$ \\
\hline $\mathrm{H}<+>$ & $\mathrm{Cl}<->$ & & $\mathrm{R}^{*} \beta^{(0)}$ & $1.476 \mathrm{E}+00$ \\
\hline $\mathrm{H}<+>$ & $\mathrm{Cl}<->$ & & $\mathrm{R} * \beta^{(1)}$ & $2.449 \mathrm{E}+00$ \\
\hline $\mathrm{H}<+>$ & Cl<-> & & $\mathrm{R}^{*} C^{\phi}$ & $6.652 \mathrm{E}-03$ \\
\hline $\mathrm{OH}<->$ & $\mathrm{CO} 3<2->$ & & $\mathrm{R}^{*} \phi$ & $8.314 \mathrm{E}-01$ \\
\hline
\end{tabular}


Table 10.2 Calculated solution phase activity coefficients, resin phase fractional loading for $\mathrm{Ca}^{+2}$ and equilibrium quotient for the cation-exchange reaction between $\mathrm{Ca}^{+2}$ and $\mathrm{Cu}^{+2}$ on Duolite $\mathrm{C} 26$ at a total solution phase concentration for $\mathrm{Ca}^{+2}$ of 0.0243 moles/litre.

\begin{tabular}{|c|c|c|c|c|c|c|c|c|c|c|c|}
\hline \multirow{2}{*}{$\begin{array}{c}\text { Resin } \\
\text { vol } \\
{[\mathrm{ml}]}\end{array}$} & \multirow{2}{*}{\begin{tabular}{|c} 
Soln \\
vol \\
{$[\mathrm{ml}]$}
\end{tabular}} & \multicolumn{3}{|c|}{ Equilibrium concentration } & \multicolumn{5}{|c|}{ Species activity coefficients } & \multirow{2}{*}{$\begin{array}{c}\text { Resin } \\
\text { loading } \\
\mathrm{Ca}^{2+}\end{array}$} & \multirow{2}{*}{$\begin{array}{c}\text { Equil } \\
\text { quotient }\end{array}$} \\
\hline & & $\begin{array}{c}\mathrm{Ca}^{2+} \\
{[\mathrm{mol} / \mathrm{l}]}\end{array}$ & $\begin{array}{c}\mathrm{Cl}^{-} \\
{[\mathrm{mol} / \mathrm{l}]}\end{array}$ & $\begin{array}{c}\mathrm{Cu}^{2+} \\
{[\mathrm{mol} / \mathrm{l}]}\end{array}$ & $\mathrm{Ca}^{2+}$ & $\mathrm{Cl}^{-}$ & $\mathrm{Cu}^{2+}$ & $\mathbf{H}^{+}$ & $\mathbf{O H}^{-}$ & & \\
\hline \multicolumn{12}{|c|}{$\mathrm{Ca}^{2+}$} \\
\hline 48.0 & 250 & $1.2 \mathrm{E}-03$ & 4.3E-02 & 1.9E-02 & 0.419 & 0.824 & 0.413 & 0.790 & 0.777 & 0.095 & 2.2327 \\
\hline 25.0 & 250 & 2.5E-03 & 4.5E-02 & $1.9 \mathrm{E}-02$ & 0.412 & 0.821 & 0.406 & 0.787 & 0.772 & 0.175 & 2.2581 \\
\hline 17.4 & 250 & 3.7E-03 & 4.6E-02 & $1.8 \mathrm{E}-02$ & 0.410 & 0.821 & 0.404 & 0.786 & 0.771 & 0.238 & 2.2113 \\
\hline 12.8 & 250 & $5.2 \mathrm{E}-03$ & 4.8E-02 & $1.7 \mathrm{E}-02$ & 0.407 & 0.819 & 0.401 & 0.784 & 0.768 & 0.301 & 2.1489 \\
\hline 9.8 & 250 & $6.7 \mathrm{E}-03$ & 4.8E-02 & $1.6 \mathrm{E}-02$ & 0.407 & 0.820 & 0.400 & 0.784 & 0.768 & 0.362 & 2.0853 \\
\hline 8.2 & 250 & 7.9E-03 & 4.7E-02 & $1.5 \mathrm{E}-02$ & 0.407 & 0.820 & 0.400 & 0.785 & 0.768 & 0.401 & 2.0003 \\
\hline 7.2 & 250 & 8.7E-03 & $4.8 \mathrm{E}-02$ & $1.4 \mathrm{E}-02$ & 0.407 & 0.820 & 0.400 & 0.785 & 0.768 & 0.434 & 2.0160 \\
\hline 3.6 & 250 & $1.4 \mathrm{E}-02$ & 4.8E-02 & $9.2 \mathrm{E}-03$ & 0.405 & 0.821 & 0.398 & 0.784 & 0.767 & 0.589 & 2.1786 \\
\hline \multicolumn{4}{|c|}{$\mathrm{Ca}^{2+}$} & \multicolumn{8}{|c|}{$1.2 \mathrm{E}-02[\mathrm{~mol} / \mathrm{l}]$} \\
\hline 49.0 & 500 & $6.5 \mathrm{E}-04$ & $2.3 \mathrm{E}-02$ & $1.0 \mathrm{E}-02$ & 0.507 & 0.854 & 0.503 & 0.833 & 0.827 & 0.095 & 415 \\
\hline 24.6 & 500 & 1.3E-03 & 2.3E-02 & 9.7E-03 & 0.504 & 0.854 & 0.500 & 0.832 & 0.826 & 0.180 & 2.3169 \\
\hline 17.2 & 500 & $1.9 \mathrm{E}-03$ & 2.3E-02 & $9.4 \mathrm{E}-03$ & 0.502 & 0.854 & 0.498 & 0.831 & 0.825 & 0.244 & 2.3033 \\
\hline 12.4 & 500 & 2.7E-03 & 2.3E-02 & $8.6 \mathrm{E}-03$ & 0.501 & 0.854 & 0.497 & 0.830 & 0.825 & 0.311 & 2.1281 \\
\hline 9.8 & 500 & $3.5 \mathrm{E}-03$ & 2.4E-02 & $7.9 \mathrm{E}-03$ & 0.500 & 0.853 & 0.496 & 0.830 & 0.824 & 0.362 & 2.0078 \\
\hline 8.0 & 500 & 4.2E-03 & 2.3E-02 & $7.2 \mathrm{E}-03$ & 0.500 & 0.854 & 0.496 & 0.830 & 0.824 & 0.409 & 1.9762 \\
\hline 6.9 & 500 & 4.7E-03 & 2.4E-02 & $6.7 \mathrm{E}-03$ & 0.498 & 0.853 & 0.494 & 0.830 & 0.823 & 0.441 & 1.9254 \\
\hline 3.8 & 500 & $6.8 \mathrm{E}-03$ & 2.3E-02 & $4.8 \mathrm{E}-03$ & 0.498 & 0.854 & 0.493 & 0.830 & 0.823 & 0.580 & 2.1907 \\
\hline \multicolumn{4}{|c|}{$\mathrm{Ca}^{2+}$} & \multicolumn{8}{|c|}{ 2.4E-03 [mol/l] } \\
\hline 20.5 & 1000 & $1.5 \mathrm{E}-04$ & $4.8 \mathrm{E}-03$ & $2.1 \mathrm{E}-03$ & 0.705 & 0.919 & 0.704 & 0.912 & 0.913 & 0.090 & 1.8187 \\
\hline 9.8 & 1000 & $3.0 \mathrm{E}-04$ & $4.8 \mathrm{E}-03$ & $2.0 \mathrm{E}-03$ & 0.704 & 0.919 & 0.702 & 0.911 & 0.912 & 0.178 & 1.9911 \\
\hline 7.1 & 1000 & $4.2 \mathrm{E}-04$ & $4.9 \mathrm{E}-03$ & $1.9 \mathrm{E}-03$ & 0.701 & 0.918 & 0.700 & 0.910 & 0.911 & 0.233 & 2.0607 \\
\hline 5.2 & 1000 & 5.7E-04 & 4.9E-03 & $1.8 \mathrm{E}-03$ & 0.702 & 0.919 & 0.701 & 0.911 & 0.911 & 0.295 & 1.9528 \\
\hline 4.3 & 1000 & $6.8 \mathrm{E}-04$ & $4.9 \mathrm{E}-03$ & $1.6 \mathrm{E}-03$ & 0.702 & 0.919 & 0.701 & 0.911 & 0.911 & 0.332 & 1.8881 \\
\hline 3.4 & 1000 & $8.1 \mathrm{E}-04$ & $4.8 \mathrm{E}-03$ & $1.5 \mathrm{E}-03$ & 0.702 & 0.919 & 0.700 & 0.911 & 0.911 & 0.391 & 1.9748 \\
\hline 3.0 & 1000 & $9.1 \mathrm{E}-04$ & $4.8 \mathrm{E}-03$ & $1.4 \mathrm{E}-03$ & 0.702 & 0.919 & 0.700 & 0.911 & 0.911 & 0.416 & 1.8944 \\
\hline 1.5 & 1000 & $1.4 \mathrm{E}-03$ & $4.8 \mathrm{E}-03$ & $9.5 \mathrm{E}-04$ & 0.701 & 0.919 & 0.699 & 0.910 & 0.911 & 0.544 & 1.6833 \\
\hline
\end{tabular}

The presence of a gaseous phase was also considered and was taken to be in equilibrium with the aqueous phase. As mentioned in Chapter 9 of this dissertation the equilibrium distribution of the various species between the gaseous phase and the aqueous phase was calculated using a Gibbs free energy optimisation routine supplied 
by the CHEMAPP software of GGT-Technologies. The same approach is used in the calculations of this chapter.

The various Pitzer ion-interaction parameters used in the above mentioned calculations for this chapter are given in Table 10.1. The values of all of the parameters given in Table 10.1 were multiplied with the gas constant $R$ as given in Table 10.1. The values of various Pitzer parameters obtained from the literature are multiplied by various factors and the user should ensure that the values of the parameters are converted using the correct factors.

The values for the Pitzer interaction parameters were used to calculate the solution phase activity coefficients for the various species present in the bivalent-bivalent RIP slurry mixture system of $\mathrm{Cu}^{+2}$ and $\mathrm{Ca}^{+2}$. From these values the experimental values for the equilibrium quotient were calculated; this is required in the optimisation routine to obtain the model parameters for the consolidated equilibrium model for the RIP slurry mixture system.

The results of these calculations are shown in Table 10.2. With the values of Table 10.2 the optimisation routine was used to obtain the values for the thermodynamic equilibrium constant and the Wilson interaction parameters for the ion-exchange reaction. The experimental tests were performed for three total solution phase concentrations of the $\mathrm{Ca}^{+2}$ ions. The concentrations used were representative of typical solution phase concentrations of the various species encountered in RIP slurry mixture systems, depending on the amount of ion-exchange resin used per unit volume of the slurry mixture. 


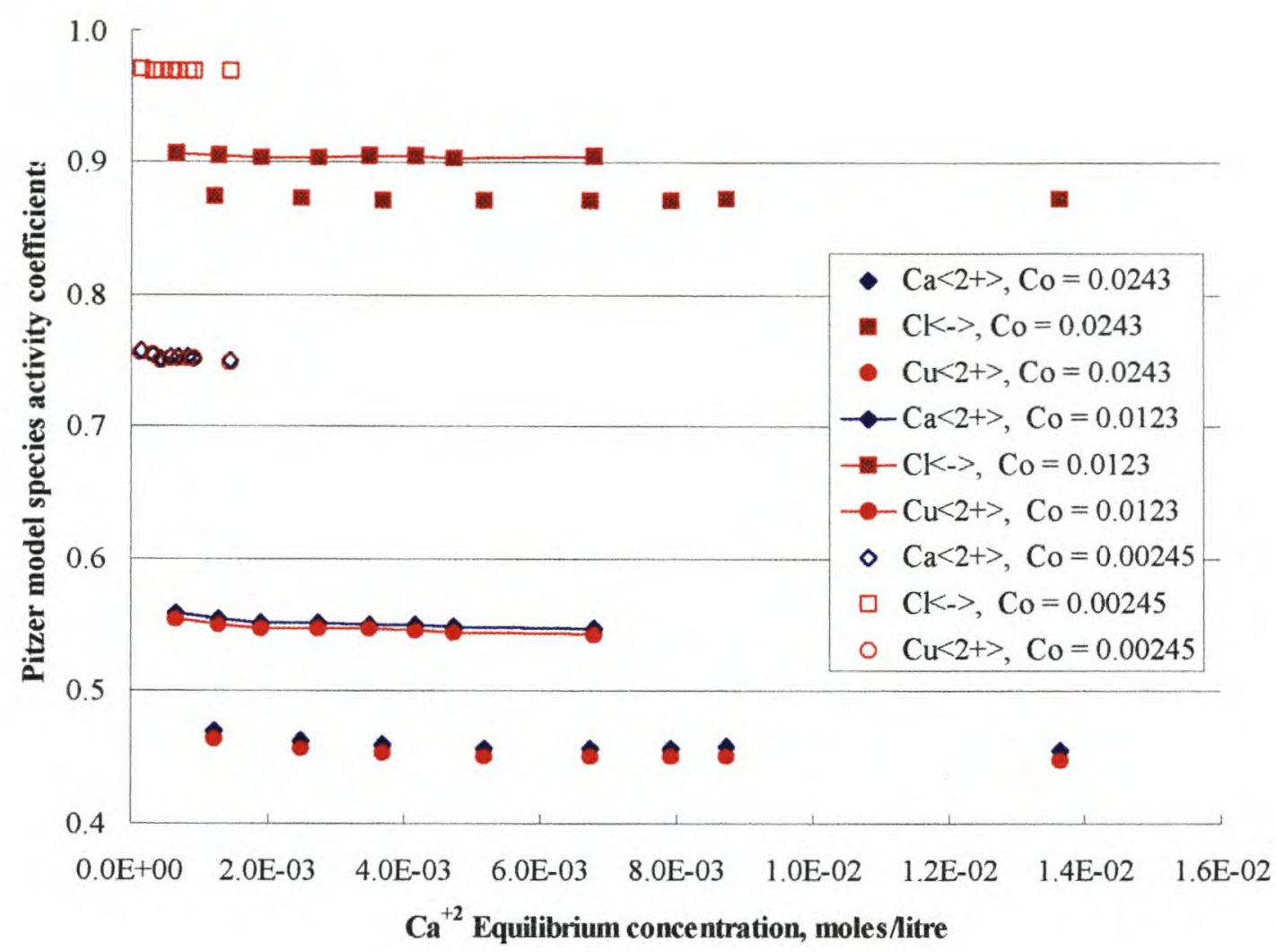

Figure 10.1 Calculated Pitzer model activity coefficients for the aqueous phase species in the resin / solution system for the cation-exchange reaction between $\mathrm{Ca}^{+2}$ and $\mathrm{Cu}^{+2}$ with $\mathrm{Cl}^{-}$as the co-ion for total solution phase concentrations of the $\mathrm{Ca}^{+2}$ species.

Figure 10.1 is a graphical representation of the values of the activity coefficients as given in Table 10.2. From Figure 10.1 it is evident that the activity coefficients for the $\mathrm{Cu}^{+2}$ and $\mathrm{Ca}^{+2}$ ions are very similar for all three solution phase concentrations. This is expected due to the fact that the electrochemical valences of the $\mathrm{Ca}^{+2}$ and $\mathrm{Cu}^{+2}$ ions are the same. It is further evident that a significant decrease in the values of the activity coefficients for the $\mathrm{Ca}^{+2}$ and $\mathrm{Cu}^{+2}$ ions is observed for an increase in the total solution phase concentration. The activity coefficient values decrease from an average value of approximately 0.75 to 0.45 for an increase in the total $\mathrm{Ca}^{+2}$ solution phase concentration from 0.0123 to 0.0243 mole/litre.

The decrease in the solution phase activity coefficients represents significant nonideal behaviour and justifies the use of an appropriate activity coefficient model for 
the moderate to low solution phase concentrations encountered in the RIP slurry mixture system. Chapter 3 of this dissertation spent considerable effort on the identification of various activity coefficient models available in the literature that are suitable for use in the model equations of the consolidated equilibrium model. The Pitzer ion-interaction model for the prediction of solution phase activity coefficients proved to be the most useful of the identified models primarily due to the availability of model parameters for an extensive number of electrolyte solutions and the accuracy of the model. The behaviour of the $\mathrm{Cl}^{-}$ions in the aqueous solutions listed in Table 10.2 proved to be more ideal compared to the other species as is evident from Figure 10.1 .

\subsection{CONSOLIDATED EQUILIBRIUM MODEL CALCULATIONS FOR THE BIVALENT-BIVALENT $\mathrm{CaSO}_{4}$ RIP SLURRY MIXTURE SYSTEM}

Equation (10.7) represents the thermodynamic dissolution constant for the bivalentbivalent RIP slurry mixture system for the exchange reaction between $\mathrm{Ca}^{+2}$ and $\mathrm{Cu}^{+2}$ ions. From Equation (10.7) it is evident that both the solubility product of the sparingly soluble solid and the thermodynamic equilibrium constant for the exchange reaction play an important role in the model predictions of the consolidated equilibrium model. From the discussions in Chapter 9 of this dissertation it was evident that the values of the thermodynamic equilibrium constant obtained from the experimental data are not necessarily constant for a changing total solution phase concentration. This implies that the thermodynamic dissolution constant for the bivalent-bivalent RIP system may change with a change in the total solution phase concentration. From discussions in Chapters 8 and 9 it was also evident that the total solution ionic strength of the RIP slurry changes as more of the sparingly soluble solid dissolves, making a change in the thermodynamic dissolution constant more likely.

Figures (10.2) to (10.4) give the model parameter estimations of the thermodynamic equilibrium constant and the Wilson interaction parameters for the exchange reaction between $\mathrm{Ca}^{+2}$ and $\mathrm{Cu}^{+2}$. From Figures (10.2) to (10.4) it is evident that there are experimental errors associated with the data points where the resin fractional loading approaches extreme boundary conditions. The same boundary effects of the data 
points at extreme boundary conditions were observed in Chapter 9 for the equilibrium quotient data calculated for the exchange reactions between the $\mathrm{Ca}^{+2}$ species and the different monovalent cation species. From Figure (10.2) and (10.3) it is clear that the most significant deviations from the model trend lines are observed for the data points where the $\mathrm{Ca}^{+2}$ fractional loading has a value in excess of 0.8 . It is further evident from Figures (10.2) to (10.4) that the values of the thermodynamic equilibrium constant varies with varying total solution phase concentration of the $\mathrm{Ca}^{+2}$ ions, summarised in Figure (10.5). This phenomenon was also evident from Figure (9.25) in Chapter 9 of this dissertation and was confirmed by various sources in the literature that list experimentally determined values of the thermodynamic equilibrium constant for different total solution phase concentrations (Allen et al., 1989).

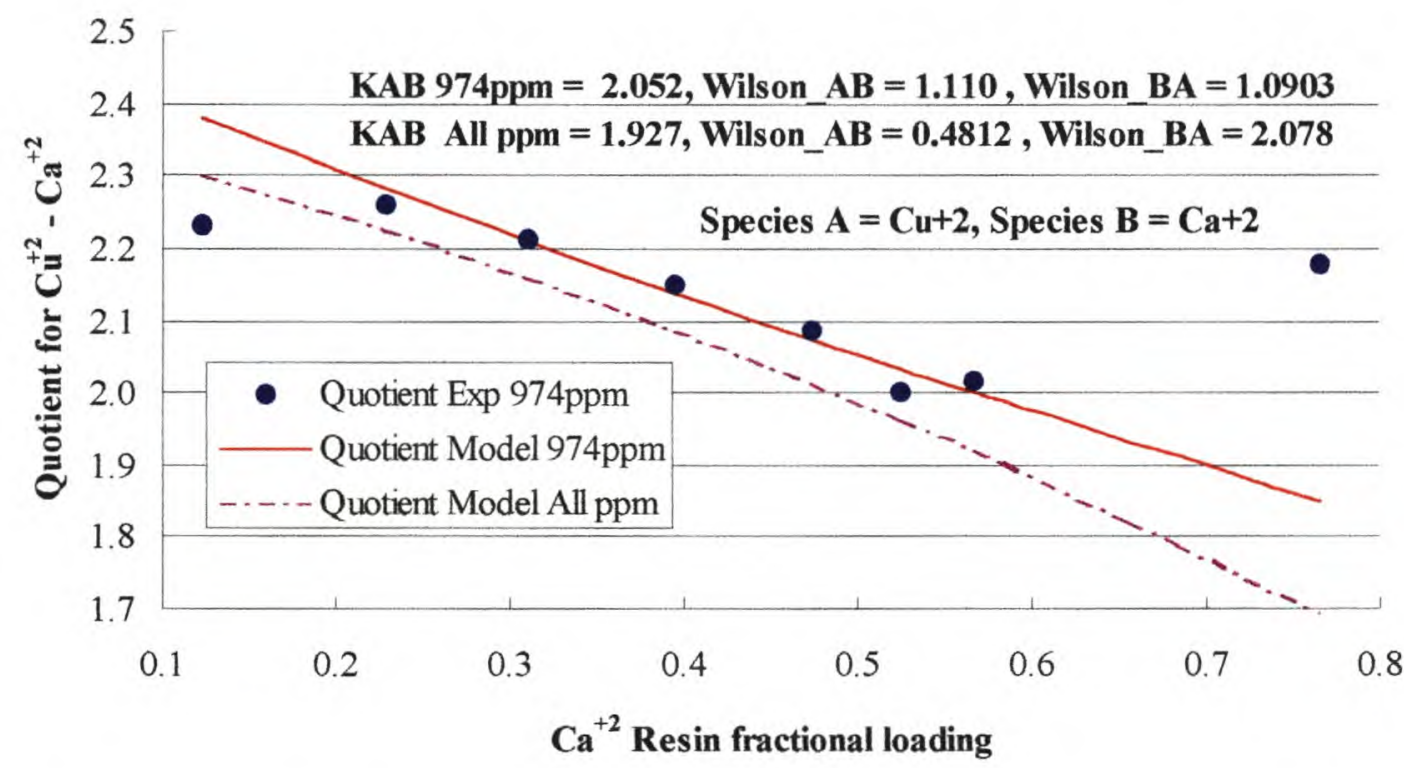

Figure 10.2 Model prediction of the equilibrium quotient for the exchange reaction between $\mathrm{Ca}^{+2}$ and $\mathrm{Cu}^{+2}$ for a solution phase concentration of 0.0243 moles/litre.

The change in the value of the thermodynamic equilibrium constant with changing total solution phase concentration implies that Equation (10.7) does not represent a "true" constant for a typical bivalent-bivalent RIP slurry mixture system. The proposed procedure for the calculation of the equilibrium isotherms for the RIP slurry mixture system, as presented in Chapter 6 of this dissertation, therefore needs to use the appropriate value of the thermodynamic equilibrium constant applicable to the 
specific solution phase concentration. The values of the thermodynamic equilibrium constant obtained need to be defined as a function of the solution phase concentration and re-calculated at every iteration step of the model procedure.

Once the value of the thermodynamic equilibrium constant for the ion-exchange reaction is obtained, the value of the resin fractional loading of the species may be calculated from Equation (6.49) of Chapter 6 of this dissertation. In most cases a straightforward calculation from this equation is not possible and a suitable objective function needs to be defined that may be solved with a suitable optimisation routine to find the value of the resin fractional loading that satisfies the equation.

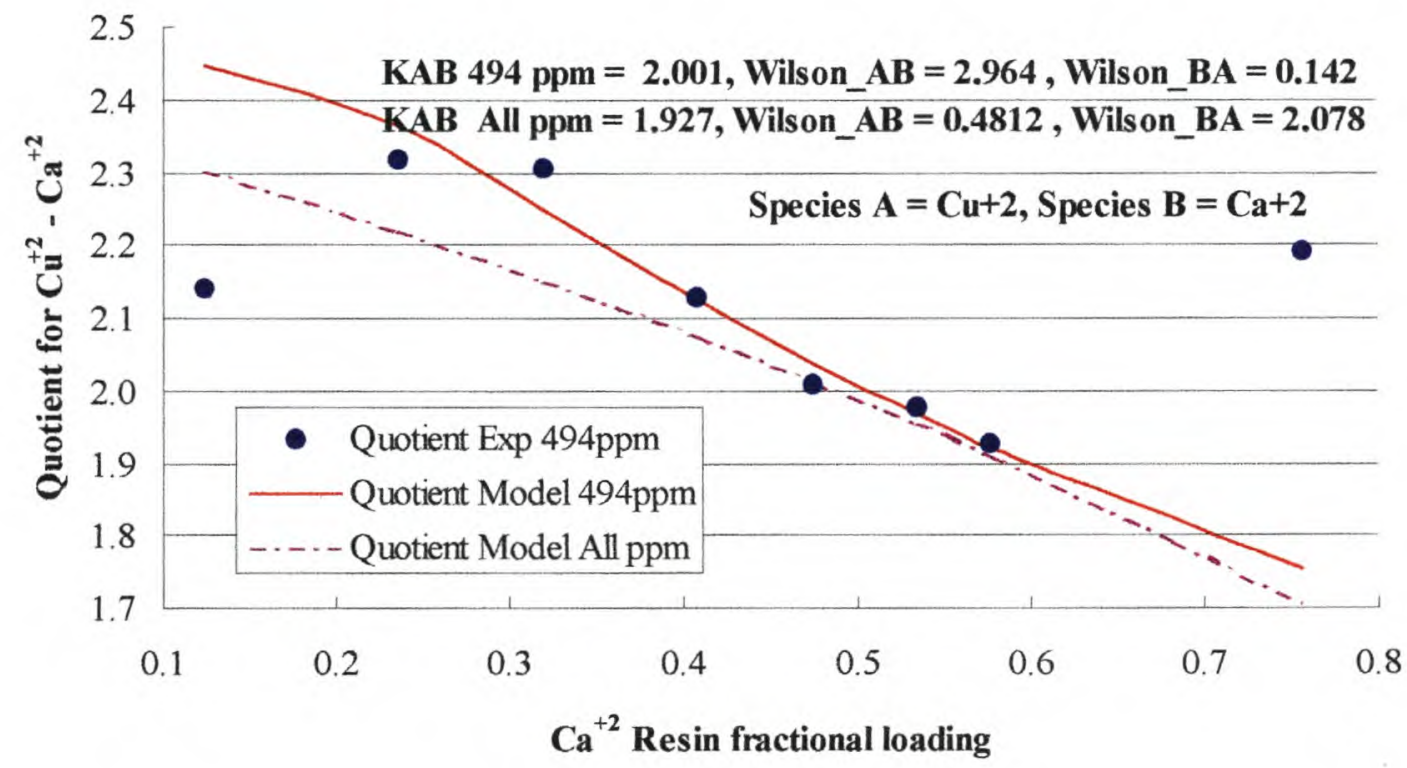

Figure 10.3 Model prediction of the equilibrium quotient for the exchange reaction between $\mathrm{Ca}^{+2}$ and $\mathrm{Cu}^{+2}$ for a solution phase concentration of 0.0123 moles/litre.

From Equation (6.49) the following objective function may be derived that is used in the calculation of the resin fractional loading for the cation species of interest.

The objective function defined by Equation (10.8) is similar to the objective function used in the literature to calculate the resin fractional loading of species $B$ for a resin / solution equilibrium system with no sparingly soluble solid present (Allen et al., 
1989). To obtain the best possible starting values for the model procedure described in Chapter 6 a similar objective function to Equation (10.8) may be derived from the expression of the thermodynamic dissolution constant for the RIP system.

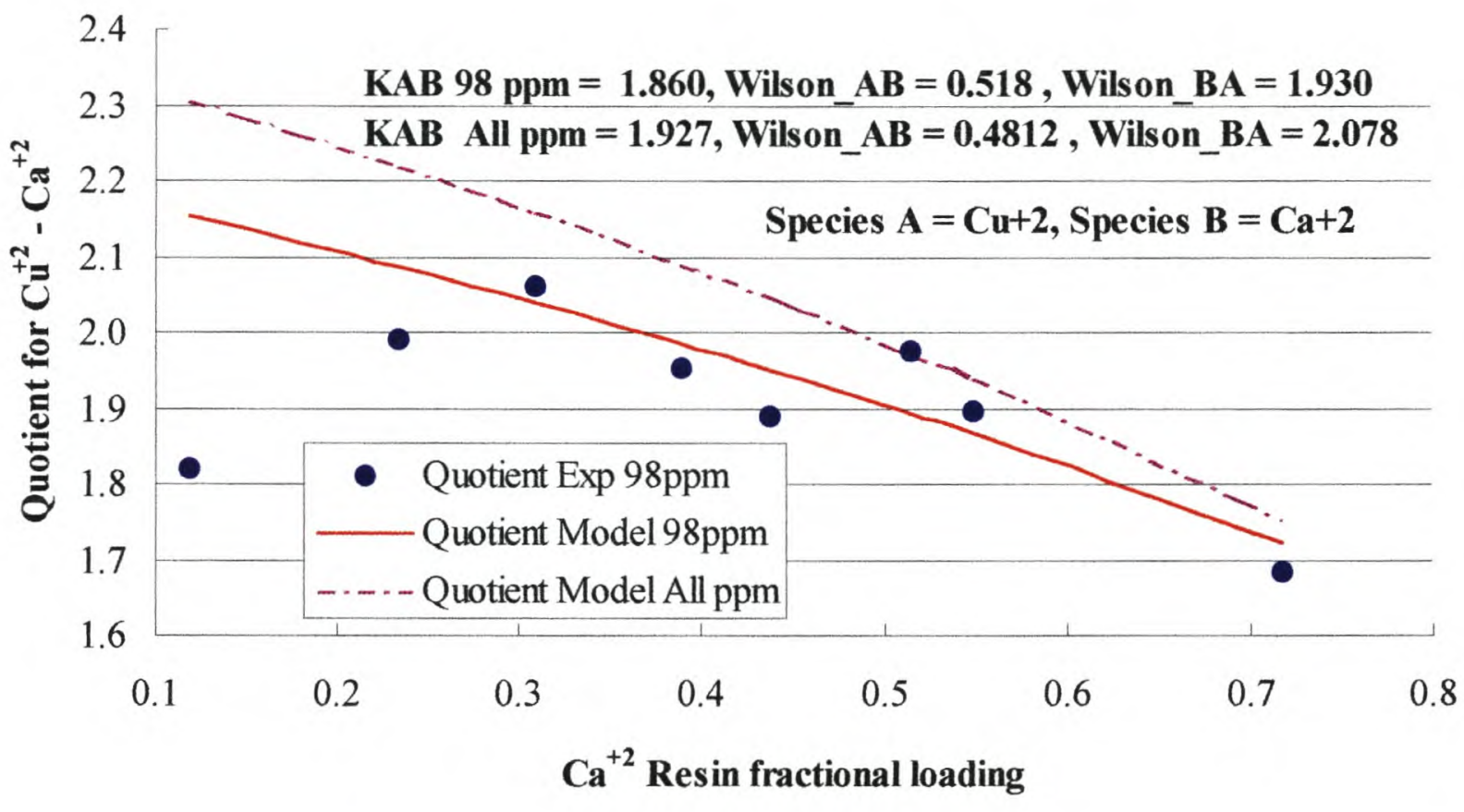

Figure 10.4 Model prediction of the equilibrium quotient for the exchange reaction between $\mathrm{Ca}^{+2}$ and $\mathrm{Cu}^{+2}$ for a solution phase concentration of 0.0024 moles/litre.

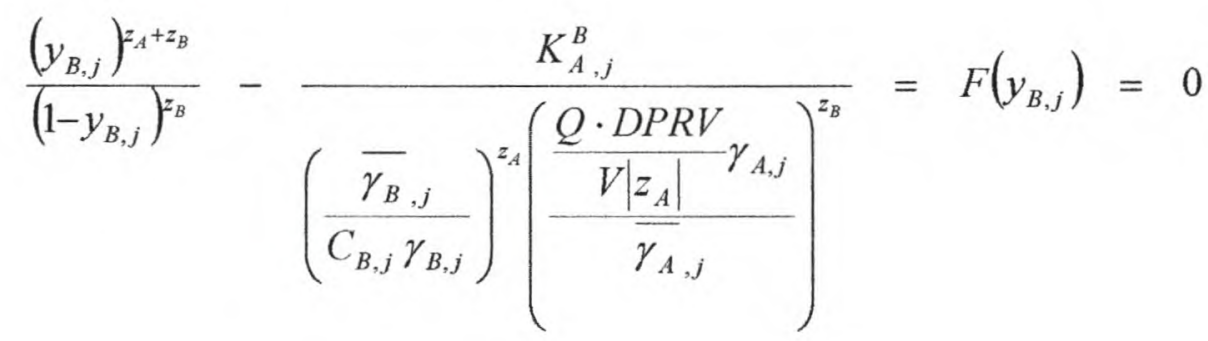

Tables 6.1 and 6.2 list the expressions of the thermodynamic dissolution constant for the RIP slurry mixture systems containing only a cation or anion exchange resin. Equation (10.9) gives the objective function based on the thermodynamic dissolution 
constant for a bivalent-bivalent RIP exchange reaction between two cations s derived from row entry four in Table 6.1.

$$
\frac{\left(y_{B}\right)}{\left(1-y_{B}\right)}-\frac{K_{\text {diss }}}{\gamma_{Y} C_{Y}\left(\frac{\overline{\gamma_{B}}}{\gamma_{A}}\right) \gamma_{A} C_{A}}=F\left(y_{B}\right)=0
$$

It is evident from comparing Equations (10.8) and (10.9) with one another that they are similar in format. The values obtained for the resin loading of the species from Equation (10.9) may be used as initial values for the iterative model procedure described in Chapter 6 of this dissertation when solving the consolidated equilibrium model equations for the bivalent-bivalent RIP slurry mixture system.

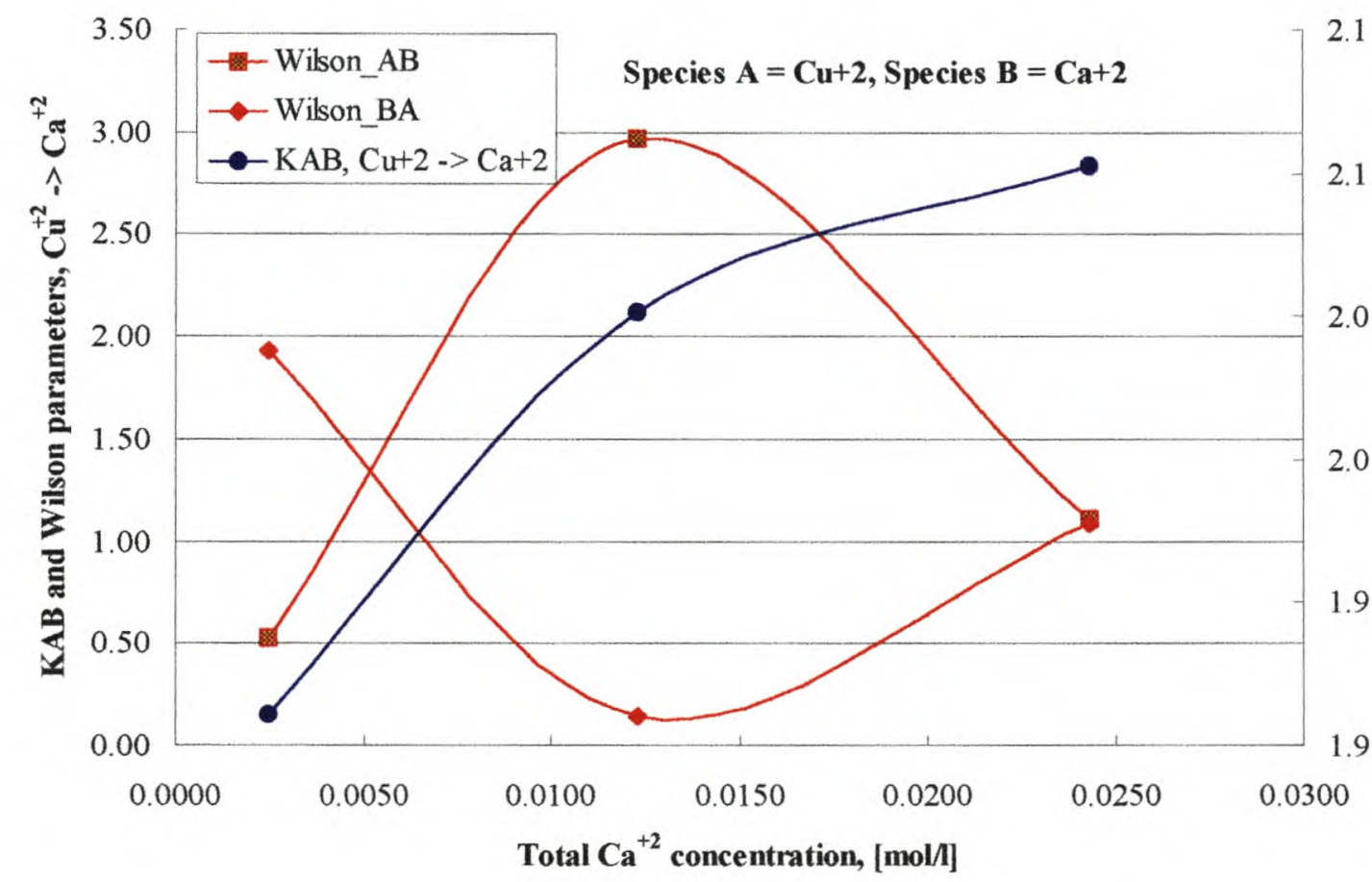

Figure 10.5 Thermodynamic equilibrium constant $\mathrm{K}_{\mathrm{CuCa}}$ and Wilson interaction parameters for the ion-exchange reaction between $\mathrm{Ca}^{+2}$ and $\mathrm{Cu}^{+2}$ for different solution phase concentrations of the $\mathrm{Ca}^{+2}$ ions on Duolite C26. 
When solving Equations (10.8) or (10.9) the appropriate values of the thermodynamic equilibrium constant for the specific total solution phase concentration as obtained from Figure (10.5) need to be used. The corresponding resin phase fractional loading of the $\mathrm{Ca}^{+2}$ species may then be obtained and used in the calculations of the consolidated equilibrium model for the RIP slurry mixture system. The objective function as given by Equation (10.8) was used in the calculations of the resin fractional loading of the $\mathrm{Ca}^{+2}$ ions in Chapter 9 and is used in the same form in the calculations of the following chapters. The format of Equation (10.9) differs slightly from that of a monovalent-bivalent and trivalent-bivalent RIP slurry mixture system, as can be derived from the expressions in Table 6.1 of Chapter 6.

The optimisation procedure as described in Appendix $\mathrm{E}$ of this dissertation was used to calculate the values of the thermodynamic equilibrium constant and the Wilson interaction parameters for each of the individual data sets for the different total solution phase concentrations of the $\mathrm{Ca}^{+2}$ ions.

Table 10.3 Calculated values for thermodynamic equilibrium constant and Wilson parameters for the exchange reaction between $\mathrm{Ca}^{+2}$ and $\mathrm{Cu}^{+2}$ ions on Duolite C26.

\begin{tabular}{|c|c|c|c|c|c|c|c|c|}
\hline $\begin{array}{c}\text { Species } \\
\mathbf{A}\end{array}$ & $\begin{array}{c}\text { Species } \\
\mathbf{B}\end{array}$ & $\begin{array}{c}\text { Species } \\
\mathbf{C}\end{array}$ & $K_{A}^{B}$ & $\begin{array}{c}\text { Wilson } \\
\Lambda_{A B}\end{array}$ & $\begin{array}{c}\text { Wilson } \\
\Lambda_{B A}\end{array}$ & $\begin{array}{c}\text { Objective } \\
\text { Function } \\
\text { Value }\end{array}$ & $\begin{array}{c}\text { Total } \\
\mathbf{C a}^{+2} \\
\mathbf{m o l} / \text { litre }\end{array}$ & $\mathbf{N}$ \\
\hline $\mathrm{Cu}^{+2}$ & $\mathrm{Ca}^{+2}$ & $\mathrm{Cl}^{-}$ & 1.927 & 0.4812 & 2.0781 & 0.00437 & All & 24 \\
$\mathrm{Cu}^{+2}$ & $\mathrm{Ca}^{+2}$ & $\mathrm{Cl}^{-}$ & 2.052 & 1.1103 & 1.0903 & 0.00010 & 0.0243 & 8 \\
$\mathrm{Cu}^{+2}$ & $\mathrm{Ca}^{+2}$ & $\mathrm{Cl}^{-}$ & 2.001 & 2.9641 & 0.1417 & 0.00011 & 0.0123 & 8 \\
$\mathrm{Cu}^{+2}$ & $\mathrm{Ca}^{+2}$ & $\mathrm{Cl}^{-}$ & 1.860 & 0.5181 & 1.9300 & 0.00079 & 0.0024 & 8 \\
\hline
\end{tabular}

The values of these parameters together with the final value of the objective function represented by Equation (5.35) of Chapter 5 are given in Table 10.3. An additional value for the thermodynamic equilibrium constant is also given as determined on all of the individual data sets for the different total solution phase concentrations of the $\mathrm{Ca}^{+2}$ ions combined. When the variation in the values of the thermodynamic equilibrium constant with changing solution phase concentration is relative small the 
overall value may be used as an average for all of the concentration ranges for which the value was determined.

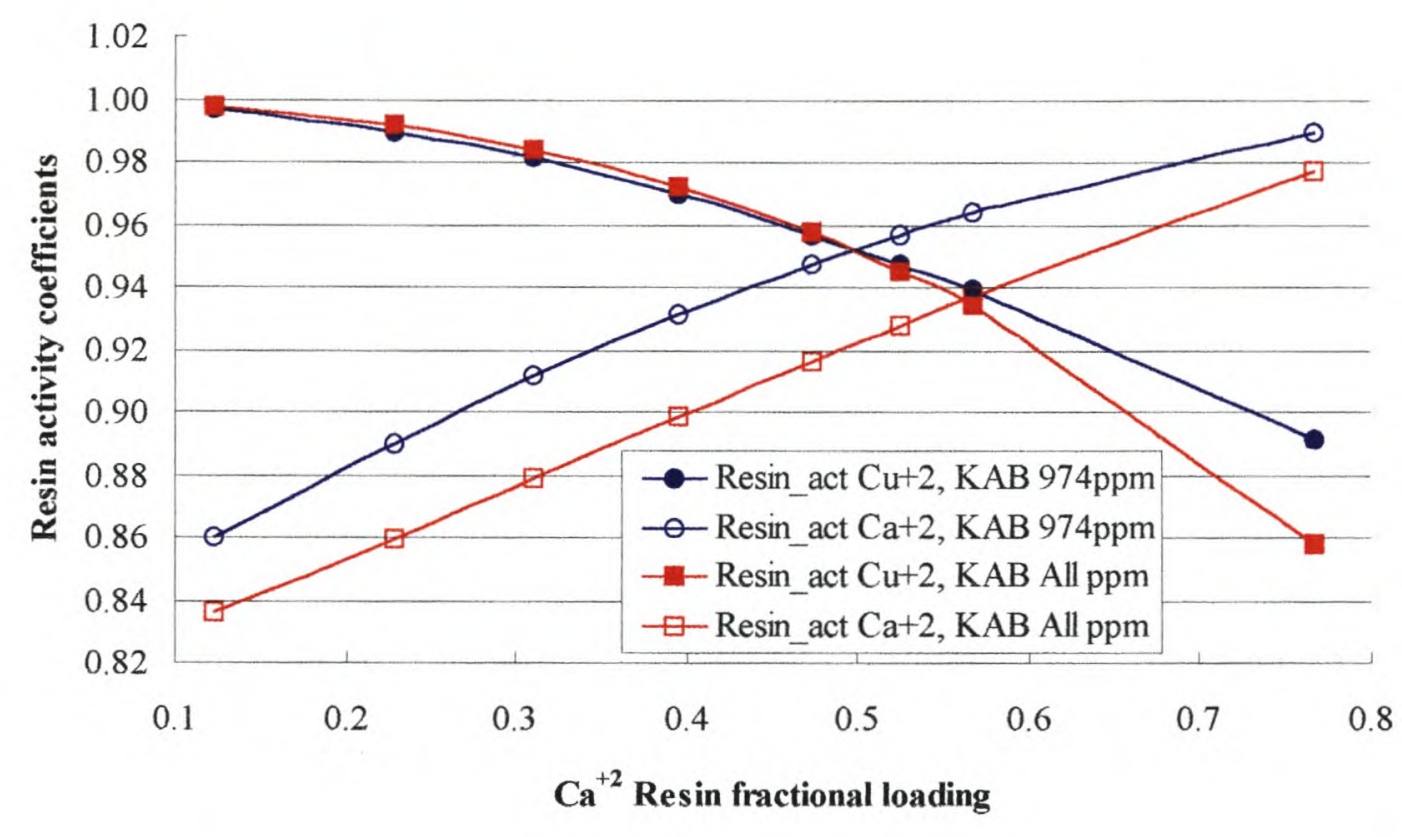

Figure 10.6 Resin activity coefficients for $\mathrm{Cu}^{+2}-\mathrm{Ca}^{+2}$ exchange at $974 \mathrm{ppm} \mathrm{Ca}^{+2}$.

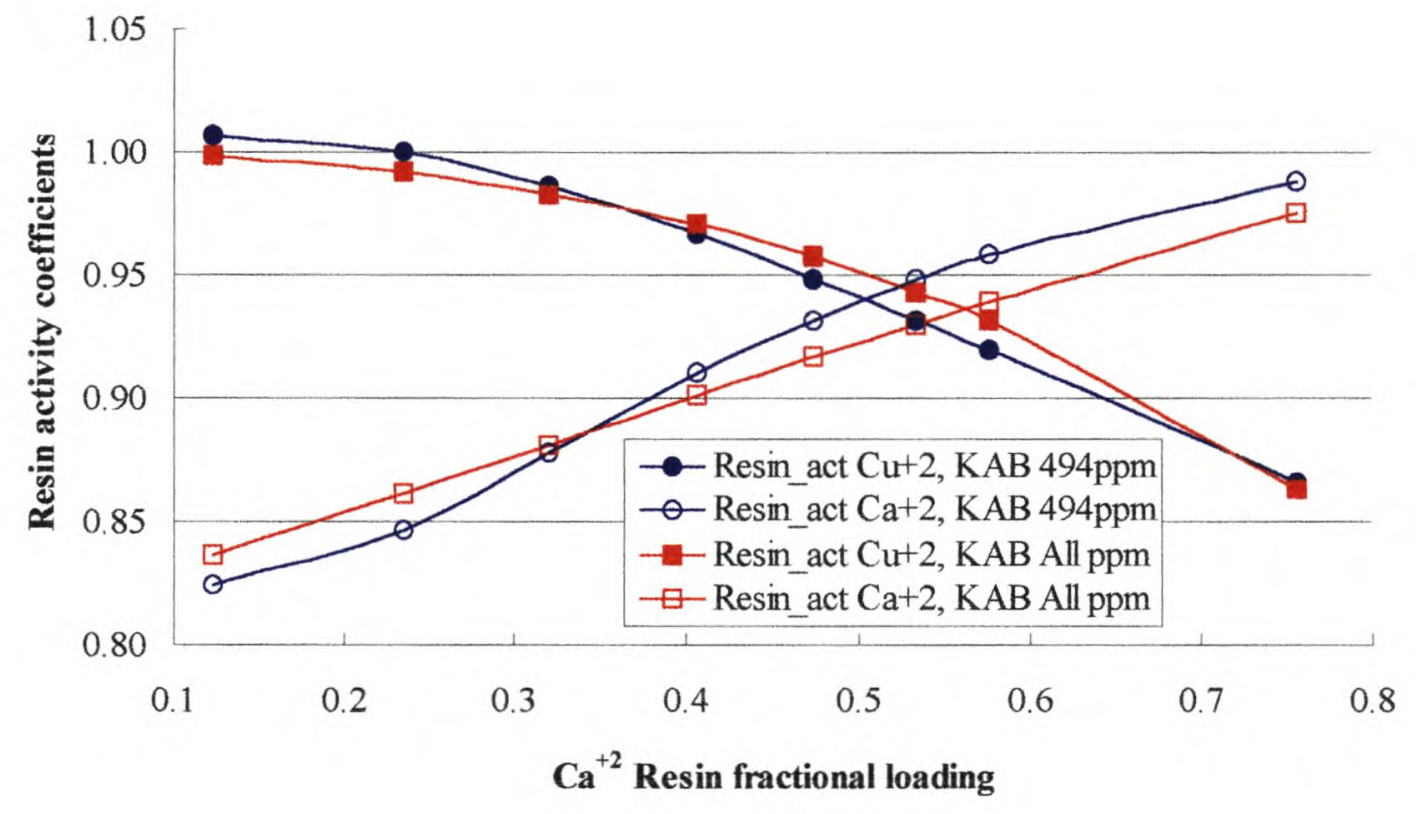

Figure 10.7 Resin activity coefficients for $\mathrm{Cu}^{+2}-\mathrm{Ca}^{+2}$ exchange at $494 \mathrm{ppm} \mathrm{Ca}^{+2}$. 


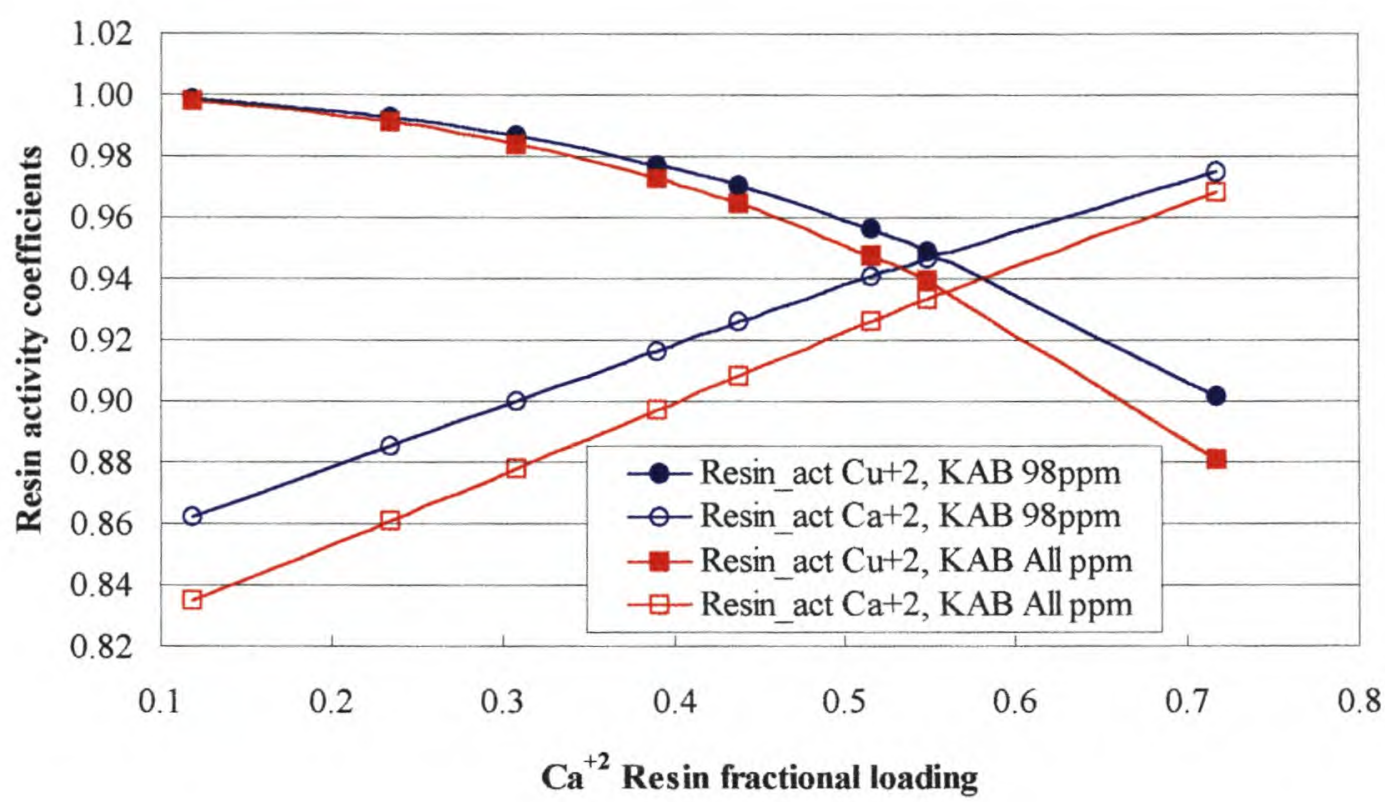

Figure 10.8 Resin activity coefficients for $\mathrm{Cu}^{+2}-\mathrm{Ca}^{+2}$ exchange at $98 \mathrm{ppm} \mathrm{Ca}{ }^{+2}$.

Care should be exercised in using the average values for the thermodynamic equilibrium constant and the Wilson interaction parameters, and the model predictions obtained in this manner should be checked with experimental data to confirm the feasibility of this procedure. As discussed in Chapter 6 it was evident that the model predictions of the consolidated equilibrium are sensitive to slight changes in the calculated values of the solution and resin phase activity coefficients of the species participating in the exchange reactions. This is due to the fact that most of the equilibrium isotherm curves for the resin / solution equilibrium conditions have very steep curves in the low solution phase concentration ranges of interest to the RIP slurry mixtures. This was evident from the experimental data presented in Chapter 8 of this dissertation, Figures (8.10) to (8.14).

From Figure (9.27) in Chapter 9 it is evident that the value of the thermodynamic equilibrium constant for the exchange reaction between $\mathrm{Ca}^{+2}$ and $\mathrm{Na}^{+}$changes significantly with a change in the total solution phase concentration of the $\mathrm{Ca}^{+2}$ ions. For this case the average value of the thermodynamic equilibrium constant and the Wilson interaction parameters will not be suitable for calculations in the consolidated 
RIP slurry mixture model over extensive concentration ranges. The average value for the thermodynamic equilibrium constant of $K_{A}^{B}=1.927$ may be used for first approximation calculations for the exchange reaction between $\mathrm{Ca}^{+2}$ and $\mathrm{Cu}^{+2}$ in the bivalent-bivalent RIP slurry mixture system presented by Figures (10.2) to (10.4). The average values obtained were tested on the different solution phase concentration ranges and from Figures (10.2) to (10.4) it is evident that the average value for the thermodynamic equilibrium constant $K_{A}^{B}$ gives similar values as the individual estimated values for each of the individual data sets. The average value is therefore suitable for first approximation calculations using Equation (10.9).

Table 10.4 Parameters used in the differential evolution optimisation procedure in the calculation of the consolidated equilibrium model parameters for a typical RIP slurry mixture system

\begin{tabular}{|l|c|}
\hline Initial Population Size of possible solution vectors, Np & 250 \\
\hline Vector scaling coefficient & $90 \%$ \\
\hline Crossover probability between vectors & $100 \%$ \\
\hline Total number of Generations & 800 \\
\hline Optimisation strategy, described in Appendix E & Scheme DE1 \\
\hline
\end{tabular}

The values of the resin phase activity coefficients as calculated with the Wilson interaction parameters also change with changing total solution phase concentration. For a specific total solution phase concentration the values of the resin phase activity coefficients, as calculated with Equations (5.25) and (5.26) in Chapter 5 of this dissertation, are only dependent on the resin fractional loading of the species. Figures (10.6) to (10.8) give the calculated values of the resin phase activity coefficients as calculated with the individual and average Wilson interaction parameters $\Lambda_{A B}$ and $\Lambda_{B A}$ presented in Table 10.3. It is evident that the values in each of Figures (10.6) to (10.8) as calculated with the different values for the Wilson interaction parameters are close to one another and suitable for first approximation calculations. It would therefore be feasible to use the average parameters of the thermodynamic equilibrium constant $K_{A}^{B}$ and the Wilson interaction parameters $\Lambda_{A B}$ and $\Lambda_{B A}$ for simulations of 
the consolidated equilibrium model for the bivalent-bivalent RIP slurry mixture system for the exchange reaction between $\mathrm{Ca}^{+2}$ and $\mathrm{Cu}^{+2}$.

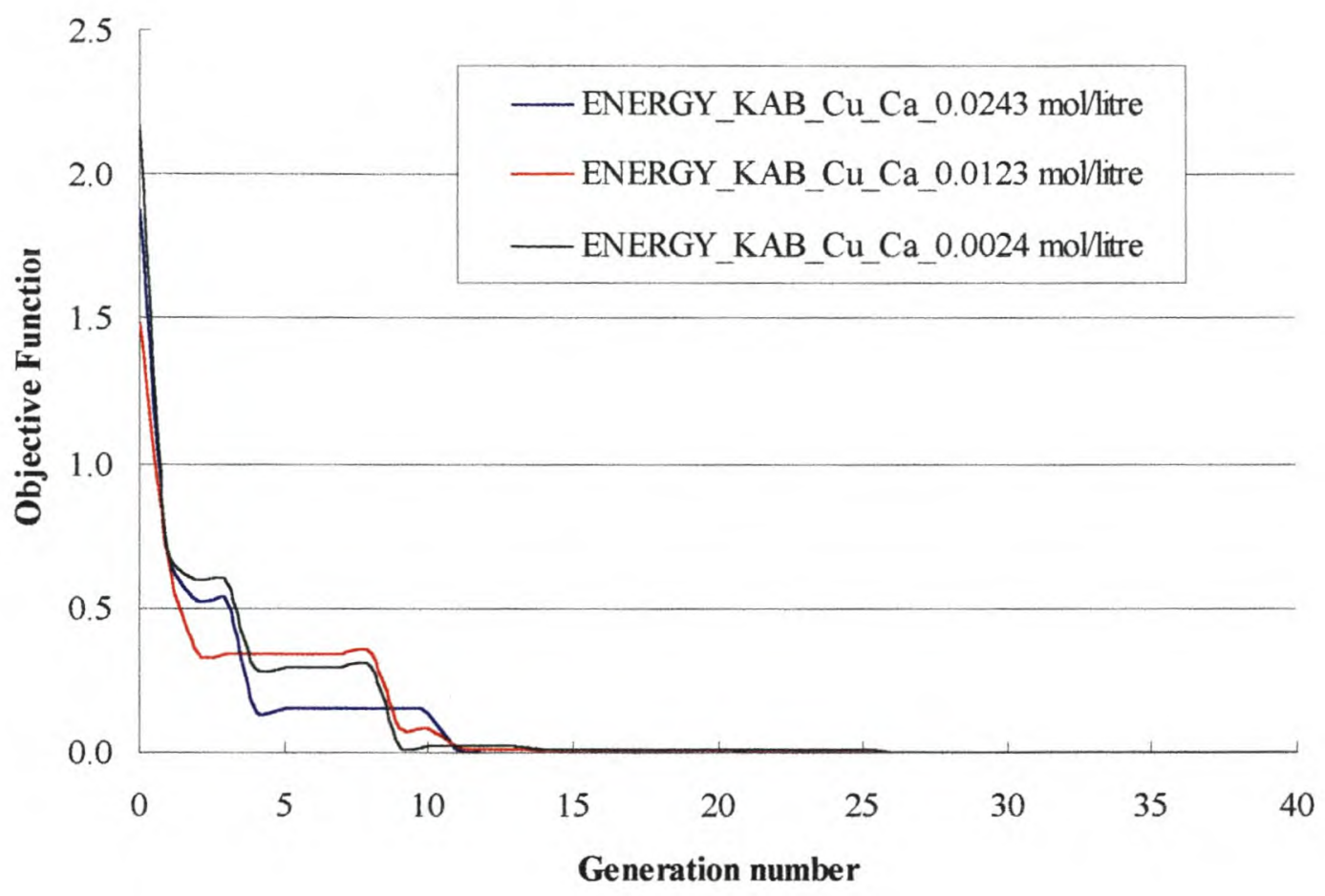

Figure 10.9 Objective function value versus generation number for the differential evolution optimisation simulation in the calculation of the consolidated equilibrium model for the RIP slurry mixture system

Table 10.4 gives the values of the parameters as used in the optimisation routine of Appendix $\mathrm{E}$ used in the calculation of the various model parameters for the consolidated equilibrium model. The values presented were used in all of the calculations performed in Chapter 9 and the following chapters of this dissertation. From the discussions in Appendix $\mathrm{E}$ it is evident that multiple initial vector matrices are proposed as possible solutions to the model parameters. The number of these matrices and the distribution of the model parameters in them should cover the whole surface area of the objective function in order to ensure that the true global minimum of the objective function is reached. 
For most of the optimisation routines performed in the evaluation of the model parameters for the consolidated model the convergence of the objective function was relatively fast. Figure (10.9) gives the value of the objective function as defined by Equation (5.35) in Chapter 5 as a function of the number of generations performed by the optimisation algorithm described in Appendix E. The curves for the three total $\mathrm{Ca}^{+2}$ solution phase concentrations for the $\mathrm{Ca}^{+2}-\mathrm{Cu}^{+2} \mathrm{RIP}$ slurry mixture system are shown. From Table 10.4 it is evident that the maximum number of generations were set at 800 and Figure (10.9) indicates that $99 \%$ of the convergence was obtained within the first 50 generations performed. It is therefore clear that the differential evolution procedure succeeded in obtaining the global minimum for the objective function within a relatively low number of iterations.

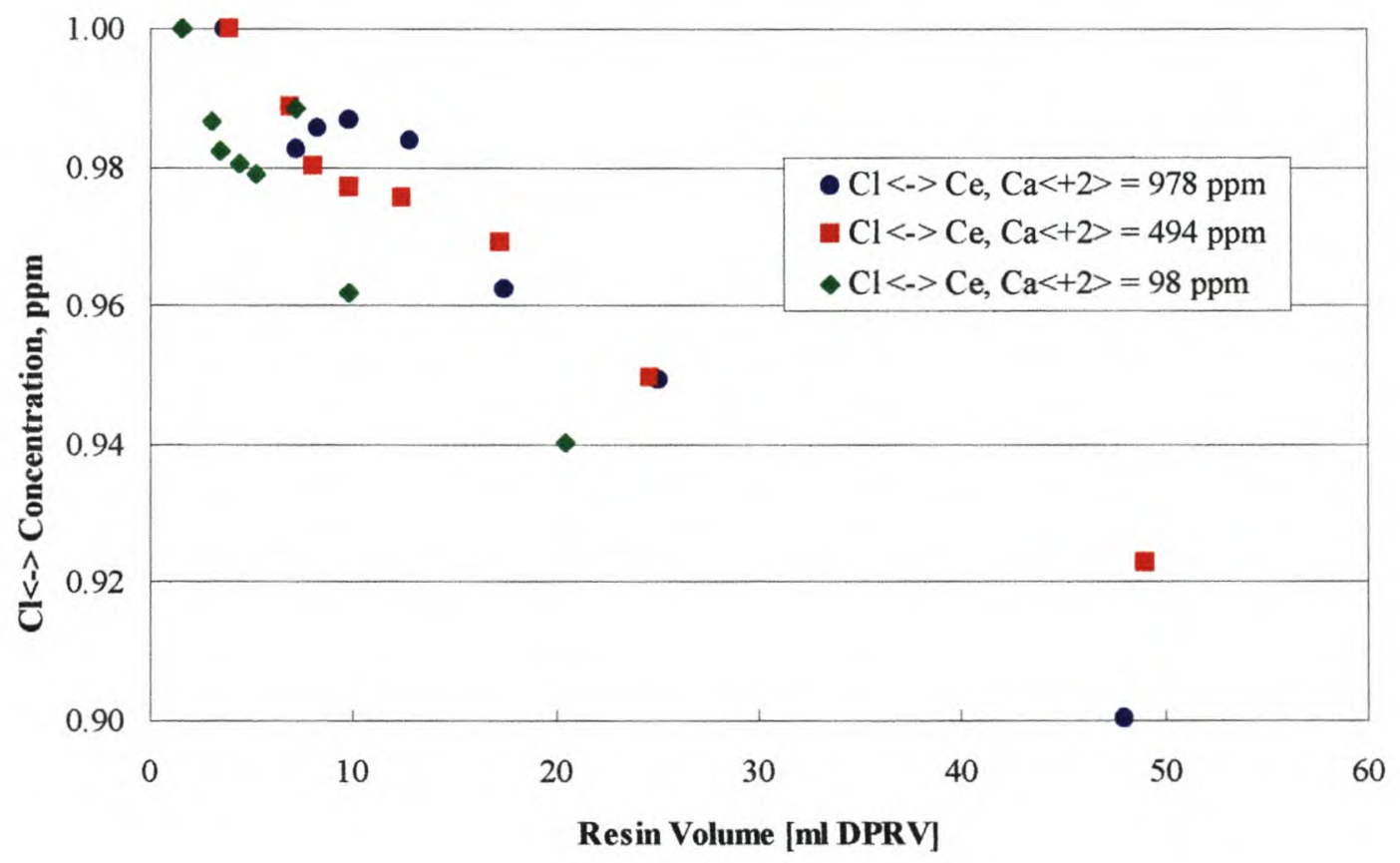

Figure 10.10 Equilibrium electrolyte adsorption of $\mathrm{Cl}^{-}$ions by a macroreticular cation exchange resin, Duolite $\mathrm{C} 26$, for the binary anion exchange reaction between $\mathrm{Ca}^{+2}$ and $\mathrm{Cu}^{+2}$.

From the discussions and experimental data presented in Chapter 8 it was evident that electrolytic sorption existed for the anion exchange reactions. Figure (10.10) gives the total solution phase concentrations of the $\mathrm{Cl}^{-}$co-ion in the exchange reaction 
between $\mathrm{Ca}^{+2}$ and $\mathrm{Cu}^{+2}$ on Duolite $\mathrm{C} 26$ for different total solution phase concentrations of the $\mathrm{Ca}^{+2}$ ion as a function of the cation resin volume used in the experiments.

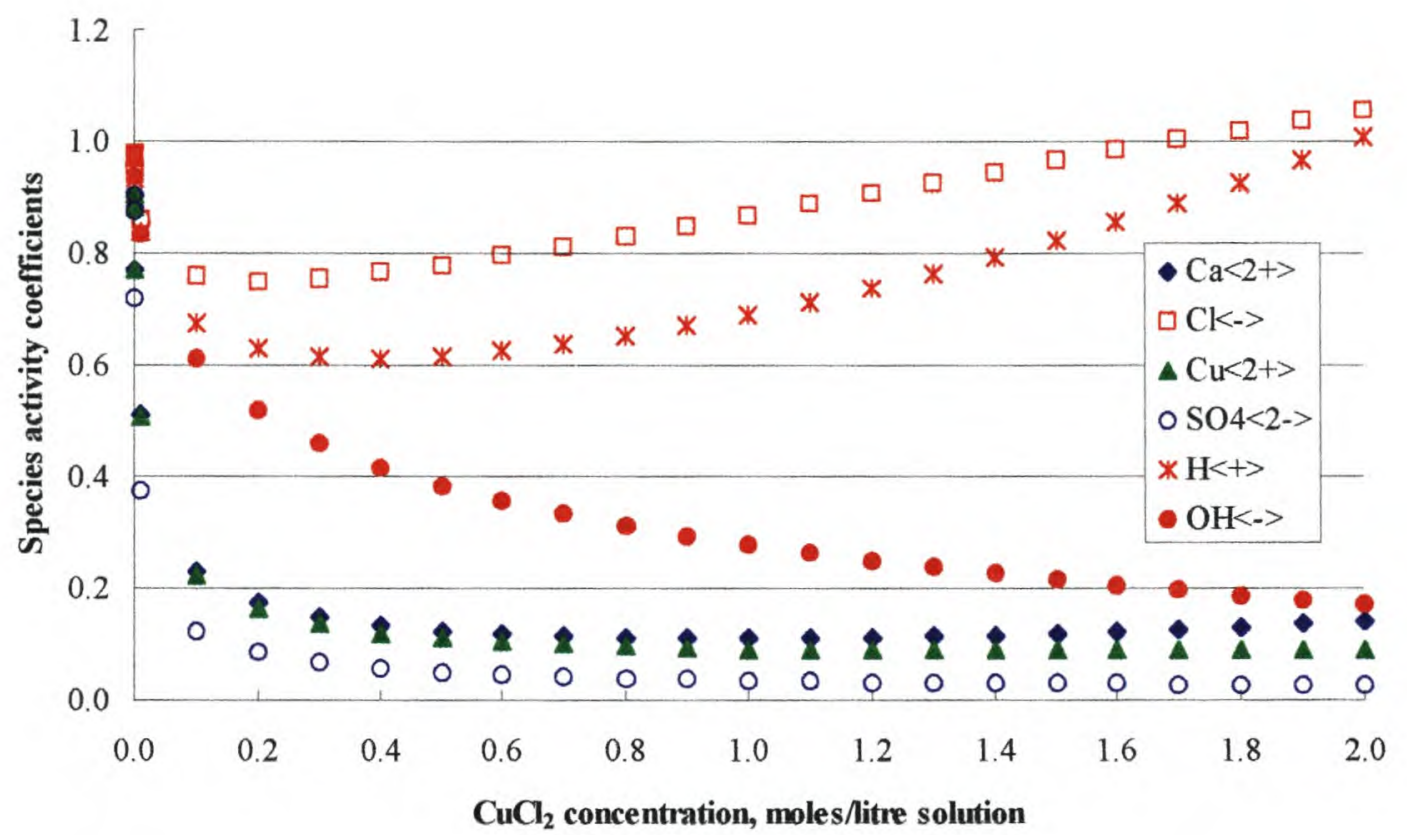

Figure 10.11 Calculated aqueous phase activity coefficients for the solubility of $\mathrm{CaSO}_{4} \cdot 2 \mathrm{H}_{2} \mathrm{O}$ in a $\mathrm{CuCl}_{2}$ aqueous electrolyte solution at $25^{\circ} \mathrm{C}$ and $101.325 \mathrm{kPa}$ pressure with the use of a Pitzer activity coefficient model.

It is evident from Figure (10.10) that electrolytic sorption of the $\mathrm{Cl}^{-}$ions occurs. The presence of electrolytic sorption increases the ion-exchange capacity of the ionexchange resin, as discussed in Chapter 8 . The increased capacity of the resin was defined as the "sorption capacity" of the resin in paragraph 4.2 .3 of Chapter 4 . The values of the thermodynamic equilibrium constant and Wilson interaction parameters are estimated from the "sorption capacity", which includes the amount of the cations adsorbed as a result of the electrolytic sorption. All of the resin / solution experimental data collected for the purposes of this dissertation are used in this manner to obtain the values of the thermodynamic equilibrium constant and the Wilson interaction parameters. From the discussion in Chapter 4 it followed that the 
modelling of the electrolytic sorption as a function of the resin and solution concentration of the species is extremely complex and it was accounted for as discussed above and in Chapter 6 and 8 of this dissertation.

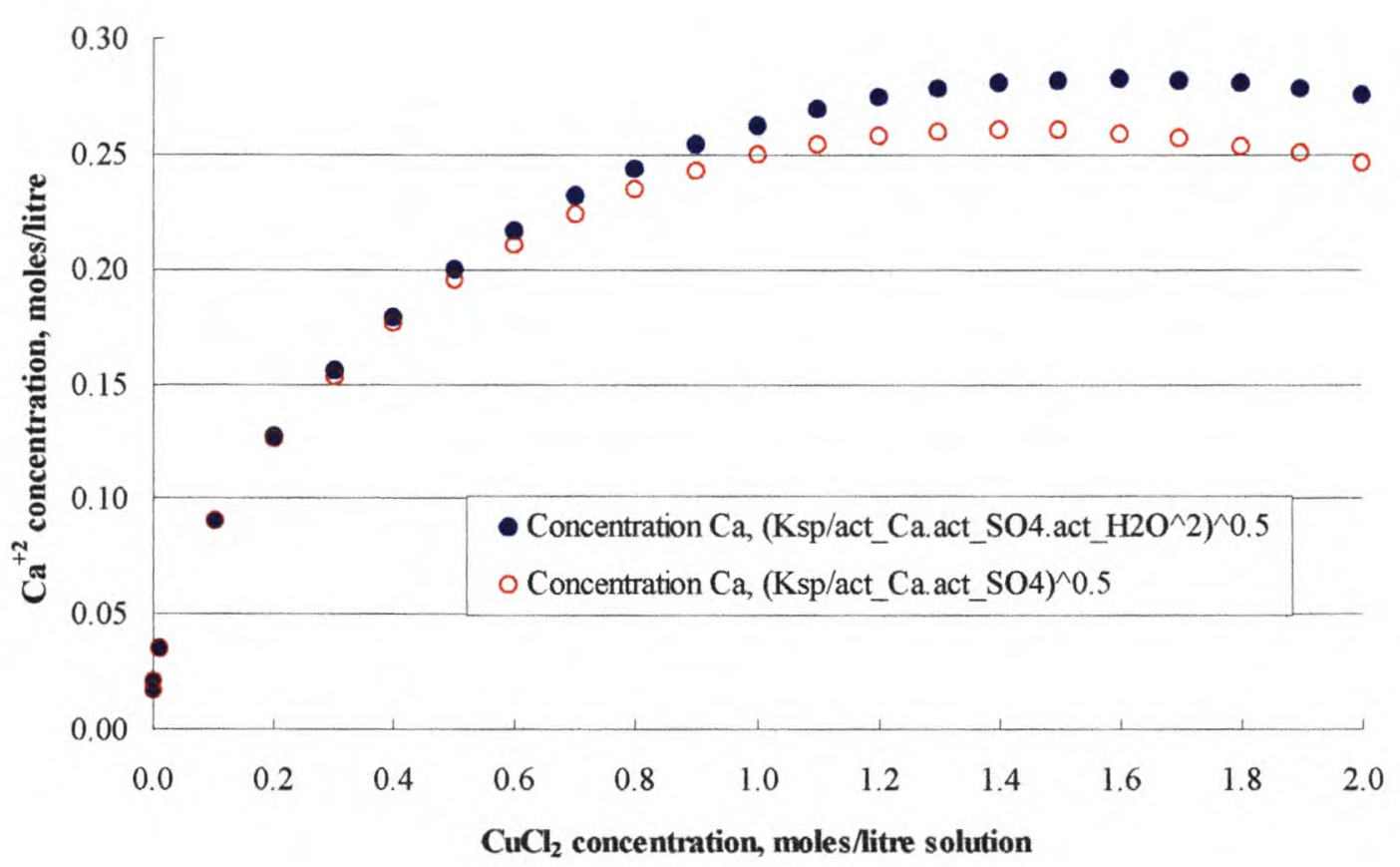

Figure 10.12 Calculated solubility of $\mathrm{CaSO}_{4} \cdot 2 \mathrm{H}_{2} \mathrm{O}$ in a $\mathrm{CuCl}_{2}$ aqueous electrolyte solution at $25^{\circ} \mathrm{C}$ and $101.325 \mathrm{kPa}$ pressure with the use of a Pitzer activity coefficient model.

The solubility of the $\mathrm{CaSO}_{4} \cdot 2 \mathrm{H}_{2} \mathrm{O}$ in a $\mathrm{CuCl}_{2}$ aqueous electrolyte solution was also calculated and used in the model equations of the consolidated equilibrium model for the bivalent-bivalent RIP slurry mixture system model. Figure (10.11) gives the Pitzer solution phase activity coefficients for these calculations. In Chapter 11 of this dissertation the solubility product for the $\mathrm{CaSO}_{4} \cdot 2 \mathrm{H}_{2} \mathrm{O}$ precipitate is calculated from the experimental data and compared with values available from the literature. A $K_{s p}$ value of $2.31 \mathrm{E}-04$ was obtained, which correlated to within $98.6 \%$ of the solubility values obtained from Zemaitis et al. (1986). With the $K_{s p}$ value and the calculated solution phase activity coefficients the saturation concentration of the $\mathrm{Ca}^{+2}$ ions in the electrolyte solution was calculated as given by Figure (10.12). In Figure (10.12) the solubility was calculated with use of Equation (10.3) with the inclusion of the species 
solution activity coefficients and also for the case where the water activity was taken into account. Equation (10.2) may be written as follows,

$$
K_{s p}=\left(a_{-} C u\right)\left(a_{-} S O_{4}\right)\left(a_{-} \text {water }\right)^{2}
$$

where the water activity is included in the solubility product. Equation (10.10) represents the "true" solubility product of the $\mathrm{CaSO}_{4} \cdot 2 \mathrm{H}_{2} \mathrm{O}$ precipitate. It is evident from Figure (10.12) that the inclusion of the water activity in the solubility calculations only becomes important at higher solution phase concentrations and that for the relatively low solution concentration ranges it may be omitted from the solubility calculations.

\subsection{SUMMARY}

From the above discussions it was evident that the model equations represented the various equilibrium conditions of the RIP slurry mixture system satisfactorily. From Chapter 9 it was evident that the quality of the thermodynamic data used in the model equations was of significant importance. This was also the case for the calculations performed in this chapter. The values of the Pitzer interaction parameters listed in Table 10.1 were validated with parameter values obtained from various literature sources. This comparison is performed with the use of the SQL7 data base constructed for the purposes of this dissertation.

In the calculations performed for the model equations it was found that all of the species behaved non-ideally to varying degrees as was evident from the calculated values of the solution and resin phase activity coefficients presented in figures (10.1) and (10.6) to (10.8). The inclusion of an appropriate activity coefficient model in the model equations of the consolidated equilibrium model for both the resin and solution phases is important. It was found that the thermodynamic equilibrium constant for the ion-exchange reaction between the $\mathrm{Cu}^{+2}$ and $\mathrm{Ca}^{+2}$ ions varied to a lesser extent than was the case for the monovalent-bivalent exchange reactions discussed in Chapter 9. This implies that the average values for the thermodynamic equilibrium constant and the Wilson interaction parameters may be used for simulations of the consolidated 
equilibrium model as a first approximation. Equation (10.9) is useful in these simulations to obtain initial values for the species concentrations when performing the consolidated equilibrium model calculations. It was also found that the differential evolution optimisation routine performed well for the calculations performed to obtain the various model parameters.

The presence of electrolytic sorption was evident from the experimental data for all of the experimental tests performed and the calculated values of the thermodynamic equilibrium constant and the Wilson interaction parameters accounted for this phenomenon. The effect was accounted for due to the fact that contribution of the electrolytic sorption to the overall exchange capacity of the ion exchanger was included in the calculation of the equilibrium quotient values used in the objective function of the optimisation routine. 


\section{CHAPTER 11}

\section{RESULTS FOR THE BIVALENT-TRIVALENT SLURRY RESIN SYSTEM}

In Chapter 10 of this dissertation the results for the bivalent-bivalent Resin-in-Pulp (RIP) slurry mixture system were discussed. From Table 9.1 it is evident that various bivalent-bivalent RIP slurry mixture systems were investigated experimentally with the cation resin in the $\mathrm{Cu}^{+2}$ ionic form. For the monovalent-bivalent RIP slurry mixture system discussed in Chapter 9 of this dissertation the resin was in the $\mathrm{H}^{+}, \mathrm{Na}^{+}$ and $\mathrm{K}^{+}$ionic form. For the purposes of investigating a bivalent-trivalent RIP slurry mixture system the cation in the $\mathrm{Al}^{+3}$ ionic form was used. The $\mathrm{Al}^{+3}$ form was used due to the fact that cation resin could be converted to the $\mathrm{Al}^{+3}$ ionic form with relative ease. The $\mathrm{Al}^{+3}$ ionic form also allowed for relatively easy analysis of the $\mathrm{Al}^{+3}$ concentrations in the solution phase as described in the experimental procedures of Chapter 7 of this dissertation.

\subsection{OBJECTIVES OF THIS CHAPTER}

In this Chapter the general case of a bivalent-trivalent RIP slurry mixture system will be investigated. As mentioned above it was clear that the $\mathrm{Al}^{+3}$ ionic form of the cation resin was used to obtain an exchange reaction with a cation species with an electrochemical valence of three. One of the objectives of this chapter is to perform calculations for the solubility of the $\mathrm{CaSO}_{4} \cdot 2 \mathrm{H}_{2} \mathrm{O}$ and $\mathrm{PbSO}_{4}$ sparingly soluble solids in electrolyte solutions of the RIP slurry mixture system containing the $\mathrm{Al}^{+3}$ species. In order to perform these solubility and other consolidated equilibrium model calculations the values for the Pitzer ion-interaction model are required. Values for higher order valence species are more difficult to obtain from the literature due to the fact that very little test work has been performed on these systems to date. In order to perform the solubility calculations as well as the model parameter estimations for the values of the thermodynamic equilibrium constant for the ion exchange reaction, values are required for the various interactions of the $\mathrm{Al}^{+3}$ ion with other aqueous 
phase species. In Chapter 10 of this dissertation it was mentioned that Pitzer (1991) showed that there is a relationship between the two parameters $\beta^{(0)}$ and $\beta^{(1)}$. It was found that the relationship between these two parameters for most electrolyte solutions existed, but that the relationship was not an exact dependence (Pitzer, 1991). This dependence is still good enough for the estimation of $\beta^{(0)}$ parameters from the $\beta^{(1)}$ parameter if no other value is available. For the calculation of the thermodynamic equilibrium constant for the ion exchange reaction between $\mathrm{Ca}^{+2}$ and $\mathrm{Al}^{+3}$ with $\mathrm{Cl}^{-}$as the anion, represented by Equation (11.4), the Pitzer model parameters were estimated on the principle that a relationship exists between the $\beta^{(0)}$ and $\beta^{(1)}$ parameter. Recent experimental work performed in the literature recommends the parameters $\beta^{(0)}=0.854, \beta^{(1)}=18.53, \beta^{(1)}=-500$ and $C^{\phi}=-$ 0.0911 as a first approximation when considering $\mathrm{Al}_{2}\left(\mathrm{SO}_{4}\right)_{3}$ electrolyte solutions (Pitzer, 1991). These parameters account for the interaction between the $\mathrm{Al}^{+3}$ and $\mathrm{SO}_{4}{ }^{2-}$ ions in the RIP slurry mixture system.

\subsection{GENERAL MECHANISTIC CONSIDERATIONS FOR THE

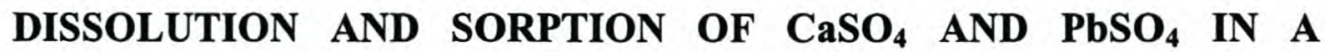 BIVALENT-TRIVALENT RIP SLURRY MIXTURE SYSTEM}

As performed in Chapter 10 of this dissertation the final expressions for the equations for the dissolution of the sparingly soluble solid and the thermodynamic equilibrium dissolution constant for the RIP slurry mixture system may be obtained from Table 6.1 in Chapter 6 of this dissertation. The individual equations may be obtained from paragraph 2.2 of Appendix B of this dissertation. The equations may be written for the $\mathrm{CaSO}_{4} \cdot 2 \mathrm{H}_{2} \mathrm{O}$ RIP slurry mixture system containing the cation resin in the $\mathrm{Al}^{+3}$ ionic form as given below.

The dissolution reaction for the $\mathrm{CaSO}_{4} \cdot 2 \mathrm{H}_{2} \mathrm{O}$ precipitate is given by Equation (11.1) below

$$
\left\lfloor\left(\mathrm{Ca}^{2+}\right)\left(\mathrm{SO}_{4}{ }^{2-}\right)\right\rfloor_{s} \stackrel{\mathrm{K}_{s p}}{\longleftrightarrow} \mathrm{Ca}^{2+}+\mathrm{SO}_{4}^{2-}
$$


The solubility product for the $\mathrm{CaSO}_{4} \cdot 2 \mathrm{H}_{2} \mathrm{O}$ precipitate is defined by Equation (11.2),

$$
K_{s p}=\left(a_{-} C u\right)\left(a_{-} S_{4}\right)
$$

with the solubility of the $\mathrm{Ca}^{+2}$ ions given by Table 2.2 of Chapter 2 as represented by Equation (11.3) below for a sparingly soluble solid dissolving ideally in a stoichiometric one-to-one manner.

$$
S=\left(K_{s p}\right)^{\frac{1}{2}}
$$

The general ion-exchange reaction with the cation exchange resin in the $\mathrm{Al}^{+3}$ ionic form is given by Equation (11.4) below.

$$
2\left[\left(R^{-}\right)_{3} A l^{3+}\right]+3 C a^{2+} \stackrel{K_{A}^{B}}{\longleftrightarrow} 3\left[\left(R^{-}\right)_{2} C a^{2+}\right]+2 A l^{3+}
$$

For the ion-exchange reaction above the thermodynamic equilibrium constant, as defined by Equation (5.21) of Chapter 5, may be written as follows.

$$
K_{A l}^{C a}=\frac{\left(\overline{a_{-} C a}\right)^{3}\left(a_{-} A l\right)^{2}}{\left(\overline{a_{-} A l}\right)^{2}\left(a_{-} C a\right)^{3}}
$$

By combining the dissolution reaction for the $\mathrm{CaSO}_{4} \cdot 2 \mathrm{H}_{2} \mathrm{O}$ precipitate and the ionexchange reaction between the dissolved $\mathrm{Ca}^{+2}$ and $\mathrm{Al}^{+3}$ ions on the cation exchange resin the simultaneous dissolution and sorption reaction for the RIP slurry mixture system may be obtained, as represented by Equation (11.6).

$$
\left.3 \mid\left(\mathrm{Ca}^{2+}\right)\left(\mathrm{SO}_{4}{ }^{2-}\right)\right]_{5}+2\left[\left(\mathrm{R}^{-}\right)_{3} \mathrm{Al}^{3+}\right] \stackrel{\mathrm{K}_{\text {diss }} \longrightarrow}{\longrightarrow} 3\left[\left(\mathrm{R}^{-}\right)_{2} \mathrm{Ca}^{2+}\right]+2 \mathrm{Al}^{3+}+3 \mathrm{SO}_{4}{ }^{2-}
$$

From Equation (11.6) the thermodynamic dissolution constant for the RIP slurry mixture system may be derived, given by Equation (11.7) below, 


$$
\begin{aligned}
& K_{\text {diss }}=\frac{\left(\overline{a_{-} C a}\right)^{3}\left(a_{-} A l\right)^{2}\left(a_{-} S O_{4}\right)^{3}}{\left(\overline{a_{-} A l}\right)^{2}} \\
& =\left[\left(a_{-} C a\right)\left(a_{-} S O_{4}\right)\right]^{3}\left[\frac{\left(\overline{a_{-} C a}\right)^{3}\left(a_{-} A l\right)^{2}}{\left(\overline{a_{-} A l}\right)^{2}\left(a_{-} C a\right)^{3}}\right] \\
& =\left[K_{s p}\right]^{3} K_{A}^{B} \\
& =\left[K_{s p}\right]^{3} K_{A l}^{C a}
\end{aligned}
$$

which may be used to calculate the equilibrium isotherms for the RIP slurry mixture system given that the values of the activities of the species in the various phases are known.

When comparing Equations (10.7) and (11.7) with one another it is evident that they are similar in format except for the power to which the value of the solubility product of the sparingly soluble solid is raised. As mentioned earlier the notation followed in the representation of the $K_{A}^{B}$ value for the ion-exchange reaction is done in such a way that $A$ always present the species initially saturating the ion-exchange resin, which is exchanged for species $B$. A similar equation to Equation (11.7) may be written for the thermodynamic dissolution constant for the $\mathrm{PbSO}_{4} \mathrm{RIP}$ slurry mixture system, represented by Equation (11.8)

$$
\begin{aligned}
& K_{\text {diss }}=\left[\left(a_{-} C a\right)\left(a_{-} S O_{4}\right)\right]^{3}\left[\frac{\left(\overline{a_{-} C a}\right)^{3}\left(a_{-} A l\right)^{2}}{\left(\overline{a_{-} A l}\right)^{2}\left(a_{-} C a\right)^{3}}\right] \\
& =\left[K_{s p}\right]^{3} K_{A l}^{C a}
\end{aligned}
$$

As mentioned in Chapter 9 and Chapter 10 the value of the thermodynamic equilibrium constant $K_{A}^{B}$ may vary substantially with a variation in the total solution phase concentration. This phenomenon was confirmed by Allen et al. (1989) in a 
summary providing the results of various literature sources on the values of the thermodynamic equilibrium constant $K_{A}^{B}$.

\subsection{CALCULATION OF THE THERMODYNAMIC EQUILIBRIUM CONSTANT $K_{A}^{B}$ FOR THE BIVALENT-TRIVALENT RIP SLURRY MIXTURE SYSTEM OF CaSO $4 \mathrm{AND} \mathrm{PbSO}_{4}$}

From Chapter 5 of this dissertation it was evident that the thermodynamic equilibrium constant $K_{A}^{B}$ and the Wilson interaction parameters $\Lambda_{A B}$ and $\Lambda_{B A}$ for the ionexchange reaction are estimated from experimentally determined values of the equilibrium quotient, described by Equation (5.28).

Table 11.1 Values for the Pitzer model parameters $\beta^{(0)}, \beta^{(1)}, C^{\phi}, \phi$ and $\psi$ used in the calculation of the thermodynamic equilibrium constant $K_{A l}^{P b}$ for the exchange reaction between $\mathrm{Pb}^{+2}$ and $\mathrm{Al}^{+3}$ with $\mathrm{NO}_{3}{ }^{-}$as the co-ion. Parameters obtained from SQL7 data base. All Pitzer values shown are multiplied with the gas constant $R=8.31441 \mathrm{~kJ} / \mathrm{kmol} . \mathrm{K}$.

\begin{tabular}{|c|c|c|c|c|}
\hline Species A & Species B & Species C & $\begin{array}{c}\mathbf{R} * \text { Pitzer Parameter } \\
\mathbf{R}=\mathbf{8 . 3 1 4 4 1} \mathbf{~ k J / k m o l . K}\end{array}$ & Value \\
\hline $\mathrm{CO} 3<2->$ & $\mathrm{HCO} 3<->$ & $\mathrm{R} * \phi$ & $-3.326 \mathrm{E}-01$ \\
$\mathrm{H}<+>$ & $\mathrm{NO} 3<->$ & & $\mathrm{R} * \beta^{(0)}$ & $9.711 \mathrm{E}-01$ \\
$\mathrm{H}<+>$ & $\mathrm{NO} 3<->$ & $\mathrm{R} * \beta^{(1)}$ & $2.948 \mathrm{E}+00$ \\
$\mathrm{H}<+>$ & $\mathrm{NO} 3<->$ & $\mathrm{R} * C^{\phi}$ & $-4.481 \mathrm{E}-02$ \\
$\mathrm{OH}<->$ & $\mathrm{CO} 3<2->$ & $\mathrm{R} * \phi$ & $8.314 \mathrm{E}-01$ \\
$\mathrm{~Pb}<2+>$ & $\mathrm{NO} 3<->$ & $\mathrm{R} * \beta^{(0)}$ & $-3.006 \mathrm{E}-01$ \\
$\mathrm{~Pb}<2+>$ & $\mathrm{NO} 3<->$ & $\mathrm{R} * \beta^{(1)}$ & $2.370 \mathrm{E}+00$ \\
$\mathrm{~Pb}<2+>$ & $\mathrm{NO} 3<->$ & $\mathrm{R} * C^{\phi}$ & $4.431 \mathrm{E}-02$ \\
\hline
\end{tabular}

In order to calculate the equilibrium quotient the values of the activity coefficients of the species for the solution phase are required, which are obtained from the Pitzer ioninteraction model described in Chapter 3. Once the experimental value for the equilibrium quotient is determined the optimisation routine in Appendix $\mathrm{E}$ is used to 
obtain the values of $K_{A}^{B}, \Lambda_{A B}$ and $\Lambda_{B A}$ with the objective function defined by Equation (5.35).

Table 11.2 Values for the Pitzer model parameters $\beta^{(0)}, \beta^{(1)}, C^{\phi}, \phi$ and $\psi$ used in the calculation of the thermodynamic equilibrium constant $K_{A l}^{C a}$ for the exchange reaction between $\mathrm{Ca}^{+2}$ and $\mathrm{Al}^{+3}$ with $\mathrm{Cl}^{-}$as the co-ion. Parameters obtained from SQL7 data base. All Pitzer values shown are multiplied with the gas constant $R=8.31441 \mathrm{~kJ} / \mathrm{kmol}$.K.

\begin{tabular}{|c|c|c|c|c|}
\hline Species A & Species B & Species C & $\begin{array}{c}\mathbf{R} * \text { Pitzer Parameter } \\
\mathbf{R}=\mathbf{8 . 3 1 4 4 1} \mathbf{k J} / \mathbf{k m o l . K}\end{array}$ & \\
\hline $\mathrm{Al}<3+>$ & $\mathrm{Cl}<->$ & & $\mathrm{R} * \beta^{(0)}$ & $5.815 \mathrm{E}+00$ \\
$\mathrm{Al}<3+>$ & $\mathrm{Cl}<->$ & & $\mathrm{R} * \beta^{(1)}$ & $4.859 \mathrm{E}+01$ \\
$\mathrm{Al}<3+>$ & $\mathrm{Cl}<->$ & & $\mathrm{R} * C^{\phi}$ & $2.272 \mathrm{E}-02$ \\
$\mathrm{Ca}<2+>$ & $\mathrm{H}<+>$ & & $\mathrm{R} * \phi$ & $7.649 \mathrm{E}-01$ \\
$\mathrm{Ca}<2+>$ & $\mathrm{H}<+>$ & $\mathrm{Cl}<->$ & $\mathrm{R} * \psi$ & $-1.247 \mathrm{E}-01$ \\
$\mathrm{Ca}<2+>$ & $\mathrm{Cl}<->$ & & $\mathrm{R} * \beta^{(0)}$ & $2.627 \mathrm{E}+00$ \\
$\mathrm{Ca}<2+>$ & $\mathrm{Cl}<->$ & & $\mathrm{R} * \beta^{(1)}$ & $1.342 \mathrm{E}+01$ \\
$\mathrm{Ca}<2+>$ & $\mathrm{Cl}<->$ & & $\mathrm{R} * C^{\phi}$ & $-2.822 \mathrm{E}-03$ \\
$\mathrm{Ca}<2+>$ & $\mathrm{Cl}<->$ & $\mathrm{OH}<->$ & $\mathrm{R} * \psi$ & $-2.079 \mathrm{E}-01$ \\
$\mathrm{Ca}<2+>$ & $\mathrm{HCO}<->$ & & $\mathrm{R} * \beta^{(0)}$ & $3.324 \mathrm{E}+00$ \\
$\mathrm{Ca}<2+>$ & $\mathrm{HCO}<<->$ & & $\mathrm{R} * \beta^{(1)}$ & $2.476 \mathrm{E}+01$ \\
$\mathrm{Cl}<->$ & $\mathrm{OH}<->$ & & $\mathrm{R} * \phi$ & $-4.157 \mathrm{E}-01$ \\
$\mathrm{Cl}<->$ & $\mathrm{CO} 3<2->$ & & $\mathrm{R} * \phi$ & $-1.663 \mathrm{E}-01$ \\
$\mathrm{Cl}<->$ & $\mathrm{HCO}<->$ & & $\mathrm{R} * \phi$ & $2.494 \mathrm{E}-01$ \\
$\mathrm{CO} 3<2->$ & $\mathrm{HCO} 3<->$ & & $\mathrm{R} * \phi$ & $-3.326 \mathrm{E}-01$ \\
$\mathrm{H}<+>$ & $\mathrm{Cl}<->$ & & $\mathrm{R} * \beta^{(0)}$ & $1.476 \mathrm{E}+00$ \\
$\mathrm{H}<+>$ & $\mathrm{Cl}<->$ & & $\mathrm{R} * \beta^{(1)}$ & $2.449 \mathrm{E}+00$ \\
$\mathrm{H}<+>$ & $\mathrm{Cl}<->$ & & $\mathrm{R} * C^{\phi}$ & $6.652 \mathrm{E}-03$ \\
$\mathrm{OH}<->$ & $\mathrm{CO}<2->$ & & $8.314 \mathrm{E}-01$ \\
\hline
\end{tabular}

It was evident from discussions in Chapters 9 and 10 that the experimental inaccuracies associated the data points at the phase composition extremes had a significant effect on the estimated values of the $K_{A}^{B}, \Lambda_{A B}$ and $\Lambda_{B A}$ parameters. This difficulty has been recognised by other researchers in the literature who used the objective function in the form as described by Equation (5.35) in order to minimise 
the effect of the data points at the phase extremes on the estimated values of the parameters (Mehablia et al., 1994).

In the calculation of the solution phase activity coefficients used in the determination of the experimental values for the equilibrium quotient the Pitzer parameters as given by Tables 11.1 and 11.2 were used for the $\mathrm{PbSO}_{4}$ and $\mathrm{CaSO}_{4} \cdot 2 \mathrm{H}_{2} \mathrm{O}$ RIP slurry mixture systems respectively. It is evident from Table 11.1 that no ion-interaction model parameters were available for the interaction between the $\mathrm{Al}^{+3}$ and $\mathrm{NO}_{3}{ }_{3}$ ions in the $\mathrm{Pb}\left(\mathrm{NO}_{3}\right)_{2}$ resin / solution system.

The results of the solution phase activity coefficients and the equilibrium quotient calculations are shown in Tables 11.3 and 11.4 for the $\mathrm{CaSO}_{4} .2 \mathrm{H}_{2} \mathrm{O}$ and $\mathrm{PbSO}_{4} \mathrm{RIP}$ slurry mixture systems respectively. All of the inputs to Equation (5.28) for the calculation of the equilibrium quotient for the $\mathrm{CaSO}_{4} \cdot 2 \mathrm{H}_{2} \mathrm{O}$ and $\mathrm{PbSO}_{4} \mathrm{RIP}$ slurry mixture systems are given by Tables 11.3 and 11.4 respectively.

From Tables 11.3 and 11.4 it is evident that the activity coefficients for the $\mathrm{Al}^{+3}$ and $\mathrm{Ca}^{+2}$ ions and the $\mathrm{Al}^{+3}$ and $\mathrm{Pb}^{+2}$ ions differ substantially from one another. This is expected due to the fact that the electrochemical valences of the $\mathrm{Ca}^{+2}$ and $\mathrm{Pb}^{+2}$ ions differ from the $\mathrm{Al}^{+3}$ ions. This scenario differs from Chapter 9 where it was evident that activity coefficients for the $\mathrm{Ca}^{+2}$ and $\mathrm{Cu}^{+2}$ ions were very similar. It is further evident from Tables 11.3 that a decrease in the values of the activity coefficients for the $\mathrm{Ca}^{+2}$ ions is observed for an increase in the total solution phase concentration of these species. It is evident that the activity coefficient values for the $\mathrm{Ca}^{+2}$ species decrease from an average value of 0.7 to 0.4 for an increase in the total $\mathrm{Ca}^{+2}$ solution phase concentration from 0.0024 to 0.024 mole/litre. This sharp decrease in the activity coefficients of the cation species was not observed for the $\mathrm{Pb}^{+2}$ species as is evident from Table 11.4. It should be noted that the solution concentration of the $\mathrm{Pb}^{+2}$ species varies less for the three different experiments than was the case for the $\mathrm{Ca}^{+2}$ species. In the case of the $\mathrm{Pb}^{+2}$ species the total solution phase concentration varies from 0.0049 to 0.0012 mole/litre while the total solution phase concentration for the $\mathrm{Ca}^{+2}$ species varied from 0.0024 to 0.024 mole/litre. It is therefore expected that the activity coefficients of the $\mathrm{Pb}^{+2}$ species will vary a lot less than is the case for the $\mathrm{Ca}^{+2}$ species. This is evident from Table 11.4 and 11.3 respectively. 
Table 11.3 Calculated solution phase activity coefficients, resin phase fractional loading for $\mathrm{Ca}^{+2}$ and equilibrium quotient for the cation-exchange reaction between $\mathrm{Ca}^{+2}$ and $\mathrm{Al}^{+3}$ on Duolite $\mathrm{C} 26$ for different total solution phase concentrations for $\mathrm{Ca}^{+2}$.

\begin{tabular}{|c|c|c|c|c|c|c|c|c|c|c|c|}
\hline \multirow{2}{*}{$\begin{array}{c}\text { Resin } \\
\text { vol } \\
{[\mathrm{ml}]}\end{array}$} & \multirow{2}{*}{\begin{tabular}{|c|} 
Soln \\
vol \\
{$[\mathrm{ml}]$}
\end{tabular}} & \multicolumn{3}{|c|}{$\begin{array}{c}\text { Equilibrium } \\
\text { concentration }\end{array}$} & \multicolumn{5}{|c|}{ Species activity coefficients } & \multirow{2}{*}{$\begin{array}{c}\text { Resin } \\
\text { Loadin } \\
\mathbf{g}^{2+} \\
\mathbf{C a}^{2+}\end{array}$} & \multirow{2}{*}{$\begin{array}{c}\text { Equil } \\
\text { quotient }\end{array}$} \\
\hline & & $\begin{array}{c}\mathrm{Ca}^{2+} \\
{[\mathrm{mol} / \mathrm{l}]}\end{array}$ & $\begin{array}{c}\mathrm{Cl}^{-} \\
{[\mathrm{mol} / \mathrm{l}]}\end{array}$ & $\begin{array}{c}\mathbf{A l}^{3+} \\
{[\mathrm{mol} / \mathrm{l}]}\end{array}$ & $\mathrm{Ca}^{2+}$ & $\mathrm{Cl}^{-}$ & $\mid \mathbf{A l}^{3+}$ & $\mathbf{H}^{+}$ & $\mathrm{OH}^{-}$ & & \\
\hline \multicolumn{4}{|c|}{$\mathrm{Ca}^{2+}$} & \multicolumn{8}{|c|}{$2.4 \mathrm{E}-02[\mathrm{~mol} / \mathrm{l}]$} \\
\hline 49.3 & 250 & $3.0 \mathrm{E}-03$ & $4.5 \mathrm{E}-02$ & $1.1 \mathrm{E}-02$ & 0.368 & 0.851 & 0.129 & 0.737 & 0.757 & 0.106 & 0966 \\
\hline 23.3 & 250 & $6.7 \mathrm{E}-03$ & $4.8 \mathrm{E}-02$ & $9.8 \mathrm{E}-03$ & 0.364 & 0.846 & 0.125 & 0.738 & 0.753 & 0.193 & .1464 \\
\hline 15.0 & 250 & $9.5 \mathrm{E}-03$ & $4.8 \mathrm{E}-02$ & $8.5 \mathrm{E}-03$ & 0.366 & 0.843 & 0.124 & 0.742 & 0.753 & 0.256 & 0.8062 \\
\hline 11.5 & 250 & $1.1 \mathrm{E}-02$ & $4.9 \mathrm{E}-02$ & $7.8 \mathrm{E}-03$ & 0.368 & 0.840 & 0.124 & 0.745 & 0.753 & 0.300 & 0.7563 \\
\hline 9.6 & 250 & $1.2 \mathrm{E}-02$ & $4.9 \mathrm{E}-02$ & $7.0 \mathrm{E}-03$ & 0.372 & 0.839 & 0.127 & 0.750 & 0.755 & 0.328 & 0.6653 \\
\hline 8.2 & 250 & $1.3 \mathrm{E}-02$ & $4.8 \mathrm{E}-02$ & $6.4 \mathrm{E}-03$ & 0.375 & 0.838 & 0.127 & 0.752 & 0.756 & 0.352 & 0.5783 \\
\hline 7.0 & 250 & $1.4 \mathrm{E}-02$ & $4.8 \mathrm{E}-02$ & $5.7 \mathrm{E}-03$ & 0.378 & 0.836 & 0.129 & 0.756 & 0.757 & 0.372 & 0.4611 \\
\hline 3.8 & 250 & $1.8 \mathrm{E}-02$ & $4.9 \mathrm{E}-02$ & $3.9 \mathrm{E}-03$ & 0.383 & 0.832 & 0.130 & 0.764 & 0.759 & 0.461 & 0.2831 \\
\hline \multicolumn{4}{|c|}{$\mathrm{Ca}^{2+}$} & \multicolumn{6}{|c|}{$1.2 \mathrm{E}-02[\mathrm{~mol} / \mathrm{l}]$} & & \\
\hline 50.0 & 500 & $2.3 \mathrm{E}-03$ & $2.4 \mathrm{E}-02$ & $6.1 \mathrm{E}-03$ & 0.446 & 0.866 & 4 & & 0.000 & & 140 \\
\hline 24.6 & 500 & $3.6 \mathrm{E}-03$ & $2.4 \mathrm{E}-02$ & $5.3 \mathrm{E}-03$ & 0.452 & 65 & 0.187 & 0.790 & 0.808 & 0.189 & 2.4103 \\
\hline 16.5 & 500 & $4.8 \mathrm{E}-03$ & $2.3 \mathrm{E}-02$ & $4.6 \mathrm{E}-03$ & 0.458 & 0.864 & 0.191 & 0.795 & 0.810 & 0.242 & 1.7833 \\
\hline 13.0 & 500 & $5.7 \mathrm{E}-03$ & $2.3 \mathrm{E}-02$ & $4.0 \mathrm{E}-03$ & 0.462 & 0.863 & 0.193 & 0.799 & 0.812 & 0.272 & 768 \\
\hline 10.0 & 500 & $6.7 \mathrm{E}-03$ & $2.4 \mathrm{E}-02$ & $3.4 \mathrm{E}-03$ & 0.466 & 0.861 & 0.195 & 0.803 & 0.812 & 0.298 & 0.7897 \\
\hline 8.2 & 500 & 7.4E-03 & $2.4 \mathrm{E}-02$ & $3.0 \mathrm{E}-03$ & 0.470 & 0.860 & 0.197 & 0.806 & 0.813 & 18 & 0.5673 \\
\hline 7.0 & 500 & $7.9 \mathrm{E}-03$ & $2.4 \mathrm{E}-02$ & $2.7 \mathrm{E}-03$ & 0.471 & 0.860 & 0.198 & 0.808 & 0.814 & 36 & 4732 \\
\hline 3.5 & 500 & $9.7 \mathrm{E}-03$ & $2.4 \mathrm{E}-02$ & $1.6 \mathrm{E}-03$ & 0.480 & 0.857 & 0.202 & 0.816 & 0.816 & 0.391 & 0.1558 \\
\hline \multicolumn{4}{|c|}{$\mathrm{Ca}^{2+}$} & \multicolumn{6}{|c|}{$2.4 \mathrm{E}-03[\mathrm{~mol} / \mathrm{l}]$} & & \\
\hline 20.4 & 1000 & $8.5 \mathrm{E}-04$ & $5.2 \mathrm{E}-03$ & $8.0 \mathrm{E}-04$ & 0.686 & 0.919 & 0.440 & 0.900 & 0.907 & 0.076 & 0.3288 \\
\hline 9.6 & 1000 & $1.1 \mathrm{E}-03$ & $4.9 \mathrm{E}-03$ & $6.9 \mathrm{E}-04$ & 0.690 & 0.920 & 0.443 & 0.902 & 0.909 & 0.139 & 0.8185 \\
\hline 7.0 & 1000 & $1.2 \mathrm{E}-03$ & $4.8 \mathrm{E}-03$ & $6.0 \mathrm{E}-04$ & 0.691 & 0.920 & 0.444 & 0.903 & 0.909 & 0.168 & 0.7904 \\
\hline 5.0 & 1000 & $1.4 \mathrm{E}-03$ & $4.9 \mathrm{E}-03$ & $5.1 \mathrm{E}-04$ & 0.693 & 0.920 & 0.444 & 0.904 & 0.909 & 0.199 & 0.6621 \\
\hline 4.2 & 1000 & $5 \mathrm{E}-03$ & $4.8 \mathrm{E}-03$ & $4.6 \mathrm{E}-04$ & 0.694 & 0.920 & 0.445 & 0.905 & 0.910 & 0.219 & 0.6723 \\
\hline 3.5 & 1000 & $6 \mathrm{E}-03$ & $4.9 \mathrm{E}-03$ & 4.2E-04 & 0.694 & 0.919 & 0.445 & 0.905 & 0.910 & 0.236 & 0.5616 \\
\hline 3.0 & 1000 & 7E-03 & $4.9 \mathrm{E}-03$ & $3.7 \mathrm{E}-04$ & 0.694 & 0.919 & 0.444 & 0.905 & $\mid 0.909$ & 0.247 & 0.4471 \\
\hline 1.8 & 1000 & $1.9 \mathrm{E}-03$ & $4.8 \mathrm{E}-03$ & $2.7 \mathrm{E}-04$ & 0.695 & 0.919 & 0.443 & 0.907 & 0.910 & 0.284 & 0.2582 \\
\hline
\end{tabular}


Table 11.4 Calculated solution phase activity coefficients, resin phase fractional loading for $\mathrm{Pb}^{+2}$ and equilibrium quotient for the cation-exchange reaction between $\mathrm{Pb}^{+2}$ and $\mathrm{Al}^{+3}$ on Duolite $\mathrm{C} 26$ for different total solution phase concentrations for $\mathrm{Pb}^{+2}$.

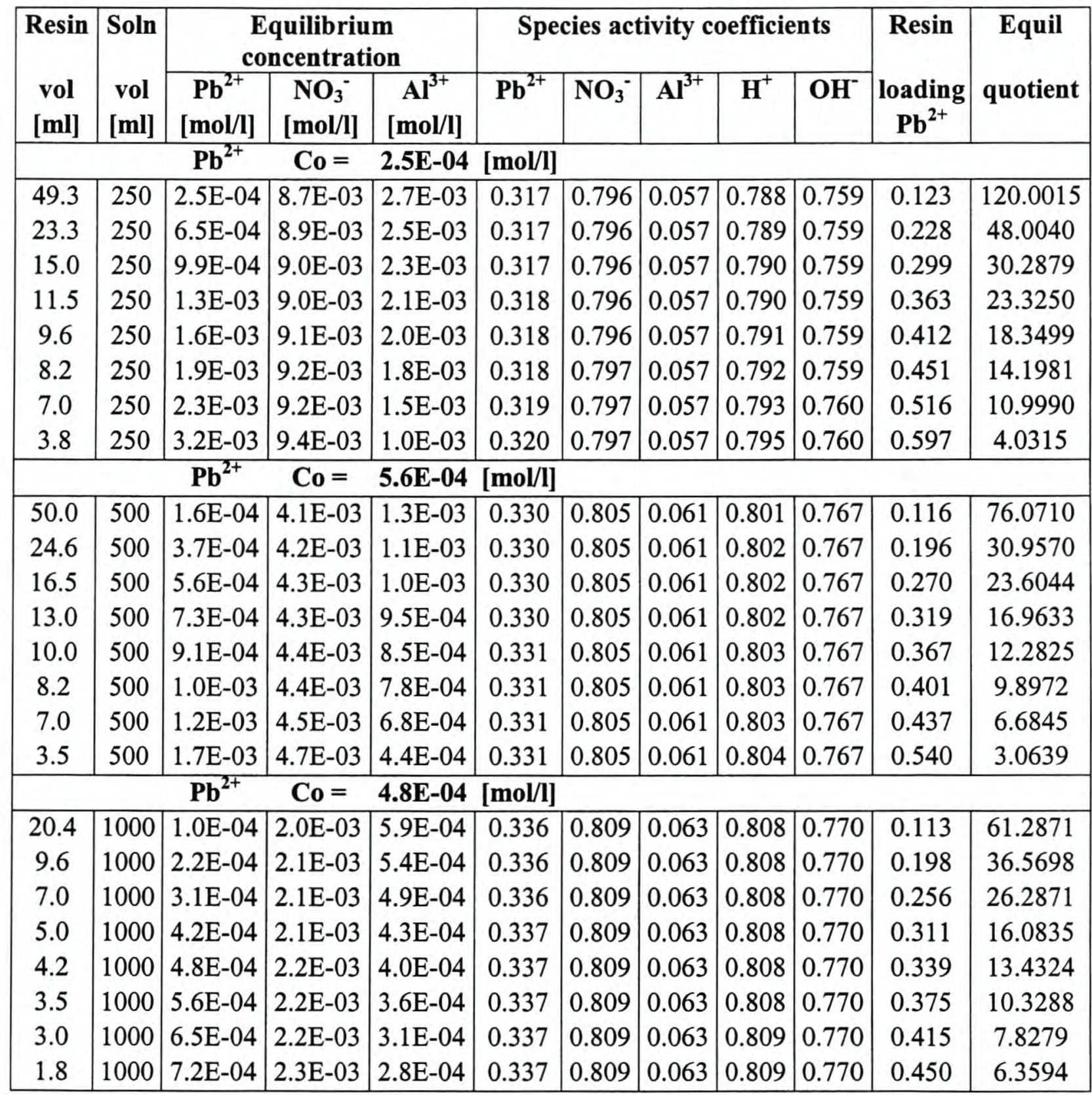




\subsection{CONSOLIDATED EQUILIBRIUM MODEL CALCULATIONS FOR THE SOLUBILITY OF $\mathrm{CaSO}_{4}$ AND $\mathrm{PbSO}_{4}$ IN ELECTROLYTE SOLUTIONS}

The importance of verifying the quality of thermodynamic data obtained from the literature has been discussed in previous chapters. To illustrate the possible variation in the values of thermodynamic properties obtained from the literature the values for the solubility of $\mathrm{CaSO}_{4} \cdot 2 \mathrm{H}_{2} \mathrm{O}$ are discussed below. In the experimental procedures various chemical substances were used as listed in Table 7.27 of Chapter 7. The chemicals listed in this table were used as the sparingly soluble solids in the experimental procedures described in Chapter 7 of this dissertation. It is evident from Table 7.27 that most of the chemicals are not $100 \%$ pure.

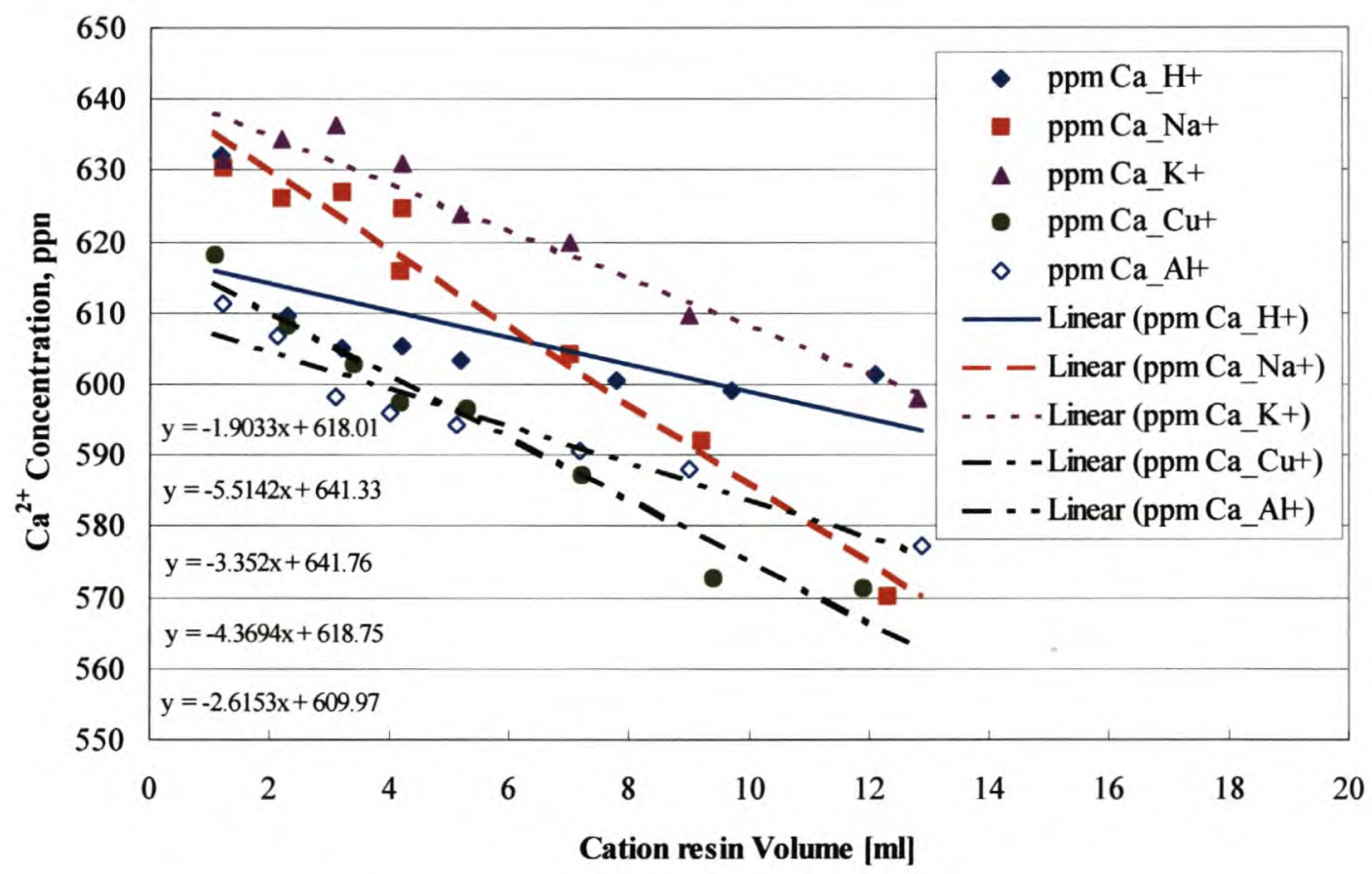

Figure 11.1 Extrapolation curves for the saturation solution phase concentration of $\mathrm{Ca}^{+2}$ ions in a RIP slurry mixture system containing only a cation exchange resin.

The presence of impurities in the chemicals made it necessary to benchmark the value of the solubility of the sparingly soluble solid obtained from the literature with the 
values determined experimentally and used in the model equations of the consolidated equilibrium model for the RIP slurry mixture system.

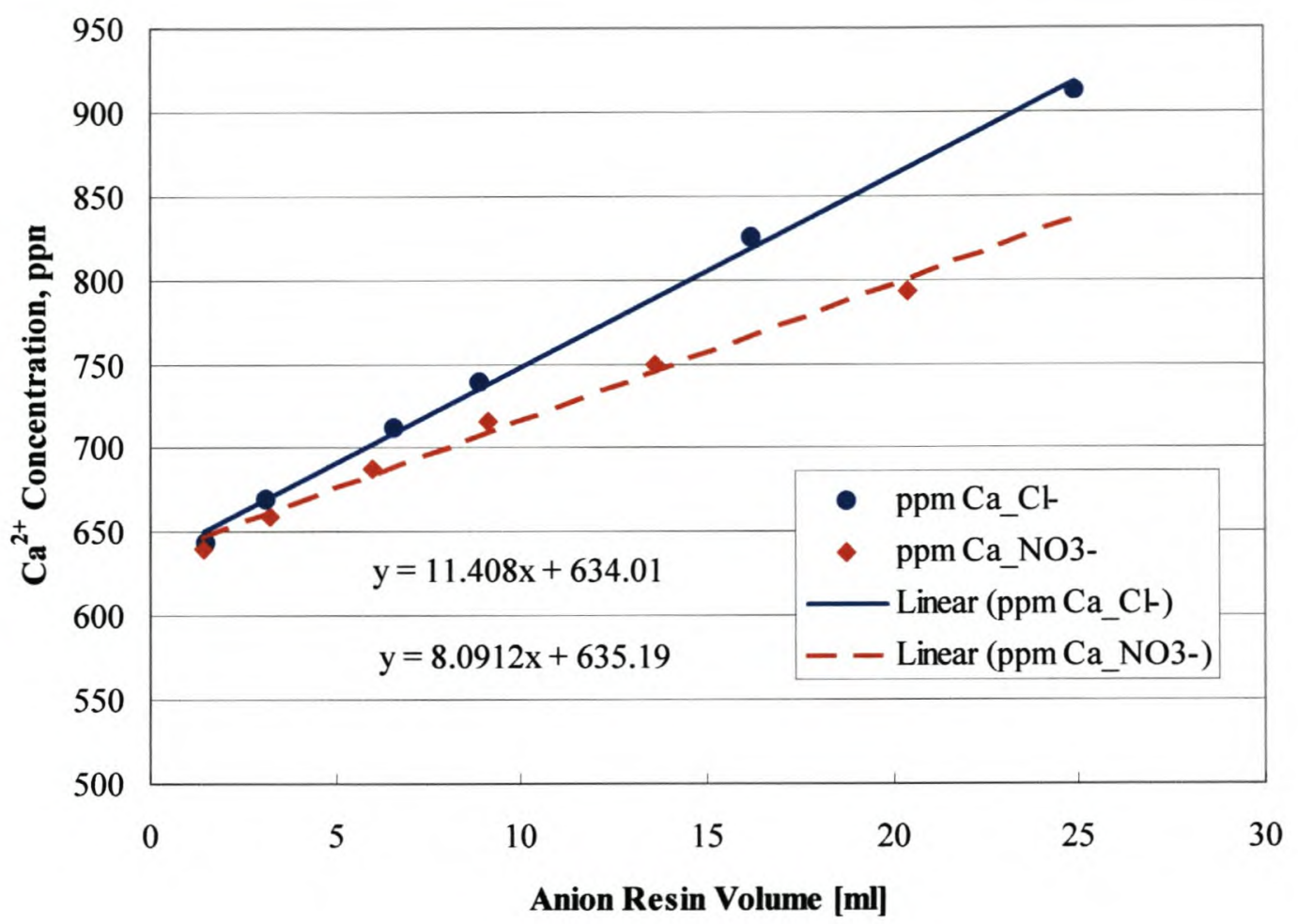

Figure 11.2 Extrapolation curves for the saturation solution phase concentration of $\mathrm{Ca}^{+2}$ ions in a RIP slurry mixture system containing only an anion exchange resin.

Table 11.5 Values for the solubility of $\mathrm{CaSO}_{4} \cdot 2 \mathrm{H}_{2} \mathrm{O}$ obtained from various literature sources

\begin{tabular}{|c|c|c|c|c|}
\hline Literature Source & $\begin{array}{c}\text { CaSO } \\
\text { moles / litre }\end{array}$ & Ksp & $\begin{array}{c}\mathbf{C a}^{+2} \mathbf{p p m} \\
\text { infinite dilution }\end{array}$ & $\begin{array}{c}\mathbf{S O}_{\mathbf{4}}{ }^{2-} \mathbf{p p m} \\
\text { infinite dilution }\end{array}$ \\
\hline Perry et al., 1999 & $4.70 \mathrm{E}-04$ & $2.21 \mathrm{E}-07$ & 19 & 45 \\
\hline $\begin{array}{c}\text { James A. Plambeck,1995 } \\
\text { (Jim.Plambeck@ualberta.ca) }\end{array}$ & $\mathbf{8 . 4 3 \mathrm { E } - 0 3}$ & $7.10 \mathrm{E}-05$ & 338 & 809 \\
\hline Zemaitis et al., 1986 & $1.51 \mathrm{E}-02$ & $2.28 \mathrm{E}-04$ & 605 & 1450 \\
\hline
\end{tabular}


Due to the large number of experiments performed the cost associated with high grade pure chemicals would have been enormous and it was decided to use the analytical grade chemicals for the purposes of this dissertation. Due to the observed variation in the thermodynamic data from the literature the more reliable values for the solubility of the sparingly soluble solid will be the experimentally determined values. For the case of highly insoluble solids the value of the solution phase concentrations of the constituent ions is extremely low and sometimes difficult to measure. This is especially true for the metal sulphides used in the experiments as listed in Table 9.1 of Chapter 9.

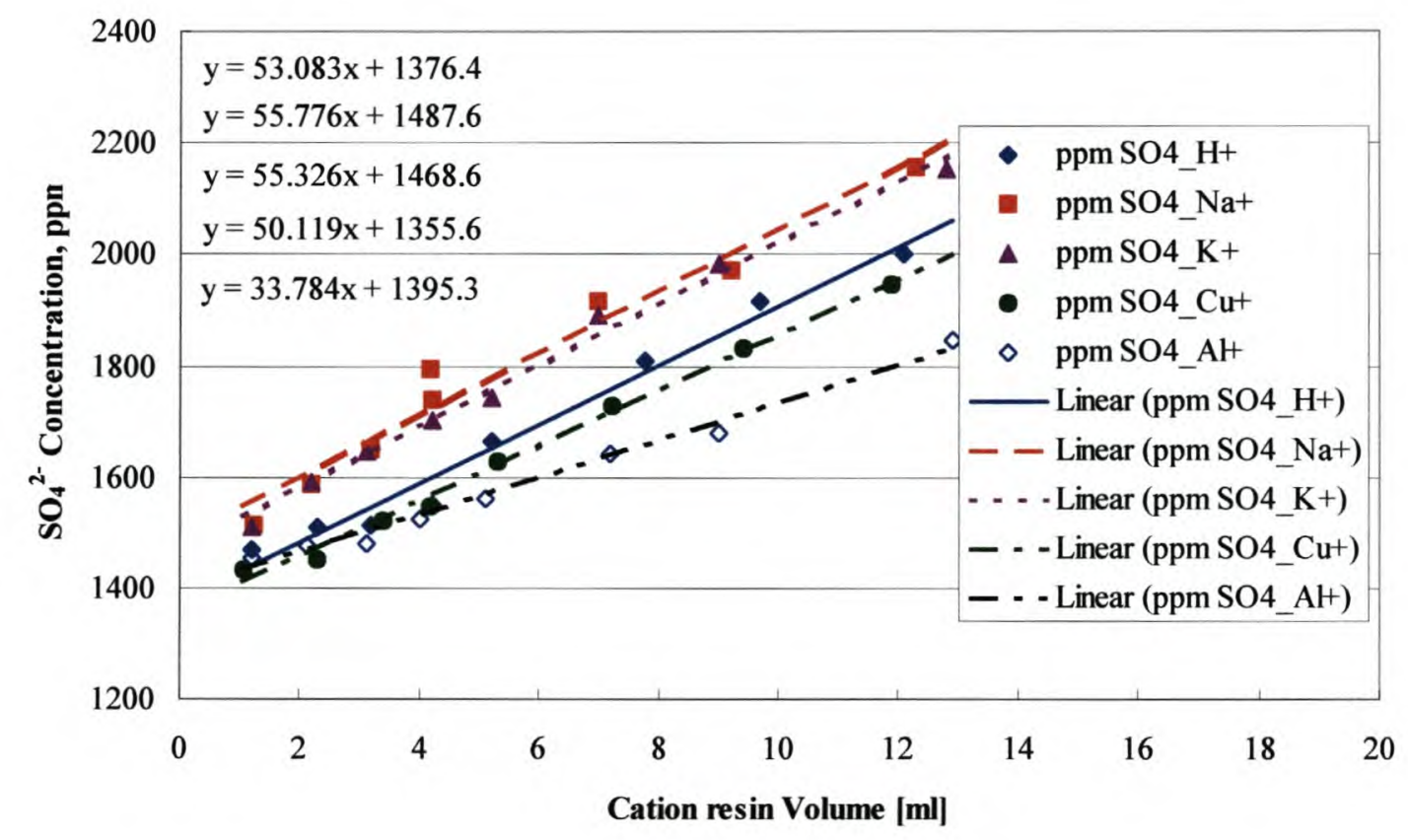

Figure 11.3 Extrapolation curves for the saturation solution phase concentration of $\mathrm{SO}_{4}{ }^{2-}$ ions in a RIP slurry mixture system containing only a cation exchange resin.

Table 11.5 lists the values of the solubility product for $\mathrm{CaSO}_{4} \cdot 2 \mathrm{H}_{2} \mathrm{O}$ obtained from various literature sources. The values in Table 11.5 were chosen to illustrate the fact that significant variations in the value of a single thermodynamic property may occur in the literature. There are several other literature sources available that list values for the solubility of $\mathrm{CaSO}_{4} \cdot 2 \mathrm{H}_{2} \mathrm{O}$ and other sparingly soluble solids not shown in Table 
11.5. It is evident from Table 11.5 that significant variations in the literature values for the $\mathrm{CaSO}_{4} \cdot 2 \mathrm{H}_{2} \mathrm{O}$ solubility exist. When using thermodynamic property data from the literature caution should be exercised in the choice of the values used. The value for a specific property obtained from the literature should preferably be validated between various sources. To assist in the verification of the data quality a SQL7 data base, as discussed in paragraph 6.8 of Chapter 6 , was created. The purpose of the data base is to store thermodynamic data obtained from the literature for various properties of the species used in this dissertation and to benchmark the values of the different literature sources with one another. This ensures that only validated values for the thermodynamic properties of interest are used in the model equations of the consolidated equilibrium model for the RIP slurry mixture system. The values in Table 11.5 were also benchmarked against experimental data collected for the purposes of this dissertation.

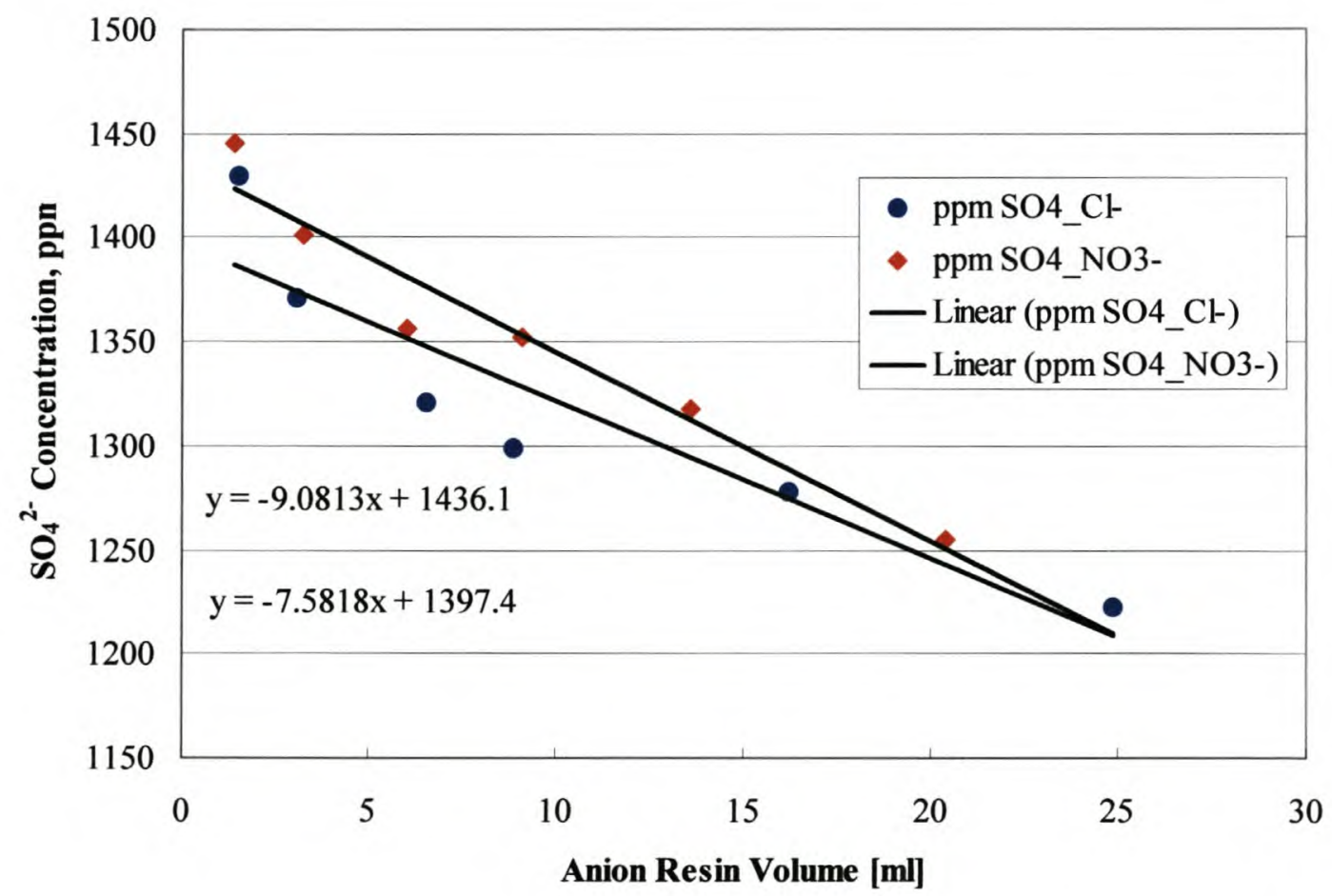

Figure 11.4 Extrapolation curves for the saturation solution phase concentration of $\mathrm{SO}_{4}{ }^{2-}$ ions in a RIP slurry mixture system containing only an anion exchange resin. 
The solubility as measured for the $\mathrm{CaSO}_{4} \cdot 2 \mathrm{H}_{2} \mathrm{O}$ precipitate in the various RIP slurry mixture experiments was used for this purpose. The measurements of the solution phase concentrations of the $\mathrm{Ca}^{+2}$ and $\mathrm{SO}_{4}{ }^{2-}$ ions are extrapolated to a scenario where no ion-exchange resin is present in the slurry mixture system, which should be representative of the saturation concentrations of the $\mathrm{Ca}^{+2}$ and $\mathrm{SO}_{4}{ }^{2-}$ ions in an aqueous solution containing no other electrolytes.

Various experiments were performed for the different RIP slurry mixture systems. In some of the experiments only a cation exchange resin was present and in others only an anion-exchange resin. Several experiments were performed where both a cation and anion exchange resin were present, referred to as a mixed resin bed experiment for the purposes of this dissertation. The experiments performed with only a cation or only an anion exchange resin were used to extrapolate the values for the solution phase concentrations of the $\mathrm{Ca}^{+2}$ and $\mathrm{SO}_{4}{ }^{2-}$ ions. Figures (11.1) and (11.2) give the extrapolation curves for the $\mathrm{Ca}^{+2}$ ions in a RIP slurry mixture with only a cation and anion resin respectively. Figures (11.3) and (11.4) give the extrapolation curves for the $\mathrm{SO}_{4}{ }^{2-}$ ions for the same RIP slurry mixture systems presented by Figures (11.1) and (11.2).

From the $y$-axis intercepts in Figures (11.1) to (11.4) the average values for the solubility of the $\mathrm{CaSO}_{4} \cdot 2 \mathrm{H}_{2} \mathrm{O}$ precipitate may be calculated if it is considered that the saturation concentration in moles/litre of solution of the $\mathrm{Ca}^{+2}$ and $\mathrm{SO}_{4}{ }^{2-}$ ions should be equal to one another. This is evident from the dissolution reaction presented by Equation (11.1). A $K s p$ value of $2.31 \mathrm{E}-04$ is obtained from the experimental data, which relates to a saturation concentration of the $\mathrm{Ca}^{+2}$ and $\mathrm{SO}_{4}{ }^{2-}$ species of $1.52 \mathrm{E}-4$ moles/litre of the aqueous solution. The saturation concentrations in parts per million at infinite dilution were calculated as $609.5 \mathrm{ppm}$ and $1460.7 \mathrm{ppm}$ for the $\mathrm{Ca}^{+2}$ and $\mathrm{SO}_{4}{ }^{2-}$ species respectively. It is evident from Table 11.5 that good agreement between the experimentally determined value and the value obtained from Zemaitis et al. (1986) exists for the solubility product of the $\mathrm{CaSO}_{4} \cdot 2 \mathrm{H}_{2} \mathrm{O}$ precipitate. The values are within $98.6 \%$ of one another. For the purposes of this dissertation the values for the solubility of the $\mathrm{CaSO}_{4} \cdot 2 \mathrm{H}_{2} \mathrm{O}$ precipitate as obtained from Zemaitis et al. (1986) are used in the model calculations of the consolidated equilibrium model for the RIP slurry mixture system. 


\subsection{CONSOLIDATED EQUILIBRIUM MODEL CALCULATIONS FOR THE BIVALENT-TRIVALENT $\mathrm{CaSO}_{4}$ AND $\mathrm{PbSO}_{4}$ RIP SLURRY MIXTURE SYSTEM}

Equations (11.7) and (11.8) represent the thermodynamic dissolution constant for the bivalent-trivalent RIP slurry mixture systems of $\mathrm{CaSO}_{4} \cdot 2 \mathrm{H}_{2} \mathrm{O}$ and $\mathrm{PbSO}_{4}$ for the exchange reactions between $\mathrm{Ca}^{+2}$ and $\mathrm{Al}^{+3}$ and $\mathrm{Pb}^{+2}$ and $\mathrm{Al}^{+3}$ respectively. From the discussions in Chapter 9 and 10 it was evident the value of the thermodynamic equilibrium constant played an important role in the model predictions of the consolidated equilibrium model. It was evident from Figures (9.27) and (10.5) that the value of the thermodynamic equilibrium constant varied with changing total solution phase concentration of the species. This implied that the value of the thermodynamic dissolution constant for RIP systems might vary with a change in the total solution phase concentration.

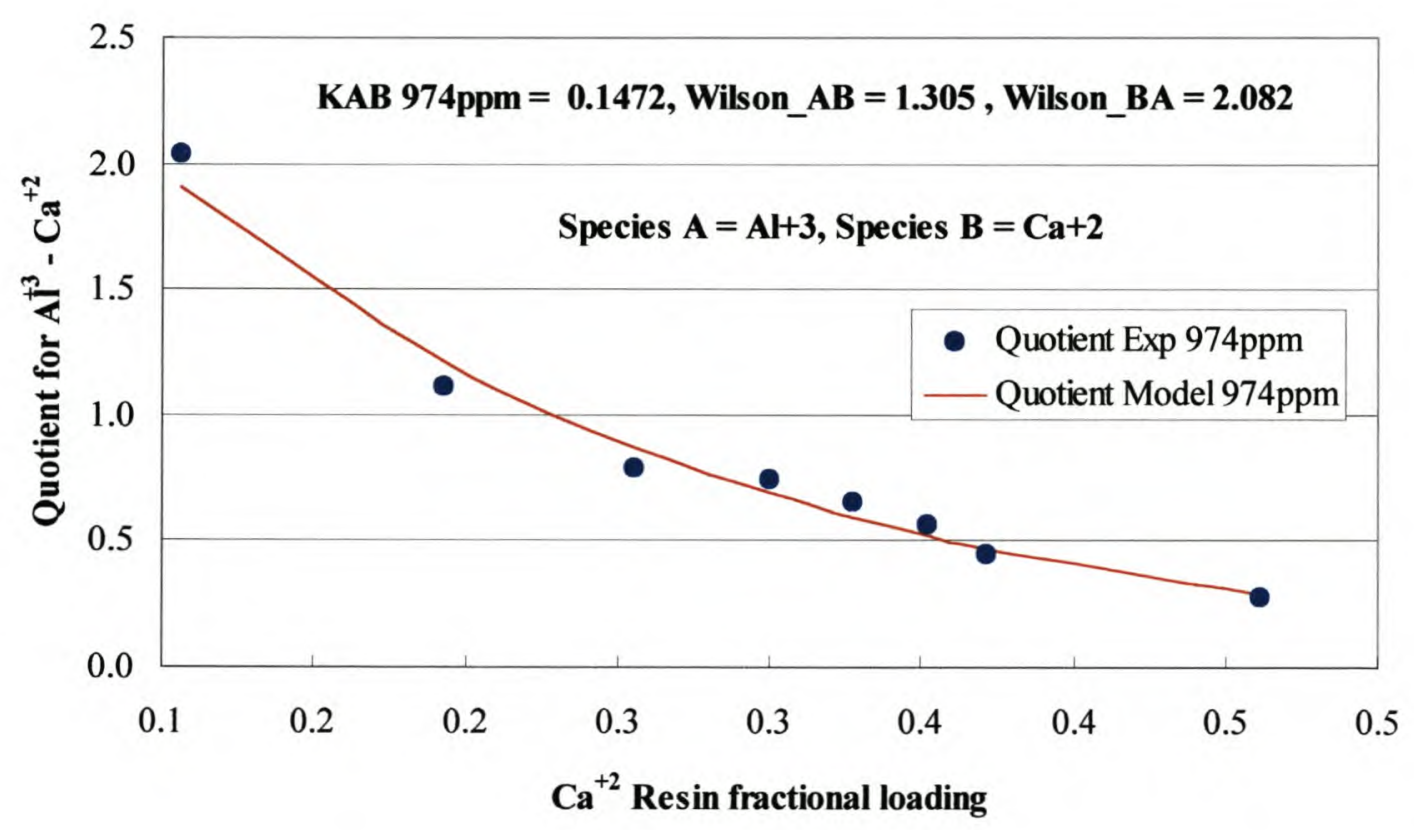

Figure 11.5 Model prediction of the equilibrium quotient for the exchange reaction between $\mathrm{Ca}^{+2}$ and $\mathrm{Al}^{+3}$ for a solution phase concentration of 0.0243 moles/litre. 
The experimental data presented in Chapter 9 indicated clearly that the total solution ionic strength of the RIP slurry changes with changing amounts of the ion-exchange resins present in the system. This implies that the thermodynamic dissolution constant will change for a RIP slurry mixture system if the thermodynamic equilibrium constant for the specific system changes.

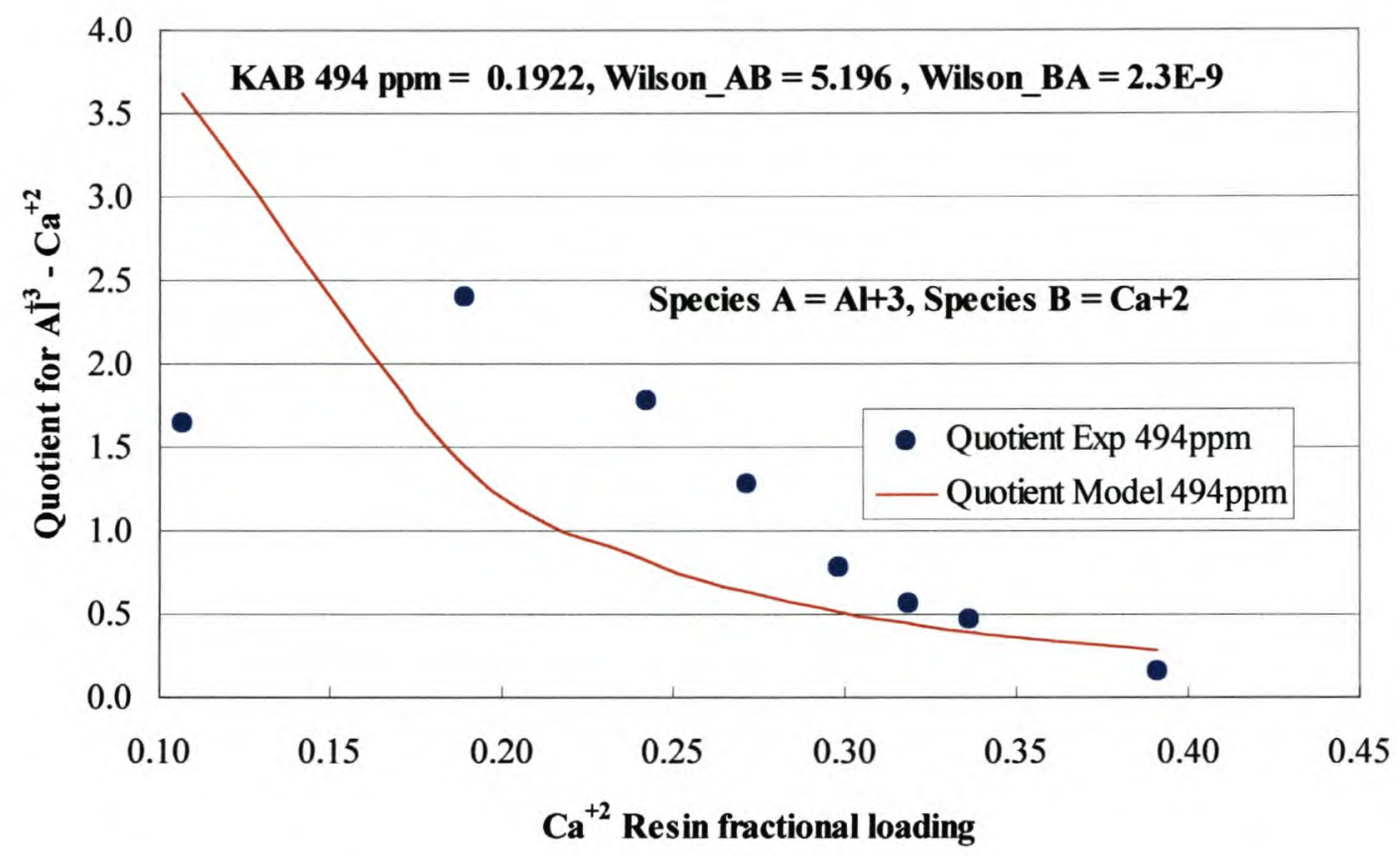

Figure 11.6 Model prediction of the equilibrium quotient for the exchange reaction between $\mathrm{Ca}^{+2}$ and $\mathrm{Al}^{+3}$ for a solution phase concentration of 0.0123 moles/litre.

Figures (11.5) to (11.7) give the model results for the equilibrium quotient for the $\mathrm{CaSO}_{4} \cdot 2 \mathrm{H}_{2} \mathrm{O}$ RIP slurry mixture system with the values for the $\mathrm{PbSO}_{4}$ system given by Figures (11.8) to (11.10). It is evident from Figures (11.6) and (11.7) that the model had difficulty in predicting the experimental data for the exchange reaction between $\mathrm{Ca}^{+2}$ and $\mathrm{Al}^{+3}$. This may be attributed to the fact that the values for the solution phase activity coefficients for the $\mathrm{Al}^{+3}$ species were calculated with the estimated values of the Pitzer ion-interaction parameters for the $\mathrm{Al}^{+3}-\mathrm{Cl}^{-}$interaction given in Table 11.2. Figures (11.8) to (11.10) indicate that good agreement between 
the model prediction and the experimentally determined values are obtained for the exchange reaction between $\mathrm{Pb}^{+2}$ and $\mathrm{Al}^{+3}$.

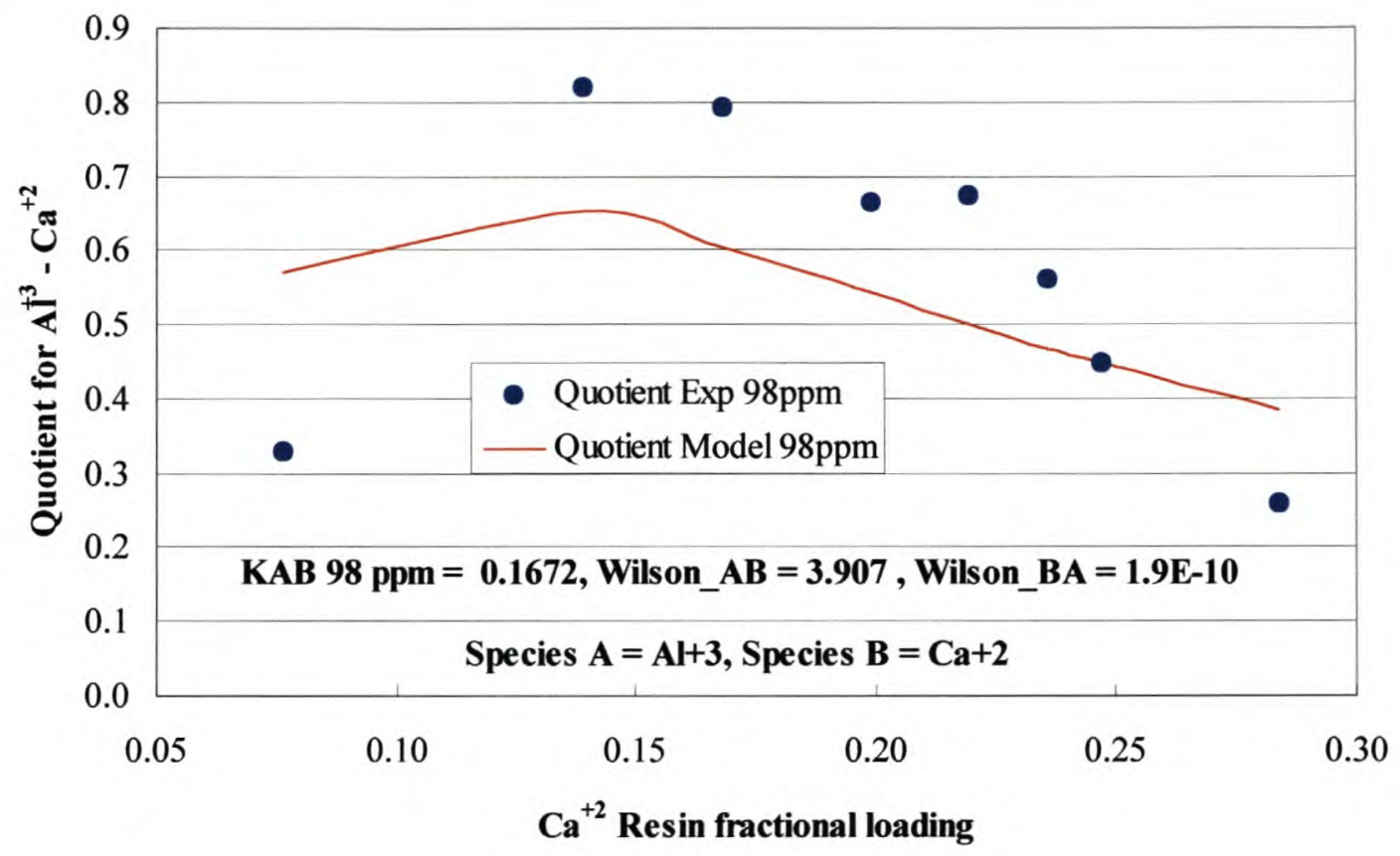

Figure 11.7 Model prediction of the equilibrium quotient for the exchange reaction between $\mathrm{Ca}^{+2}$ and $\mathrm{Al}^{+3}$ for a solution phase concentration of 0.0024 moles/litre.

The values for the thermodynamic equilibrium constant $K_{A}^{B}$ and the Wilson interaction parameters $\Lambda_{A B}$ and $\Lambda_{B A}$ for the $\mathrm{Ca}^{+2}$ and $\mathrm{Al}^{+3}$ exchange reaction are given by Table 11.6. From Table 11.6 it is evident that the value of $K_{A}^{B}$ is relatively constant for the change in the total solution phase concentration of the $\mathrm{Ca}^{+2}$ ions from 0.0024 to 0.024 mole/litre.

The objective function designated by F2 in Table 11.6 is represented by Equation (5.35) of Chapter 5 of this dissertation. The final values of the objective function are also given, which is an indication of the accuracy of the model prediction of the experimentally determined values of equilibrium quotient for the exchange reaction between $\mathrm{Ca}^{+2}$ and $\mathrm{Al}^{+3}$. The experimentally determined values for the equilibrium quotient are given by Table 11.6. All of the variables required to determine the value of the equilibrium quotient with the use of Equation (5.27) are given by Table 11.6. 
Table 11.6 Calculated values for thermodynamic equilibrium constant and Wilson parameters for the exchange reaction between $\mathrm{Ca}^{+2}$ and $\mathrm{Al}^{+3}$ ions on Duolite C26.

\begin{tabular}{|c|c|c|c|c|c|c|c|c|c|}
\hline $\begin{array}{c}\text { Species } \\
\mathbf{A}\end{array}$ & $\begin{array}{c}\text { Species } \\
\mathbf{B}\end{array}$ & $\begin{array}{c}\text { Species } \\
\mathbf{C}\end{array}$ & $K_{A}^{B}$ & $\begin{array}{c}\text { Wilson } \\
\Lambda_{A B}\end{array}$ & $\begin{array}{c}\text { Wilson } \\
\Lambda_{B A}\end{array}$ & $\begin{array}{c}\text { Objective } \\
\text { Function } \\
\text { Equation }\end{array}$ & $\begin{array}{c}\text { Objective } \\
\text { Function } \\
\text { Value }\end{array}$ & $\begin{array}{c}\text { Total } \\
\mathbf{C a}^{+2} \\
\text { mol/litre }\end{array}$ & $\begin{array}{c}\mathbf{N} \\
\text { data }\end{array}$ \\
\hline $\mathrm{Al}^{+3}$ & $\mathrm{Ca}^{+2}$ & $\mathrm{Cl}^{-}$ & 0.1472 & 1.3051 & 2.0820 & $\mathrm{~F} 2$ & 0.044 & 0.0243 & 8 \\
$\mathrm{Al}^{+3}$ & $\mathrm{Ca}^{+2}$ & $\mathrm{Cl}^{-}$ & 0.1922 & 5.1957 & $2.32 \mathrm{E}-09$ & $\mathrm{~F} 2$ & 0.031 & 0.0123 & 8 \\
$\mathrm{Al}^{+3}$ & $\mathrm{Ca}^{+2}$ & $\mathrm{Cl}^{-}$ & 0.1672 & 3.9074 & $1.90 \mathrm{E}-10$ & $\mathrm{~F} 2$ & 0.023 & 0.0024 & 8 \\
\hline
\end{tabular}

From the discussions in Chapter 9 and 10 and the experimental data presented it was clear that experimental errors were associated with the equilibrium isotherms data points when either the solution or resin phase composition for a specific species approached an extreme.

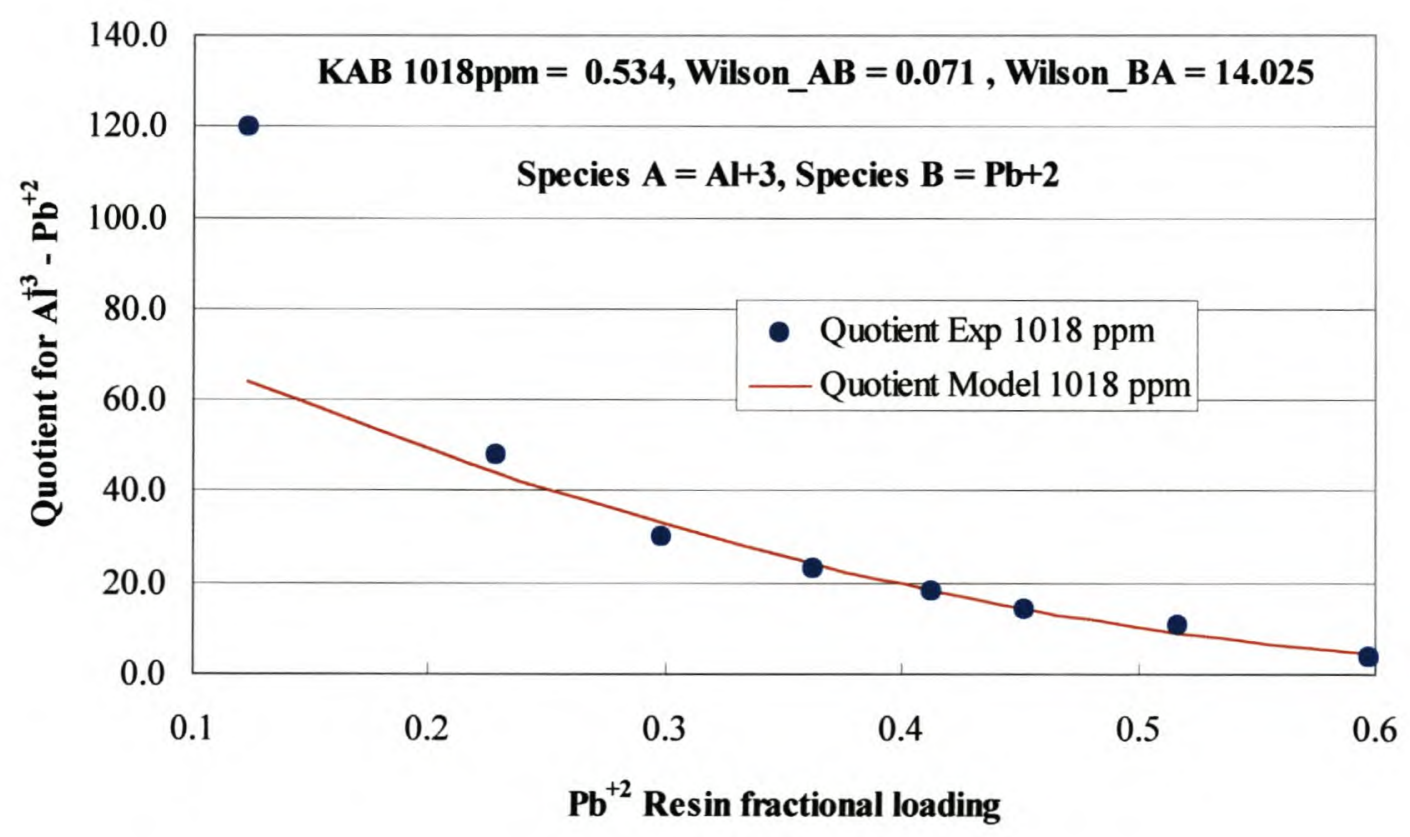

Figure 11.8 Model prediction of the equilibrium quotient for the exchange reaction between $\mathrm{Pb}^{+2}$ and $\mathrm{Al}^{+3}$ for a solution phase concentration of 0.0049 moles/litre. 
This problem was identified by other researchers in the literature (Mehablia et al., 1994) and the objective function as represented by Equation (5.35) was an attempt to obtain more accurate values for the thermodynamic equilibrium constant $K_{A}^{B}$ and the Wilson interaction parameters $\Lambda_{A B}$ and $\Lambda_{B A}$ from the experimental data. From Figures (11.6) and (11.7) it is evident that the same deviation in the calculated values of the equilibrium quotient exist for the exchange reaction between $\mathrm{Ca}^{+2}$ and $\mathrm{Al}^{+3}$ as was the case for the values of the equilibrium quotient in Chapters 9 and 10. When comparing Figures (11.5) to (11.7) with Figures (11.8) to (11.9) it is evident these deviations in the value of the calculated equilibrium quotient are absent for the exchange reaction between $\mathrm{Pb}^{+2}$ and $\mathrm{Al}^{+3}$.

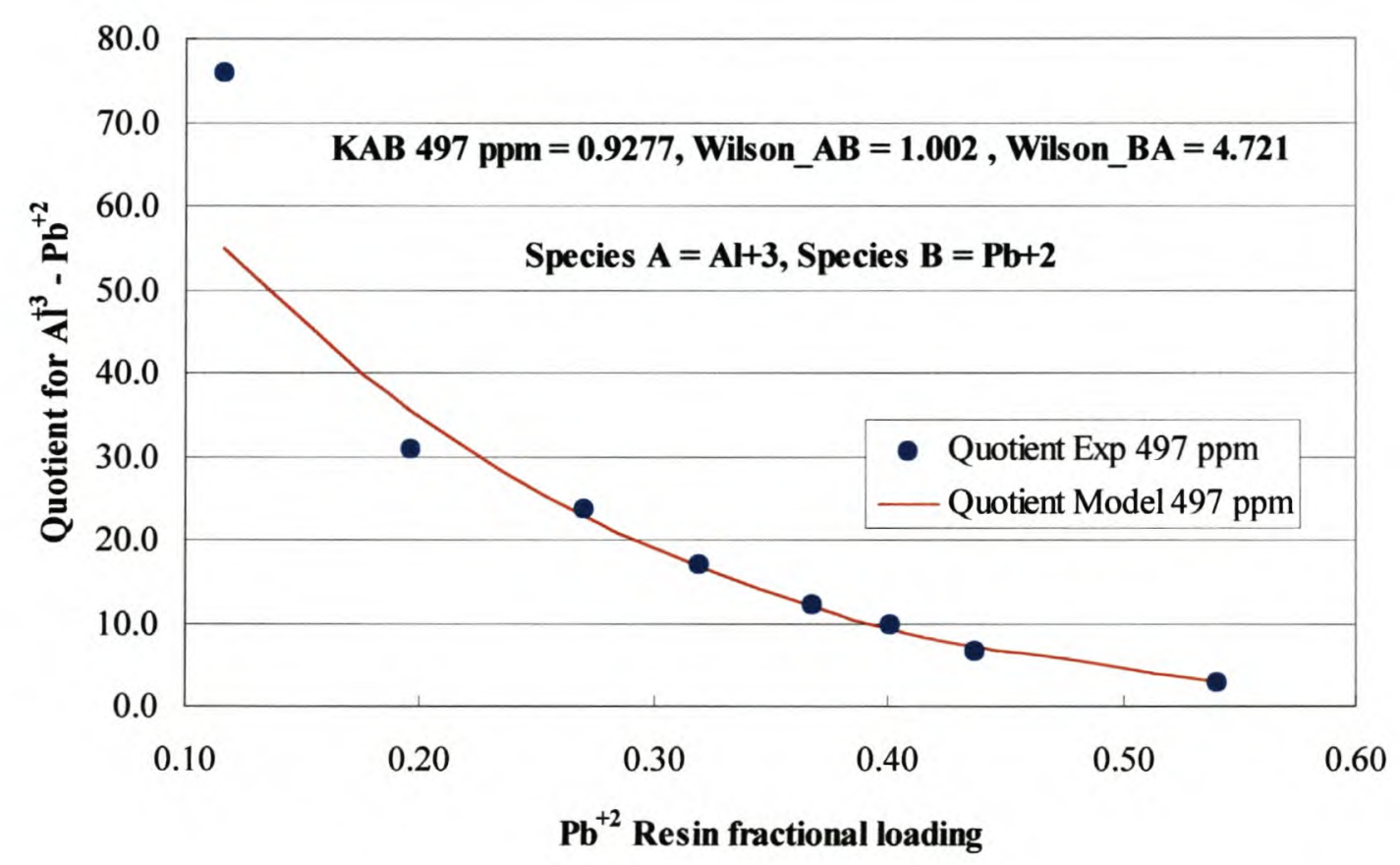

Figure 11.9 Model prediction of the equilibrium quotient for the exchange reaction between $\mathrm{Pb}^{+2}$ and $\mathrm{Al}^{+3}$ for a solution phase concentration of 0.0024 moles/litre.

The values for the thermodynamic equilibrium constant $K_{A}^{B}$ and the Wilson interaction parameters $\Lambda_{A B}$ and $\Lambda_{B A}$ for the $\mathrm{Pb}^{+2}$ and $\mathrm{Al}^{+3}$ exchange reaction are given by Table 11.7. From the values of the objective function presented in Table 
11.7 it is evident that fairly accurate model predictions of the equilibrium quotient are obtained with the given values of the equilibrium quotient and the Wilson interaction parameters.

Table 11.7 Calculated values for thermodynamic equilibrium constant and Wilson parameters for the exchange reaction between $\mathrm{Pb}^{+2}$ and $\mathrm{Al}^{+3}$ ions on Duolite C26.

\begin{tabular}{|c|c|c|c|c|c|c|c|c|c|}
\hline $\begin{array}{c}\text { Species } \\
\mathbf{A}\end{array}$ & $\begin{array}{c}\text { Species } \\
\mathbf{B}\end{array}$ & $\begin{array}{c}\text { Species } \\
\mathbf{C}\end{array}$ & $K_{A}^{B}$ & $\begin{array}{c}\text { Wilson } \\
\Lambda_{A B}\end{array}$ & $\begin{array}{c}\text { Wilson } \\
\Lambda_{B A}\end{array}$ & $\begin{array}{c}\text { Objective } \\
\text { Function } \\
\text { Equation }\end{array}$ & $\begin{array}{c}\text { Objective } \\
\text { Function } \\
\text { Value }\end{array}$ & $\begin{array}{c}\text { Total } \\
\mathbf{P b}^{+2} \\
\text { mol/litre }\end{array}$ & $\begin{array}{c}\mathbf{N} \\
\text { data }\end{array}$ \\
\hline $\mathrm{Al}^{+3}$ & $\mathrm{~Pb}^{+2}$ & $\mathrm{NO}_{3}^{-}$ & 0.5340 & 0.0713 & 14.025 & $\mathrm{~F} 2$ & 0.009 & 0.0049 & 8 \\
$\mathrm{Al}^{+3}$ & $\mathrm{~Pb}^{+2}$ & $\mathrm{NO}_{3}^{-}$ & 0.9276 & 1.0021 & 4.72172 & $\mathrm{~F} 2$ & 0.003 & 0.0024 & 8 \\
$\mathrm{Al}^{+3}$ & $\mathrm{~Pb}^{+2}$ & $\mathrm{NO}_{3}^{-}$ & 3.0063 & 1.7204 & 1.92539 & $\mathrm{~F} 2$ & 0.001 & 0.0012 & 8 \\
\hline
\end{tabular}

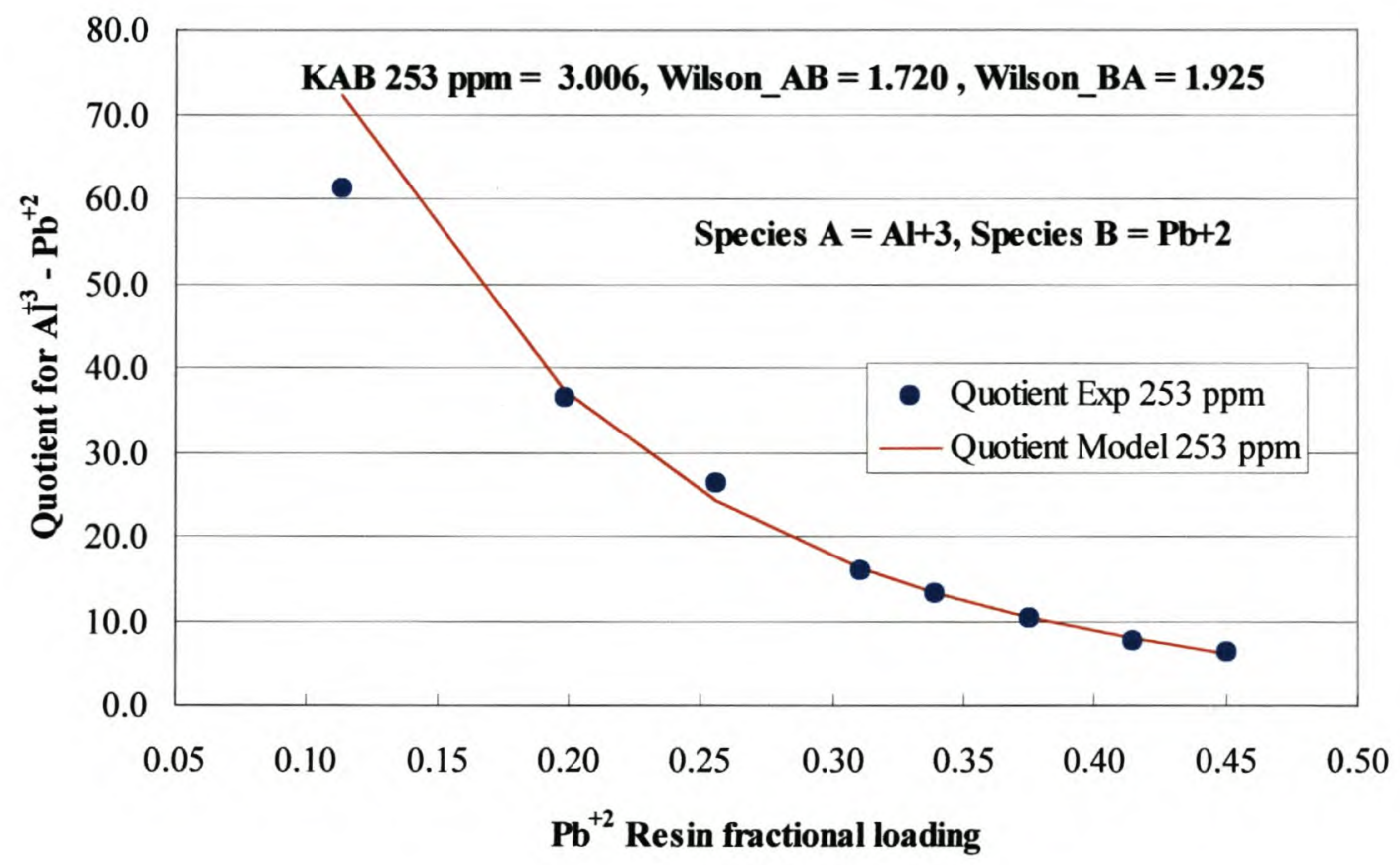

Figure 11.10 Model prediction of the equilibrium quotient for the exchange reaction between $\mathrm{Pb}^{+2}$ and $\mathrm{Al}^{+3}$ for a solution phase concentration of 0.0012 moles/litre. 
It is further evident that the value of the thermodynamic equilibrium constant $K_{A}^{B}$ for the $\mathrm{Pb}^{+2}$ and $\mathrm{Al}^{+3}$ exchange reaction varies more significantly than was the case for the $\mathrm{Ca}^{+2}$ and $\mathrm{Al}^{+3}$ exchange reaction. It should also be kept in mind that the solution phase concentration of the $\mathrm{Pb}^{+2}$ species varied less compared to the solution phase concentration of the $\mathrm{Ca}^{+2}$ species in the calculation of the thermodynamic equilibrium constants presented by Tables 11.6 and 11.7 respectively. This makes the variation in the $K_{A}^{B}$ values for the $\mathrm{Pb}^{+2}$ and $\mathrm{Al}^{+3}$ exchange reaction more significant.

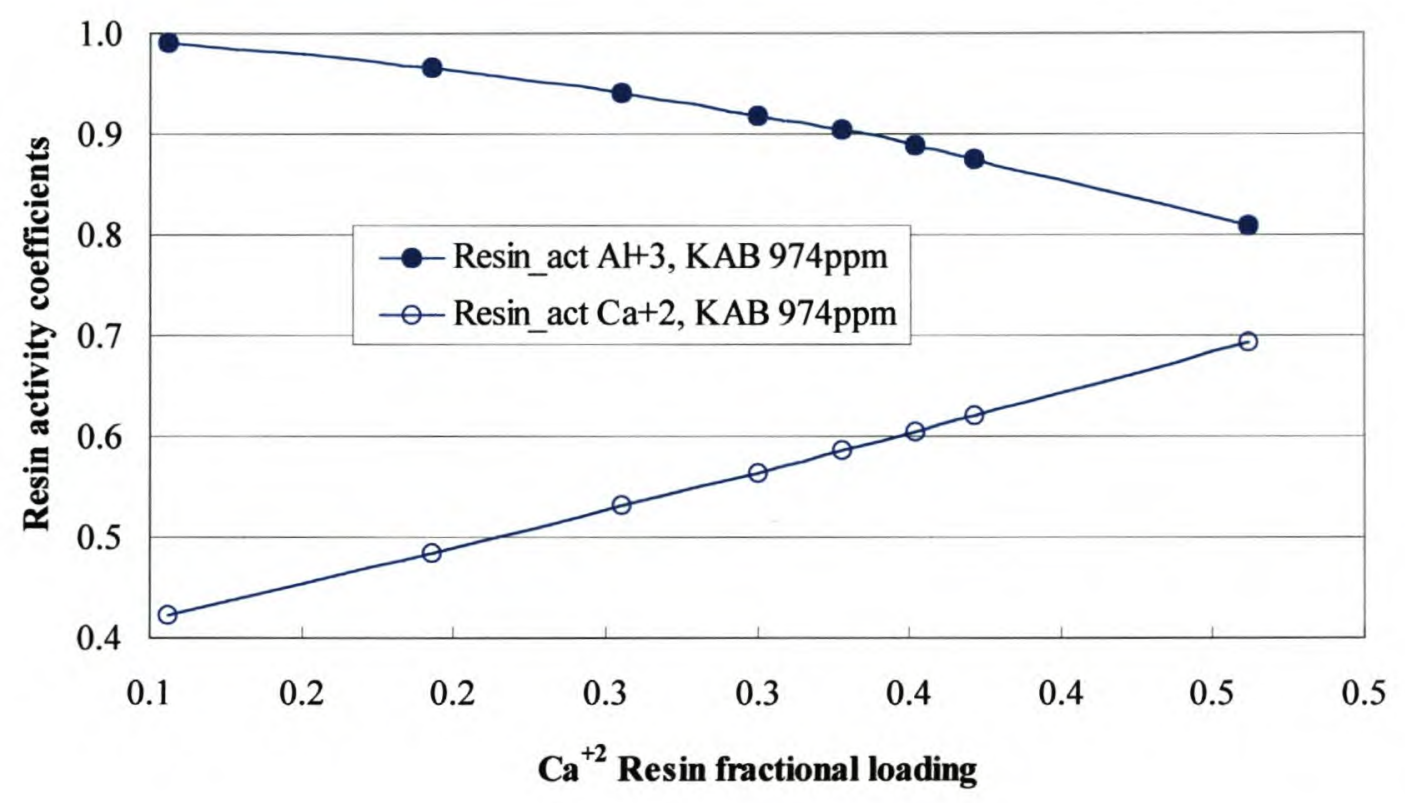

Figure 11.11 Resin activity coefficients for $\mathrm{Al}^{+3}-\mathrm{Ca}^{+2}$ exchange at $974 \mathrm{ppm} \mathrm{Ca}{ }^{+2}$.

In the simulation of the consolidated equilibrium model for the $\mathrm{PbSO}_{4}$ system an average $K_{A}^{B}$ value will not be feasible due to the significant changes with changes in the total solution phase concentration. The $K_{A}^{B}$ value therefore needs to be obtained as a function of the total solution phase concentration for use in the consolidated equilibrium model equations. This poses a significant difficulty when extrapolating the $K_{A}^{B}$ value beyond the total solution phase concentrations for which it was determined. The same difficulty exists for the values of the Wilson interaction parameters $\Lambda_{A B}$ and $\Lambda_{B A}$ for the exchange reaction between $\mathrm{Pb}^{+2}$ and $\mathrm{Al}^{+3}$. From the discussions in Chapter 9 it followed that the same scenario existed for the exchange 
reaction between $\mathrm{Ca}^{+2}$ and $\mathrm{Na}^{+}$for the bivalent-monovalent RIP slurry mixture system, represented by Figure (9.27). Figure (10.5) in Chapter 10 showed the same trend for the exchange reaction between $\mathrm{Ca}^{+2}$ and $\mathrm{Cu}^{+2}$ for the bivalent-bivalent RIP slurry mixture system. This trend was also found by other researchers in the literature and Allen et al. (1989) summarised the $K_{A}^{B}$ values obtained from various literature sources for cation exchange reactions clearly indicating the trend that the value of the thermodynamic equilibrium constant $K_{A}^{B}$ varies with varying total solution phase concentrations.

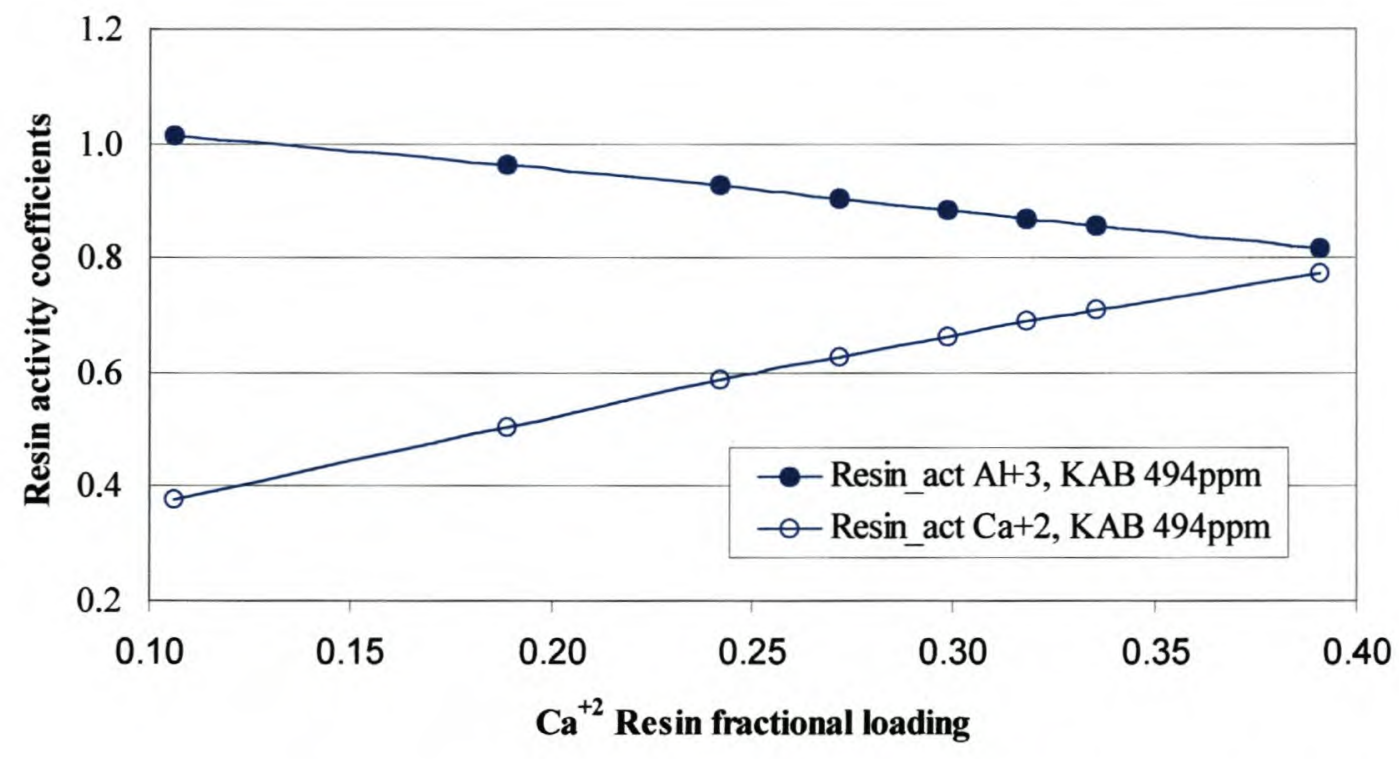

Figure 11.12 Resin activity coefficients for $\mathrm{Al}^{+3}-\mathrm{Ca}^{+2}$ exchange at $494 \mathrm{ppm} \mathrm{Ca}^{+2}$.

Figures (11.11) to (11.13) give the values of the resin phase activity coefficients for the exchange reaction between $\mathrm{Ca}^{+2}$ and $\mathrm{Al}^{+3}$ for different total solution phase concentrations of the $\mathrm{Ca}^{+2}$ species ranging from 0.024 to 0.0024 mole/litre. The values of the resin phase activity coefficients represented in these figures are used in the consolidated equilibrium model calculations for the $\mathrm{CaSO}_{4} \cdot 2 \mathrm{H}_{2} \mathrm{O}$ RIP slurry mixture system. Figures (11.14) to (11.16) gives the resin phase activity coefficients for the exchange reaction between $\mathrm{Pb}^{+2}$ and $\mathrm{Al}^{+3}$ for different solution phase concentrations of the $\mathrm{Pb}^{+2}$ species ranging from 0.0049 to $0.0012 \mathrm{~mole} / \mathrm{litre}$. 


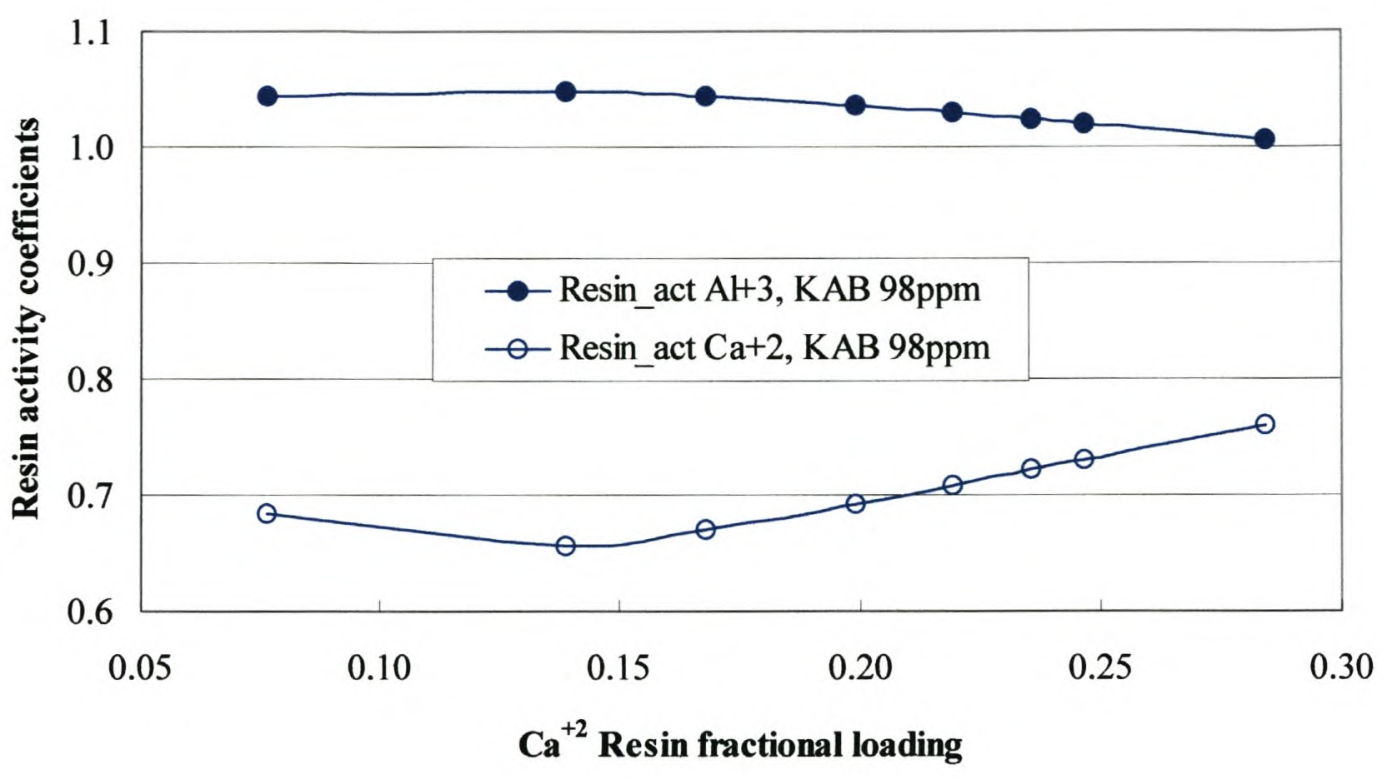

Figure 11.13 Resin activity coefficients for $\mathrm{Al}^{+3}-\mathrm{Ca}^{+2}$ exchange at $98 \mathrm{ppm} \mathrm{Ca}{ }^{+2}$.

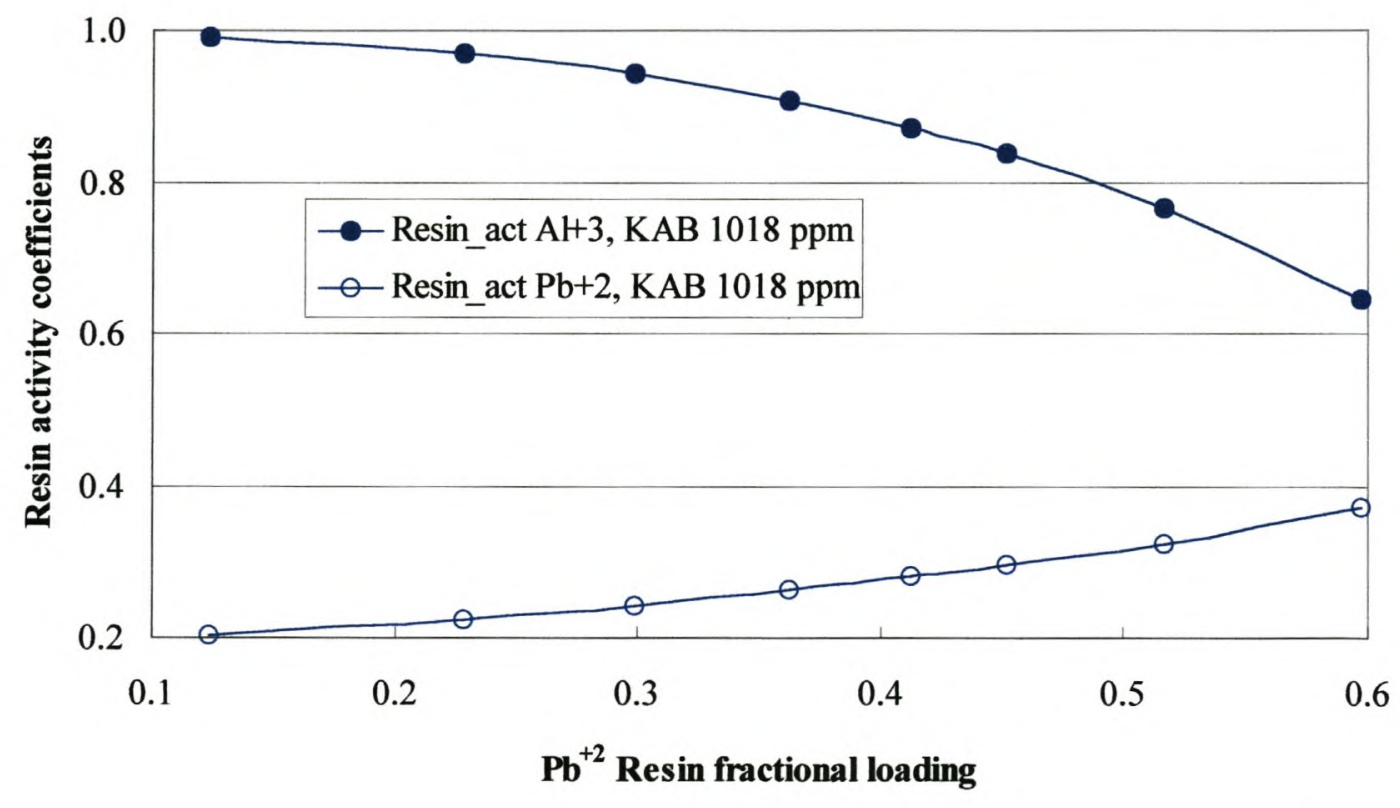

Figure 11.14 Resin activity coefficients for $\mathrm{Al}^{+3}-\mathrm{Pb}^{+2}$ exchange at $1018 \mathrm{ppm} \mathrm{Pb}^{+2}$. 


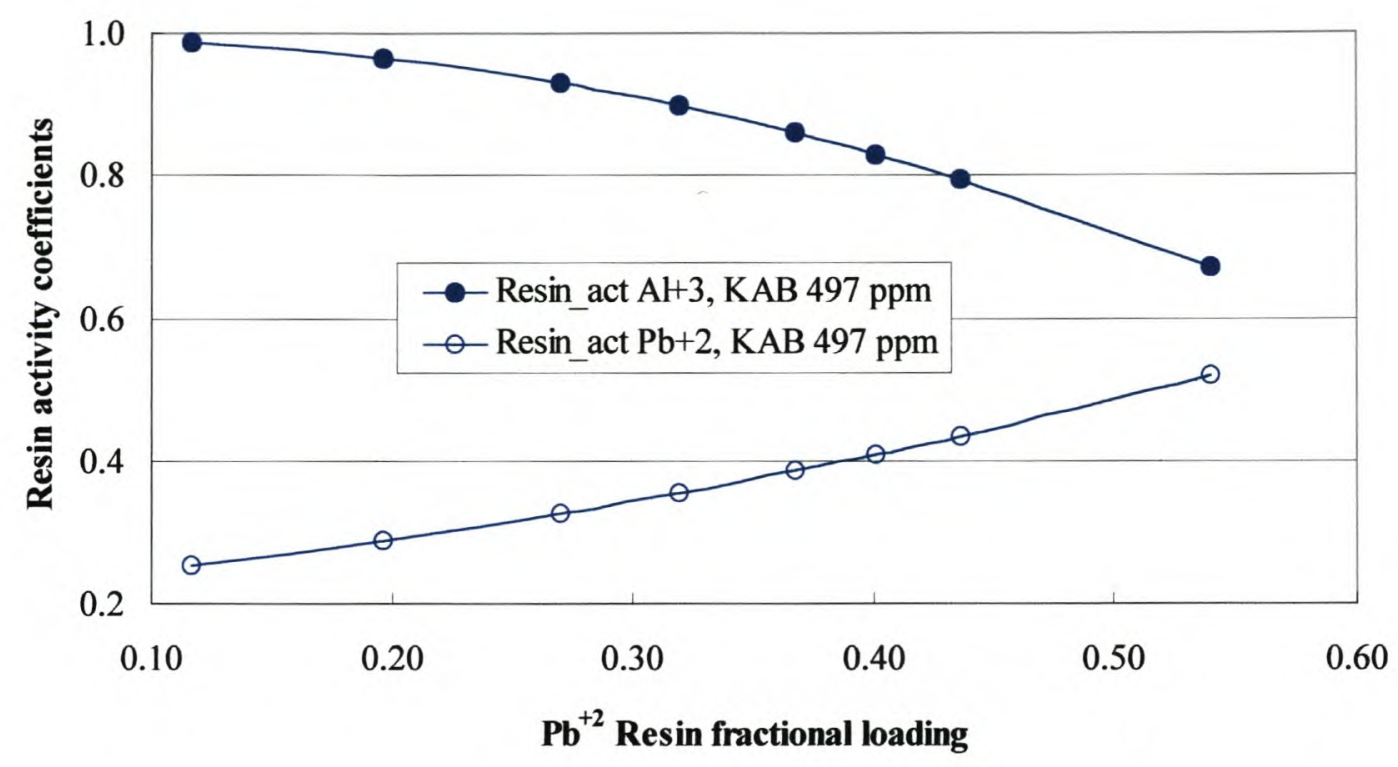

Figure 11.15 Resin activity coefficients for $\mathrm{Al}^{+3}-\mathrm{Pb}^{+2}$ exchange at $497 \mathrm{ppm} \mathrm{Pb}^{+2}$.

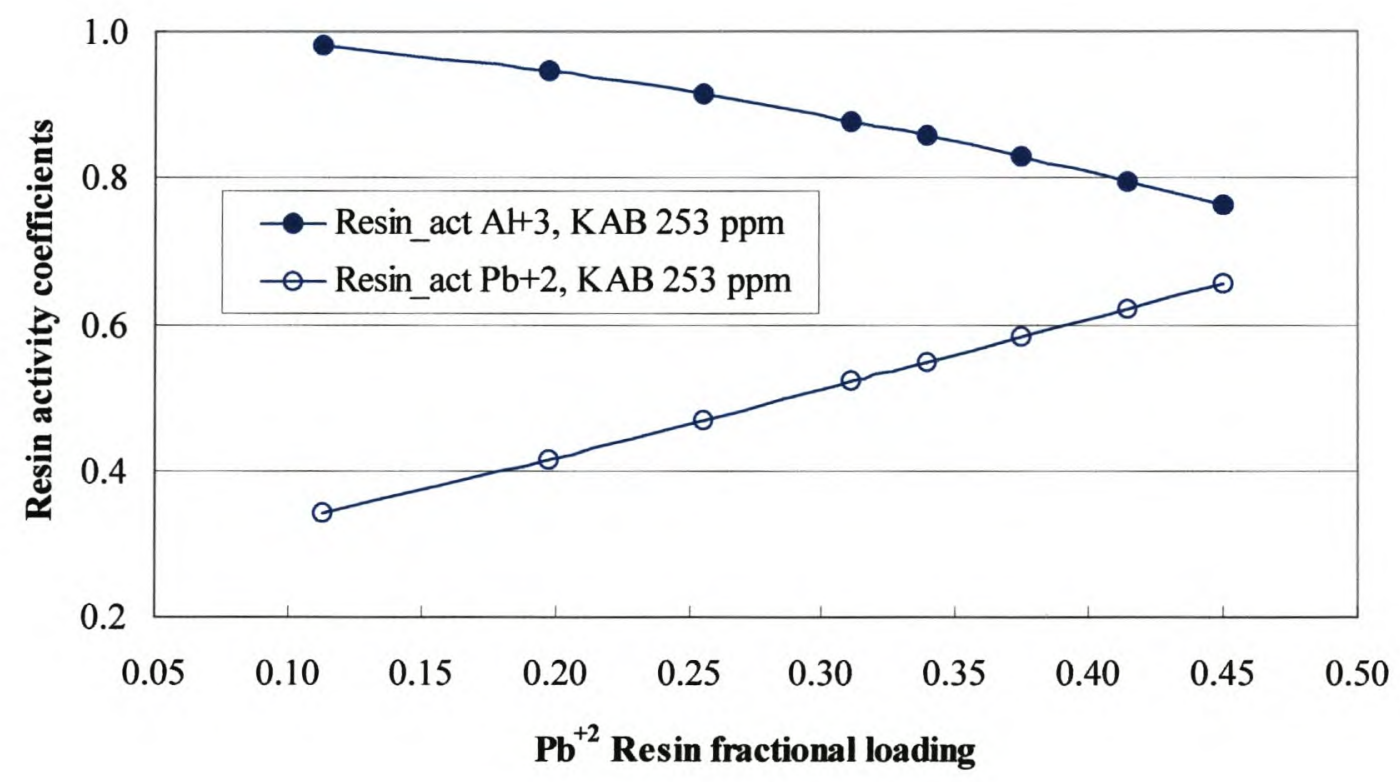

Figure 11.16 Resin activity coefficients for $\mathrm{Al}^{+3}-\mathrm{Pb}^{+2}$ exchange at $253 \mathrm{ppm} \mathrm{Pb}^{+2}$.

It is evident when comparing Figures (11.11) to (11.13) with Figures (11.14) to (11.16) that similar trends exist for the resin phase activity coefficients of the $\mathrm{Al}^{+3}$ species. The resin phase activity coefficients of the $\mathrm{Ca}^{+2}$ and $\mathrm{Pb}^{+2}$ species also show 
similar trends. This may be expected since both the $\mathrm{Ca}^{+2}$ and $\mathrm{Pb}^{+2}$ species participate in an exchange reaction with the $\mathrm{Al}^{+3}$ species and both reactions are bivalent-trivalent in nature.

Figure (11.17) gives the total solution phase concentrations of the $\mathrm{Cl}^{-}$co-ion in the exchange reaction between $\mathrm{Ca}^{+2}$ and $\mathrm{Al}^{+3}$ on Duolite $\mathrm{C} 26$ for different total solution phase concentrations of the $\mathrm{Ca}^{+2}$ ion as a function of the cation resin volume used in the experiments.

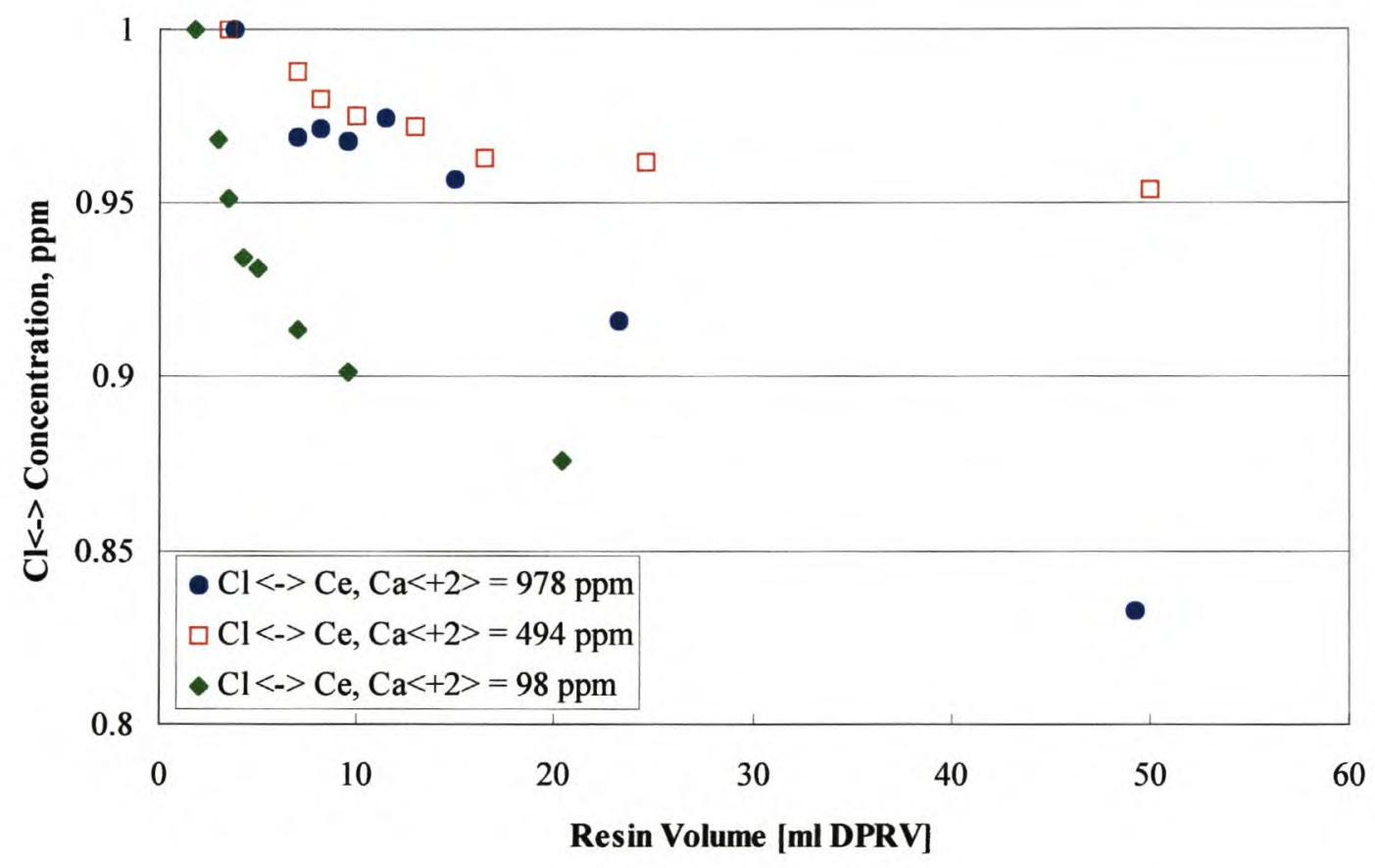

Figure 11.17 Equilibrium electrolyte adsorption of $\mathrm{Cl}^{-}$ions by a macroreticular cation exchange resin, Duolite C26, for the binary anion exchange reaction between $\mathrm{Ca}^{+2}$ and $\mathrm{Al}^{+3}$.

From the discussions in Chapter 8 and 9 it was evident that electrolytic sorption did occur for the various resin / solution and RIP slurry mixture systems. From Figure (11.17) it is clear that electrolytic sorption of the $\mathrm{Cl}^{-}$ions does occur for the bivalenttrivalent system as well. In Chapter 4 the effect of electrolytic sorption on the ionexchange capacity of the ion-exchange resin was discussed and the definitions for the "sorption capacity" of the resin given in paragraph 4.2.3. 
Table 11.8 Pitzer model parameters $\beta^{(0)}, \beta^{(1)}, C^{\phi}, \phi$ and $\psi$ used in the calculation of the thermodynamic equilibrium constant $K_{C l}^{S O 4}$ for the exchange reaction between $\mathrm{SO}_{4}{ }^{2-}$ and $\mathrm{Cl}^{-}$with $\mathrm{Na}^{+}$as the co-ion. Values shown are multiplied with $R=8.31441 \mathrm{~kJ} / \mathrm{kmol} . \mathrm{K}$.

\begin{tabular}{|c|c|c|c|c|c|c|c|c|c|}
\hline $\begin{array}{c}\text { Species } \\
\text { A } \\
\end{array}$ & $\begin{array}{c}\text { Species } \\
\text { B }\end{array}$ & $\begin{array}{c}\text { Species } \\
\text { C }\end{array}$ & $\mathbf{R}$ * Pitzer Parameter & Value & $\begin{array}{c}\text { Species } \\
\text { A }\end{array}$ & $\begin{array}{c}\text { Species } \\
\text { B }\end{array}$ & $\begin{array}{c}\text { Species } \\
\text { C }\end{array}$ & $\mathbf{R} *$ Pitzer Parameter & Value \\
\hline $\mathrm{Cl}<->$ & $\mathrm{OH}<->$ & & $\mathrm{R}^{*} \phi$ & -0.4157205 & $\mathrm{Na}<+>$ & $\mathrm{Cl}<->$ & & $\mathrm{R} * C^{\phi}$ & 0.010559301 \\
\hline $\mathrm{Cl}<->$ & $\mathrm{CO} 3<2->$ & & $\mathrm{R} * \phi$ & -0.1662882 & $\mathrm{Na}<+>$ & $\mathrm{Cl}<->$ & $\mathrm{OH}<->$ & $\mathrm{R}^{*} \psi$ & -0.04988646 \\
\hline $\mathrm{Cl}<->$ & $\mathrm{HCO} 3<->$ & & $\mathrm{R} * \phi$ & 0.2494323 & $\mathrm{Na}<+>$ & $\mathrm{Cl}<->$ & $\mathrm{CO} 3<2->$ & $\mathrm{R}^{*} \psi$ & 0.070672485 \\
\hline $\mathrm{CO} 3<2->$ & $\mathrm{HCO} 3<->$ & & $\mathrm{R} * \phi$ & -0.3325764 & $\mathrm{Na}<+>$ & $\mathrm{Cl}<->$ & $\mathrm{HCO} 3<->$ & $\mathrm{R} * \psi$ & -0.12471615 \\
\hline $\mathrm{H}<+>$ & $\mathrm{SO} 4<2->$ & $\mathrm{Cl}<->$ & $\mathrm{R} * \psi$ & 0 & $\mathrm{Na}<+>$ & $\mathrm{OH}<->$ & & $\mathrm{R} * \beta^{(0)}$ & 0.718365024 \\
\hline $\mathrm{H}<+>$ & $\mathrm{Cl}<->$ & & $\mathrm{R} * \beta^{(0)}$ & 1.475807775 & $\mathrm{Na}<+>$ & $\mathrm{OH}<->$ & & $\mathrm{R} * \beta^{(1)}$ & 2.10354573 \\
\hline $\mathrm{H}<+>$ & $\mathrm{Cl}<->$ & & $\mathrm{R} * \beta^{(1)}$ & 2.448593745 & $\mathrm{Na}<+>$ & $\mathrm{OH}<->$ & & $\mathrm{R} * C^{\phi}$ & 0.036583404 \\
\hline $\mathrm{H}<+>$ & $\mathrm{Cl}<->$ & & $\mathrm{R} * C^{\phi}$ & 0.006651528 & $\mathrm{Na}<+>$ & $\mathrm{OH}<->$ & $\mathrm{CO} 3<2->$ & $\mathrm{R} * \psi$ & -0.14134497 \\
\hline $\mathrm{Na}<+>$ & $\mathrm{H}<+>$ & & $\mathrm{R} * \phi$ & 0.29931876 & $\mathrm{Na}<+>$ & $\mathrm{CO} 3<2->$ & & $\mathrm{R} * \beta^{(0)}$ & 0.301189502 \\
\hline $\mathrm{Na}<+>$ & $\mathrm{H}<+>$ & $\mathrm{Cl}<->$ & $\mathrm{R}^{*} \psi$ & -0.03325764 & $\mathrm{Na}<+>$ & $\mathrm{CO} 3<2->$ & & $\mathrm{R} * \beta^{(1)}$ & 12.5526805 \\
\hline $\mathrm{Na}<+>$ & $\mathrm{SO} 4<2->$ & & $\mathrm{R} * \beta^{(0)}$ & 0.162754576 & $\mathrm{Na}<+>$ & $\mathrm{CO} 3<2->$ & & $\mathrm{R} * C^{\phi}$ & 4.32E-02 \\
\hline $\mathrm{Na}<+>$ & $\mathrm{SO} 4<2->$ & & $\mathrm{R} * \beta^{(1)}$ & 9.25393833 & $\mathrm{Na}<+>$ & $\mathrm{CO} 3<2->$ & $\mathrm{HCO} 3<->$ & $\mathrm{R} * \psi$ & 0.01662882 \\
\hline $\mathrm{Na}<+>$ & $\mathrm{SO} 4<2->$ & & $\mathrm{R} * C^{\phi}$ & $4.14 \mathrm{E}-02$ & $\mathrm{Na}<+>$ & $\mathrm{HCO} 3<->$ & & $\mathrm{R} * \beta^{(0)}$ & 0.23280348 \\
\hline $\mathrm{Na}<+>$ & $\mathrm{SO} 4<2->$ & $\mathrm{Cl}<->$ & $\mathrm{R} * \psi$ & 0.03325764 & $\mathrm{Na}<+>$ & $\mathrm{HCO} 3<->$ & & $\mathrm{R} * \beta^{(1)}$ & 0.36583404 \\
\hline $\mathrm{Na}<+>$ & $\mathrm{SO} 4<2->$ & $\mathrm{OH}<->$ & $\mathrm{R} * \psi$ & $-7.48 \mathrm{E}-02$ & $\mathrm{OH}<->$ & $\mathrm{CO} 3<2->$ & & $\mathrm{R} * \phi$ & 0.831441 \\
\hline $\mathrm{Na}<+>$ & $\mathrm{SO} 4<2->$ & $\mathrm{CO} 3<2->$ & $\mathrm{R} * \psi$ & -0.04157205 & $\mathrm{SO} 4<2->$ & $\mathrm{Cl}<->$ & & $\mathrm{R} * \phi$ & -0.1662882 \\
\hline $\mathrm{Na}<+>$ & $\mathrm{SO} 4<2->$ & $\mathrm{HCO} 3<->$ & $\mathrm{R} * \psi$ & -0.04157205 & $\mathrm{SO} 4<2->$ & $\mathrm{OH}<->$ & & $\mathrm{R} * \phi$ & -0.10808733 \\
\hline $\mathrm{Na}<+>$ & $\mathrm{Cl}<->$ & & $\mathrm{R} * \beta^{(0)}$ & 0.636052365 & $\mathrm{SO} 4<2->$ & $\mathrm{CO} 3<2->$ & & $\mathrm{R} * \phi$ & 0.1662882 \\
\hline $\mathrm{Na}<+>$ & $\mathrm{Cl}<->$ & & $\mathrm{R} * \beta^{(1)}$ & 2.214958824 & $\mathrm{SO} 4<2->$ & $\mathrm{HCO} 3<->$ & & $\mathrm{R} * \phi$ & 0.0831441 \\
\hline
\end{tabular}


Table 11.9 Values for the Pitzer model parameters $\beta^{(0)}, \beta^{(1)}, C^{\phi}, \phi$ and $\psi$ used in the calculation of the thermodynamic equilibrium constant $K_{N O 3}^{S O 4}$ for the exchange reaction between $\mathrm{SO}_{4}{ }^{2-}$ and $\mathrm{NO}_{3}{ }^{-}$with $\mathrm{Na}^{+}$as the co-ion. Parameters obtained from $\mathrm{SQL7}$ data base. All Pitzer values shown are multiplied with the gas constant $R=8.31441 \mathrm{~kJ} / \mathrm{kmol} . \mathrm{K}$.

\begin{tabular}{|c|c|c|c|c|c|c|c|c|c|}
\hline $\begin{array}{c}\text { Species } \\
\text { A }\end{array}$ & $\begin{array}{c}\text { Species } \\
\text { B }\end{array}$ & $\begin{array}{l}\text { Species } \\
\text { C }\end{array}$ & $\mathbf{R}$ * Pitzer Parameter & Value & $\begin{array}{c}\text { Species } \\
\text { A }\end{array}$ & $\begin{array}{c}\text { Species } \\
\text { B }\end{array}$ & $\begin{array}{c}\text { Species } \\
\text { C }\end{array}$ & R * Pitzer Parameter & Value \\
\hline $\mathrm{CO} 3<2->$ & $\mathrm{HCO} 3<->$ & & $\mathrm{R}^{*} \phi$ & -0.3325764 & $\mathrm{Na}<+>$ & $\mathrm{OH}<->$ & & $\mathrm{R}^{*} \beta^{(0)}$ & 0.718365024 \\
\hline $\mathrm{H}<+>$ & NO3<-> & & $\mathrm{R}^{*} \beta^{(0)}$ & 0.971123088 & $\mathrm{Na}<+>$ & $\mathrm{OH}<->$ & & $\mathrm{R} * \beta^{(1)}$ & 2.10354573 \\
\hline $\mathrm{H}<+>$ & NO3<-> & & $\mathrm{R} * \beta^{(1)}$ & 2.948289786 & $\mathrm{Na}<+>$ & $\mathrm{OH}<->$ & & $\mathrm{R}^{*} C^{\phi}$ & 0.036583404 \\
\hline $\mathrm{H}<+>$ & NO3<-> & & $\mathrm{R}^{*} C^{\phi}$ & -0.04481467 & $\mathrm{Na}<+>$ & $\mathrm{OH}<->$ & CO3<2-> & $\mathrm{R}^{*} \psi$ & -0.14134497 \\
\hline $\mathrm{Na}<+>$ & $\mathrm{H}<+>$ & & $\mathrm{R}^{*} \phi$ & 0.29931876 & $\mathrm{Na}<+>$ & $\mathrm{CO} 3<2->$ & & $\mathrm{R} * \beta^{(0)}$ & 0.301189502 \\
\hline $\mathrm{Na}<+>$ & $\mathrm{SO} 4<2->$ & & $\mathrm{R}^{*} \beta^{(0)}$ & 0.162754576 & $\mathrm{Na}<+>$ & $\mathrm{CO} 3<2->$ & & $\mathrm{R} * \beta^{(1)}$ & 12.5526805 \\
\hline $\mathrm{Na}<+>$ & SO4<2-> & & $\mathrm{R}^{*} \beta^{(1)}$ & 9.25393833 & $\mathrm{Na}<+>$ & $\mathrm{CO} 3<2->$ & & $\mathrm{R}^{*} C^{\phi}$ & 4.32E-02 \\
\hline $\mathrm{Na}<+>$ & SO4<2-> & & $\mathrm{R}^{*} C^{\phi}$ & 4.14E-02 & $\mathrm{Na}<+>$ & $\mathrm{CO} 3<2->$ & $\mathrm{HCO} 3<->$ & $\mathrm{R}^{*} \psi$ & 0.01662882 \\
\hline $\mathrm{Na}<+>$ & SO4<2-> & $\mathrm{OH}<->$ & $\mathrm{R}^{*} \psi$ & $-7.48 \mathrm{E}-02$ & $\mathrm{Na}<+>$ & $\mathrm{HCO} 3<>>$ & & $\mathrm{R} * \beta^{(0)}$ & 0.23280348 \\
\hline $\mathrm{Na}<t>$ & $\mathrm{SO} 4<2->$ & $\mathrm{CO} 3<2->$ & $\mathrm{R}^{*} \psi$ & -0.04157205 & $\mathrm{Na}<+>$ & $\mathrm{HCO} 3<>>$ & & $\mathrm{R} * \beta^{(1)}$ & 0.36583404 \\
\hline $\mathrm{Na}<+>$ & SO4<2-> & HCO3<-> & $\mathrm{R} * \psi$ & -0.04157205 & $\mathrm{OH}<->$ & $\mathrm{CO} 3<2->$ & & $\mathrm{R}^{*} \phi$ & 0.831441 \\
\hline $\mathrm{Na}<+>$ & NO3<-> & & $\mathrm{R}^{*} \beta^{(0)}$ & 0.056537988 & SO4<2-> & $\mathrm{OH}<->$ & & $\mathrm{R}^{*} \phi$ & -0.10808733 \\
\hline $\mathrm{Na}<+>$ & $\mathrm{NO} 3<->$ & & $\mathrm{R} * \beta^{(1)}$ & 1.482459303 & $\mathrm{SO} 4<2->$ & $\mathrm{CO} 3<2->$ & & $\mathrm{R} * \phi$ & 0.1662882 \\
\hline $\mathrm{Na}<+>$ & NO3 $<->$ & & $\mathrm{R}^{*} C^{\phi}$ & -0.005986375 & SO4<2-> & $\mathrm{HCO} 3<->$ & & $\mathrm{R}^{*} \phi$ & 0.0831441 \\
\hline
\end{tabular}


It was also clear from the discussions in Chapter 8 and 9 that the values of the thermodynamic equilibrium constant and Wilson interaction parameters are estimated from the "sorption capacity" and that this phenomenon is accounted for in this manner.

Table 11.10 Calculated values for thermodynamic equilibrium constant and Wilson parameters for the exchange reaction between $\mathrm{Cl}^{-}$and $\mathrm{SO}_{4}{ }^{2-}$ ions on Duolite A161.

\begin{tabular}{|c|c|c|c|c|c|c|c|c|c|}
\hline $\begin{array}{c}\text { Species } \\
\mathbf{A}\end{array}$ & $\begin{array}{c}\text { Species } \\
\mathbf{B}\end{array}$ & $\begin{array}{c}\text { Species } \\
\mathbf{C}\end{array}$ & $K_{A}^{B}$ & $\begin{array}{c}\text { Wilson } \\
\Lambda_{A B}\end{array}$ & $\begin{array}{c}\text { Wilson } \\
\Lambda_{B A}\end{array}$ & $\begin{array}{c}\text { Objective } \\
\text { Function } \\
\text { Equation }\end{array}$ & $\begin{array}{c}\text { Objective } \\
\text { Function } \\
\text { Value }\end{array}$ & $\begin{array}{c}\text { Total } \\
\text { SO}_{4}{ }^{2-} \\
\text { mol/litre }\end{array}$ & $\begin{array}{c}\mathbf{N} \\
\text { data }\end{array}$ \\
\hline $\mathrm{Cl}^{-}$ & $\mathrm{SO}_{4}{ }^{2-}$ & $\mathrm{Na}^{+}$ & 0.7046 & 0.0000 & 2.3171 & $\mathrm{~F} 2$ & 0.003 & 0.0249 & 20 \\
$\mathrm{Cl}^{-}$ & $\mathrm{SO}_{4}{ }^{2-}$ & $\mathrm{Na}^{+}$ & 0.7059 & 0.0224 & 2.14544 & $\mathrm{~F} 2$ & 0.003 & 0.0099 & 20 \\
$\mathrm{Cl}^{-}$ & $\mathrm{SO}_{4}{ }^{2-}$ & $\mathrm{Na}^{+}$ & 0.5290 & 0.4168 & 1.21796 & $\mathrm{~F} 2$ & 0.000 & 0.0025 & 10 \\
\hline
\end{tabular}

From the discussions in Chapter 6 it followed that the constituent anion of the sparingly soluble solid may also be adsorbed by an anion exchange resin for a mixed resin bed RIP slurry mixture. The term mixed resin bed refers to a RIP slurry mixture system that contains both a cation and anion exchange resin. Table 6.2 in Chapter 6 gives the thermodynamic dissolution constant for a RIP slurry mixture system containing only an anion exchange resin.

For the RIP systems of $\mathrm{CaSO}_{4} \cdot 2 \mathrm{H}_{2} \mathrm{O}$ and $\mathrm{PbSO}_{4}$ the constituent anion of both these sparingly soluble solids is the $\mathrm{SO}_{4}{ }^{2-}$ anion. From Table 9.1 of Chapter 9 it followed that the anion exchange resin was used in various ionic forms in mixed and single bed RIP slurry mixture systems containing the anion exchange resin. For the purposes of this chapter the exchange reactions between the $\mathrm{SO}_{4}{ }^{2-}$ ion and the $\mathrm{Cl}^{-}$and $\mathrm{NO}_{3}{ }^{-}$ions will be investigated. The thermodynamic equilibrium constants for these exchange reactions have been calculated and Tables 11.8 and 11.9 give the Pitzer ioninteraction parameters used in the calculation of the solution phase activity coefficients for the $\mathrm{SO}_{4}{ }^{2-}-\mathrm{Cl}^{-}$and $\mathrm{SO}_{4}{ }^{2-}-\mathrm{NO}_{3}{ }^{-}$exchange reactions respectively. 
Table 11.11 Calculated values for thermodynamic equilibrium constant and Wilson parameters for the exchange reaction between $\mathrm{NO}_{3}{ }^{-}$and $\mathrm{SO}_{4}{ }^{2-}$ ions on Duolite A161.

\begin{tabular}{|c|c|c|c|c|c|c|c|c|c|}
\hline $\begin{array}{c}\text { Species } \\
\mathbf{A}\end{array}$ & $\begin{array}{c}\text { Species } \\
\mathbf{B}\end{array}$ & $\begin{array}{c}\text { Species } \\
\mathbf{C}\end{array}$ & $K_{A}^{B}$ & $\begin{array}{c}\text { Wilson } \\
\Lambda_{A B}\end{array}$ & $\begin{array}{c}\text { Wilson } \\
\Lambda_{B A}\end{array}$ & $\begin{array}{c}\text { Objective } \\
\text { Function } \\
\text { Equation }\end{array}$ & $\begin{array}{c}\text { Objective } \\
\text { Function } \\
\text { Value }\end{array}$ & $\begin{array}{c}\text { Total } \\
\mathbf{S O}_{4}{ }^{2-} \\
\text { mol/litre }\end{array}$ & $\begin{array}{c}\mathbf{N} \\
\text { data }\end{array}$ \\
\hline $\mathrm{NO}_{3}{ }^{-}$ & $\mathrm{SO}_{4}{ }^{2-}$ & $\mathrm{Na}^{+}$ & 0.0884 & 3.0981 & 0.073299 & $\mathrm{~F} 2$ & 0.000 & 0.0248 & 10 \\
$\mathrm{NO}_{3}{ }^{-}$ & $\mathrm{SO}_{4}{ }^{2-}$ & $\mathrm{Na}^{+}$ & 0.1252 & 0.0000 & 2.52416 & $\mathrm{~F} 2$ & 0.001 & 0.0099 & 10 \\
$\mathrm{NO}_{3}{ }^{-}$ & $\mathrm{SO}_{4}{ }^{2-}$ & $\mathrm{Na}^{+}$ & 0.1458 & 0.0000 & 2.54281 & $\mathrm{~F} 2$ & 0.000 & 0.0025 & 10 \\
\hline
\end{tabular}

The results for these calculations are given by Tables 11.10 and 11.11 for the $\mathrm{SO}_{4}{ }^{2-}$ $\mathrm{Cl}^{-}$and $\mathrm{SO}_{4}{ }^{2-}-\mathrm{NO}_{3}{ }^{-}$exchange reactions respectively. From Table 11.10 it is evident that the thermodynamic equilibrium constant for the exchange reaction between $\mathrm{SO}_{4}{ }^{2-}$ and $\mathrm{Cl}^{-}$is relatively constant and varies slightly with a variation in the total solution phase concentration of the $\mathrm{SO}_{4}{ }^{2-}$ ions. The objective function designated by $\mathrm{F} 2$ in Tables 11.10 and 11.11 are given by Equation (5.35). From Table 11.11 it is evident that the values of the thermodynamic equilibrium constant $K_{A}^{B}$ for the $\mathrm{SO}_{4}{ }^{2-}-\mathrm{NO}_{3}{ }^{-}$ exchange reaction varies more significantly than was the case for the $\mathrm{SO}_{4}{ }^{2-}-\mathrm{Cl}^{-}$ exchange reaction.

The model predictions of the equilibrium quotients for the exchange reaction between $\mathrm{SO}_{4}{ }^{2-}$ and $\mathrm{Cl}^{-}$are given by Figures (11.21) to (11.23) while the model predictions for the $\mathrm{SO}_{4}{ }^{2-}-\mathrm{NO}_{3}{ }^{-}$exchange reaction are given by Figures (11.18) to (11.20). It is evident from Figures (11.18) to (11.20) that the model predictions follow the general trend of the experimentally determined values for the equilibrium quotient. From the discussions in Chapters 9 and 10 and the discussions above it was evident that the phase boundary extreme data points tend to be more inaccurate than the other data points. This trend is also visible from Figures (11.18) to (11.20) that indicates the deviation of the experimentally determined values of the equilibrium quotient from the general trend when the resin phase loading of the $\mathrm{SO}_{4}{ }^{2-}$ ion becomes very low, typically below a value of 0.15 . 


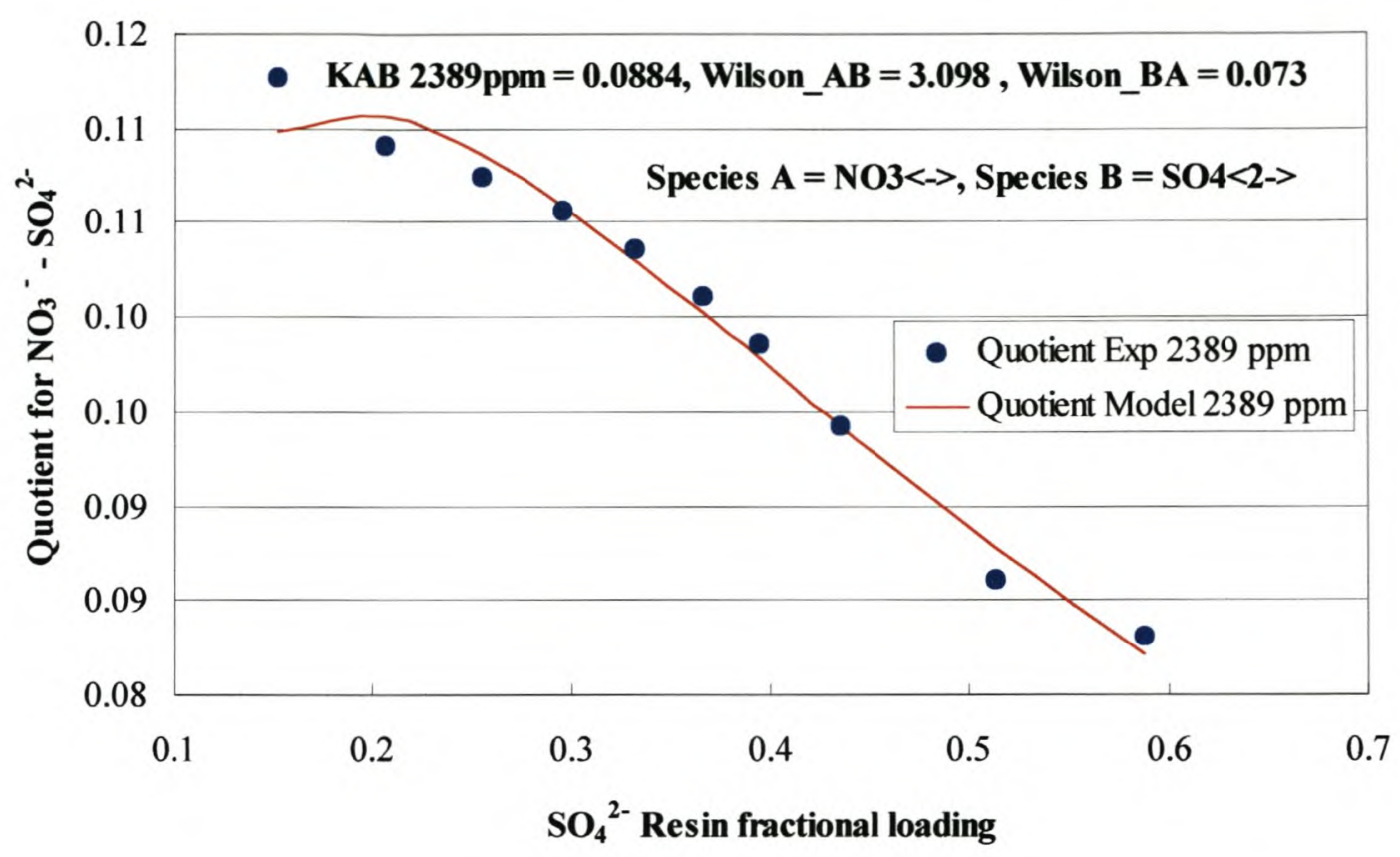

Figure 11.18 Model prediction of the equilibrium quotient for the exchange reaction between $\mathrm{NO}_{3}{ }^{-}$and $\mathrm{SO}_{4}{ }^{2-}$ for a solution phase concentration of 0.0249 moles/litre.

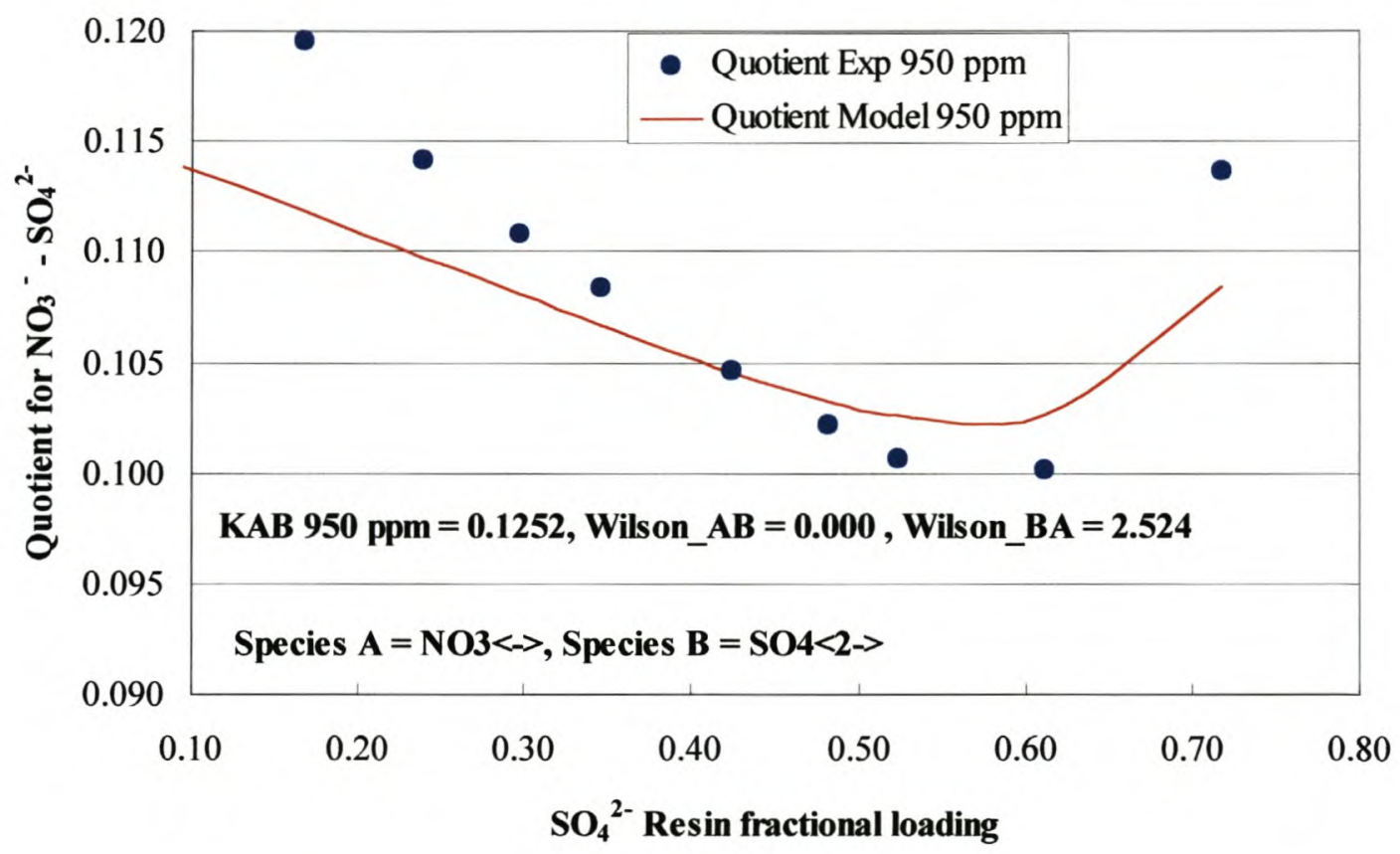

Figure 11.19 Model prediction of the equilibrium quotient for the exchange reaction between $\mathrm{NO}_{3}{ }^{-}$and $\mathrm{SO}_{4}{ }^{2-}$ for a solution phase concentration of 0.0099 moles/litre. 


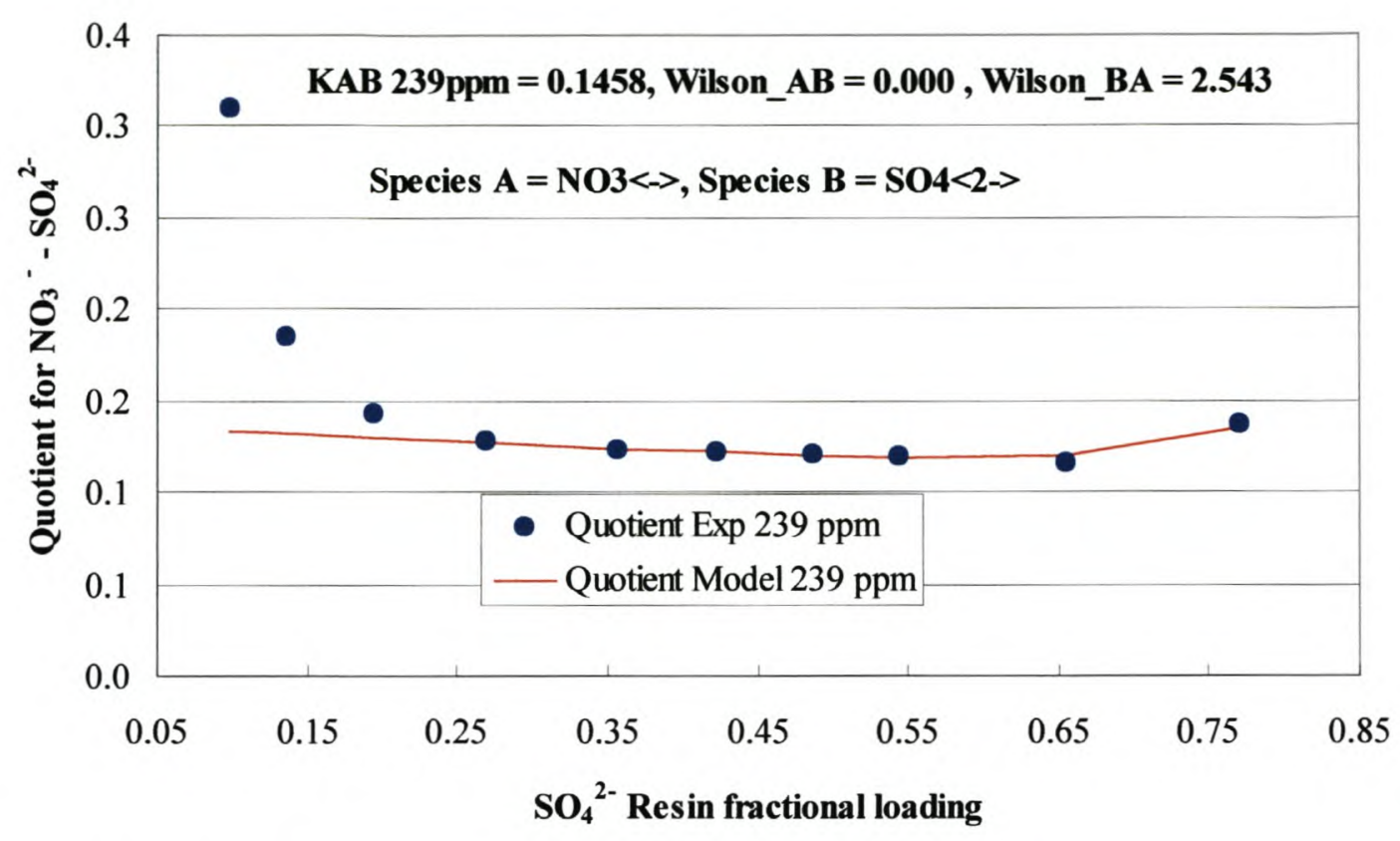

Figure 11.20 Model prediction of the equilibrium quotient for the exchange reaction between $\mathrm{NO}_{3}{ }^{-}$and $\mathrm{SO}_{4}{ }^{2-}$ for a solution phase concentration of 0.0025 moles/litre.

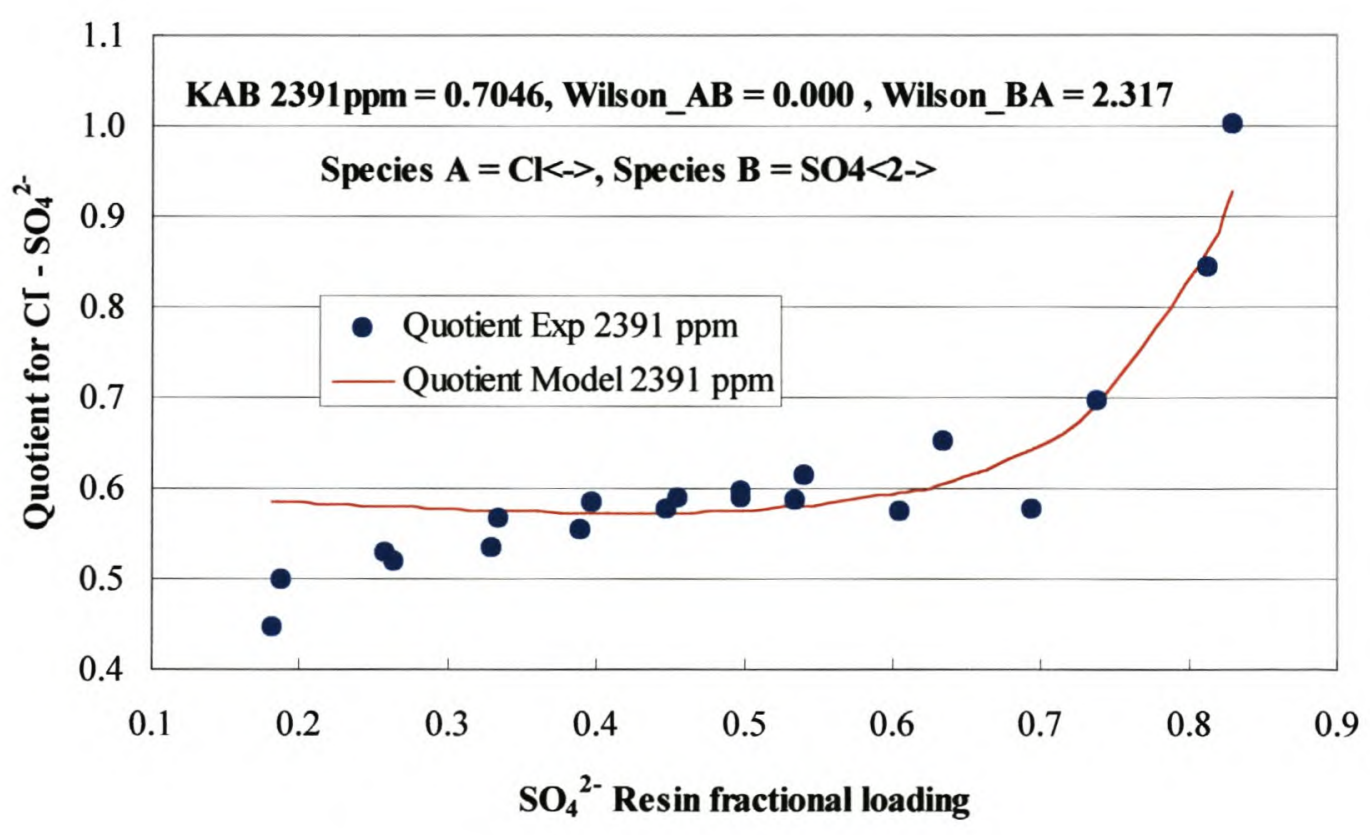

Figure 11.21 Model prediction of the equilibrium quotient for the exchange reaction between $\mathrm{Cl}^{-}$and $\mathrm{SO}_{4}{ }^{2-}$ for a solution phase concentration of 0.0249 moles/litre. 
From Figures (11.21) to (11.23) it is evident that the model predictions follow the general trend of the equilibrium quotient calculated for the exchange reaction between $\mathrm{Cl}^{-}$and $\mathrm{SO}_{4}{ }^{2-}$ for different total solution phase concentrations of the $\mathrm{SO}_{4}{ }^{2-}$ ion. The same deviation for the calculated values of the equilibrium quotient from the general trend line is observed for the low and high values of the $\mathrm{SO}_{4}{ }^{2-}$ resin fractional loadings. From Table 11.10 it is evident that the value of the thermodynamic equilibrium constant for the $\mathrm{Cl}^{-}$and $\mathrm{SO}_{4}{ }^{2-}$ exchange reaction increases for an increase in the total solution phase concentration. This trend in the value of the thermodynamic equilibrium constant was also evident from the discussions in Chapter 10 .

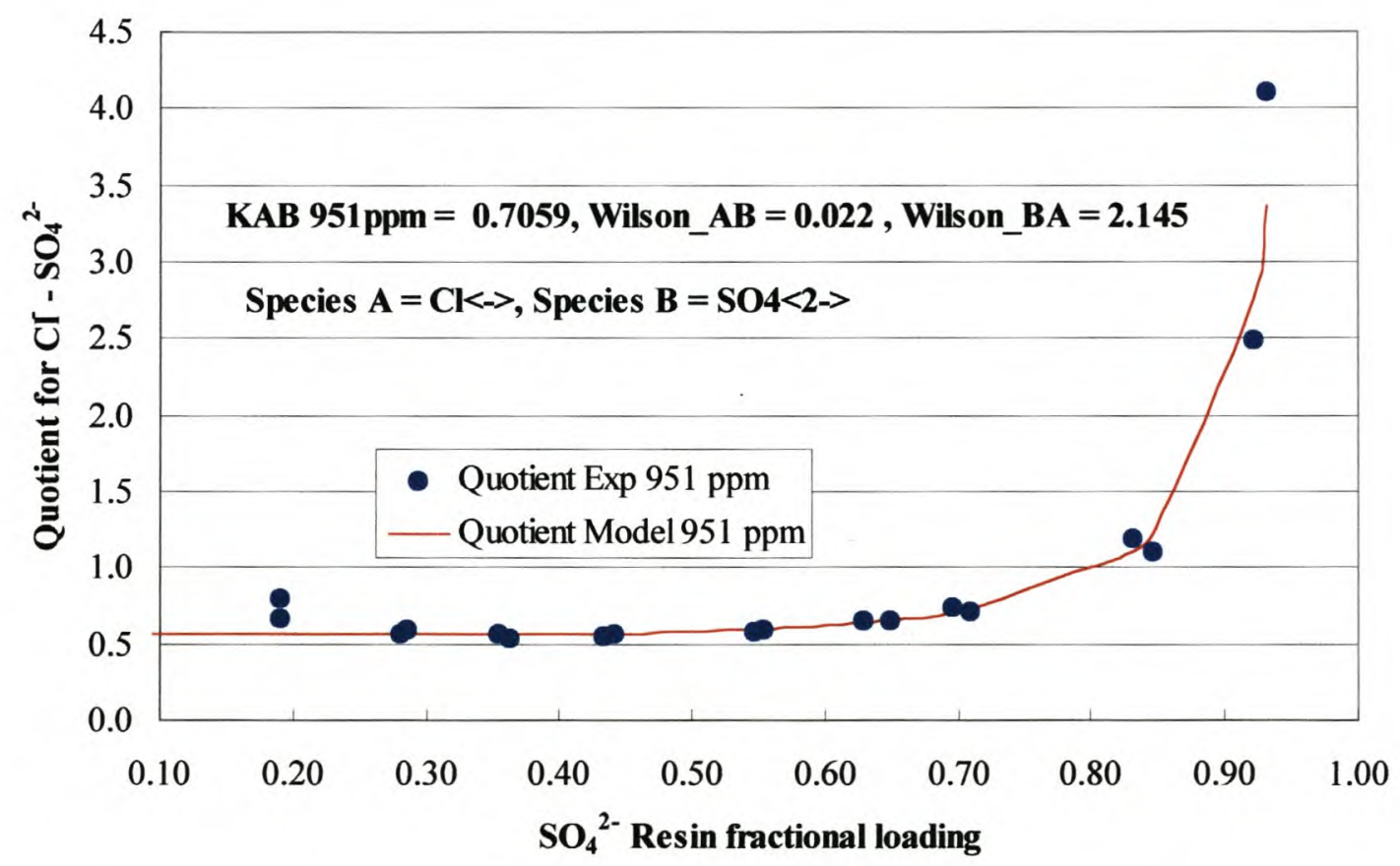

Figure 11.22 Model prediction of the equilibrium quotient for the exchange reaction between $\mathrm{Cl}^{-}$and $\mathrm{SO}_{4}{ }^{2-}$ for a solution phase concentration of 0.0099 moles/litre. 


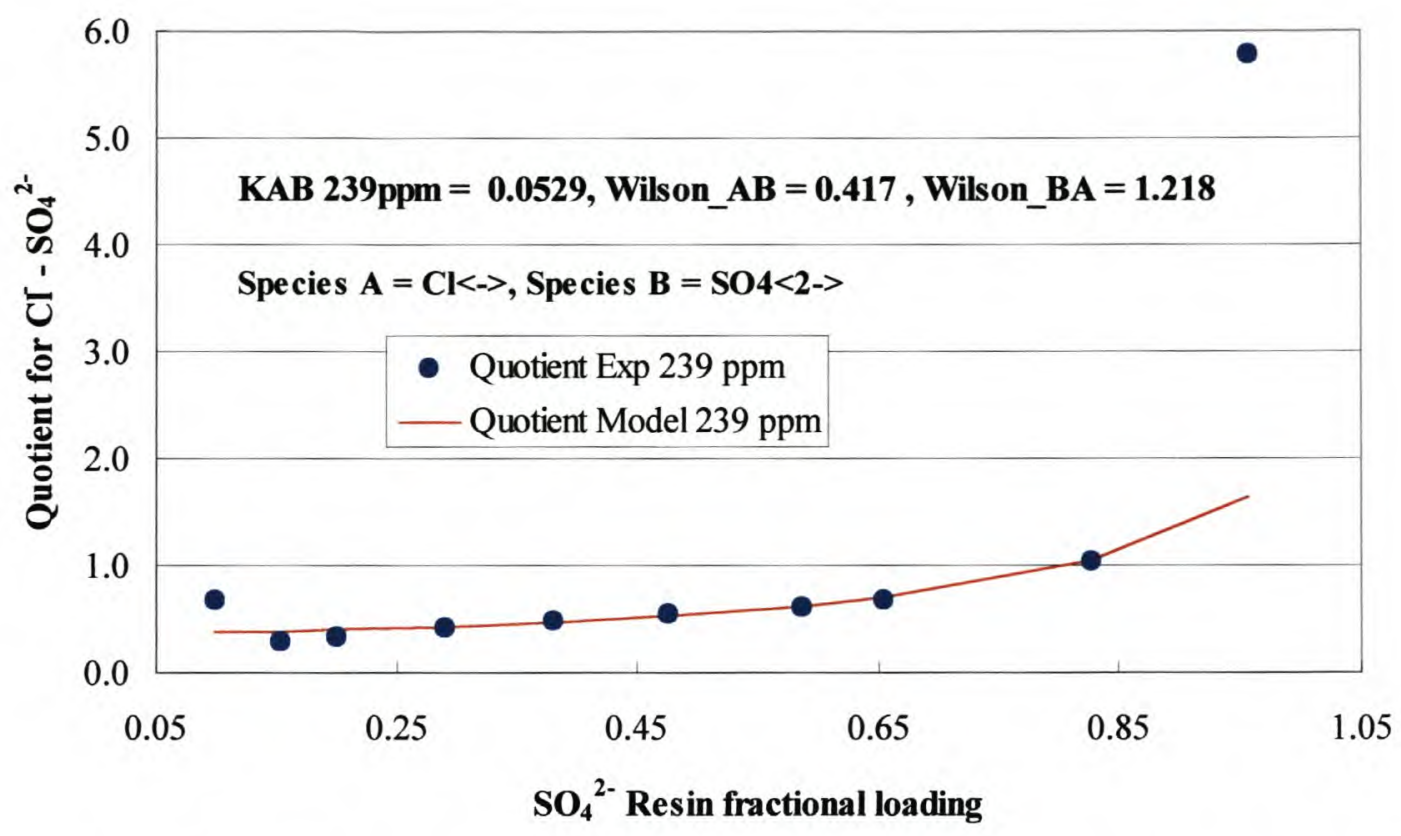

Figure 11.23 Model prediction of the equilibrium quotient for the exchange reaction between $\mathrm{Cl}^{-}$and $\mathrm{SO}_{4}{ }^{2-}$ for a solution phase concentration of 0.0025 moles/litre.

In general the model predictions give satisfactory predictions except for the data points close to the phase boundary extremes. The deviation may be attributed to experimental errors that are amplified in the calculation of the equilibrium quotient with the use of Equation (5.27). From Equation (5.27) it is evident that the calculated solution phase activity coefficients and the resin phase fractional loadings are used to obtain the value of the equilibrium quotient from the experimental data. The various parameters used in Equation (5.27) are raised to different powers depending on the values of the electrochemical valences of the species. The same scenario exists for the thermodynamic dissolution constant of the RIP slurry mixture system as represented in Tables 6.1 and 6.2 for systems containing only a cation and anion exchange resin respectively.

With the use of the thermodynamic equilibrium constants $K_{A}^{B}$ for the various cation and anion exchange reactions the value of the thermodynamic dissolution constant may be calculated by combining the $K_{A}^{B}$ values with solubility calculations for the sparingly soluble solid that may exist in the RIP slurry mixture system. Figure 11.24 
gives the values of the solution phase activity coefficients for the various species present in a mixed bed RIP slurry mixture system with the cation in the $\mathrm{Al}^{+3}$ ionic form and the anion exchange resin in the $\mathrm{Cl}^{-}$ionic form. If substantial amounts of the ion exchange resins are present in the system a scenario may develop where significant dissolution of the $\mathrm{CaSO}_{4} \cdot 2 \mathrm{H}_{2} \mathrm{O}$ precipitate occurs that results in exchange reactions with both the cation and anion exchange resins. The resultant electrolytic solution is an $\mathrm{AlCl}_{3}$ electrolyte that may influence the solubility of the $\mathrm{CaSO}_{4} \cdot 2 \mathrm{H}_{2} \mathrm{O}$ precipitate. From Figure (11.24) it is evident that for an increase in the concentration of the $\mathrm{AlCl}_{3}$ electrolyte substantial changes may occur in the values of the solution phase activity coefficients of the various species present in the RIP slurry mixture system.

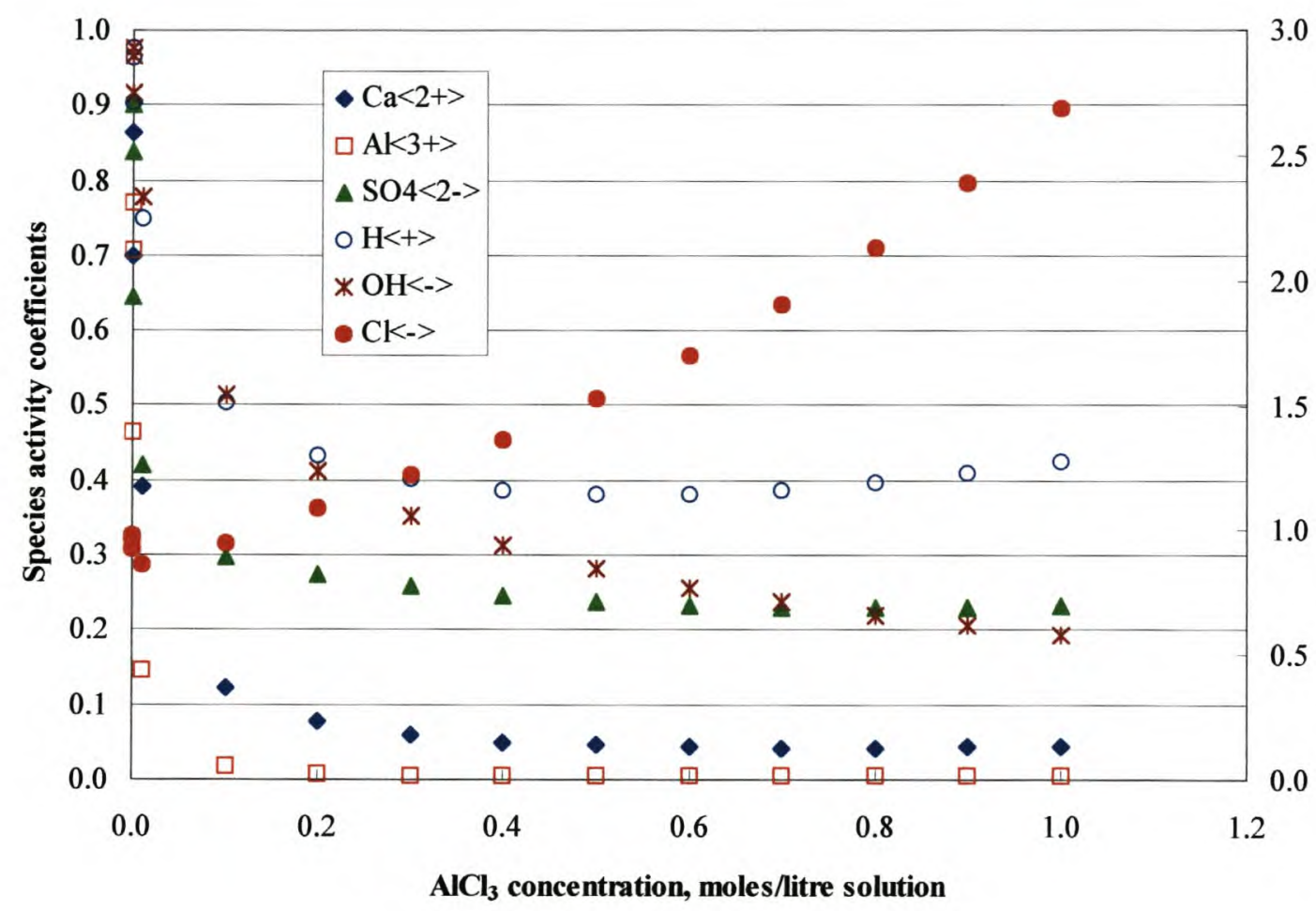

Figure 11.24 Calculated aqueous phase activity coefficients for the solubility of $\mathrm{CaSO}_{4} \cdot 2 \mathrm{H}_{2} \mathrm{O}$ in an $\mathrm{AlCl}_{3}$ aqueous electrolyte solution at $25^{\circ} \mathrm{C}$ and $101.325 \mathrm{kPa}$ pressure with the use of a Pitzer activity coefficient model. 
From the values of the solution phase activity coefficients the solubility of the $\mathrm{CaSO}_{4} \cdot 2 \mathrm{H}_{2} \mathrm{O}$ precipitate may be calculated with the use of the solubility product as determined in paragraph 11.5. Figure (11.25) gives the calculated solubility of the $\mathrm{CaSO}_{4} .2 \mathrm{H}_{2} \mathrm{O}$ precipitate. It is evident from Figure (11.25) that the solubility of the precipitate will increase for an increase in the solution phase concentration of the $\mathrm{AlCl}_{3}$ aqueous electrolyte provided that the concentrations of both the $\mathrm{Ca}^{+2}$ and $\mathrm{SO}_{4}{ }^{2-}$ ions remain low so that the common-ion effect does not occur.

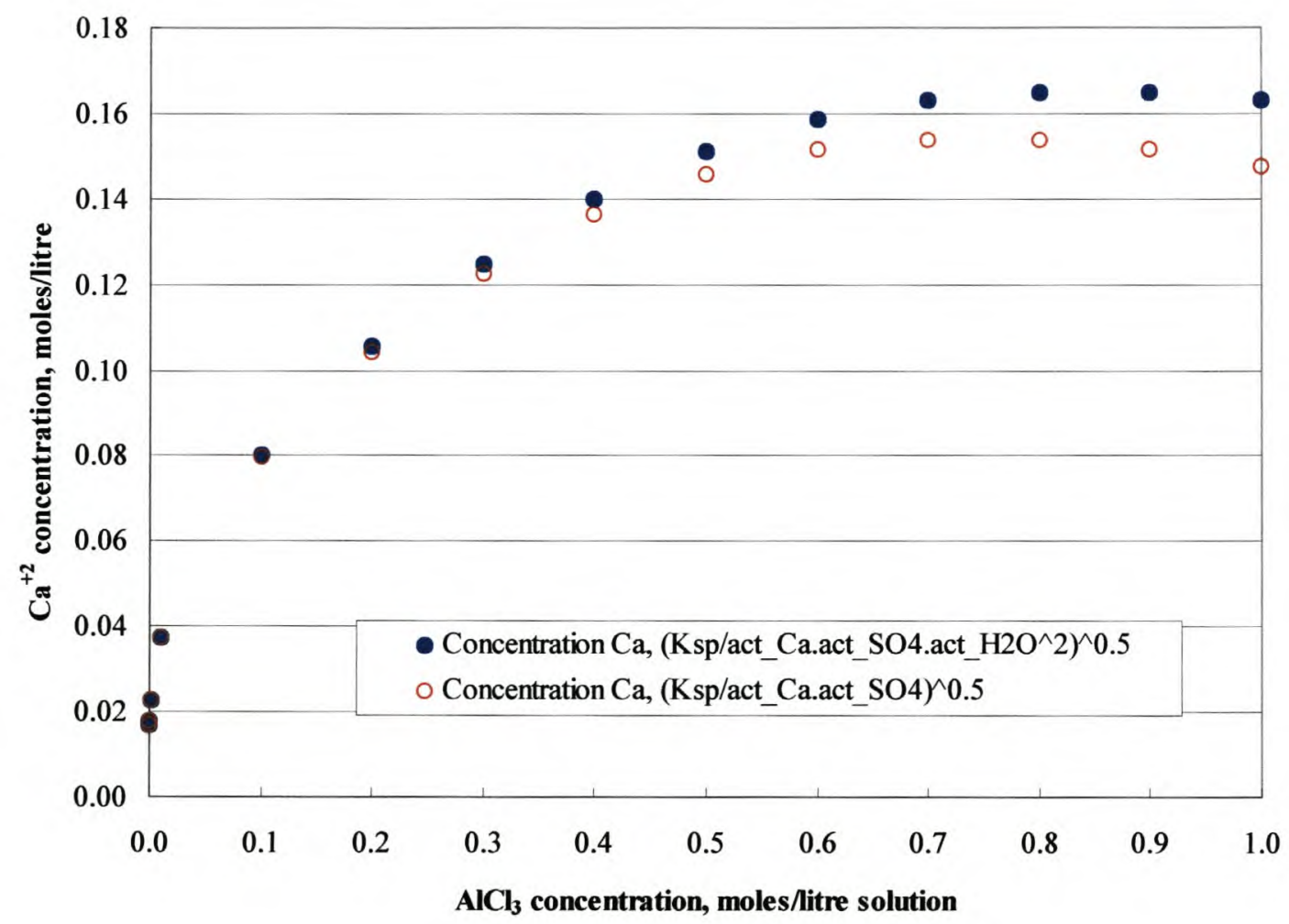

Figure 11.25 Calculated solubility of $\mathrm{CaSO}_{4} \cdot 2 \mathrm{H}_{2} \mathrm{O}$ in an $\mathrm{AlCl}_{3}$ aqueous electrolyte solution at $25^{\circ} \mathrm{C}$ and $101.325 \mathrm{kPa}$ pressure with the use of a Pitzer activity coefficient model.

The values for various electrolyte solutions may be calculated as the total concentration and composition of the solution phase change for the RIP slurry mixture system as the equilibrium condition is approached. From Equations (11.7) and (11.8) it is evident that the solubility product of the sparingly soluble solid plays an 
important role in the value of the thermodynamic dissolution constant for the RIP slurry mixture system.

\subsection{SUMMARY}

From the discussions above it is evident that significant variations in the values of thermodynamic properties for species may exist in the literature. It was evident that the value for the solubility product for the $\mathrm{CaSO}_{4} \cdot 2 \mathrm{H}_{2} \mathrm{O}$ precipitate showed significant discrepancies between various literature sources. The value for the solubility product $K_{s p}$ was calculated from the experimental data and a value of $2.3 \mathrm{E}-04$ was obtained which agreed to within $98.6 \%$ of the literature value obtained from Zematis et al. (1986).

Model calculations for the RIP system of $\mathrm{CaSO}_{4} .2 \mathrm{H}_{2} \mathrm{O}$ and $\mathrm{PbSO}_{4}$ were performed and it was found that satisfactory model predictions were obtained for the prediction of the equilibrium quotient for the various exchange reactions. The values for the thermodynamic equilibrium constant $K_{A}^{B}$ were obtained for different total solution phase concentrations. It was found that most of the $K_{A}^{B}$ values decreased in value for a decrease in the total solution phase concentration. This trend was confirmed with data from the literature (Allen et al., 1989), which gives a summary of the $K_{A}^{B}$ values for various ion-exchange reactions for different total solution phase concentrations.

From the discussions in Chapter 9 and 10 it followed that significant deviations may occur in the calculated values of the equilibrium quotient from the general trend when one of the phase boundaries approached an extreme. This scenario was also observed for the experimentally determined values of the equilibrium quotient in this chapter. From the discussions above it is evident that any experimental error may be amplified in the calculation of the equilibrium quotient due to the nature of Equation (5.27) in Chapter 5 of this dissertation. Other researchers in the literature also recognised the fact that data points at the phase boundary extremes may have larger experimental errors associated with it (Mehablia et al., 1994). 


\section{CHAPTER 12}

\section{CONCLUSIONS}

From the discussions in Chapter 1 of this dissertation in became evident that very few publications related to the simultaneous dissolution and sorption of sparingly soluble solids were available in the literature. For the development of the consolidated equilibrium model for the typical Resin-in-Pulp (RIP) slurry mixture system very few quantitative experimental data could be obtained from the literature. This resulted in an extensive experimental program where several thousand equilibrium data points were collected for different types of sparingly soluble solids in resin / solution and RIP slurry mixture systems. The data collected are therefore a valuable source for future planning of further experimental test work in this particular field. In the execution of the experiments various properties of the RIP slurry mixture were investigated and the experiments were designed in such a manner that information could be extracted from the results regarding the effects on the solubility of the sparingly soluble solid; the effect cation and anion resins; the effect of resin ionic forms; precipitation of new solids as a result of the changing solution composition; the effects of mixed resin beds on the composition of the RIP mixture; the effect of species valence on the process and many more.

From the data collected general trends could be identified that assisted in the synthesis of the consolidated equilibrium model for the RIP slurry mixture system. The consolidated equilibrium model is a combination of various thermodynamically based equilibrium models for the various equilibrium conditions that exist in a typical RIP slurry mixture system. It was evident from the discussions on the model that the model could account for the equilibrium distribution of the different species in the RIP slurry mixture between the various phases. The primary phases considered were the resin phases, the solution phase and the various precipitates that may exist depending on the composition of the aqueous solution phase. From the discussions in Chapter 2 it followed that various researchers in the literature have developed equilibrium models that are applicable to the modelling of some of the equilibrium 
conditions between the different phases. Various models are available that may account for the solubility of a typical sparingly soluble solid in an aqueous solution of varying composition and it is evident from the literature that much work in this area has been done (Zemaitis et al., 1986).

From the experimental data collected for the purposes of this dissertation it became evident that the solution phase concentrations of the species of interest to the consolidated equilibrium model are typically in the extremely low concentration range. This is expected since the solution phase concentrations of the species were driven by their solubility products, which are low for sparingly soluble solids. As the exchange reactions took place in the RIP slurry mixture system these concentrations became even lower due to decreases in the solubility of the sparingly soluble solid as a result of the common-ion effect discussed in Chapter 2 of this dissertation. These extremely low solution phase concentrations pose several difficulties to the synthesis of the consolidated equilibrium model for various reasons.

From an experimental point of view it is more difficult to obtain reliable analysis of the solution phase composition for species present at extremely low solution phase concentrations. In many cases these analyses could not be performed and mass balance equations had to be used to obtain estimates of these concentration values for the species. Further possibilities had to be investigated and in the case where mass balance equations could not be performed the resin phase itself had to be analysed. In order to do this, detailed experimental procedures were followed as discussed in Chapter 7 of this dissertation.

The second difficulty encountered in modelling the RIP slurry mixture systems is obtaining reliable thermodynamic data for the species at these low concentration levels. From the discussions in Chapter 3 it followed that the Pitzer ion-interaction model was identified as a suitable model for the typical composition of the solution phase of the RIP system. Parameters for the Pitzer model describing the interaction between the constituent ions of the sparingly soluble solid are typically scarce due to the fact the data available for the estimation of the parameters are solubility limited to dilute solutions (Pitzer, 1991). The concentration ranges for the different species in a typical RIP slurry mixture system may vary significantly and a reliable model such as 
the Pitzer model is required that has the ability to model the species interactions over a wide concentration range. From the discussions in Chapter 3 it was evident that considerable effort has been made in the literature by various researchers to develop thermodynamic models that could predict the deviations from ideal solution behaviour encountered in the aqueous phase solutions that are typical to the RIP slurry mixture system. Detailed discussions on the most frequently used of these models are available in the literature (Zemaitis et al., 1986).

In the development of the consolidated equilibrium model it became apparent from the experimental data that electrolytic sorption of the species from the solution phase onto the ion-exchange reaction exists. The definition of electrolytic sorption and the various factors influencing it are discussed in Chapter 4 of this dissertation. The experimental data of Chapters 8 to 11 clearly indicated the presence of this phenomenon in RIP slurry mixture systems. Due to the complexity of the process it was decided not to develop or include an existing model describing this phenomenon in the set of model equations for the consolidated equilibrium model. The user should take note of this effect and the limitations it may place on the use of the consolidated equilibrium model proposed in Chapter 6 of this dissertation. From the above discussion it followed that the solution phase concentrations of the constituent ions of the sparingly soluble solid sometime needed to be calculated from mass balance equations. In many cases it is not possible to include the effect of electrolytic sorption in these calculations which made the estimation of the solution phase concentrations of the species even more difficult. The effect of the electrolytic sorption phenomenon was accounted for in the model equations of the consolidated equilibrium model by defining the capacity of the ion-exchange resin as the "sorption capacity" as discussed in Chapter 4 of this dissertation. This capacity included the contribution of the electrolytic sorption phenomenon towards the total capacity of the ion-exchange resin and was used in the determination of the thermodynamic equilibrium constant for the exchange reaction.

From the discussions in Chapter 2 it is evident that various techniques may be used to calculate the solubility of the sparingly soluble solid. These techniques include the use of the solubility product $\mathrm{K}_{\mathrm{sp}}$ or the Gibbs free energy of formation for the species present in the aqueous phase solution. Both of these techniques have been used in the 
calculation of the results presented in Chapters 9 to 11 and it was found that very different results may be obtained for the same system. The reliability of the thermodynamic data plays an important role in this respect and it was shown that significantly different values might be obtained from the literature for the same thermodynamic properties. Care should therefore be exercised in the selection of thermodynamic data from the literature and the values should preferably be verified between different sources for consistency. In order to assist in this regard a SQL7 data base have been designed and populated with the required thermodynamic data for the consolidated equilibrium model from various literature sources. The data base was then used to check the values of the thermodynamic data for consistency between the different literature sources to ensure that only consistent data are used in the model equations of the consolidated equilibrium model. Linkson (1996) indicated the importance of consistent thermodynamic data used in solubility calculations for sparingly soluble solids. From the discussions in this dissertation it is also evident that the calculation of the species solution phase activities are of paramount importance for any solubility calculation, irrespective of which technique is used, $\mathrm{K}_{\mathrm{sp}}$ or Gibbs free energy minimisation.

From the above discussions it is evident that there are several difficulties associated with use of any thermodynamic model in the modern chemical industry. Reliable experimental and thermodynamic data are only some the stumbling blocks that may be encountered. Despite all of the difficulties associated with thermodynamic modelling of complex aqueous phase solutions and species solubilities it still remain of significant importance to the understanding of the fundamental principles driving these processes. The developed consolidated equilibrium model may be used to model various other hydrometallurgical processes of interest, which needs to be understood and analysed in a more fundamental way. Some of these processes are discussed briefly in Chapter 1 of this dissertation. It is evident from these discussions that there are several industrial processes employing the RIP technology. Once a more fundamental understanding of the typical RIP slurry mixture is obtained other possibilities may be investigated. It was therefore one of the principal objectives of this dissertation to develop a thermodynamic model for the RIP slurry mixture system that may be used to simulate such processes in order to better understand the process from a fundamental point of view. 
From the discussions in Chapter 5 it was evident that various models exist that may be used to model multi component ion-exchange equilibria. The models differ in their approach towards non-idealities in the solution and resin phases. The most comprehensive models available are those that assume non-ideal behaviour of the species in both phases. From the model equations describing the consolidated model for the RIP system presented in Chapter 6 it is evident that non-ideal behaviour of the species in both the resin and solution phase is assumed. The thermodynamic equilibrium constant for the ion-exchange reaction is used as the model describing the equilibrium distribution of the species between the solution and resin phase. From the experimental data and model calculation results presented in Chapters 9 to 10 it is evident that species behave non-ideally in both the solution and resin phase, which justifies the use of computationally more intensive models in the modelling equations describing the consolidated equilibrium model.

As mentioned earlier it was stated that numerous experimental procedures were followed in the collection of thousands of experimental data points for various RIP slurry mixture system configurations. From Chapter 7 of this dissertation the extent of these procedures is evident. Valuable information on the analyses of resin samples is provided which may be used to accurately analyse for the concentrations of species adsorbed on the resin phase. These procedures were followed in the collection of the data presented in Chapters 8 to 11 of this dissertation.

From the discussions on the experimental data and the model results presented in Chapters 8 to 11 it is evident that the constituent ion of a sparingly soluble solid may be extracted from an aqueous slurry mixture of the solid. This is possible because of the steep nature of the equilibrium isotherm curves of many ion-exchange reactions in the extremely low solution phase concentration range. From the experimental data presented in Chapter 9 for the $\mathrm{PbSO}_{4} \mathrm{RIP}$ slurry mixture system it is evident that the recovery of the $\mathrm{Pb}^{+2}$ ions from the RIP slurry mixture system is highly feasible. Significantly high resin loadings for the $\mathrm{Pb}^{+2}$ ion may be obtained for the low solution phase concentrations of the species present in the aqueous phase. Chapters 9 to 11 also indicated that the electrochemical valences of the species present in the aqueous solution play an important role in the recovery of the species from the sparingly 
soluble solids. This is primarily the case because of the nature of the selectivity of the ion-exchange resins used for species of different electrochemical valences. From the experimental and modelling results presented in Chapters 8 to 11 it is evident that the selectivity of the ion-exchange resins increases with an increase in the electrochemical valence of the species. The recovery of the sparingly soluble solid species may further be enhanced with the use of mixed bed RIP slurry mixture systems containing both a cation and anion exchange resin. The combination of the cation and anion exchange resin prevents an increase in the solution phase concentration of the constituent ions of the sparingly soluble solid that causes the solubility of the solid to decrease because of the common ion effect. The mathematical equations describing this phenomenon are presented in Chapter 6 of this dissertation. The proposed iterative solution procedure for the consolidated equilibrium model is presented in Chapter 6. From the discussions in Chapter 9 to 11 it was evident that there are several objective function equations that may be used to solve the model equations for the various equilibrium conditions existing between the three primary phases of the RIP slurry mixture, i.e. the resin phase, aqueous solution phase and the various precipitates present in the solution. In the solution of the modelling equations it became evident that the quality of the experimental data used to derive the thermodynamic equilibrium constant for the ion-exchange reaction and the consistency of the various thermodynamic values used in the model equations are of paramount importance to the model predictions. The user should take care in the selection and determination of these values required for the consolidated equilibrium model equations as well as the solubility calculations that are performed for the sparingly soluble solid. It is evident from the discussions in Chapter 6 that the final output of the consolidated equilibrium model is a non-linear combination of the predictions of the various sub-models describing the equilibrium distribution of the species between the various phases. If the results for any one of these sub-models are inaccurate as a result of poor quality data used in the estimation of model parameters or the selection of inconsistent thermodynamic data from the literature the result of the consolidated equilibrium model be inaccurate as well. This poses a significant importance on the availability of high quality experimental and thermodynamic data required for the model equations of the consolidated equilibrium for a typical RIP slurry mixture system. 


\section{REFERENCES}

Allen, R.M. and Addison, P.A., "Ion exchange equilibria for ternary systems from binary exchange data," Chemical Engineering Journal, Vol. 44, pp. 113-118, 1990

Allen, R.M., Addison, P.A. and Dechapunya, A.H., "The characterisation of binary and ternary ion exchange equilibria," Chemical Engineering Journal, Vol. 40, pp. $151-158,1989$

Ananth, M.S. and Ramachandran, S., "Self-consistent local composition model of electrolyte solutions," AIChE Journal, Vol. 36, No. 3, pp. 370-386, 1990

Andrews, D.H. and Kokes, R.J., "Fundamental Chemistry," John Wiley and Sons, Inc., United States of America, pp. 427-429, 1965

Antonio de Lucas Martinez, Pablo Canizares and Jacinto Zarca Diaz, "Binary ion exchange equilibrium for $\mathrm{Ca}^{+2}, \mathrm{Mg}^{+2}, \mathrm{~K}^{+}, \mathrm{Na}^{+}$and $\mathrm{H}^{+}$ions on Amberlite IR120," Chemical Eng. Technol., Vol. 16, pp. 35-39, 1993

Apelblat, A., "Activity and osmotic coefficients in electrolyte solutions at elevated temperatures," AIChE Journal, Vol. 39, No. 5, pp. 918-923, 1993

Astle, M.J. and Weast, R.C., "CRC Handbook of Chemistry and Physics," CRC Press, Inc., Boca Raton, Florida, 62nd edition, pp. B242, 1981-1982

Bassett, L.G., Bunce, S.C., Carter, A.E., Clark, H.M. and Hollinger, H.B., "Principles Of Chemistry," Prentice-Hall, Inc., Englewood Cliffs, New Jersey, pp. 693, 1966

Bradley, D.J. and Pitzer, K.S., "Thermodynamics of electrolytes. 12 Dielectric properties of water and Debye-Hückel parameters to $350{ }^{\circ} \mathrm{C}$ and $1 \mathrm{kbar}$," Journal of Physical Chemistry, Vol. 83, No. 12, pp. 1599-1603, 1979

Brewer, S., "Solving Problems in Analytical Chemistry," John Wiley and Sons, Inc., pp. $218-254,1980$

Brinkman, N.D., Tao, L.C. and Weber, J.H., "The calculation of the parameters for the Wilson equation for a ternary system," Industrial and Engineering Chemistry Fundamentals, Vol. 13, No. 2, pp. 156-157, 1974 
Brinkman, N.D., Tao, L.C. and Weber, J.H., "A study of the effect of optimisation function on calculated parameters of Wilson equation," The Canadian Journal of Chemical Engineering, Vol. 52, pp. 397-404, 1974

Bromley, L.A., "Thermodynamic properties of strong electrolytes in aqueous solutions," AIChE Journal, Vol. 19, No. 2, pp. 313-320, 1973

Brown, T.L. and LeMay, H.E.JR., “Chemistry. The Central Science,” Prentice-Hall, Inc., Englewood Cliffs, New Jersey 07632, pp. 809-810, 1981

Bueche, F.J., "Introduction to Physics for Scientists and Engineers," McGraw-Hill, Fourth Edition, pp. 513, 908, 1986

Christian, G.D. and O'Reilly, J.E., "Instrumental Analysis," Allyn and Bacon, Inc., Second Edition, pp. 141, 900, 1986

Cisternas, L.A. and Galleguillos, H.R., "Effects of temperature on activity coefficients in aqueous electrolyte solutions," AIChE Journal, Vol. 35, No. 7, pp. 1215-1218, 1989

Chakravarti, A.K. and Fritzsch, G., "Multi-component ion-exchange equilibria. II Prediction of ternary equilibria for the system $\mathrm{Ca}^{+2}-\mathrm{Mg}^{+2}-\mathrm{H}^{+}$from the data of the binary systems," Reactive Polymers, Vol. 8, pp. 51-68, 1988

Cloete, F.L.D. and Marais, A.P., "Recovery of very dilute acetic acid using ion exchange," Ind. Eng. Chem. Res., Vol. 34, pp. 2464-2467, 1995

Costa, E., Sotelo, J.L., Calleja, G. and Marron, C., "Adsorption of binary and ternary hydrocarbon gas mixtures on activated carbon: Experimental determination and theoretical prediction of the ternary equilibrium data," AIChE Journal, Vol. 27, No. 1, pp. 5-12, 1981

de Lucas Martinez, A. , Canizares, P. and Zarca Diaz, J., "Binary ion exchange equilibrium for $\mathrm{Ca}^{+2}, \mathrm{Mg}^{+2}, \mathrm{~K}^{+}, \mathrm{Na}^{+}$and $\mathrm{H}^{+}$ions on Amberlite IR-120," Chemical Eng. Technol., Vol. 16, pp. 35-39, 1993

De Dardel, F and Arden, T.V., "Ion Exchange. Principles and Applications. Separation Technologies," Vol. A14., 1989 
Elprince, A.M. and Babcock, K.L., "Prediction of ion-exchange equilibria in aqueous systems with more than two counter-ions," Soil Science, Vol. 120, No. 5, pp. 332338,1975

Fritz, W. and Schluender, E.U., "Simultaneous adsorption equilibria of organic solutes in dilute aqueous solutions on activated carbon," Chemical Engineering Science, Vol. 29, pp. 1279-1282, 1974

Gaines, G.L. Jr. and Thomas, H., “Adsorption studies on clay minerals. II A formulation of the thermodynamics of exchange adsorption," Journal of Chemical Physics, Vol. 21, No. 4, pp. 714-718, 1953

Guggenheim, E.A., "The specific thermodynamic properties of aqueous solutions of strong electrolytes, " Phil. Mag. J. Ser. 7, 19, pp. 588-643, 1935

Guggenheim, E.A. and Stokes, R.H., "Equilibrium properties of aqueous solutions of single strong electrolytes," Pergamon Press, Oxford, 1969

Hamer, W.J., "Theoretical mean activity coefficients of strong electrolytes in aqueous solutions from $0^{\circ}$ to $100^{\circ} \mathrm{C}$," National Bureau of Standards, Washington D.C., 271 pp. (CA 70:51192s), 1968

Hamer, W.J. and Wu, Y-C., "Osmotic coefficients and mean activity coefficients of uniunivalent electrolytes in water at $25^{\circ} \mathrm{C}$," J. Phys. Chem. Ref. Data, Vol. 1, pp. 1047,1972

Harland, C.E., "Ion Exchange. Theory and Practice," Second edition, The Royal Society of Chemistry, 1994

Harned, H.S. and Owen, B.B., "Physical Chemistry of Electrolyte Solutions," Third edition, Appendix A, Reinhold, New York, 1958

Harvie, C.E. and Weare, J.H., Geochim. Cosmochim. Acta, Vol. 44, pp. 981, 1980

Haub, C.E. and Foutch, G.L., "Mixed-bed ion exchange at concentrations approaching the dissociation of water. 1. Model development," Industrial and Engineering Chemistry Fundamentals, Vol. 25, pp. 373-381, 1986

Helfferich, F., "Ion Exchange," Mcraw-Hill Book Company, Inc., United States of America, 1962 
Hiranuma, M. and Honma, K., "Estimation of unlike-pair potential parameter in singleparameter Wilson equation,” Ind. Eng. Chem. Process Des. Dev., Vol. 14, No. 3, pp. 221-226, 1975

Hogfeldt, E., "Application of a simple thermodynamic model to various ion-exchange data," Reactive Polymers, Vol. 7, pp. 81-87, 1988

Hogfeldt, E., "Ten years experience of a simple three-parameter model to fit ionexchange data, " Reactive Polymers, Vol. 11, pp. 199-219, 1989

Holl, W.H., Horst, J. and Eberle, S., "Application of the surface complex formation model to exchange equilibria on ion-exchange resins. Part I. Weak-acid resins," Reactive Polymers, Vol. 13, pp. 209-231, 1990

Holl, W.H., Horst, J. and Wernet, M., "Application of the surface complex formation model to exchange equilibria on ion-exchange resins. Part II. Chelating resins," Reactive Polymers, Vol. 14, pp. 251-261, 1991

Horvath, A.L., "Handbook of Aqueous Electrolyte Solutions. Physical Properties, Estimation and Correlation Methods," Ellis Horwood Limited, England, 1985

Ji, Wei-Rong and Hou, Y.C., "Prediction of equilibrium data of adsorptions from liquid mixtures," Ind. Eng. Chem. Res., Vol. 29, pp. 560-564, 1990

Jianmin, L., Shaokun, W. and Jun, S., "Flexibility, multiplicity and symmetry of Wilson parameters and vapour-liquid equilibrium in multicomponent systems," Chemical Engineering Science, Vol. 45, No. 1, pp. 199-204, 1990

Jones, I.L. and Carta, G., "Ion-exchange of amino acids and dipeptides on cation resins with varying degree of cross-linking. 1. Equilibrium," Ind. Eng. Chem. Res., Vol. 32, pp. 107-117, 1993

Kadlec, V., Huber, P. and Dukla, C.K.D., "Combined ion exchange-precipitation process for minimising liquid wastes in water treatment. Ion exchange for industry," Ellis Horwood Limited, pp. 148-155, 1988

Kataoka, T. and Yoshida, H., "Ion exchange equilibria in ternary systems," Journal of Chemical Engineering of Japan, Vol. 13, No. 4, pp. 328-330, 1980 
Kim, H. and Frederick, W.J. Jr., "Evaluation of Pitzer ion interaction parameters of aqueous electrolytes at $25^{\circ} \mathrm{C}$. 1. Single salt parameters," J. Chem. Eng. Data, Vol. 33, pp. 177-184, 1988(a)

Kim, H. and Frederick, W.J. Jr., "Evaluation of Pitzer ion interaction parameters of aqueous mixed electrolyte solutions at $25^{\circ} \mathrm{C}$. 2. Ternary mixing parameters," J. Chem. Eng. Data, Vol. 33, pp. 278-283, 1988(b)

Klein, G., Tondeur. and Vermeulen, T., "Multicomponent ion exchange in fixed beds," Industrial and Engineering Chemistry Fundamentals., Vol. 6, pp. 339-351, 1967

Kusik, C.L. and Meissner, H.P., "Vapour pressures of water over aqueous solutions of strong electrolytes," Ind. Eng. Chem. Process Des. Develop., Vol. 12, No. 1, pp. $112-115,1973$

Kusik, C.L., Meissner, H.P. and Field, E.L., "Estimation of phase diagrams and solubilities for aqueous multi-ion systems," AIChE Journal, Vol. 25, No. 5, pp. 759-762, 1979

Laidler, K.J. and Meisner, J.H., "Physical Chemistry," The Benjamin/Cummings Publishing Company, Inc., 1982

Lee, G.L., "Principles of Chemistry. A Structural Approach," International Textbook Company, pp. $514-515,1970$

Lewis, G.N. and Randall, M., Journal of the American Chemical Society, Vol. 43, pp. 1112-1154, 1921

Linkson, P., "Modeller's Beware," Chemical Engineer, No. 620, pp. 35-38, 1996

$\mathrm{Lu}, \mathrm{X}$ and Maurer, G., "Model for describing activity coefficients in mixed electrolyte aqueous solutions," AIChE Journal, Vol. 39, No. 9, pp. 1527-1538, 1993

Manning, M.J. and Meisheimer, S.S., "Binary and ternary ion-exchange equilibria with a perfluorosulfonic acid membrane," Industrial and Engineering Chemistry Fundamentals, Vol. 22, pp. 311-317, 1983

Marton, A. and Inczedy, J., "Application of the concentrated electrolyte solution model in the evaluation of ion exchange equilibria," Reactive Polymers, Vol. 7, pp. 101109, 1988 
Mehablia, M.A., Shallcross, D.C and Stevens, G.W., "The Wilson equation applied to the non-idealities of the resin phase of multicomponent ion exchange equilibria," Ion Exchange advances, Proceedings of IEX'92, Elsevier Applied Science, London and New York, pp. 151-158, 1992

Mehablia, M.A., Shallcross, D.C and Stevens, G.W., "Prediction of multicomponent ion exchange equilibria," Chemical Engineering Science, Vol. 49, No. 14, pp. 22772286, 1994

Meissner, H.P. and Kusik, C.L., "Activity coefficients of strong electrolytes in multicomponent aqueous solutions," AIChE Journal, Vol. 18, No. 2, pp. 294-298, 1972

Meissner, H.P. and Tester, J.W., "Activity coefficients of strong electrolytes in aqueous solutions," Ind. Eng. Chem. Process Des. Develop., Vol. 11, No. 1, pp. 128-133, 1972

Meissner, H.P., Kusik, C;L. and Tester, J.W., “Activity coefficients of strong electrolytes in aqueous solution-Effect of temperature," AIChE Journal, Vol. 18, No. 3, pp. 661-662, 1972

Meissner, H.P. and Kusik, C.L., "Aqueous solutions of two or more strong electrolytes. Vapour pressures and solubilities," Ind. Eng. Chem. Process Des. Develop., Vol. 12, No. 2, pp. 205-208, 1973

Meissner, H.P. and Peppas, N.A., “Activity coefficients-Aqueous solutions of polybasic acids and their salts," AIChE Journal, Vol. 19, No. 4, pp. 806-809, 1973

Meissner, H.P. and Kusik, C.L., "Electrolyte activity coefficients in inorganic processing," AIChE Symposium Series, No. 173, Vol. 74, pp. 14-20, 1978

Meissner, H.P. and Kusik, C.L., “Double salt solubilities,” Ind. Eng. Chem. Process Des. Develop., Vol. 18, No. 3, pp. 391-394, 1979

Melis, S., Cao, G. and Morbidelli, M., "A new model for the simulation of ion exchange equilibria," Ind. Eng. Chem. Res., Vol. 34, pp. 3916-3924, 1995

Nagahama, K., Suzuki, I. and Hirata, M., "Estimation of Wilson parameters," Journal of Chemical Engineering of Japan, Vol. 4, No. 1, pp. 1-5, 1971 
Nishino, T., "Dissolution process of Portland cement powder in aqueous suspension containing ion exchange resin," New Developments In Ion Exchange. Materials, Fundamentals, and Applications, Proceedings of the International Conference on Ion Exchange, ICIE '91, Tokyo, Japan, 1991, Kodansha Ltd., Tokyo, pp. 3-6, 1991

Novosad,J. and Meyers, A.L., "Thermodynamics of ion exchange as an adsorption process," The Canadian Journal of Chemical Engineering, Vol. 60, pp. 500-503, 1982

Perona, J.J., "Model for Sr-Cs-Ca-Mg-Na ion-exchange equilibria on chabazite," AIChE Journal, Vol. 39, No. 10, pp. 1716-1720, 1993

Perry, R.H., Green, D.W. and Maloney, J.O, "Perry's Chemical Engineers' Handbook," McGraw-Hill, 1999

Pitzer, K.S., "Activity coefficients in electrolyte solutions," $2^{\text {nd }}$ Edition, CRC Press, Boca Raton, 1991

Pitzer, K.S., "Theory: ion interaction approach. Activity coefficients in electrolyte solutions," Vol. 1, CRC Press, Boca Raton, pp. 157-208, 1979

Pitzer, K.S., "Ion interaction approach: theory and data correlation," Activity Coefficients in electrolyte Solutions, Second Edition, CRC Press, Boca Raton, pp. 75-153, 1991

Pitzer, K.S., "Electrolyte theory-improvements since Debye and Hückel," Accounts of Chemical Research, Vol. 10, pp. 371-377, 1977

Pitzer, K.S., "Thermodynamics of electrolytes. I Theoretical basis and general equations,” Journal of Physical Chemistry, Vol. 77, No. 2, pp. 268-277, 1973

Pitzer, K.S., "Thermodynamics of electrolytes. V Effects of higher-order electrostatic terms," Journal of Solution Chemistry, Vol. 4, No. 3, pp. 249-265, 1975

Pitzer, K.S. and Kim, J.J., "Thermodynamics of electrolytes. IV Activity and osmotic coefficients for mixed electrolytes," Journal of the American Chemical Society, Vol. 96, pp. 5701-5707, 1974 
Pitzer, K.S. and Mayorga, G., "Thermodynamics of electrolytes. II Activity and osmotic coefficients for strong electrolytes with one or both ions univalent," Journal of Physical Chemistry, Vol. 77, No. 19, pp. 2300-2308, 1973

Pitzer, K.S. and Mayorga, G., "Thermodynamics of electrolytes. III Activity and osmotic coefficients for 2-2 electrolytes," Journal of Solution Chemistry, Vol. 3, No. 7, pp. 539-546, 1974

Pitzer, K.S., Peterson, J.R. and Silvester, L.F., "Thermodynamics of electrolytes. IX Rare earth chlorides, nitrates, and perchlorates," Journal of Solution Chemistry, Vol. 7, No. 1 , pp. $45-56,1978$

Pitzer, K.S. and Peiper, J.C., "Activity coefficient of aqueous $\mathrm{NaHCO}_{3}$," Journal of Physical Chemistry, Vol. 84, No. 19, pp. 2396-2402, 1980

Pitzer, K.S., Roy, R.N. and Silvester, L.F., "Thermodynamics of electrolytes. 7 Sulfuric Acid," Journal of the American Chemical Society, Vol. 99, pp. 4930-4936, 1977

Pitzer, K.S. and Silvester, L.F., “Thermodynamics of electrolytes. VI Weak electrolytes including $\mathrm{H}_{3} \mathrm{PO}_{4}$," Journal of Solution Chemistry, Vol. 5, No. 4, pp. 269-278, 1976

Pitzer, K.S. and Silvester, L.F., "Thermodynamics of electrolytes. 11 Properties of 3:2, $4: 2$, and other high valence types," Journal of Physical Chemistry, Vol. 82, No. 11, pp. 1239-1242, 1978

Prausnitz, J.M., Eckert, C.A., Orye, R.V. and O’Connel, J.P., “Computer calculations for multicomponent vapour-liquid equilibria," Prentice Hall, Englewood Cliffs, NJ, 1967

Radke, C.J. and Prausnitz, J.M., "Thermodynamics of multi-solute adsorption from dilute liquid solutions," AIChE Journal, Vol. 18, No. 4, pp. 761-765, 1972

Robinson, S.M., Arnold, W.D. and Byers, C.H., "Mass-transfer mechanisms for zeolite ion exchange in wastewater treatment," AIChE Journal, Vol. 40, No. 12, pp. 2045-2054, 1994

Robinson, R.A. and Stokes, R.H., "Electrolyte Solutions," Second edition, Academic Press, New York, 1959 
Ru'an, C., "Extraction of rare earths from a low-grade, kaolinitic ore by percolation leaching," Rare Earths. Extraction, Preparation and applications, Publication of The Minerals, Metals and Materials Society, Pensylvania, 1988

Sengupta, M. and Paul, T.B., "Multicomponent ion exchange equilibria I. $\mathrm{Zn}^{+2}-\mathrm{Cd}^{+2}-\mathrm{H}^{+}$and $\mathrm{Cu}^{+2}-\mathrm{Ag}^{+}-\mathrm{H}^{+}$on Amberlite IR 120," Reactive Polymers, Vol. 3, pp. 217-229, 1985

Sengupya, A.K. and Yuewei, Z., "Metals sorption by chelating polymers: a unique role of ionic strength," AIChE Journal, Vol. 38, No. 1, pp. 153-157, 1992

Shallcross, D.C., Hermann, C.C. and McCoy, B.J., "An improved model for the prediction of multicomponent ion exchange equilibria," Chemical Engineering Science, Vol. 43, No. 2, pp. 279-288, 1988

Silvester, L.F. and Pitzer, K.S., "Thermodynamics of electrolytes. 8 High-temperature properties, including enthalpy and heat capacity, with application to sodium chloride,” Journal of Physical Chemistry, Vol. 81, No. 19, pp. 1822-1828, 1977

Silvester, L.F. and Pitzer, K.S., "Thermodynamics of electrolytes. $X$ Enthalpy and the effect of temperature on the activity coefficients," Journal of Solution Chemistry, Vol. 7, No. 5, pp. 327-337, 1978

Smith, R.P. and Woodburn, E.T., "Prediction of multicomponent ion exchange equilibria for the ternary system $\mathrm{SO}_{4}^{2-}-\mathrm{NO}_{3}^{-}-\mathrm{Cl}^{-}$data of binary systems," $\mathrm{AIChE}$ Journal, Vol. 24, No. 4, pp. 577-587, 1978

Sohnel, O. and Garside, J., "Precipitation. Basic principles and industrial applications," Butterworth-Heinemann Ltd, 1992

Soldatov, V.S., "Mathematical modelling of ion exchange equilibria on polymer ion exchangers," Ion Exchange advances, Proceedings of IEX'92, Elsevier Applied Science, London and New York, pp. 159-166, 1992

Soldatov, V.S., "Mathematical modelling of ion exchange equilibria on resinous ion exchangers, " Reactive Polymers, Vol. 19, pp. 105-121, 1993

Soldatov, V.S. and Bichkova, V.A., "Binary ion exchange selectivity coefficients in multi-ionic systems, " Reactive Polymers, Vol. 3, pp. 199-206, 1985 
Song, W. and Larson, M.A., "Activity coefficient model of concentrated electrolyte solutions," AIChE Journal, Vol. 36, No. 12, pp. 1896-1900, 1990

Tamon, H., Mori, H., Ohyama, S. and Okazaki, M., "Correlation of adsorption equilibrium of uranium by taking into account its chemical species in seawater," Journal of Chemical Engineering of Japan, Vol. 23, No. 4, pp. 433-438, 1990

Tao, L.C. and Ceplecha, S.P., "Flexibility and symmetry of the Wilson equation for vapour-liquid equilibrium studies," Industrial and Engineering Chemistry Fundamentals, Vol. 25, pp. 504-506, 1986

Vazquez Una, G., Pampin, R.M. and Caeiro, R.B., "Caracterizacion del equilibrio de intercambio ionico en sistemas binarios," Anales de Quimica Ser., A, Vol. 81, pp. 135-140, 1985

Vermeer, D.J., Lynn, S. and Vermeulen, T., “Cation-exchange column behaviour in a desalination process with regenerant recovery," Ind. Eng. Chem., Process Des. Dev., Vol. 14, No. 3, pp. 290-297, 1975

Wilson, G.M., "Vapour-liquid XI. A new expression for the excess energy of mixing," Journal of the American Chemical Society, Vol. 86, pp. 127-130, 1964

Yang, S., Gao, H. and Su, Y., "Study on adsorption equilibrium of sorbic acid from dilute solution by TRPO extracting resin," New Developments In Ion Exchange. Materials, Fundamentals and Applications, Proceedings of the International Conference on Ion Exchange, ICIE ‘91, Tokyo, Japan, pp. 31-34, 1991

Yoshida, H., Shimizu, K. and Kataoka, T., "Adsorption of amine and paints on H-form resin from electrodeposition wastewater," AIChE Journal, Vol. 36, No. 12, pp. 1815-1821, 1990

Zemaitis, J.F., Jr., Clark, D.M., Rafal, M. and Scrivner, N.C., "Handbook Of Aqueous Electrolyte Thermodynamics," AIChE, Inc., New York, 1986 